Final Report

\title{
DESIGN METHODS FOR THE CONTROL OF RESTRAINED SHRINKAGE CRACKING
}

FHWA/IN/JTRP-2006/32

by

\author{
Robert J. Frosch \\ Principal Investigator \\ Purdue University \\ and
}

Jacob K. Bice, Graduate Research Assistant

Jared B. Erickson, Graduate Research Assistant

School of Civil Engineering

Purdue University

Joint Transportation Research Program

Project No. C-36-56MMM

File No. 7-4-63

SPR-2792

Prepared in Cooperation with the

Indiana Department of Transportation

U.S. Department of Transportation

Federal Highway Administration

The contents of this report reflect the views of the authors who are responsible for the facts and the accuracy of the data presented herein. The contents do not necessarily reflect the official views or policies of the Indiana Department of Transportation or the Federal Highway Administration at the time of publication. This report does not constitute a standard, specification, or regulation.

Purdue University

West Lafayette, Indiana 47907

September 2006 


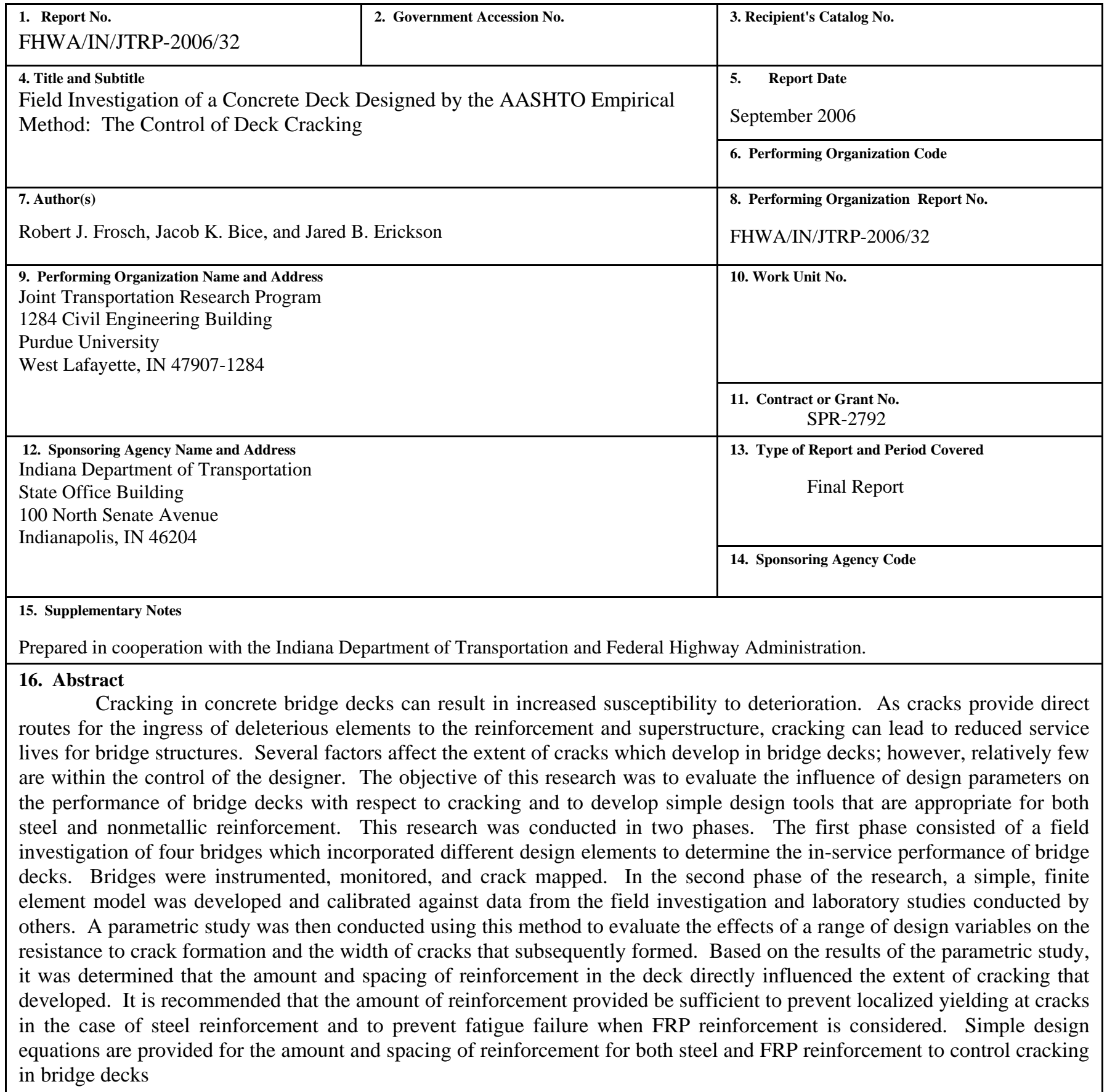

\begin{tabular}{|l|l|l|l|}
\hline \multicolumn{2}{|l|}{ 17. Key Words } & \multicolumn{1}{l|}{ 18. Distribution Statement } \\
$\begin{array}{l}\text { bridge deck, concrete, transverse cracking, restrained } \\
\text { shrinkage, shrinkage, temperature and shrinkage } \\
\text { reinforcement, restraint }\end{array}$ & $\begin{array}{l}\text { No restrictions. This document is available to the public through the } \\
\text { National Technical Information Service, Springfield, VA 22161 }\end{array}$ \\
\hline $\begin{array}{l}\text { 19. Security Classif. (of this report) } \\
\text { Unclassified }\end{array}$ & $\begin{array}{l}\text { 20. Security Classif. (of this page) } \\
\text { Unclassified }\end{array}$ & 21. No. of Pages & 235 \\
\hline
\end{tabular}




\section{ACKNOWLEDGMENTS}

This work was supported by the Joint Transportation Research Program (JTRP) administered by the Indiana Department of Transportation (INDOT) and Purdue University through contract SPR-2792. The support of the Indiana Department of Transportation (INDOT) and the Federal Highway Administration (FHWA) are gratefully acknowledged. The authors would like to extend thanks to Dr. Tommy Nantung from the INDOT Division of Research for his support throughout the project. In addition, thanks are extended to members of the Study Advisory Committee for their participation and thoughtful comments throughout the project. These members include Youlanda Belew, Keith Hoernschemeyer, John Jordan, and Don Leonard. 


\section{TABLE OF CONTENTS}

LIST OF TABLES

LIST OF FIGURES .......................................................................................................................... vii

CHAPTER 1 INTRODUCTION ...................................................................................... 1

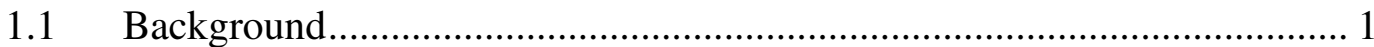

$1.2 \quad$ Factors Influencing Early Age Cracking …………..................................... 1

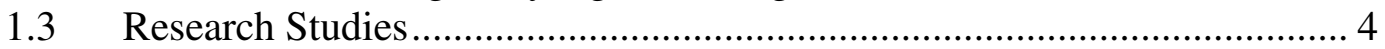

1.3.1 Portland Cement Association .......................................................... 4

1.3.2 Cady, Carrier, Bakr, and Theisen .................................................... 5

1.3.3 Purvis, Babei, Udani, Qanbari, and Williams .................................... 5

1.3.4 Schmitt and Darwin................................................................... 5

1.3.5 Krauss and Rogalla.......................................................................... 6

1.3.6 Eppers, French, and Hajjar ............................................................ 7

1.3.7 Le, French, and Hajjar ............................................................... 8

1.3.8 Frosch, Radabaugh, and Blackman ................................................... 9

1.3.9 Xi, Shing, Abu-Hejleh, Asiz, Suwito, Xie, and Ababneh .................. 9

1.4 Control of Temperature and Shrinkage Cracks ……................................ 10

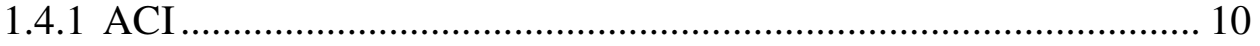

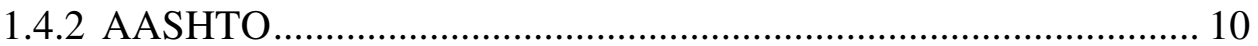

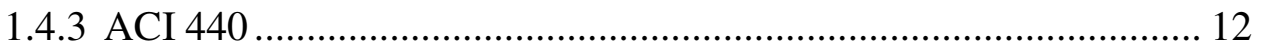

1.5 History of Code Requirements to Control Shrinkage Cracking ................ 12

1.5.1 ACI Requirements ................................................................... 12

1.5.2 AASHTO Requirements ……………………………………..... 16

1.6 Crack Control Provided by Reinforcement …….................................... 17

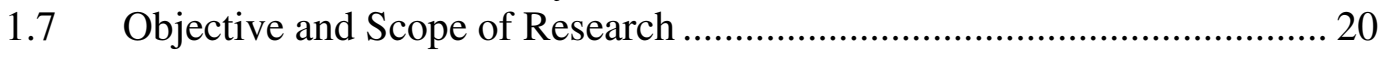

CHAPTER 2 FIELD STUDIES …............................................................................. 22

2.1 Overview of Investigated Bridges ........................................................ 22

2.2 Overview of Instrumentation Design .................................................... 23

$2.3 \quad$ Interstate 65 over State Road 25 ....................................................... 23

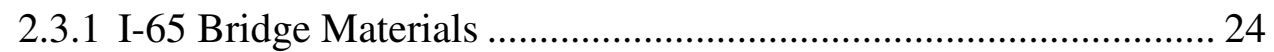

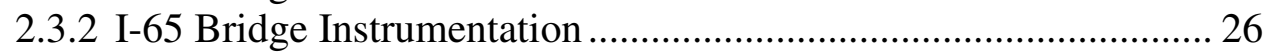

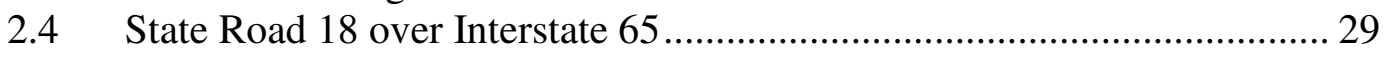

2.4.1 SR 18 Materials ....................................................................... 30

2.4.2 SR 18 Instrumentation............................................................... 34

$2.5 \quad$ State Road 23 over U.S. Highway 20 ...................................................... 41

2.5.1 SR 23 Materials ........................................................................ 43

2.5.2 SR 23 Instrumentation.............................................................. 45

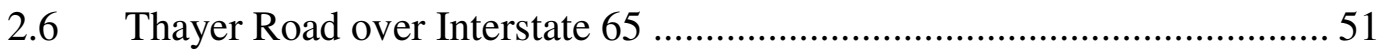

2.6.1 Thayer Road Bridge Materials ...................................................... 53 
CHAPTER 3 FIELD RESULTS _....................................................................................... 60

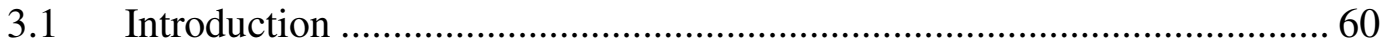

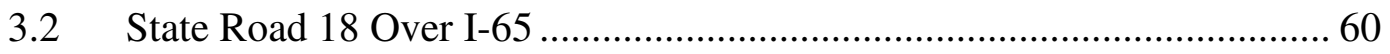

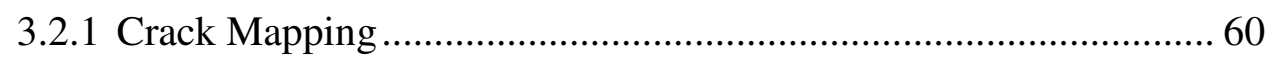

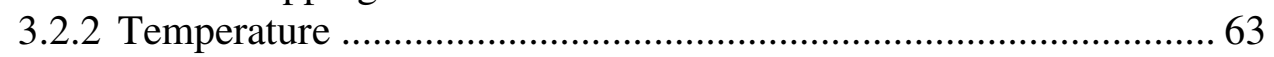

3.2.3 Behavior of Longitudinal Reinforcement (SR 18 AASHTO Span) 66

3.2.4 Behavior of Longitudinal Reinforcement (SR 18 Purdue Span)..... 70

3.3 State Road 23 Over U.S. 20................................................................. 74

3.3.1 Field Free Shrinkage Specimens ………………………………..... 74

3.3.2 Crack Mapping .............................................................................. 76

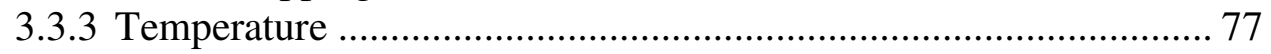

3.3.4 Behavior of the Longitudinal Reinforcement in SR 23 ................... 78

$3.4 \quad$ Thayer Road Bridge over I65 ………………................................... 82

3.4.1 Crack Mapping ……………………………………………..... 82

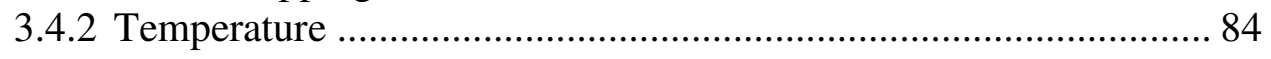

3.4.3 Correction of FRP Strain Gages for Temperature ........................... 84

3.4.4 Behavior of Longitudinal Reinforcement in Thayer Road Bridge.. 86

CHAPTER 4 ANALYSIS OF FIELD RESULTS.........................................................91

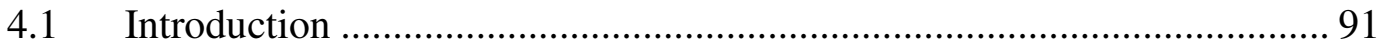

4.2 Comparison of Cracking in Bridges ........................................................... 91

4.3 Comparison of Behavior of Longitudinal Reinforcement .......................... 92

4.4 Behavior of Reinforcement Across a Crack ............................................ 96

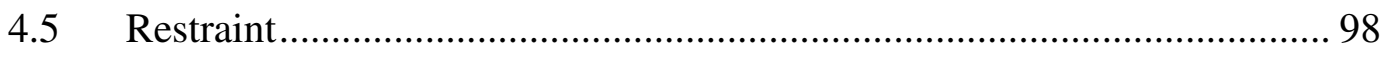

4.5.1 Level of Restraint from Concrete Girders ....................................... 98

4.5.2 Level of Restraint from Steel Girders ........................................... 102

4.5.3 Level of Restraint from Abutment ................................................. 104

CHAPTER 5 ANALYTICAL MODEL .............................................................112

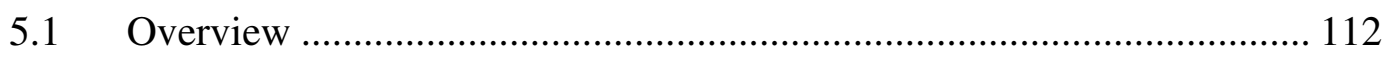

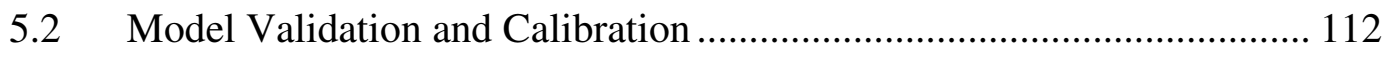

5.2.1 Model Characteristics.................................................................... 112

5.2.2 Applied Shrinkage Model .......................................................... 115

5.2.3 Material Properties …………………………………................... 119

5.2.4 Comparison of Model to Restrained Shrinkage Specimens.......... 119

5.3 Bridge Model Characteristics ................................................................. 126

$5.4 \quad$ Shrinkage Loads with Time................................................................... 131

5.5 Comparison of Model Results to Field Studies ....................................... 132

5.5.1 State Road 18 ......................................................................... 133

5.5.2 Thayer Road Bridge .............................................................. 137

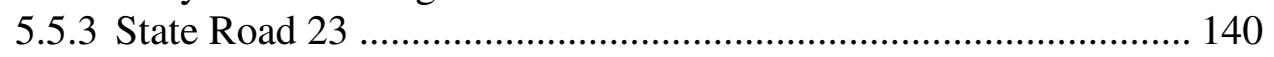

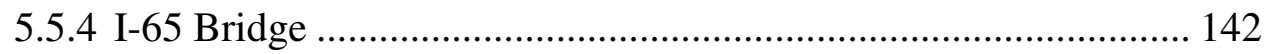

$5.6 \quad$ Summary and Conclusions ................................................................... 143 
CHAPTER 6 PARAMETRIC STUDY ................................................................. 145

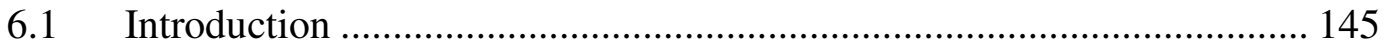

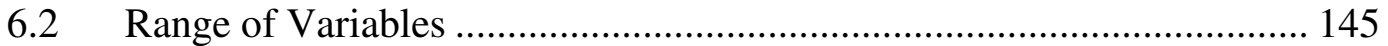

6.3 Control Model............................................................................... 146

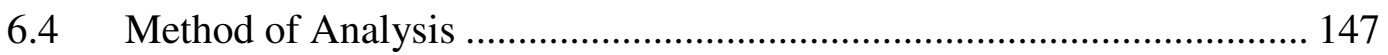

6.5 Influence of Reinforcement ............................................................... 148

6.5.1 Reinforcement Amount ................................................................ 148

6.5.2 Reinforcement Spacing ............................................................. 151

6.5.3 Reinforcement Material............................................................. 154

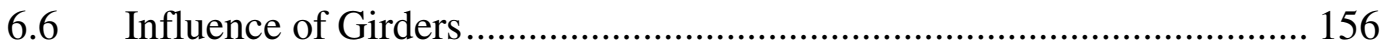

6.6.1 Girder Depth............................................................................. 156

6.6.2 Girder Spacing........................................................................ 160

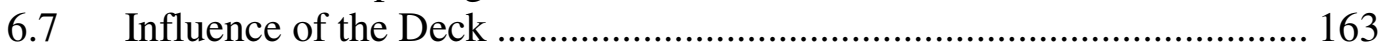

6.7.1 Deck Thickness ......................................................................... 163

6.7.2 Deck Concrete Strength .............................................................. 165

6.8 Analysis of Parametric Study ........................................................... 168

6.8.1 Reinforcement Stress............................................................... 170

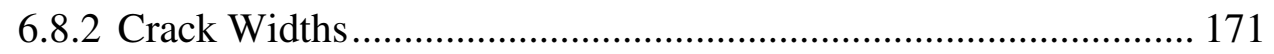

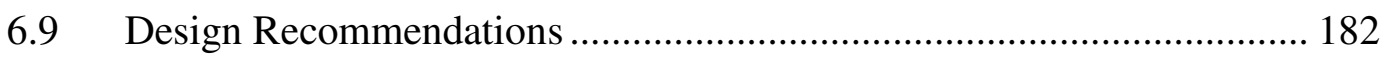

CHAPTER 7 SUMMARY AND CONCLUSIONS................................................186

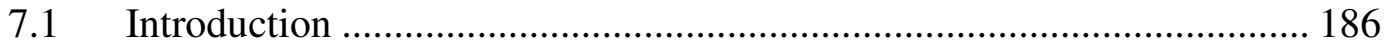

7.2 Control of Bridge Deck Cracking..................................................... 186

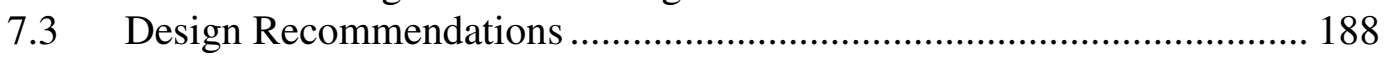

7.4 Recommendations for Future Research.................................................. 189

LIST OF REFERENCES ............................................................................................................. 191

APPENDICIES .................................................................................................................. 195

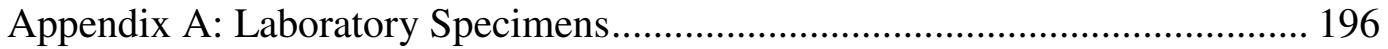

Appendix B: Bridge Plans ........................................................................... 211

Appendix C: ANSYS Command Files ............................................................ 221 


\section{LIST OF TABLES}

Table Page

2.1: Characteristics of Bridges in Field Investigation............................................... 22

2.2: Characteristics of Deck Reinforcement in Field Investigation ............................... 23

2.3: INDOT Class C Mix Design on I-65 Bridge (Radabaugh 2001) .............................. 24

2.4: INDOT Class C Mix Design on SR 18 Bridge (Erickson 2004) .............................. 31

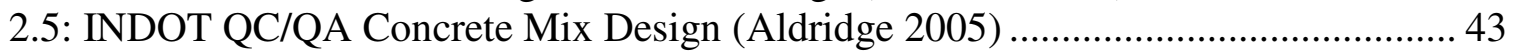

2.6: INDOT Class C Mix Design on Thayer Road Bridge .............................................. 54

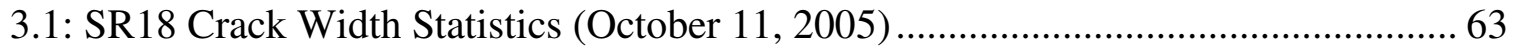

3.2: Maximum Stresses in AASHTO Midspan Reinforcement.................................... 70

3.3: Maximum Stresses in Purdue Midspan Reinforcement........................................... 74

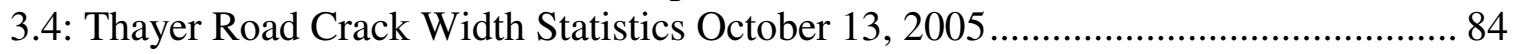

3.5: Maximum Stress in Thayer Road Bridge Reinforcement..................................... 89

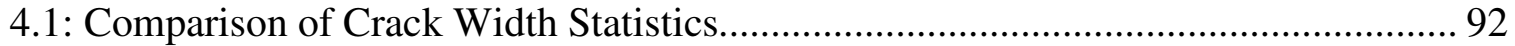

5.1: Comparison of Laboratory Study Mix Designs ..................................................... 116

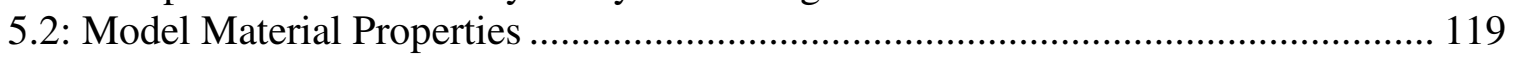

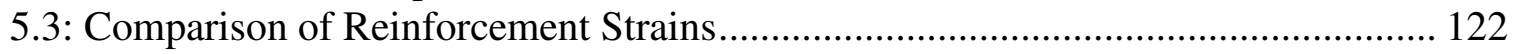

5.4: Comparison of Deflections .............................................................................. 123

5.5: Comparison of SR 18 Crack Widths (Uniform Shrinkage) .................................. 136

5.6: Comparison of SR 18 Crack Widths (Linear Shrinkage) ..................................... 136

5.7: Range of Predicted Crack Widths Compared to Measured Crack Widths (SR 18) ......

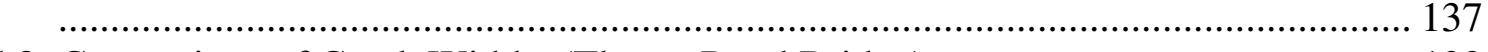

5.8: Comparison of Crack Widths (Thayer Road Bridge) .......................................... 139

5.9: Range of Predicted Crack Widths Compared to Measured Crack Widths (Thayer

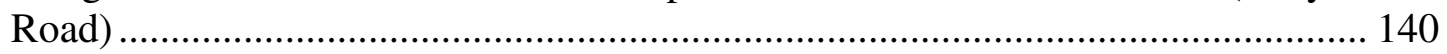

5.10: Range of Predicted Crack Widths (SR 23) ....................................................... 142

5.11: Range of Predicted Crack Widths Compared to Measured Crack Widths (Day 2204)

6.1: Range of Variables in Parametric Study ....................................................... 146

Appendix Table Page

A.1: Characteristics of Free Shrinkage Specimens (Blackman 2002) .......................... 198 


\section{LIST OF FIGURES}

Figure

Page

1.1: Full-Depth Transverse Crack in a Bridge Deck......................................................... 1

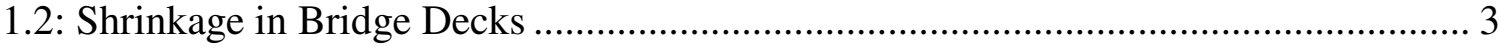

1.3: Shrinkage Restrained by Reinforcement in a Symmetrically Reinforced Section

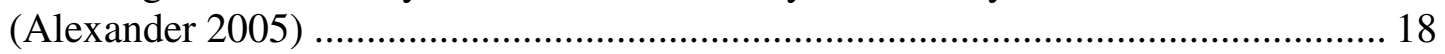

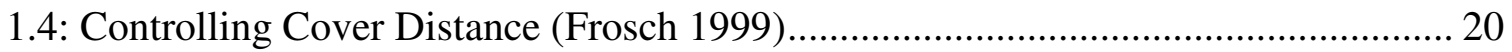

2.1: Longitudinal Reinforcement Design in I-65 over SR 25 Bridge ............................ 24

2.2: Compressive Strength Gain Curve for I-65 Bridge (Radabaugh 2001).................... 26

2.3: Plan View of Strain Gage Locations in I-65 Bridge over SR 25 (Radabaugh 2001) ....

2.4: Elevation View of Strain Gage Locations on I-65 Bridge over SR 25 (Radabaugh

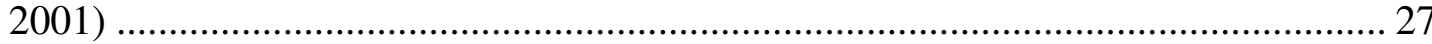

2.5: Plan View of Thermocouple Locations in I-65 Bridge over SR 25 (Radabaugh

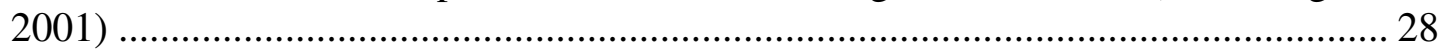

2.6: Elevation View of Thermocouple Locations in I-65 Bridge over SR 25 (Radabaugh 2001)

2.7: Reinforcement Designs in State Road 18 Bridge Deck ............................................ 30

2.8: SR 18 Concrete Compressive Strength (Erickson 2004) .......................................... 32

2.9: SR 18 Average Split Cylinder Tensile Strength ..................................................... 33

2.10: Split Cylinder Strength to $f_{t}=6 \sqrt{f_{c}}$ Comparison .............................................. 33

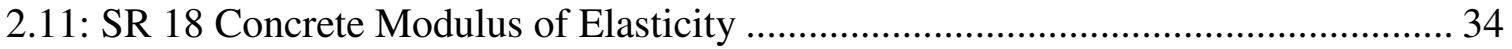

2.12: Plan View of Strain Gage Locations on SR 18 Bridge (Erickson 2004) ................. 35

2.13: Elevation View of Strain Gage Locations on SR 18 Bridge (Erickson 2004)........ 36

2.14: Plan View of Embedded Concrete Strain Gage Locations (Erickson 2004) ........... 37

2.15: Embedded Concrete Strain Gage Locations through the Depth of the Deck

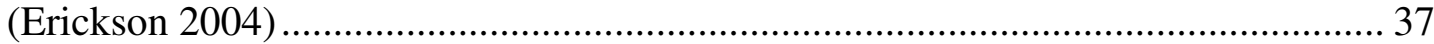

2.16: Plan View of Thermocouple Locations (Erickson 2004) ..................................... 38

2.17: Thermocouple Locations through the Depth of the Deck and Girder (Erickson

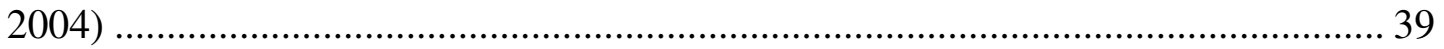

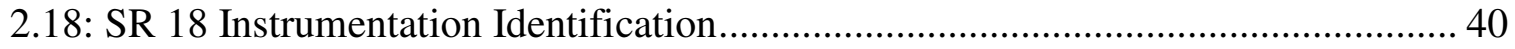

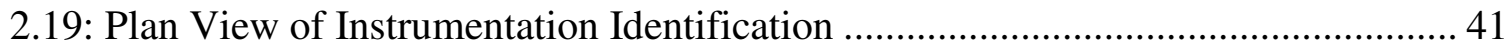

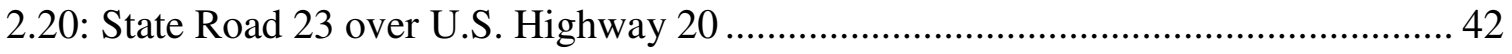

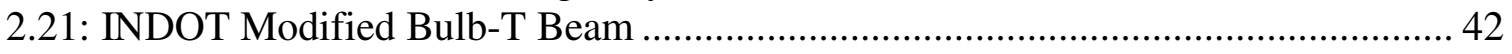

2.22: SR 23 Concrete Compressive Strength (Aldridge 2005) ....................................... 44

2.23 SR 23 Split Cylinder Tensile Strength (Aldridge 2005) ........................................ 44

2.24: SR 23 Concrete Modulus of Elasticity at Day 28 (Aldridge 2005) ...................... 45

2.25: Site Plan of State Road 23 over U.S. Highway 20 ........................................... 46

2.26: Plan View of Instrumentation on State Road 23 Bridge...................................... 47

2.27: Schematic of 20-foot Instrumented Bar.............................................................. 48

2.28: Cross Section View of Instrumentation at Midspan ............................................. 48 
2.29: Plan View of Free Shrinkage Slab Model (Aldridge 2005).................................... 50

2.30: Plan View of Free Shrinkage Prism (Aldridge 2005) ........................................... 50

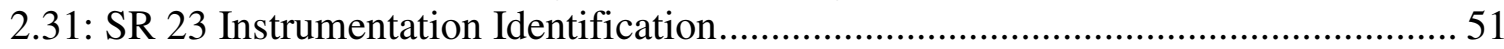

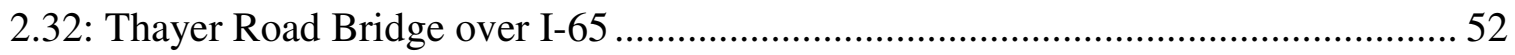

2.33: Longitudinal Reinforcement in Thayer Road Bridge Deck ..................................... 53

2.34: Thayer Road Bridge Concrete Compressive Strength............................................ 54

2.35: V-ROD GFRP Stress versus Strain (Pay 2005)...................................................... 55

2.36: Plan View of Longitudinal Strain Gages (Thayer Road Bridge)............................. 56

2.37: Pier 3 Locations of Longitudinal Strain Gages (Thayer Road Bridge) .................... 56

2.38: Span C and Span D Locations of Longitudinal Gages (Thayer Road Bridge) ........ 57

2.39: Plan View of Thermocouple Locations on Thayer Road Bridge............................. 58

2.40: Locations of Thermocouples at Pier 3 ............................................................... 58

2.41: Instrument Identification Scheme for Thayer Road Bridge..................................... 59

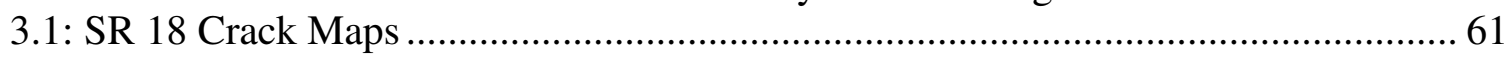

3.2: Average Crack Width Growth versus Time .............................................................. 62

3.3: Comparison of Cracks in SR 18 Positive Moment Region (October 11, 2005)........ 63

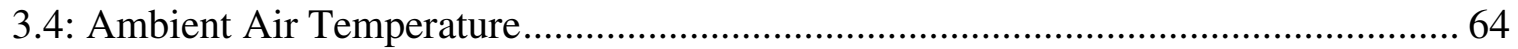

3.5: Comparison of Ambient Temperature to Bottom Flange Temperature...................... 65

3.6: Estimated Ambient Temperature (Bottom Flange Thermocouple) ............................. 65

3.7: AASHTO Midspan Over Girder 3 (Bottom Bar) ……………………....................... 66

3.8: AASHTO Midpsan Between Girders 2 and 3 (Bottom Bar) ..................................... 67

3.9: AASHTO Midspan Over Girder 2 (Bottom Bar) ..................................................... 67

3.10: Location of Strain Gages Relative to Cracks at AASHTO Midspan........................ 68

3.11: AASHTO Midspan Over Girder 3 (Top Bar) ...................................................... 69

3.12: Purdue Midspan Over Girder 3 (Bottom Bar) ………………................................ 71

3.13: Purdue Midspan Between Girders 2 and 3 (Bottom Bar) ...................................... 71

3.14: Purdue Midspan Over Girder 2 (Bottom Bar) …………………....................... 72

3.15: Location of Strain Gages Relative to Cracks at Purdue Midspan............................ 73

3.16: 6"x6"x12" Specimen Shrinkage Strain.............................................................. 75

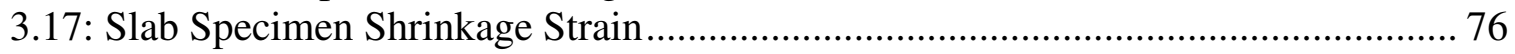

3.18: SR 23 Crack Map......................................................................................... 77

3.19: SR 23 Recorded Ambient Temperatures ……………...................................... 78

3.20: SR 23 Midspan Strains over Girder 3 ............................................................. 79

3.21: SR 23 Midspan Strains Midbay Between Girders 2 and 3 .................................... 80

3.22: SR 23 Instrumented Bar and Concrete Strains .................................................... 81

3.23: Instrumented Bar Strain at $11 \mathrm{Ft}$ (Gage d) from Midspan ...................................... 82

3.24: Thayer Road Bridge Crack Map ………………….............................................. 83

3.25: Thayer Road Bridge Crack Widths in Positive Moment Regions ............................. 83

3.26: Ambient Temperature Data from Thayer Road Bridge ........................................... 84

3.27: Corrected and Uncorrected FRP Dummy Bar Strain............................................ 85

3.28: Thayer Road Bridge Steel Control Strain ............................................................ 86

3.29: Deck Strain Gradient Midspan over Girder 3 (Span C).......................................... 87

3.30: Strain Gradient Midspan over Girder 3 (Span D) ................................................ 88

3.31: Location of Instrumentation Relative to Crack in Span C ....................................... 88

3.32: Stress in Top Reinforcement (Thayer Road Bridge, Span C)................................. 89 


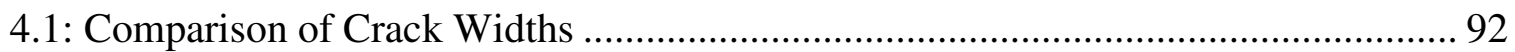

4.2: Comparison of Top Mat Reinforcement Strains at Midspan .................................... 93

4.3: I-65 Reinforcement Strain over Girder 1 (Top Bar) .................................................. 94

4.4: I65 Deck Temperature at Top Reinforcement Mat................................................... 95

4.5: I-65 Reinforcement Strain over Girder 4 (Top Bar) ................................................. 96

4.6: Comparison of Temperature and Strain Variations in I-65 Bridge .......................... 97

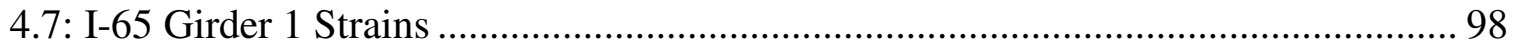

4.8: Comparison of Slab Specimen Strain to Bridge Deck Strains Between Girders

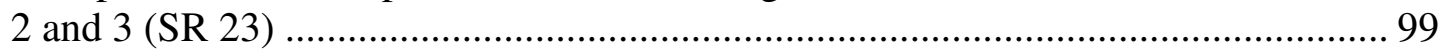

4.9: Comparison of Reinforcement Strain over Girder 3 and Midbay (Top Bar - SR 23)

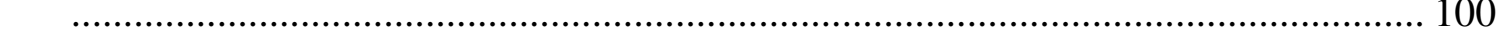

4.10: Comparison of Concrete Strain over Girder 3 and Midbay (SR 23) ..................... 101

4.11: Strains Measured Under Varying Degrees of Restraint.......................................... 102

4.12: Comparison of AASHTO Span Reinforcement Strains (Top Bar)........................ 103

4.13: Comparison of Effective Slab Spans (SR 18 and SR 23) ...................................... 103

4.14: Comparison of AASHTO Span Concrete Strains (Top Bar) ................................... 104

4.15: SR 23 Integral Abutment Schematic ……………............................................ 105

4.16: Comparison of Concrete Strains to Temperature (SR 23) .................................... 106

4.17: Comparison of Girder Top Flange Strains (SR 23) ............................................. 106

4.18: Reinforcement Strains During Expansion Phase (SR 23) .................................... 107

4.19: Girder Strains During Expansion Phase (SR 23) ............................................... 108

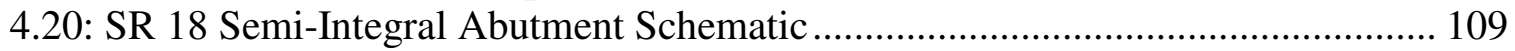

4.21: SR 18 Bridge Temperatures (Year One) ......................................................... 110

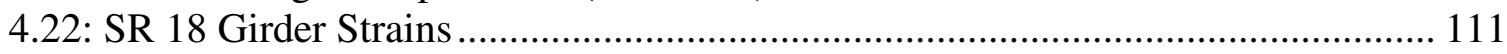

5.1: ANSYS Model Restrained Shrinkage Specimen................................................... 113

5.2: Model Boundary Conditions and Deck-Slab Coupling ............................................ 114

5.3: Slab-Girder Coupling Across Width of Top Flange Elements ................................ 114

5.4: Free Shrinkage Strains (Specimen 9) (Blackman 2002)........................................ 117

5.5: As-Built Specimen Reinforcement Strain Compared to Wet-Cure Duration........... 117

5.6: Free Shrinkage Strains (Specimen 8) (Blackman 2002)........................................ 118

5.7: Linear Shrinkage Model .................................................................................. 119

5.8: Center Slab Instrumentation Locations............................................................... 120

5.9: Reinforcement Strains (As-Built Specimen) .......................................................... 121

5.10: Reinforcement Strains (Wood Forms) ............................................................... 121

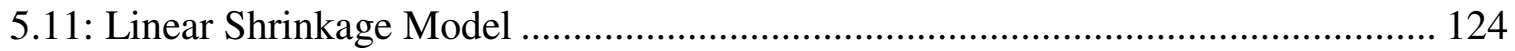

5.12: Comparison of Deflections (As-Built Specimen to Linear Shrinkage) ................. 124

5.13: Comparison of Deflections (Wood Form Specimen to Uniform Shrinkage) ........ 125

5.14: Ratio of Reinforcement Strains versus Girder Depth ............................................ 126

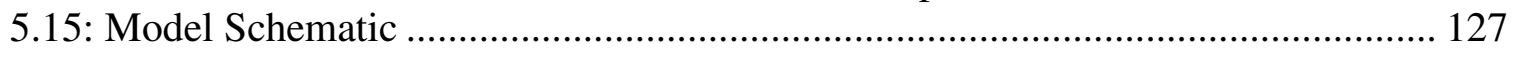

5.16: Modeled Section of Actual Structure............................................................... 128

5.17: Progressive Cracking Methodolgy................................................................ 129

5.18: Distribution of Longitudinal Stresses ................................................................. 130

5.19: Sensitivity of Crack Widths to Amount of Cracking............................................ 131

5.20: Relationship of Model Stress and Crack Widths to Time-Dependent Shrinkage.. 
5.21: SR 18 Shrinkage to Initiate Cracking (AASHTO Span) ……………………….... 134

5.22: SR 18 Shrinkage to Initiate Cracking (Purdue Span) .......................................... 135

5.23: Control Gage Free Shrinkage Strain (Thayer Road) ……………........................ 138

5.24: Deck Temperatures (Thayer Road)................................................................. 138

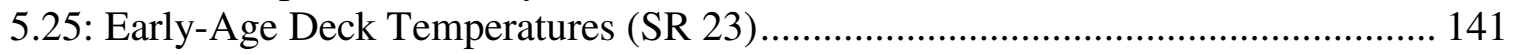

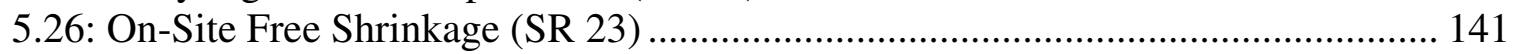

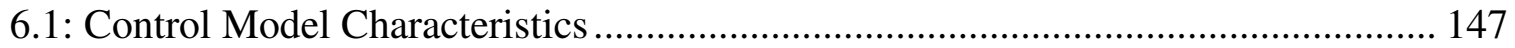

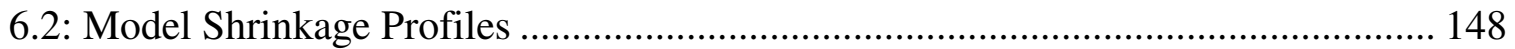

6.3: Variation of Initial Crack Widths Across Width of Deck ....................................... 149

6.4: Effect of Reinforcement Amount on Crack Widths .............................................. 150

6.5: Effect of Reinforcement Amount on Reinforcement Stress .................................... 150

6.6: Effect of Amount of Reinforcement on Shrinkage Required for Cracking ............. 151

6.7: Effect of Bar Spacing on Crack Widths (Uniform Shrinkage) ................................ 152

6.8: Effect of Bar Spacing on Average Crack Widths .................................................. 152

6.9: Effect of Bar Spacing on Reinforcement Stress ................................................... 153

6.10: Effect of Bar Spacing on Reinforcement Stress (Initial Cracking) ....................... 153

6.11: Effect of Bar Spacing on Shrinkage Required for Cracking ................................ 154

6.12: Comparison of Crack Widths (Steel versus FRP) .............................................. 155

6.13: Effect of Bar Spacing on Crack Widths (Steel and FRP) ...................................... 156

6.14: Constant Stiffness Girder Dimensions............................................................ 157

6.15: Effect of Girder Depth on Crack Widths (Variable Stiffness)............................... 157

6.16: Effect of Girder Depth on Crack Widths (Constant Stiffness) .............................. 158

6.17: Effect of Girder Depth on Bar Stress (Variable Stiffness) .................................... 158

6.18: Effect of Girder Depth on Reinforcement Stress (Constant Stiffness) .................. 159

6.19: Effect of Girder Depth on Shrinkage Required for Cracking (Constant Girder

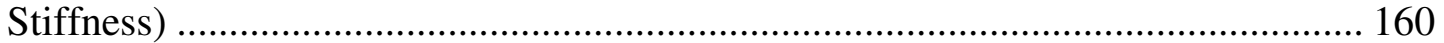

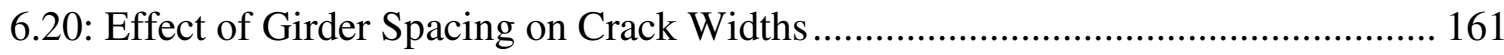

6.21: Effect of Girder Spacing on Reinforcement Stress.............................................. 162

6.22: Effect of Girder Spacing on Shrinkage Required for Cracking ............................. 162

6.23: Effect of Deck Thickness on Crack Widths......................................................... 163

6.24: Effect of Deck Thickness on Reinforcement Stress ............................................. 164

6.25: Effect of Deck Thickness on Shrinkage Required for Cracking .......................... 165

6.26: Effect of Concrete Strength on Crack Widths ...................................................... 166

6.27: Effect of Concrete Compressive Strength on Reinforcement Stress ..................... 166

6.28: Effect of Concrete Tensile Strength on Reinforcement Stress ............................... 167

6.29: Effect of Concrete Strength on Shrinkage Required for Cracking ........................ 167

6.30: Effect of Concrete Modulus of Elasticity on Shrinkage Required for Cracking ... 168

6.31: Average Stress versus Girder Moment of Inertia .................................................... 169

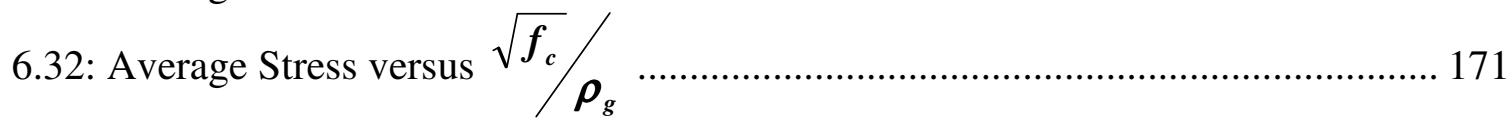

6.33: Effect of Element Slip Length on Predicted Crack Width....................................... 172

6.34: Uncalibrated Stress Modification Factor versus Slip Length ................................ 173

6.35: Calibrated Stress Modification Factor versus Slip Length ..................................... 173

6.36: Comparison of Crack Width Expression to Model Crack Widths........................... 175

6.37: Relationship of Slip Length Factor to Reinforcement Amount............................... 176 
6.38: Comparison of Crack Width Expressions to Model Crack Widths ...................... 177

6.39: Effect of Reinforcement Amount and Spacing on Crack Widths......................... 178

6.40: Relationship of Crack Width and Effective Depth of Cover ............................... 179

6.41: Relationship between Spacing Factor and Effective Depth of Cover .................. 180

6.42: Comparison of Crack Width Expression to Predicted Crack Widths .................... 181

6.43: Grade 60 Reinforcement Spacing ................................................................... 183

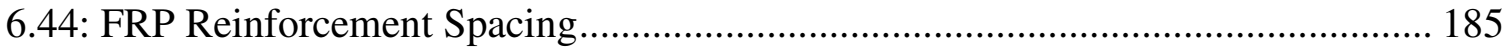

Appendix Figure $\quad$ Page

A.1: Cross Section View of Reinforced Specimens (Blackman 2002) ........................ 198

A.2: Plan View of Reinforced Specimens (From Blackman 2002) .............................. 199

A.3: Concrete Strength - Free Shrinkage Specimens (Blackman 2002)....................... 200

A.4: Concrete Modulus of Elasticity - Free Shrinkage Specimens (Blackman 2002)... 201

A.5: Reinforcement Stress versus Displacement (Blackman 2002) ............................. 202

A.6: Reinforcement Strain Gage Locations (Blackman 2002) ................................... 203

A.7: As-built Specimen without Reinforcement.......................................................... 204

A.8: Free-shrinkage Specimen without Reinforcement........................................... 205

A.9: Top Reinforcement - Restrained Shrinkage Specimens .................................... 206

A.10: Bottom Reinforcement - Restrained Shrinkage Specimens ............................... 207

A.11: Strength Gain for Concrete Compressive Cylinders (Radabaugh 2001) ............. 208

A.12: Strength Gain Curve for Split Cylinder Tests (Radabaugh 2001) ....................... 209

A.13: Restrained Specimen Instrumentation (Plan View) ......................................... 210

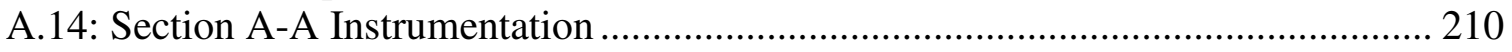

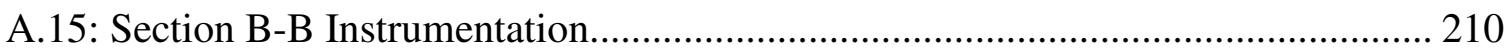

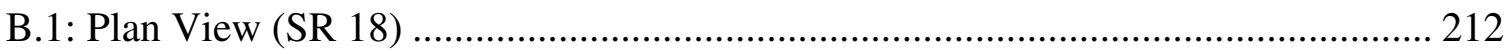

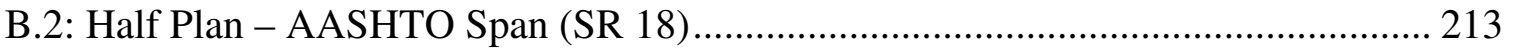

B.3: Half Plan - Purdue Span (SR 18) .................................................................. 214

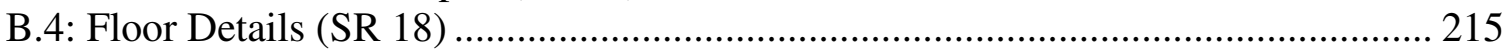

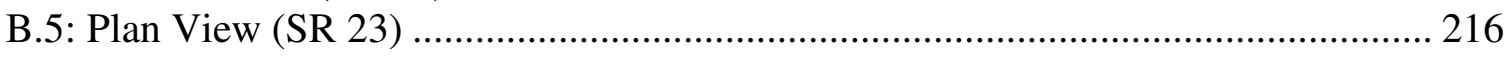

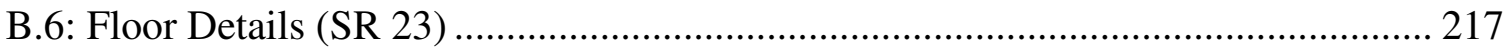

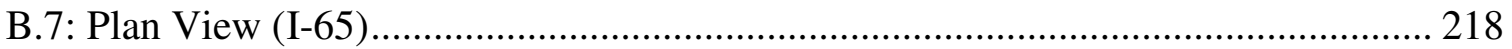

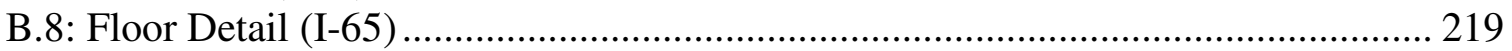

B.9: Plan View (Thayer Road Bridge)................................................................... 220 


\section{CHAPTER 1 INTRODUCTION}

\subsection{Background}

Corrosion of reinforcement in concrete bridge decks subjected to an aggressive environment ultimately causes deterioration of the concrete and loss of serviceability. Cracks in the deck increase the susceptibility of the reinforcement to harmful agents in the service environment such as moisture and chlorides from deicing salts and result in expediting the decay of the reinforcement (Aldea, Shah and Karr 1999). Throughout the United States, many bridges have experienced cracking soon after construction (Krauss and Rogalla 1996). From a survey of 52 state agencies, it is estimated that more than 100,000 bridges develop early-age cracking. These cracks occur before the deck is one month old and are typically transverse, full-depth, and spaced between 3 and 10-ft.

Figure 1.1 exemplifies this type of cracking as well as the effect such a crack has on the deck such as corrosion and delamination along the plane of reinforcement.

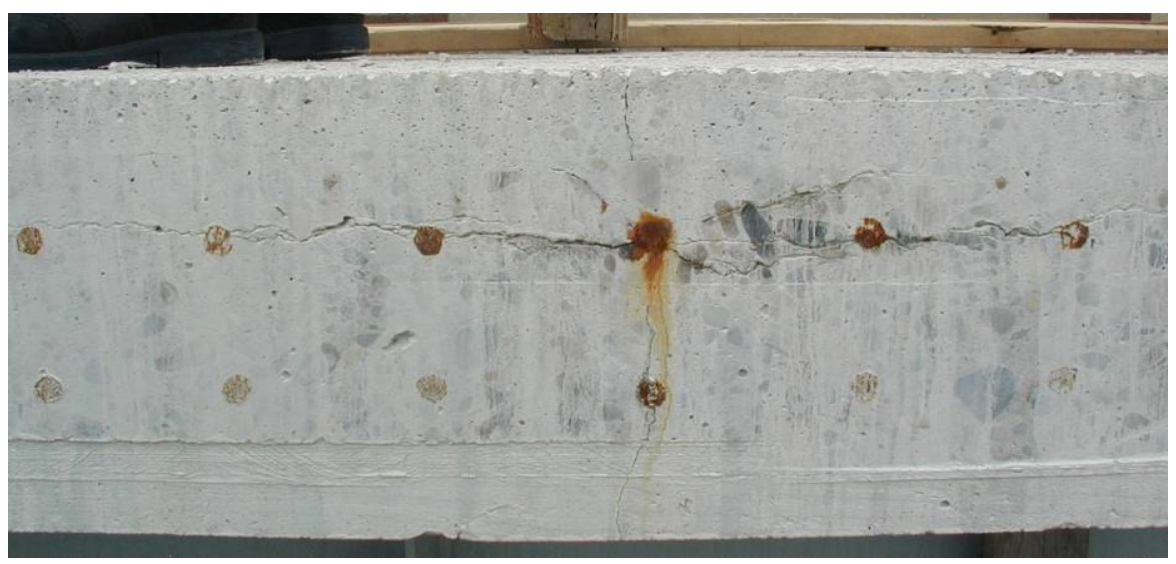

Figure 1.1: Full-Depth Transverse Crack in a Bridge Deck

\subsection{Factors Influencing Early Age Cracking}

Early-age cracking is caused primarily by volumetric changes of the deck being restrained by structural elements of the bridge (Krauss and Rogalla 1996, Radabaugh 2001, Frosch et al 2003). Thus, the amount of shrinkage and the level of restraint present in a bridge have a direct and interrelated effect on the amount of cracking that will develop in the deck. Concrete which is able to shrink without any restraint will not 
develop internal stress and thus will not develop cracks. Likewise, a completely restrained concrete member which experiences no volume change will not develop cracks. Thus, some shrinkage as well as some restraint must be present for cracking to occur in a bridge deck.

Several factors have been identified as having an influence on the extent of earlyage cracking in bridge decks. These factors can be classified into following five different categories:

- Concrete Shrinkage

- Construction Practices

- Formwork

- Restraint

- Design Detailing

In general, greater of concrete shrinkage will result in increased of cracking. It should be noted that while concrete shrinkage and restraint are generally independent of one another, design detailing, formwork, and construction practices influence both the shrinkage and restraint occurring in bridge decks. Furthermore, the designer often has the ability to control only three of the five factors: restraint, design detailing, and formwork.

ACI 209 defines the three types of shrinkage as drying, autogenous, and carbonation (1992). Drying shrinkage is the strain caused by the loss of moisture from concrete. Unlike drying shrinkage, autogenous shrinkage occurs when self-dessication occurs during hydration and occurs without any loss of moisture from the concrete. Carbonation shrinkage results from a reaction between hydrated cement and carbon dioxide in the atmosphere (Mindess et al. 2003). Typically, drying shrinkage is the dominant form of shrinkage occurring in concrete.

The performance of bridge decks can be enhanced by controlling the amounts of shrinkage which occur through appropriate concrete mix design. The use of mix designs which incorporate shrinkage compensating cements has been successful in reducing early age cracking (Gruner and Plain 1993); however, these mixes are more expensive, can be more difficult to place, require stricter attention to construction procedures (Phillips et al. 1997), and have not been widely implemented at this time. Similarly, shrinkage can be controlled by limiting the water-cement $(\mathrm{w} / \mathrm{c})$ ratio of the concrete as in concrete decks placed with high performance concrete (HPC), which the use of has increased in recent years. However, autogenous shrinkage of the concrete will significantly increase as lower w/c ratios are used (Weiss et al. 1998). Furthermore, autogenous shrinkage typically occurs at an early age before the concrete can develop its full strength and thus can be more susceptible to cracking (Weiss et al. 1998).

Concrete develops its strength and ability to resist cracking over the first days of its life. Therefore, the rate at which shrinkage strains develop can significantly influence the performance of a bridge deck. By employing construction procedures, such as wet curing, concrete shrinkage can be reduced and delayed until the concrete develops sufficient tensile strength (Krauss and Rogalla 1996). Furthermore, early finishing can reduce the number and width of cracks which develop in concrete. (Rogalla et al. 1995).

While appropriate mix design and curing influences the amount of shrinkage that occurs, the type of formwork used during construction affects how shrinkage varies 
through the depth of the deck. Drying shrinkage in a bridge deck is not uniform because the concrete near the surface will dry more quickly than concrete in the middle of the deck (Carlson 1937). When both faces of a bridge deck are exposed, the deck will shrink relatively uniformly as illustrated in Figure 1.2. Decks constructed with stay-in-place (SIP) formwork will have shrinkage at the exposed surface and virtually none at the sealed surface. Internal equilibrium is maintained by the deck curling as shown in Figure 1.2. Thus, bridge decks constructed with SIP forms must not only resist internal axial tension but also an internal moment due to shrinkage. Furthermore, the use of SIP steel forms provides a small amount of additional restraint to the bridge deck at the bottom surface of the deck (Radabaugh 2001).

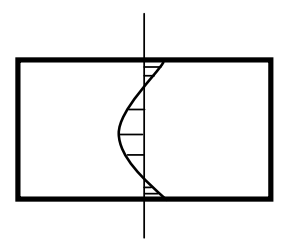

Internal Shrinkage

Stress

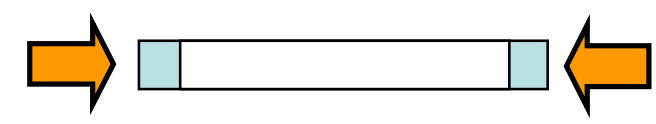

"Uniform" Shrinkage Action

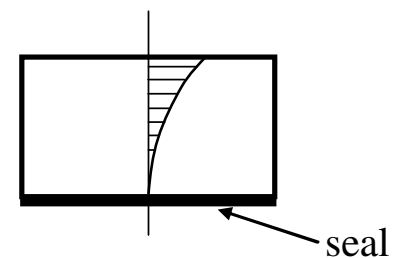

Internal Shrinkage Stress

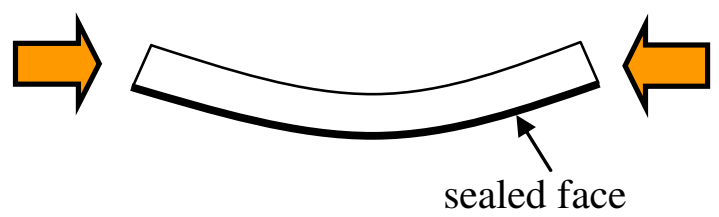

Curling Action due to Sealing

Figure 1.2: Shrinkage in Bridge Decks

While the concrete mix design, construction practices, and the formwork used in the bridge deck is the primary factor affecting the shrinkage that develops, certain design characteristics impact the level of restraint experienced by the deck. Composite behavior between the concrete deck and girders is the primary source of restraint in bridge decks (Krauss and Rogalla 1996). The practice of designing decks fully composite with the girders to decrease the size of the girders is common. Composite action makes the deck essentially completely restrained by the girders. Nevertheless, removal of this restraint is not economical, and the current trend in design has been to develop greater composite action, and thus greater restraint, through larger amounts of shear connectors installed on girders. The amount of restraint present in a bridge deck is also affected by several different design characteristics. The length of the span, type of girders, skew of the deck, amount of reinforcement, type of abutments, and spacing of the girders all influence the restraint in the deck and thus, the degree of cracking (Krauss and Rogalla 1996). 


\subsection{Research Studies}

Several studies have been conducted regarding transverse bridge deck cracking and its effect on the durability of concrete bridge decks.

\subsubsection{Portland Cement Association}

A cooperative study between the Portland Cement Association, the Bureau of Public Roads, and ten state highway departments was performed to ascertain factors affecting the durability of concrete bridge decks. The objectives of the study were to determine the types and extent of concrete bridge deck durability problems, causes of the various types of deterioration, methods for obtaining improved durability, and methods for retarding existing deterioration (PCA 1970).

The study noted that temperature variations in the deck are larger than in the rest of a bridge structure and restraint of the resulting volume changes induce cracking in the concrete deck. The study also indicates that all aspects of bridge deck construction must receive special attention, including deck design, materials quality, and construction procedures.

Transverse cracking was found to be the most common type of cracking observed with older decks and longer spans typically displaying more transverse cracking. Additionally, the type of superstructure affected the occurrence of transverse cracks. Continuous span bridges and steel girders seemed to exacerbate transverse cracking, while simply supported spans and reinforced concrete girders alleviated transverse cracking.

No one factor could be determined to be the singular cause of transverse cracking. Important factors affecting the development of transverse cracking were found to be:

- Restraint from the girders on the early and long term shrinkage of the deck;

- Influence of top slab reinforcement as a source of internal restraint in the concrete; and

- Internal restraint of the concrete due to differential drying shrinkage; Other important conclusions were that live load stresses appeared to play a minor role in transverse cracking on steel girders, and that the vibration characteristics of bridge superstructures were not found to be a factor in the deterioration of bridge decks.

The PCA report recommended the following:

- Limit slump to 2 in. \pm 0.5 in.

- Maintain the water-cement ratio less than 0.48

- Use large-sized aggregates

- Reduce bleeding by having a smooth grading curve

- Select aggregates with low shrinkage

- Avoid placement temperatures over $80^{\circ} \mathrm{F}$ and consider nighttime deck placement

- Provide 1.5 in. minimum concrete cover for top mat reinforcement.

The PCA report also recommended further research be conducted on appropriate amounts, spacing, and location of temperature and shrinkage reinforcement in the bridge deck. 


\subsubsection{Cady, Carrier, Bakr, and Theisen}

Cady et al. (1971) surveyed 249 four year old bridge decks in Pennsylvania to investigate the extent and causes of deterioration in concrete bridge decks. Transverse cracks were found to be the most prevalent type of cracking observed. The study found that transverse cracks occurred in $60 \%$ of all spans and in $71 \%$ of all bridges. In addition, the study determined:

- Decks constructed with SIP forms exhibited much less cracking than those built with removable forms.

- The transverse crack intensity (total length of cracks per $100 \mathrm{ft}^{2}$ ) increased as the span length increased.

- Superstructure type had a significant effect on the amount of cracking observed. Steel bridges had more cracking than prestressed concrete bridges.

- Continuous span bridges showed more cracking than simply supported span bridges.

- Construction practices were the single most influential variable in the extent of cracking observed in bridge decks.

\subsubsection{Purvis, Babei, Udani, Qanbari, and Williams}

Purvis et al. (1995) performed 99 field surveys and 12 in-depth surveys of different bridges in Pennsylvania to assess the causes of transverse cracking in bridge decks. The in-depth surveys included crack mapping, crack width measurement, rebar location and depth surveys, and concrete coring. Background design and construction records were also reviewed.

The researchers found that transverse cracks intersected coarse aggregate particles indicating that transverse cracking was occurring in hardened concrete and was likely caused by drying and thermal shrinkage. Transverse cracks occurred through the plane of the transverse reinforcement due to planes of weakness caused by settlement-induced strains occurring while the concrete was still plastic.

The researchers also performed a laboratory shrinkage study to investigate the effects of aggregate types on shrinkage of concrete, the effects of cement source and type on drying and thermal shrinkage, and the effect of fly-ash on shrinkage.

The researchers recommended that the maximum differential deck/beam temperature be limited to $22^{\circ} \mathrm{F}\left(12^{\circ} \mathrm{C}\right)$ for 24 hours after the deck is placed. The study also recommended limiting the 4-month concrete drying shrinkage to 700 microstrain.

\subsubsection{Schmitt and Darwin}

The Kansas Department of Transportation sponsored research to study the effects of different variables on bridge deck cracking. The study divided the variables into five categories: (1) material properties, (2) site conditions, (3) construction procedures, (4) design specifications, and (5) traffic and age (Schmitt and Darwin 1995).

The material properties considered in the study included admixtures, slump, percent volume of water and cement, water content, cement content, water-cement ratio, 
air content, and compressive strength. The researchers determined that deck cracking increased with increasing slump, water content, cement content, and water-cement ratio. Cracking was found to increase as the water and cement volumes grew above 27.5 percent. Furthermore, cracking was found to increase as compressive strength increased which corresponded to increasing cement content. Cracking decreased as air contents increased, particularly for air contents greater than $6 \%$. No correlation was determined between deck cracking and the type of admixture used.

The site conditions considered in the study included average air temperature, low air temperature, high air temperature, daily temperature range, relative humidity, average wind velocity, and evaporation. The researchers were not able to discern trends between average or low air temperature and cracking. However, cracking increased significantly as the maximum daily air temperature increased. Cracking also increased when the daily temperature range increased. The researchers did not find a relationship between cracking and relative humidity, average wind velocity, or evaporation rate.

The construction procedures considered in the study included placing sequence, length of placement, and curing. The researchers did not observe any relationship between length of placement or type of curing materials and cracking. Due to a lack of information, the researchers were not able to draw conclusions regarding the effect of placing sequence on deck cracking.

The design parameters considered in the study were structure type, deck type, deck thickness, top cover, transverse reinforcing bar size, transverse reinforcing bar spacing, girder end conditions, span length, bridge length, span type, and skew. The researchers found that structure type had little effect on cracking. The researchers were unable to evaluate the effect of deck thickness as the majority of bridge decks studied were 8.5 in. thick. No clear conclusions were drawn with respect to the effects of top cover and transverse reinforcement bar size on cracking; however, cracking did increase as transverse reinforcement spacing increased. The researchers noted that girder end condition appeared to affect deck cracking as fixed girders had more cracks than pinned girders. While no clear relationship between span length and cracking was observed, increasing bridge length increased cracking. The researchers did not observe any clear trends between cracking and span type or skew.

The traffic and age variables considered in this study included the average annual daily traffic (AADT) and the age of the deck. The researchers found that cracking increased with traffic volume, and that bridges constructed prior to 1988 exhibited less cracking than bridges constructed after 1988. The researchers attribute the increase in cracking in newer bridges (1988 and later) to changes in construction, material properties, and design specifications which occurred over the years.

\subsubsection{Krauss and Rogalla}

Krauss and Rogalla (1996) surveyed 52 transportation agencies in the United States and Canada to evaluate the extent of early age transverse cracking. The researchers found that over 100,000 bridges in the United States developed early transverse cracks. The survey respondents indicated that stiffer decks and larger amounts 
of reinforcement $\left(\rho_{g}=220 / \sqrt{s}\right.$ versus $\rho_{g}=100 / \sqrt{s}$, where $\rho_{g}$ is the percentage of reinforcement with respect to the gross section and $s$ is the effective span length in $\mathrm{ft}$, as recommended by AASHTO) reduced transverse cracking. The respondents also recommended a minimum clear cover of 1.5 in. over the reinforcement and a maximum clear cover of 3 in. Additionally, the minimum recommended thickness of the deck should be between 8 and 9 in.

In addition, the analytical studies were performed using both theoretical and finite element analysis techniques to evaluate the influence of various parameters on transverse cracking. These factors included drying shrinkage, creep, hydration temperatures and other thermal effects, position and amount of reinforcing steel, girder size and spacing, single- and two-span conditions, and age. The parametric study included bridge decks constructed on steel girders, reinforced concrete girders, precast-prestressed concrete girders, and cast-in-place post-tensioned girders. Three different temperature profiles and two different deck drying shrinkage profile conditions were also studied. From the parametric study, the researchers determined that the design factors which most significantly affected cracking were span type, concrete strength, and girder type.

The researchers also observed that the amount of restraint provided, the amount of drying shrinkage, thermal movements of the deck and girders, and effective modulus of elasticity of the concrete affect the stresses and risk of transverse cracking in a bridge deck. The material properties of the concrete such as cement content, cement composition, early-age elastic modulus, creep, aggregate type, heat of hydration, and drying shrinkage also influenced cracking.

\subsubsection{Eppers, French, and Hajjar}

Eppers et al. (1998) surveyed 72 bridge decks in Minnesota. Dominant design factors impacting transverse cracking were identified as longitudinal restraint, deck thickness, and top transverse bar size. Material related parameters most affecting transverse cracking were found to be cement content, aggregate type and quantity, and air content. Additionally, the researchers observed that decks constructed on simply supported prestressed girder bridges were in good condition relative to those constructed on continuous steel girder bridges. Furthermore, diaphragms caused stress concentrations, and staggered diaphragms with closer spacing resulted in more tightly spaced cracks, which indicated smaller crack widths.

Based on the field study, the researchers recommended the following:

- Reduce restraint by using bridge expansion joints, simply supported spans, increasing girder spacing, and providing fewer shear connectors.

- Use \#5 top transverse bars in concrete bridge decks on steel girders.

- Reduce the paste volume of the mix designs being used, use lower water-cement ratios, select minimum air content between $5.5 \%$ and $6.0 \%$, maximize the coarse and fine aggregate content, and improve curing in the field. 


\subsubsection{Le, French, and Hajjar}

Le et al. (1998) performed a shrinkage study for two Minnesota Department of Transportation mix designs and a parametric study to assess the effects of individual parameters on transverse cracking in bridge decks. A change in the standard mix design used by the state was suspected as the cause of increased transverse cracking. The shrinkage study determined that there was not a significant difference in free shrinkage between the two mix designs. Nonetheless, both mix designs exhibited higher initial shrinkage rates compared to that predicted by ACI 209 (ACI 1992). An observed preponderance of cracking in both old and new decks was credited to the high initial shrinkage rates observed in both mix designs considered in the shrinkage study.

The parametric study considered bridges with steel and prestressed concrete girders. The variables considered for the steel girder bridges included: end conditions; girder stiffness; locations of cross frames, girder splices, and supplemental reinforcing bars; shrinkage properties; concrete modulus; and temperature differential due to heat of hydration. The variables for the prestressed girder bridge included the times casting relative to the times of both strand release and deck casting, and shrinkage properties of the both the deck and the girders. The parametric study determined the following:

- Prestressed girder bridges with typical construction timelines did not exhibit transverse cracking due to lack of restraint at the end supports and the ability of concrete girders to shrink with the deck over time.

- Prestressed girder bridges where strand release was delayed resulted in higher tensile stresses in the deck.

- Decks placed on aged, prestressed girders developed high tensile stresses as a result of differential shrinkage between the girder and the deck.

- Steel girder bridges exhibited cracking in both the positive and negative moment regions of the bridge deck.

- Differential shrinkage between the deck and the girders was cited as the main cause of cracking.

- Ultimate shrinkage did not significantly affect the tensile stresses in the deck due to mitigation of stress through creep of the concrete.

- End conditions significantly affected the amount of transverse cracking. Cracking was most extensive in the fixed-fixed case and not observed in the simplysupported case.

- Girder stiffness, cross frames, and splices dictated crack locations.

The parametric study recommended reducing longitudinal restraint of the concrete deck by reducing the continuity of the deck over interior supports through the use of expansion joints on continuous girders, minimizing girder restraint through increased girder spacings, and minimizing shear connector restraint by using fewer rows of studs, and constructing with shorter, smaller diameter studs. Nevertheless, the researchers concede that reducing restraint in the deck may significantly affect bridge performance (larger girders and greater deflections) and must be implemented with consideration given to other aspects of bridge performance. 


\subsubsection{Frosch, Radabaugh, and Blackman}

Frosch et al. (2003) investigated factors affecting transverse and longitudinal bridge deck cracking. The researchers performed a field study and instrumented a typical bridge structure to observe the behavior of transverse cracks in a concrete bridge deck. The field study determined that transverse cracks form as a result of longitudinal restraint of shrinkage of the deck by the girders.

Based on the findings of the field study, the researchers constructed laboratory specimens to evaluate the effects of differing bridge deck designs on the control of overall shrinkage and to determine the contribution of SIP steel forms to the formation of transverse cracking. Laboratory specimens were also constructed to assess the effect of formwork type on restrained shrinkage. The laboratory study determined:

- The stiffness of SIP deck forms contribute to reducing overall shrinkage. The sealing effect of SIP forms tended to reduce the total amount of shrinkage, but also increased curling in the specimens.

- Shrinkage in reinforced specimens is restrained by the reinforcement. Specimens containing reinforcement had slightly lower measured shrinkage strains.

- SIP deck forms increased the amount of restraint in specimens.

- Specimens with non-permanent forms experienced an increase in strain rate after forms were removed, which indicated decks constructed with removable forms may experience larger total shrinkage than those constructed with SIP forms. The effect of reinforcing bar spacing and epoxy coating thickness on crack width and spacing were also evaluated in this study. The researchers observed:

- The spacing of reinforcement significantly affected the width and spacing of cracks. As reinforcement spacing increased, crack widths increased.

- Epoxy coating thickness also affected the width and spacing of cracks. As epoxy coating thickness increased, crack widths increased.

The researchers recommended that drying shrinkage of concrete be minimized through mix design and materials selection. Concrete compressive strength should also be minimized to take advantage of the beneficial effects of creep in the deck. The researchers also recommended that additional reinforcement be provided above current practice to control crack widths in concrete decks. In addition, the spacing of reinforcement should be decreased to control bridge deck cracking.

\subsubsection{Xi, Shing, Abu-Hejleh, Asiz, Suwito, Xie, and Ababneh}

The Colorado Department of Transportation sponsored research to assess the extent and causes of transverse cracking in newly constructed Colorado bridge decks. A database analysis of 72 bridge decks constructed between 1993 and 2002 in Colorado was performed. Recommendations for changes to material properties, construction procedures, and design specifications were made. The researchers recommended limiting cement content to $470 \mathrm{lb} / \mathrm{yd}^{3}$ or less, using a w/c ratio of 0.4 , limiting silica fume content to $5 \%$ by weight of cement, and using large, well graded aggregates. Design recommendations were provided and included decreasing bar size in negative moment regions, increasing amounts of longitudinal reinforcement, reducing end restraints, using 
girders with greater flexibility, offsetting top transverse bars from bottom transverse bars, and using a minimum deck thickness of 8.5 in.

\subsection{Control of Temperature and Shrinkage Cracks}

General provisions for the control of shrinkage and temperature cracking in concrete structures are provided by the American Concrete Institute (ACI). Provisions for the design of bridge decks are provided by the American Association of State Highway and Transportation Officials (AASHTO).

\subsubsection{ACI}

ACI 318-05 specifies the amount of reinforcement for control of temperature and shrinkage cracking as $0.18 \%$ of the gross area for Grade 60 reinforcement; however, this is based solely on empirical observations (ACI 2005). Furthermore, ACI 224-01 states that a reinforcement ratio of $0.18 \%$ will not control crack widths at acceptable levels, and a ratio of $0.60 \%$ should be used instead (ACI 2001). These recommendations are for the case of unrestrained shrinkage. For the restrained shrinkage case, ACI 318-05 states that the effects of shrinkage shall be considered, but does not give any further guidance. In addition to these requirements, ACI 318-05 requires that reinforcement not be spaced more than the lesser of three times the thickness of the deck or $18 \mathrm{in}$.

\subsubsection{AASHTO}

AASHTO currently provides two different methods for performing bridge design: The Standard Specifications and the LRFD Bridge Design Specifications. The AASHTO Standard Specifications are based on a design philosophy known as working stress design, wherein allowable stresses are specified as a given fraction or percentage of a given material's load-carrying capacity (AASHTO 2004). The AASHTO LRFD design specifications are based on a philosophy which incorporates both the variabilities in the properties of structural elements as well as the variabilities of applied loads (AASHTO 2004).

\subsubsection{AASHTO Standard Specifications}

The $17^{\text {th }}$ edition AASHTO standard specifications (AASHTO 2002) state that reinforcement to control shrinkage and temperature effects shall be provided if not otherwise reinforced. The total area of reinforcement provided shall be at least $1 / 8 \mathrm{in} .^{2}$ per foot in both directions and cannot be spaced greater than the lesser of three times the slab thickness or 18 in. 


\subsubsection{AASHTO LRFD Specifications}

The AASHTO LRFD bridge specifications (AASHTO 2004) allow designers two methods for designing reinforcement in the bridge deck. The traditional method is based on a rigorous analysis of flexural loads applied to the bridge deck. The empirical method allows designers to specify a given amount of reinforcement provided the bridge deck meets certain criteria.

\subsection{Traditional Design}

The $3^{\text {rd }}$ edition AASHTO LRFD bridge specifications (AASHTO 2004) state that the designer must check that a minimum amount of reinforcement for control of temperature and shrinkage cracks is provided:

$$
A_{s} \geq 0.11 \frac{A_{g}}{f_{y}}
$$

where:

$$
\begin{aligned}
f_{y} & =\text { yield stress of reinforcement, } \mathrm{ksi} \\
A_{s} & =\text { area of reinforcement, in. }{ }^{2} \\
A_{g} & =\text { gross area of concrete, in. }{ }^{2}
\end{aligned}
$$

However, the LRFD specifications also require distribution reinforcement be provided as a percentage of the primary reinforcement. When the primary reinforcement is parallel to traffic the distribution reinforcement is computed as:

$$
\frac{100}{\sqrt{S}} \leq 50 \%
$$

where:

$$
\begin{aligned}
S= & \text { effective span length, } \mathrm{ft} \text {; which is defined for slabs on } \\
& \text { steel or concrete girders as the distance between flange } \\
& \text { tips plus the flange overhang }
\end{aligned}
$$

For the case of primary reinforcement perpendicular to the traffic, the distribution reinforcement required is computed as:

$$
\frac{220}{\sqrt{S}} \leq 67 \%
$$

Typically, the amount of steel required for distribution reinforcement will control over the minimum amount specified to control temperature and shrinkage. The reinforcement is not allowed to be spaced greater than either three times the thickness of the slab or 18 in.

\subsection{Empirical Design}

The AASHTO LFRD (AASHTO 2004) empirical design method allows engineers to specify the amount of steel reinforcement in the deck without performing a rigorous design provided the bridge deck meets certain criteria. The deck must meet the following criteria:

- Fully cast-in-place and made composite with the supporting structure

- Depth of at least 7 in. 
- Compressive strength $f_{c}^{\prime}$ of at least $4 \mathrm{ksi}$

- Effective slab span no more than $13.5 \mathrm{ft}$ between girders

- Constructed with diaphragms between the girders at lines of support

If these requirements are met, four layers of isotropic reinforcement can be provided with the following minimum requirements: $0.27 \mathrm{in}{ }^{2} / \mathrm{ft}$ for each bottom layer and $0.18 \mathrm{in.}^{2} / \mathrm{ft}$ for each top layer (AASHTO 2004).

Empirical design of bridge decks is based on internal arch action occurring in the deck between the girders (AASHTO 2004). Arch action alone cannot carry the full flexural load (AASHTO 2004); therefore, a minimum amount of reinforcement must be provided to resist a small portion of flexure as well as confine the deck concrete so that arching can occur (Fang et al. 1986).

The empirical deck design is solely based on strength considerations and does not consider durability concerns. The only stipulation is that the reinforcement shall not be spaced greater than $18 \mathrm{in.} \mathrm{(AASHTO} \mathrm{2004).} \mathrm{The} \mathrm{commentary} \mathrm{states} \mathrm{that} \mathrm{a} \mathrm{reinforcement}$ ratio of $0.3 \%$ for the bottom layer was selected by AASHTO to better control cracks in the positive moment region (which corresponds to $0.27 \mathrm{in} .{ }^{2} / \mathrm{ft}$ for a $7.5 \mathrm{in}$. thick deck). However, this requirement as based on load-induced flexure cracking and not shrinkage and temperature.

\subsubsection{ACI 440}

ACI 440 provides guidance for the design of structural concrete reinforced with FRP bars. As there is no experimental data available for the minimum amount of reinforcement required for shrinkage and temperature with FRP bars, ACI 440 modified the recommendation provided by ACI 318 (Section 7.12.2) for steel reinforcement by simply multiplying by the modular ratio. The amount of temperature and shrinkage reinforcement to be provided when using deformed FRP reinforcement can be computed as:

$$
\rho_{f, t s}=0.0018 \times \frac{60,000}{f_{f u}} \frac{E_{s}}{E_{f}}
$$

ACI 440 further recommends that the amount of temperature and shrinkage reinforcement provided should not be less than $0.14 \%$. The spacing of temperature and shrinkage FRP reinforcement should not exceed the lesser of three times the slab thickness or 12 in. (ACI 440 2006).

\subsection{History of Code Requirements to Control Shrinkage Cracking}

\subsubsection{ACI Requirements}

Prior to the first concrete building code, engineers were considering the effects of restrained shrinkage in their designs. As early as 1912, the use of temperature and 
shrinkage reinforcement in amounts between 0.002 and 0.004 were being used in practice to control surface cracks (Hool 1912). Hool notes that these amounts are less than the theoretical amounts required but, "experience shows this amount to give very satisfactory results where the foundations are stable".

\subsubsection{ACI 1920}

The first standards of any kind for control of cracking due to volumetric changes of concrete are found in the 1920 version of the concrete code, Standard Specifications No. 23.

For slabs designed to span one way, steel having an area of at least two-tenths of one percent $(0.2 \%)$ of section of slab shall be provided transverse to main reinforcement.

\subsubsection{ACI 1936}

The first precursor to modern temperature and shrinkage specifications can be found in Article 116 of The Report of the Joint Committee on Standard Specifications for Concrete and Reinforced Concrete in 1924 (Sutherland and Clifford 1926). The article gives a requirement for transverse reinforcement in the top of a slab, "not less in amount than 0.3 per cent of the sectional area of the slab," and the spacing of the bars was not to exceed 18 in. (Sutherland and Clifford 1926).

ACI 501-36-T first explicitly defined the requirements for control of temperature and shrinkage steel in Section 708. The 1936 code incorporated the tentative standards defined by the ACI committee E-1 report (PCA 1928). The code states that shrinkage and temperature steel will be placed normal to the principal reinforcement in regions where principal reinforcement extends in only one direction (PCA 1928, ACI 1936). The reinforcement spacing is limited to the lesser of five times the thickness of the slab or 18 inches (PCA 1928, ACI 1936). The code also defined the amount of reinforcement to be used as the following ratios per gross area:

Floor slabs where plain bars are used. 0.0025

Floor slabs where deformed bars are used...................0.002

Floor slabs where wire fabric is used, having welded intersections not farther apart than 12 inches....................................................0.0018

Roof slabs where plain bars are used..........................0.003

Roof slabs where deformed bars are used ..................0.0025

Roof slabs where wire fabric is used, having welded intersections not farther apart than 12 inches .0 .0022 


\subsubsection{ACI 1956}

The requirements defined in the 1936 code remained unchanged until 1956. Nonetheless, there were indications that the minimum amounts given by the specifications were inadequate and that it was appropriate to compute the amounts provided from "fundamental mechanics" (Large 1950).

The separate requirements differentiating roof slabs from floor slabs were discontinued in the 1956 edition of the code (ACI 1956). Additionally, in Appendix A of the 1956 code, (ACI-ASCE Joint Report on Ultimate Strength Design), the first specification for designing for the effects of significant forces resulting from shrinkage and temperature were provided.

In arches the effect of shortening of the arch axis, temperature, shrinkage, and secondary moments due to deflections shall be considered.

\subsubsection{ACI 1963}

While the spacing requirements for shrinkage reinforcement remained unchanged, in the 1963 code, Section 707 was changed to Section 807 and high strength reinforcing steel bars were given consideration.

Slabs where plain bars are used 0.0025

Slabs where deformed bars with specified yield strengths less

than 60,000 psi are used. .0 .002

Slabs where deformed bars with 60,000 psi specified yield strength

or welded wire fabric having welded intersections not farther apart in the direction of stress than 12 in. are used.. 0.0018

Additionally, Section 903 was added to the code stating that, "Consideration shall be given to the effects of forces due to...shrinkage, [and] temperature changes..." (ACI 1963). Furthermore, the commentary in Section 807 of the code states:

The amounts specified are empirical, but have been used satisfactorily for many years... The provisions of this section apply to 'structural floor and roof slabs' only and not to slabs on ground.

With the inclusion of the commentary in the 1963 edition, the committee states for the first time that the amounts of reinforcement specified are empirical. 


\subsubsection{ACI 1971}

In 1971, the requirements for temperature and shrinkage reinforcement were included in Section 7.13 and rewritten as follows:

Slabs where Grade 40 or 50

deformed bars are used. 0.0020

Slabs where Grade 60 deformed

bars or welded wire fabric, deformed or plain are used. .0 .0018

Slabs where reinforcement with a yield strength exceeding 60,000 psi measured at a yield strain of 0.35 percent is used ...... $\frac{0.0018 \times 60,000}{f_{y}}$

In addition to the minimum requirements for temperature and shrinkage, Section 9.3.7 states that,

Where the structural effects of differential settlement, creep, shrinkage or temperature change may be significant, they shall be included with the dead load $D$ and strength $U$ shall be at least equal to $0.75(1.4 D+1.7 L)$.

\subsubsection{ACI 1977}

The code was reorganized in 1977, and the minimum requirements for amount and spacing of reinforcement were moved to Section 7.12. The provisions which consider significant effects of temperature and shrinkage were moved to Section 8.2.4.

Consideration shall be given to effects of forces due to prestressing, crane loads, vibration, impact, shrinkage, temperature changes, creep, and unequal settlement of supports

The manner in which to consider significant loads were placed in Section 9.2.7 and rewritten as follows:

Where structural effects $T$ of differential settlement, creep, shrinkage, or temperature change may be significant in design, required strength $U$ shall be at least

$U=0.75(1.4 D+1.4 T+1.7 L)$

but required strength $U$ shall not be less than 


$$
U=1.4(D+T)
$$

\subsubsection{ACI 1995}

In 1995, Section 7.12.2.1 of the code, which prescribes the amounts of reinforcement required for control of temperature and shrinkage remained unchanged from previous editions. The commentary to the code states that the minimum requirements for temperature and shrinkage reinforcement specified by Section 7.12 are, "satisfactory where temperature and shrinkage movements are permitted to occur (ACI 1995)." The code requires in Section 7.12.1.2

Where shrinkage and temperature movements are

significantly restrained, the requirements of 8.2.4 and 9.2.7 shall be considered.

The code refers the designer to Section 8.2.4 wherein the code simply states that significant effects of temperature and shrinkage shall be considered. No guidance is provided as to what cases are significant or how to appropriately design for restrained shrinkage. The commentary for Section 8.2.4 provides some additional guidance:

For cases where structural walls or large columns provide significant restraints to temperature and shrinkage movements, it may be necessary to increase the amount of reinforcement normal to the flexural reinforcement.

While the commentary recognizes that additional reinforcement may be necessary for a restrained shrinkage condition, it does not provide guidance regarding how much reinforcement is required. Furthermore, the code does not consider whether or not the spacing requirements are appropriate when restraint is present.

\subsubsection{ACI 2005}

The current edition of the code has not changed since the 1995 edition, with respect to control of temperature and shrinkage.

\subsubsection{AASHTO Requirements}

The 1941 American Association of State Highway Officials (AASHO) specifications stipulates in Section 3.7.5 that provision for temperature changes shall be made in all spans having a clear length greater than $40 \mathrm{ft}$. Furthermore, it is stated that "for continuous bridges, the engineer shall design to resist thermal stress or means for movement due to temperature changes will be provided (AASHO 1941)". However, the specifications do not specify the amount or spacing of reinforcement to be provided to 
resist volumetric changes of the concrete. Expansion and contraction of the bridges were to be allowed through means of "hinged columns, rockers, sliding plates or other devices (AASHO 1941)". Common design and construction practices were intended to minimize restraint and thus reduce the potential for cracking.

Provisions for composite beam construction in bridges were first provided in 1944 (AASHO 1944); however, the code did not specify any requirements for resisting restrained shrinkage of the concrete deck by the girder. In 1957, the specifications state that if concrete with "expansive characteristics" were used, composite construction "should be used with caution and provision must be made in the design to accommodate the expansion (AASHO 1957)." As with the provisions for expansion under general concrete construction, the code mandated that volumetric changes be given freedom of movement, typically achieved through the use of joints, rockers, or sliding plates. These designs eliminated restraint in the end conditions, but failed to account for the lines of restraint present in the deck through the coupling of the deck to the steel girders. Furthermore, the code did not provide guidance in regards to the reinforcement required to resist stresses induced in the concrete from shrinkage or temperature changes.

The 1965 edition of AASHO standard specifications included requirements for distribution reinforcement in the slab for the first time. The amounts specified are identical to the current requirements for distribution reinforcement as defined by Equations 1.2 and 1.3 in Section 1.4.2.2.1 (AASHO 1965). While no specifications are provided which relate specifically to temperature and shrinkage reinforcement, in general, the distribution reinforcement requirements control the amount of reinforcement which will resist temperature and shrinkage effects.

The first explicit specifications for temperature and shrinkage reinforcement were provided in the $10^{\text {th }}$ edition of the AASHO standard specifications (AASHO 1969). Section 1.5.6 $(\mathrm{H})$ of the specifications states:

Not less than $1 / 8$ square inch of reinforcement per foot shall be placed in each direction of all concrete surfaces to resist the formation of temperature and shrinkage cracks. The maximum spacing shall be 18-inches. This reinforcement is not required if the surface is covered by at least $11 / 2$ feet of earth.

For an 8 in. thick deck, this requirement results in a reinforcement ratio of $\rho_{g}=$ $0.13 \%$ for the gross section of the deck, which is less than the amount specified by ACI $\left(\rho_{g}=0.18 \%\right)$ for control of temperature and shrinkage effects.

\subsection{Crack Control Provided by Reinforcement}

As reinforced concrete shrinks, the reinforcement does not. As such, prior to crack formation, reinforcement acts as an additional source of restraint to the shrinkage of concrete and thereby increases the susceptibility of the concrete to cracking. The amount of restraint provided by the reinforcement can be quantified as the difference in the 
unrestrained and restrained concrete shrinkage strains. Until cracking occurs, compatibility between the concrete and the reinforcement is maintained. Thus, the reinforcement is "pushed on" (compression) by the concrete and the concrete is "pulled on" (tension) by the reinforcement. Alexander (2005) developed a rational approach for providing sufficient reinforcement for controlling cracking in direct tension. The internal restraint provided by the reinforcement in a symmetrically reinforced section is illustrated in Figure 1.3, and the restrained shrinkage can be defined as:

$$
\varepsilon_{c r}=\varepsilon_{s}=\frac{\varepsilon_{c s}}{1+n \rho_{n}}
$$

where:

$$
\begin{aligned}
& \varepsilon_{c r}=\text { restrained concrete shrinkage strain } \\
& \varepsilon_{s}=\text { strain in the reinforcement } \\
& \varepsilon_{c s}=\text { unrestrained concrete shrinkage strain } \\
& n=\text { modular ratio between steel and concrete, } E_{s} / E_{c} \\
& \rho_{n}=\text { reinforcement ratio, } A_{s} / A_{c}
\end{aligned}
$$

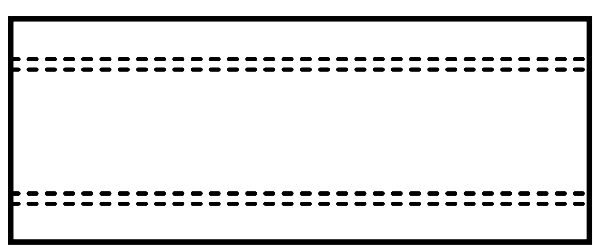

a. Before Shrinkage

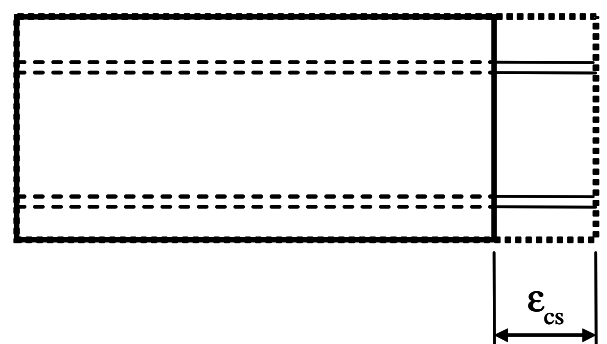

b. After unrestrained shrinkage

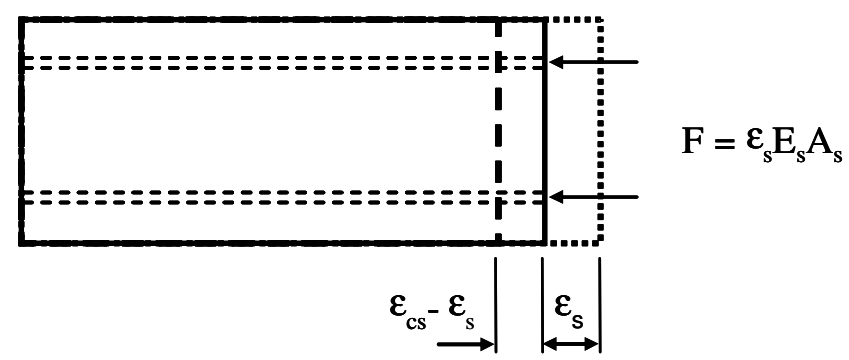

c. Shrinkage restrained by reinforcement

Figure 1.3: Shrinkage Restrained by Reinforcement in a Symmetrically Reinforced Section (Alexander 2005) 
It is not until after cracks develop in the concrete that reinforcement is able to control cracks. Thus, while reinforcement does not contribute to preventing cracks, it does limit the severity of cracks which do develop. After the concrete cracks, compatibility between the steel and concrete is no longer present. The reinforcement across the crack will be in tension, while the reinforcement away from the crack will remain in compression. Therefore, it is necessary to ensure that the reinforcement crossing the crack does not yield and cause excessive crack widths to occur. Frosch et al. (2003) recommended that the total amount of reinforcing steel to prevent uncontrolled crack growth is:

$$
A_{s}=\frac{6 \sqrt{f^{\prime}{ }_{c}}}{f_{y}} A_{g}
$$

where:

$$
\begin{aligned}
A_{g} & =\text { gross area of section, in. }{ }^{2} \\
A_{s} & =\text { area of reinforcement in cross-section, in. }{ }^{2} \\
f_{c}^{\prime} & =\text { specified compressive strength of concrete, psi. } \\
f_{y} & =\text { specified yield strength of reinforcement, psi. }
\end{aligned}
$$

This recommendation is based on the tensile strength of concrete in direct tension taken as $6 \sqrt{f_{c}^{\prime}}$ and full transfer of stress in the concrete at the location of the crack prior to cracking into the reinforcement. For 4000 psi concrete and 60,000 psi reinforcement, this recommendation results in $0.63 \%$ steel in the deck cross-section (Frosch et al. 2003). In comparison, design by AASHTO empirical method results in $0.5 \%$ steel for a $7.5 \mathrm{in}$. thick deck. For further comparison, a deck designed by the AASHTO traditional design requires the percentage of distribution reinforcement would be $\rho_{\mathrm{g}}=0.54 \%$ when the spacing between girders is $7 \mathrm{ft}$, an $8 \mathrm{in}$. bridge deck, and primary reinforcement selected as \#5 bars at 12 in. perpendicular to traffic $\left(\mathrm{A}_{\mathrm{s}}=0.78 \mathrm{in} .{ }^{2} / \mathrm{ft}, \rho_{\mathrm{g}}=0.81 \%\right)$.

Controlling the amount of reinforcement alone, however, will not prevent excessive crack widths. The spacing of the reinforcement influences the effectiveness of the amount of reinforcement provided with respect to controlling crack widths. For flexure, it is well established that the width of the crack is proportional to the effective depth of cover (Broms 1965). The effective depth of cover, $d^{*}$, in a slab is illustrated in Figure 1.4. It is evident that by decreasing the spacing of the reinforcement, the effective depth of cover is reduced. Based on this relationship, Frosch (1999) developed a model that recommends that the maximum spacing of reinforcement as a function of cover be given as:

$$
s=12 \alpha_{s}\left[2-\frac{d_{c}}{3 \alpha_{s}}\right] \leq 12 \alpha_{s}
$$

where:

$$
\alpha_{s}=\frac{36}{f_{s}} \gamma_{c}
$$

$d_{c}=$ thickness of the concrete cover, in

$s \quad=$ maximum spacing of reinforcement, in. 

$f_{s} \quad=$ reinforcing steel stress; can be approximated as $0.6 f_{y} \mathrm{ksi}$
$\alpha_{s}=$ reinforcement factor
$\gamma_{c} \quad=$ reinforcement coating factor: 1.0 for uncoated reinforcement; 0.5 for epoxy-coated reinforcement, unless test data can justify a higher value.

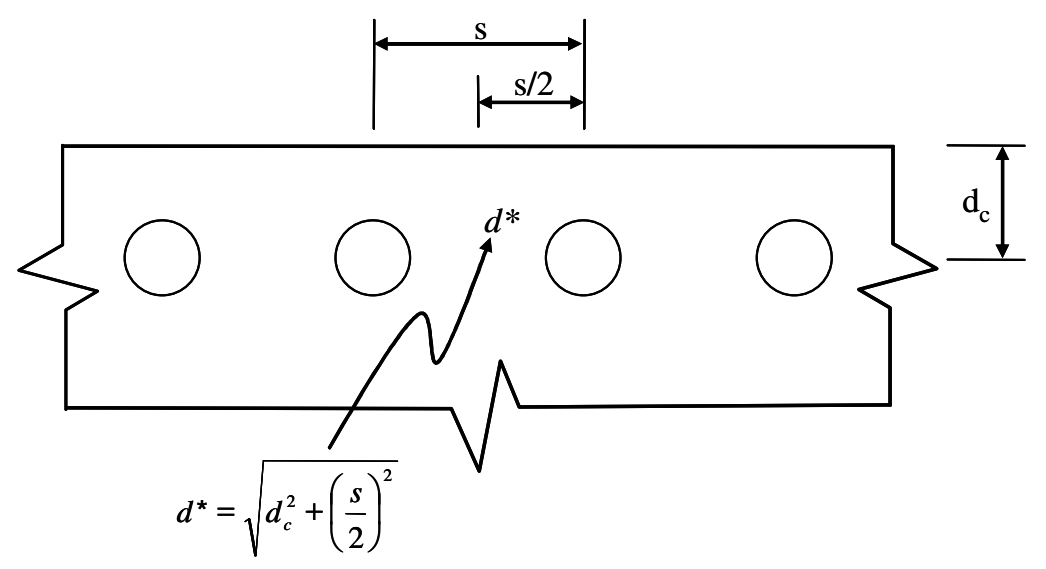

Figure 1.4: Controlling Cover Distance (Frosch 1999)

To further refine the value of $\gamma_{c}$, Blackman and Frosch determined that within the range of normal epoxy coating thicknesses, both average and maximum crack widths were approximately $30 \%$ larger than structures when uncoated reinforcement is incorporated (2005). Furthermore, the researchers determined that reinforcement spacing less than $18 \mathrm{in}$. is required to limit cracks to a maximum of 16 mil for both uncoated and epoxy coated reinforcement (Blackman and Frosch 2005). For epoxy coated steel bars and a deck with a cover of 1.5 in., Blackman and Frosch recommended limiting the maximum spacing of the reinforcement to 6 in. (2005).

\subsection{Objective and Scope of Research}

Current design methods for control of shrinkage cracks in reinforced concrete are based on empirical observation. While current design recommendations are provided for shrinkage reinforcement, the recommendations are not applicable to the case of restrained shrinkage. Furthermore, very limited guidance is available for cases where restraint is present. The objective of this research is to develop rational design recommendations for the control of restrained shrinkage cracking that can be used for structures which incorporate either steel or FRP reinforcement. While a variety of design characteristics will be considered, the research will focus on reinforcement as the primary design parameter for the control of shrinkage cracks that form in concrete bridge decks.

This research will be conducted in two phases. The first phase of this research will consist of a field investigations on four different bridges which incorporate different 
designs and materials. The relative performances of the bridges will be compared and data will be collected and analyzed to provide insight into the global behavior of the bridges as they experienced volumetric changes in the deck as well as the superstructure. In the second phase of this research an analytical investigation will be performed. A simple, finite element model will be developed to simulate the behavior of reinforced concrete bridge decks. The model will be developed and calibrated in direct consideration of data from both laboratory and field studies. Using this model a parametric study will be performed wherein the impact if various design characteristics of bridges will be evaluated. Based on these results, design recommendations for the control of shrinkage cracking for both steel and FRP reinforcement will be provided. A goal of the study is to provide comprehensive design tools for the control of both restrained and unrestrained concrete shrinkage. 


\section{CHAPTER 2 FIELD STUDIES}

\subsection{Overview of Investigated Bridges}

Field investigations were performed to assess the relative performance of bridge decks with differing reinforcement designs as well as to provide data that could be used to calibrate analytical models. As a part of previous research to observe the early-age behavior of bridge decks in actual field conditions, Radabaugh (2001) instrumented and monitored the Interstate 65 (I-65) bridge over State Road 25 (SR 25). The State Road 18 (SR 18) bridge over I-65, Thayer Road Bridge over I-65, and State Road 23 (SR 23) bridge over U.S. Highway 20 (US 20) were instrumented and monitored as a part of the current research program. The characteristics of the different bridges considered are summarized in Table 2.1. Each bridge deck used a different design method which allows comparison of the influence of different design methods on the early-age behavior of the bridge deck. The different deck designs are summarized in Table 2.2.

Table 2.1: Characteristics of Bridges in Field Investigation

\begin{tabular}{|c|c|c|c|c|c|}
\hline Bridge & $\begin{array}{c}\text { No. of } \\
\text { Spans }\end{array}$ & $\begin{array}{c}\text { Length of Spans } \\
(\mathbf{f t})\end{array}$ & Girder Type & $\begin{array}{c}\text { Abutment } \\
\text { Type }\end{array}$ & $\begin{array}{c}\text { Skew } \\
\text { (degrees) }\end{array}$ \\
\hline $\begin{array}{c}\text { I 65 over } \\
\text { SR 25 }\end{array}$ & 2 & 76,76 & Steel & Integral & 25 \\
\hline $\begin{array}{c}\text { SR 18 over } \\
\text { I 65 }\end{array}$ & 2 & 123,123 & Steel & Semi-Integral & 30 \\
\hline $\begin{array}{c}\text { SR 23 over } \\
\text { US 20 }\end{array}$ & 2 & 101,101 & $\begin{array}{c}\text { Precast/Prestressed } \\
\text { Concrete }\end{array}$ & Integral & 11 \\
\hline $\begin{array}{c}\text { Thayer Rd } \\
\text { over I 65 }\end{array}$ & 5 & $39,63,77,63,39$ & Steel & Rockers & 5 \\
\hline
\end{tabular}


Table 2.2: Characteristics of Deck Reinforcement in Field Investigation

\begin{tabular}{|c|c|c|c|c|c|c|}
\hline \multirow{2}{*}{ Bridge } & \multicolumn{2}{|c|}{$\begin{array}{c}\text { Type of } \\
\text { Reinforcement }\end{array}$} & \multicolumn{2}{c|}{ Bar Size (\#) } & \multicolumn{2}{c|}{$\begin{array}{c}\text { Longitudinal } \\
\text { Reinforcement } \\
\text { Spacing (in.) }\end{array}$} \\
\cline { 2 - 7 } & Top & Bottom & Top & Bottom & Top & Bottom \\
\hline I 65 over SR 25 & Steel & Steel & 4 & 5 & 12 & 12 \\
\hline $\begin{array}{c}\text { SR 18 over I 65 } \\
\text { (Eastern Span) }\end{array}$ & Steel & Steel & 4 & 4 & 6 & 6 \\
\hline $\begin{array}{c}\text { SR 18 over I 65 } \\
\text { (Western Span) }\end{array}$ & Steel & Steel & 5 & 5 & 18 & 12 \\
\hline SR 23 over US 20 & Steel & Steel & 5 & 5 & 6 & 6 \\
\hline $\begin{array}{c}\text { Thayer Rd over } \\
\text { I 65 }\end{array}$ & GFRP & Steel & 5 & 5 & 6 & 9 \\
\hline
\end{tabular}

\subsection{Overview of Instrumentation Design}

Instrumentation was installed on all of the bridges in this study to gain insight into the behavior of the bridge deck with respect to cracking as it experiences volumetric changes (both shrinkage and thermal). Thus, instrumentation was designed to capture behavior at locations where cracking was probable. For concrete specimens restrained along the base or at the ends, cracks form first at the middle of the specimen, and then, as shrinkage continues, cracks will form subsequently at the quarter points, eighth points, and so forth until stresses in the concrete are less than the tensile strength of the concrete (ACI 207 1995). Thus, in general, strain gages were installed on reinforcement and embedded in the concrete deck at the midspans of the bridges investigated to capture the behavior of reinforcement crossing a crack.

The coefficient of thermal expansion of strain gages installed in the bridges was selected to match the coefficient of thermal expansion of the materials used. Thus, expansion and contraction resulting from temperature change are not measured if the strain gage and material of interest are free to undergo volume changes. However, when thermal volume changes are restrained, the measured strain is proportionally opposite with respect to the amount of restraint (i.e. increase in temperature results in a measured compressive strain). Therefore, thermocouples were installed through the depth of the superstructures monitored in this study as an additional means of evaluating restraint in the bridge.

\subsection{Interstate 65 over State Road 25}

Radabaugh (2001) instrumented the I-65 bridge over SR 25 in Lafayette, Indiana to assess design characteristics which would induce transverse cracking. This bridge is a 
$150 \mathrm{ft}$, two-span, continuous, steel superstructure bridge, which uses composite action and stay-in-place (SIP) steel forms. This bridge was designed and constructed to conform to the requirements in the Standard Specifications for Highway Bridges, $16^{\text {th }}$ Edition (AASHTO 1996) and INDOT Standard Specifications dated 1999 (INDOT 1999). The bridge deck was reinforced with \#4 bars in the top and \#5 bars in the bottom spaced at 12 in., as illustrated in Figure 2.1. The abutments were constructed fully integral with the girders. Complete details of the I- 65 bridge construction, materials, and instrumentation are discussed by Radabaugh (2001).

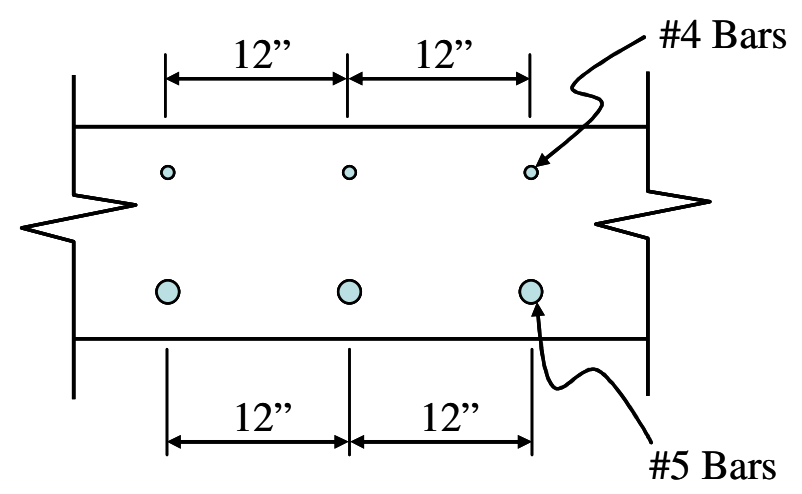

Figure 2.1: Longitudinal Reinforcement Design in I-65 over SR 25 Bridge

\subsubsection{I-65 Bridge Materials}

\subsubsection{Concrete}

An INDOT standard Class C concrete mix design was specified for the I-65 bridge deck with a design compressive strength of 4000 psi and a maximum aggregate size of $3 / 4$-in. The mix design is provided in Table 2.3.

Table 2.3: INDOT Class C Mix Design on I-65 Bridge (Radabaugh 2001) 


\begin{tabular}{|c|c|c|}
\hline Materials & Batch Weights & Specifications/Suppliers \\
\hline Cement & $659 \mathrm{lb} / \mathrm{yd}^{3}$ & ASTM C-150, Type I, Essroc Cement Co. \\
\hline Sand & $1220 \mathrm{lb} / \mathrm{yd}^{3}$ & $\begin{array}{c}\text { ASTM C-33 \& INDOT Specification \#23 Sand } \\
\text { from Vulcan Materials, Battleground , IN }\end{array}$ \\
\hline Stone & $1800 \mathrm{lb} / \mathrm{yd}^{3}$ & \#8 Stone from US Aggregate, Delphi, IN \\
\hline Water & $292 \mathrm{lb} / \mathrm{yd}^{3}$ & - \\
\hline Ash & None & - \\
\hline Micro-Silica & None & - \\
\hline Water Reducer & $13.2 \mathrm{oz} / \mathrm{yd}^{3}$ & $\begin{array}{c}\text { ASTM C-494, Water Reducer Type A Pozzolith } \\
\text { Water Reducer Pozzolith 440N (plant added). } \\
\text { Optional High Range Water Reducer (Super) } \\
\text { Daracem 100 (plant added) }\end{array}$ \\
\hline Air & $5-8 \%$ & $\begin{array}{c}\text { ASTM C-260 Air Entrainment, Micro Air by } \\
\text { Master Builders }\end{array}$ \\
\hline Slump & $4 \mathrm{in}$. & \multicolumn{2}{c}{ - } \\
\hline
\end{tabular}

Radabaugh (2001) obtained standard 6 in. by 12 in. compressive cylinder samples (ASTM C31) at the time of casting of the bridge deck. The cylinders were wet cured for the same duration as the deck. The concrete compressive strength was determined in accordance with ASTM C39. Figure 2.2 shows the strength-gain of the compressive cylinders from the I- 65 bridge. The average 28 -day compressive strength was $5800 \mathrm{psi}$. Radabaugh did not measure the split cylinder tensile strength or the modulus of elasticity of the concrete. 


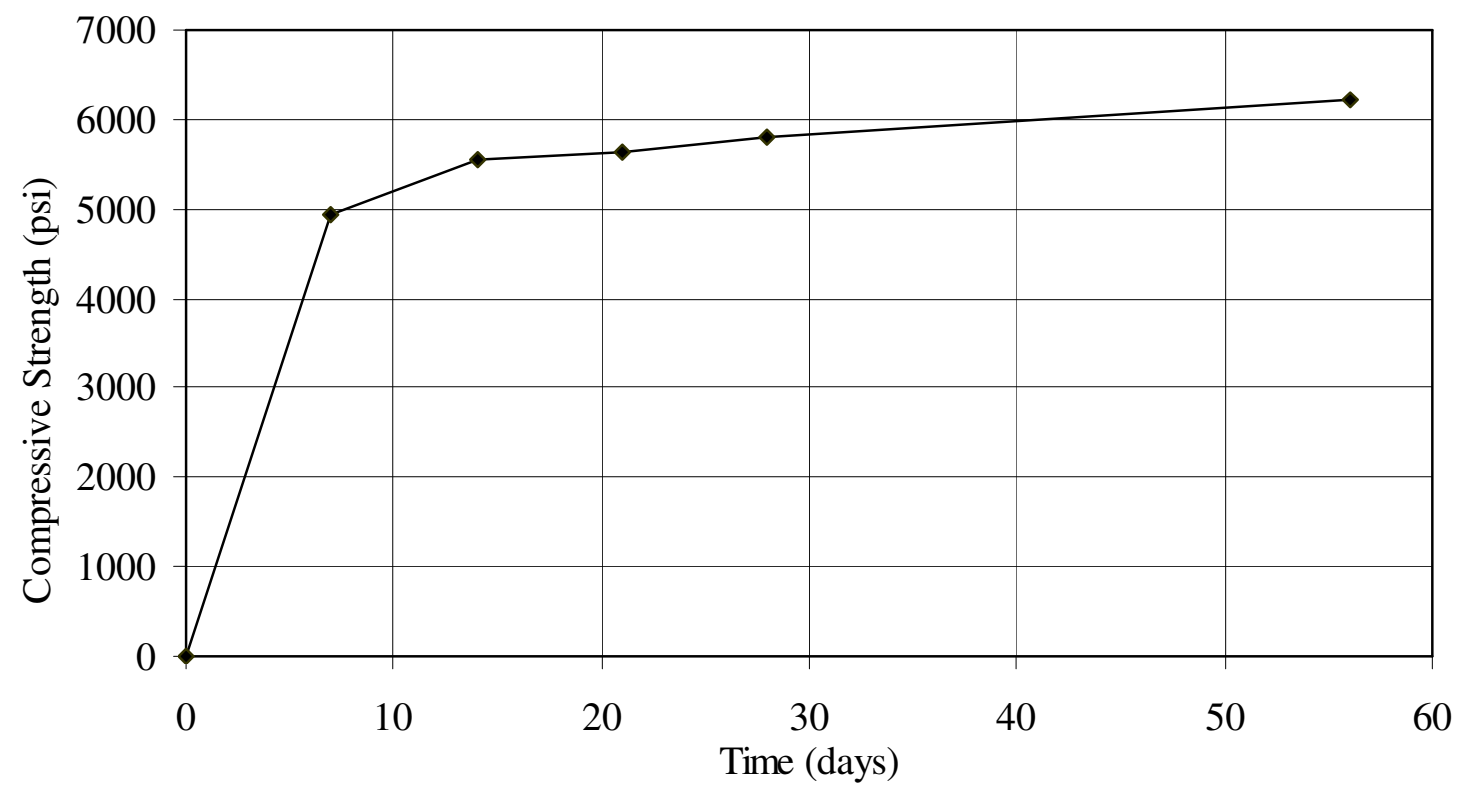

Figure 2.2: Compressive Strength Gain Curve for I-65 Bridge (Radabaugh 2001)

\subsubsection{Reinforcement}

The deck reinforcement comprised 3 bar sizes: \#4, \#5, and \#7. All reinforcing steel conformed to ASTM A615 Grade 60 and was epoxy coated (Radabaugh 2001).

\subsubsection{I-65 Bridge Instrumentation}

The I-65 bridge over SR 25 was instrumented with strain gages and thermocouples to measure and record the early-age strain and thermal gradients. Measurements were recorded using a Campbell Scientific CR10X datalogger every 10 minutes. Data collection began in August 2000 and was discontinued in April 2004. Complete details of the instrumentation installed on the I- 65 bridge are provided by Radabaugh (2001).

\subsubsection{Strain Gages}

Uniaxial, foil-backed, wire resistance strain gages were installed in the top and bottom reinforcement mats as well as on the girders (Radabaugh 2001). Figure 2.3 illustrates the locations of strain gages installed on the I- 65 bridge, and Figure 2.4 shows the locations of strain gages through the depth of the deck and girders. 


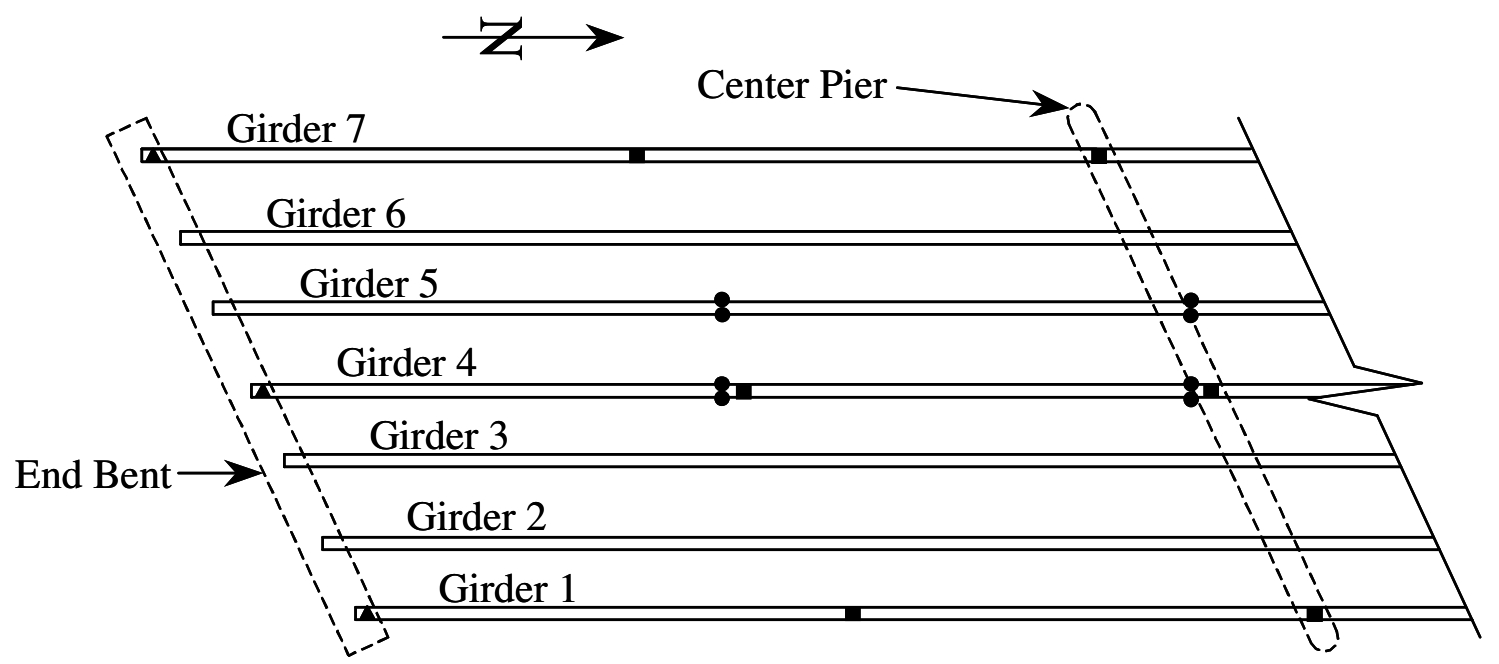

- Indicates 5 Longitudinal Strain Gages

- Indicates 3 Longitudinal Strain Gages

- Indicates 1 Transverse Strain Gage

Figure 2.3: Plan View of Strain Gage Locations in I-65 Bridge over SR 25 (Radabaugh 2001)

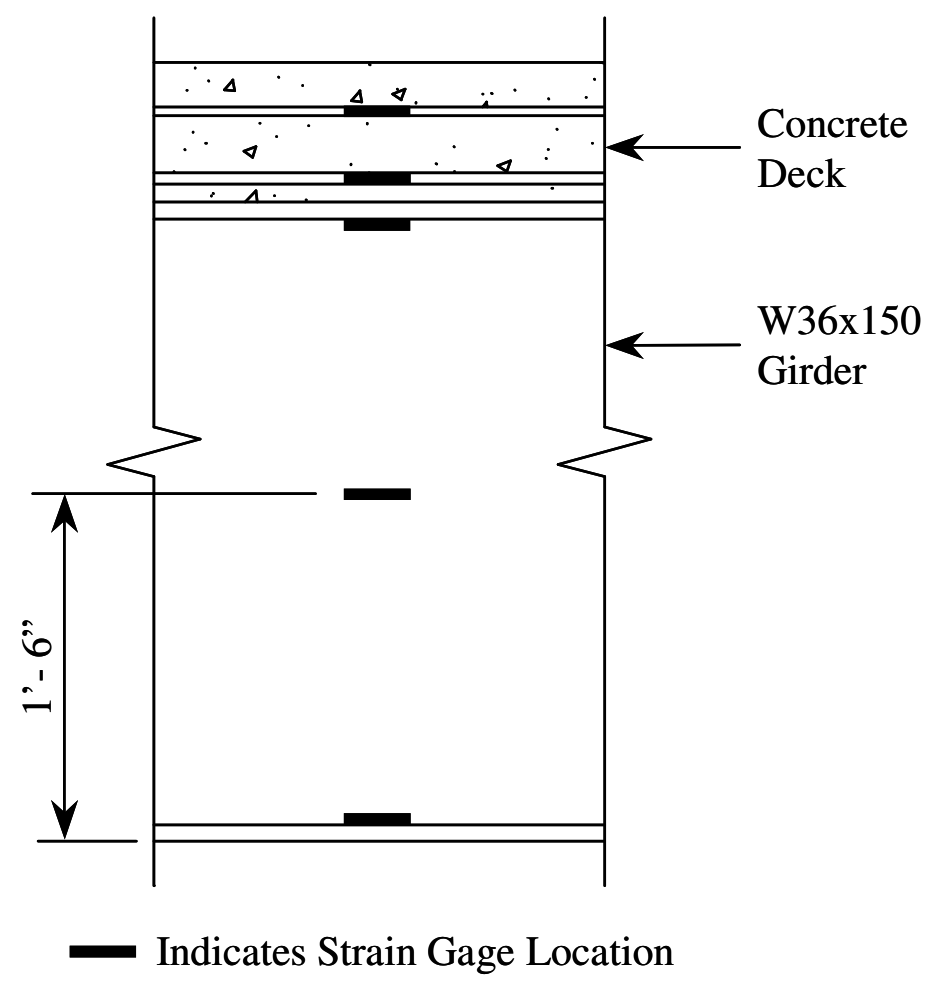

Figure 2.4: Elevation View of Strain Gage Locations on I-65 Bridge over SR 25 (Radabaugh 2001) 


\subsubsection{Thermocouples}

Thermocouples were installed in the bridge deck and on the girders to monitor the thermal gradients through the depth of the superstructure. In addition, a thermocouple was hung underneath the bridge, out of direct sunlight, to record ambient air temperatures. Figure 2.5 shows the locations of thermocouples installed on the I-65 bridge, and Figure 2.6 illustrates the locations of thermocouples through the depth of the deck and girders.

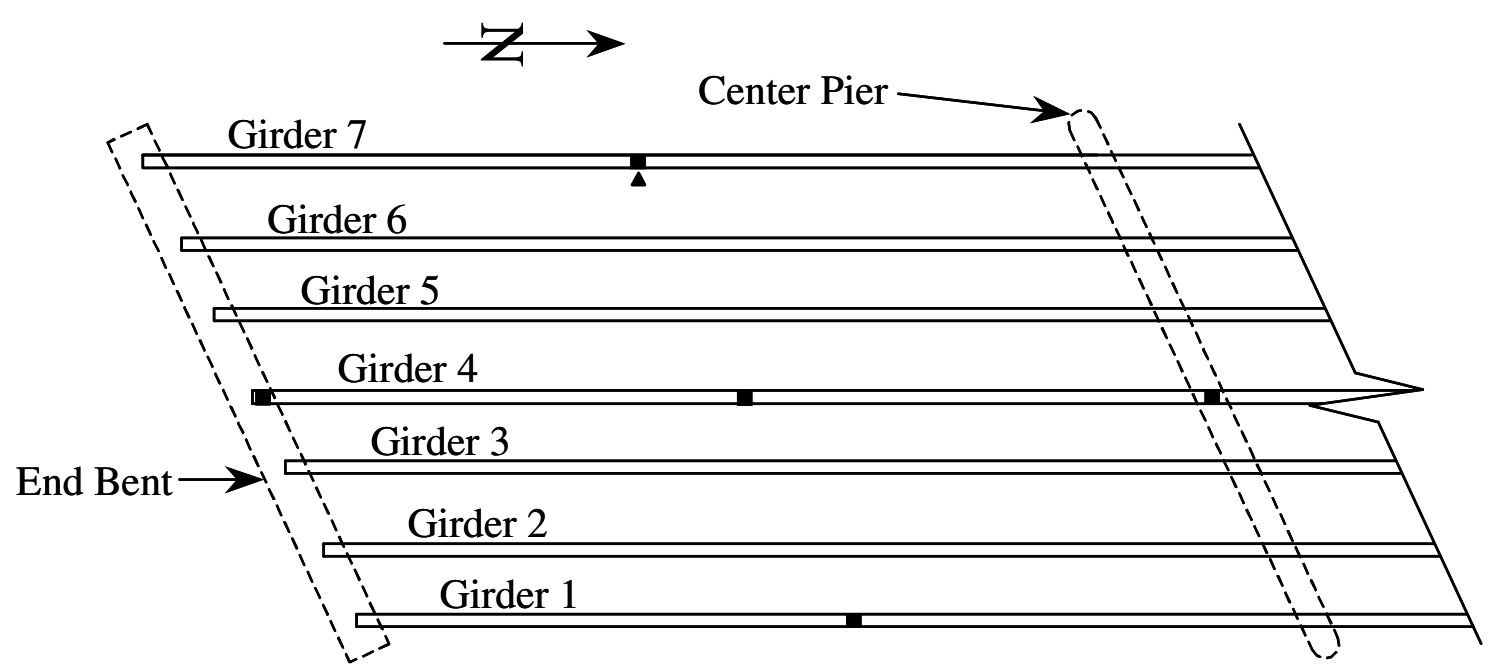

- Indicates 4 Thermocouples

\ Ambient Temperature Thermocouple

Figure 2.5: Plan View of Thermocouple Locations in I-65 Bridge over SR 25 (Radabaugh 2001) 


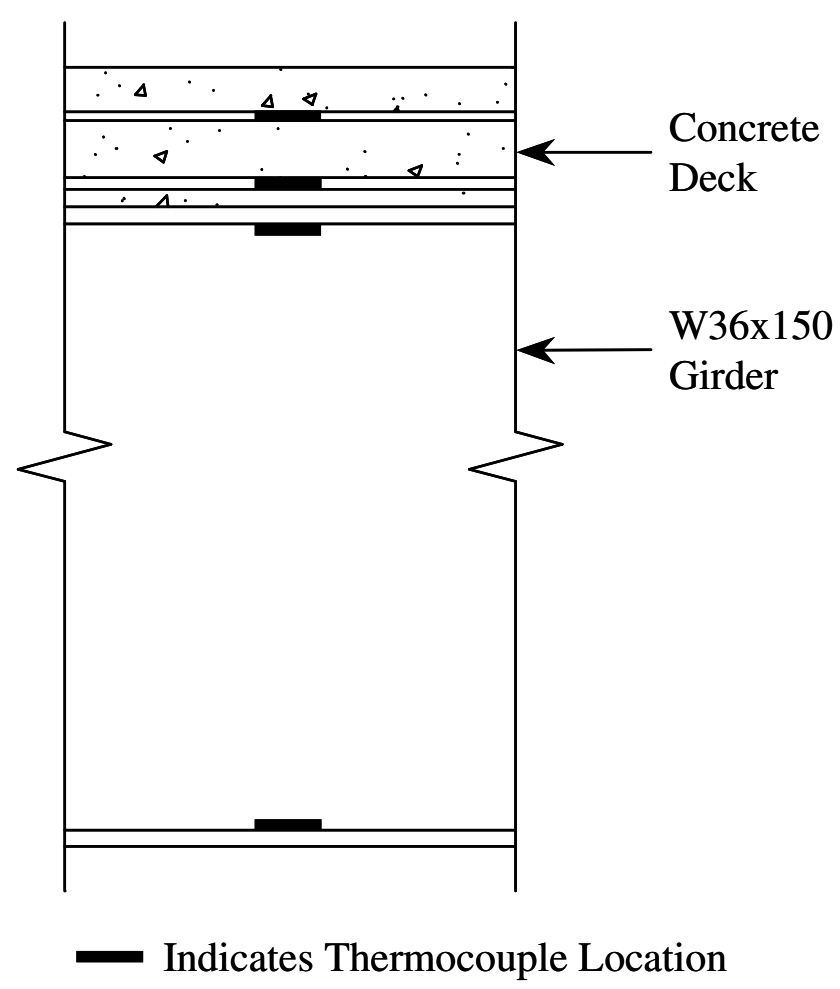

Figure 2.6: Elevation View of Thermocouple Locations in I-65 Bridge over SR 25 (Radabaugh 2001)

\subsection{State Road 18 over Interstate 65}

To investigate the durability and performance, specifically in terms of transverse cracking, of a reinforced concrete bridge deck designed using the AASHTO LRFD Empirical Method, a bridge deck designed by this method was instrumented. In addition, it was of interest to compare the performance of an AASHTO empirically designed bridge deck to a deck that incorporated recommendations by Frosch et al. (Frosch et al. 2003), referred to as the "Purdue Empirical" deck design. No bridges under design or contract for construction or rehabilitation in Indiana at the start of this investigation had incorporated either deck design. Therefore, a bridge was selected and designed with a bridge deck that incorporated both designs.

The SR 18 over I- 65 bridge in Brookston, Indiana was selected, and the existing design was changed to incorporate deck design using the empirical methods. This bridge is a $242-1 / 2 \mathrm{ft}$, two-span, continuous, steel superstructure bridge with $30^{\circ}$ skew, which integrates the use of composite action and semi-integral abutments. Each span of the bridge is $123 \mathrm{ft}-3 \mathrm{in}$. long and is supported on $51 \mathrm{in}$. deep steel plate girders. The abutments of the bridge are constructed semi-integral with the bridge girders. The deck in both spans was formed with SIP steel forms and was cured for seven days using wet burlene mats. The western span of the bridge utilizes the AASHTO LRFD (AASHTO 1998) empirical design while the eastern span was designed using the recommendations by Frosch et al. (2003). The reinforcement in the two spans is illustrated in Figure 2.7. Both spans used epoxy-coated steel reinforcement. 


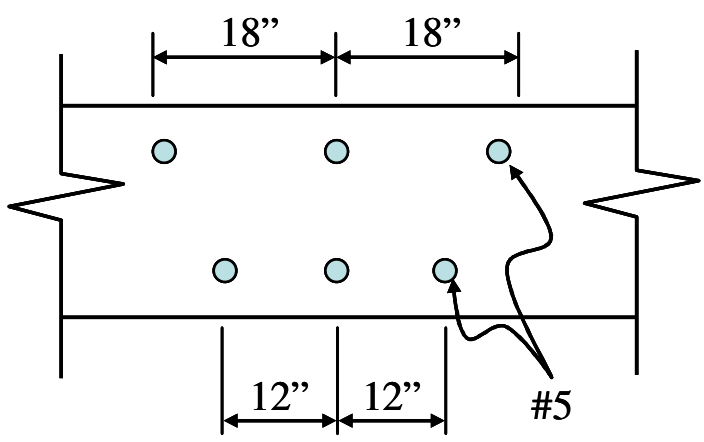

(a) AASHTO Empirical (West Span)

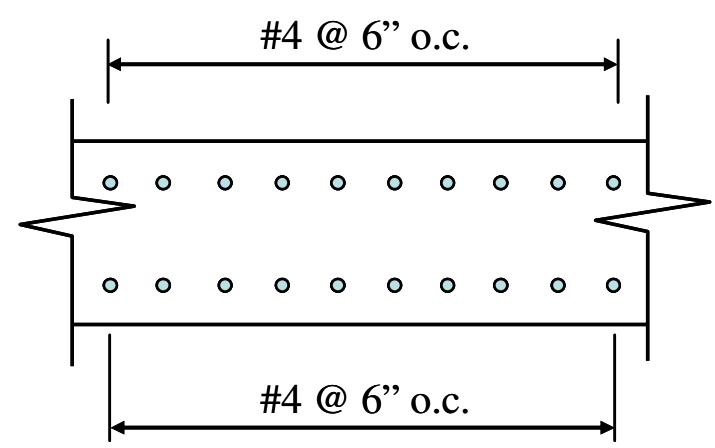

(b) Purdue Empirical (East Span)

Figure 2.7: Reinforcement Designs in State Road 18 Bridge Deck

The bridge deck was constructed in two phases. The eastbound lanes were constructed in Phase I (May-July 2003), and the westbound lanes were constructed in Phase II (July-October 2003).

\subsubsection{SR 18 Materials}

\subsubsection{Concrete}

An INDOT standard Class $\mathrm{C}$ concrete mix design was used for the SR 18 bridge deck, and the mix design is provided in Table 2.4. 
Table 2.4: INDOT Class C Mix Design on SR 18 Bridge (Erickson 2004)

\begin{tabular}{|c|c|c|}
\hline Material & $\begin{array}{c}\text { Batch } \\
\text { Weights }\end{array}$ & Specifications/Suppliers \\
\hline Cement & $658 \mathrm{lb} / \mathrm{yd}^{3}$ & $\begin{array}{l}\text { ASTM C-150, Type I, Lonestar Industries, } \\
\text { Inc., Greencastle, IN }\end{array}$ \\
\hline Sand & $1328 \mathrm{lb} / \mathrm{yd}^{3}$ & $\begin{array}{c}\text { ASTM C-33 \& INDOT Specification \#23 } \\
\text { Sand from Segal Sand and Gravel, Delphi, IN }\end{array}$ \\
\hline Stone & $1710 \mathrm{lb} / \mathrm{yd}^{3}$ & \#8 Stone from Vulcan Materials, Monon, IN \\
\hline Water & $200 \mathrm{lb} / \mathrm{yd}^{3}$ & - \\
\hline Ash & None & - \\
\hline Micro-Silica & None & - \\
\hline \multicolumn{3}{|c|}{ Phase I Concrete Admixtures } \\
\hline Water Reducer & $3.0 \mathrm{oz} / \mathrm{yd}^{3}$ & $\begin{array}{c}\text { ASTM C-494 Water Reducer, Type A } \\
\text { Pozzolith 200N, Master Builders } \\
\end{array}$ \\
\hline Air & $0.99 \mathrm{oz} / \mathrm{yd}^{3}$ & $\begin{array}{l}\text { ASTM C-260 Air Entrainment, Micro Air by } \\
\text { Master Builders } \\
\end{array}$ \\
\hline \multicolumn{3}{|c|}{ Phase II Concrete Admixtures } \\
\hline Water Reducer & $13 \mathrm{oz} / \mathrm{yd}^{3}$ & $\begin{array}{c}\text { ASTM C-494 Water Reducer, Type A } \\
\text { Pozzolith 200N, Master Builders }\end{array}$ \\
\hline Air & $5.3 \mathrm{oz} / \mathrm{yd}^{3}$ & $\begin{array}{c}\text { ASTM C-260 Air Entrainment, Micro Air by } \\
\text { Master Builders }\end{array}$ \\
\hline
\end{tabular}

Standard 6 in. by 12 in. cylinders (ASTM C31) were cast on-site to determine the compressive strength, split-cylinder tensile strength, and modulus of elasticity of the concrete at 7, 14, 21, 28, and 56 days. The specimens were field cured with wet burlap mats covered with plastic sheeting for seven days in the same manner as the bridge deck. The concrete compressive strength was determined in accordance with ASTM C39. The resulting compressive strength curve is shown in Figure 2.8. The average 28-day compressive strength considering both phases is $4870 \mathrm{psi}$. 


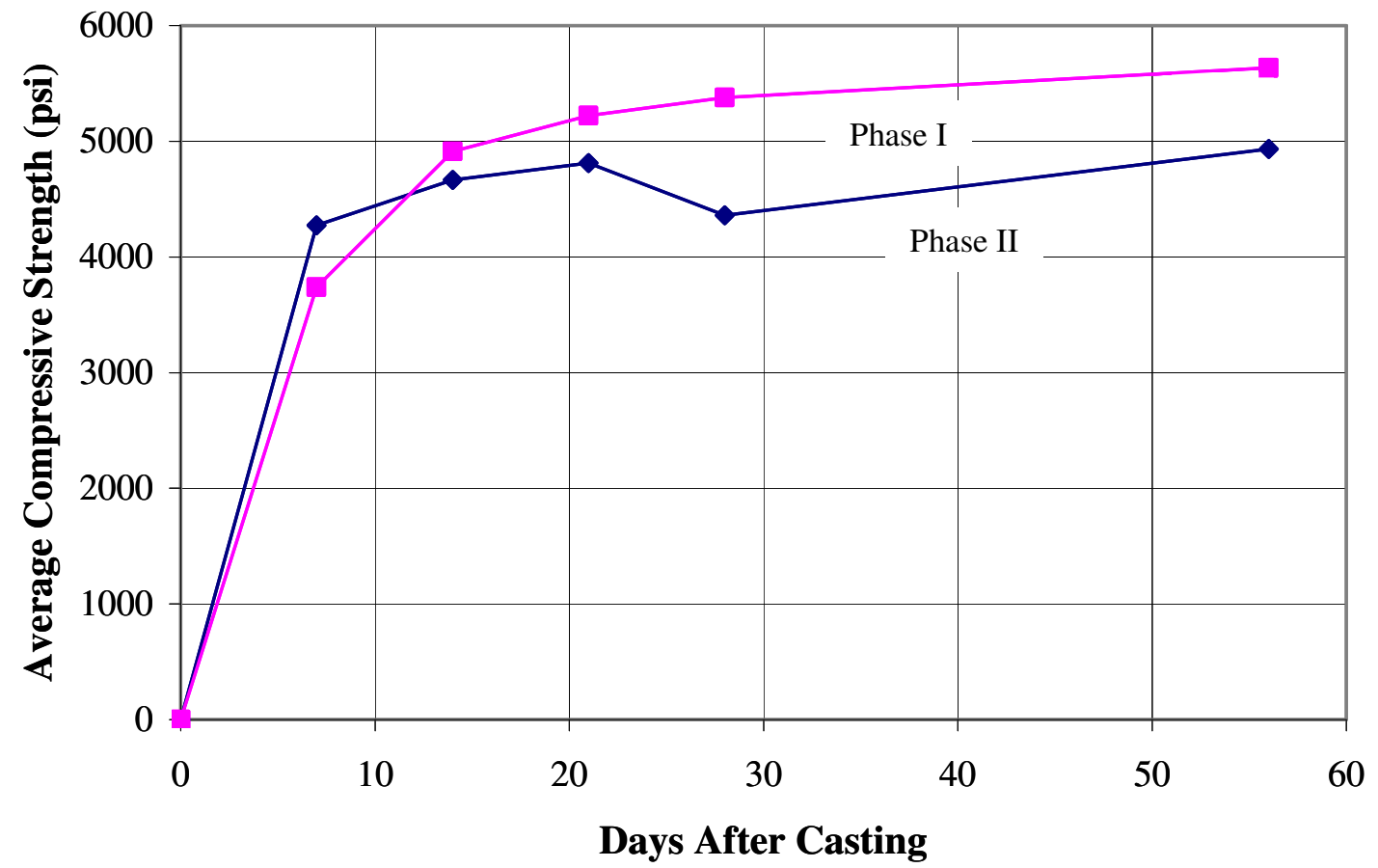

Figure 2.8: SR 18 Concrete Compressive Strength (Erickson 2004)

To determine the tensile strength of the concrete, split cylinder tests were performed in accordance with ASTM C496. Figure 2.9 shows the average split cylinder tensile strength for both phases, and Figure 2.10 shows a comparison of the split cylinder strength to the tensile strength of concrete, $f_{t}$, estimated by $6 \sqrt{f_{c}}$. As shown, there is good correlation between the experimental tensile strengths and that determined for the concrete compressive strength. 


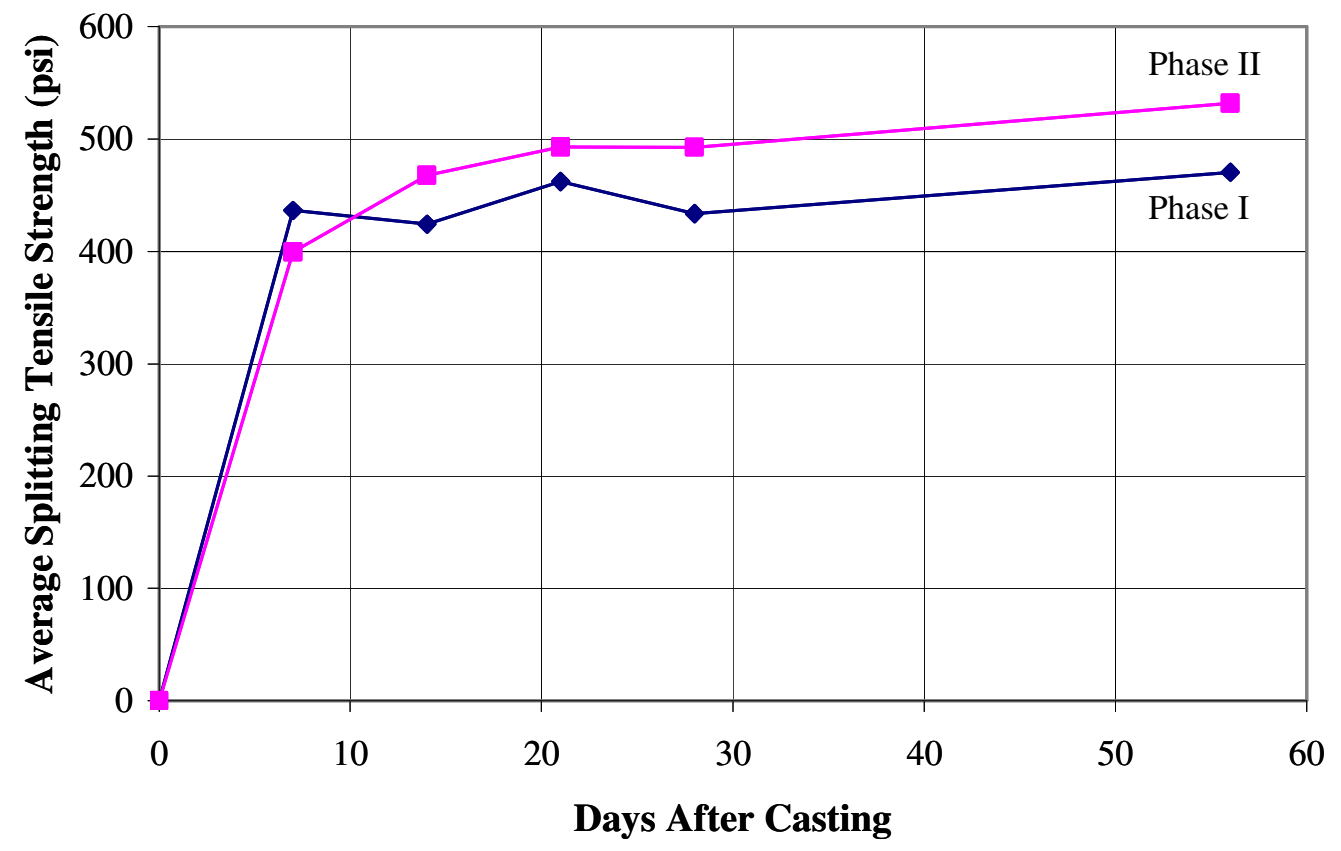

Figure 2.9: SR 18 Average Split Cylinder Tensile Strength

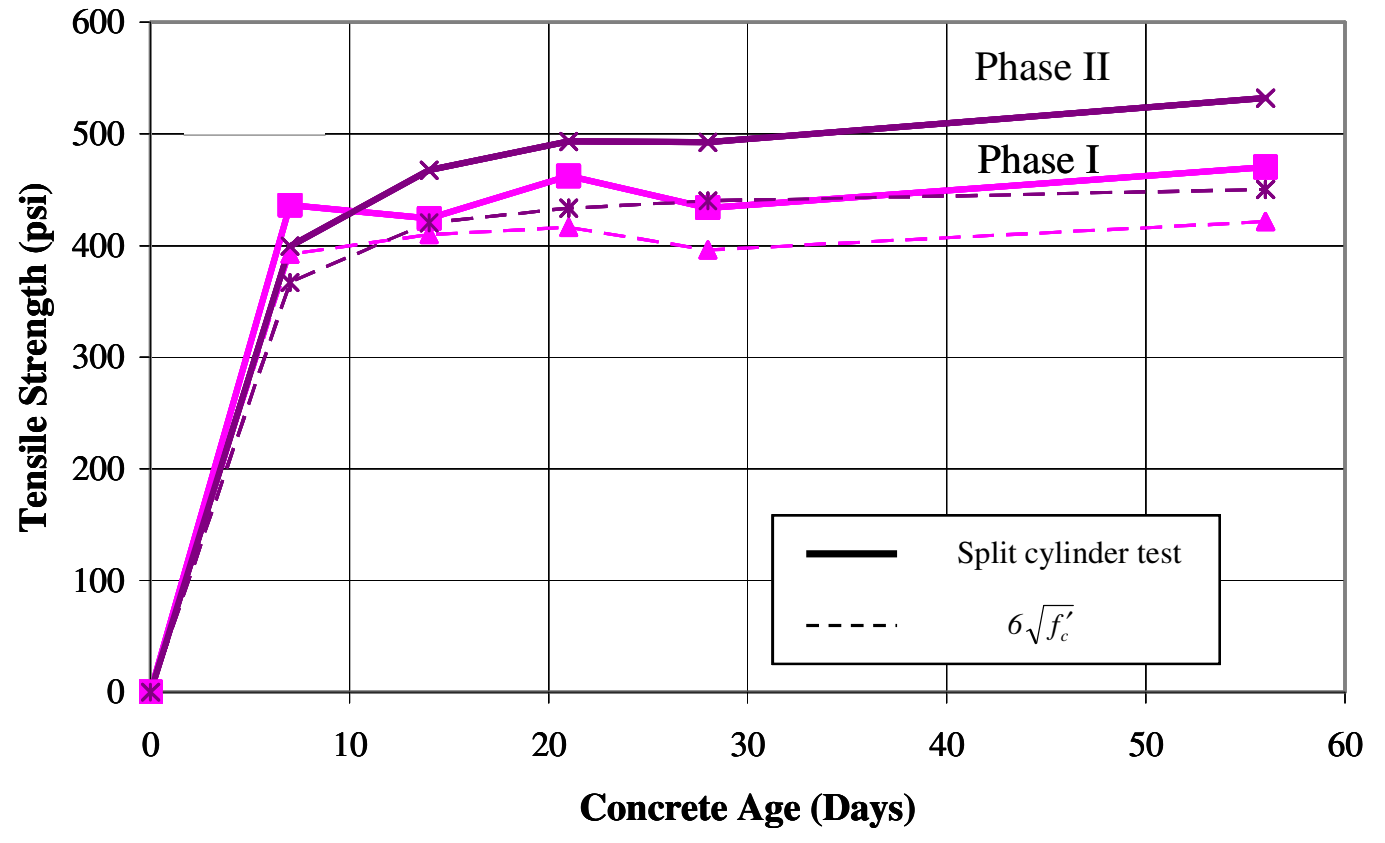

Figure 2.10: Split Cylinder Strength to $f_{t}=6 \sqrt{f_{c}}$ Comparison 
The modulus of elasticity of the concrete was determined in accordance with ASTM C469. Two standard cylinders (ASTM C31) were tested on days 7, 14, 21, 28, and 56. Figure 2.11 shows the modulus elasticity of the concrete for both phases. The average modulus was $4560 \mathrm{ksi}$ and $4180 \mathrm{ksi}$ for Phases I and II, respectively. ACI 31805, Section 8.5.1 estimates the concrete modulus of elasticity as $3760 \mathrm{ksi}$ and $4180 \mathrm{ksi}$ for Phases I and II, respectively. The ACI estimate agrees reasonably well with the measured values.

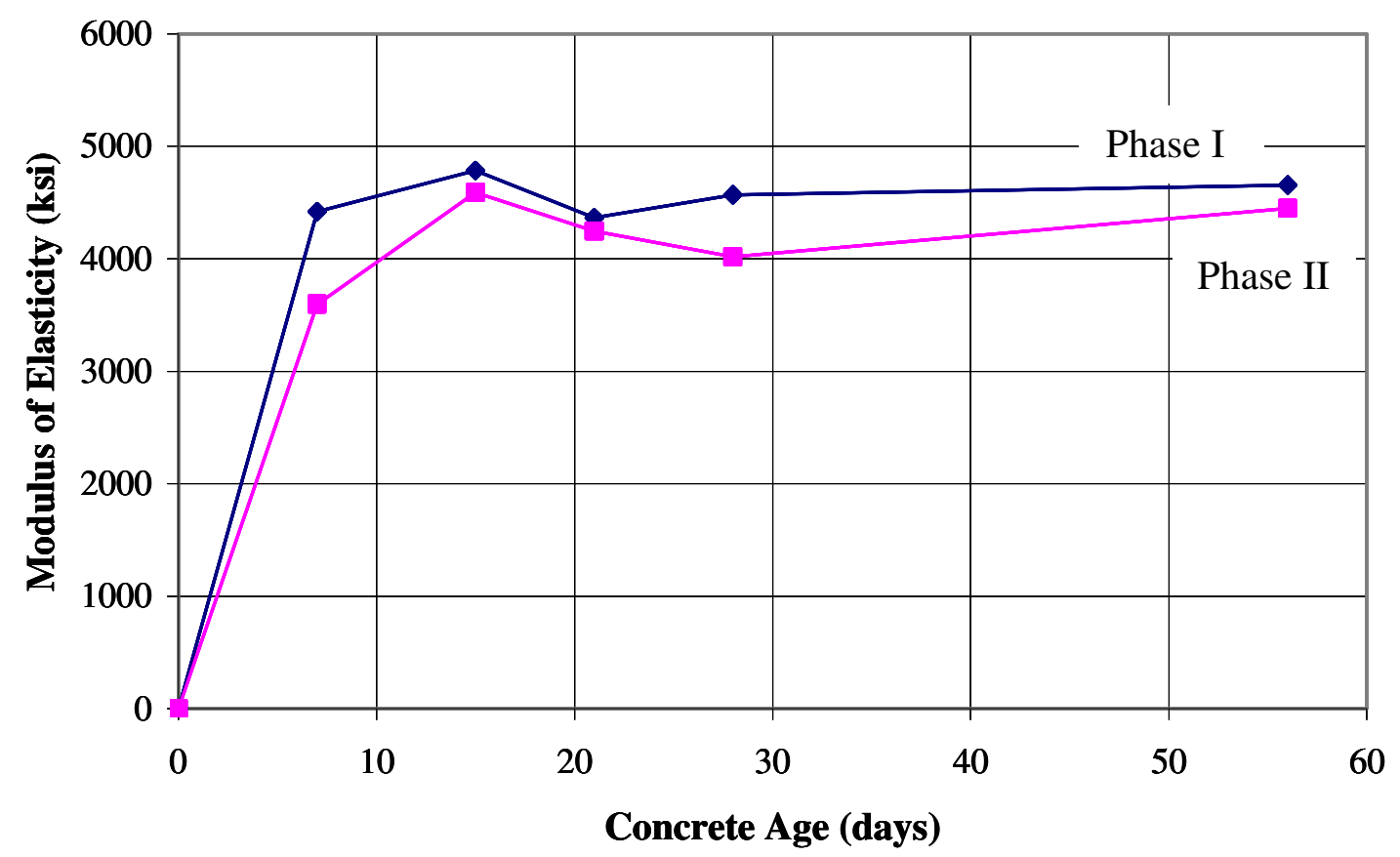

Figure 2.11: SR 18 Concrete Modulus of Elasticity

\subsubsection{SR 18 Instrumentation}

Since girders restrain the volumetric changes concrete undergoes during hydration and subsequent drying, it is necessary to obtain direct measurements of the strain occurring in a bridge deck. Furthermore, thermal effects may also contribute to shrinkage as well as induce additional volumetric changes through diurnal temperature variations. SR 18 over I-65 was instrumented with strain gages on the reinforcement and girders, embedded concrete strain gages, and thermocouples to observe the behavior of the bridge deck. Data from the instruments installed on the bridge deck during the first phase of construction were recorded at 15 minute intervals. Three days prior to the placement of the bridge deck during Phase II construction, data were collected every 5 minutes, and continued at that frequency until 59 days after Phase II deck casting. The datalogger program was then changed to record data every 15 minutes. 


\subsubsection{Strain Gages}

Strain gages locations were selected as probable sites for initial early-age crack formation due to restrained shrinkage. In addition, it was necessary that the gages not be located in the negative moment region of the bridge or adjacent to the ends of the bridge. Within the negative moment region and adjacent to the ends of the bridge, additional reinforcement is required per AASHTO LRFD (AASHTO 2004). Furthermore, cracking is attributed to dead and live loads rather than restrained shrinkage of the concrete in these negative moment regions.

The strain gages were oriented in the longitudinal direction of the bridge. Figure 2.12 provides a plan view of the strain gage locations in the bridge, and Figure 2.13 shows the locations of uniaxial strain gages through depth of the superstructure. Strain gages were mounted on the reinforcement in the top and bottom mats. Strain gages were also installed on the girders on the top and bottom flanges as well as the mid-height of the web.

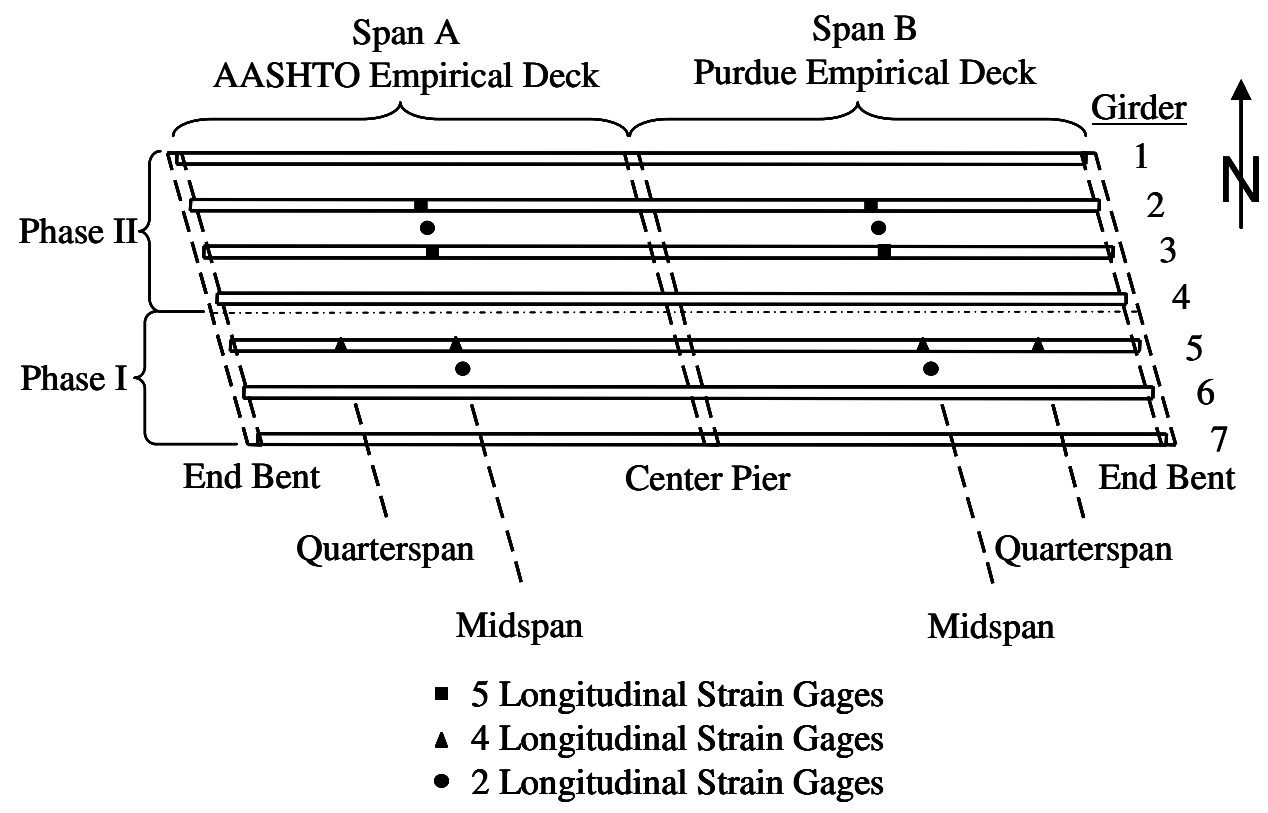

Figure 2.12: Plan View of Strain Gage Locations on SR 18 Bridge (Erickson 2004) 


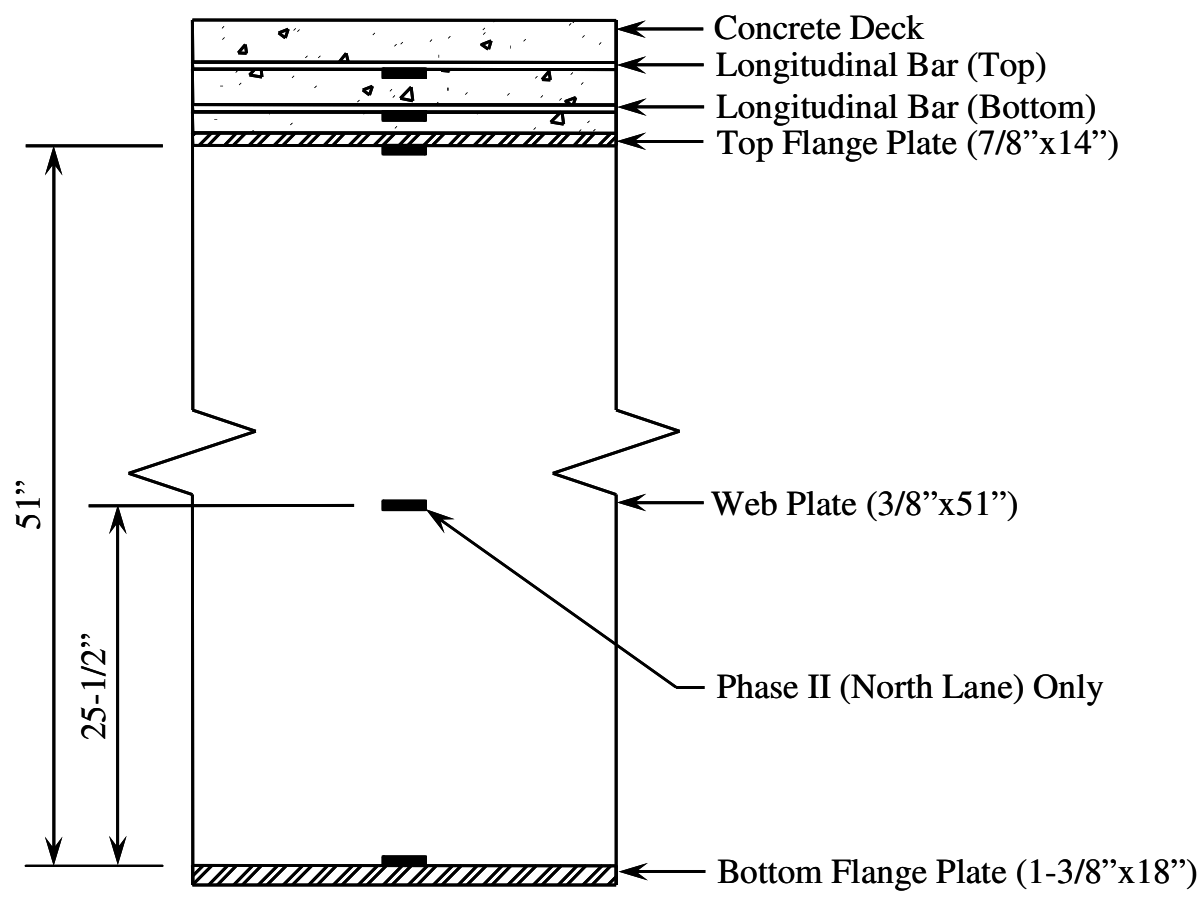

- Strain Gage Location

\section{Figure 2.13: Elevation View of Strain Gage Locations on SR 18 Bridge (Erickson 2004)}

In addition to strain gages installed on reinforcing bars, embedded concrete gages were installed to monitor strains in the concrete. Figure 2.14 shows a plan view of the embedded gage locations, and Figure 2.15 gives the location of the embedded gages through the depth of the deck. Embedded concrete gages were installed adjacent to reinforcement strain gages to provide a comparison of the strain measured in the concrete and steel at these locations. 


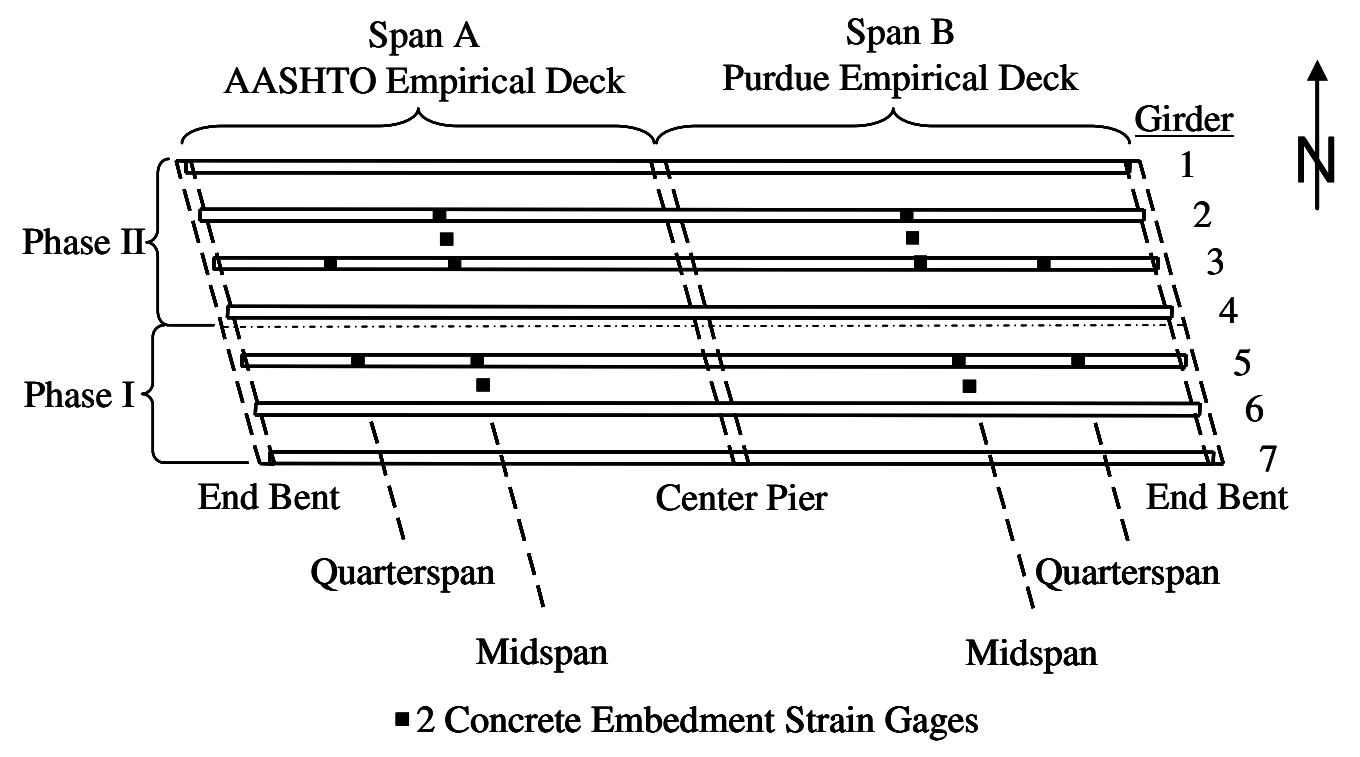

Figure 2.14: Plan View of Embedded Concrete Strain Gage Locations (Erickson 2004)

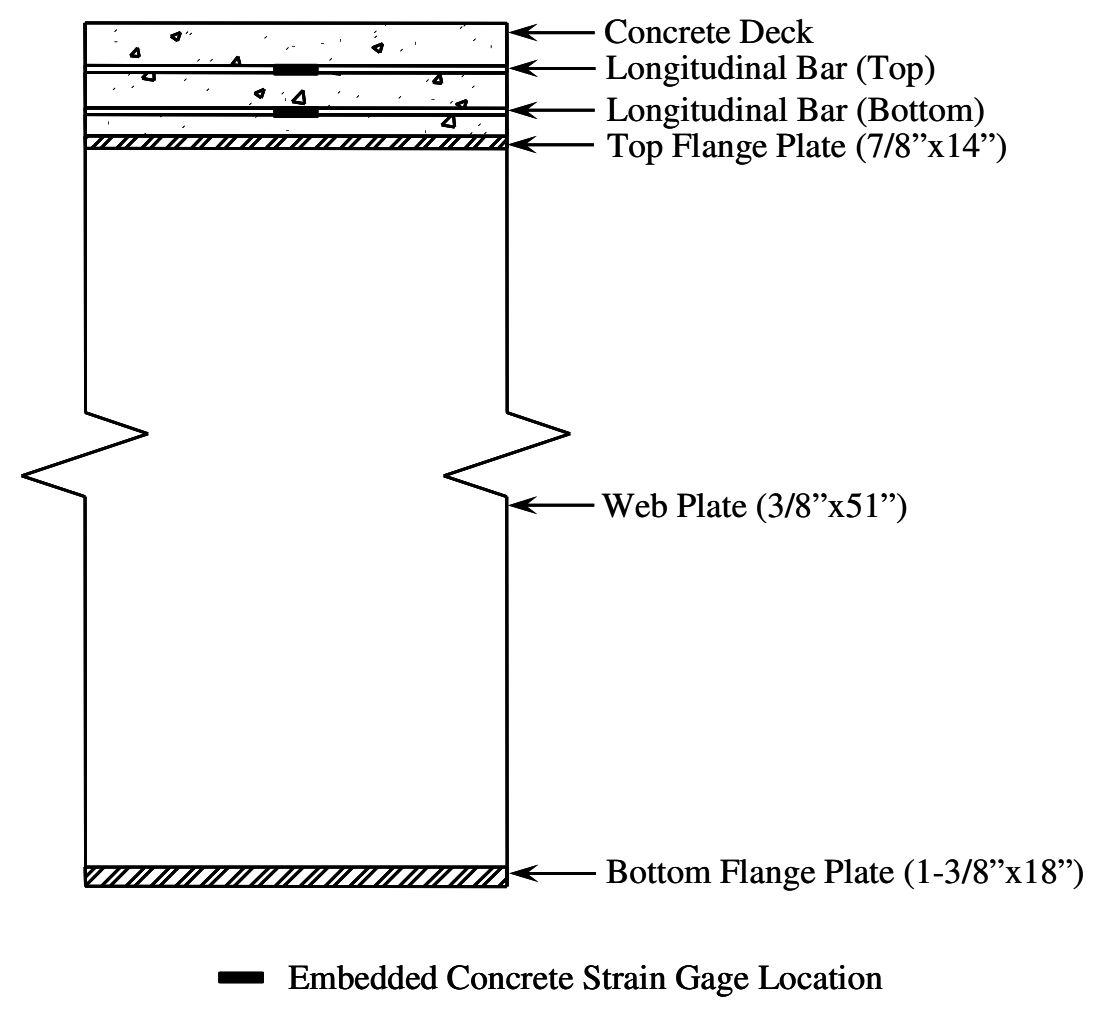

Figure 2.15: Embedded Concrete Strain Gage Locations through the Depth of the Deck (Erickson 2004) 


\subsubsection{Thermocouples}

Thermocouples were installed in the deck and on the girders to measure the temperature gradient through the depth of the section. Figure 2.16 shows a plan view of thermocouple locations, and Figure 2.17 presents the thermocouple locations through the depth of the superstructure. Thermocouples were installed at midspan in both Phase I and II in the AASHTO and Purdue empirical spans. These locations were selected to provide temperature gradients for a majority of the strain gages installed in the bridge deck.

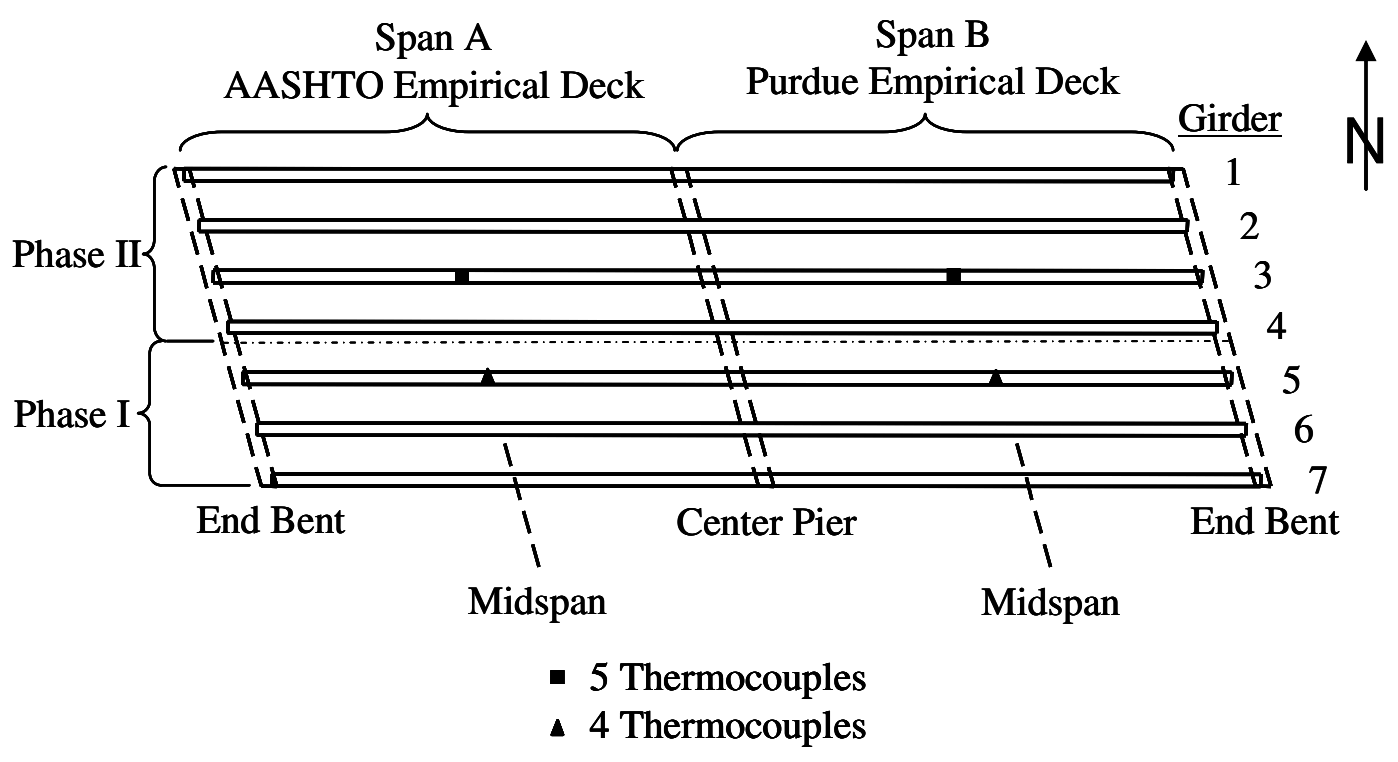

Figure 2.16: Plan View of Thermocouple Locations (Erickson 2004) 


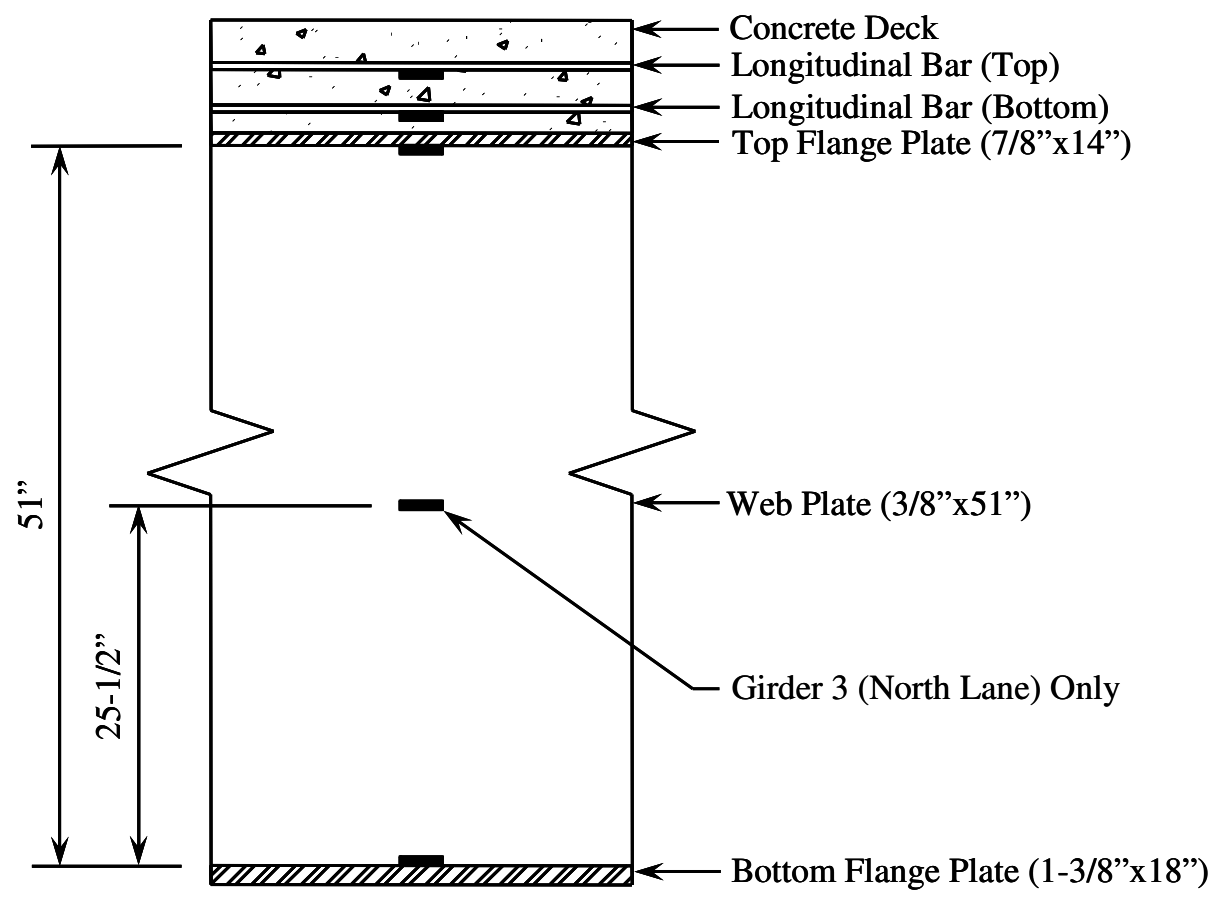

Thermocouple Location

Figure 2.17: Thermocouple Locations through the Depth of the Deck and Girder (Erickson 2004)

\subsubsection{SR 18 Instrumentation Identification}

An identification system for the gages is presented in Figure 2.18. This system assigns to each gage a unique four character instrument identification as shown. The locations described as part of the identification system are shown in Figure 2.19. 
Longitudinal Location

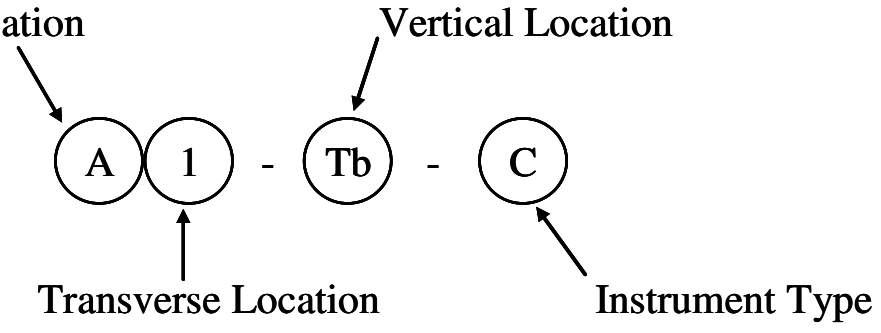

\section{Longitudinal Location: $\quad$ A - Quarterspan AASHTO Empirical \\ B - Midspan AASHTO Empircal \\ C - Midspan Purdue Empirical \\ D - Quarterspan Purdue Empirical}

\begin{tabular}{ll}
\hline Transverse Location: & $\mathbf{1}$ - Mid-bay between Girders 5 and 6 \\
& $\mathbf{2}-$ Girder 5 \\
& $\mathbf{3}-$ Girder 3 \\
& $\mathbf{4}-$ Mid-bay between Girders 2 and 3 \\
& $\mathbf{5}$ - Girder 2 \\
\hline Vertical Location: & Tb - Top Reinforcement Bar \\
& Bb - Bottom Reinforcement Bar \\
& Tf - Top Flange \\
& W - Mid-height of girder web \\
& Bf - Bottom Flange \\
& $\mathbf{S}-$ Uniaxial foil-backed strain gage \\
& $\mathbf{C}-$ Embedded Concrete Gage \\
& TC - Thermocouple
\end{tabular}

Figure 2.18: SR 18 Instrumentation Identification 


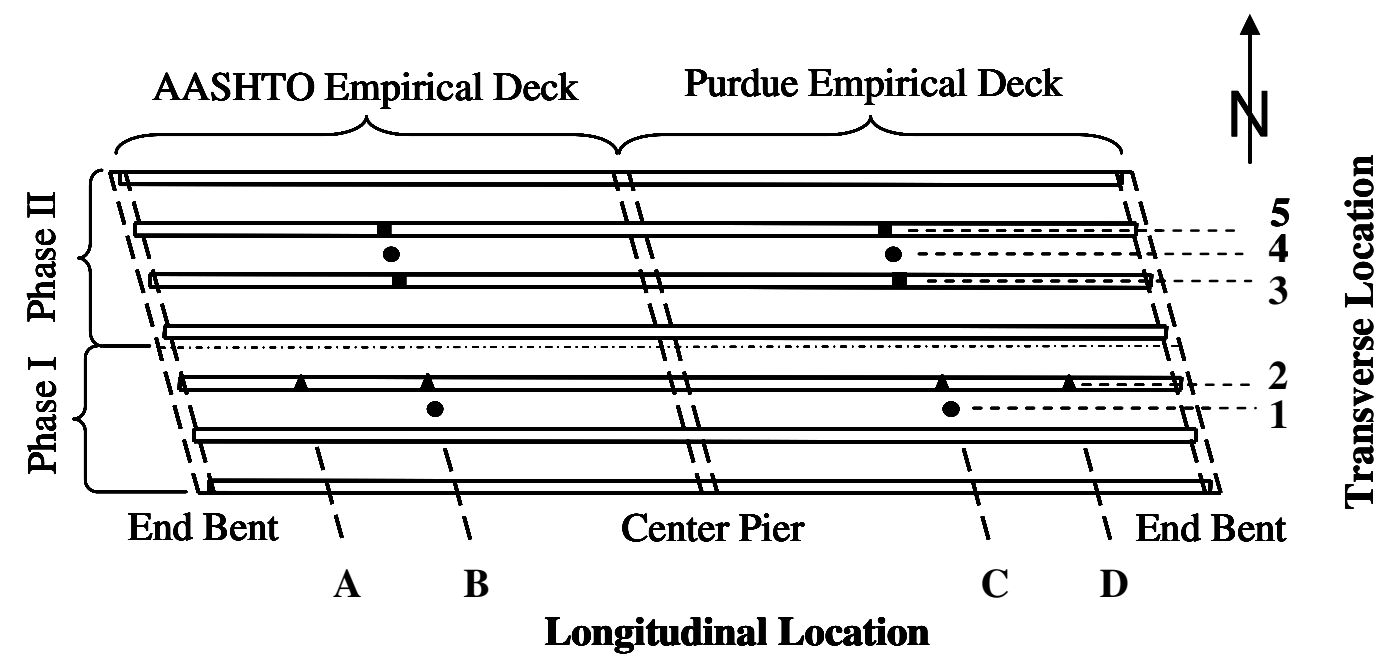

Figure 2.19: Plan View of Instrumentation Identification

\subsection{State Road 23 over U.S. Highway 20}

To investigate the performance, in terms of transverse cracking, of a reinforced concrete bridge deck incorporating a high-performance concrete (HPC) mix design in combination with the design recommendations by Frosch et al. (2003), the SR 23 bridge over US 20 was instrumented. Of particular interest was the comparison of this bridge deck to that of the SR 18 bridge as the deck reinforcement was similar.

The SR 23 bridge over US 20 is a two span, $204 \mathrm{ft}$, continuous bridge on prestressed concrete girders in South Bend, Indiana (Figure 2.20). The bridge has two, $101 \mathrm{ft}$ spans and an $11^{\circ}$ skew. The concrete deck was designed fully composite with INDOT modified bulb-tee girders (Figure 2.21). The bridge deck on SR 23 over US 20 was constructed with SIP steel deck forms and was cured for seven days with wet burlene mats. The bridge deck was designed with \#5, epoxy coated steel bars spaced at 6 in. on center in both directions in the top and bottom reinforcement mats. Complete details regarding the SR 23 bridge are provided by Aldridge (2005). 


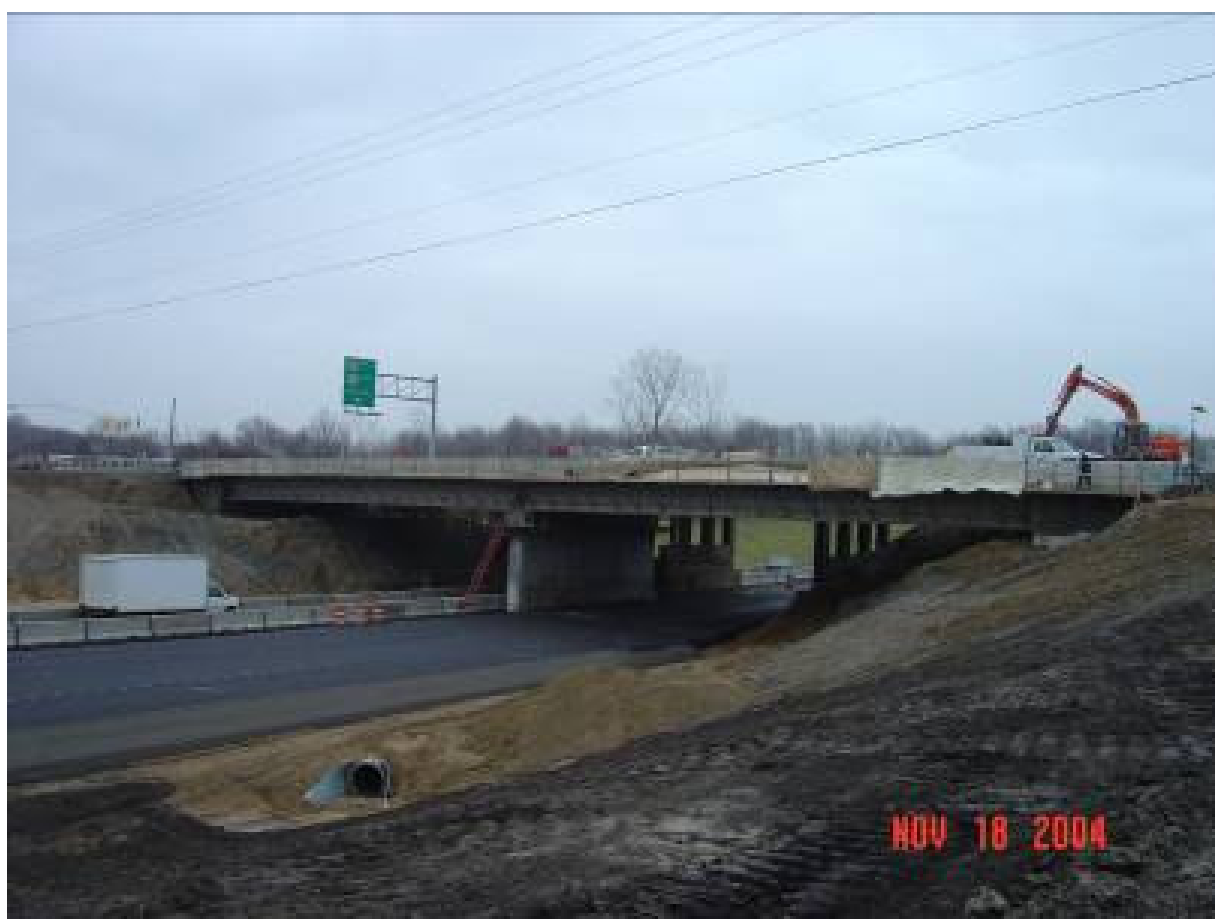

Figure 2.20: State Road 23 over U.S. Highway 20

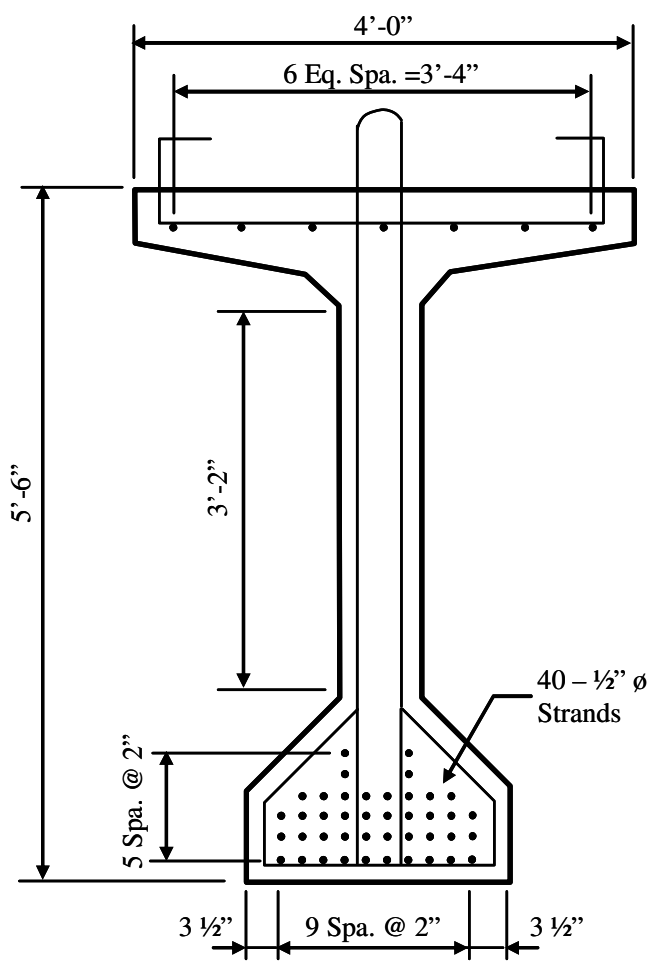

Figure 2.21: INDOT Modified Bulb-T Beam 


\subsubsection{SR 23 Materials}

\subsubsection{Concrete}

The concrete for this project was obtained from Kuert Concrete, Inc., a local ready mix supplier in the South Bend area. The mixture proportions and specifications for this concrete are provided in Table 2.5.

Table 2.5: INDOT QC/QA Concrete Mix Design (Aldridge 2005)

\begin{tabular}{|c|c|c|}
\hline Material & Quantity & Specifications/Suppliers \\
\hline Cement & $420 \mathrm{lb} / \mathrm{yd}^{3}$ & Type 1, Lafarge, Alpena MI \\
\hline Fly Ash (Class C) & $112 \mathrm{lb} / \mathrm{yd}^{3}$ & ISG, Shafer unit 15 \\
\hline Silica Fume & $28 \mathrm{lb} / \mathrm{yd}^{3}$ & Condensed, Rheomac SF 100 \\
\hline Sand & $1289 \mathrm{lb} / \mathrm{yd}^{3}$ & \#23 NS from Moose Lake, SC\#2472 \\
\hline Stone & $1782 \mathrm{lb} / \mathrm{yd}^{3}$ & $\# 8$ CS from Material Service, SC\#2472 \\
\hline Water & $224 \mathrm{lb} / \mathrm{yd}^{3}$ & City of South Bend \\
\hline Air & $3.5 \mathrm{fl} \mathrm{oz/cwt}$ & Micro Air, AEA, Master Builders \\
\hline Water Reducer & $20.0 \mathrm{fl} \mathrm{oz/} \mathrm{cwt}$ & Rheobuild, HRWR, Master Builders \\
\hline W/C & 0.4 & \\
\hline
\end{tabular}

Standard 6 in. by 12 in. compressive test cylinders (ASTM C31) were collected in the field at the time of deck casting. The concrete samples were obtained after pumping as it was placed on the bridge deck. To simulate the deck concrete, the cylinders were cured in the field under conditions matching those of the bridge deck as much as possible. The test cylinders were wet cured using wet burlap mats under plastic sheeting for seven days and then transported to the Bowen Laboratory at Purdue University for testing. Compressive tests were performed at 7, 14, 21, 28, and 56 days, and in accordance with ASTM C39. The resulting strength-gain curve is provided in Figure 2.22. The average 28-day compressive strength was $6930 \mathrm{psi}$. Splitting tensile strength according to ASTM C496 was also tested. Three specimens were tested at 7 and 28 days. The resulting strength-gain curve is provided in Figure 2.23. 


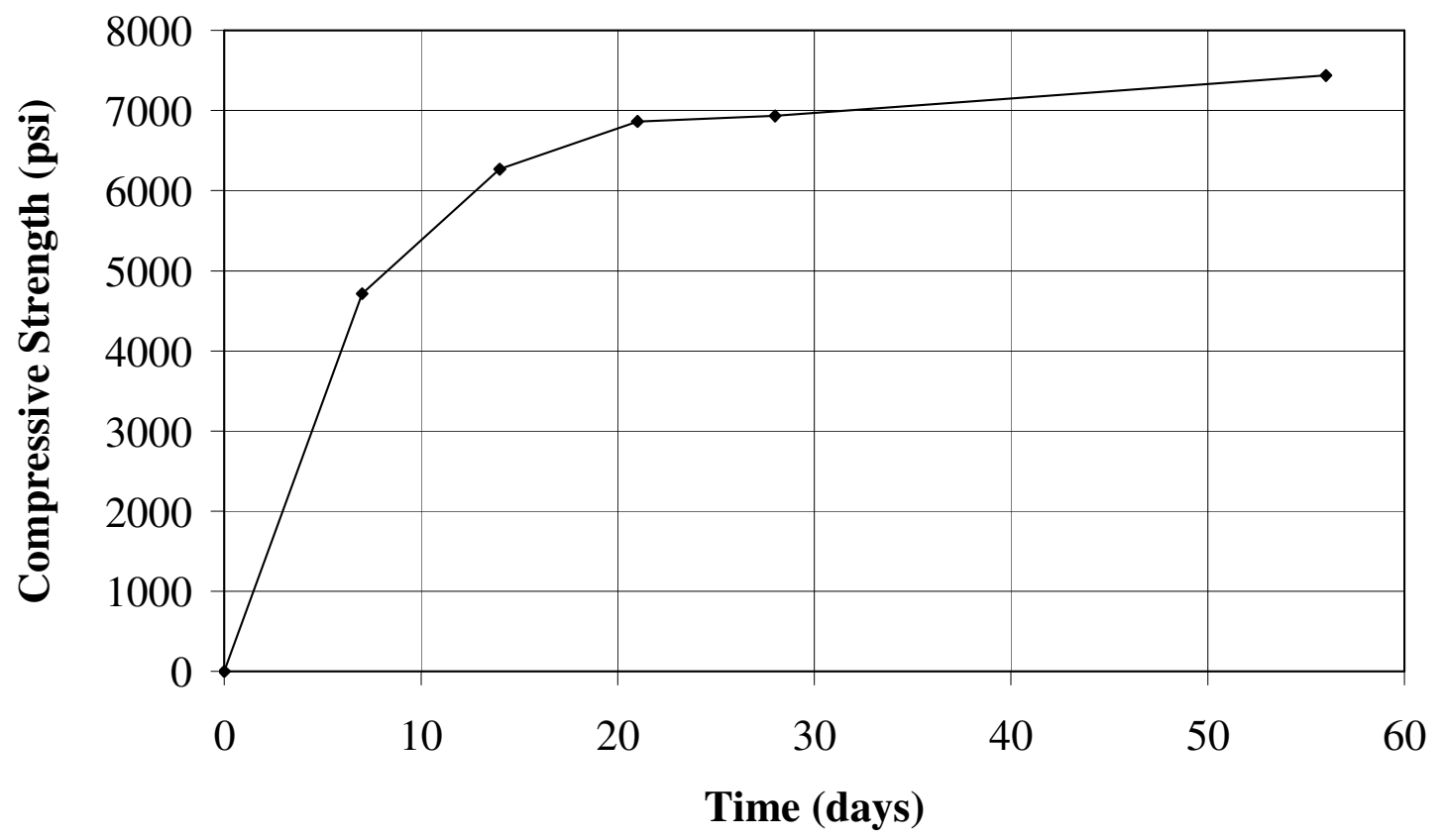

Figure 2.22: SR 23 Concrete Compressive Strength (Aldridge 2005)

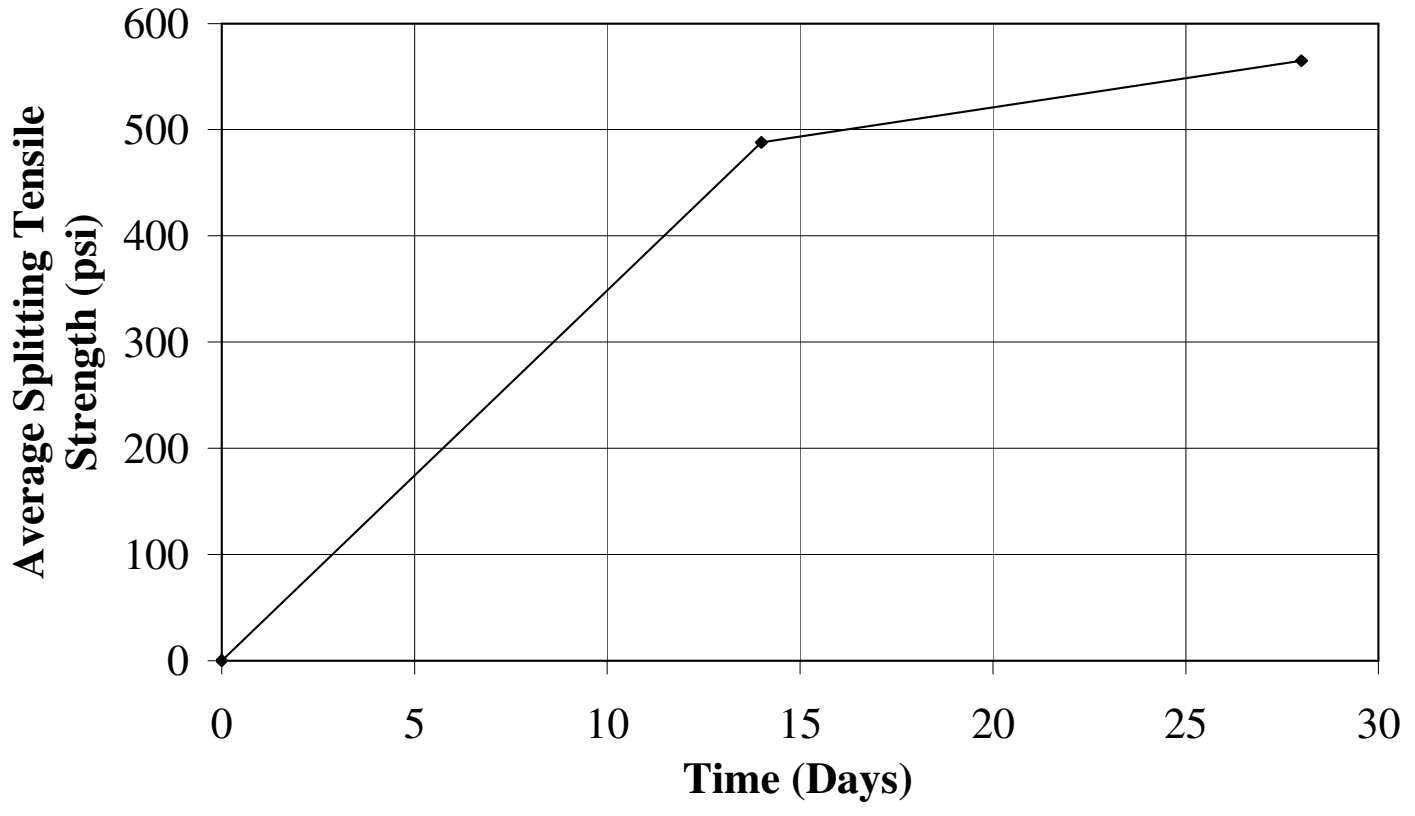

Figure 2.23 SR 23 Split Cylinder Tensile Strength (Aldridge 2005) 
The modulus of elasticity at 28 days was measured by Aldridge (2005). Two cylinders were tested for comparison. The average modulus of elasticity was determined as 5,200 ksi (Figure 2.24). The four curves plotted in Figure 2.24 are the three distinct loading cycles stipulated by ASTM C469 and the secant between 0 and $0.3 f_{c}^{\prime}$. Aldridge computed the modulus of elasticity as the secant between 0 and $0.3 f_{c}^{\prime}$, rather than $0.4 f_{c}^{\prime}$ as specified by ASTM C469. Nevertheless, the modulus measured by Aldridge is considered an accurate measurement. The results were also compared with the expression provided by ACI 318-05 (ACI Section 8.5.1). The ACI equation results in a modulus of 4,700 ksi which agrees reasonably well with the measured value.

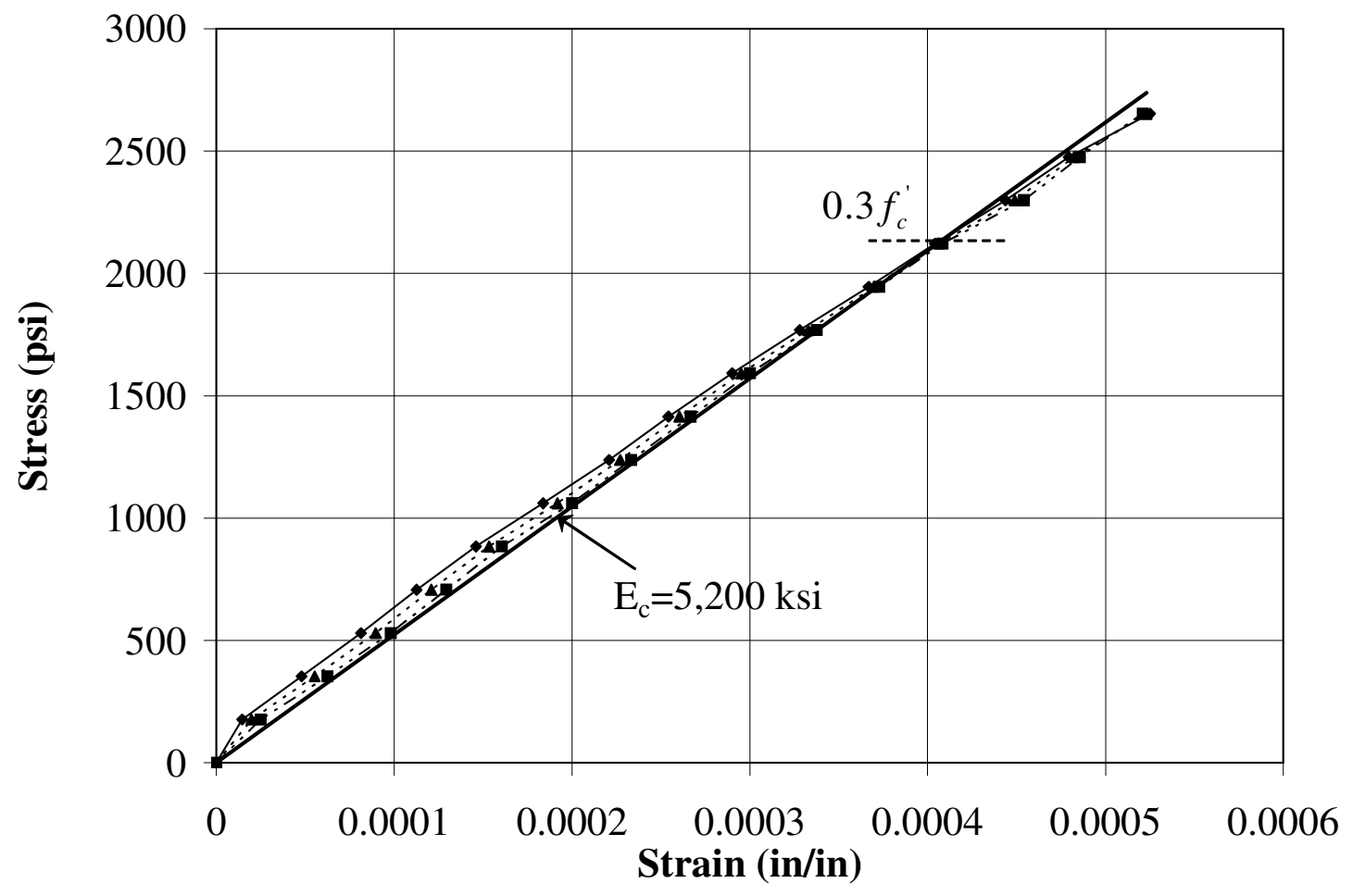

Figure 2.24: SR 23 Concrete Modulus of Elasticity at Day 28 (Aldridge 2005)

\subsubsection{SR 23 Instrumentation}

SR 23 was instrumented with strain gages and thermocouples to observe strain and thermal gradients through the depth of the deck and on the girders, analogous to instrumentation on the I-65 and SR 18 bridges. However, instrumentation was also designed such that a continuum of strain data over the longitudinal reinforcement could be measured. All instrumentation was concentrated in the span shown in Figure 2.25. In addition, free shrinkage specimens were cast on-site and instrumented to provide field free shrinkage data for the HPC mix. Data from the bridge instrumentation and the free shrinkage specimens was recorded every 10 minutes by a Campbell Scientific CR10X datalogger housed in a Type M traffic cabinet that was sited as illustrated in Figure 2.25. 


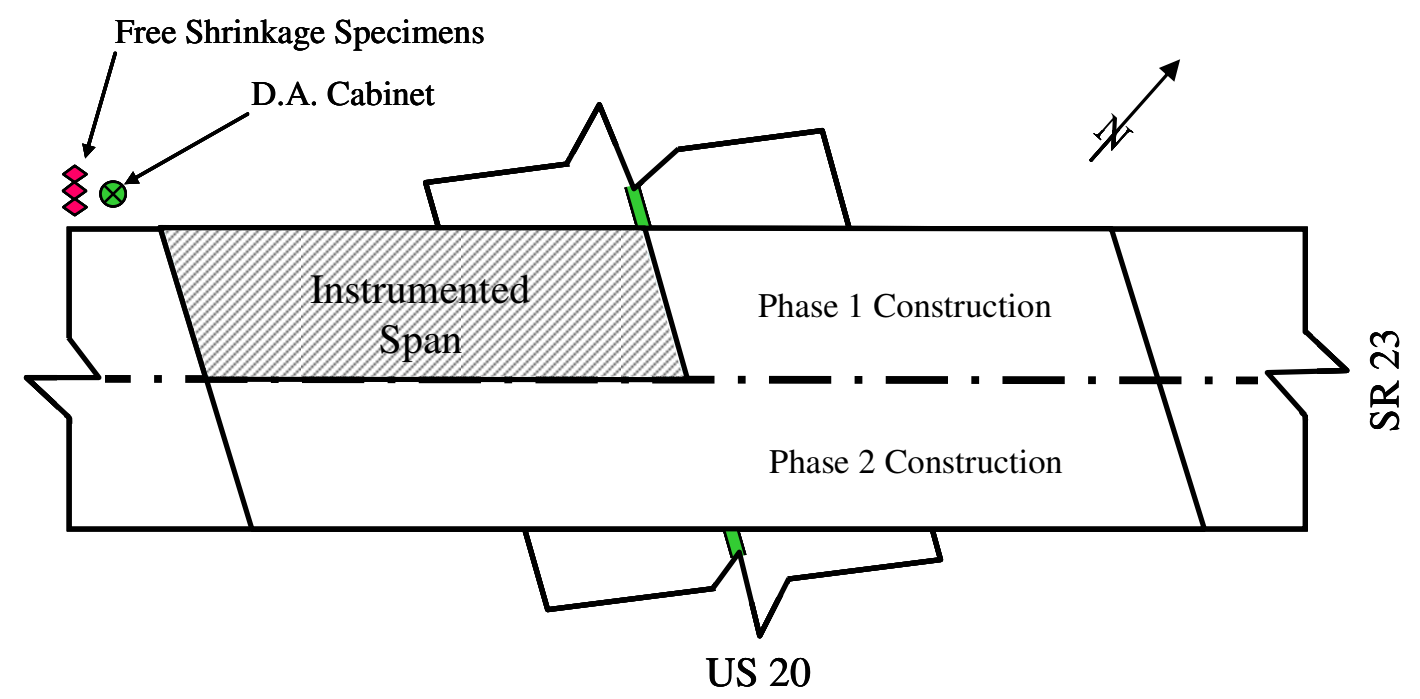

Figure 2.25: Site Plan of State Road 23 over U.S. Highway 20

\subsubsection{Strain Gages}

Uniaxial strain gages were installed on structural reinforcement in the top mat of the bridge deck. The strain gages were oriented in the longitudinal direction of the bridge. As illustrated in Figure 2.26, strain gages on the reinforcement were located over girders at the midspan of the instrumented span. The gages were positioned at midspan for two primary reasons: (1) to make it possible to draw comparisons between the performance of reinforcement and concrete in SR 23 to previously instrumented bridges in the field study, and (2) the midspan is a probable location of first cracking due to restrained volumetric variations. 


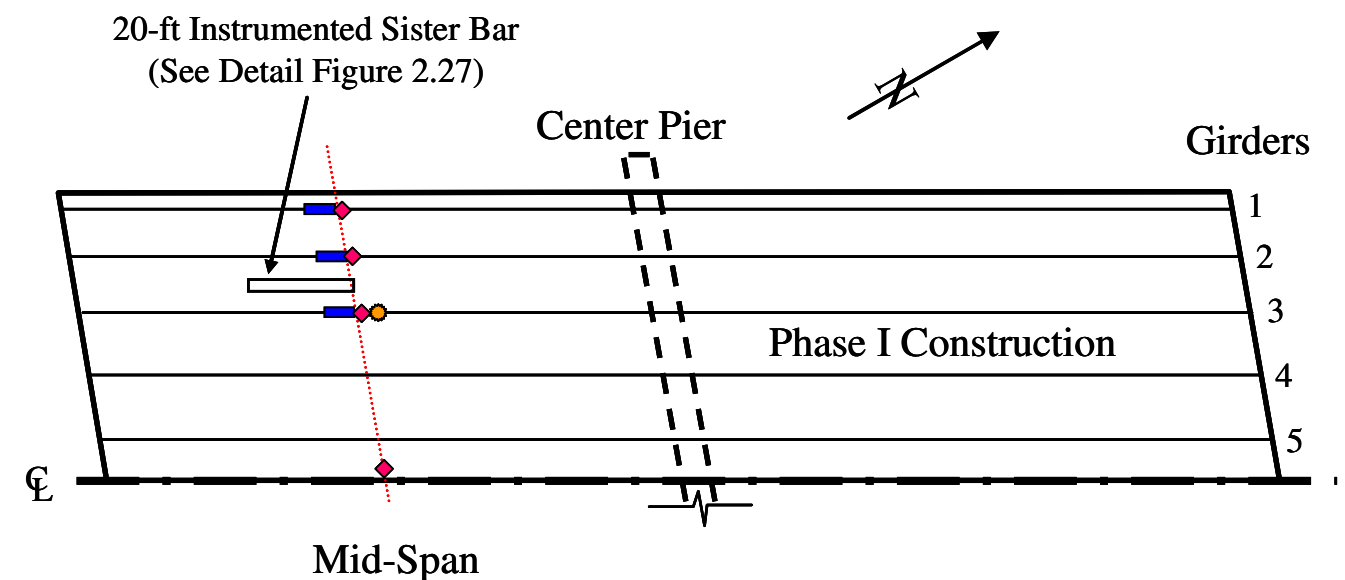

Legend:

- Reinforcement Strain Gage

$\diamond$ Embedded Concrete Strain Gage

- Thermocouple

Figure 2.26: Plan View of Instrumentation on State Road 23 Bridge

Embedded concrete strain gages were installed in the bridge deck to monitor concrete strains over time. As shown in Figure 2.26, embedded concrete gages were located directly beneath reinforcement strain gages to provide a comparison of the concrete strain to the reinforcement strain at a given location. The embedded gages were hung from the top reinforcement mat using tie wire to both ensure complete embedment of the concrete gage as well as eliminate any potential influence of the reinforcing bar on observed strains which may be present if the embedded gage were tied directly to the bar.

In addition to measurements at discrete locations, it was of interest to discern the variation in strains along the length of the bridge deck. As it was not feasible to install strain gages over the entire length of the span, a $20 \mathrm{ft}$ long sister bar was instrumented with strain gages and tied into the top reinforcement mat as illustrated in Figure 2.26. A schematic of the instrumented bar is presented in Figure 2.27. As shown, embedded concrete gages were located directly beneath strain gages mounted on the sister bar. The strain gages and the corresponding embedded concrete strain gages allowed the variation in strain in both the reinforcement and concrete along the length of the bar to be measured. 


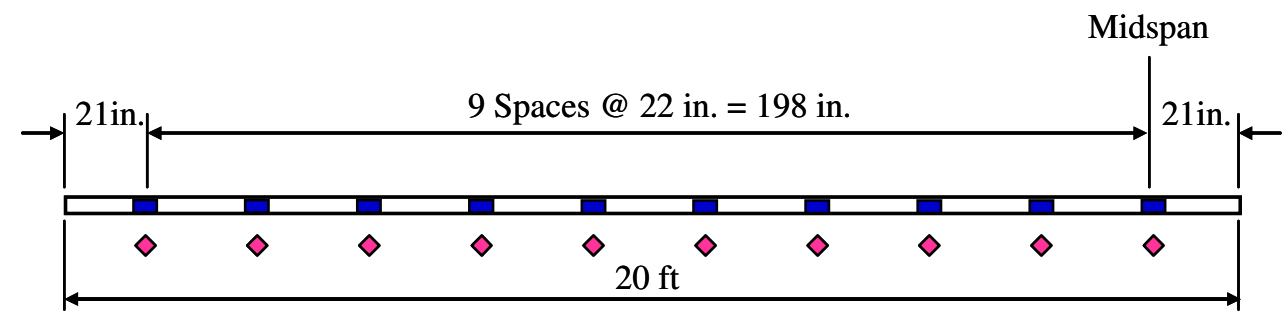

Legend:

- Reinforcement Strain Gage

$\diamond$ Embedded Concrete Strain Gage

Figure 2.27: Schematic of 20-foot Instrumented Bar

Strain gages were also installed on the side face of the top flange of the bulb-tee girder at the locations shown in Figure 2.28. The strain gage on the top flange was installed to enable measurement of the strain gradient at this location. A 2 in. surface mounted wire resistance gage was used. The longer gage length was selected to enable more reliable strain measurements of the girder.

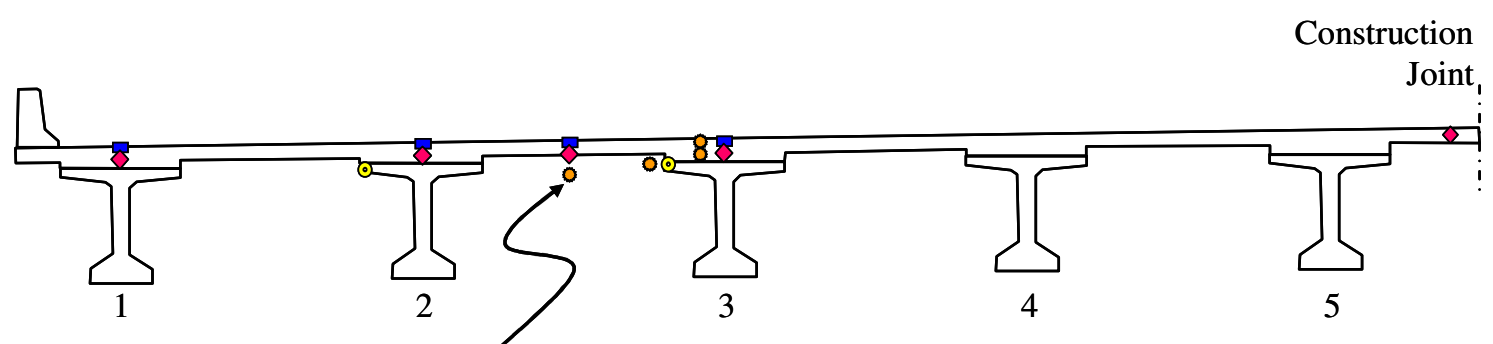

Ambient Thermocouple

All Gauges in Longitudinal Direction

Legend:

- Reinforcement Strain Gage

$\diamond$ Embedded Concrete Strain Gage

๑ Girder Strain Gage

- Thermocouple

Figure 2.28: Cross Section View of Instrumentation at Midspan

\subsubsection{Thermocouples}

As illustrated in Figure 2.28 thermocouples were placed in the bridge deck at midspan adjacent to the strain gage in the top reinforcement mat and the embedded concrete gage. A thermocouple was also adhered to the top flange of the bulb-tee adjacent to the girder strain gage. These thermocouples allowed the variation of temperature through the thickness of the deck to be observed. In addition, the 
thermocouples located near the strain gages allowed strains developed from thermal response of the deck to be separated from those occurring due to concrete shrinkage.

The ambient air temperature was also measured to allow a comparison of internal bridge deck temperatures during hydration, curing, and service. A single thermocouple was suspended at midbay between Girders 2 and 3 out of direct sunlight as shown in Figure 2.28.

\subsubsection{State Road 23 Field Free Shrinkage Specimens}

In addition to the instrumentation installed on the SR 23 bridge, two free shrinkage specimens were cast on-site and instrumented to provide a measurement of the free shrinkage potential of the high performance concrete under field conditions. Both specimens were located adjacent to the bridge ensuring that the specimens were exposed to similar curing and environmental conditions.

A representative slab 8" $\times 30$ " $\times 30$ " was constructed. The edges of the slab were sealed using aluminum tape to eliminate moisture loss at the sides and simulate the conditions of the bridge deck concrete. Embedded concrete gages were installed in the slab to measure strains resulting from shrinkage. As shown in Figure 2.29, an embedded gage was located at the geometric center of the slab specimen. A secondary gage was located closer to the corner of the specimen to evaluate any difference and monitor the effectiveness of sealing the edge. The slab was placed in a vertical position once curing was completed (Day 7) to reduce restraint.

In addition to the slab, a 6"x6"x16" concrete prism was cast and cured on-site. This prism was also instrumented with an embedded concrete strain gage at its geometric center (Figure 2.30). 


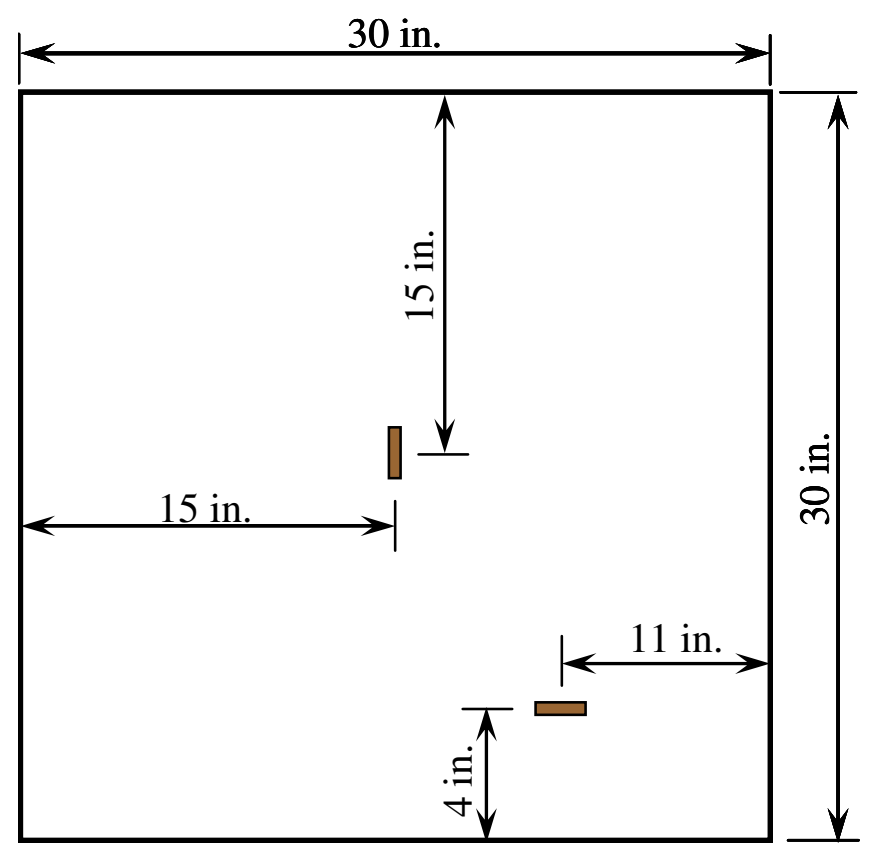

$\square$ Embedded Concrete Strain Gage

Note: Gages Located 4 in. Below Top Surface

Figure 2.29: Plan View of Free Shrinkage Slab Model (Aldridge 2005)

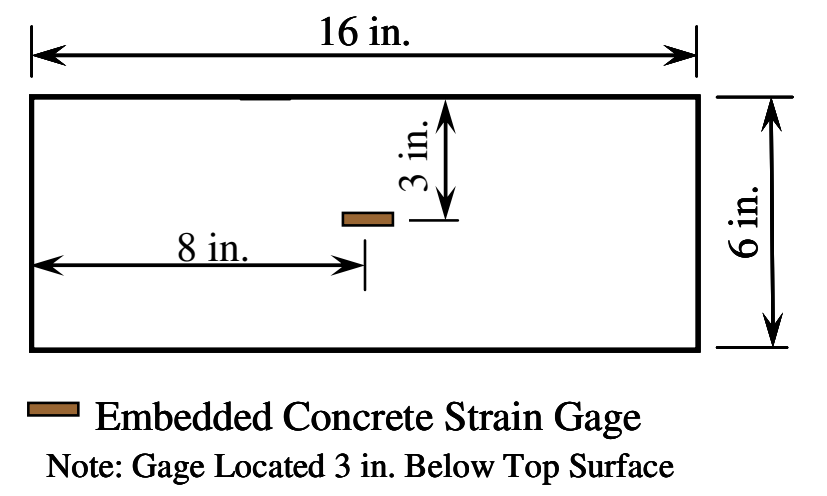

Figure 2.30: Plan View of Free Shrinkage Prism (Aldridge 2005)

\subsubsection{SR 23 Instrumentation Identification}

Instrumentation installed in the SR 23 bridge was given a unique three character identification number. Figure 2.31 presents the identification system used for SR 23 instruments. 


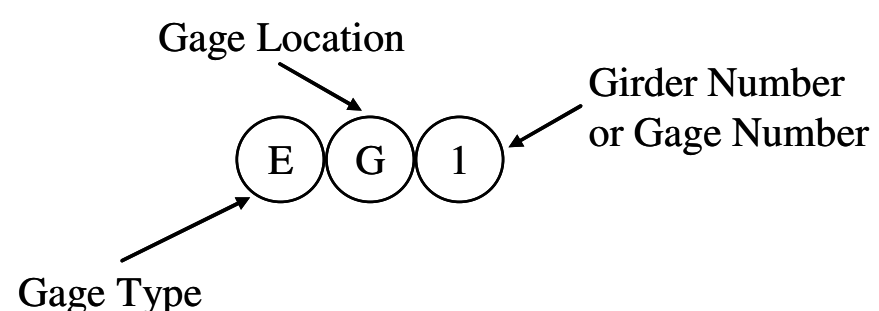

Gage Type:

E - Embedded Concrete Strain Gage

$\mathbf{R}$ - Reinforcing Steel Strain Gage

G - Girder Flange Strain Gage

Gage Location:

G - Above or On Girder

B - On or Below Instrumented Bar

\section{Girder Number or Gage Number:}

If Gage Location is G:

1 - Above or On Girder 1

2 - Above or On Girder 2

3 - Above or On Girder 3

If Gage Location is B:

1-10 - On or below instrumented bar with 10 at midpsan and progressing

back to 1 towards bridge approach

Figure 2.31: SR 23 Instrumentation Identification

\subsection{Thayer Road over Interstate 65}

Field studies of the I- 65 bridge, the SR 18 bridge, and the SR 23 bridge allowed the performance of bridge decks with differing epoxy coated steel designs to be observed and compared. It was of interest to instrument a bridge deck which incorporated FRP reinforcement to observe the behavior of this type of deck, as well as to provide a comparison of performance of the FRP reinforcement to epoxy coated steel with respect to the control of shrinkage cracks. The lower stiffness of the reinforcement and the potential differences in the bonding characteristics of FRP reinforcement can provide interesting information regarding the effect of reinforcing material on restrained shrinkage. 
The Thayer Road Bridge over I-65 in Roselawn, Indiana (Figure 2.32) was the first bridge deck in Indiana constructed which used glass FRP (GFRP) reinforcement. The bridge is a $218 \mathrm{ft}$, five-span, continuous bridge with a steel superstructure and has a horizontal radius of curvature of $1148 \mathrm{ft}(350 \mathrm{~m})$. The steel girders are supported on rockers at the abutments; therefore, they are not integral with the abutments. The other bridges utilize either integral or semi-integral abutments (Table 2.1).

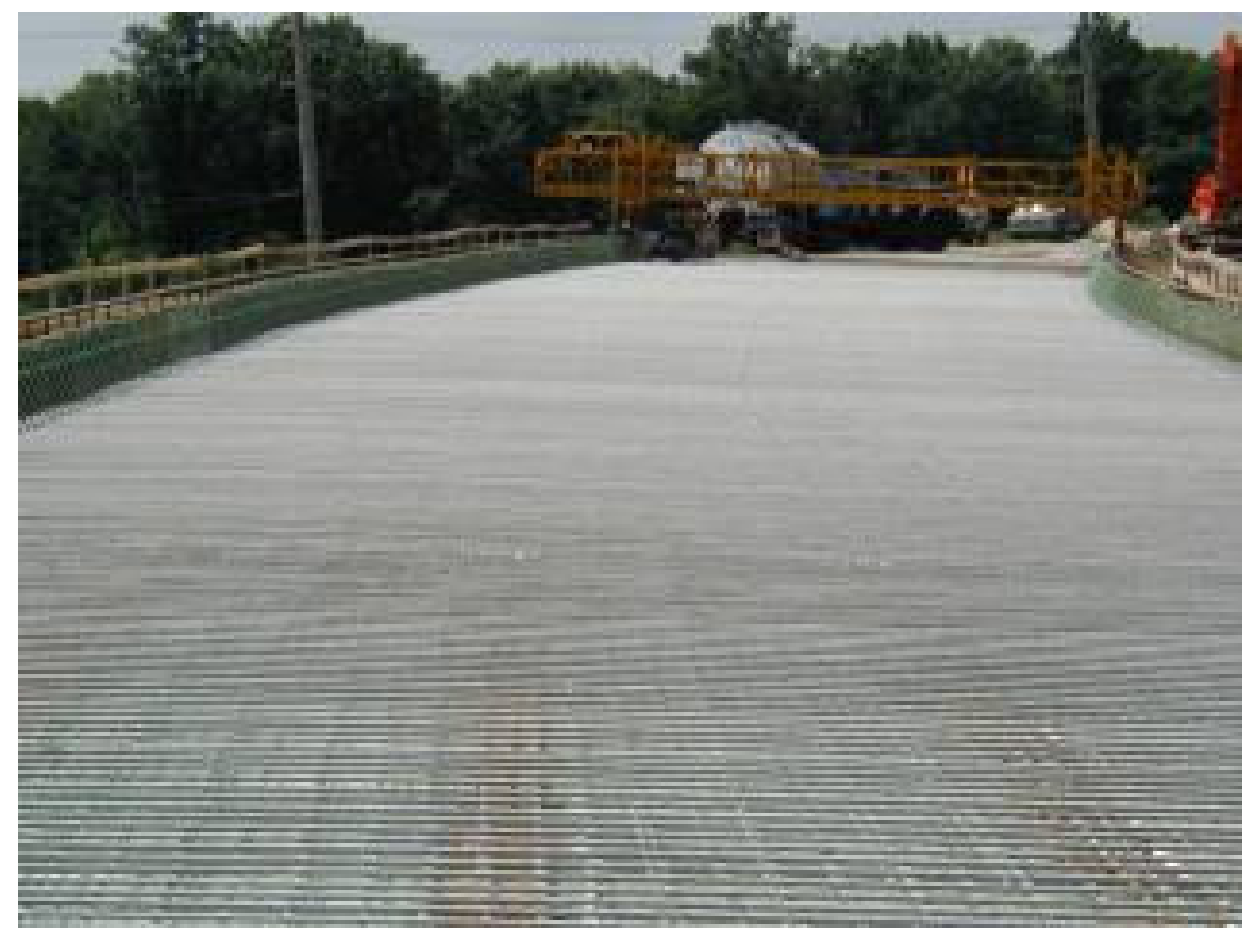

Figure 2.32: Thayer Road Bridge over I-65

The bridge has five spans of varying length. The two endspans are $39 \mathrm{ft}$ long, the two interior spans are $63 \mathrm{ft}$ long, and the center span is $77 \mathrm{ft}$ long. The bridge deck was constructed on SIP steel forms and wet cured for seven days with wet burlene. The deck was designed with \#5 GFRP bars spaced at 6 in. on center for the longitudinal top reinforcement mat and \#6 GFRP bars spaced at 6 in. as the transverse top reinforcement mat as illustrated in Figure 2.33. The bottom mat reinforcement was \#5 epoxy coated steel bars spaced at 12 in. on center in the longitudinal direction and 8 in. on center in the transverse direction. 


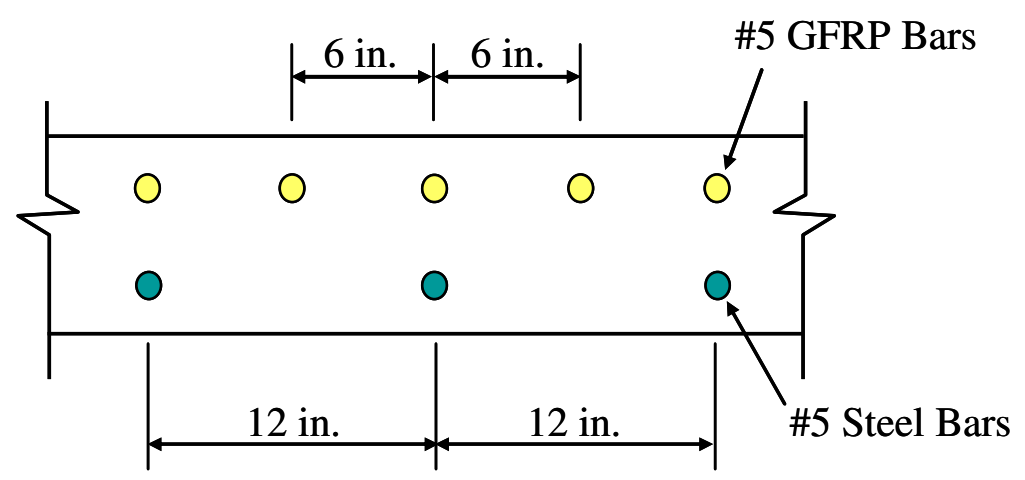

Figure 2.33: Longitudinal Reinforcement in Thayer Road Bridge Deck

\subsubsection{Thayer Road Bridge Materials}

\subsubsection{Concrete}

An INDOT Class $\mathrm{C}$ mix design was used for the concrete in the Thayer Road bridge deck, and is presented in Table 2.6.

Standard 6 in. by 12 in. concrete cylinders were taken at the time the bridge deck was cast. The cylinders were tested at the Bowen Laboratory using a 600 kip Forney compression testing machine. The compressive strength of the concrete was determined in accordance with ASTM C39 and is provided in Figure 2.34. The 28-day compressive strength was determined to be 6400 psi. 
Table 2.6: INDOT Class C Mix Design on Thayer Road Bridge

\begin{tabular}{|c|c|c|}
\hline Materials & Batch Weights & Specifications/Suppliers \\
\hline Cement & 658 & ASTM C-150, Type I, Essroc Cement Co. \\
\hline Sand & $1231 \mathrm{lb} / \mathrm{yd}^{3}$ & $\begin{array}{l}\text { ASTM C-33 \& INDOT Specification \#23 Sand } \\
\text { from IMI, Kewanna, IN }\end{array}$ \\
\hline Stone & $1771 \mathrm{lb} / \mathrm{yd}^{3}$ & \#8 Stone from Wulcan Materials, IN \\
\hline Water & $273 \mathrm{lb} / \mathrm{yd}^{3}$ & - \\
\hline Ash & None & - \\
\hline Micro-Silica & None & - \\
\hline Water Reducer & $19.7 \mathrm{oz} / \mathrm{yd}^{3}$ & $\begin{array}{c}\text { ASTM C-494, Water Reducer Type D Daratard } 17 \\
\text { (plant added) }\end{array}$ \\
\hline Air & $6.50 \%$ & $\begin{array}{l}\text { ASTM C-260 Air Entrainment, Micro Air by } \\
\text { Master Builders }\end{array}$ \\
\hline Slump & 4 in. & - \\
\hline
\end{tabular}

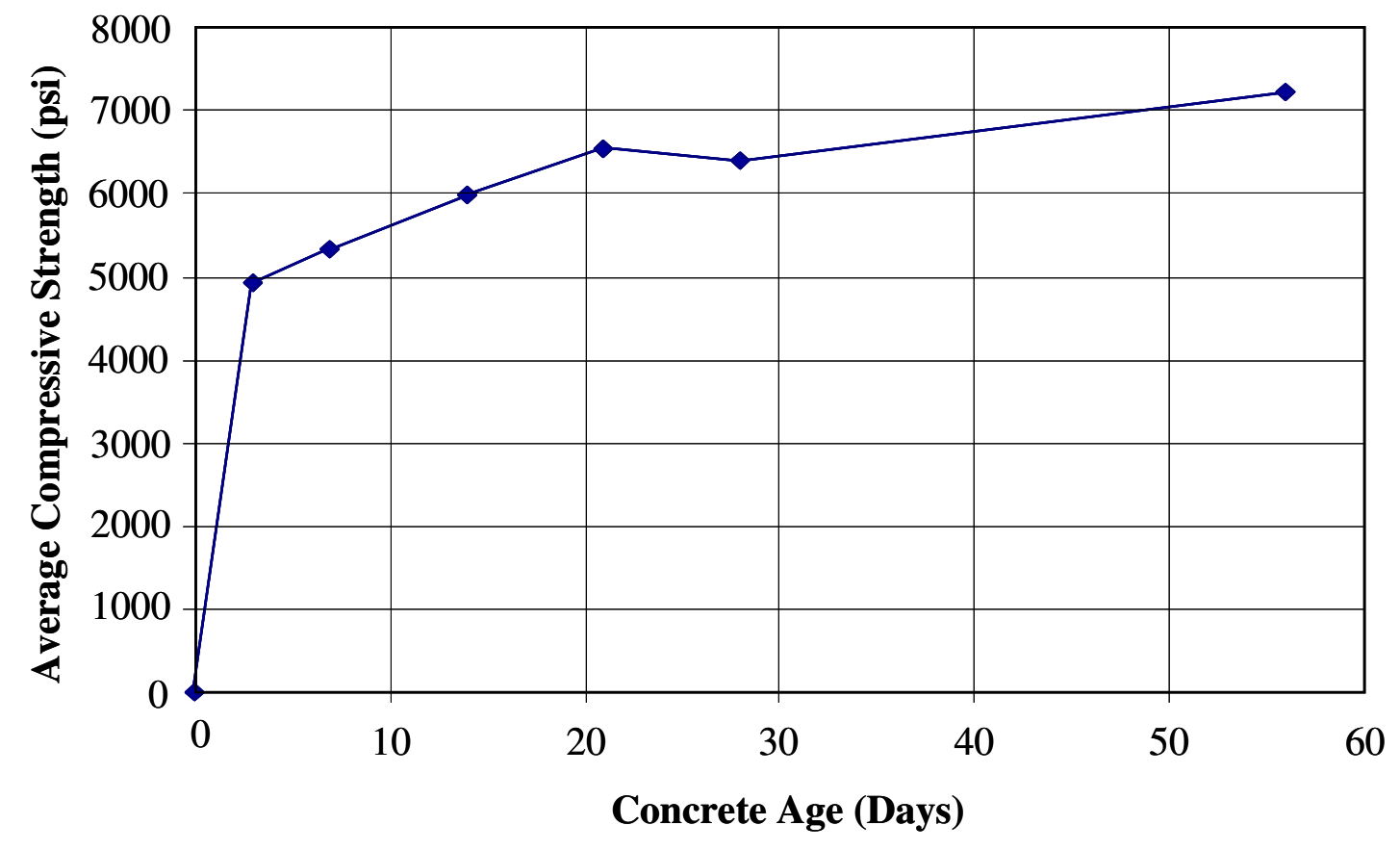

Figure 2.34: Thayer Road Bridge Concrete Compressive Strength

\subsubsection{Reinforcement}

The Thayer Road Bridge was constructed using both steel and glass FRP (GFRP) reinforcement. The GFRP reinforcement utilized in the top mat reinforcement was produced by Putrall Inc, commercially named V-ROD. The V-ROD bars were produced 
with 25\% vinyl ester resin and 75\% type-E glass fibers (Pay 2005). To improve the bond characteristics of the bars with the concrete, an embedded sand coating was applied to the bars. The stress-strain curve is plotted in Figure 2.35. The bars had an average modulus of elasticity $E_{f}=6900 \mathrm{ksi}$ and an ultimate strength, $\sigma_{u}$, of $89 \mathrm{ksi}$ (Pay 2005). The steel reinforcing bars were Grade 60 steel and were epoxy coated.

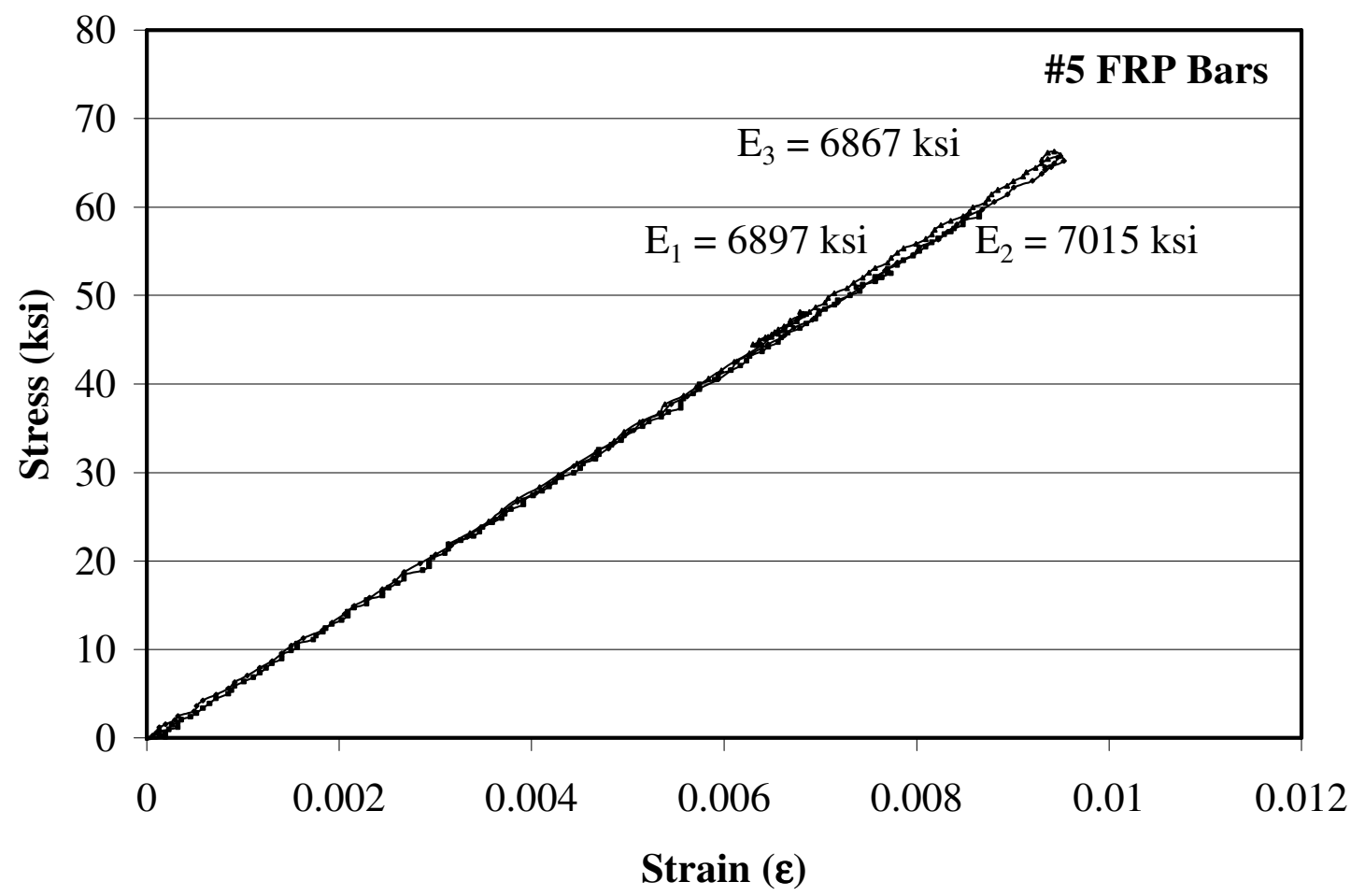

Figure 2.35: V-ROD GFRP Stress versus Strain (Pay 2005)

\subsubsection{Thayer Road Bridge Instrumentation}

\subsubsection{Strain Gages}

Strain gages were installed on longitudinal reinforcement in both the top and bottom reinforcement mats (Figure 2.36). These measurements allow for evaluation of the strain gradient through the deckas well as a comparison of strains occurring in reinforcement of two different materials.

In addition to the reinforcement gages, embedded concrete strain gages were installed and orientated longitudinally at the same location to provide a comparison of behavior of the reinforcement and adjacent concrete (Figure 2.36). The embedded gages were suspended using tie wire from the top reinforcement at the mid-height of the deck (Figure 2.37 and Figure 2.38). 
Strain gages were also attached on the top and bottom flanges of the steel girders at Pier 3 (Figure 2.37). These gages provide insight into the overall behavior of the bridge in addition to the strain gradient through the depth of the superstructure.

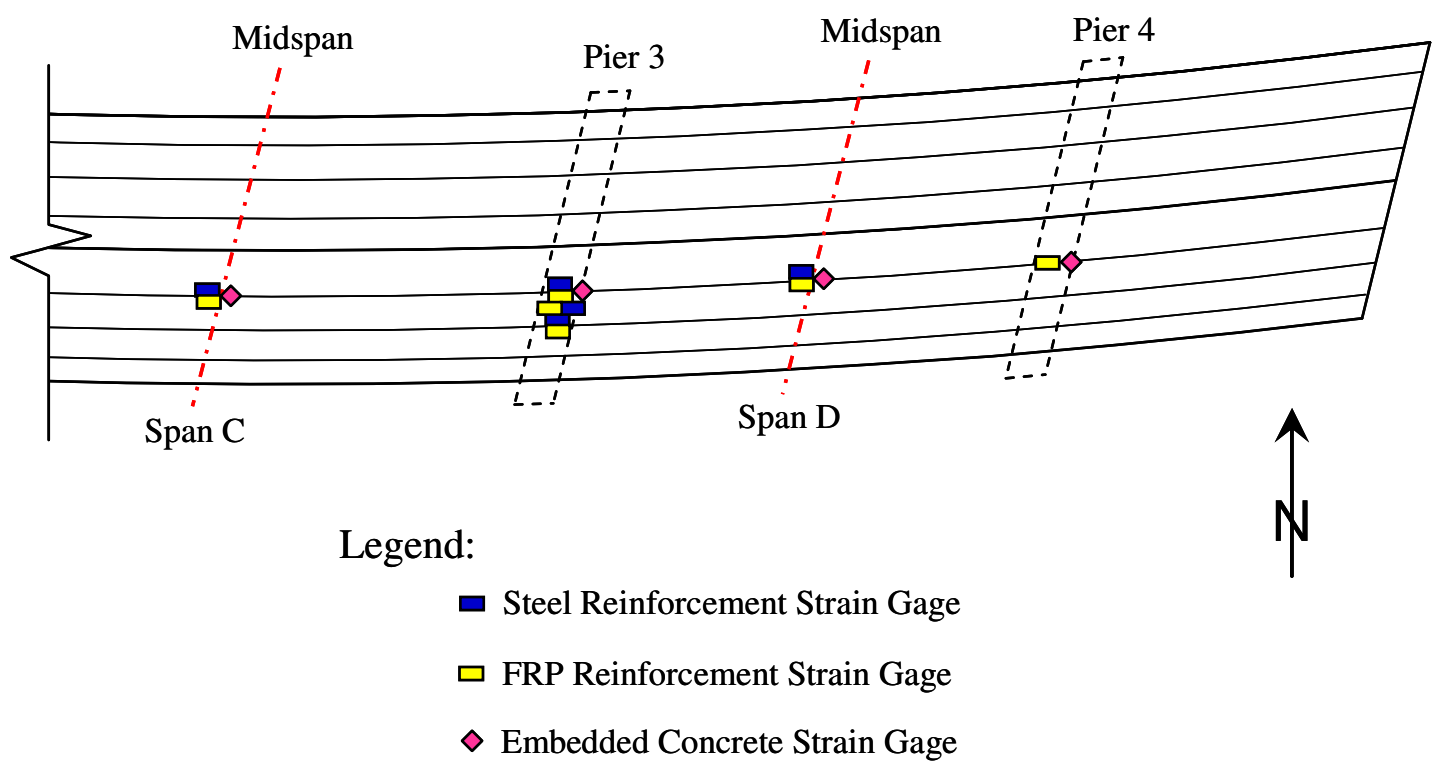

Figure 2.36: Plan View of Longitudinal Strain Gages (Thayer Road Bridge)

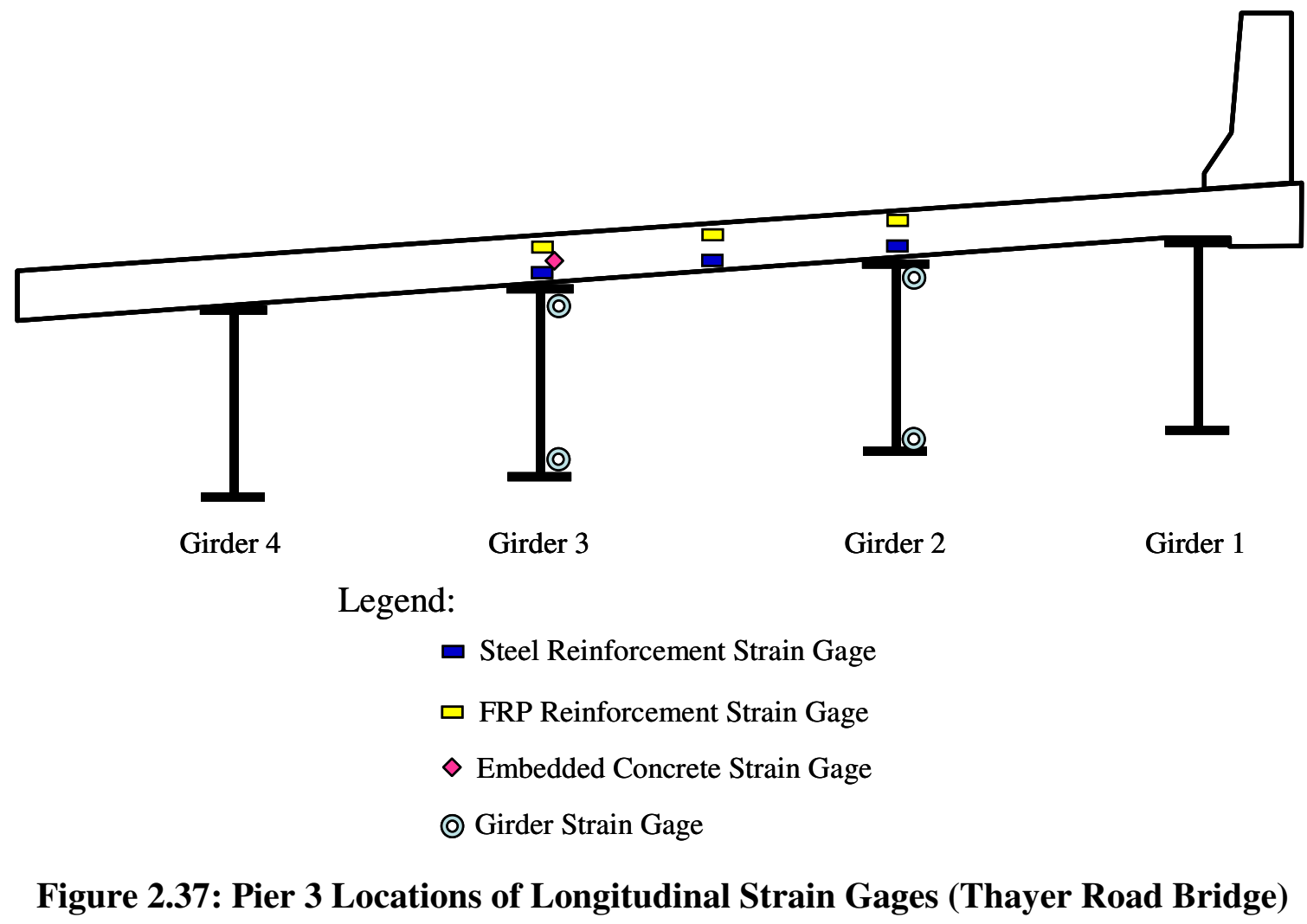




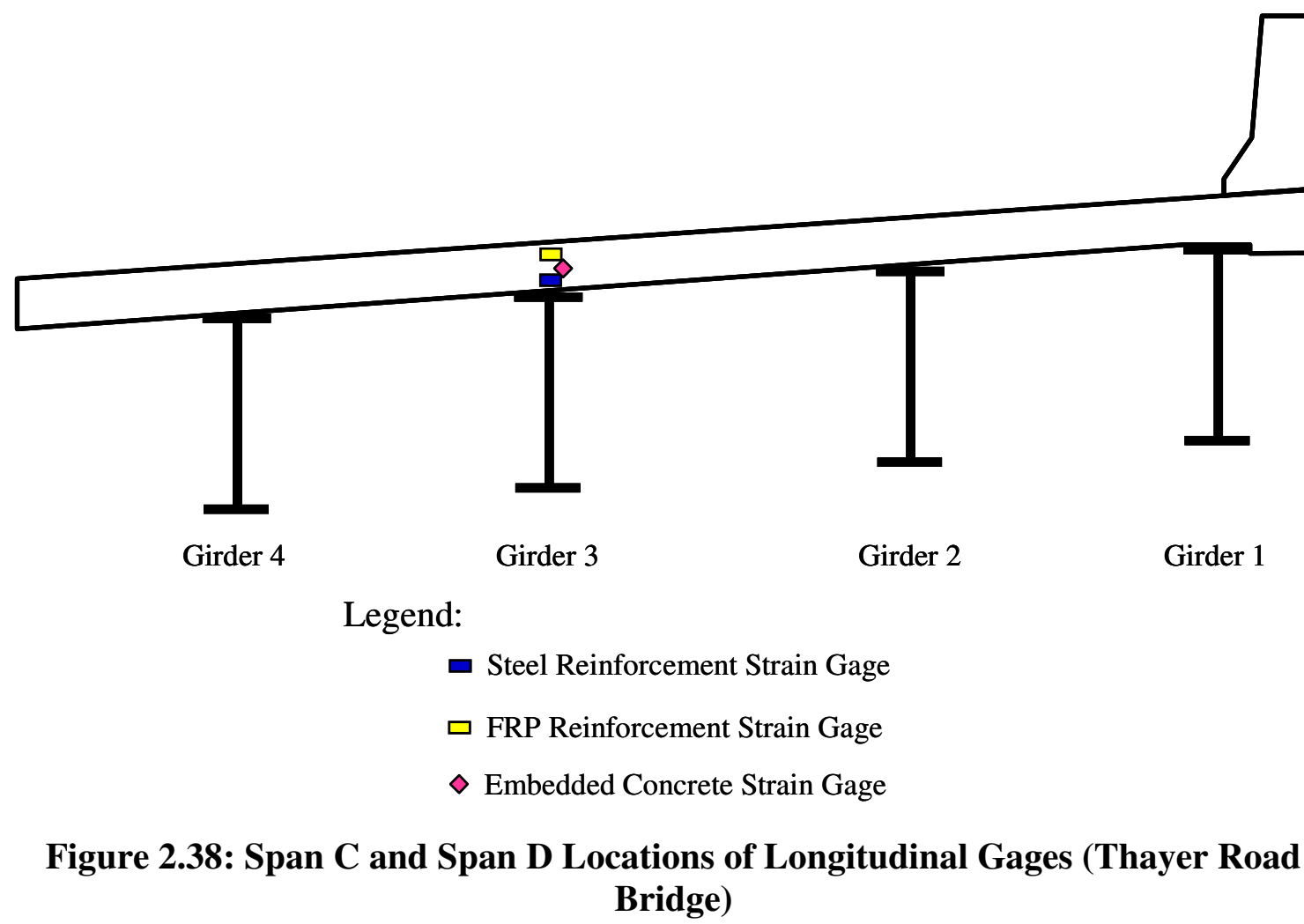

\subsubsection{Thermocouples}

Thermocouples were installed to monitor the thermal gradient through the depth of the superstructure. Thermocouples were installed in the deck over Girder 3 at Pier 3 (Figure 2.39). As shown in Figure 2.40, thermocouples were placed in both the top and bottom mats. These thermocouples were secured to the reinforcement adjacent to the longitudinal strain gages that were installed on the reinforcement. Thermocouples were also mounted on the girder at the top and bottom flanges as well as at the mid-height of the web. Finally, a thermocouple was suspended beneath the deck between Girders 3 and 4 to measure the ambient air temperature (Figure 2.40). 


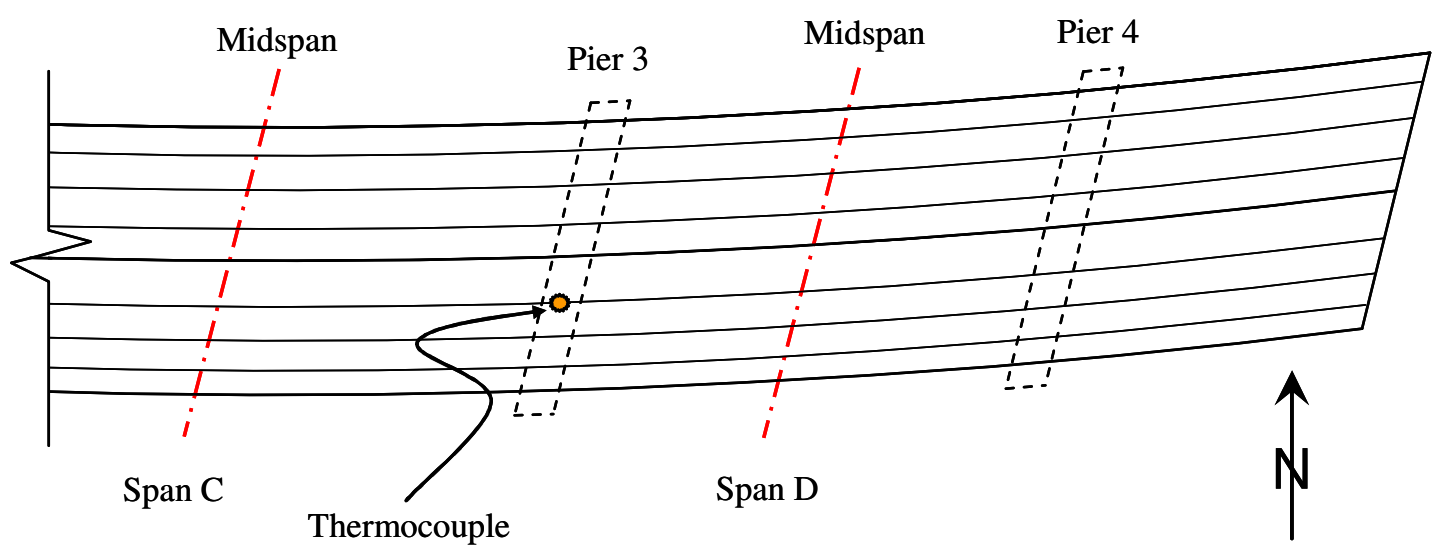

Figure 2.39: Plan View of Thermocouple Locations on Thayer Road Bridge

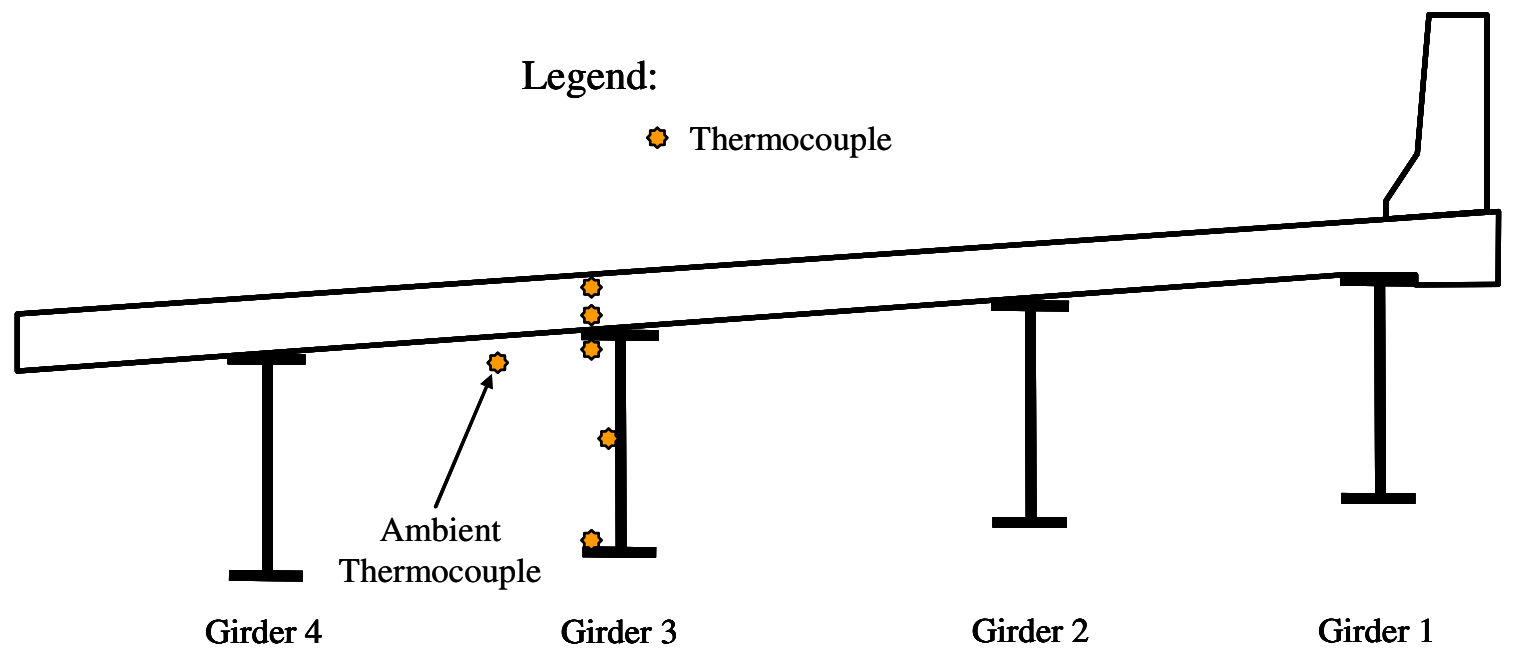

Figure 2.40: Locations of Thermocouples at Pier 3

\subsubsection{Thayer Road Bridge Instrumentation Identification}

The instrumentation installed on the Thayer Road bridge was assigned a unique four character identification code. The identification codes used are described in Figure 2.41 . 
Longitudinal Location

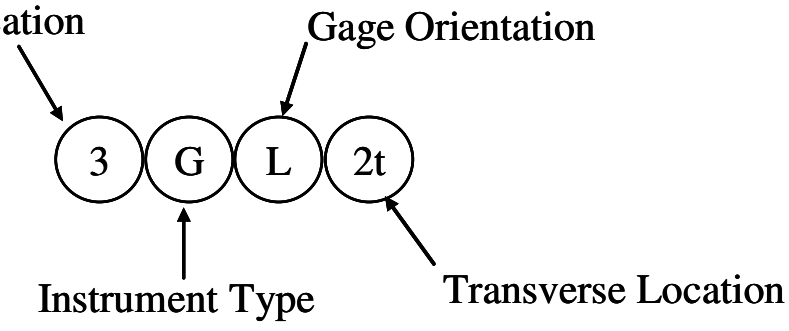

Longitudinal Location: $\quad$ C - Midspan of Span C

D - Midspan of Span D

4 - Over Pier \#4

5 - Over Pier \#5

\begin{tabular}{ll}
\hline Instrument Type: & F - Strain Gage on FRP Bar \\
& S - Strain Gage on Steel Bar \\
& $\mathbf{G}-$ Strain Gage on Girder \\
& $\mathbf{C}-$ Embedded Concrete Gage \\
& Tx - Thermocouple \\
\hline Gage Orientation: & L - Longitudinal Orientation \\
& $\mathbf{T}-$ Transverse Orientation \\
\hline Transverse Location: & $\mathbf{2}-$ Girder 2 \\
& $\mathbf{3}-$ Girder 3 \\
& $\mathbf{B}-$ Bay between Girders 2 and 3 \\
\hline
\end{tabular}

Notes: (1) For instruments designated (Tx) no orientation is given

(2) For instruments designated (G) Transverse location character may include an additional character ( $\mathrm{t}$ ) or (b) which indicate the strain gage is installed on either the top flange or the bottom flange, respectively.

Figure 2.41: Instrument Identification Scheme for Thayer Road Bridge 


\section{CHAPTER 3 FIELD RESULTS}

\subsection{Introduction}

To evaluate the bridge deck behavior of the four bridges described in Chapter 3 , the field results were analyzed. Data recorded by instrumentation on the reinforcement and embedded in deck were used to estimate the amount of restraint present in the respective bridges, provide comparisons of behavior between the different materials and designs, and better understand the long-term deck behavior of these bridges. Cracks were mapped and crack widths were measured to observe the effectiveness of the different deck designs and materials on controlling cracking.

\subsection{State Road 18 Over I-65}

The State Road 18 Bridge was instrumented to observe the differences in behavior with respect to restrained shrinkage between two spans with different empirical reinforcement designs. Crack mapping was performed on the deck, and temperature and strains from the deck were measured and recorded.

\subsubsection{Crack Mapping}

Cracking in the SR 18 deck was mapped on the $15^{\text {th }}$ day after placement of the deck during the first phase of construction. Crack widths were also measured at this time. Crack widths were measured subsequently on Days 30, 37, 44, 51, and 350. On October 11, 2005 (Day 799), a complete crack map of the bridge deck, including both Phases I and II, was completed. The Day 15 and Day 799 crack maps are presented in Figure 3.1. All crack widths were measured adjacent to the construction joint between the two phases. For Days 15 through 350, crack widths were measured using an Edmund Direct 50X microscope. For Day 799, crack widths were measured using a Bausch and Lomb crack scope.

The Bausch and Lomb crack scope was used in later crack mappings because of the limitations of the Edmund Direct microscope. The angled tip of the Edmund Direct microscope can limit the amount of light entering the lens, making the crack difficult to see through the microscope. In addition, the Edmund Direct microscope is ill suited for use on the rough surface of the bridge deck (i.e. broom finish, tine finish, scaling, etc) because the microscope is intended to rest directly on the surface of the member being mapped. Furthermore, the Bausch and Lomb crack scope includes a calibrated reticle which provides for greater precision in the measurements. 


\section{$£$}

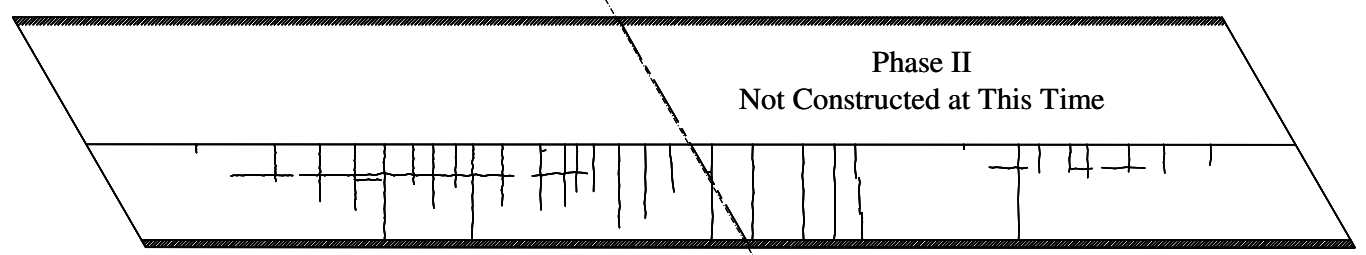

(a) Day 15

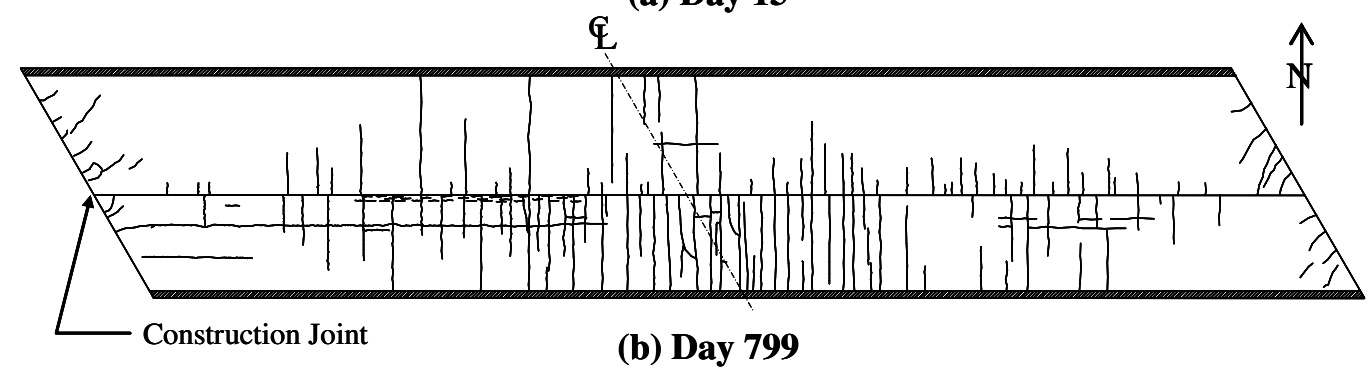

Figure 3.1: SR 18 Crack Maps

At the time of mapping, specific cracks were selected to have their widths measured and tracked over time. Figure 3.2a shows the change in selected crack widths over time while Figure 3.2b shows the change in average crack widths over time. Crack widths in the AASHTO span were generally larger and grew wider over time. The average crack width in the span with the AASHTO empirical reinforcement grew from 6.6 mils to 8.6 mils from Day 15 to Day 51. The average crack width in the span reinforced with the Purdue empirical reinforcement grew from 3.8 mils to 5.8 mils during the same time period. In both spans, the average crack width grew by 2 mils between Days 15 and 51. 


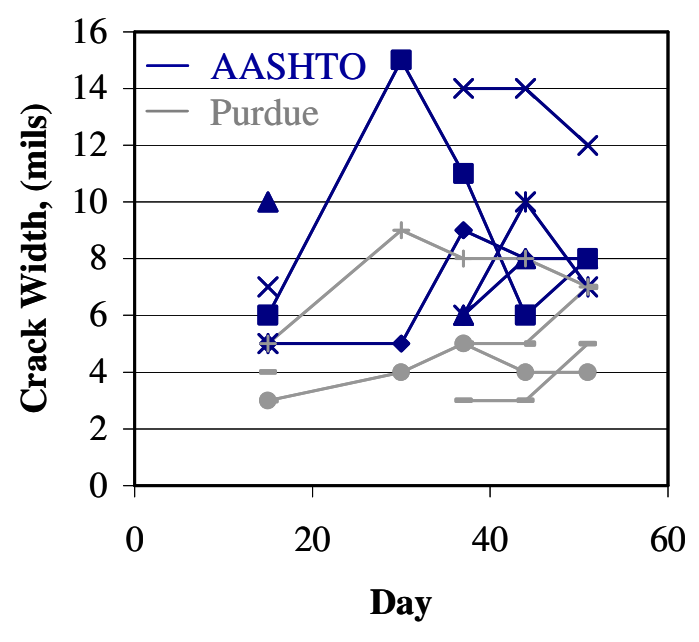

(a) Individual Crack Widths

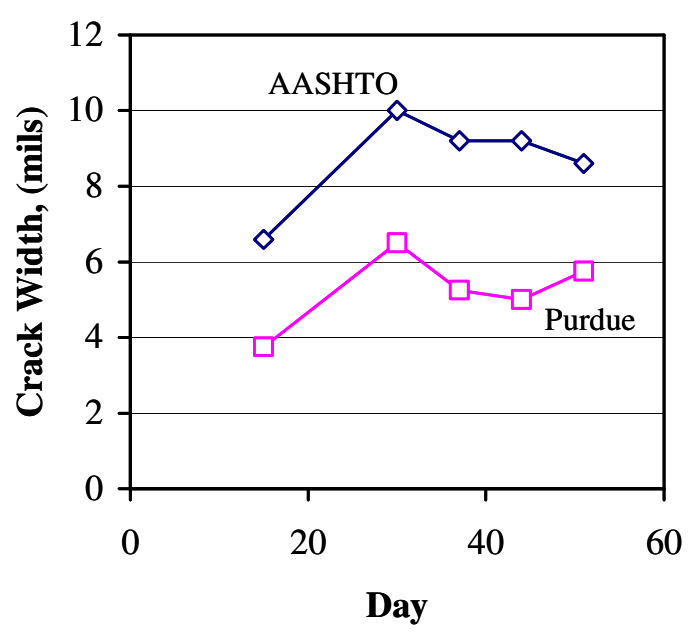

(b) Average Crack Widths

Figure 3.2: Average Crack Width Growth versus Time

Figure 3.3 shows the relative performance of the two spans on October 11, 2005 after 799 days. In addition, Table 3.1 presents statistical data regarding the cracking in both spans after 799 days. Though the Purdue empirical span had 47\% more cracks than the AASHTO empirical span, the average crack width was $43 \%$ greater in the AASHTO empirical span than in the Purdue empirical span. Similarly, the maximum crack width observed in the AASHTO empirical span was $38 \%$ greater than in the Purdue empirical span. It is also interesting that ACI Committee 224 recommends limiting crack widths to 0.007 in. in structures exposed to corrosive environments (ACI 2242001 ). In the

AASHTO Span, $60 \%$ of the cracks observed exceeded this limit while $37 \%$ of the cracks observed in the Purdue Span exceeded 0.007 in. An aesthetic limit for crack widths is 0.016 in. (ACI 318 2001). In the AASHTO Span, 13\% of the cracks observed exceeded this limit while $9 \%$ of the cracks observed in the Purdue Span exceeded 0.016 in. 


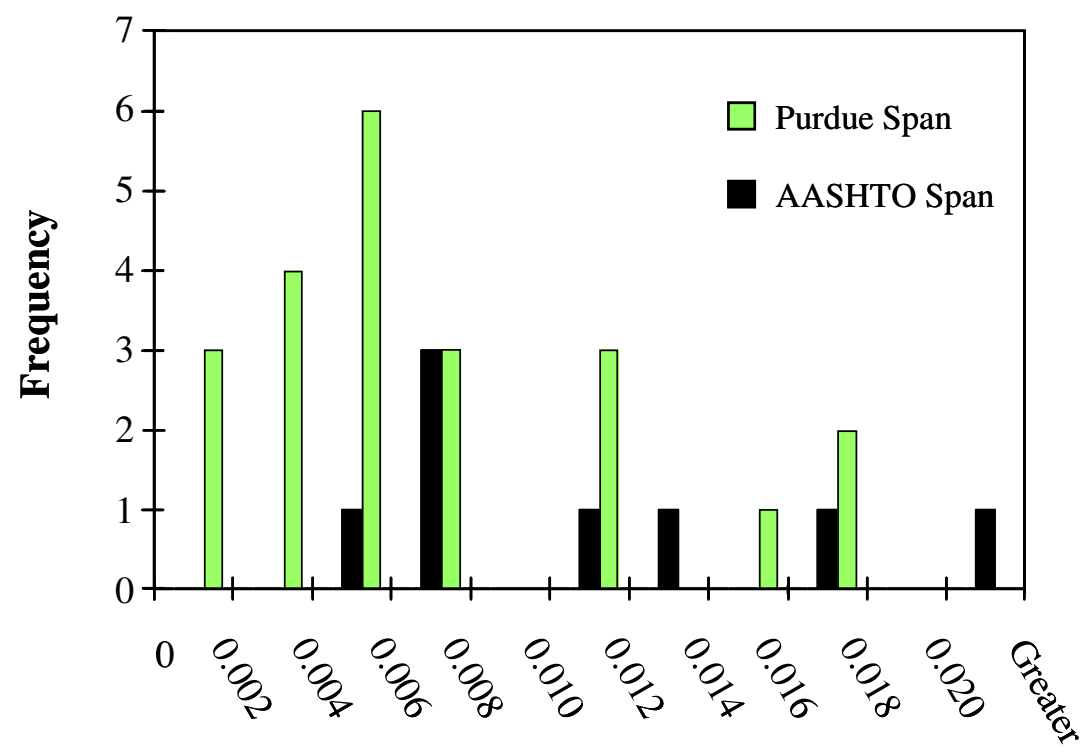

Crack Width (in.)

Figure 3.3: Comparison of Cracks in SR 18 Positive Moment Region (October 11, 2005)

Table 3.1: SR18 Crack Width Statistics (October 11, 2005)

\begin{tabular}{|c|c|c|}
\hline Crack Statistics & Purdue Span & AASHTO Span \\
\hline Number of Cracks & 22 & 15 \\
\hline Mean Crack Widths (in.) & 0.007 & 0.010 \\
\hline Standard Deviation (in.) & 0.005 & 0.008 \\
\hline Maximum Crack Width (in.) & 0.018 & 0.025 \\
\hline Variance & $2.53 \times 10^{-5}$ & $3.11 \times 10^{-5}$ \\
\hline
\end{tabular}

\subsubsection{Temperature}

The ambient air temperature was initially measured using a Campbell Scientific CS500 temperature probe located inside the Type-M cabinet which housed the data acquisition system on-site. The temperature probe was removed from the cabinet on Day 14 and suspended underneath the superstructure because temperatures inside the cabinet were significantly higher than the ambient air temperature. As shown in Figure 3.4, the temperature probe malfunctioned on Day 79 (October 20, 2003). However, the ambient probe was not replaced since temperature data from the bottom flange thermocouple was found to correspond closely with the ambient probe, as illustrated in Figure 3.5. It should be noted that initially the ambient probe temperatures appear higher than those recorded by the bottom flange thermocouple. However, the ambient probe was originally installed 
inside the metal data acquisition cabinet at the site where temperatures were higher than ambient due to the cabinet being heated by direct sunlight. The probe was moved underneath the bridge superstructure on Day 14. After that time, the bottom flange thermocouple and ambient probe data are nearly identical. Therefore, air temperature after Day 79 was estimated using the bottom flange thermocouple (Figure 3.6).

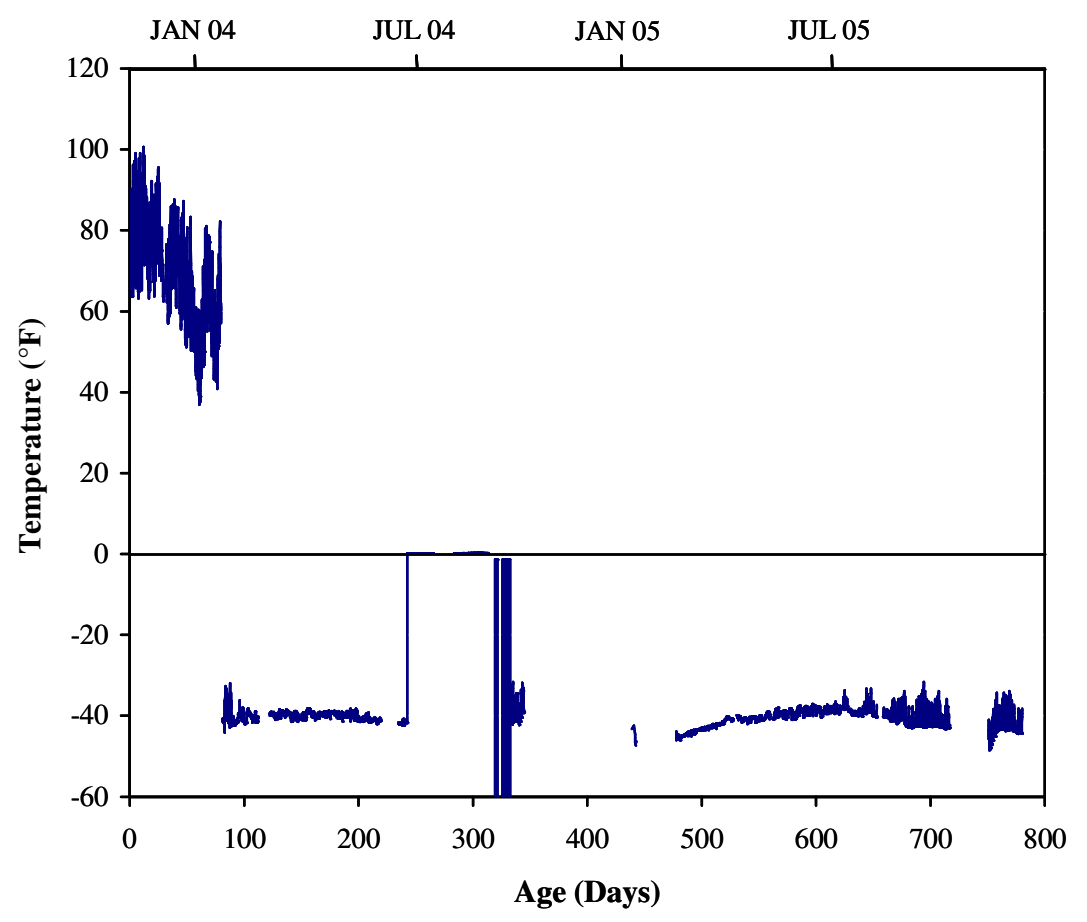

Figure 3.4: Ambient Air Temperature 


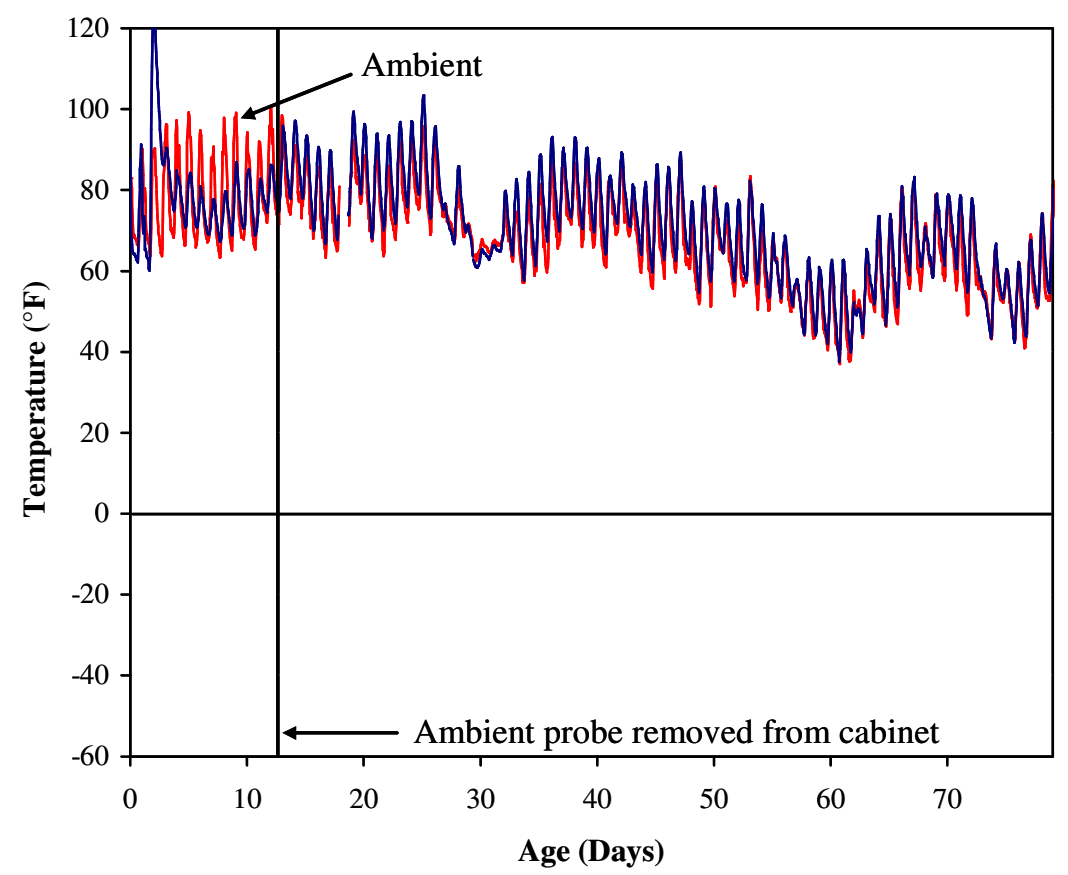

Figure 3.5: Comparison of Ambient Temperature to Bottom Flange Temperature

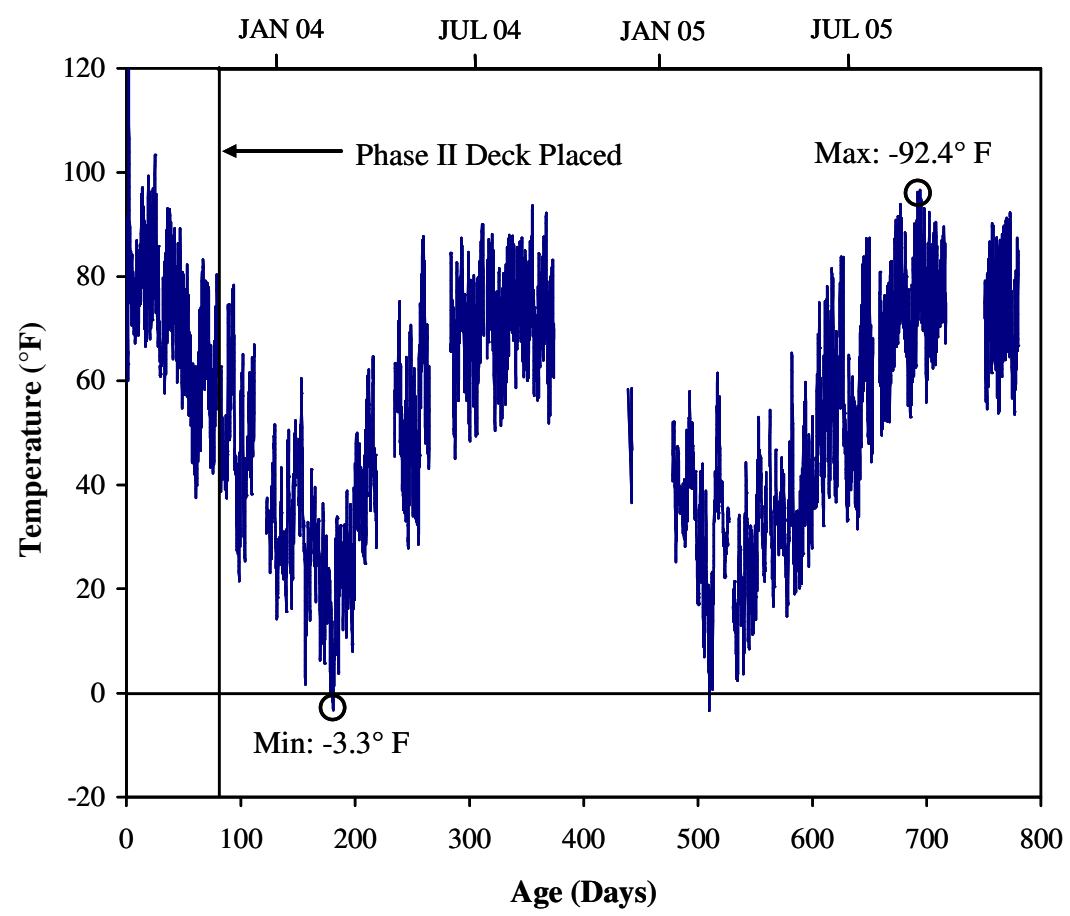

Figure 3.6: Estimated Ambient Temperature (Bottom Flange Thermocouple) 
As noted in Figure 3.6, the ambient temperature varied between a low of $-3.3^{\circ} \mathrm{F}$ and a high of $92.4^{\circ} \mathrm{F}$. Thus, if the coefficient of thermal expansion for the deck is estimated as $6.0 \times 10^{-6} /{ }^{\circ} \mathrm{F}$, the total "free" strain from seasonal temperature change can be approximated as $574 \mu \varepsilon$.

\subsubsection{Behavior of Longitudinal Reinforcement (SR 18 AASHTO Span)}

The strain in the concrete and the reinforcement at the level of the bottom mat of reinforcement in the AASHTO midspan over Girder 3, midbay between Girders 2 and 3, and over Girder 2 is presented in Figure 3.9 - Figure 3.7, respectively. In general, the concrete strain does not appear to vary across the bridge at midspan and is relatively insensitive to thermal variations over time.

It was observed that the reinforcement strain, however, varies with the temperature that the bridge deck experiences. As the ambient temperature decreased over the first 100 days, from an average temperature of $48^{\circ} \mathrm{F}$ to an average temperature of $10^{\circ}$ $\mathrm{F}$, strain in the reinforcement increased by $350 \mu \varepsilon$ over Girder 2, and $290 \mu \varepsilon$ midbay between Girders 2 and 3. As the ambient temperature increased from the average low of $10^{\circ} \mathrm{F}$ at the end of January 2004 to an average temperature of $77^{\circ} \mathrm{F}$ at the first of July 2004, the strain decreased by $270 \mu \varepsilon$ over Girder 3 and $340 \mu \varepsilon$ midbay between Girders 2 and 3 .

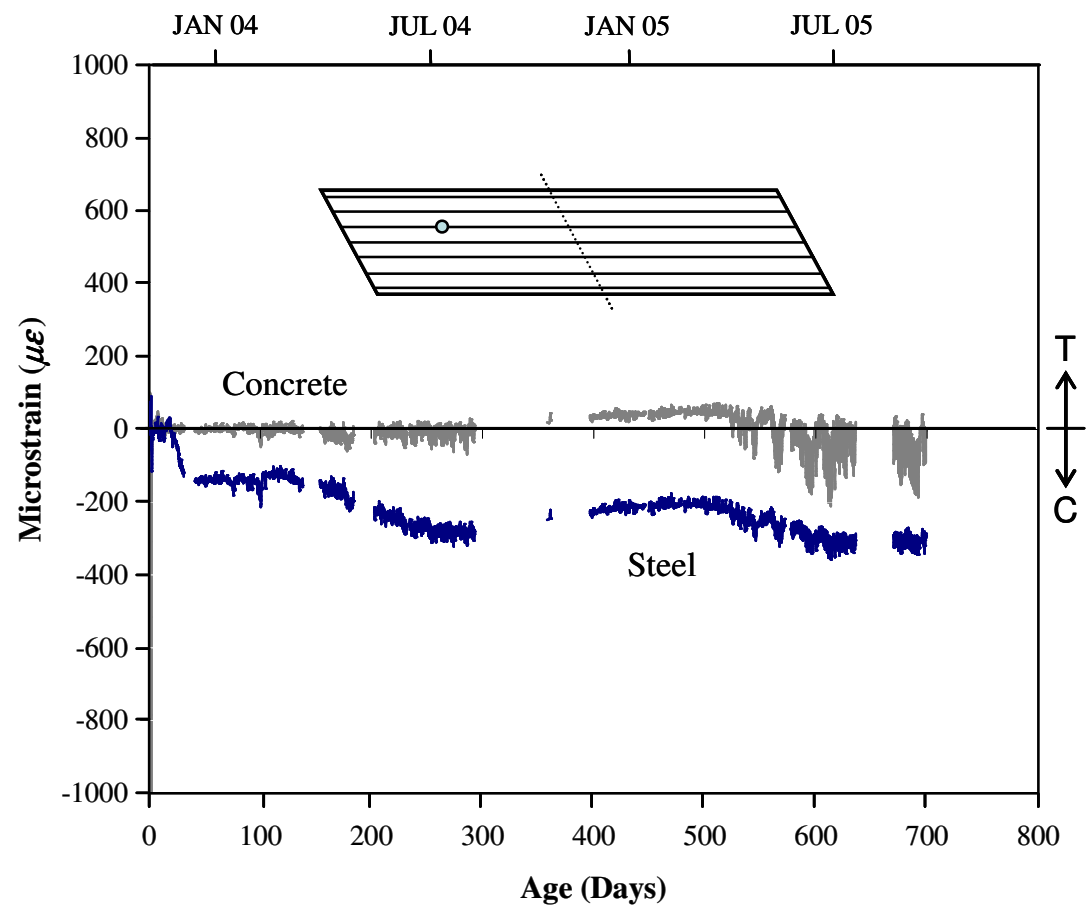

Figure 3.7: AASHTO Midspan Over Girder 3 (Bottom Bar) 


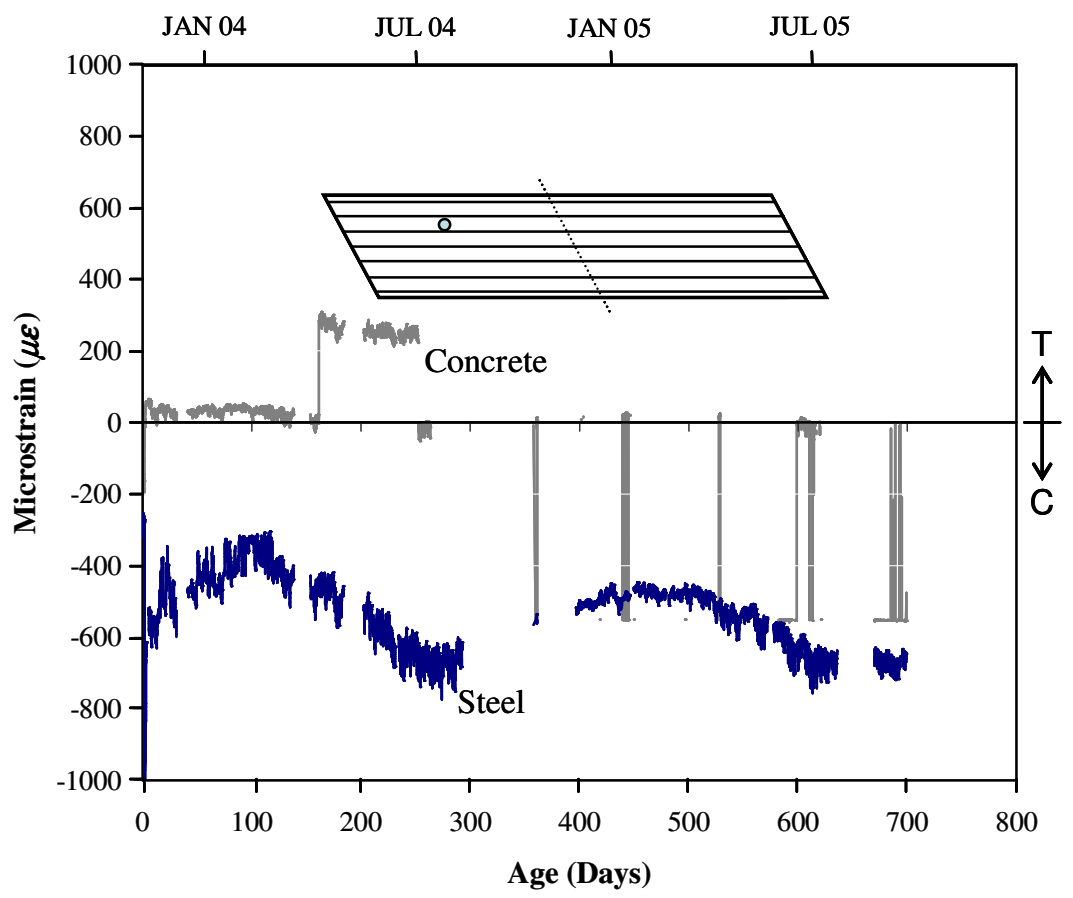

Figure 3.8: AASHTO Midpsan Between Girders 2 and 3 (Bottom Bar)

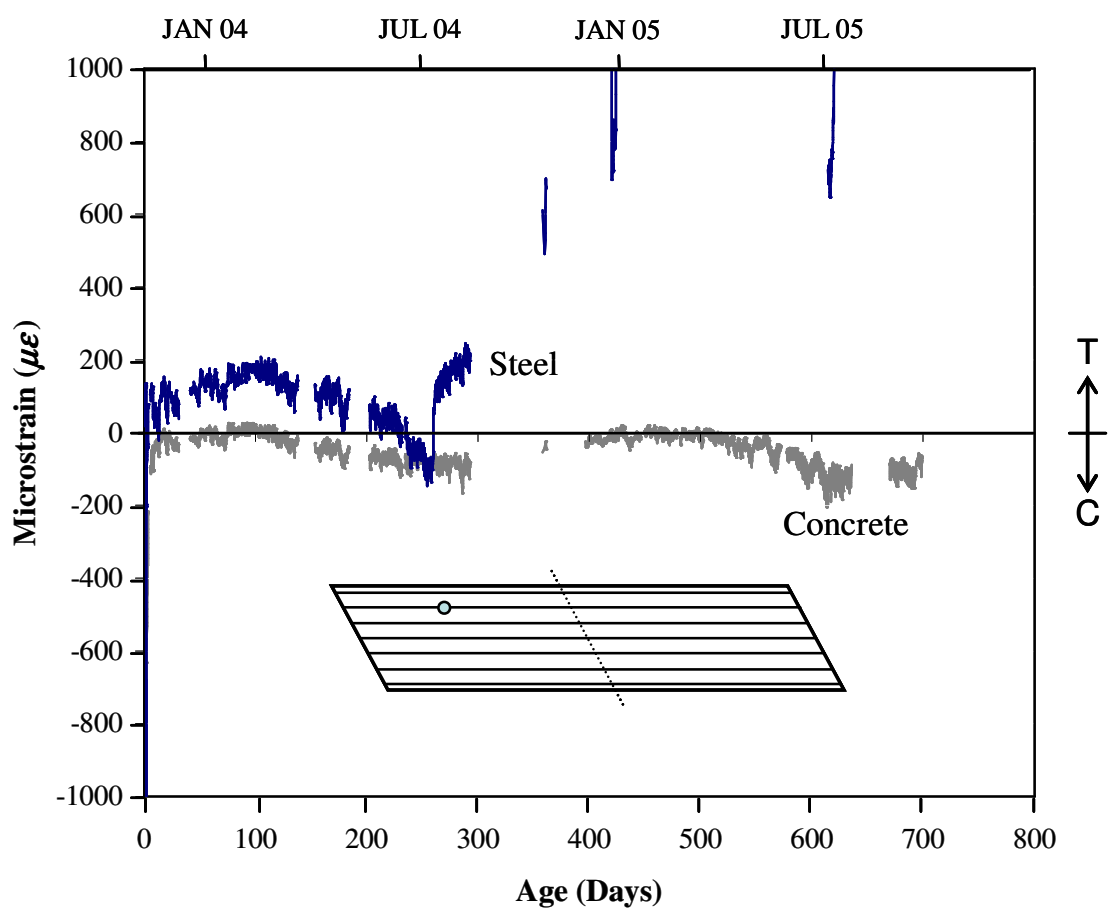

Figure 3.9: AASHTO Midspan Over Girder 2 (Bottom Bar) 
While the reinforcement over Girder 2 and midbay between Girders 2 and 3 demonstrate similar behavior, the reinforcement over Girder 3 exhibits a distinct increase in compressive strain between Day 21 and Day 30 in the bottom mat of reinforcement. The strain in the steel drops from an average of $10 \mu \varepsilon$ over the first 20 days to $140 \mu \varepsilon$ after Day 30. After Day 30, the strain in the reinforcement at this location stabilizes and behaves analogous to the reinforcement over Girder 2 and between Girders 2 and 3. The reinforcement over Girder 3 compresses as the temperature rises from January 2004 to July 2004. The compressive strain increased by $158 \mu \varepsilon$ during this period of time.

While the instrumentation was installed along the skew of the bridge $\left(30^{\circ}\right)$, the cracks that formed in the bridge deck were perpendicular to the girders and did not appear to be influenced by the skew of the deck (Figure 3.1). Thus, as shown in Figure 3.10, the distance of the instrumentation to cracks that formed varied across a section. The as-built locations of the instrumentation are noted in Figure 3.10. As noted in Section 3.2.1, cracks were measured and mapped at the construction joint. Thus, the distances of the crack relative to the instrumentation shown in Figure 3.10 are based on the measured location of the crack (at the construction joint).

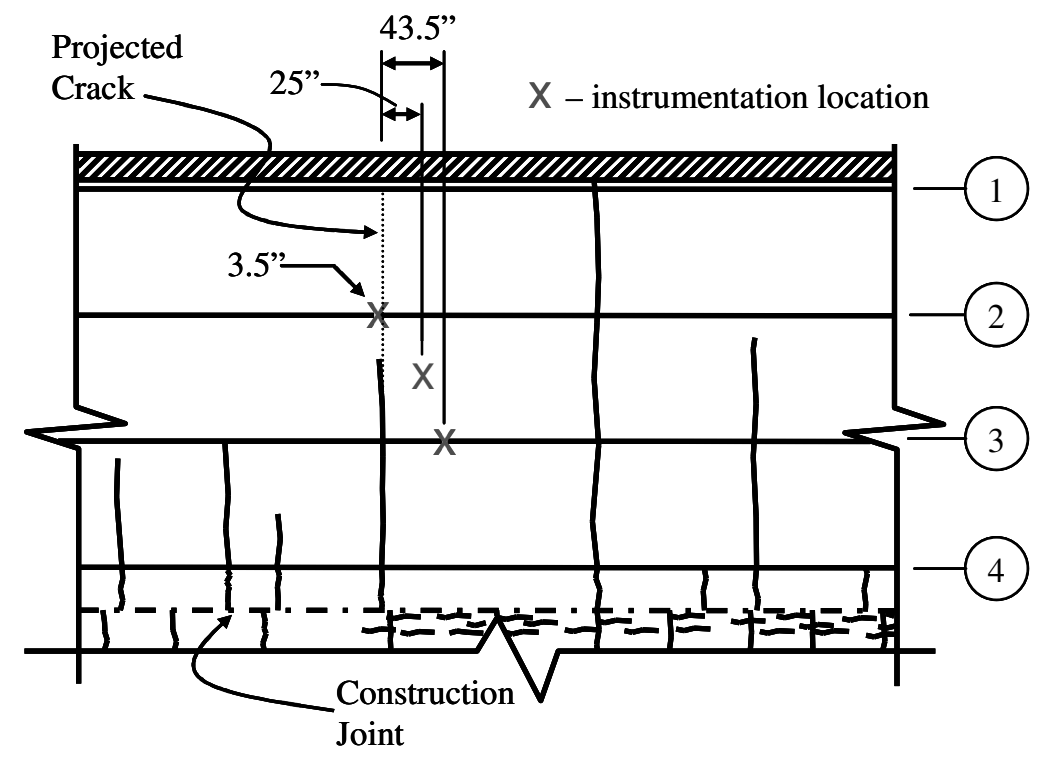

Figure 3.10: Location of Strain Gages Relative to Cracks at AASHTO Midspan

Based on the measured crack location, a crack is present 3.5 in. from the gages located over Girder 2 and 25 in. from the gages at midbay between Girders 2 and 3. The strains recorded over Girder 2 in both the bottom and top reinforcement indicate tensile strain developed in the reinforcement at this location, while the concrete strain appears to be relatively insensitive to the presence of the crack (i.e. minimal variation of strains). The strain in both the top and bottom reinforcement over Girder 2 is consistent with the behavior measured over Girder 3 and midbay between Girders 2 and 3 until Day 161 when strains sharply increase in tension before going out of range after Day 252. In 
contrast, the strains recorded in the reinforcement between the girders do not display an increase in tension, but rather only variations due to temperature.

Similarly, the instrumentation located over Girder 3 does not appear to be affected by the presence of the crack. Even though the strain in the bottom reinforcement experienced a sudden increase in compressive strain between Day 21 and Day 30, the top mat of reinforcement over Girder 3 did not display a similar increase in compressive strain at Day 21 (Figure 3.11), and it is likely that the instrumentation detected localized shrinkage cracking.

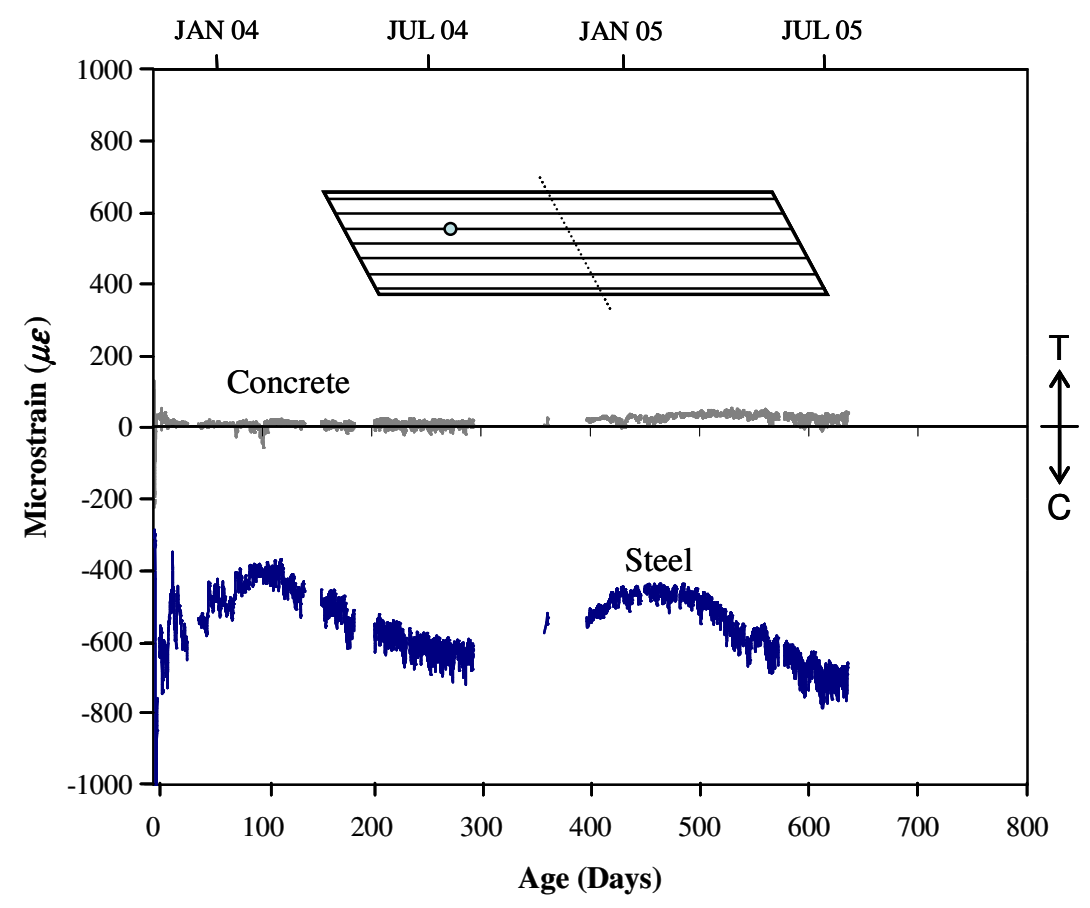

Figure 3.11: AASHTO Midspan Over Girder 3 (Top Bar)

The peak compressive and tensile stresses observed each year in the reinforcement across the AASHTO midpsan are presented in Table 3.2. The measurements from the SR 18 AASHTO span indicate that while there tends to be a slight increase in the stress in the reinforcement from the first year to the second, the longitudinal reinforcement in general experiences relatively low stress levels during service, even while cracks are present in the bridge deck. 
Table 3.2: Maximum Stresses in AASHTO Midspan Reinforcement

\begin{tabular}{|c|c|c|c|c|}
\hline \multirow{2}{*}{ Location } & \multicolumn{3}{|c|}{ Compressive Stress (ksi) } \\
\cline { 2 - 5 } & \multicolumn{2}{|c|}{ Year 1 } & \multicolumn{2}{c|}{ Year 2 } \\
\cline { 2 - 5 } & Top & Bottom & Top & Bottom \\
\hline Girder 2 & 3 & 10 & -- & -- \\
\hline Midbay & 17 & 20 & 19 & 22 \\
\hline Girder 3 & 21 & 8 & 22 & 10 \\
\hline
\end{tabular}

\begin{tabular}{|c|c|c|c|c|}
\hline \multirow{2}{*}{ Location } & \multicolumn{4}{|c|}{ Tensile Stress (ksi) } \\
\cline { 2 - 5 } & \multicolumn{2}{|c|}{ Year 1 } & \multicolumn{2}{c|}{ Year 2 } \\
\cline { 2 - 5 } & Top & Bottom & Top & Bottom \\
\hline Girder 2 & 17 & 6 & 28 & -- \\
\hline Midbay & -- & -- & -- & -- \\
\hline Girder 3 & -- & -- & -- & -- \\
\hline
\end{tabular}

-- Indicates that either tension or compression was not experienced or the gage went out of range

\subsubsection{Behavior of Longitudinal Reinforcement (SR 18 Purdue Span)}

The strain in the concrete and reinforcement at the level of the bottom mat of reinforcement in the Purdue midspan over Girder 3, midbay between Girders 2 and 3, and over Girder 2 is presented in Figure 3.12 - Figure 3.14, respectively. Similar to the behavior observed in the AASHTO span of the bridge, the concrete strain does not appear to vary significantly across the bridge at midspan and is relatively insensitive to thermal variations in the bridge over time.

The strain in the reinforcement in the Purdue span at midspan on the other hand varies as the temperature in the bridge deck varies. In general, as in the AASHTO span, the reinforcement appears to develop increasing strain (tension) as the temperature decreases. However, unlike the AASHTO span, the strain appears to continue to increase as the temperature increases (Figure 3.14). During the first 100 days in service, strain in the reinforcement increases by $175 \mu \varepsilon$ over Girder 3 and by $635 \mu \varepsilon$ midbay between Girders 2 and 3. As the ambient temperature increased from the average low of $10^{\circ} \mathrm{F}$ at the end of January 2004 to an average temperature of $77^{\circ} \mathrm{F}$ at the first of July 2004, compressive strain increased by $70 \mu \varepsilon$ over Girder 3 , but tensile strain increased by $50 \mu \varepsilon$ midbay between Girders 2 and 3. Closer inspection of the reinforcement strain between the girders shows that as temperature in the bridge increased after the low in January 2004 , compressive strain increased by $160 \mu \varepsilon$ over the 60 days following the low. After that time, the reinforcement at midbay experienced increasing tensile strain. 


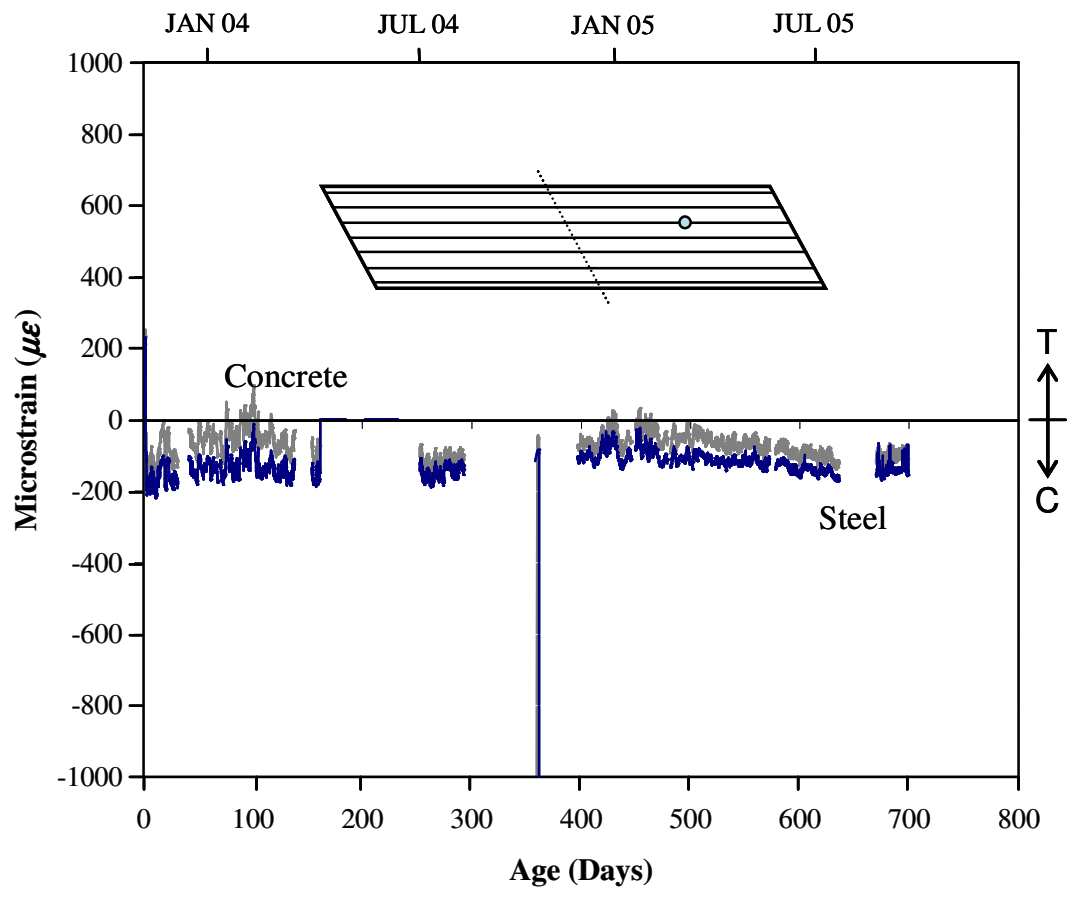

Figure 3.12: Purdue Midspan Over Girder 3 (Bottom Bar)

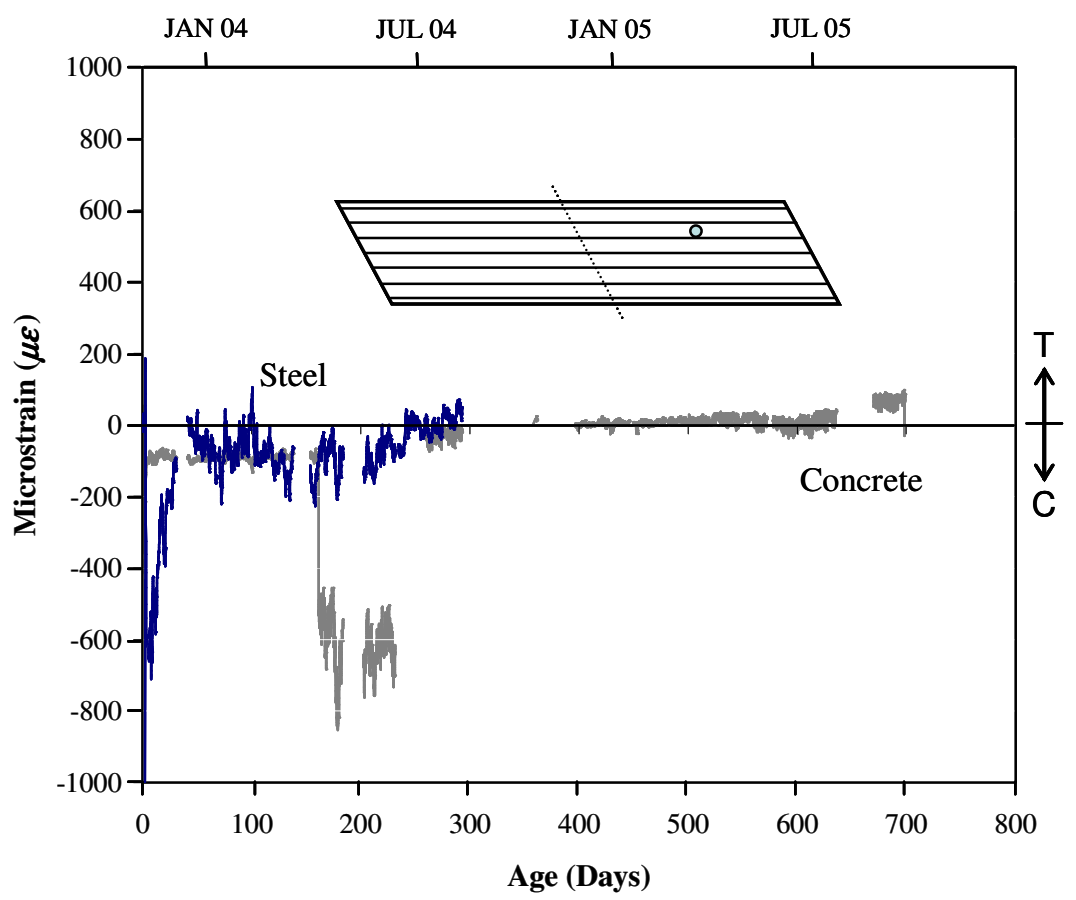

Figure 3.13: Purdue Midspan Between Girders 2 and 3 (Bottom Bar) 


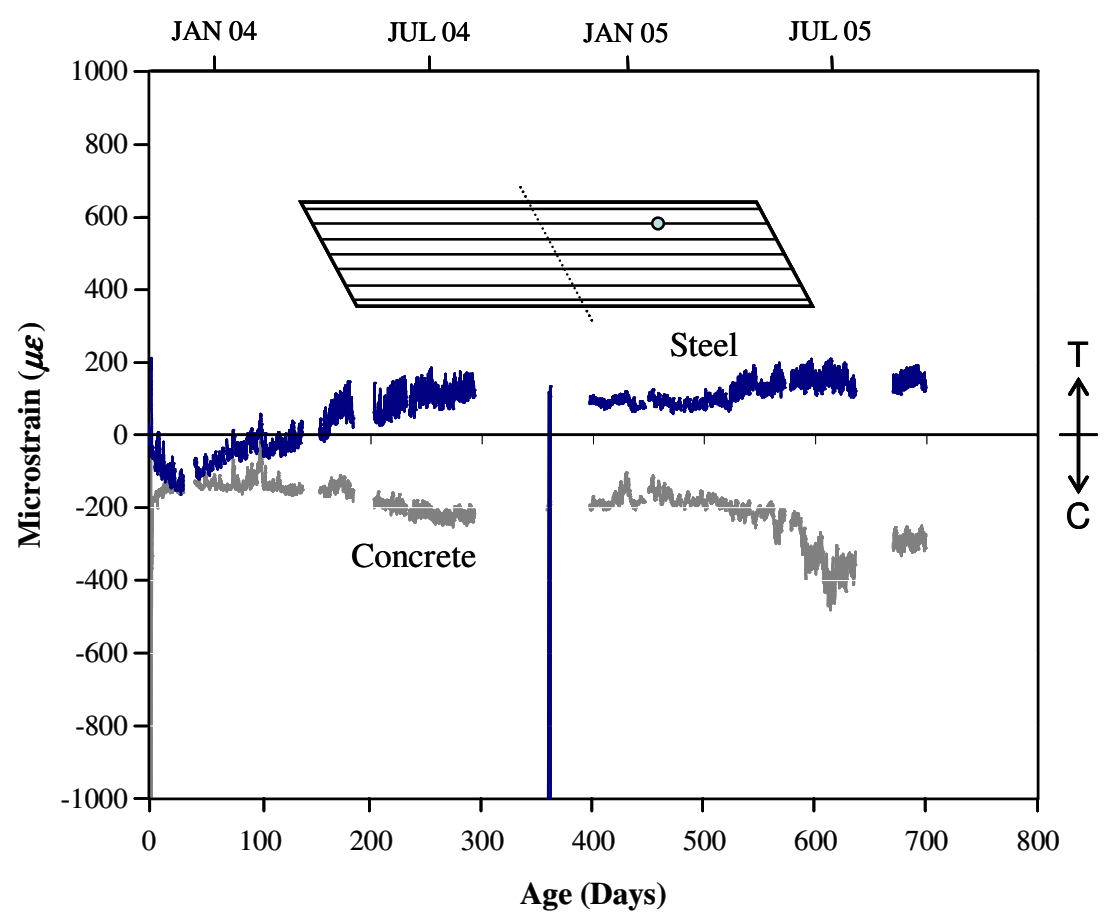

Figure 3.14: Purdue Midspan Over Girder 2 (Bottom Bar)

As evident in Figure 3.14, the behavior of the reinforcement over Girder 2 is notably different from the behavior of the reinforcement over Girder 3 and at midbay between Girders 2 and 3. Rather than exhibiting a similar initial increase into tension that was observed over Girder 3 as the temperature decreased, the reinforcement gains compressive strain as the temperature decreases and gains tensile strain as the temperature increases at the instrumented location. The difference in behavior between the two locations appears to be related to location of the instrumentation relative to the cracks which formed in the bridge deck.

As discussed previously in Section 3.2.3, the distance of strain gages to the locations of cracks that formed in the deck vary as a result of the instrumentation being installed along the skew of the bridge deck. The positions of the strain gages relative to the cracks mapped are presented in Figure 3.15. The denoted locations of instrumentation shown in Figure 3.15 are the as-built locations. At the time of mapping, cracks were not observed to have extended from the construction joint to the locations of the instrumentation. However, because of the finish on the deck (tinned), it is possible that cracks could have propagated from the construction joint to the gage locations. The dashed lines in Figure 3.15 indicate the straight line projection of the cracks from the construction joint. The strain gages installed over Girder 2 are located 32.5 in. from the closest projected crack while strain gages over Girder 3 and midbay between Girders 2 and 3 are $15 \mathrm{in.}$ and $10 \mathrm{in}$. from the closest projected crack, respectively. The relatively larger distance of instrumentation over Girder 2 could explain why strains are directly 
related to temperature at this location as opposed to the inverse relationship observed at the other locations.

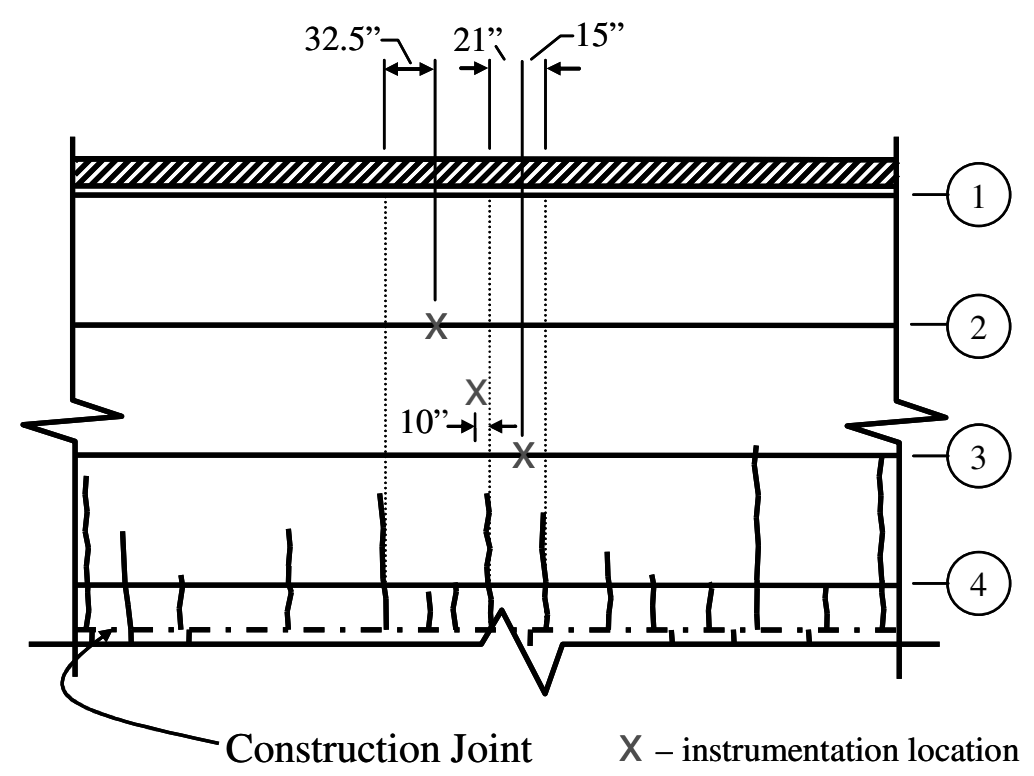

Figure 3.15: Location of Strain Gages Relative to Cracks at Purdue Midspan

The peak compressive and tensile stresses observed in the reinforcement are presented in Table 3.3. Compressive stresses in the reinforcement in the Purdue span were lower over the girders when compared to the stress observed at midspan between Girders 2 and 3. In general, the gages over the girders displayed a trend of slightly increasing tensile stress over the two year period. All stresses observed in the reinforcement at this section were relatively low.

It should be noted that the strain gage mounted on the top reinforcement at the midbay location went out of range during casting of the deck. This was a common occurrence in several of the gages and is attributed to insufficient waterproofing of the gages and splices in the deck which resulted in a short while the surrounding concrete was wet. In all cases, after a brief period following deck placement (typically 6 hours), the affected gages came back into range. The peak compressive stress recorded in Table 3.3 for the reinforcement at the midbay location is based on a strain (620 $\mu \varepsilon$, Figure 3.13) which was recorded after the strain gages at this location stabilized (i.e. consistent strain values were recorded). 
Table 3.3: Maximum Stresses in Purdue Midspan Reinforcement

\begin{tabular}{|c|c|c|c|c|}
\hline \multirow{2}{*}{ Location } & \multicolumn{3}{|c|}{ Compressive Stress (ksi) } \\
\cline { 2 - 5 } & \multicolumn{2}{|c|}{ Year 1 } & \multicolumn{2}{c|}{ Year 2 } \\
\cline { 2 - 5 } & Top & Bottom & Top & Bottom \\
\hline Girder 2 & 9 & 6 & 1 & -- \\
\hline Midbay & 23 & 17 & 20 & -- \\
\hline Girder 3 & 3 & 5 & 0 & 5 \\
\hline
\end{tabular}

\begin{tabular}{|c|c|c|c|c|}
\hline \multirow{2}{*}{ Location } & \multicolumn{3}{|c|}{ Tensile Stress (ksi) } \\
\cline { 2 - 5 } & \multicolumn{2}{|c|}{ Year 1 } & \multicolumn{2}{c|}{ Year 2 } \\
\cline { 2 - 5 } & Top & Bottom & Top & Bottom \\
\hline Girder 2 & 3 & 5 & 3 & 6 \\
\hline Midbay & 2 & 2 & -- & -- \\
\hline Girder 3 & 9 & -- & -- & 10 \\
\hline
\end{tabular}

-- Indicates that either tension or compression was not experienced or the gage went out of range

\subsection{State Road 23 Over U.S. 20}

The SR 23 bridge over U.S. 20 was constructed using a low-shrinkage concrete mix design. Cracks in the bridge deck were mapped, and temperatures and strains in the deck were measured and recorded. The instrumentation focused on capturing a continuum of strains along the length of the bridge. In addition, free shrinkage specimens were cast and kept on-site to provide a reference to the amount of free shrinkage that occurs with this low-shrinkage mix.

\subsubsection{Field Free Shrinkage Specimens}

Figure 3.16 shows the shrinkage strains recorded from the 6"x6"x12" concrete specimen that was cast and stored on-site. Compressive strain in the specimen increased by $130 \mu \varepsilon$ over the first 11 days. The specimen shrunk an additional $70 \mu \varepsilon$ after this and appears to achieve a final total shrinkage of approximately $200 \mu \varepsilon$. This level of shrinkage is considered very low compared to typical values of shrinkage strain. For comparison, in absence of other data, ACI 209 (2001) recommends a shrinkage strain of $780 \mu \varepsilon$. 


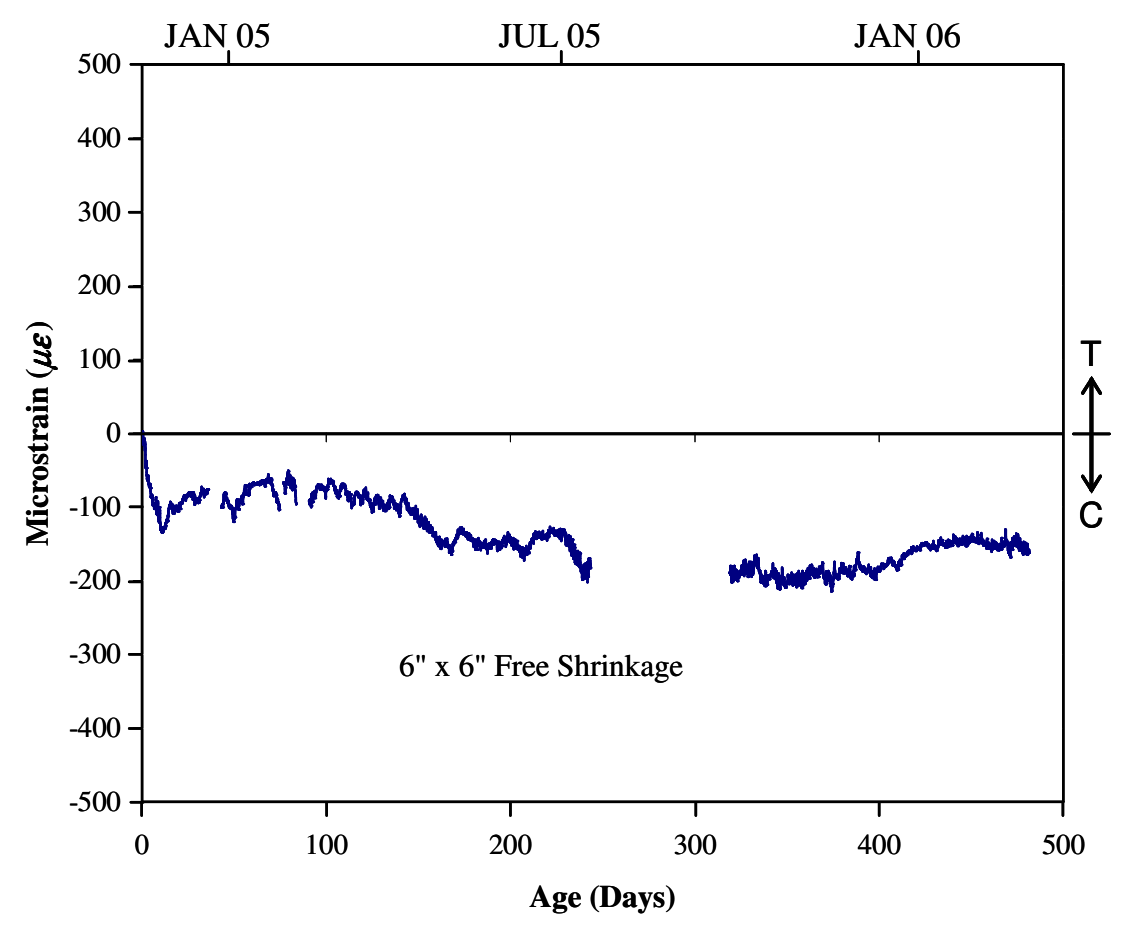

Figure 3.16: 6"x6"x12" Specimen Shrinkage Strain

Figure 3.17 shows the free shrinkage strain recorded from the slab shrinkage specimen that was cast and stored on-site. Compressive strain in the specimen increased by $44 \mu \varepsilon$ over the first 10 days, and the specimen achieved a final total shrinkage strain of $132 \mu \varepsilon$ by Day 400 . Strain data recorded from the strain gage installed at the center of the specimen closely matched the data recorded from the offset strain gage, which indicates that the aluminum tape was successful in sealing the perimeter of the slab specimen. The slab specimen, which was designed to have the same depth as the bridge deck (8 in.), provides a good indicator of the free shrinkage expected in the bridge deck. 


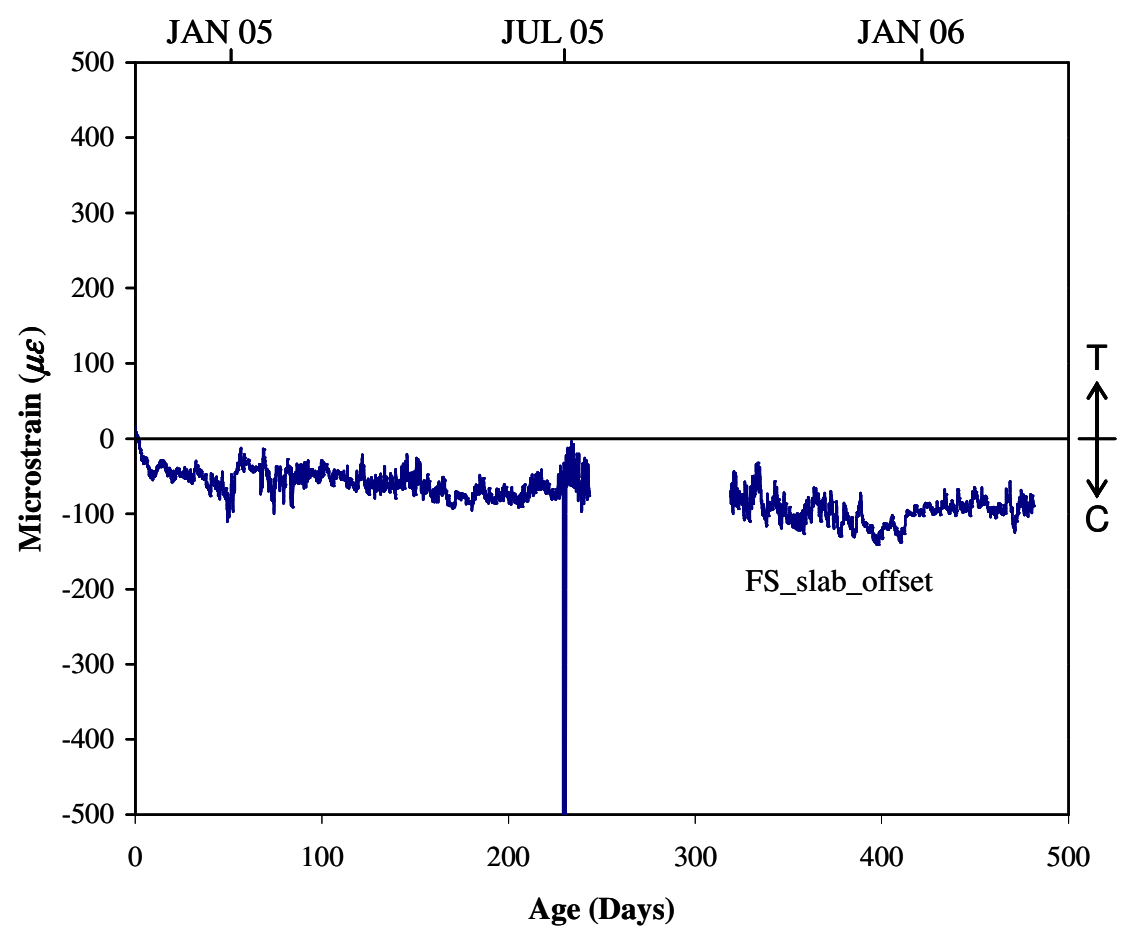

Figure 3.17: Slab Specimen Shrinkage Strain

\subsubsection{Crack Mapping}

A complete crack mapping was performed on the SR 23 bridge deck on October 22, 2005 (Day 355) and is presented in Figure 3.18. With the exception of a longitudinal crack that runs adjacent to the construction joint, the bridge deck is relatively free of cracking, particularly in the instrumented span. The longitudinal crack adjacent to the construction joint was likely caused by heavy equipment being placed along the edge of the newly placed deck after curing of the deck was completed (Phase I, Day 7).

The cracking observed in the second phase of construction occurs primarily over the center pier and was likely caused by loading from traffic rather than shrinkage cracking. Cores were taken from the instrumented span as a part of an INDOT failed materials investigation. The locations of the cores were identified as a part of the crack mapping and are also shown in Figure 3.18. 


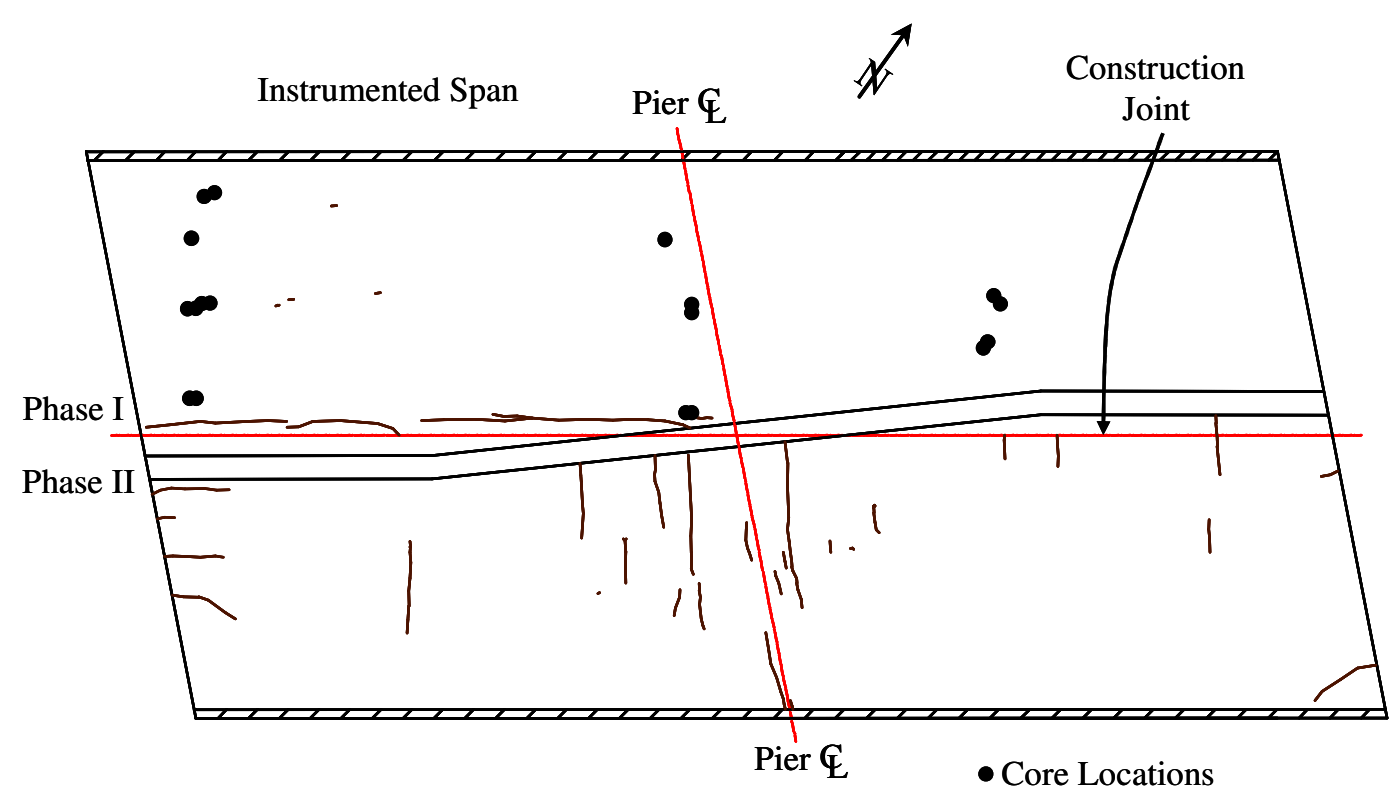

Day 355

Figure 3.18: SR 23 Crack Map

\subsubsection{Temperature}

The ambient temperature data recorded by the suspended thermocouple beneath the deck is presented in Figure 3.19. The initial ambient temperature during the deck placement was $50^{\circ} \mathrm{F}$. The temperature at the bridge varied between a low of $1.5^{\circ} \mathrm{F}$ on Day 74 and a high of $97.5^{\circ} \mathrm{F}$ on Day 233. While the bridge deck experiences a $48^{\circ} \mathrm{F}$ temperature decrease from the temperature at placement, which is equivalent to $285 \mu \varepsilon$ if the concrete coefficient of thermal expansion is taken as $6 \times 10^{-6} /{ }^{\circ} \mathrm{F}$, the deck does not experience a large amount of restraint by the girders when undergoing volumetric changes from thermal effects since the coefficient of thermal expansion of the concrete girders match that of the bridge deck. 


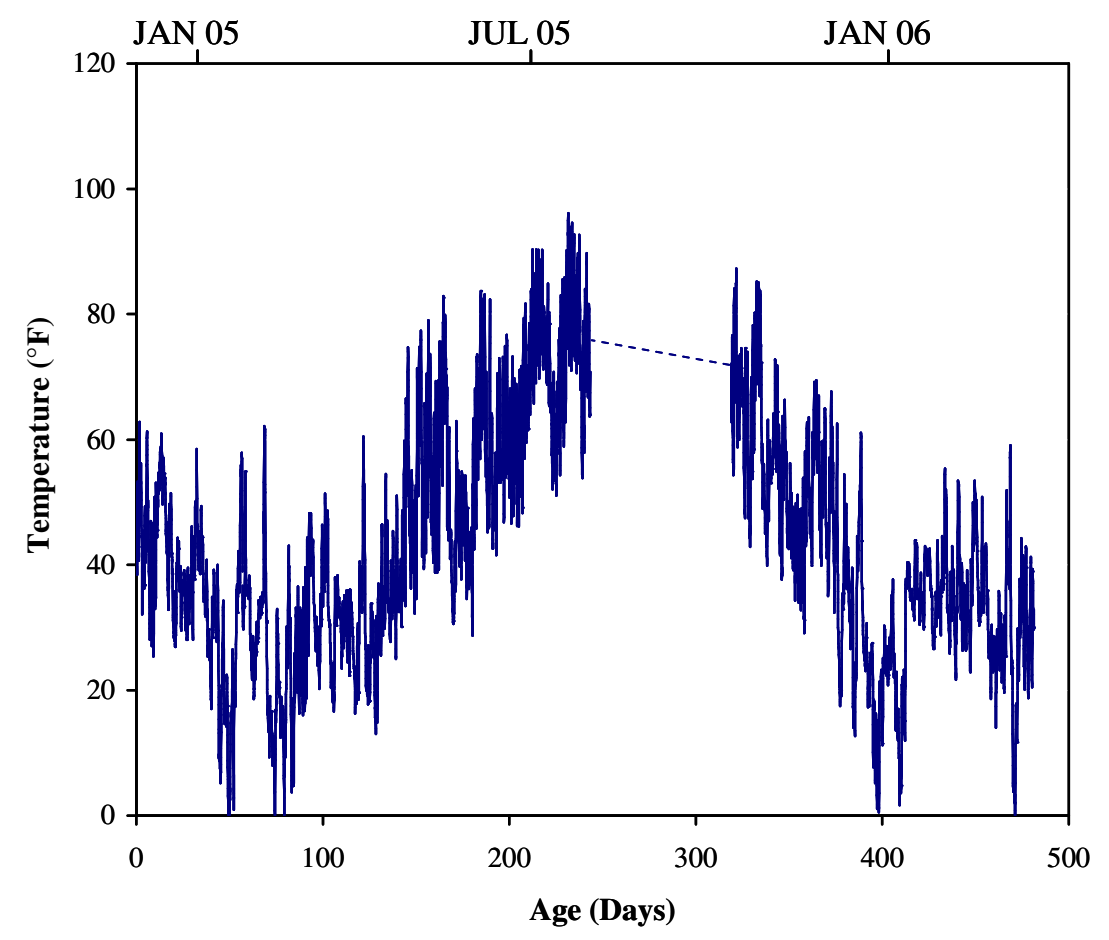

Figure 3.19: SR 23 Recorded Ambient Temperatures

\subsubsection{Behavior of the Longitudinal Reinforcement in SR 23}

The reinforcement, concrete, and girder top flange strains over Girder 3 are presented in Figure 3.20. While concrete strain gages were installed midway between the two mats of reinforcement in the deck, the concrete and the top mat reinforcement exhibit similar behavior. The concrete and the steel are relatively unaffected by the initial decrease in temperature between Day 0 and Day 74. After Day 150, as ambient temperatures exceed the temperature at the time of placement, compressive strains in both the concrete and reinforcement increase as the temperature increases. As the temperatures begin to decrease after reaching the maximum measured temperature at Day 233 , strain in the concrete and reinforcement appear to stabilize and do not exhibit a corresponding increase in tensile strain. Strain data was consistent across the width of the deck at Girders 1 and 2. 


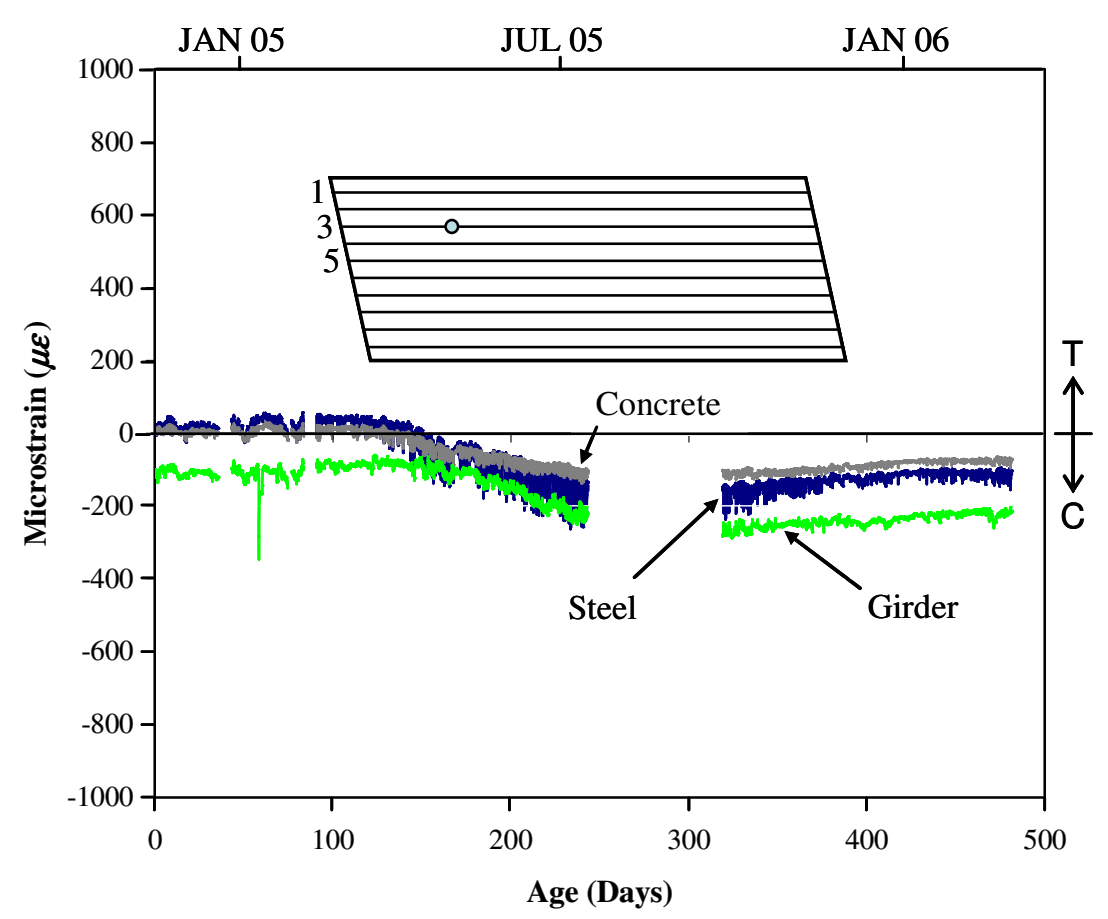

Figure 3.20: SR 23 Midspan Strains over Girder 3

The $20 \mathrm{ft}$ instrumented steel reinforcing bar (Figure 2.27) was installed such that strain gages towards the end of the bar were located at midspan, midbay between Girders 2 and 3. In general, behavior similar to the deck over the girders is observed (Figure 3.20). Strain in the top reinforcement does not change substantially until after Day 146 at which time compressive strain in the reinforcement increases. By Day 243, compressive strain in the top reinforcement at midbay was approximately $180 \mu \varepsilon$.

When the strains at midbay are compared to the strains over the girders, a slight difference in the behavior between the two locations is observed. The concrete and reinforcement at midbay exhibit a slight increase in compressive strains over the first 50 days, as shown in Figure 3.21, while the reinforcement and concrete over the girders (Figure 3.20) did not demonstrate an appreciable change in strain over the same period of time. This suggests that the girders provide some restraint to shrinkage strains that occur in the deck, while the deck midbay between the girders is relatively free to shrink. At Day 50, between Girders 2 and 3, the compressive strain was $50 \mu \varepsilon$ in the concrete and $60 \mu \varepsilon$ in the top reinforcement mat. For comparison, the free shrinkage strain in the slab specimen at the same time was $86 \mu \varepsilon$ in compression (Figure 3.17). This comparison shows that strains are reasonable and provides an estimate of the restraint present in the deck. 


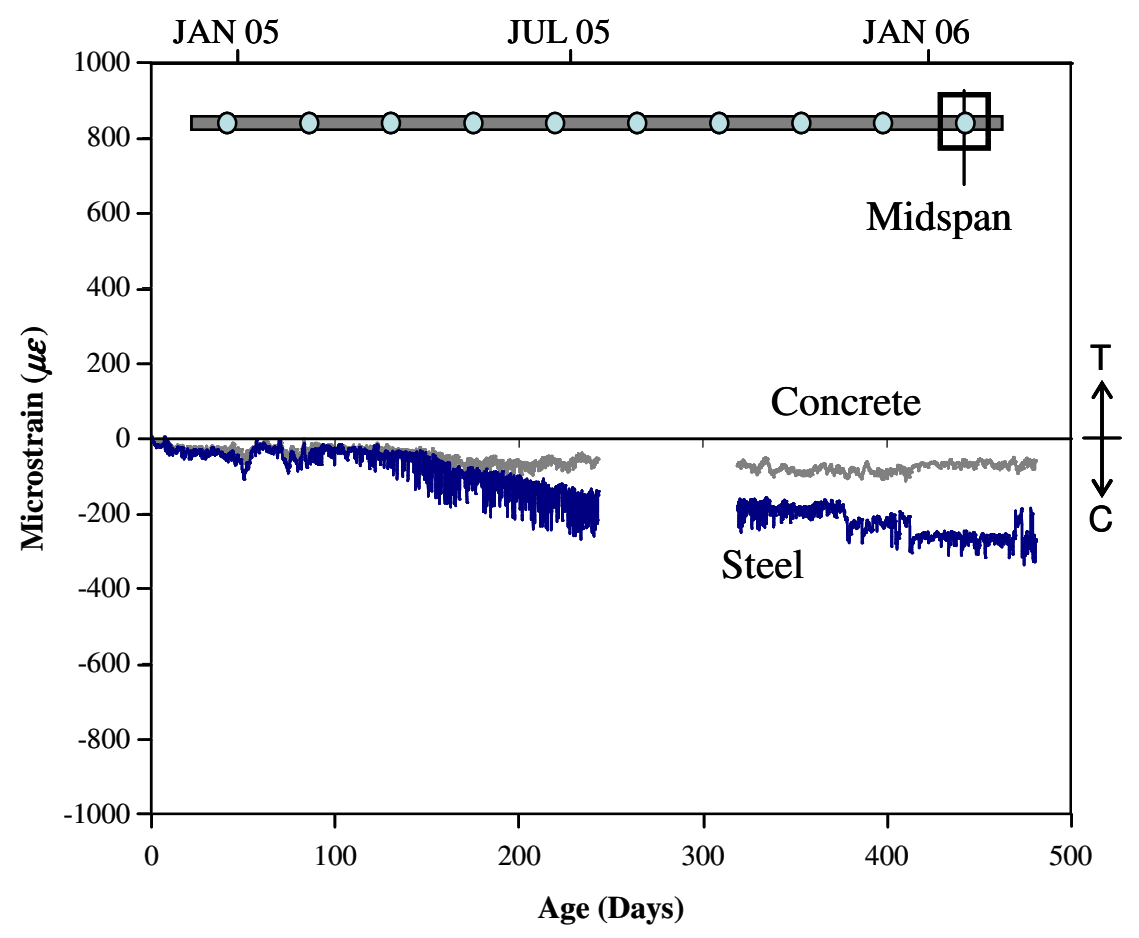

Figure 3.21: SR 23 Midspan Strains Midbay Between Girders 2 and 3

The strain recorded by the gages were representative of strains recorded at the other locations along the length of the instrumented bar. The strain data collected from the gages installed on the instrumented bar are presented in Figure 3.22. In general, the strains in the concrete and reinforcement do not vary significantly along the length of the instrumented bar. The exception to this behavior is at a location $11 \mathrm{ft}$ from midspan (Gage d) where the compressive strain in the reinforcement appears to increase between $2000 \mu \varepsilon$ and $4500 \mu \varepsilon$ after Day 330 as shown in Figure 3.23. However, upon inspection of the crack map (Figure 3.18), this location does not appear to be in close proximity to either cracks or INDOT coring locations. Furthermore, the data from the concrete gage at this location (Figure 3.22d) is consistent with the data from other locations on the instrumented bar. Therefore, it was concluded that after Day 330, the strain gage installed on the bar at this location malfunctioned. 

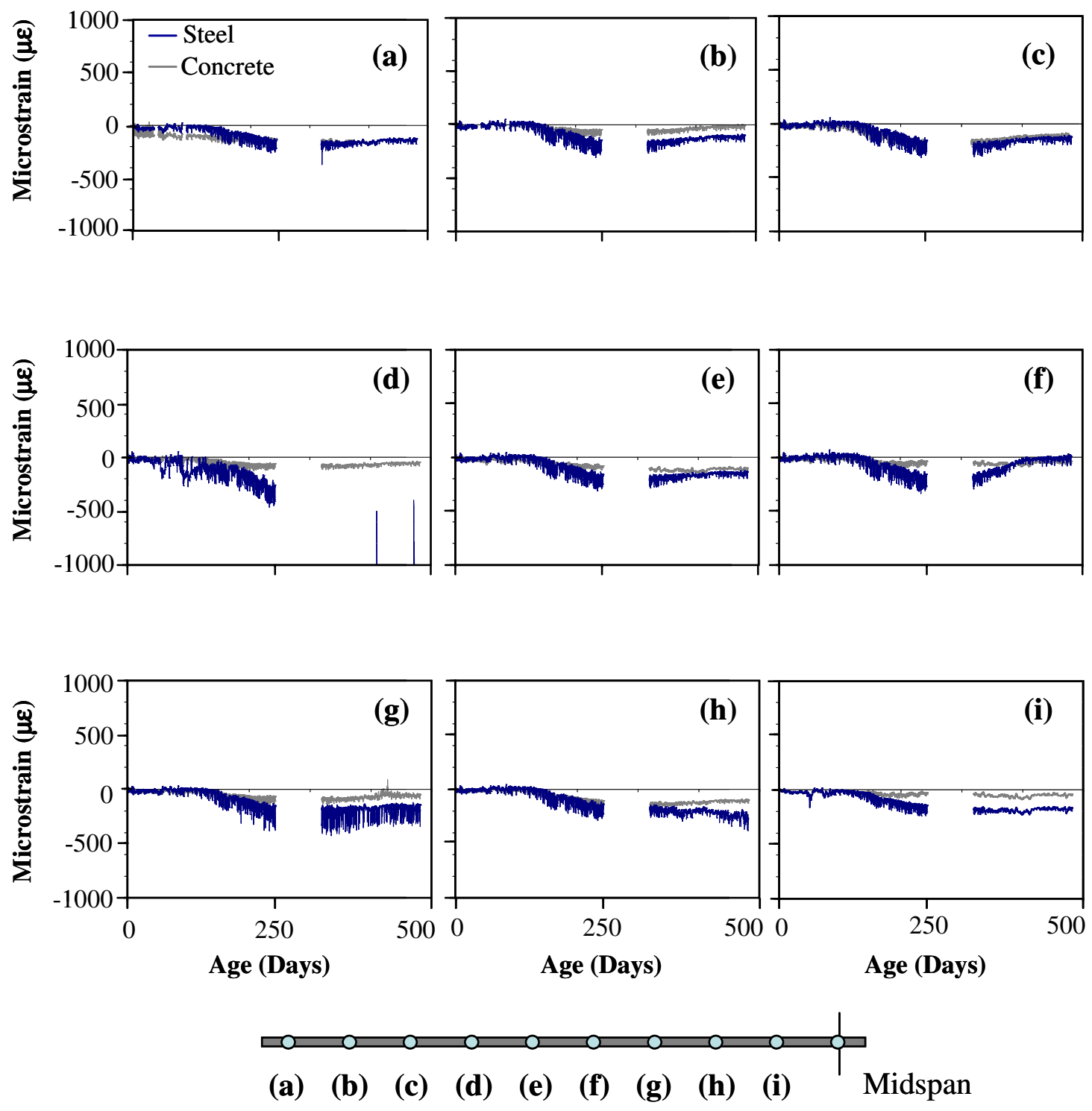

Figure 3.22: SR 23 Instrumented Bar and Concrete Strains 


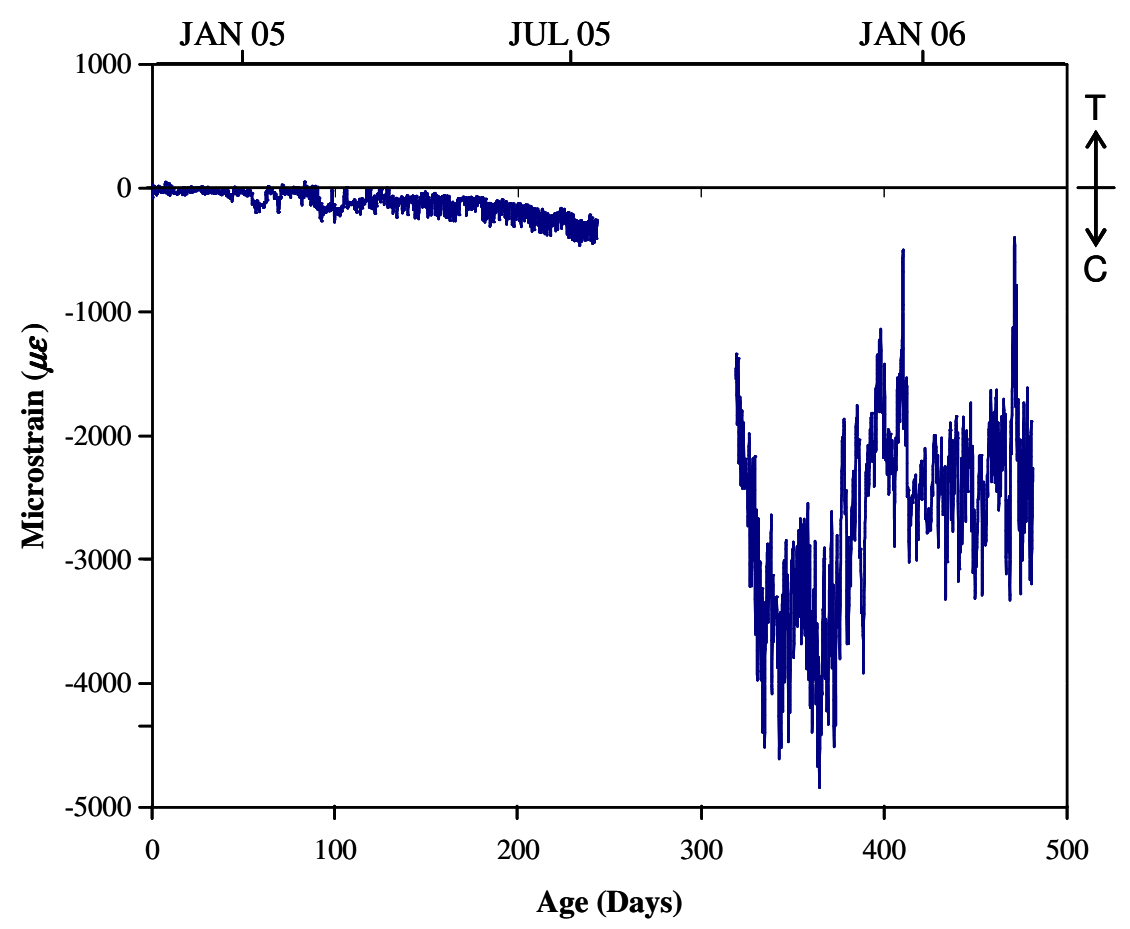

Figure 3.23: Instrumented Bar Strain at $11 \mathrm{Ft}$ (Gage d) from Midspan

As virtually no cracking was detected in the SR 23 deck, the strains in the deck were generally uniform throughout the deck. Thus, it follows that the peak stresses observed in the top reinforcement mat at midspan of the instrumented span were uniform across the deck. Reinforcement located over Girders 2 and 3 and midbay between the two girders had a peak compressive stress of $5 \mathrm{ksi}$. Furthermore, the peak stresses measured along the entire length of the instrumented bar were $5 \mathrm{ksi}$ in compression. These stresses are very low and consistent with the fact that no cracks were observed.

\subsection{Thayer Road Bridge over I65}

The Thayer Road Bridge was constructed with GFRP bars for the top reinforcement mat. The bridge deck was crack mapped, and temperatures and strains from the deck were measured and recorded.

\subsubsection{Crack Mapping}

Cracks in the Thayer Road Bridge were mapped on October 13, 2005 (Day 482); the map is presented in Figure 3.24. In general, the majority of cracks occurred in the negative moment regions over the piers. These cracks are attributed to structural cracking caused by dead and live loads. Cracks occurring greater than a distance of $10 \mathrm{ft}$ 
from the pier centerline were considered as occurring in the positive moment region of the deck and are attributed to restrained shrinkage of the deck.

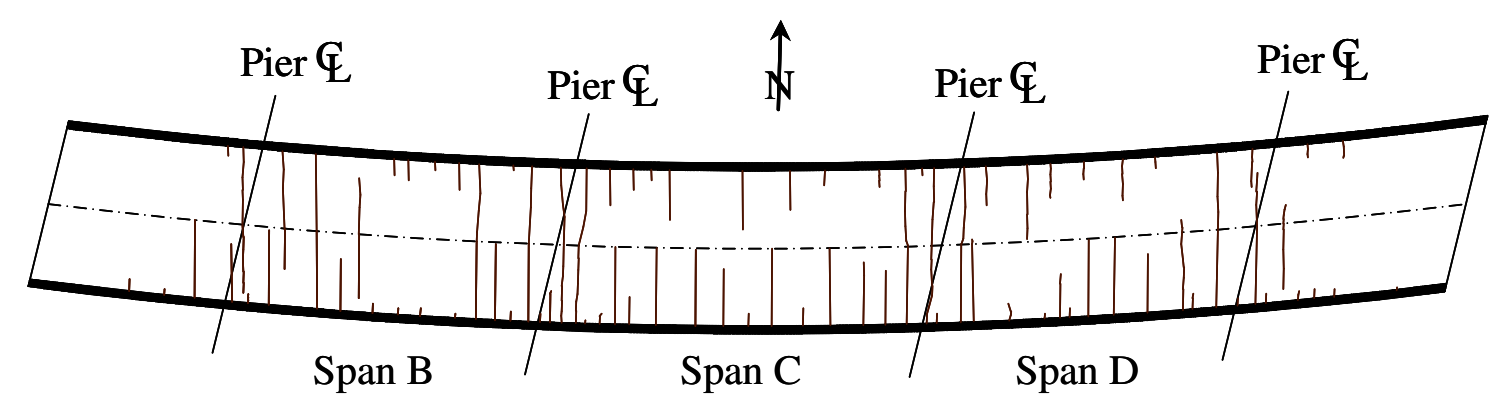

Day 482

Figure 3.24: Thayer Road Bridge Crack Map

Crack widths in the bridge deck were measured along the centerline of the bridge, analogous to the method used on the SR 18 bridge. However, the bridge deck was constructed in one casting without the use of construction joints. The distribution of cracks measured in the bridge deck are shown in Figure 3.25. The maximum crack width observed in the positive moment region of the deck was 0.026 in. Statistics of the deck crack data are provided in Table 3.4.

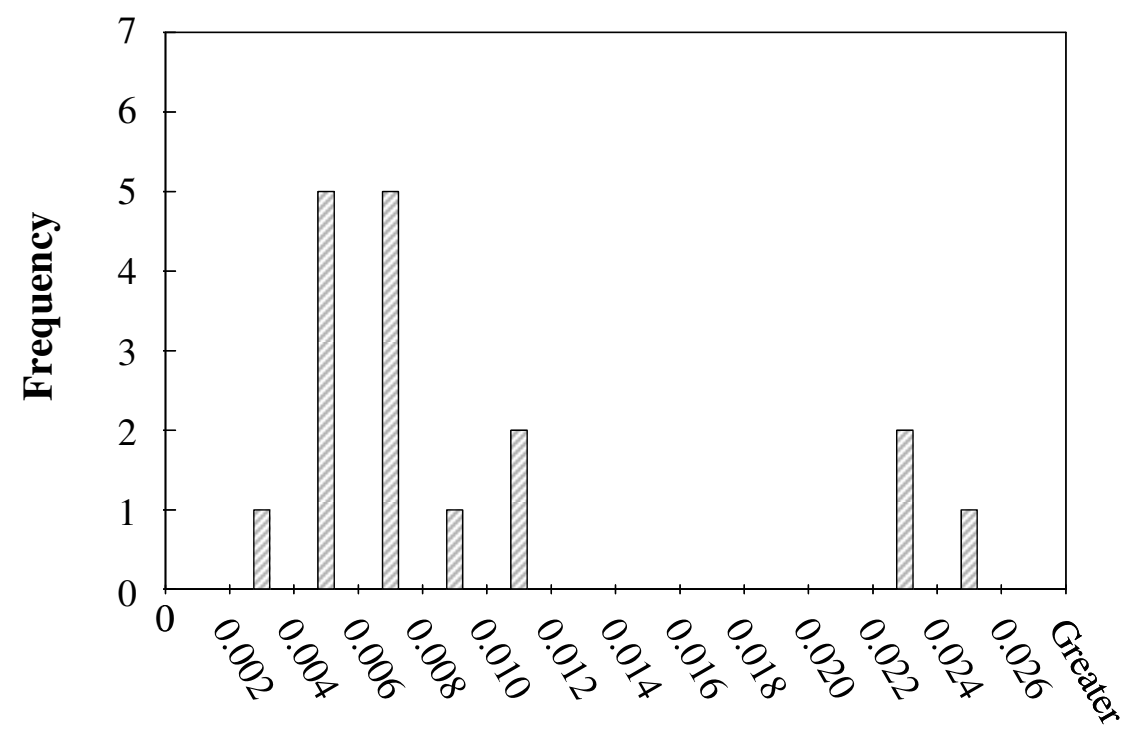

Crack Width (in.)

Figure 3.25: Thayer Road Bridge Crack Widths in Positive Moment Regions 
Table 3.4: Thayer Road Crack Width Statistics October 13, 2005

\begin{tabular}{|c|c|}
\hline Number of Cracks & 19 \\
\hline Mean Crack Widths (in.) & 0.010 \\
\hline Standard Deviation (in.) & 0.008 \\
\hline Maximum Crack Width (in.) & 0.026 \\
\hline Variance & $5.56 \times 10^{-6}$ \\
\hline
\end{tabular}

\subsubsection{Temperature}

The ambient temperature was recorded using a thermocouple suspended beneath the bridge deck as discussed in Section 2.3.2.2, and is presented in Figure 3.26. The average ambient temperature during the deck placement was $70^{\circ} \mathrm{F}$. Temperature increased over the following 13 days and peaked at $103^{\circ} \mathrm{F}$. The lowest temperature observed at the Thayer Road bridge was $-1^{\circ} \mathrm{F}$ and occurred on Day 189.

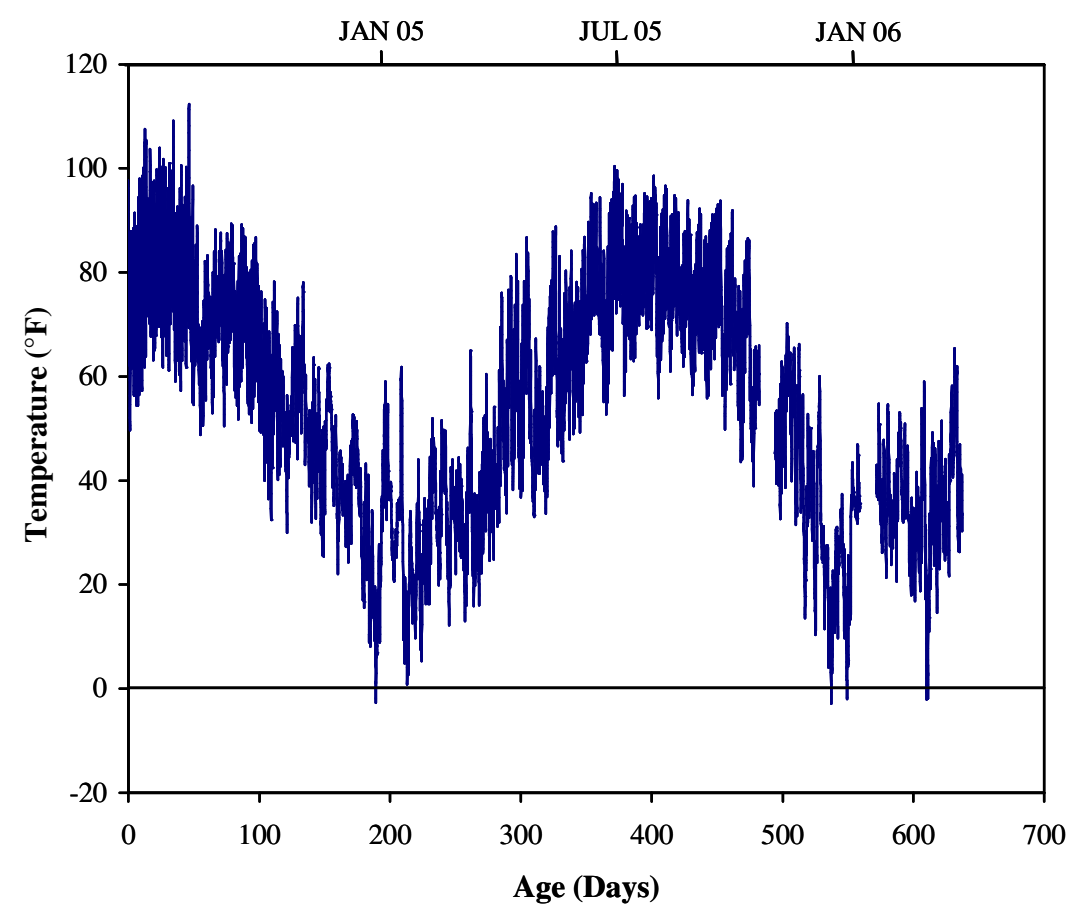

Figure 3.26: Ambient Temperature Data from Thayer Road Bridge

\subsubsection{Correction of FRP Strain Gages for Temperature}

The coefficient of thermal expansion $\left(\alpha_{t}\right)$ of the strain gages installed on the FRP reinforcement in the Thayer Road Bridge differs from the coefficient of thermal 
expansion of the FRP reinforcement. The coefficient of the gages is $6 \times 10^{-6} /{ }^{\circ} \mathrm{F}$, which corresponds to $\alpha_{t}$ of the steel reinforcement while the coefficient of the FRP

reinforcement is approximately $3.5 \times 10^{-6} /{ }^{\circ} \mathrm{F}$ (Pultrall, 2006). Because of this difference, as the temperature changes, the gage is restrained by the reinforcement it is bonded to, and the value of strain appears to vary as the temperature varies. To correct for this effect, the measured strain is adjusted by adding the difference in strain provided by the mismatched coefficients of thermal expansion. The corrected FRP strain is computed as follows:

$$
\varepsilon_{\text {corr }, i}=\varepsilon_{\text {meas }, i}+\left(\alpha_{t, \text { gage }}-\alpha_{t, F R P}\right)\left(\Delta T_{i}\right)
$$

where:

$$
\begin{aligned}
& \varepsilon_{\text {corr }, i}=\text { Temperature corrected strain for time } i \\
& \varepsilon_{\text {meas }, i}=\text { Observed strain for time } i \\
& \alpha_{t, \text { gage }}=\text { Strain gage coefficient of thermal expansion } \\
& \alpha_{t, F R P}=\text { FRP bar coefficient of thermal expansion } \\
& \Delta T_{i}=\text { Change in temperature from time of placement }
\end{aligned}
$$

Before the strain data was corrected to account for the dissimilar coefficients of thermal expansion, the data obtained from the control gage was evaluated which illustrated a distinct variation in strain with variation in temperature (Figure 3.27). As shown, the corrected strain does not exhibit the same variations in strain with temperature. When compared to the control gage mounted on steel reinforcement (Figure 3.28), it is evident that the corrected FRP control gage exhibits similar strains. All FRP reinforcement strain data presented herein were corrected for temperature.

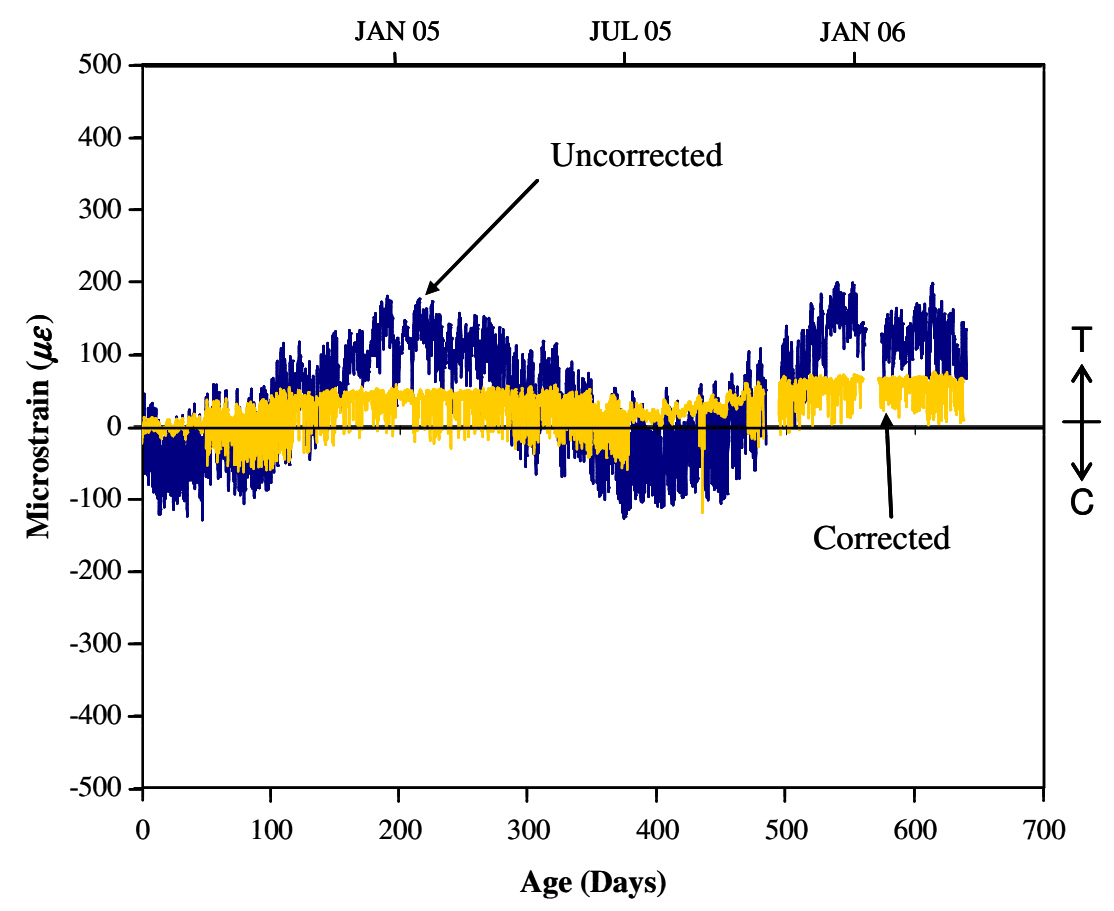

Figure 3.27: Corrected and Uncorrected FRP Dummy Bar Strain 


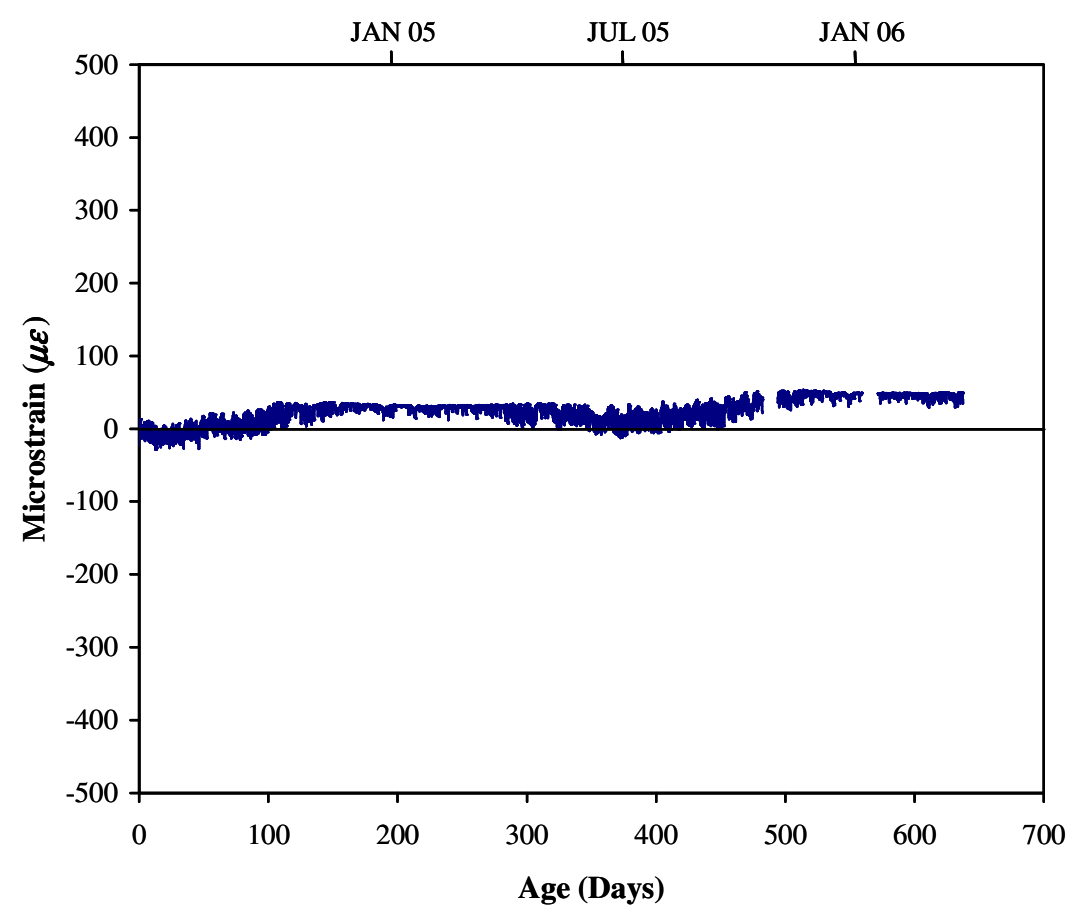

Figure 3.28: Thayer Road Bridge Steel Control Strain

\subsubsection{Behavior of Longitudinal Reinforcement in Thayer Road Bridge}

The stain in the bottom mat steel reinforcement, concrete, and top mat FRP

reinforcement at midspan in Span C and D are presented in Figure 3.29 and Figure 3.30, respectively. In general, the concrete and FRP reinforcement indicate similar behavior. Neither the concrete nor the FRP reinforcement appear to vary significantly with changes in temperature. The steel reinforcement in Span C exhibits a steady increase in tensile strain over the first 200 days. During this time, the strain increases by $250 \mu \varepsilon$. A distinct increase in tensile strain occurs between Days 209 and 211, where the strain increased by $190 \mu \varepsilon$. This increase may indicate the formation of a crack.

The concrete and the FRP reinforcement at the midspan of Span D behave similar to the FRP reinforcement and concrete in Span C. The steel reinforcement demonstrates a similar initial steady increase in tensile strain over the first 200 days, but does not exhibit the abrupt increase in strain that was observed in Span C. The tensile strain in the steel reinforcement at midpsan in Span D increases by $220 \mu \varepsilon$ during the first 200 days and then levels out.

Closer inspection of the crack map (Figure 3.24) reveals that while no cracks appear to be in close proximity to the instrumentation in Span C, a straight line projection of a crack observed near the barrier is $0.01 \mathrm{in}$. from the instrumentation location, as illustrated in Figure 3.31. It is possible that the crack mapped adjacent to the barrier projected to the location of the instrumentation at the time of mapping but was not observed. Tensile strain in the steel reinforcement on the day of mapping (Day 482) 
appears to have decreased at this time (Figure 3.29) suggesting that if a crack was present at the location at the time of mapping, it had closed. It is possible that a crack at this location may have closed as a result of the formation of an adjacent crack. The average temperature during crack mapping was $59^{\circ} \mathrm{F}$, which is lower than the average temperature during deck placement $\left(79^{\circ} \mathrm{F}\right)$. Interestingly, the FRP reinforcement at this location does not appear to exhibit any increase in strain. While a crack may have formed at the bottom of the deck, the FRP data does not seem to support formation of a crack at the top surface.

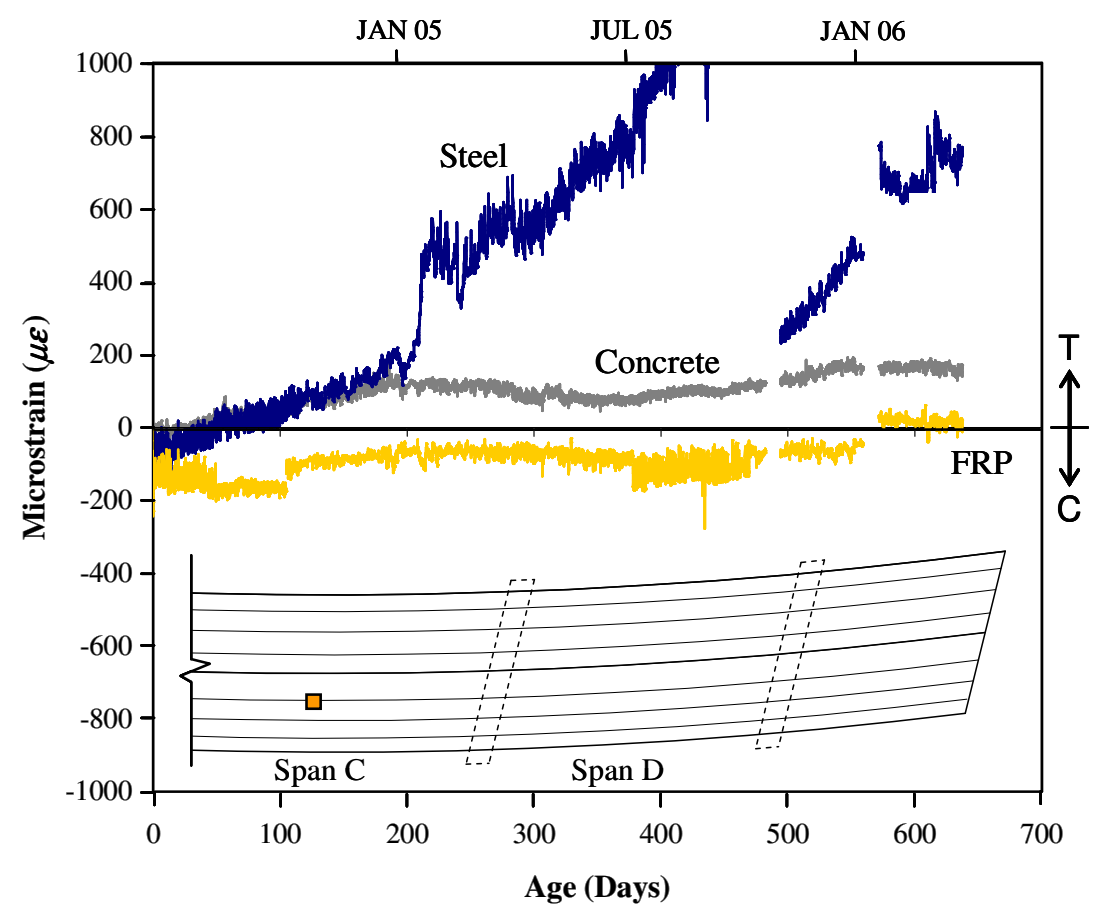

Figure 3.29: Deck Strain Gradient Midspan over Girder 3 (Span C) 


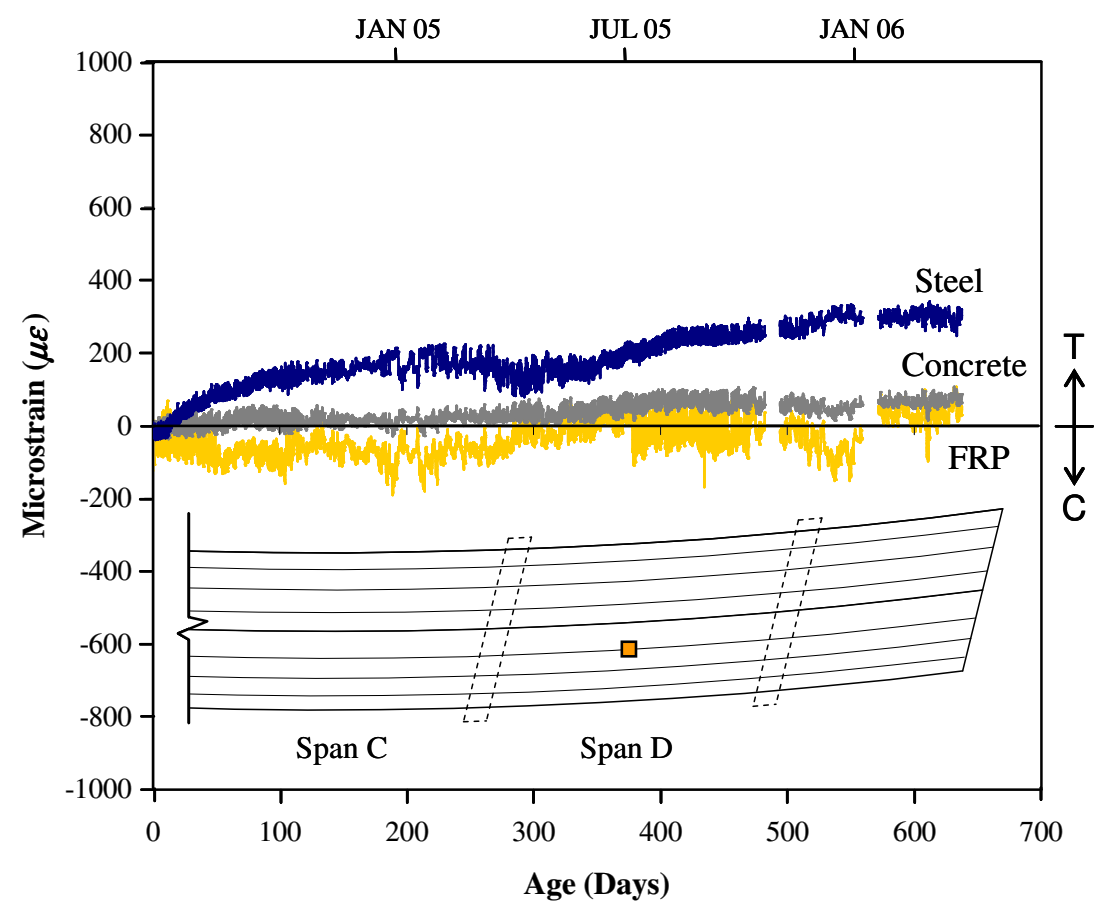

Figure 3.30: Strain Gradient Midspan over Girder 3 (Span D)

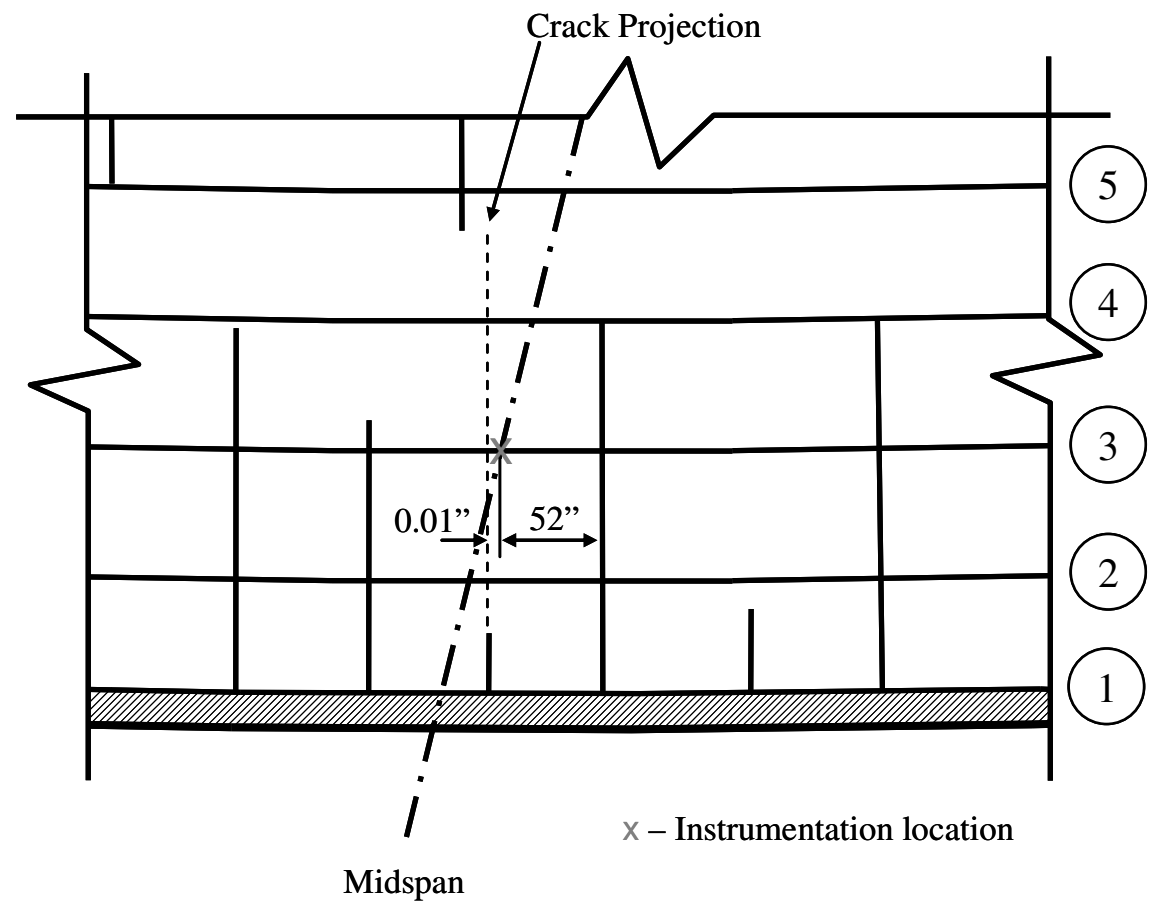

Figure 3.31: Location of Instrumentation Relative to Crack in Span C 
The maximum stresses calculated from the strains measured in the Thayer Road Bridge are presented in Table 3.5. Stress in the FRP reinforcement was essentially uniform in the midspan of both Span C and D. The steel reinforcement in Span D also experienced low service stresses. The reinforcement over Girder 3 at the midpsan of Span C, however, experienced distinctly higher stresses. In the first year, the maximum stress observed in the steel reinforcement was $23 \mathrm{ksi}$. On Day 482, the steel stress at this same location was measured at a maximum of $57 \mathrm{ksi}$ (Figure 3.32). However, on Day 597, the stress in the reinforcement decreased to $8 \mathrm{ksi}$. It is possible that these results may be due to a malfunctioning gage as the data from the FRP gage located in the top mat does not support the larger stresses indicated by this gage.

Table 3.5: Maximum Stress in Thayer Road Bridge Reinforcement

\begin{tabular}{|c|c|c|c|c|}
\hline \multirow{3}{*}{ Span } & \multicolumn{4}{|c|}{ Stress (ksi) } \\
\cline { 2 - 5 } & \multicolumn{2}{|c|}{ Steel } & \multicolumn{2}{c|}{ FRP } \\
\cline { 2 - 5 } & Tension & Compression & Tension & Compression \\
\hline C & 57 & 0 & -- & -2 \\
\hline D & 5 & 0 & 0 & -2 \\
\hline
\end{tabular}

-- Indicates no tension observed

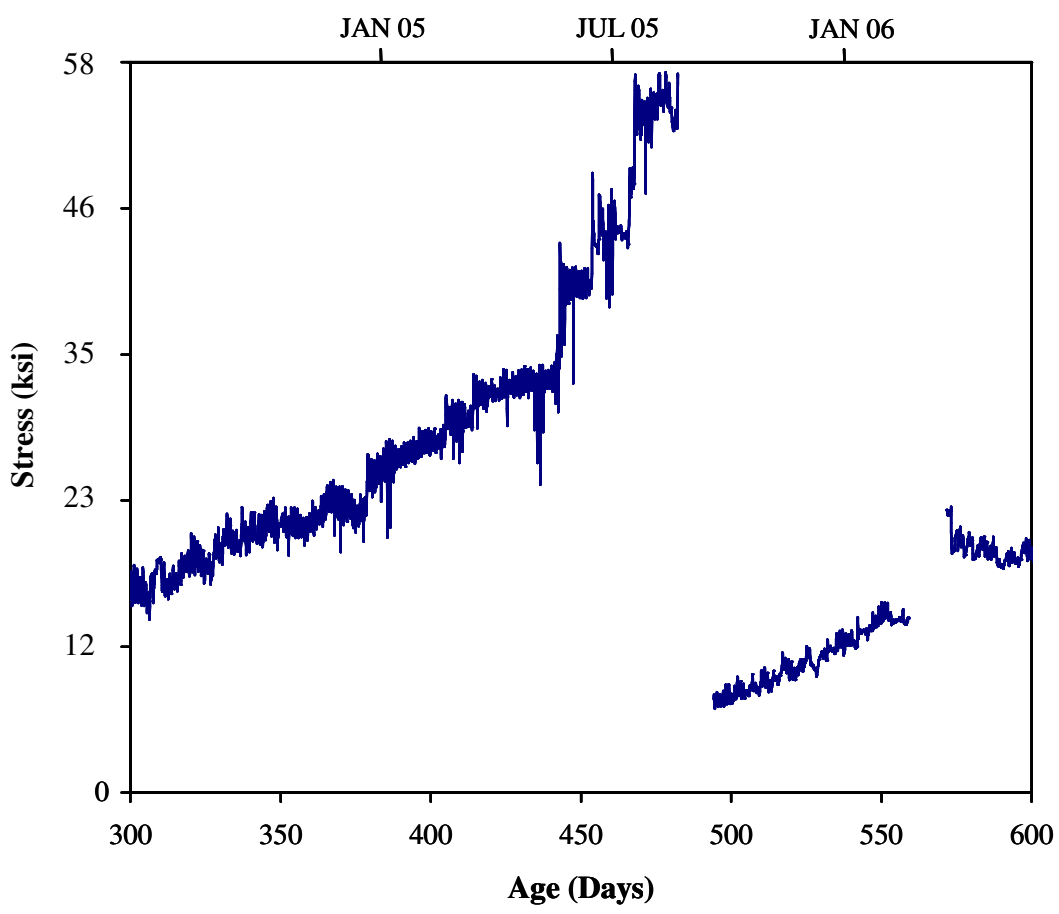

Figure 3.32: Stress in Top Reinforcement (Thayer Road Bridge, Span C) 


\section{CHAPTER 4 ANALYSIS OF FIELD RESULTS}

\subsection{Introduction}

To better understand the effect of dissimilar reinforcement designs on the performance of the bridge decks monitored in this research, the results of the field study were compared and analyzed.

\subsection{Comparison of Cracking in Bridges}

Cracks occurring in the bridge decks on the SR 18, SR 23, and Thayer Road bridges were mapped, and crack widths were recorded. As discussed in Section 3.3.2, the bridge deck on the SR 23 bridge, which was constructed with a low shrinkage concrete did not exhibit cracking in the instrumented span. The cracks detected in that bridge deck were generally located over the pier in the second phase deck and are attributed to traffic loading rather than restrained shrinkage of the concrete.

Table 4.1 provides a comparison of the crack widths recorded in the three bridge decks where cracking was observed. The Purdue empirical bridge deck demonstrated the largest number of cracks compared to the other two bridge decks in terms of cracks per $100 \mathrm{ft}$ of span. The AASHTO and Purdue span had 12.2 cracks per $100 \mathrm{ft}$ and 17.9 cracks per $100 \mathrm{ft}$, respectively. By comparison, the Thayer Road Bridge had only 6.8 cracks per $100 \mathrm{ft}$. The Purdue deck also had the smallest average and maximum crack widths compared to the AASHTO and Thayer Road bridge decks. The average crack width in both the AASHTO span and Thayer Road bridge was $43 \%$ greater than the average crack width in the Purdue span. The maximum crack widths in the AASHTO span and Thayer Road bridge were 39\% and 44\% greater than the maximum crack width recorded in the Purdue span. 
Table 4.1: Comparison of Crack Width Statistics

\begin{tabular}{|c|c|c|c|}
\hline \multirow{2}{*}{ Crack Statistics } & \multicolumn{2}{|c|}{ SR 18 } & \multirow{2}{*}{ Thayer Road } \\
\cline { 2 - 3 } & AASHTO & Purdue & \\
\hline Number of Cracks (Total) & 15 & 22 & 19 \\
\hline Number of Cracks (per 100 ft) & 12.2 & 17.9 & 6.8 \\
\hline Average Crack Widths (in.) & 0.010 & 0.007 & 0.010 \\
\hline Standard Deviation (in.) & 0.008 & 0.005 & 0.008 \\
\hline Maximum Crack Width (in.) & 0.025 & 0.018 & 0.026 \\
\hline Variance & $3.11 \times 10^{-5}$ & $2.53 \times 10^{-5}$ & $5.56 \times 10^{-6}$ \\
\hline
\end{tabular}

A comparison of the distribution of crack widths is presented in Figure 4.1. While the majority of cracks in the Thayer Road deck were relatively small (57\% less than 0.008 in.), five cracks ( $26 \%$ of observed cracks) had widths greater than $0.018 \mathrm{in}$. Similarly, the majority of crack widths in the Purdue span were less than 0.008 in. (73\% of observed cracks), and no cracks exceeded 0.018 in. By comparison, the AASHTO empirical span had a fairly even distribution of crack widths. Twenty-seven percent (27\%) of observed cracks were less than 0.008 in., and only one crack (6\% of observed cracks) was in excess of 0.018 in.

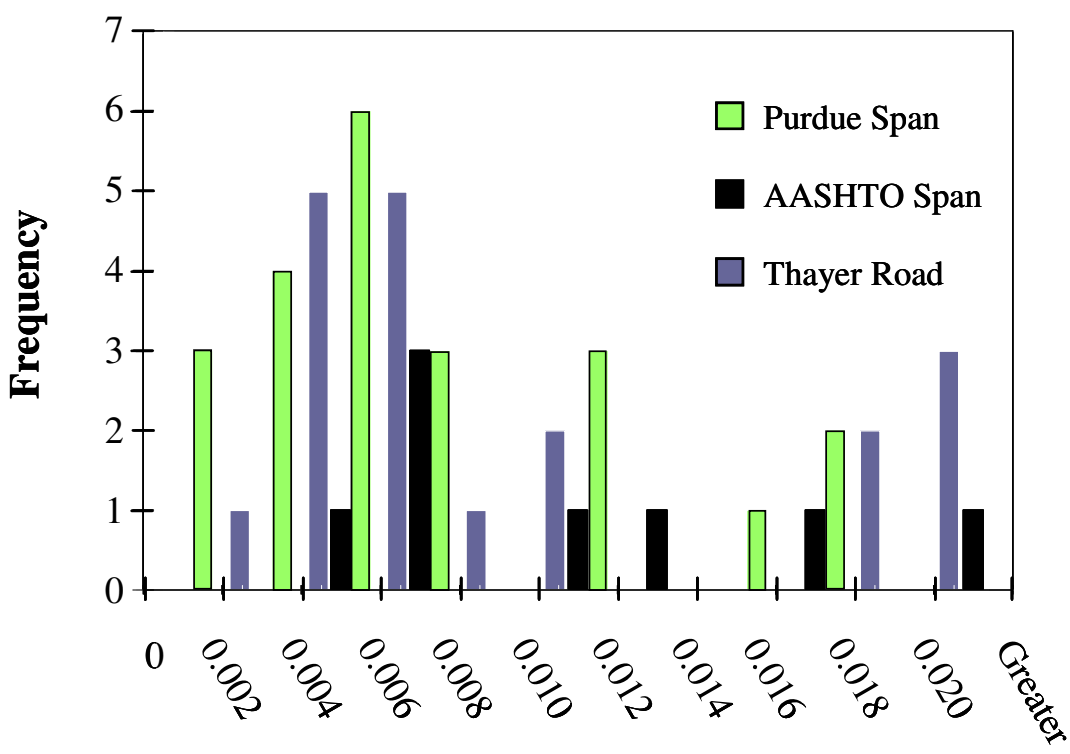

Crack Width (in.)

Figure 4.1: Comparison of Crack Widths

\subsection{Comparison of Behavior of Longitudinal Reinforcement}

Comparisons between the observed strain in the longitudinal reinforcement provides insight into the behavior of this reinforcement inside a concrete bridge deck. 
All three bridges instrumented as a part of this research, as well as the I65 bridge over SR 25 instrumented by Radabaugh (2001), share common features in the instrumentation. All four bridges were instrumented with strain gages in the top reinforcement mat, which allows for comparison of the respective behaviors. Thermocouples installed on the four bridges allow correlation of observed behaviors to the thermal response of the bridge. Figure 4.2 presents a comparison of the top mat reinforcement behavior at midspan in the four spans instrumented as a part of this research. The data is plotted according to its date; therefore, the age of each span in the figure is plotted relative to the age of the deck on the SR 18 bridge. This ensures that any variation in the reinforcement strain due to temperature is chronologically consistent with the other decks.

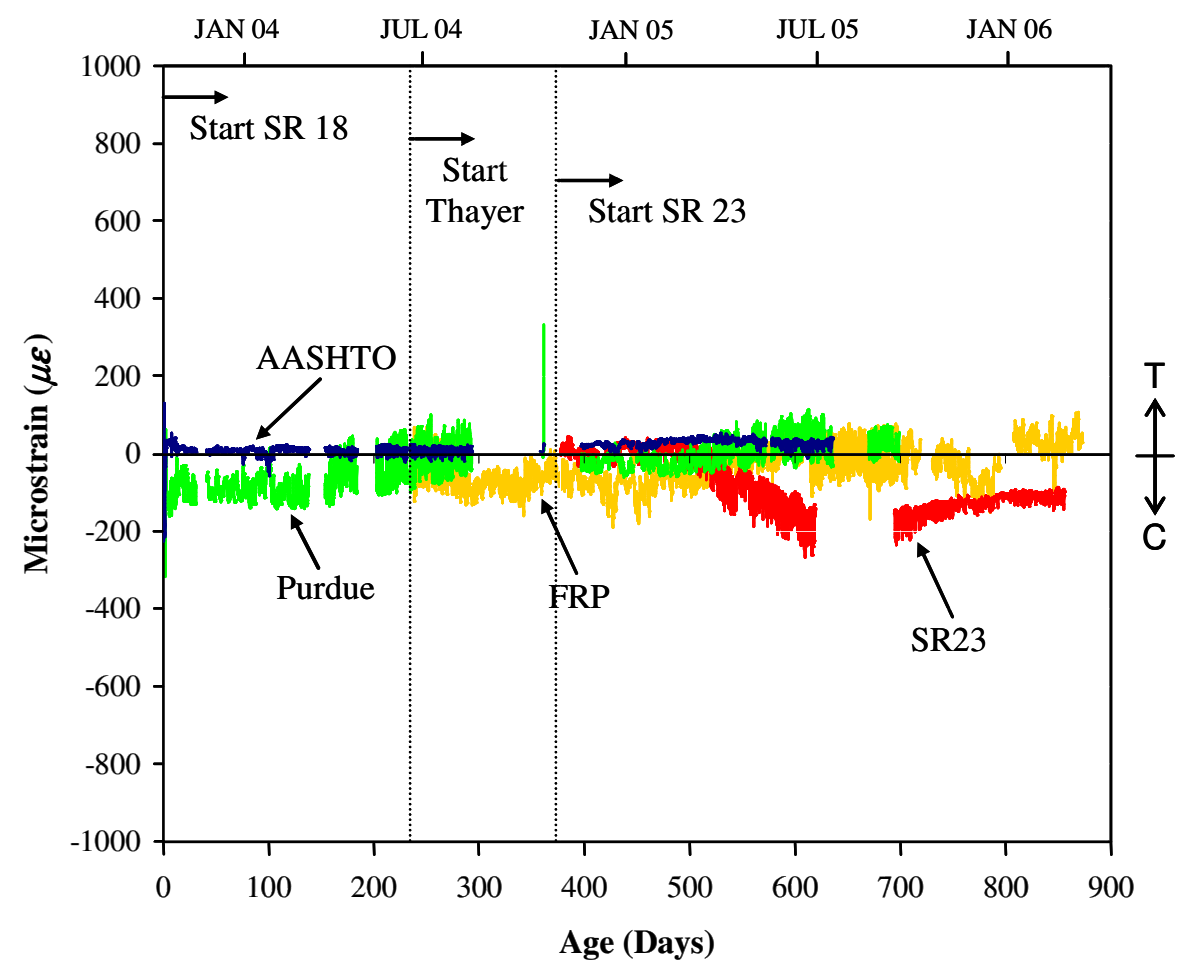

Figure 4.2: Comparison of Top Mat Reinforcement Strains at Midspan

The AASHTO, Purdue, and FRP spans demonstrate similar behavior over the monitoring period. The reinforcement in SR 23 appears to exhibit greater compressive strains after January 2005 when compared to the other three spans. A key difference between SR 23 and the other bridges monitored is the apparent absence of cracking in the bridge deck. As discussed in Section 3.3.4, the increase in compressive strain coincides with ambient temperatures greater than those on the day the deck was placed, which suggests that the increase in compressive strains is a result of a global behavior of the bridge undergoing thermal volumetric change rather than local behavior in the deck at midspan. 
As discussed in Section 2.3, Radabaugh instrumented the I65 bridge in August 2000. Strain data from this bridge was recorded continuously until April 2004. The strain in the reinforcement over Girder 1 is presented in Figure 4.3. Strain in the reinforcement at this location varied between a minimum of $-98 \mu \varepsilon$ on Day 226 and a maximum of $3019 \mu \varepsilon$ on Day 659. The measured strain in the reinforcement in the I65 bridge exhibits significantly larger seasonal variations compared to the variations observed on the SR 18, SR 23 and Thayer Road bridges.

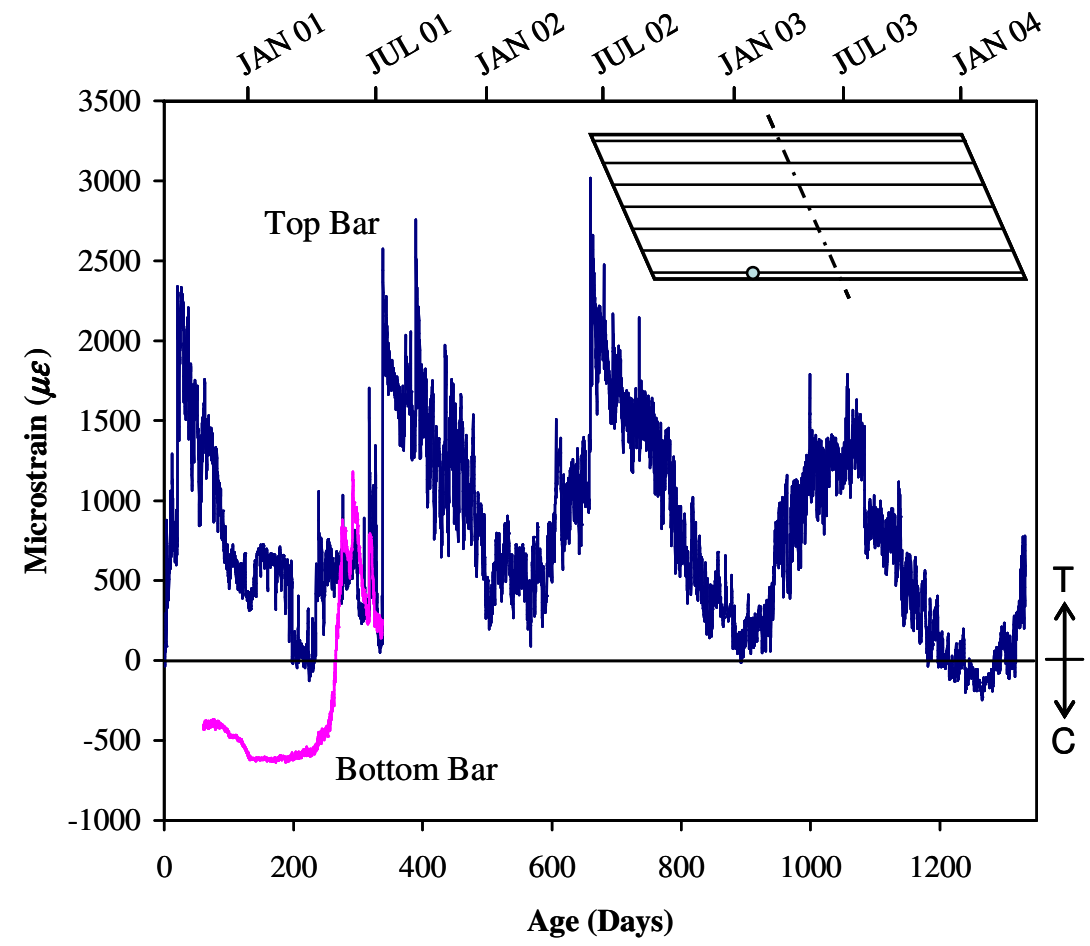

Figure 4.3: I-65 Reinforcement Strain over Girder 1 (Top Bar)

The temperature in the bridge deck at the level of the top reinforcement was also monitored over this period of time and is presented in Figure 4.4. Temperature at this location on the day of placement was recorded as $114^{\circ} \mathrm{F}$. For comparison, the ambient temperature was recorded to be $95^{\circ} \mathrm{F}$. The average temperature in the deck over the first seven days was $80^{\circ} \mathrm{F}$. Over the following 132 days, the temperature decreased to a low of $4.4^{\circ} \mathrm{F}$ for a total temperature change of approximately $110^{\circ} \mathrm{F}$. This temperature change corresponds to approximately $660 \mu \varepsilon$, or 0.61 in. of contraction of the bridge between deck placement and the first-year low on Day 132. These strains would be expected if the strain gage was not located in close proximity to a crack in the deck. 


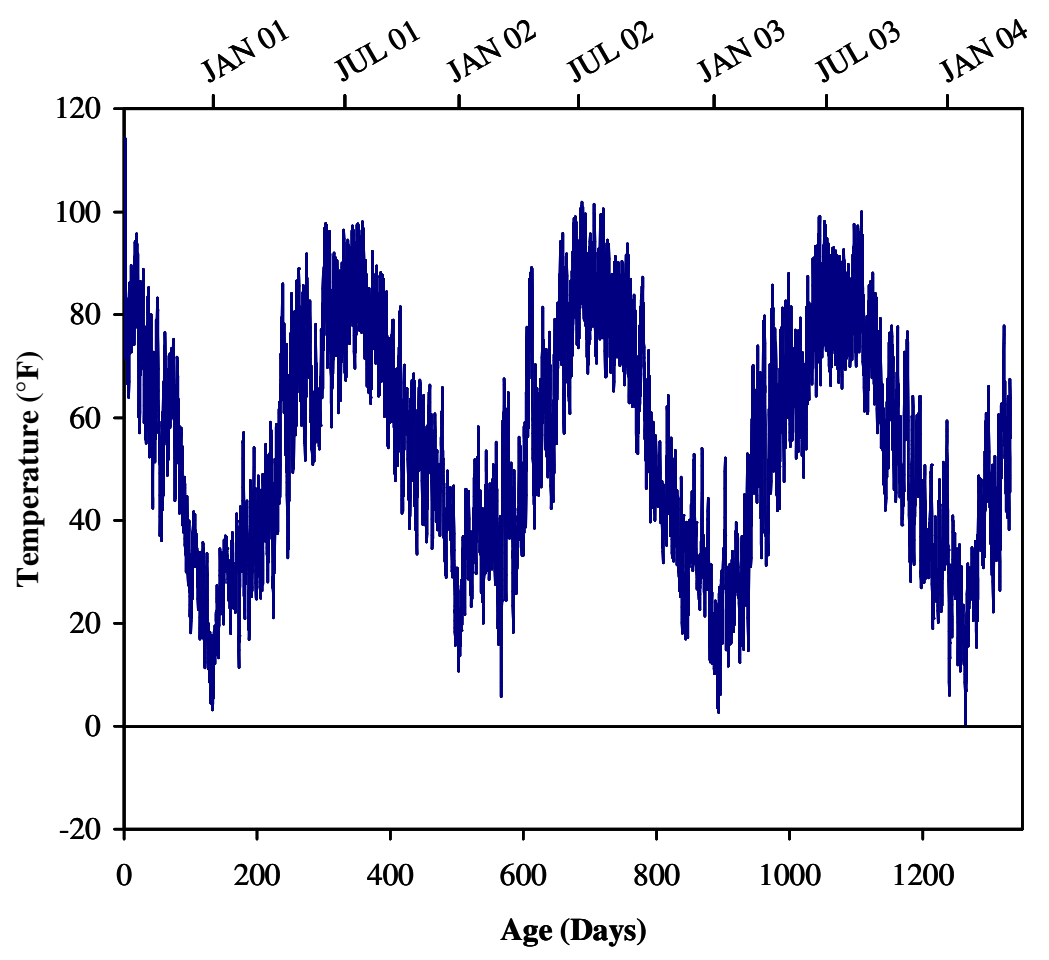

Figure 4.4: I65 Deck Temperature at Top Reinforcement Mat

As evident, strain measured in the reinforcement is significantly greater than the estimated strain expected from thermal effects if the strain gage was not located near a crack. In addition, the range of variation of the strain recorded in the reinforcement appears consistent from year to year. Furthermore, the reinforcement over Girder 4 (Figure 4.5) exhibit similar behavior as the reinforcement over Girder 1. This suggests that the strain gage is functioning properly and the data recorded is correct. It is possible that the strain gages installed on the reinforcement over Girder 1 and Girder 4 intersect a crack that formed in the bridge deck. 


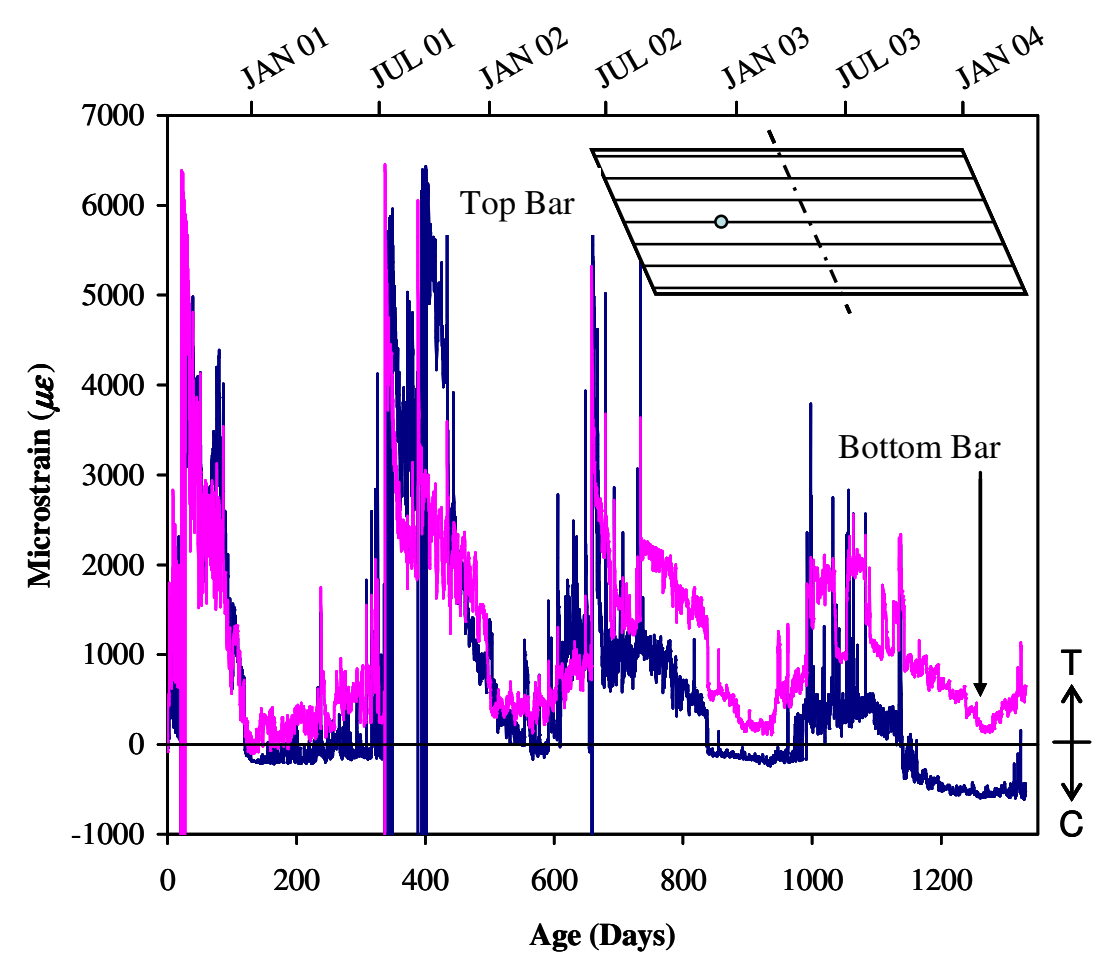

Figure 4.5: I-65 Reinforcement Strain over Girder 4 (Top Bar)

\subsection{Behavior of Reinforcement Across a Crack}

The pattern of the strain data from the reinforcement over Girder 1 of the I65 bridge over SR 25 suggests that as the temperature increases, the crack opens and as the temperature decreases, the crack width decreases and eventually closes as indicated by a relatively stable plateau between days 100 and 320 (Figure 4.3).

Inspection of the strain data from the reinforcement over Girder 1 reveals tensile strain in the reinforcement increased to a maximum of $2340 \mu \varepsilon$ over the first 20 days, and then decreased from Day 20 until reaching a minimum of $127 \mu \varepsilon$ (compression) on Day 223. From Day 0 to Day 20, temperature in the deck decreased from an average of $91^{\circ} \mathrm{F}$ to an average of $76^{\circ} \mathrm{F}$. As the strain in the reinforcement demonstrates an opposite trend with respect to temperature variation after Day 20, the data implies that a crack initially formed as a result of shrinkage of the concrete deck. When the variation in bridge temperature is compared to the variation in the strain (Figure 4.6), it is evident that the variation in strain after Day 20 is driven by thermal variations experienced by the bridge. The reinforcement strain varies consistently with the temperature from Day 20 to Day 197 , and statistical analysis results in a coefficient of correlation of 0.88 between the reinforcement strain and the measured temperature. It is interesting to note that the reinforcement does not continue to increase in tensile strain as the temperature continues to increase after Day 197, but nonetheless as the temperature achieves the next seasonal maximum (Day 363), strain in the reinforcement increases rapidly to a level analogous to strains measured on Day 20. This further supports the hypothesis that the crack is able to 
close when the temperatures decrease in the bridge deck but then opens as temperatures increase.

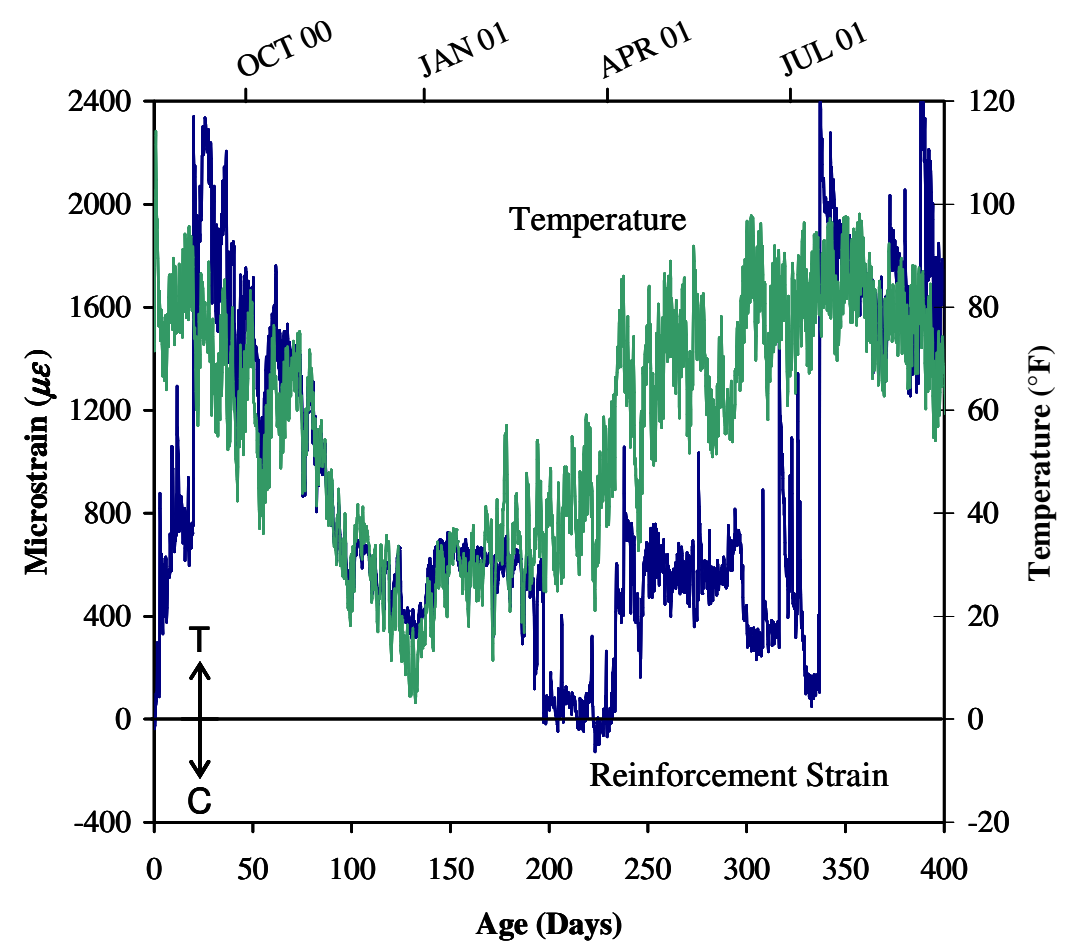

Figure 4.6: Comparison of Temperature and Strain Variations in I-65 Bridge

While the reinforcement strain shows a strong correlation to the temperature variation, the magnitude of the change in the reinforcement strain is much greater than would be expected for the corresponding temperature change. The average temperature was $75.5^{\circ} \mathrm{F}$ on Day 20 and $6.1^{\circ} \mathrm{F}$ on Day 132. This temperature change would result in contraction of $451 \mu \varepsilon\left(\alpha_{t}=6.0 \times 10^{-6} /{ }^{\circ} \mathrm{F}\right)$. The change in measured strain over this period of time was significantly greater $(1320 \mu \varepsilon)$ than that which is expected from temperature change alone. Interestingly, if only the change in strain between strain measured prior to the large increase on Day $20(759 \mu \varepsilon)$ and the strain measured on Day $132(344 \mu \varepsilon)$, the change in strain is $415 \mu \varepsilon$. The difference in strain just before the increase on Day 20 and the measured value on Day 132 demonstrates good agreement with the change in strain calculated as a result of temperature change between Days 20 and 132. Therefore, it is evident that between Days 20 and 132 the reinforcement experiences strains in addition to strains due to thermal effects.

For comparison, the strain in Girder 1 is presented in Figure 4.7. Compressive strain in the web of Girder 1 increased by an average of $95 \mu \varepsilon$ between Day 20 and Day 132. Furthermore, the girder does not exhibit a similar sudden large increase in strain as to that measured in the reinforcement in the deck. 


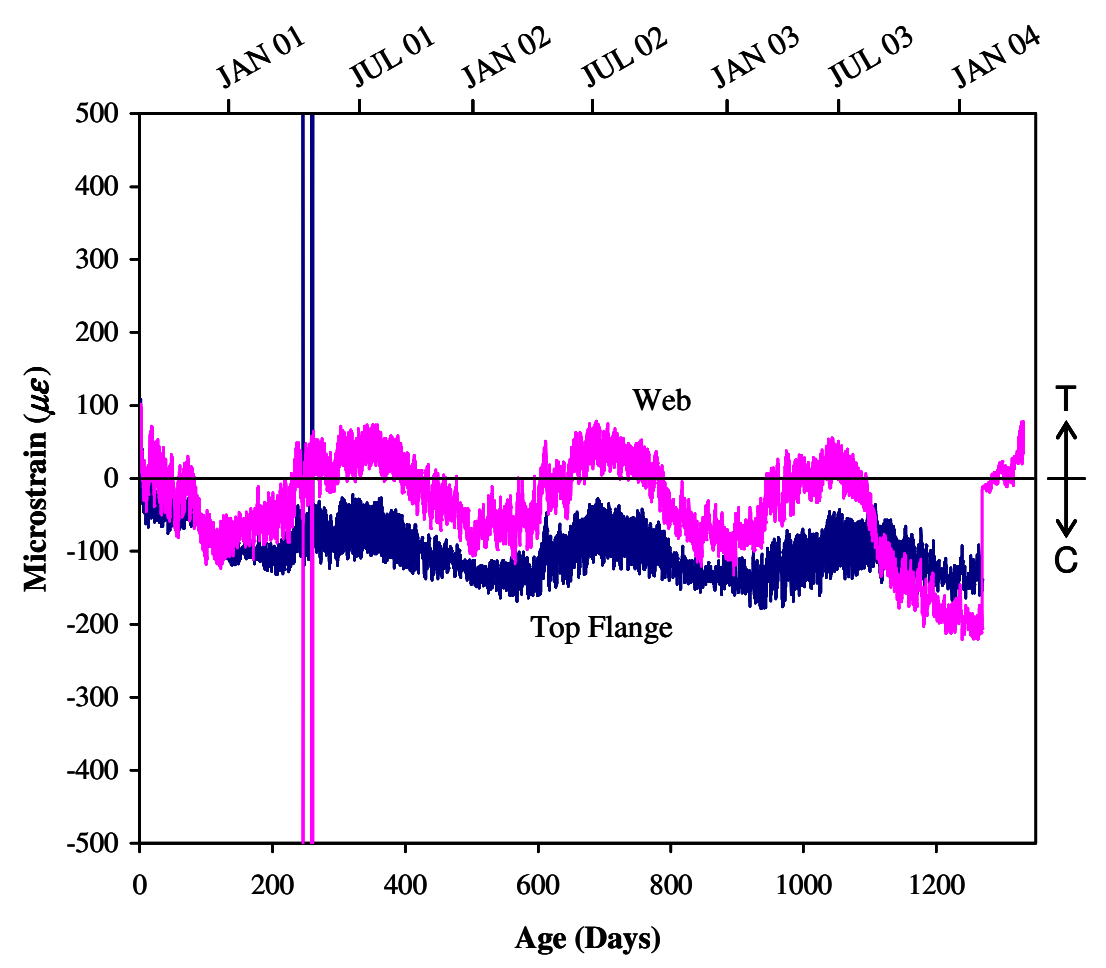

Figure 4.7: I-65 Girder 1 Strains

As evident, the change in strain in the reinforcement is significantly greater than the change in strain in the girder. The reinforcement exhibits increasing tensile strain as the temperature increases (Figure 4.6) implying that the crack opens as the temperature increases, if the instrumentation is intersected by a crack. While the concrete also attempts to undergo expansion as the deck temperatures increase, sufficient restraint from the girder could mitigate such expansion and allow a crack to be subjected to a net increase in width.

\subsection{Restraint}

The amount of restraint experienced by the concrete deck varies depending on the girder type used (concrete or steel) and the end conditions of the bridge (fixed versus hinge/roller supports). Furthermore, the amount of restraint over the girder is different from the amount of restraint midway between girders. The instrumentation installed in the bridges in this study allows the level of restraint to be evaluated for the various bridges considered.

\subsubsection{Level of Restraint from Concrete Girders}

The slab specimen that was constructed and stored at the SR 23 bridge site provides an estimate of the amount of free shrinkage that occurs with the concrete mix 
used in the SR 23 bridge. Furthermore, the geometry of this specimen combined with the seal applied to the perimeter allows for a direct comparison of shrinkage behavior between the bridge deck and the free shrinkage specimen without correcting for size effects.

Figure 4.8 compares the strain between the slab specimen and the bridge deck strains midbay between Girders 2 and 3. The measured compressive strain in the top reinforcement is generally less than the compressive strain in the slab specimen. Over the first 146 days, the average difference between the slab specimen and the midbay reinforcement was $19 \mu \varepsilon$. After this time, the compressive strain in the top reinforcement increases and exceeds the strain recorded in the slab specimen. Strain in the slab specimen is a result of shrinkage of the concrete. For the first 146 days, the strain measured in the bridge deck is attributed to concrete shrinkage. However, after Day 146, strain in the reinforcement is clearly influenced by an external force.

The strain in bridge deck concrete exhibits a similar level of restraint as measured in the reinforcement during the first 146 days. The average difference in strain between the bridge deck concrete and the slab specimen was $18 \mu \varepsilon$. However, unlike the reinforcement, the concrete strain did not exhibit an increase in compressive strains after Day 146. This behavior is consistent with the localized nature of the measurements recorded by the embedded concrete gages in all of the bridges investigated as a part of this study.

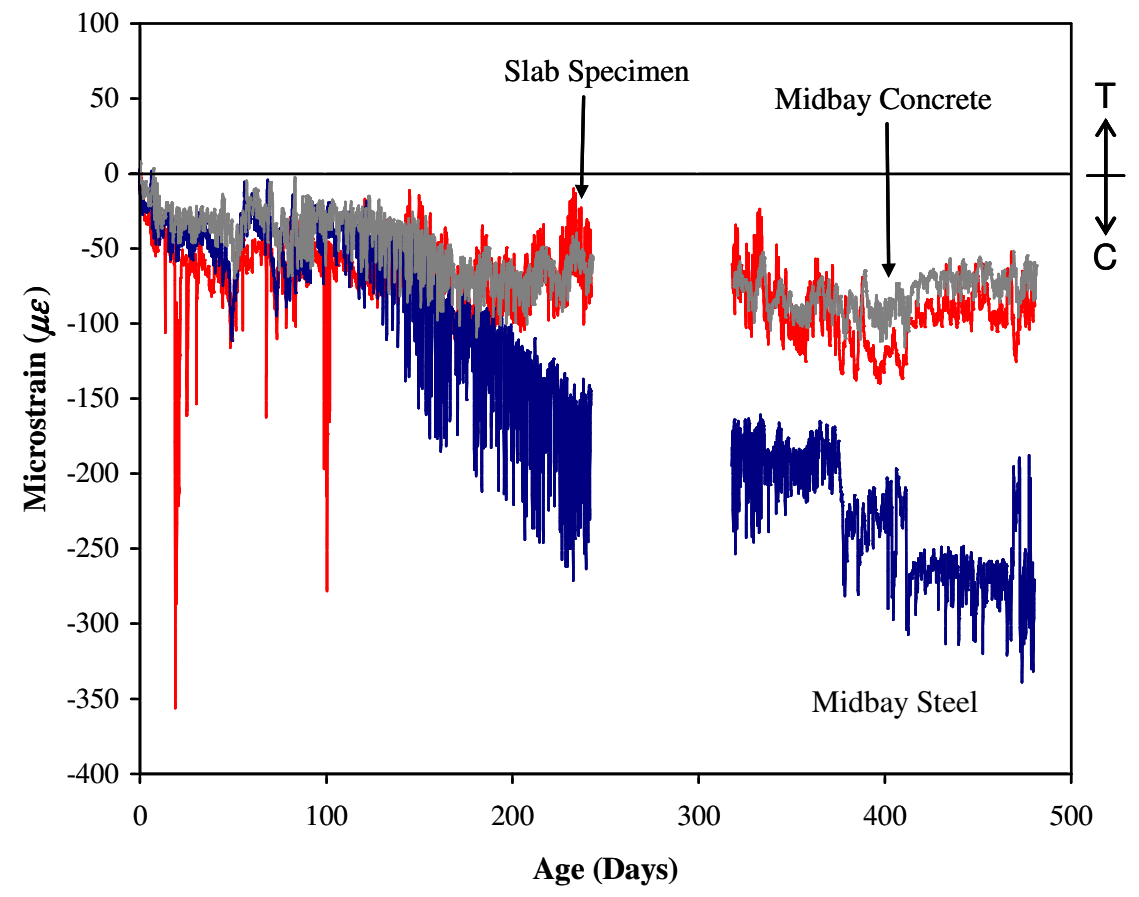

Figure 4.8: Comparison of Slab Specimen Strain to Bridge Deck Strains Between Girders 2 and 3 (SR 23) 
The increase in compressive strain experienced by the reinforcement is also evident in the reinforcement over the girders. Figure 4.9 provides a comparison of the top reinforcement strain over Girder 3 and midbay between Girders 2 and 3. After Day 146, compressive strains at both locations increase and are essentially the same by Day 238. Furthermore, as shown in Figure 4.10, the concrete over the girder experiences an increase in compressive strain after Day 146 similar to that observed in the reinforcement over the girder. When compared to the concrete strain measured at midbay, it is evident that the concrete over the girder experiences a larger degree of restraint than at midbay. Prior to Day 146 the average strain in the concrete over the girder was $5 \mu \varepsilon$ (tension) compared to $32 \mu \varepsilon$ (compression).

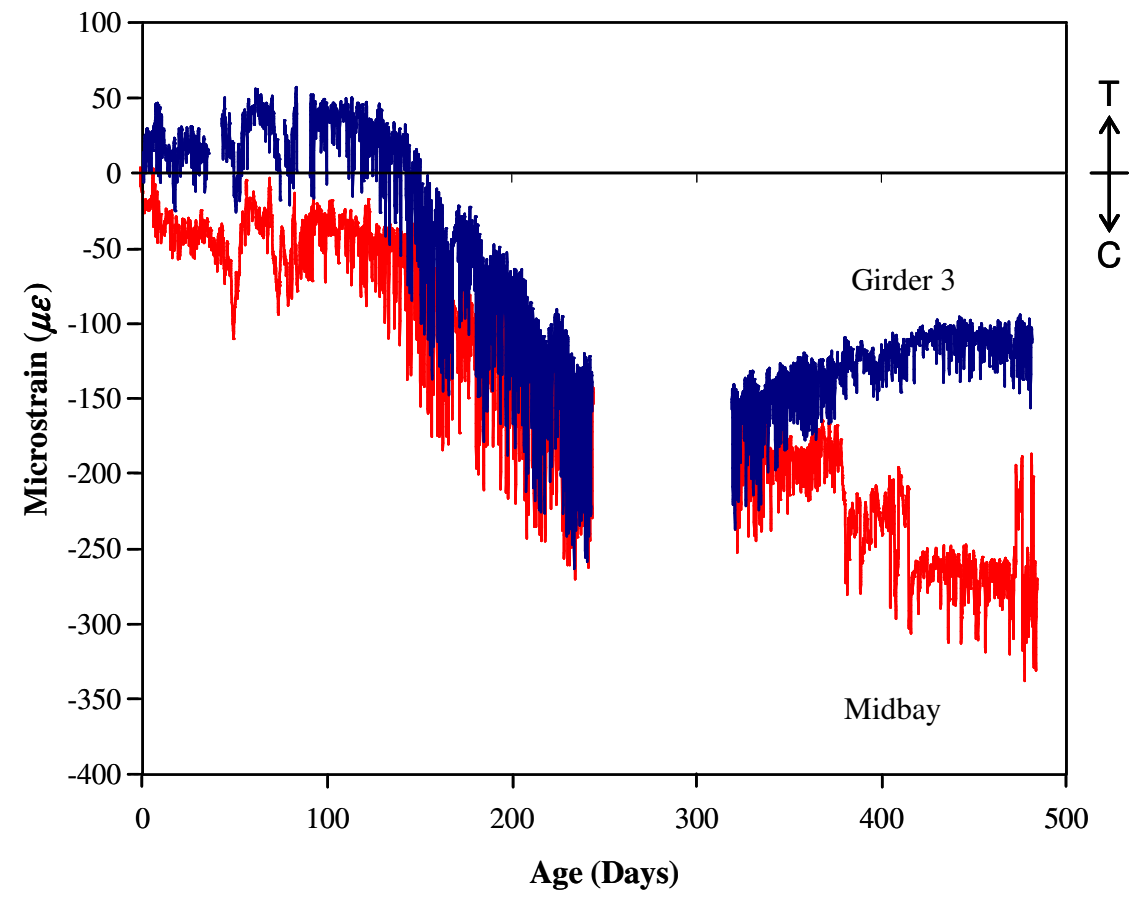

Figure 4.9: Comparison of Reinforcement Strain over Girder 3 and Midbay (Top Bar - SR 23) 


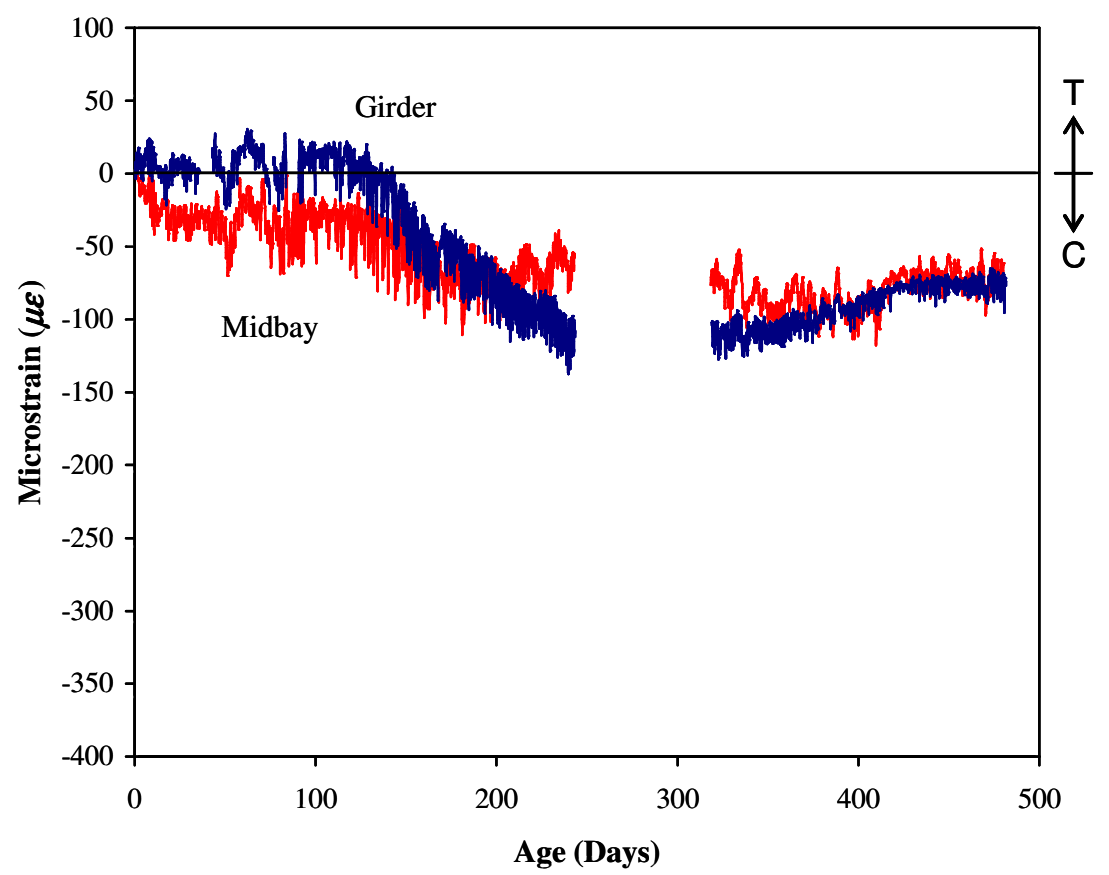

Figure 4.10: Comparison of Concrete Strain over Girder 3 and Midbay (SR 23)

While the reinforcement over Girder 3 shows a nominal increase in tensile strain (less than $50 \mu \varepsilon$ ) over the first 146 days, the reinforcement at midbay exhibits a small increase in compressive strain. This difference in behavior demonstrates the dissimilar levels of restraint present between midbay and over Girder 3. If the reinforcement (and by extension, the surrounding concrete) were completely restrained (100\% restraint), the strain in the reinforcement should be the exact opposite of the unrestrained shrinkage, as illustrated in Figure 4.11. Thus, if the deck is only partially restrained, the degree of restraint, $k$, can be computed as:

$$
k=\frac{1}{2}\left(1-\frac{\varepsilon_{m}}{\varepsilon_{f}}\right)
$$

where:

$$
\begin{aligned}
& \mathcal{E}_{m}=\text { measured strain } \\
& \mathcal{E}_{f}=\text { unrestrained (free) strain }
\end{aligned}
$$




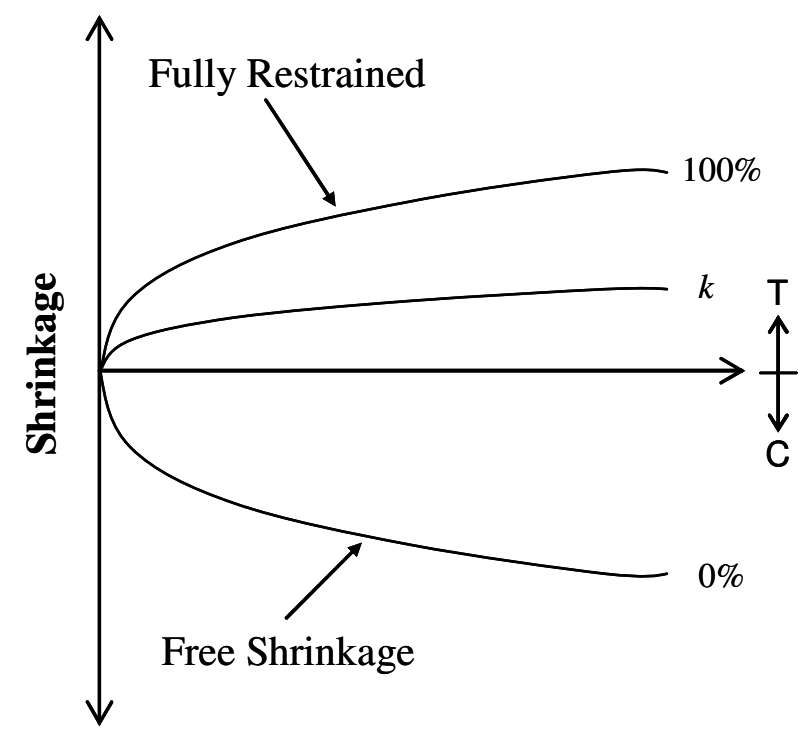

Figure 4.11: Strains Measured Under Varying Degrees of Restraint

If the unrestrained shrinkage of the bridge deck is estimated by the slab specimen on-site, then the average restraint as measured by the reinforcement over the first 146 days over Girder 3 and at midbay was $73 \%$ and $8 \%$, respectively. The average restraint in the concrete over Girder 3 and at midbay during the same period of time was $55 \%$ and $18 \%$, respectively.

\subsubsection{Level of Restraint from Steel Girders}

Concrete bridge decks constructed on steel girders may experience a difference in the amount of restraint as compared to the use of concrete girders. Figure 4.12 presents a comparison between the strain measured in the SR 18 AASHTO span reinforcement over Girder 3 and the reinforcement at midbay. Before the strain data diverges on Day 129, the reinforcement at the two locations exhibit similar behavior. The midbay reinforcement consistently experienced larger compressive strains than the reinforcement over the girders. This indicates that the deck between the girders is able to undergo volumetric changes with less restraint than the deck over the girders. The average difference in strain between the two locations was $95 \mu \varepsilon$ from Day 13 to Day 129 . Thus the deck over the girders experiences approximately $46 \%$ more shortening than the deck between the girders. By comparison, the SR 23 bridge deck experienced 54\% more shortening over the girder as compared to midbay, indicating reasonable consistency. While the center-to-center spacing of the girders is greater in the SR 18 bridge, the slab effective span length of both SR 18 and SR 23 is identical as illustrated in Figure 4.13. The similarity of restraint measured is supported by the geometric similarity of the bridges. 


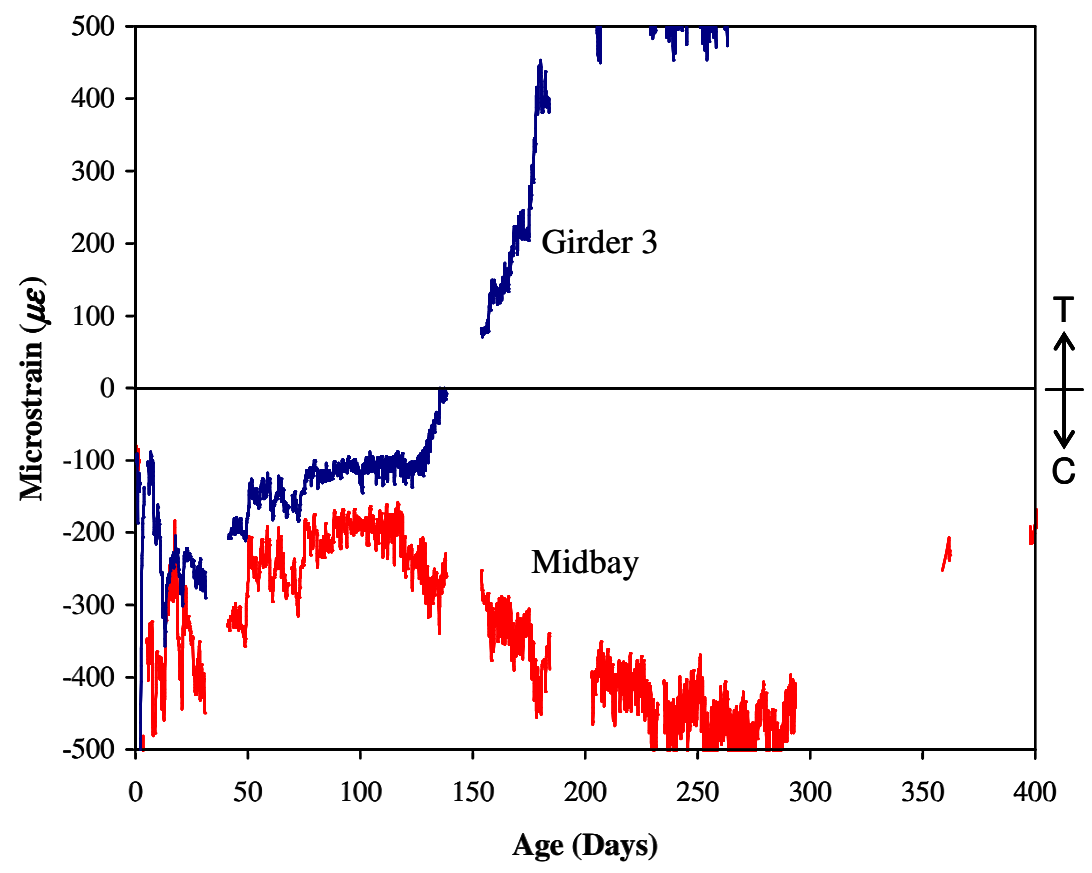

Figure 4.12: Comparison of AASHTO Span Reinforcement Strains (Top Bar)

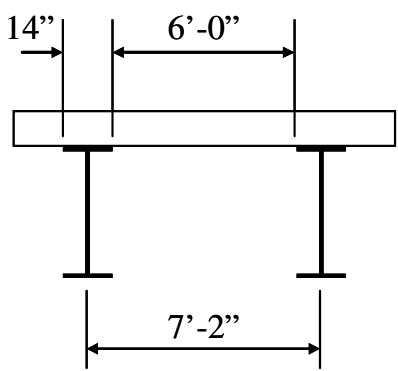

(a) SR 18

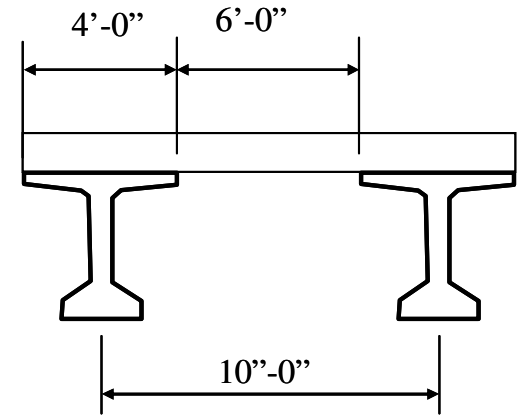

(b) SR 23

Figure 4.13: Comparison of Effective Slab Spans (SR 18 and SR 23)

Since free shrinkage measurements were not obtained from the SR 18 bridge, the level of restraint is estimated using measurements made by Blackman (2002). Specimen 8 in the Blackman study was constructed with similar concrete (INDOT Class C) and with one side sealed to prevent moisture loss, which results in a shrinkage profile similar to that expected in a deck constructed with SIP forms. Details of Blackman's specimens are provided in Appendix B. Concrete strains measured in the AASHTO span are compared to the unrestrained shrinkage measured by Blackman in Figure 4.14. The average difference in between concrete over Girder 3 and at midbay was $98 \mu \varepsilon$, which is 
consistent with the difference in reinforcement strain between the two locations. The degree of restraint as measured by both the concrete and reinforcement is estimated as $41 \%$ at midbay and $75 \%$ over the Girder 3 . It should be noted that the free-shrinkage measurements were based on lab measurements that do not consider changes in moisture as experienced in the field. Therefore, these restraint estimates should be considered upper-bounds.

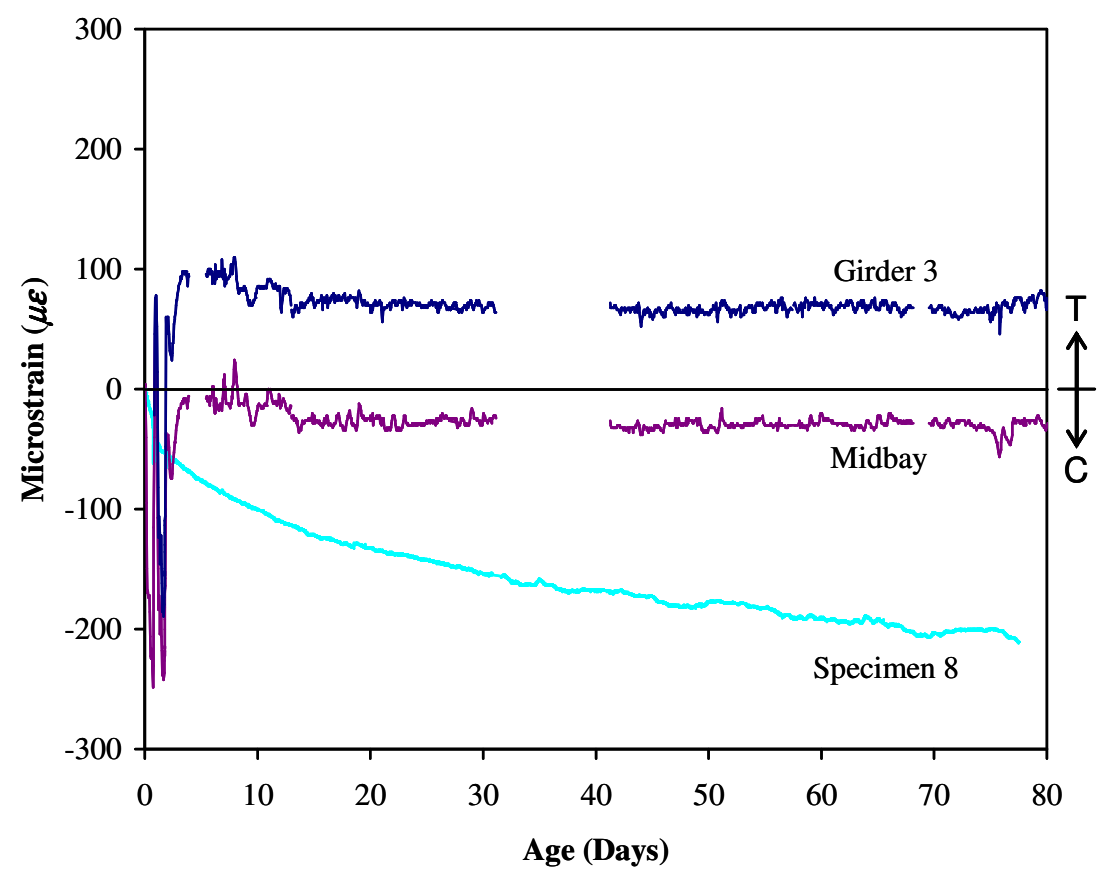

Figure 4.14: Comparison of AASHTO Span Concrete Strains (Top Bar)

\subsubsection{Level of Restraint from Abutment}

The SR 23 bridge was constructed with an integral abutment as illustrated in

Figure 4.15. The abutment was constructed with a single line of piles to allow the bridge freedom to translate longitudinally. To introduce a pin connection at the top of the pile, 1 in. of expanded polystyrene was installed around the pile head. This connection method also provides additional flexibility both longitudinally and transversely as the bridge undergoes volumetric changes. The superstructure has to undergo approximately 1 in. of longitudinal contraction before displacements are resisted by the pile. 


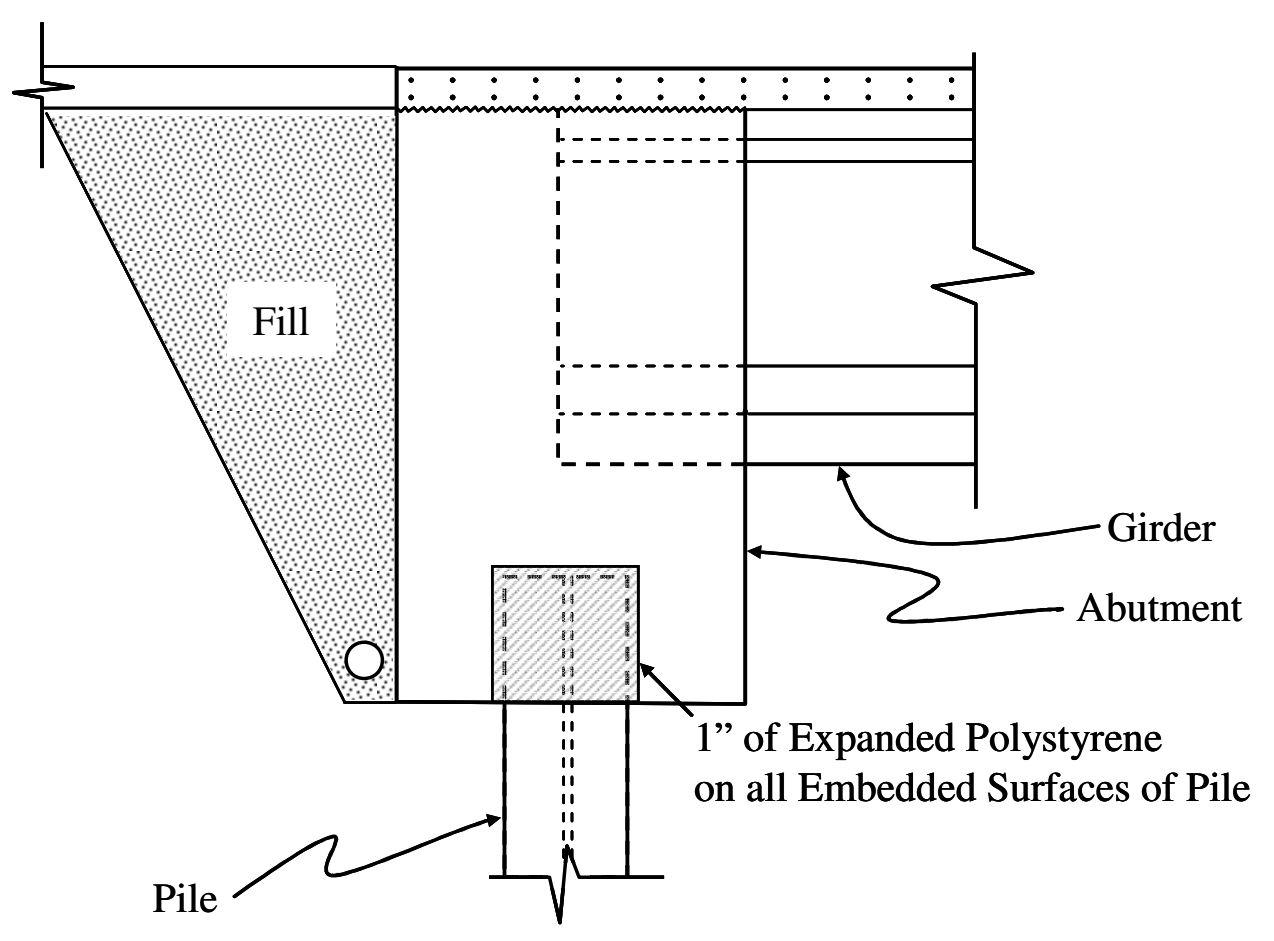

Figure 4.15: SR 23 Integral Abutment Schematic

As shown in Figure 4.16, the strain in the reinforcement at midspan does not vary significantly while ambient temperatures are less than the temperature at the time of deck placement $\left(50^{\circ} \mathrm{F}\right)$. Between Day 0 and Day 146, the bridge experienced a maximum negative temperature change of $-48.5^{\circ} \mathrm{F}$. If the coefficient of thermal expansion of the concrete bridge is estimated as $6.0 \times 10^{-6} /{ }^{\circ} \mathrm{F}$, the bridge would experience $291 \mu \varepsilon$ due to the temperature decrease. This strain over the $101 \mathrm{ft}$ span results in a $0.35 \mathrm{in}$. contraction of the bridge. Since the translation of the superstructure was less than 1 in., it is anticipated that the bridge experienced unrestrained displacement resulting in no change in strains recorded in the reinforcement. Inspection of the girder strains recorded over the first 146 days (Figure 4.17), demonstrates that the girders experienced relatively little strain as a result of thermal effects. Between Day 0 and Day 146, Girder 3 exhibited a change of only $25 \mu \varepsilon$, and the change in strain in Girder 2 was negligible. Therefore, this abutment type did not offer significant restraint to thermal effects during the contraction phase. 


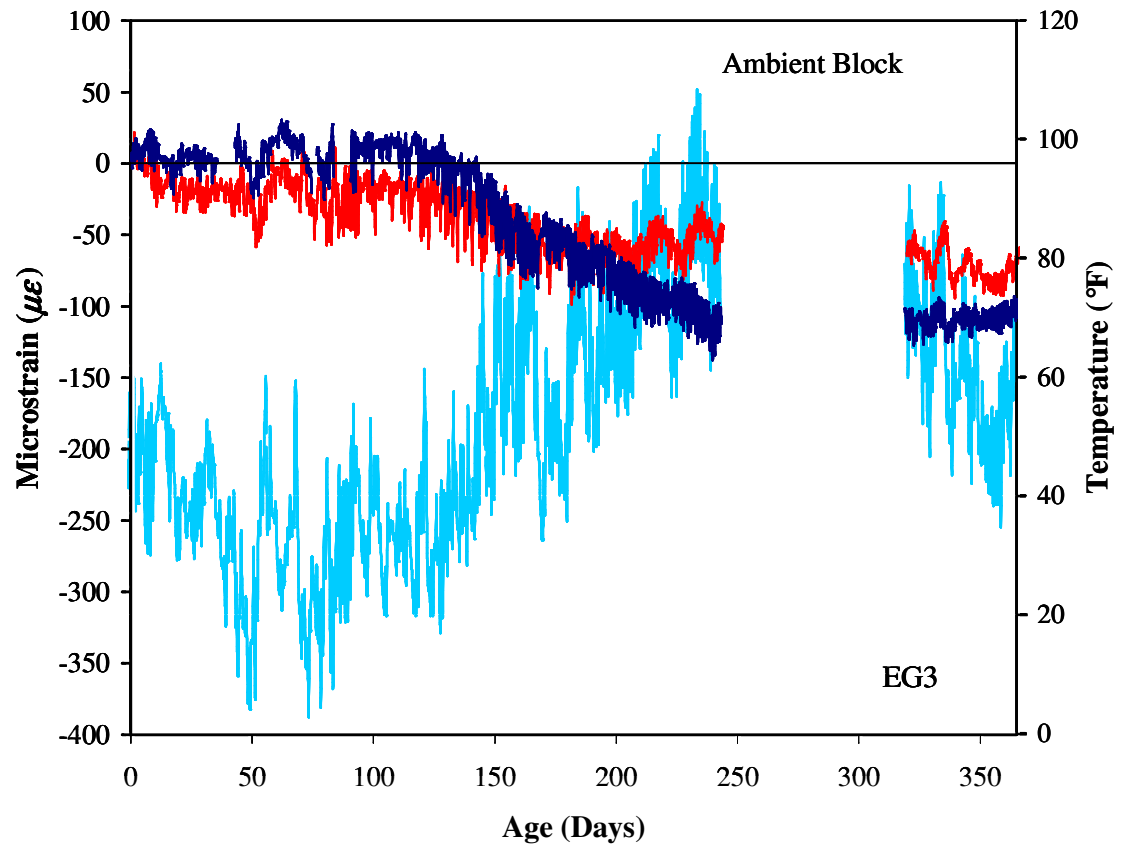

Figure 4.16: Comparison of Concrete Strains to Temperature (SR 23)

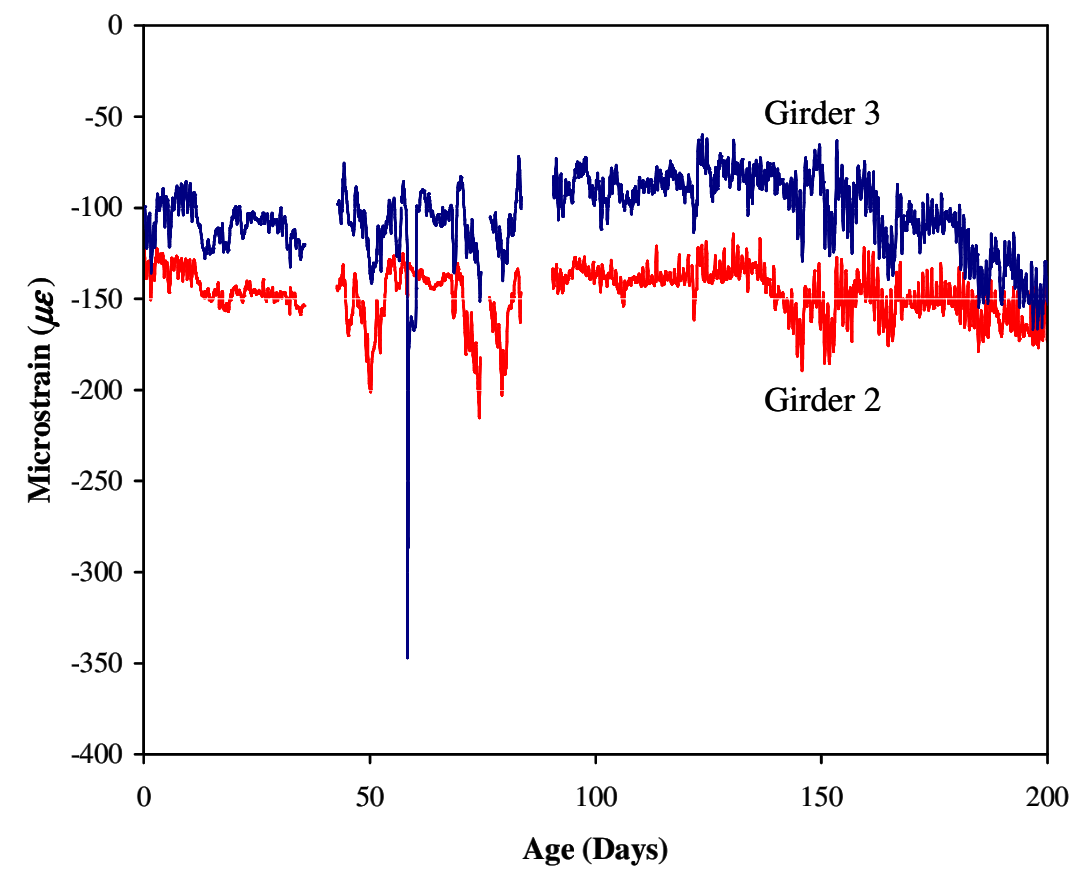

Figure 4.17: Comparison of Girder Top Flange Strains (SR 23) 
After Day 146, compressive strain in both the reinforcement and girder increase as the ambient temperature rises above the temperature at the time of casting (Figure 4.16 and Figure 4.17). This trend continues until the time the peak recorded seasonal temperature is reached on Day 238. As previously discussed in Section 4.5.1, it is evident that the reinforcement is influenced by a force other than shrinkage after Day 146. The compressive strain in the reinforcement increased by $159 \mu \varepsilon$ over both Girders 2 and 3 between Days 146 and 238 (Figure 4.18). Similarly, compressive strain in the top flange of the girders increased by $144 \mu \varepsilon$ during this time (Figure 4.19). However, the maximum temperature $\left(97.5^{\circ} \mathrm{F}\right)$ exceeded the temperature at casting $\left(50^{\circ} \mathrm{F}\right)$ by $47.5^{\circ}$ $\mathrm{F}$, which would results in a strain of $285 \mu \varepsilon$ and a total bridge expansion of $0.35 \mathrm{in}$. If the change in shrinkage strains during this time is considered to be negligible, then it can be concluded that the bridge experienced approximately $55 \%$ restraint from the integral abutments during the thermal expansion phase. Since the estimated total bridge expansion is less than $1 \mathrm{in}$., the pile is not considered to provide any resistance to expansion. Thus, the restraint to the expansion is attributed to bearing of the abutment against the backfill.

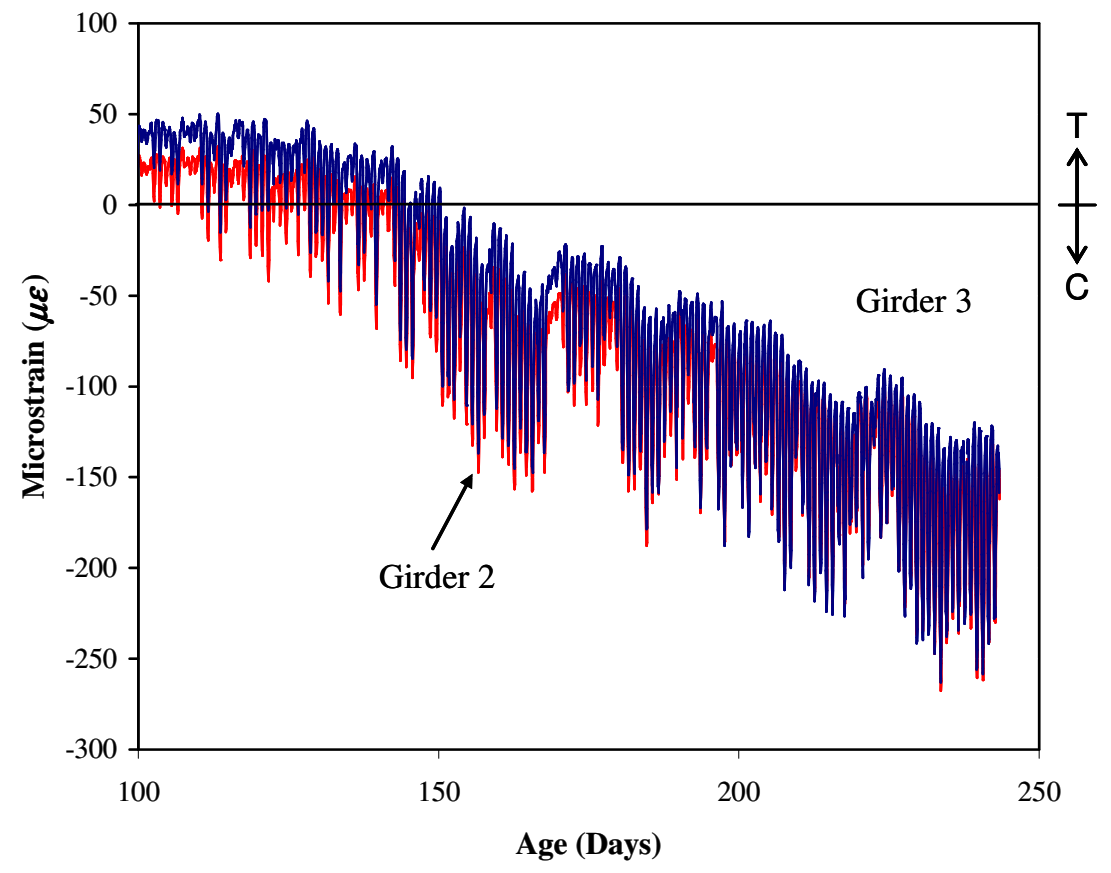

Figure 4.18: Reinforcement Strains During Expansion Phase (SR 23) 


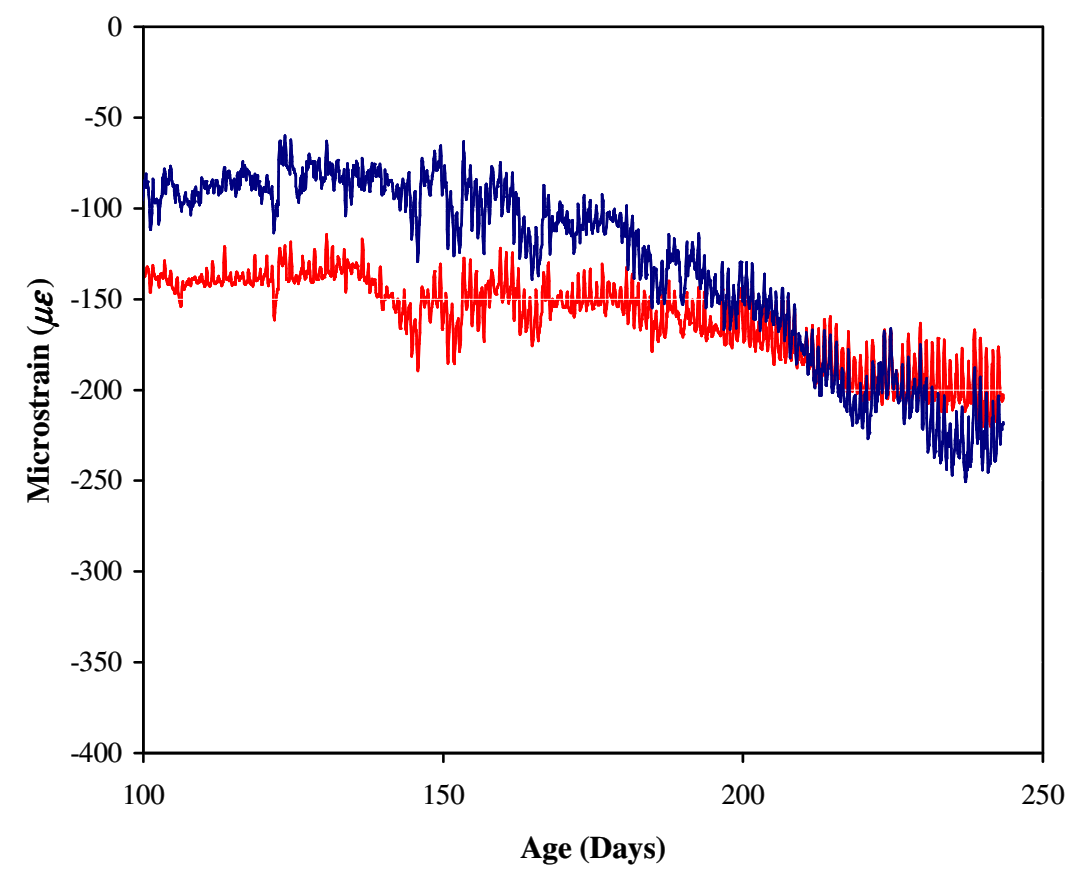

Figure 4.19: Girder Strains During Expansion Phase (SR 23)

The I- 65 bridge abutments were also constructed integral with the girders, similar to the abutments on SR 23. However, unlike SR 23, the surfaces of the pile heads were not covered with expanded polystyrene, but instead were directly incased in the abutment. In the I- 65 bridge, the temperature change that was measured between Day 20 and Day $132\left(\Delta \mathrm{T}=75.5^{\circ} \mathrm{F}\right)$ is estimated to result in a total bridge contraction of $0.81 \mathrm{in}$. If this contraction were completely restrained by the piles, strain in the girder would be expected to be approximately $451 \mu \varepsilon$. However, the change in strain measured in the girder over this period of time was only $95 \mu \varepsilon$. Thus, the girders are only $21 \%$ restrained by the abutment during the contraction phase. Due to the high temperature at the time of deck casting $\left(91^{\circ} \mathrm{F}\right.$ on average), the restraint from the abutment could not be evaluated for an expansion phase.

A different abutment type was used for SR 18 . The SR 18 bridge semi-integral abutments were constructed with a greased felt pad separating the pile cap and the abutment wall (Figure 4.20) to ensure that the abutment was not restrained from longitudinal translation by the piles. A shear keyway was constructed between the pile cap and the abutment wall with $3 / 4$ in. expanded polystyrene foam on the surfaces to allow the abutment freedom to move longitudinally while still maintaining rotational resistance (moment capacity). 


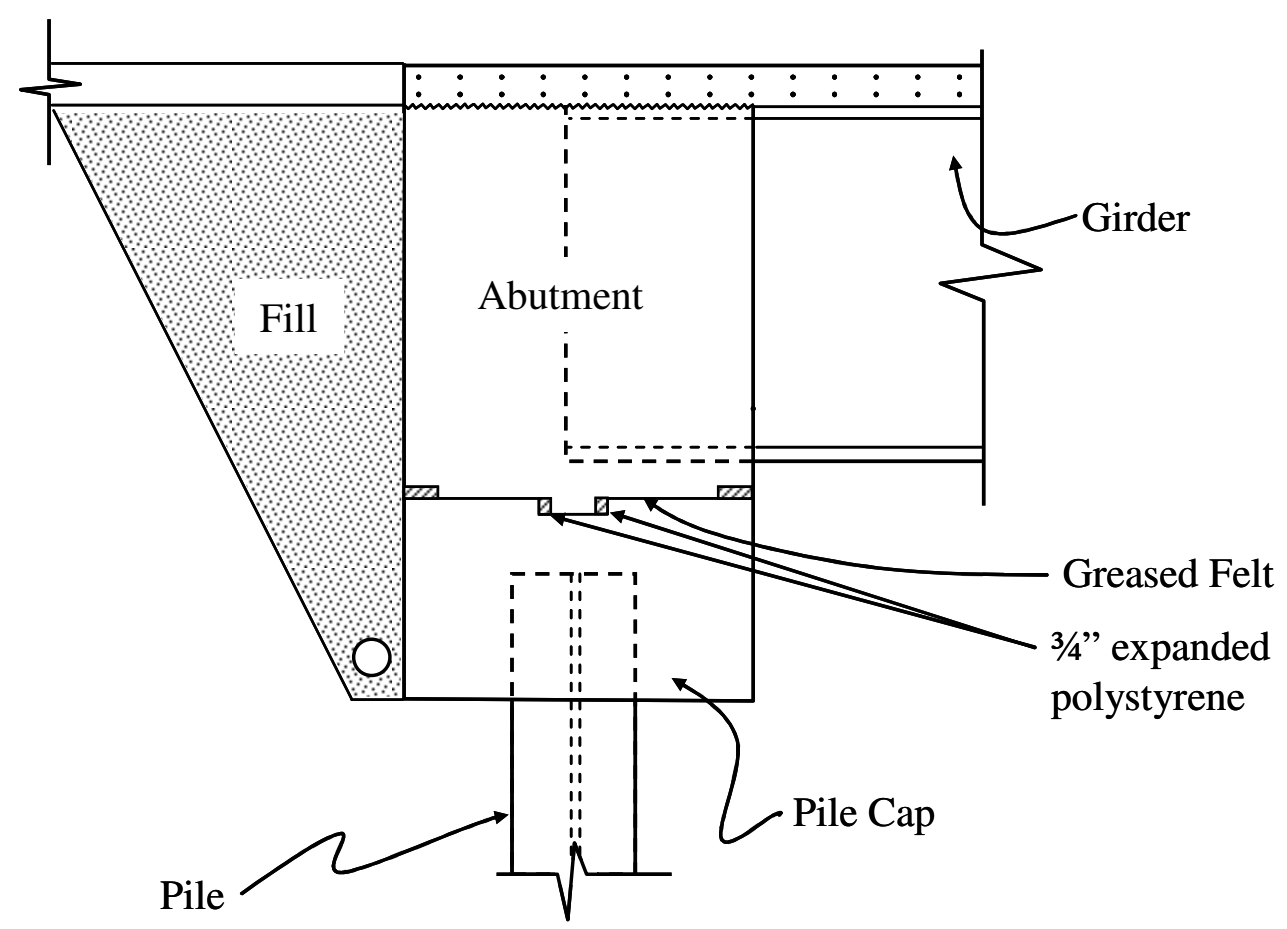

Figure 4.20: SR 18 Semi-Integral Abutment Schematic

The SR 18 bridge experienced a temperature change of $-54^{\circ} \mathrm{F}$ between Day 0 and Day 100 (Figure 4.21). This temperature change results in a strain of $324 \mu \varepsilon\left(\alpha_{t}=\right.$ $6.0 \times 10^{-6} /{ }^{\circ} \mathrm{F}$ ), which over the length of the $123 \mathrm{ft}$ span would be equivalent to $0.48 \mathrm{in}$. of total bridge contraction. Strain in the top flange of the girder between Day 0 and Day 100 increased in tension by $177 \mu \varepsilon$ which indicates only 0.22 in. of contraction was allowed (Figure 4.22).

After Day 100, the bridge began expanding as temperatures steadily increased (Figure 4.21). By Day 174, temperatures in the bridge were the same as those at the time of casting. Between Days 100 and 174, compressive strain in the girder increased by only $41 \mu \varepsilon$. As temperatures continued to increase beyond Day 174 until reaching a seasonal maximum on Day $274\left(\Delta \mathrm{T}=42^{\circ} \mathrm{F}\right)$, compressive strain in the girder increased by $36 \mu \varepsilon$. Considering linearity from the previous measured increase of $41 \mu \varepsilon$ over $54^{\circ}$ $\mathrm{F}$, for a temperature change of $42^{\circ} \mathrm{F}, 32 \mu \varepsilon$ is estimated. Therefore, it is likely that the backfill provided resistance to expansion of the bridge as soon as temperatures began increasing on Day 100.

The increase in strain measured between Days 100 and 174 is not equivalent to the $177 \mu \varepsilon$ experienced by the deck during the initial contraction phase (Days 0 - 100), it is also noted that the strain gages do not appear to provide consistent measurements until after Day 50. Thus, the change in strain between Day 100 and Day 174 may provide a better estimate of the restraint provided during the contraction phase of the bridge, assuming relatively little resistance to expansion by the backfill during this time. As girder strains measured on the SR 23 did not exhibit a significant change in strain until expansion beyond the initial temperature, this assumption is considered reasonable. 
Therefore, based on the change in strain measured between Days 100 and 174, the bridge underwent approximately 0.42 in. of contraction. Thus, the bridge was only restrained by $13 \%$ during the contraction phase.

As the temperature increased by $42^{\circ} \mathrm{F}$ between Days 174 and 274, the girder would experience $252 \mu \varepsilon$ if fully restrained. This temperature change would be equivalent to $0.37 \mathrm{in}$. of total bridge expansion during this time. As an increase of only $36 \mu \varepsilon$ in compressive strain was measured in the girder between Days 174 and 274, the girder is considered to be restrained by $14 \%$ during the expansion phase.

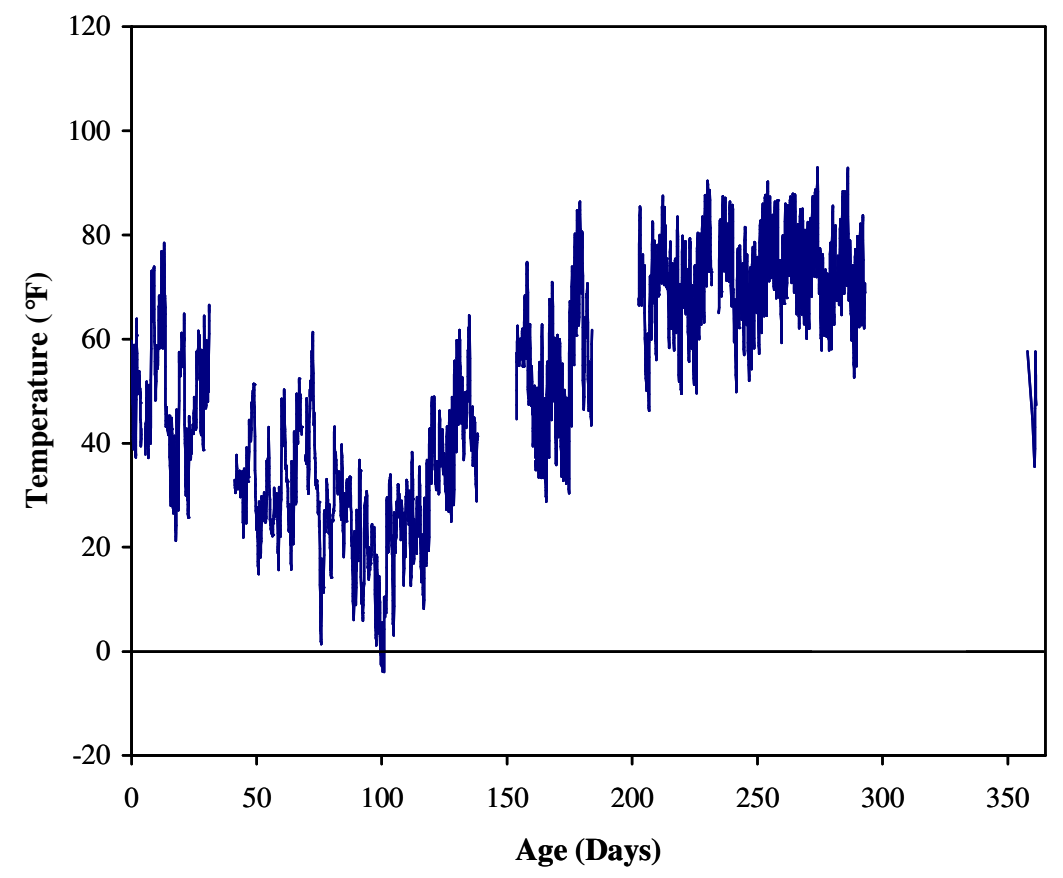

Figure 4.21: SR 18 Bridge Temperatures (Year One) 


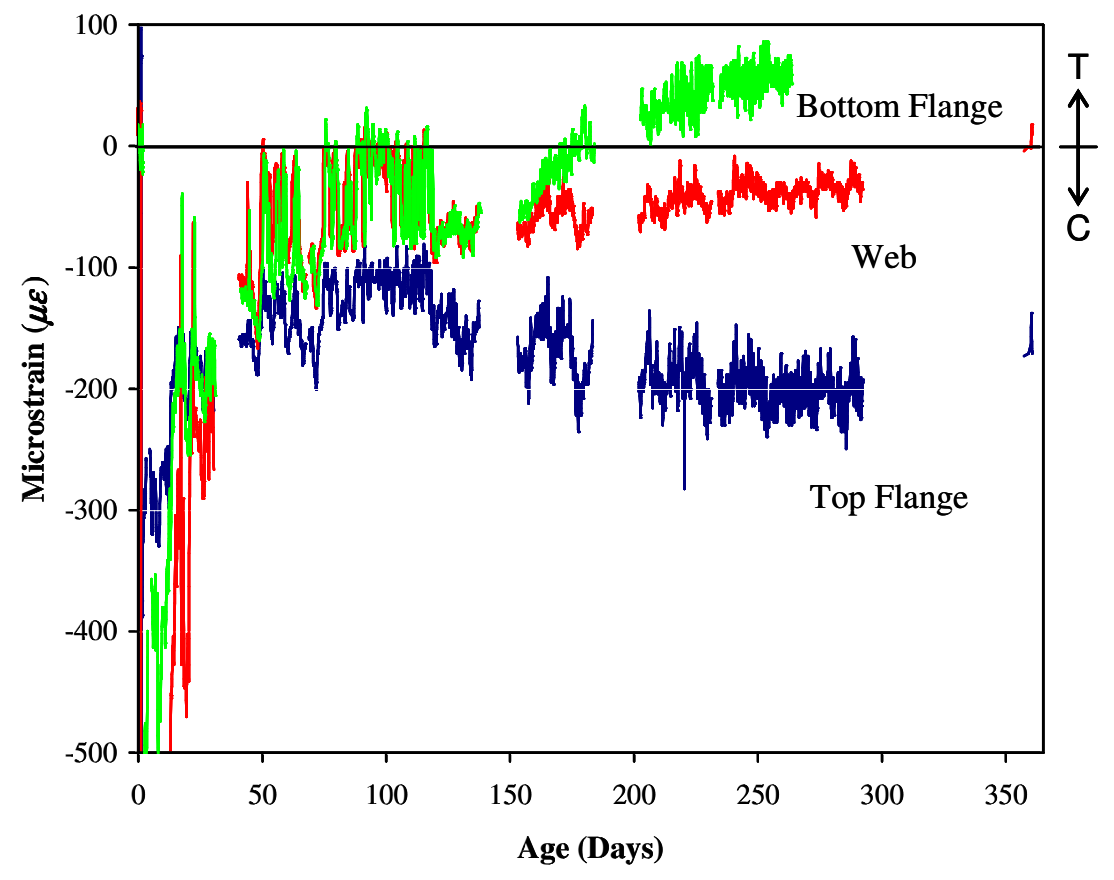

Figure 4.22: SR 18 Girder Strains 


\section{CHAPTER 5 ANALYTICAL MODEL}

\subsection{Overview}

An analytical model was developed to evaluate the influence of various design characteristics on the behavior a bridge deck with and without cracks. As the effect of both the amount and spacing of reinforcement in a bridge deck is of particular interest in this study, a three dimensional model was needed to account for the effect of the spacing of the reinforcement and to account for the existence of a crack in the bridge deck. Furthermore, the model needed to simulate the behavior of a deck constructed composite with the bridge girders.

\subsection{Model Validation and Calibration}

Data from laboratory studies performed by Blackman (2002) and Radabaugh (2001) were used to calibrate the analytical model. The sensitivity of the model to the applied shrinkage profile and the method of connecting the deck to the girders was evaluated considering these studies.

\subsubsection{Model Characteristics}

A simple, finite element model was developed using ANSYS (SAS 2004) to simulate the behavior of the restrained shrinkage specimens studied by Radabaugh (2001). The model was developed considering the work of Tarhini and Frederick (1992), who modeled the deck with a single layer of solid elements and the girders with plate elements. Instead of modeling the deck as a single layer of solid elements, four layers of solid elements were used to provide a better estimate of the variation of the deck behavior through its depth. The deck model is illustrated in Figure 5.1. Reinforcement was modeled discretely using 1D LINK8 elements and shared nodes with the concrete deck elements. The deck was modeled using 8-node SOLID45 elements. The girders were modeled using 4-node SHELL63 elements. 

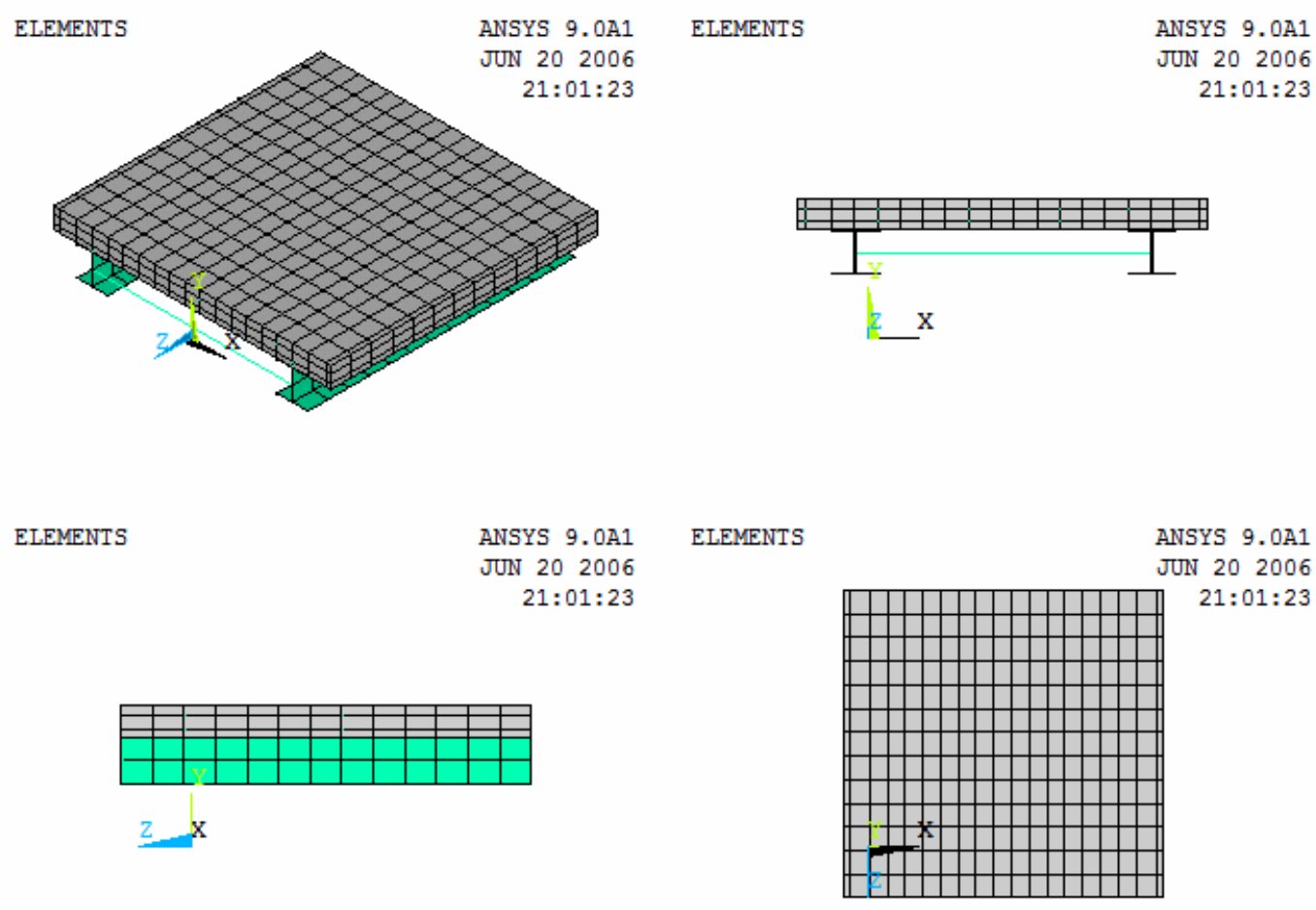

Figure 5.1: ANSYS Model Restrained Shrinkage Specimen

The deck was discretized into elements 3 in. wide by 2 in. high and 2 in. long. A fine mesh was used for the deck for two reasons: (1) to ensure that all nodes in the deck are not connected to reinforcement elements across the width of the deck and (2) to localize cracks in the deck model. As a result of reinforcement elements sharing the same nodes as concrete elements along the length of the bridge deck, compatibility between the reinforcement and the concrete is maintained in an uncracked condition. Thus, as shrinkage is applied to the model, shrinkage in concrete elements which are attached to reinforcement elements is resisted by the reinforcement elements because the reinforcement does not shrink. For a coarse mesh, wherein nodes are only placed along the lines of reinforcement, the concrete is completely restrained across the width of the deck by the reinforcement, and the model overestimates stresses in the bridge deck.

In many cases observed in the field studies, strains in the reinforcement did not exhibit large increases in tensile strain when cracks occurred in the deck unless the gages were in close proximity to the crack. Instrumentation located as close as $12 \mathrm{in}$. from cracks did not exhibit significant changes in strain as a result of crack formation. This behavior indicates that cracking in bridge decks is a highly localized event. A crack is introduced to the concrete model by assigning zero stiffness to concrete elements along the location of a crack. This method effectively smears the crack over the width of the element. Thus, in a finely meshed model, the crack is smeared over small elements and modeled as a localized phenomenon. Furthermore, the length over which slip between the reinforcement element and the concrete occurs is implicitly defined by the length of the concrete element. Thus, the slip length in the model is equal to $2 \mathrm{in}$. 
Boundary conditions were applied to the girder model as illustrated in Figure 5.2. The deck elements were coupled to the deck every $12 \mathrm{in.} \mathrm{along} \mathrm{the} \mathrm{length} \mathrm{of} \mathrm{the} \mathrm{girder}$ analogous to the spacing of the shear connectors in the restrained shrinkage specimens. In addition, nodes across the width of the girder flange were coupled to adjacent nodes in the slab (Figure 5.3). Adjacent nodes were defined as slab nodes less than $0.21 \mathrm{in}$. from the respective girder nodes. Nodes in the girders at the interface between the slab and the girders were coupled in the UX, UY, and UZ degrees of freedom (DOFs) to adjacent nodes in the slab. The boundary conditions at the supports simulate the pin-roller support system used by Radabaugh (2001).

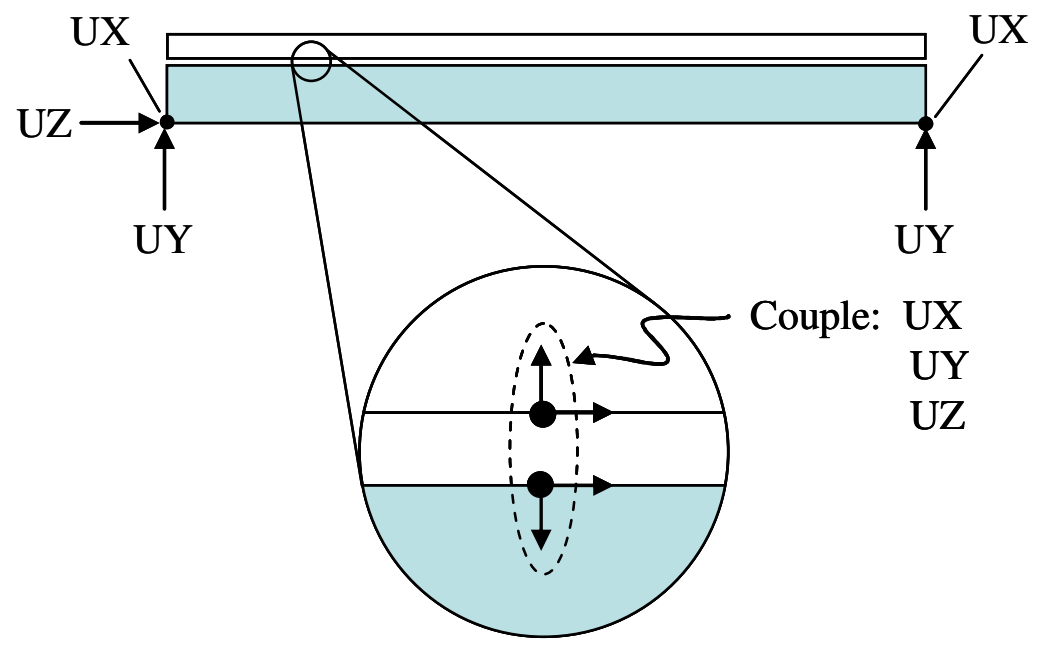

Figure 5.2: Model Boundary Conditions and Deck-Slab Coupling

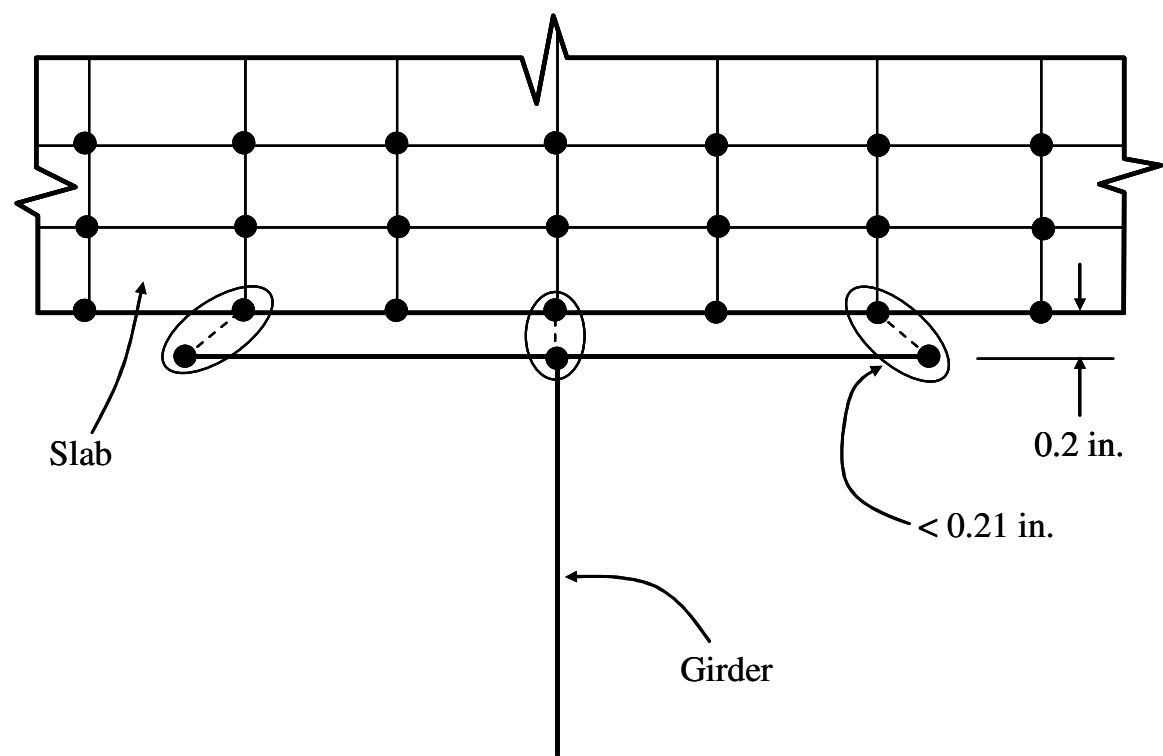

Figure 5.3: Slab-Girder Coupling Across Width of Top Flange Elements 


\subsubsection{Applied Shrinkage Model}

Shrinkage is applied to the model through the use of the coefficient of thermal expansion of the elements. A temperature body load is applied to the model that corresponds to the desired amount of free shrinkage, and the behavior of the model is evaluated. Furthermore, shrinkage gradients can be simulated through variation of the applied temperature through the depth of the slab. Thus, an estimate of the free shrinkage experienced by the slab as well as the variation of shrinkage with respect to deck thickness is needed to allow comparison of the performance of the model to the laboratory specimens.

\subsubsection{Estimation of Free Shrinkage}

While Radabaugh (2001) did not perform any free shrinkage measurements, the free shrinkage specimens tested by Blackman (2002) allow an estimation of the free shrinkage experienced by the restrained specimens to be made. The mix designs used for the respective investigations are compared in Table 5.1. The quantities of cement and aggregate are nearly identical; however, the concrete used by Blackman listed a lower water-cement ratio (w/c) than the concrete used by Radabaugh. It should be noted that Radabaugh did not specify whether or not water was added to the concrete at the time of placement. Blackman reported that 3 gallons of water were added when the concrete arrived at the lab, which increased the slump from 4 in. to 6.75 in., and included this amount in his reported amount of water (Table 5.1) (2002). The higher w/c ratio used by Radabaugh suggests that the restrained specimens experienced slightly more free shrinkage than the free shrinkage specimens constructed by Blackman. However, the higher slump reported by Blackman for similar cement and aggregate quantities indicates that the water/cement ratio was very similar if not higher. Based on this evaluation, it is expected that the free shrinkage in the Blackman specimens was the same or slightly greater than the free shrinkage in the Radabaugh specimens. 
Table 5.1: Comparison of Laboratory Study Mix Designs

\begin{tabular}{|c|c|c|}
\hline \multirow{2}{*}{ Material } & \multicolumn{2}{|c|}{ Quantities } \\
\cline { 2 - 3 } & Radabaugh (2001) & Blackman (2002) \\
\hline Cement & $659 \mathrm{lb} / \mathrm{yd}^{3}$ & $658 \mathrm{lb} / \mathrm{yd}^{3}$ \\
\hline Ash & None & None \\
\hline Micro-Silica & None & None \\
\hline Sand & $1220 \mathrm{lb} / \mathrm{yd}^{3}$ & $1280 \mathrm{lb} / \mathrm{yd}^{3}$ \\
\hline Stone & $1800 \mathrm{lb} / \mathrm{yd}^{3}$ & $1836 \mathrm{lb} / \mathrm{yd}^{3}$ \\
\hline Water & $292 \mathrm{lb} / \mathrm{yd}^{3}$ & $230 \mathrm{lb} / \mathrm{yd}^{3}$ \\
\hline Water Reducer & $13.2 \mathrm{oz} / \mathrm{yd}^{3}$ & $13 \mathrm{oz} / \mathrm{yd}^{3}$ \\
\hline W/C & 0.443 & 0.34 \\
\hline Slump & $4 \mathrm{in}$. & $6.75 \mathrm{in}$. \\
\hline
\end{tabular}

As described in Appendix A, Specimen 9 in the study by Blackman was constructed without reinforcement, SIP forms, or sealing. Furthermore, the surface area to volume ratio and thickness of this specimen are similar to the decks constructed by Radabaugh. Thus, strains measured in this specimen provide a reasonable estimate of the free shrinkage experienced by the restrained specimens. The strain from Specimen 9 is presented in Figure 5.4. It should be noted that the specimens by Blackman received a 1day wet-cure while the specimens by Radabaugh received a 4-day wet-cure. For the purposes of this discussion, shrinkage in Radabaugh's specimens is not considered to have occurred until after wet-curing had been discontinued on Day 4. As presented in Figure 5.5, it is evident that shrinkage strains do not develop until after wet-curing was completed.

Radabaugh focused his study on the behavior over the first 21 days. Therefore, the specimens are considered to have experienced only 17 days of shrinkage. Strains measured in the specimens by Blackman up to 17 days are of interest for comparison with Radabaugh's specimens. The free shrinkage measured by the embedded gage on Day 17 was $125 \mu \varepsilon$. The strain on the top surface at the same time was estimated as 177 $\mu \varepsilon$, while the strain on the bottom surface was $77 \mu \varepsilon$. Thus, the average of the three strains is calculated as $126 \mu \varepsilon$. 


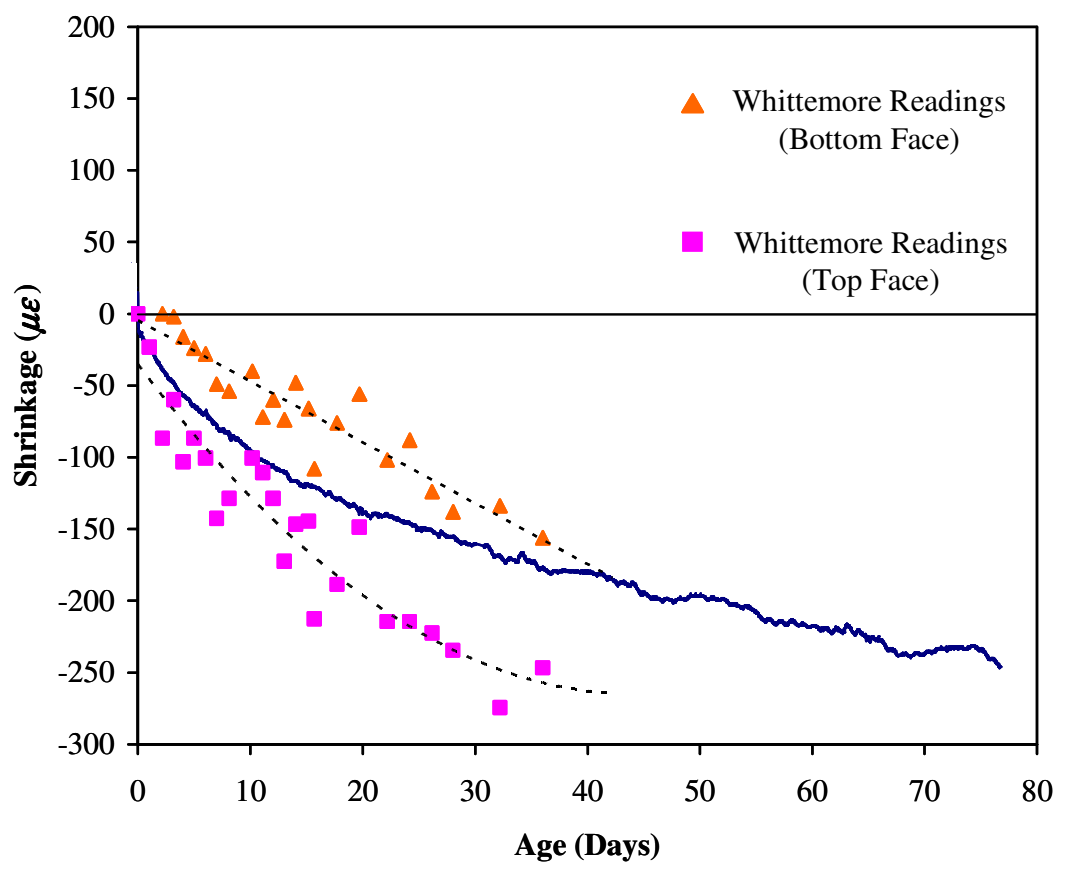

Figure 5.4: Free Shrinkage Strains (Specimen 9) (Blackman 2002)

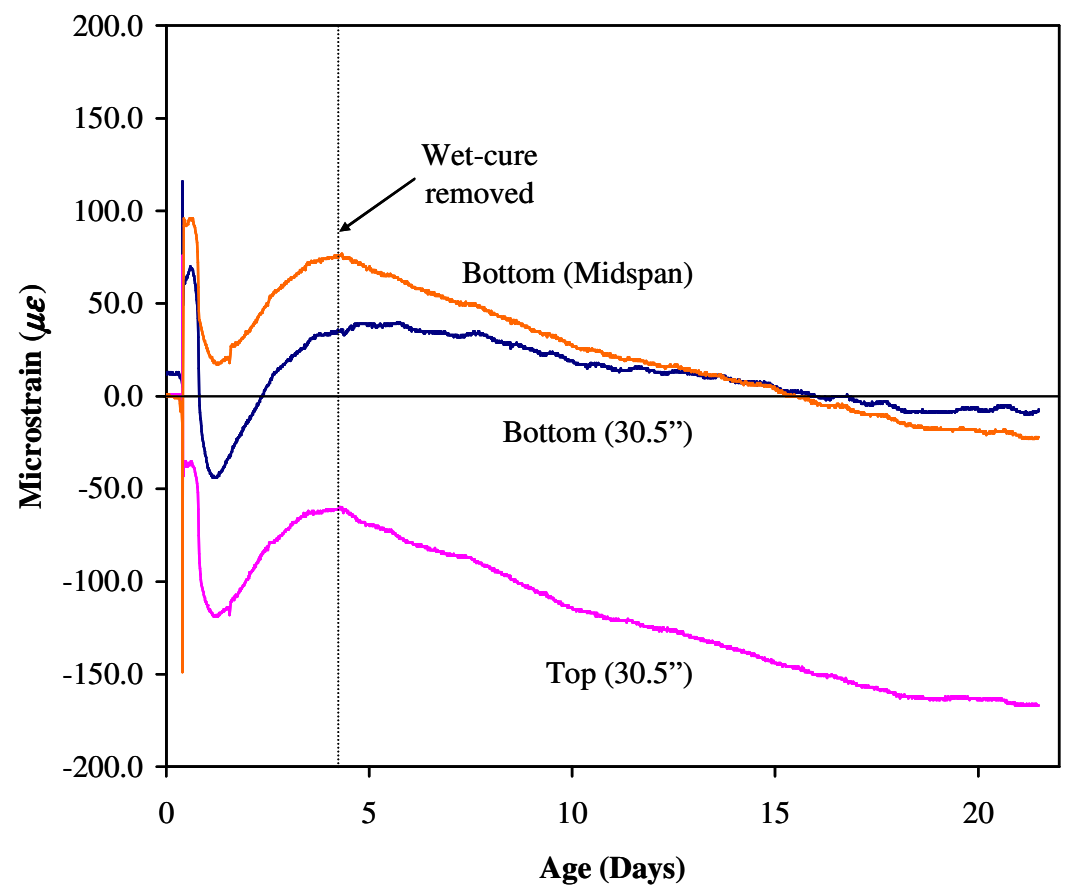

Figure 5.5: As-Built Specimen Reinforcement Strain Compared to Wet-Cure Duration 


\subsubsection{Estimation of Shrinkage Gradient}

Specimen 8, similar to Specimen 9 in the Blackman study (2002), was constructed without reinforcement or SIP forms. However, unlike Specimen 9, Specimen 8 was sealed on one side to simulate the presence of a SIP form, which would prevent moisture loss, but without the accompanying restraint of the form. Strain data from Specimen 8 is presented in Figure 5.6. On Day 17, the concrete strain was $90 \mu \varepsilon$ at mid-depth and 167 $\mu \varepsilon$ on the free surface. To estimate the variation through the thickness of the specimen, strain at the sealed face was assumed to be zero. Linear regression through these points was then used to establish a linear strain profile (Figure 5.7). The calculated strains were divided by the concrete element coefficient of thermal expansion $\left(6.0 \times 10^{-6} /{ }^{\circ} \mathrm{F}\right)$ to determine temperature loads for application to the model.

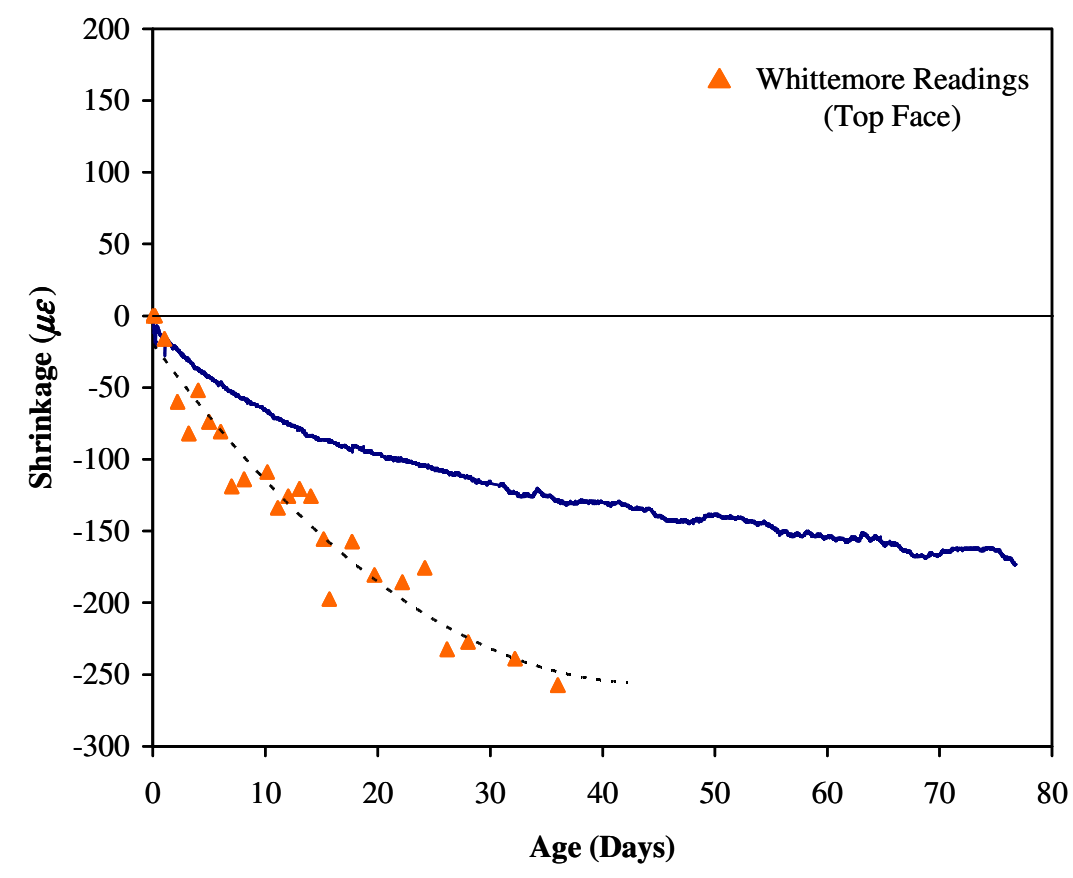

Figure 5.6: Free Shrinkage Strains (Specimen 8) (Blackman 2002) 


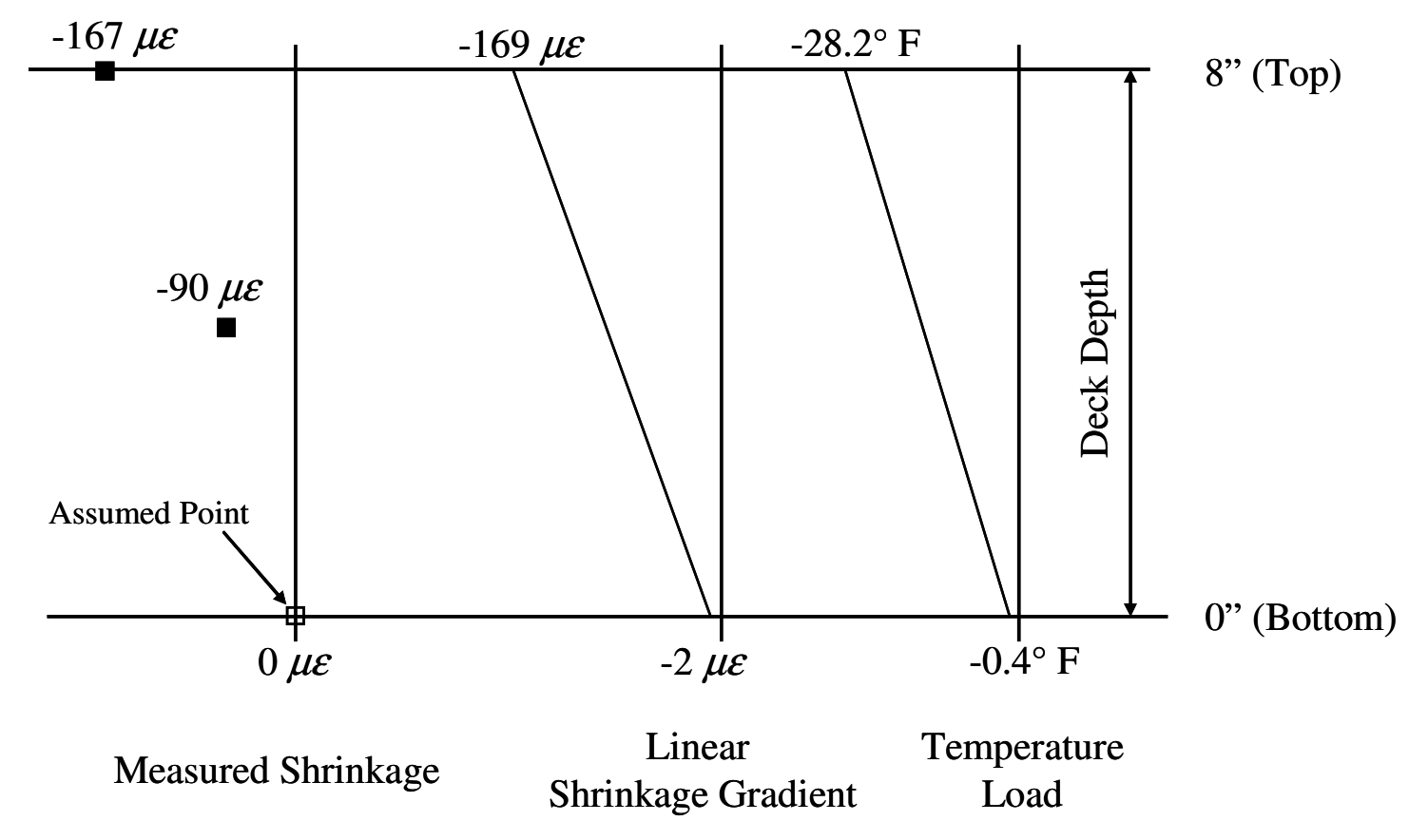

Figure 5.7: Linear Shrinkage Model

\subsubsection{Material Properties}

The material models used in the finite element analysis are summarized in Table 5.2. The modulus of elasticity of the concrete is based on 57,000 $\sqrt{f_{c}^{\prime}}$ (ACI 2005) where $f_{c}^{\prime}=4000$ psi. Steel was assigned a coefficient of thermal expansion of $0 /{ }^{\circ} \mathrm{F}$ to simulate the absence of shrinkage in the steel as temperature loads are applied.

Table 5.2: Model Material Properties

\begin{tabular}{|c|c|c|}
\hline \multirow{2}{*}{ Material Property } & \multicolumn{2}{|c|}{ Material } \\
\cline { 2 - 3 } & Steel & Concrete \\
\hline $\begin{array}{c}\text { Modulus of Elasticity, } E \\
(\mathrm{psi})\end{array}$ & $29.0 \times 10^{6}$ & $3.61 \times 10^{6}$ \\
\hline $\begin{array}{c}\text { Coefficient of Thermal } \\
\text { Expansion, } \alpha_{t}\left(/{ }^{\circ} \mathrm{F}\right)\end{array}$ & 0.0 & $6.0 \times 10^{-6}$ \\
\hline
\end{tabular}

\subsubsection{Comparison of Model to Restrained Shrinkage Specimens}

A static, linear-elastic analysis was performed using ANSYS (SAS Inc. 2004). Both uniform and linear concrete shrinkage profiles were evaluated, and the results were 
compared to the measurements taken from the specimens investigated by Radabaugh. The uniform shrinkage strain was estimated as the average strain discussed in Section 5.2.2.1 $(126 \mu \varepsilon)$. The linear shrinkage profile was estimated as previously shown in Figure 5.7. The concrete shrinkage strains measured at midspan and at $30.5 \mathrm{in}$. from midspan (Figure 5.8) in the as-built specimen and the wood form specimen are presented in Figure 5.9 and Figure 5.10, respectively. Strain in the concrete increases (swelling) while wet curing on the decks was in place until Day 4 when curing was discontinued. After that time, shrinkage occurs and compressive strain in the concrete increases. Thus, the shrinkage in the specimens is calculated as the difference between the strain at the time curing was discontinued and the final strain measurement on Day 21.

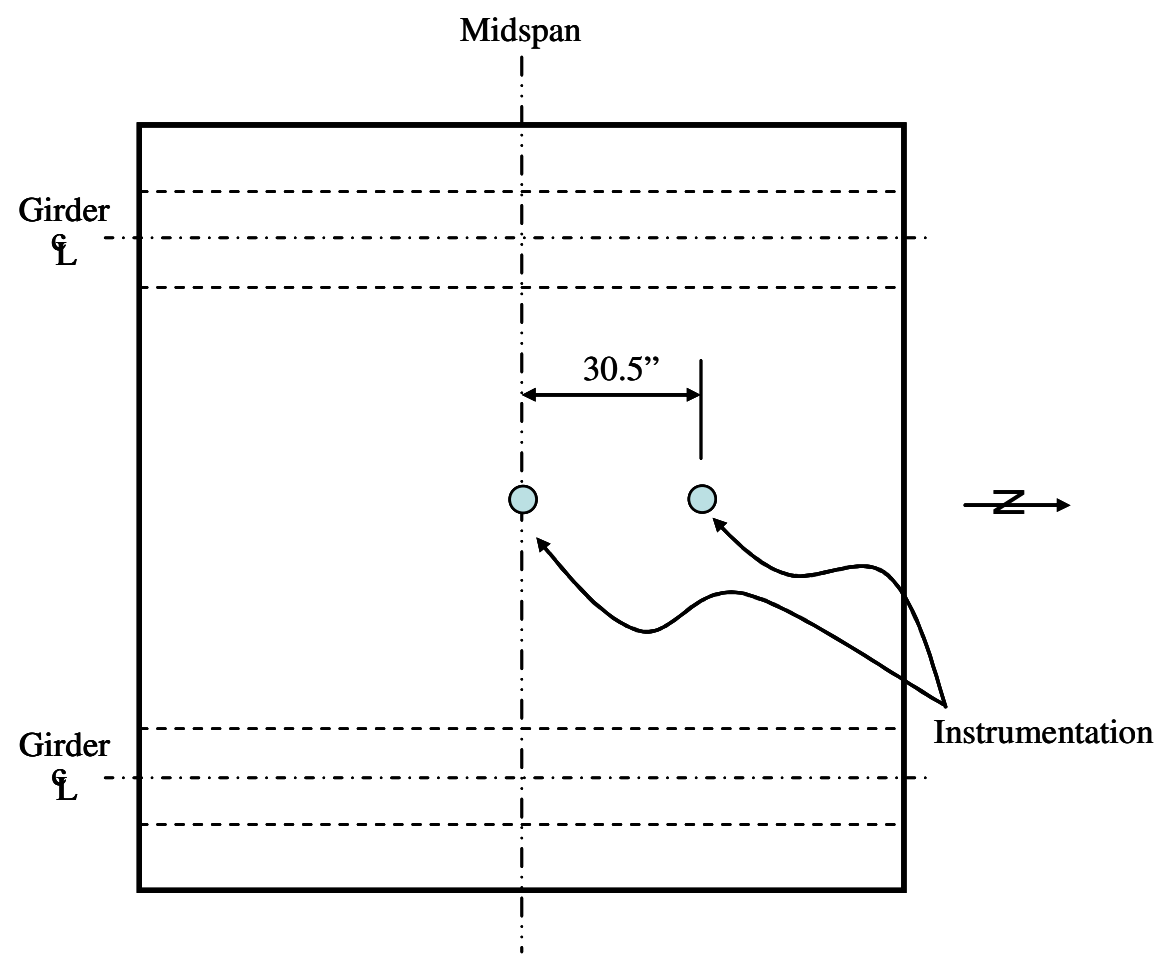

Figure 5.8: Center Slab Instrumentation Locations 


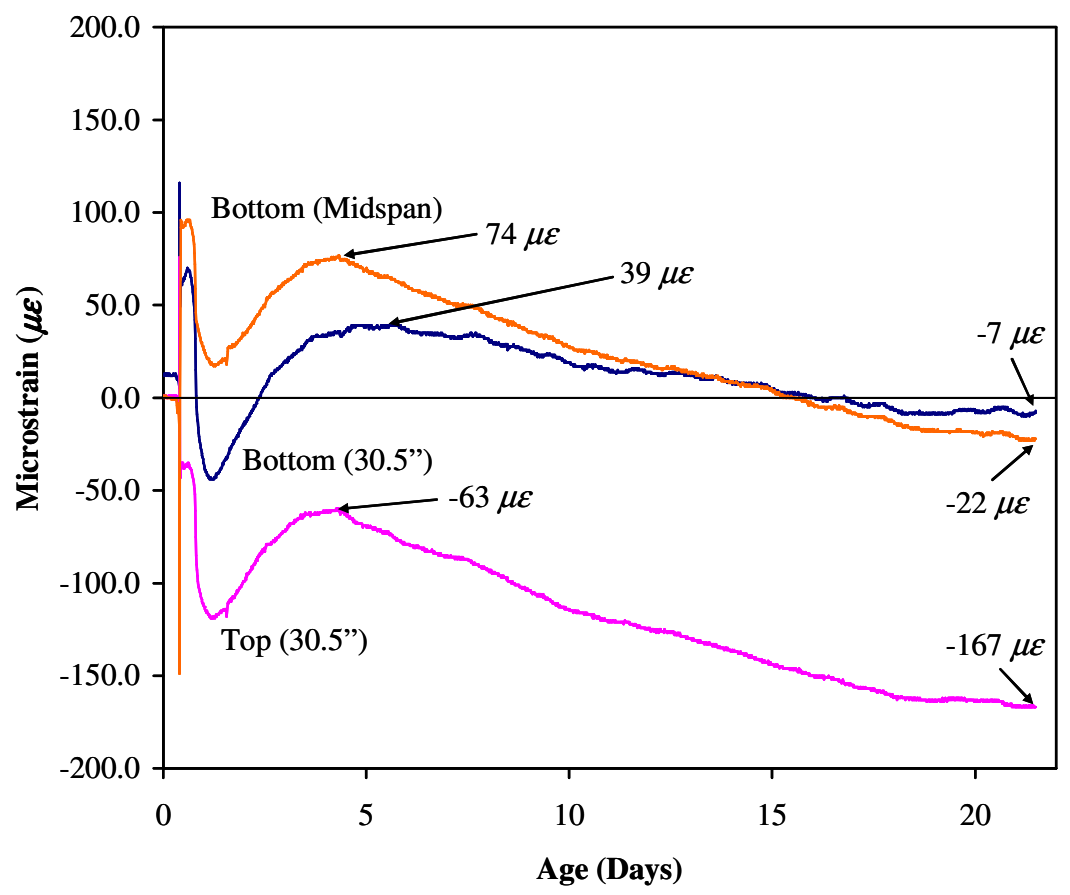

Figure 5.9: Reinforcement Strains (As-Built Specimen)

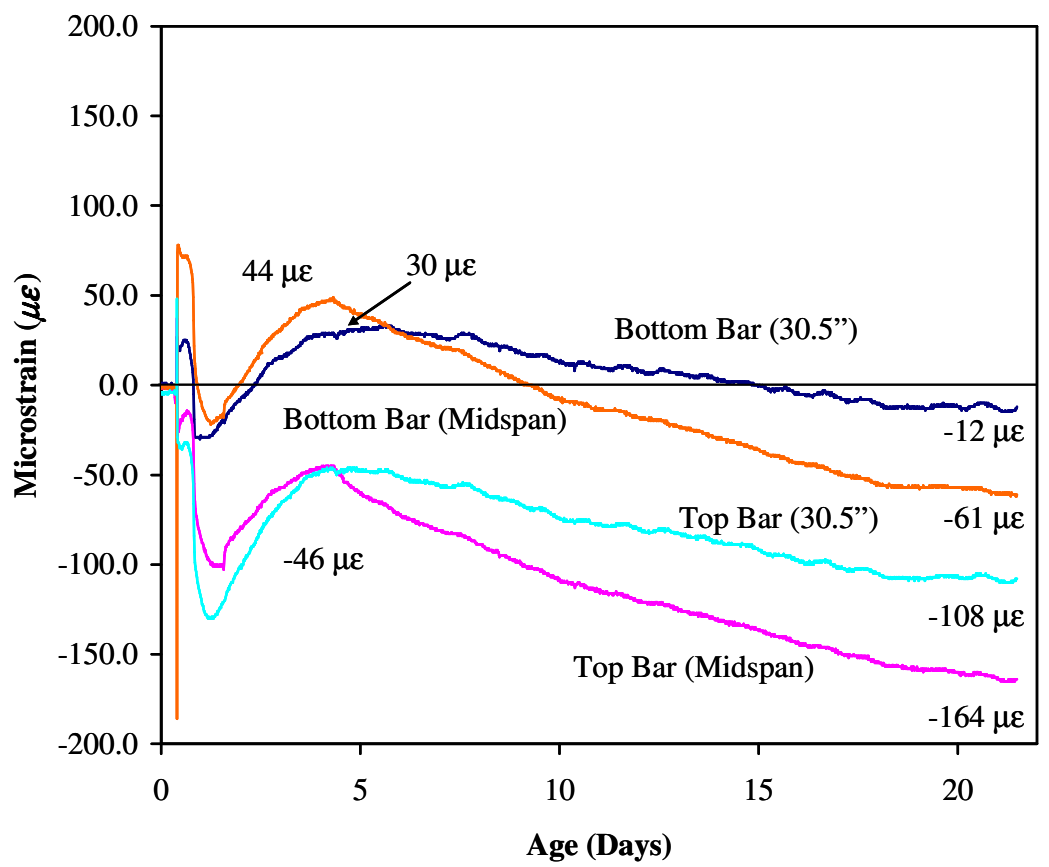

Figure 5.10: Reinforcement Strains (Wood Forms) 
The measured strains from the laboratory specimens are compared to the results of the finite element analysis in Table 5.3. The strain gage installed on the top reinforcement at midspan in the as-built specimen was lost and thus the ratio of top and bottom reinforcement strains could not be evaluated. However, strains calculated for the model with linear shrinkage show good agreement with the measured reinforcement strains in the as-built specimen. While the model slightly overestimates strain at points away from midspan, the relative strain between top and bottom reinforcement is fairly consistent. The ratio of bottom to top reinforcement strain measured $30.5 \mathrm{in}$. from midspan was 2.3 between the end of curing and Day 21. By comparison, the model estimates a ratio of 1.9 between the top and bottom reinforcement strains at the same location. The linear model also provides a reasonable estimate of the reinforcement strains in the free shrinkage specimen. While the model overestimates the strains measured 30.5 in. from midspan by $83 \%$ in the top reinforcement and $45 \%$ in the bottom reinforcement, the model only slightly underestimates strains at midspan by $12 \%$ and $34 \%$ in the top and bottom reinforcement, respectively. However, the model with linear shrinkage overestimates the ratio of strain between the top and bottom reinforcement as 1.5 at midspan and 1.9 at $30.5 \mathrm{in}$. from midspan. These ratios were measured as 1.2 at midspan and 1.1 at $30.5 \mathrm{in}$. from midpan in the free shrinkage specimen.

Table 5.3: Comparison of Reinforcement Strains

\begin{tabular}{|c|c|c|c|c|c|}
\hline \multirow{2}{*}{ Location } & \multirow{3}{*}{ Bar } & \multicolumn{4}{|c|}{ Shrinkage, Microstrain $(\boldsymbol{\mu \varepsilon})$} \\
\cline { 3 - 6 } & & \multicolumn{2}{|c|}{ Measured } & \multicolumn{2}{c|}{ Model } \\
\cline { 3 - 6 } & As-Built & Free Shrink & Uniform & Linear \\
\hline \multirow{2}{*}{ Midspan } & Top & -- & 118 & 118 & 103 \\
\cline { 2 - 6 } & Bottom & 96 & 105 & 100 & 69 \\
\hline \multirow{2}{*}{30.5 " from Midspan } & Top & 104 & 62 & 110 & 114 \\
\cline { 2 - 6 } & Bottom & 46 & 42 & 90 & 61 \\
\hline
\end{tabular}

The uniform shrinkage model significantly overestimates the reinforcement strain in both the as-built and free shrinkage (Teflon-coated wood form) specimens. However, closer inspection of the results given by the model reveals that the relative strain from top to bottom reinforcement compares well. The ratio of bottom to top reinforcement strain measured in the free shrinkage specimen was 1.1 at midspan and 1.5 at $30.5 \mathrm{in}$. from midpsan. The uniform shrinkage model estimates these ratios as 1.2 at both locations. In general, while the uniform shrinkage model overestimates the magnitude of the strains, it provides a good estimate of the relative behavior between the top and bottom reinforcement in Radabaugh's free shrinkage specimen. The linear shrinkage model provides a reasonable estimate of the magnitudes of strain experienced by both the asbuilt and free shrinkage specimens. However, the linear shrinkage model consistently overestimates the relative behavior of the top and bottom reinforcement.

The measured deflections on Day 21 are compared to the estimated deflections calculated by the model in Table 5.4. The measured deflections presented are those which occurred from the time of casting, and therefore do not account for initial positive 
(upward) deflections that were measured up until wet-curing was discontinued. However, the model deflections were offset to match the time and shrinkage at which wet-curing was removed and correspondingly negative (downward) deflections began. The model with linear shrinkage shows close agreement with the deflections measured on the as-built specimen. While the uniform shrinkage model gives a reasonable estimate of the girder deflection, the model significantly underestimates the slab center deflection for both free and as-built specimens.

Table 5.4: Comparison of Deflections

\begin{tabular}{|c|c|c|c|c|}
\hline \multirow{2}{*}{ Location } & \multicolumn{4}{|c|}{ Deflection (in.) } \\
\cline { 2 - 5 } & \multicolumn{2}{|c|}{ Measured } & \multicolumn{2}{c|}{ Model Gradient } \\
\cline { 2 - 5 } & As-Built & Free Shrink & Uniform & Linear \\
\hline Girder Midspan & -0.012 & -0.020 & -0.009 & -0.011 \\
\hline Slab Center & -0.037 & -0.044 & -0.009 & -0.028 \\
\hline
\end{tabular}

A time-dependent shrinkage model was developed based on the shrinkage measured in Blackman Specimen 8 (2002). Blackman measured strains in the free shrinkage specimens for 77 days, and thus a time dependent shrinkage model was developed for this period of time based on the shrinkage measured with the embedded concrete gage (Figure 5.6). This instrument was used because of the relative stability of the measurements compared to the measurements made using the Whittemore points on the free surface. The linear shrinkage over the first 77 days is presented in Figure 5.11. The gradient is plotted against the measured concrete shrinkage from Specimen 8 for comparison.

Based on this shrinkage model, the time-displacement behavior of the restrained specimens from the study performed by Radabaugh was estimated. Figure 5.12 presents a comparison of the displacements measured at the center of the slab and midspan of the girder versus the displacements estimated by the model. The displacements estimated by the model are offset to correspond with the time that curing was discontinued and shrinkage was measured in the specimen. The model provides a good estimate of the deflection of the specimen over the period of measurement (up to Day 21) and provides a reasonable estimate of deflections at Day 77. 


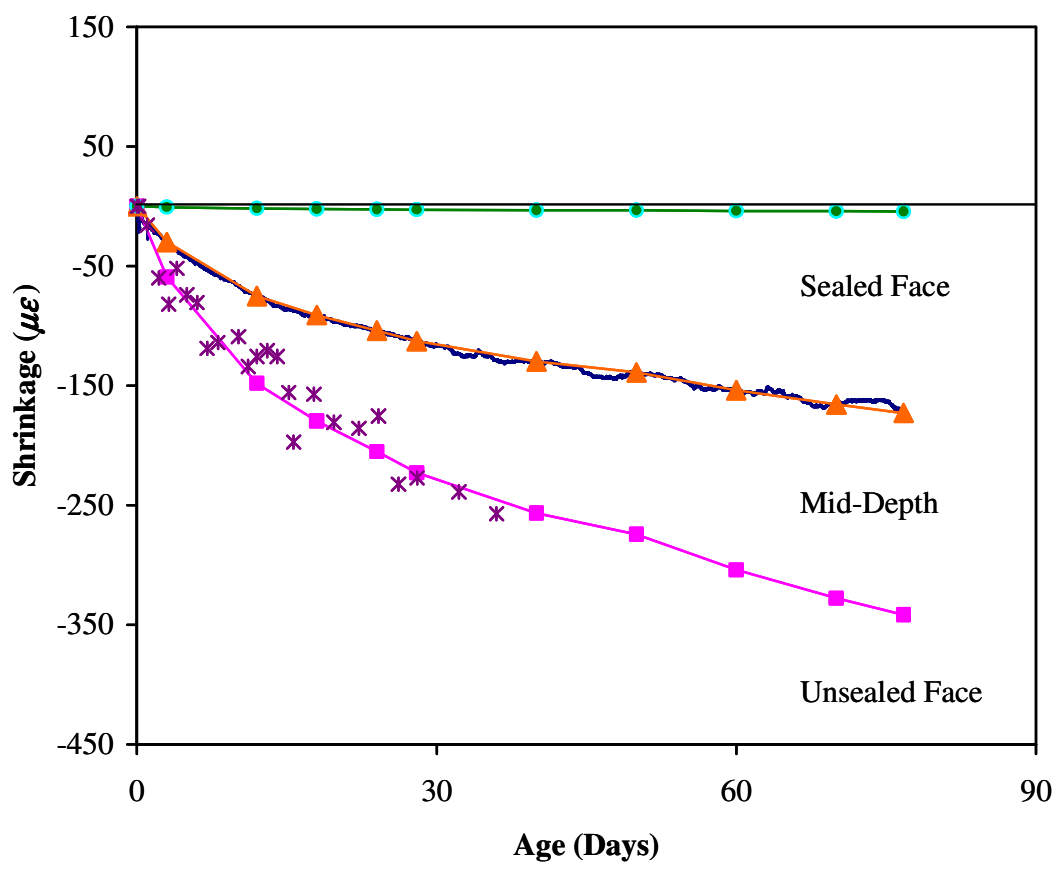

Figure 5.11: Linear Shrinkage Model

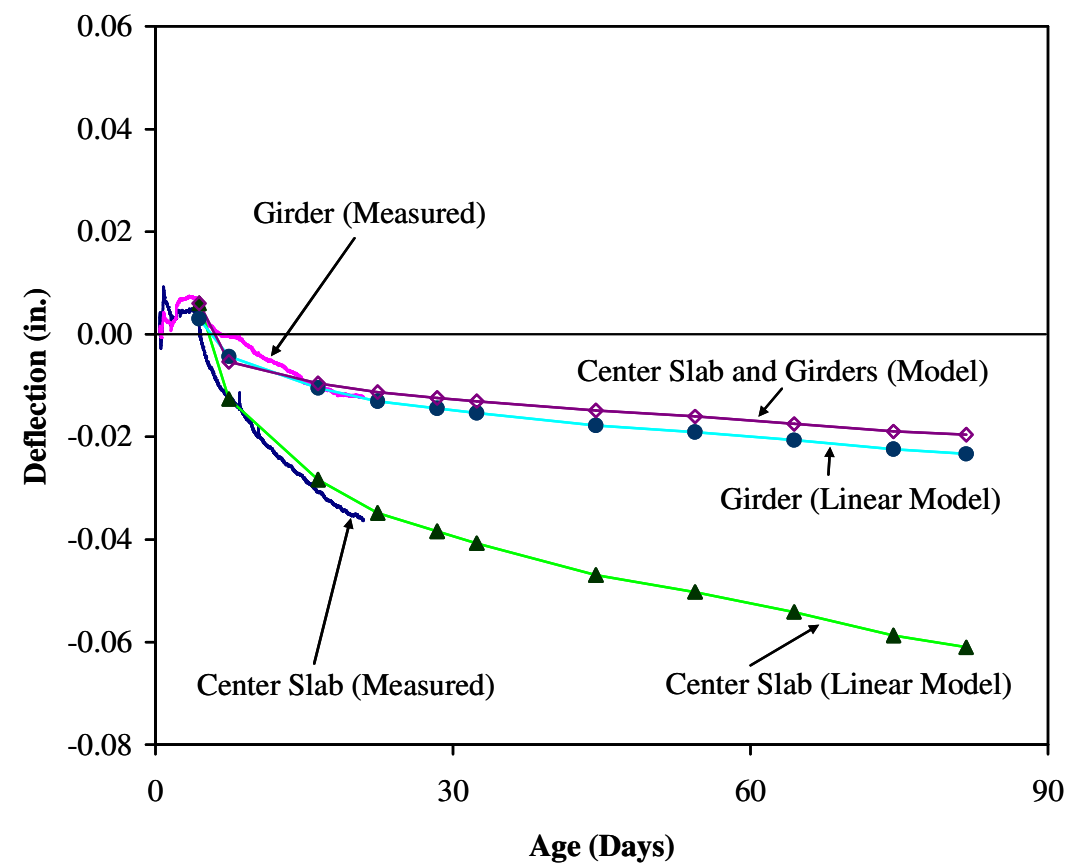

Figure 5.12: Comparison of Deflections (As-Built Specimen to Linear Shrinkage) 
The agreement of the model using linear shrinkage with both the measured reinforcement strains and the measured displacements indicates that it provides a reasonable estimate of the lab specimen considering both local and global behavior. When uniform shrinkage is used, the model provides a reasonable estimate of the reinforcement strain when compared to the measured strains in the free shrinkage (wood forms) specimen. However, the model underestimates the deflections of both the girders and the center slab when uniform shrinkage is applied, as presented in Figure 5.13.

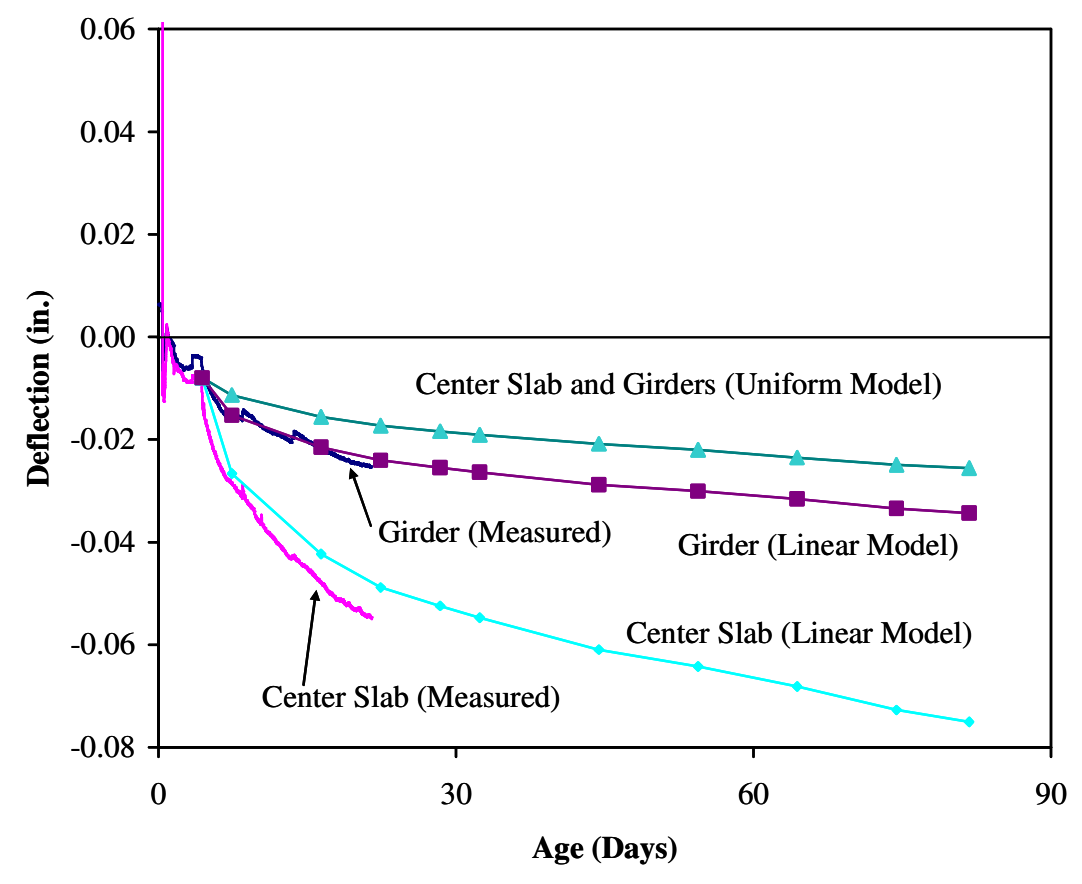

\section{Figure 5.13: Comparison of Deflections (Wood Form Specimen to Uniform Shrinkage)}

Radabaugh notes that the girders used for the laboratory specimens were chosen such that the width of the top flange corresponded with the width of the girder top flanges of the I-65 bridge girders (2001). Otherwise, the girders are much smaller and more flexible than those actually used in the field. As previously discussed, the model with linear shrinkage provides as reasonable estimate of the relative strain between top and bottom reinforcement in the as-built specimen. It was also noted that when uniform shrinkage was used, the model overestimates the strain in the bottom reinforcement. However, if the depth of the girders is increased in the model, it is observed that the model with uniform shrinkage shows closer agreement to the model with linear shrinkage with respect to the ratio of strains between top and bottom reinforcement (Figure 5.14). Thus, while the model with uniform shrinkage overestimates strain in the bottom reinforcement relative to the case when linear shrinkage is used, as girder depth in the model is increased, the difference between the ratios presented in Figure 5.14 decreases from $26 \%$ to $10 \%$ for a 40 in. girder and $9 \%$ for a 100 in. girder. 


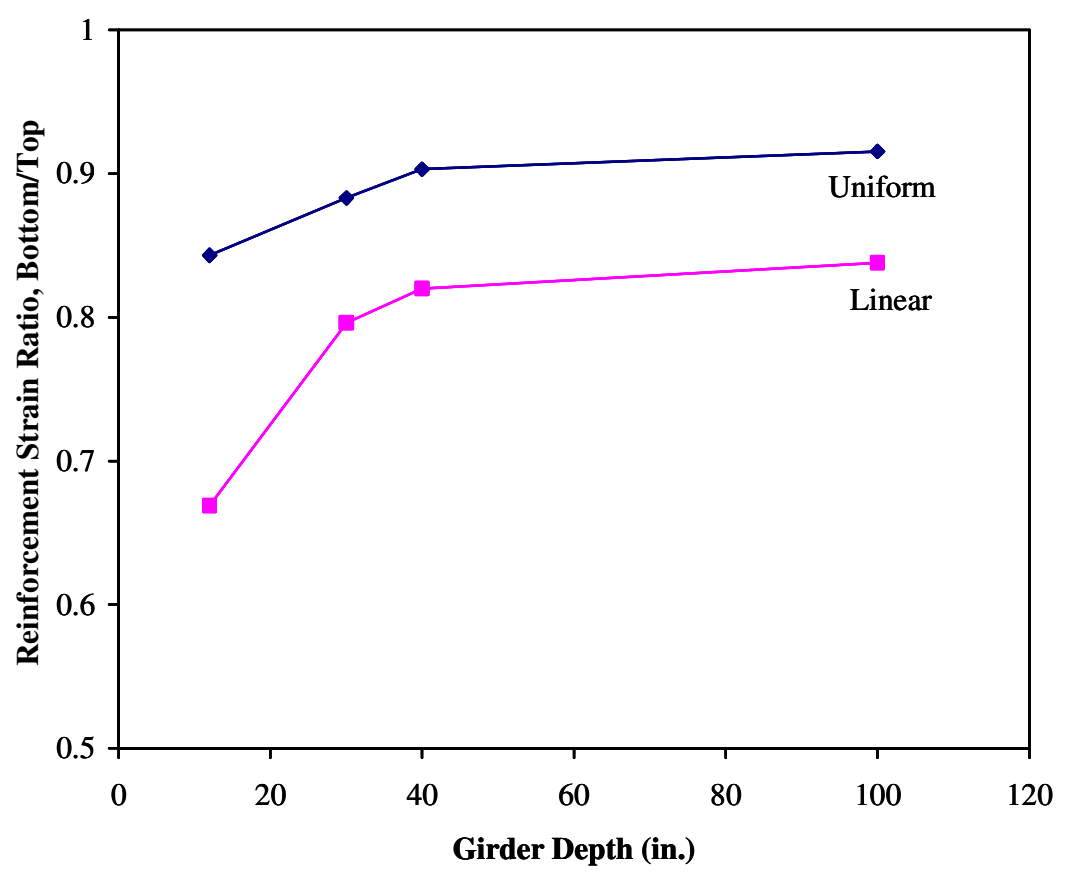

Figure 5.14: Ratio of Reinforcement Strains versus Girder Depth

\subsection{Bridge Model Characteristics}

Based on the results of the analytical model developed for the specimens tested by Radabaugh, a finite element model was developed using ANSYS (SAS 2004) to simulate the behavior of a slab-on-girder bridge undergoing volumetric change. As shown in Figure 5.15, the girder is modeled as simply supported using boundary condition restraints for the UX, UY, and UZ degrees of freedom. 


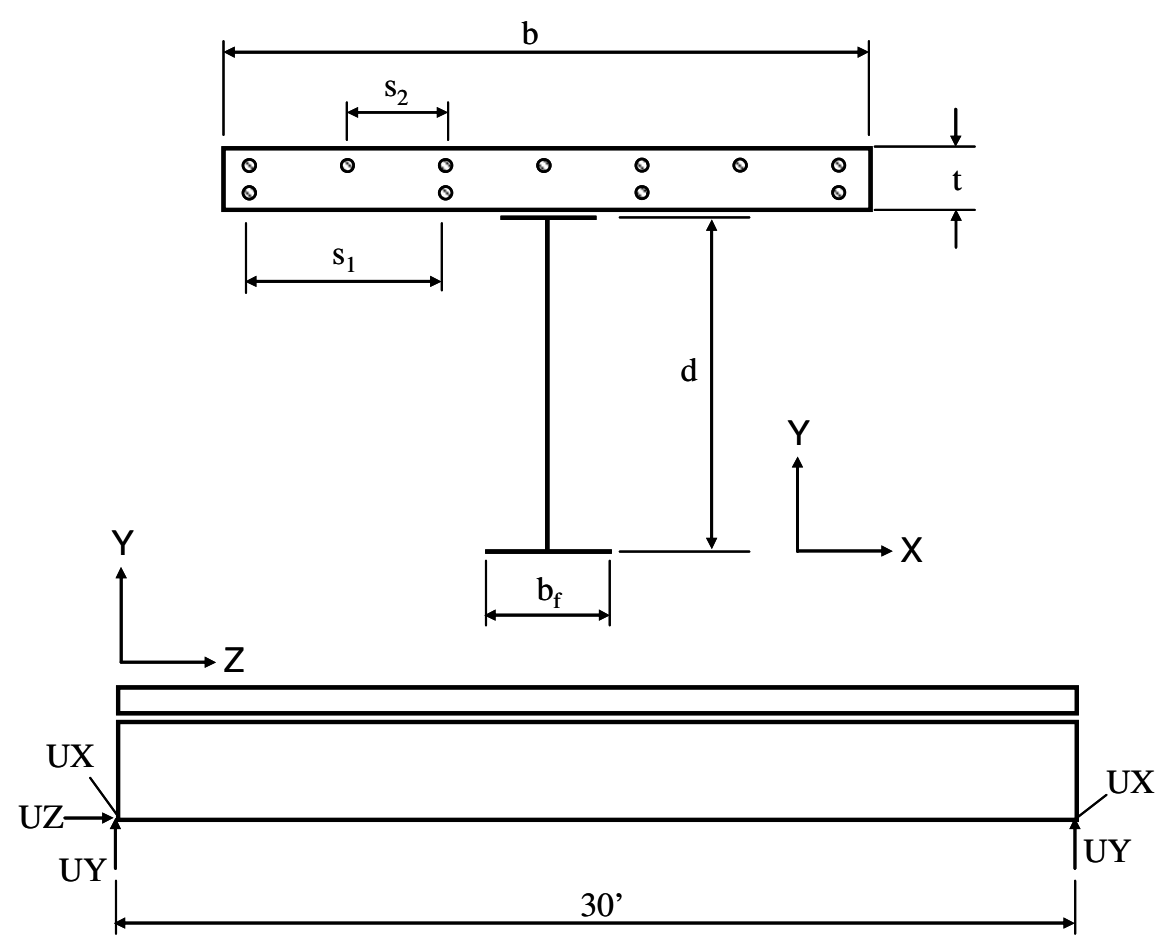

Figure 5.15: Model Schematic

As with the model for the laboratory specimens, reinforcement was modeled discretely using 1D LINK8 elements and shared nodes with the concrete deck elements. The deck was modeled using 8-node SOLID45 elements. The deck was discretized in the same manner as the laboratory model, using elements 3 in. wide by 2 in. high and 2 in. long. The girder was modeled using 4-node SHELL63 elements. The deck was coupled to the girder using the same method as for the laboratory model. Deck nodes were coupled every $12 \mathrm{in}$. along the length of the deck, which corresponds to the spacing of shear connectors installed on girders instrumented in the field studies. Symmetry boundary conditions were applied to the slab along the middle of the bays between girders as illustrated in Figure 5.16. 


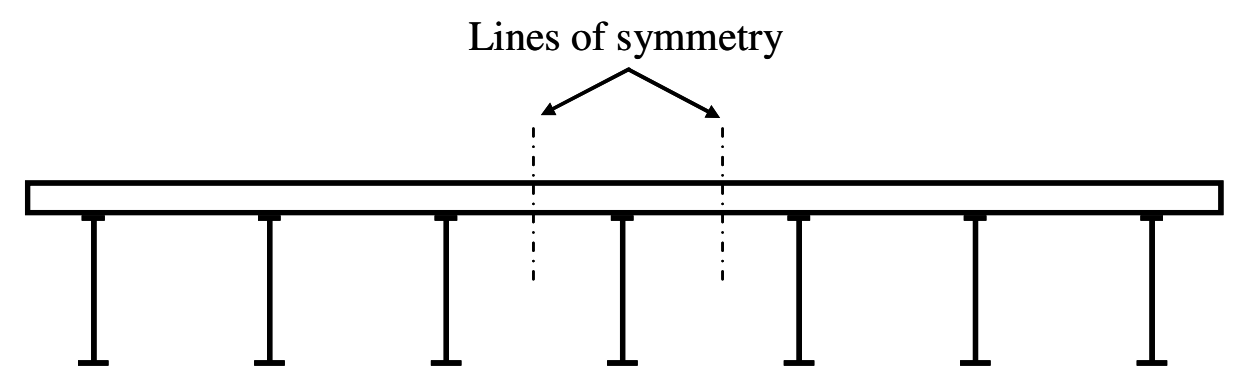

a) Real Structure

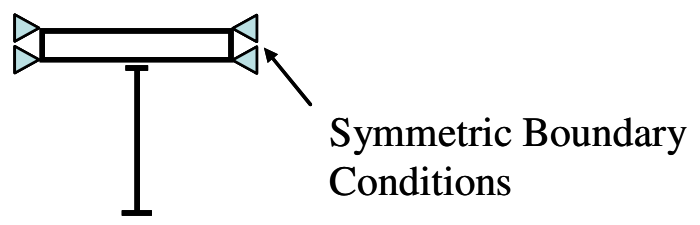

b) Modeled Structure

Figure 5.16: Modeled Section of Actual Structure

A series of static, linear-elastic analyses were performed using the model, as illustrated in Figure 5.17. The model was analyzed initially as uncracked with a total free shrinkage load of $1000 \mu \varepsilon$ applied. Stresses calculated by the model with this loading were then analyzed, and the amount of shrinkage required to initiate cracking in the deck was calculated. Cracking was assumed to occur when the stress in the deck exceeded the tensile strength of the concrete which was considered as $f_{t}=6 \sqrt{f_{c}^{\prime}}$. The model was subsequently reanalyzed with a single crack introduced at midspan with a free shrinkage load of $1000 \mu \varepsilon$ applied, and the crack width determined. The crack width computed at $1000 \mu \varepsilon$ was considered as the final crack width for the bridge deck. Crack widths were also computed at first cracking by linear interpolation considering the shrinkage strain previously calculated as initiating cracking.

Subsequent analyses were performed with a progressively increasing numbers of cracks present in the model at probable locations of crack formation until stresses in the concrete elements were lower than the tensile strength of the concrete. The overall behavior of the model was constructed based on these analyses (Figure 5.17). A total shrinkage of $1000 \mu \varepsilon$ was selected as a worst case scenario and serves as an upper bound on free shrinkage expected in a bridge deck. 


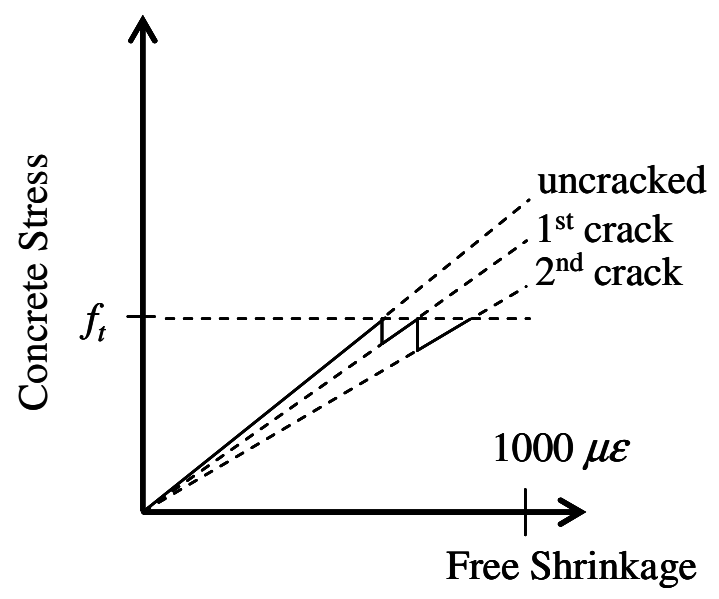

(a) Concrete Stress vs. Shrinkage Load

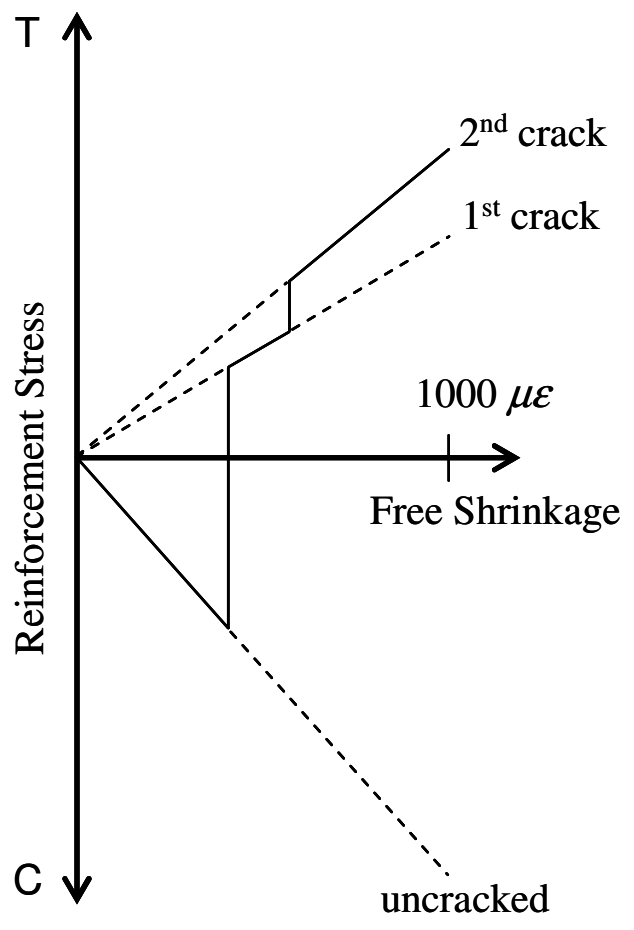

(b) Bar Stress vs. Shrinkage Load

Figure 5.17: Progressive Cracking Methodolgy

This method of progressively introducing cracks into the model was performed on a finite element model of the AASHTO span of the SR 18 bridge. Stresses in the uncracked deck model were determined to be uniform along the length of the deck at locations greater than $7 \mathrm{ft}$ from the ends of the span, as illustrated by Figure 5.18. 


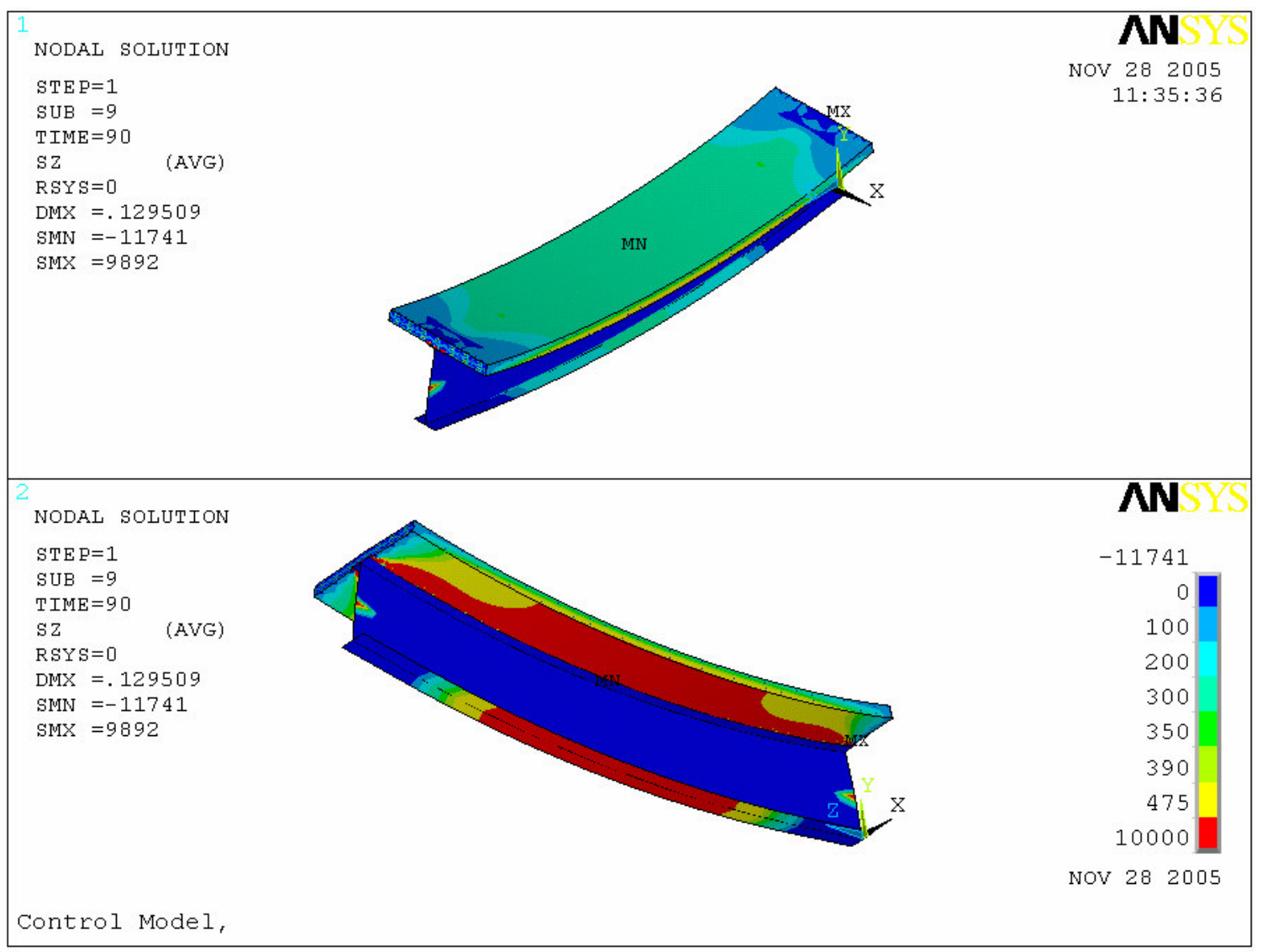

Figure 5.18: Distribution of Longitudinal Stresses

The shrinkage required to initiate a crack in the AASHTO span was calculated to be $418 \mu \varepsilon$ for uniform shrinkage and $180 \mu \varepsilon$ for linear shrinkage. A single crack located at midpsan was initially introduced to the model. Because stresses in the deck at locations away from the crack exceeded the tensile strength of the concrete, additional cracks were introduced at the same time that the single crack was inserted. Thus, the model predicts that most cracks initiate at the same time, rather than progressively. As presented in Figure 5.19, the model is relatively insensitive to the number of cracks present in the model. As the number of cracks increase, crack widths measured in the model do not vary significantly. Based on this analysis, final crack widths can be reasonably estimated using the model through consideration of only one crack. 


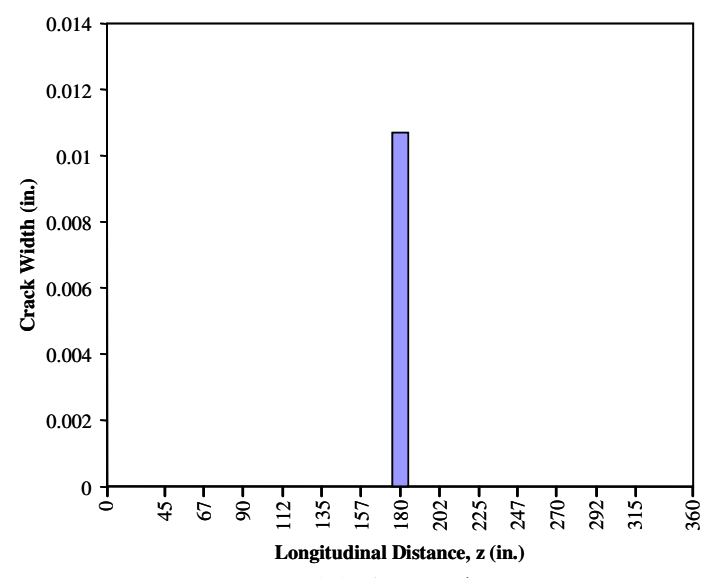

(a) 1 crack

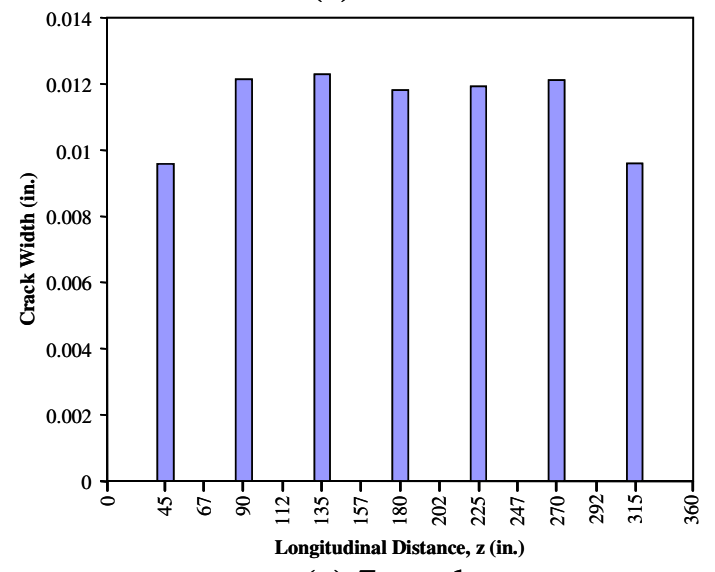

(c) 7 cracks

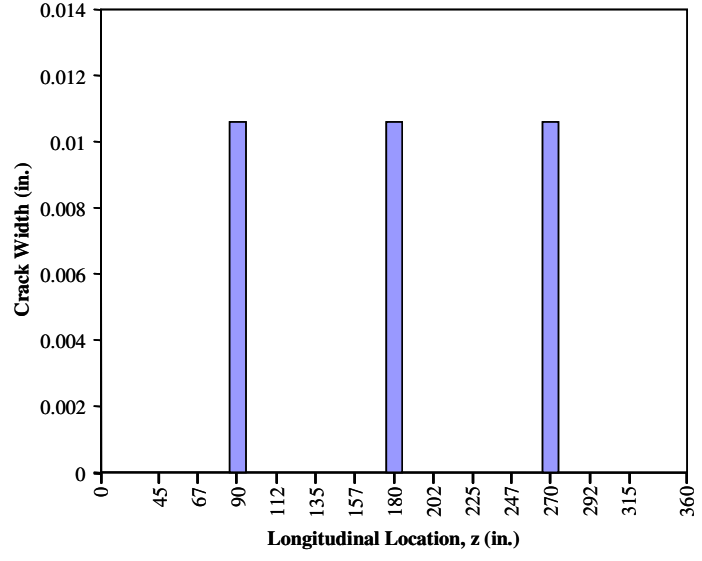

(b) 3 cracks

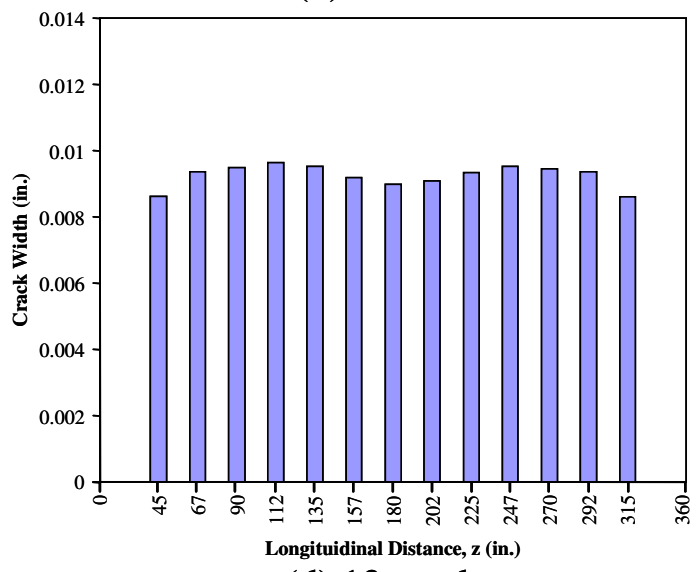

(d) 13 cracks

Figure 5.19: Sensitivity of Crack Widths to Amount of Cracking

\subsection{Shrinkage Loads with Time}

Because a static, linear-elastic analysis was performed, shrinkage loads were applied to the model using a single step with an ultimate shrinkage load equal to 1000 $\mu \varepsilon$, as illustrated in Figure 5.20. To determine behavior at other times of interest, the results of an analysis with $1000 \mu \varepsilon$ were then appropriately scaled to determine the response of the model at that time. 


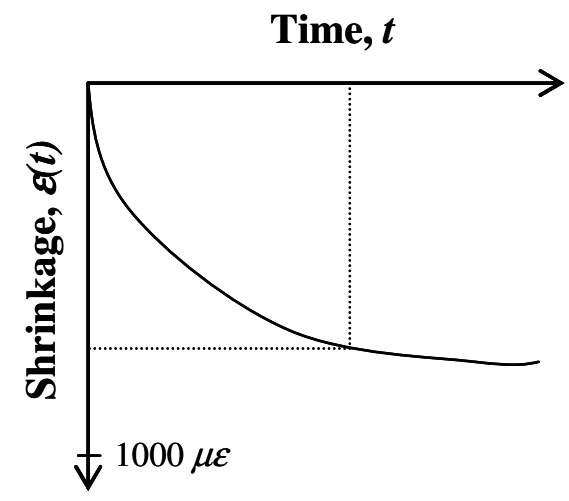

(a) Time-dependent Shrinkage

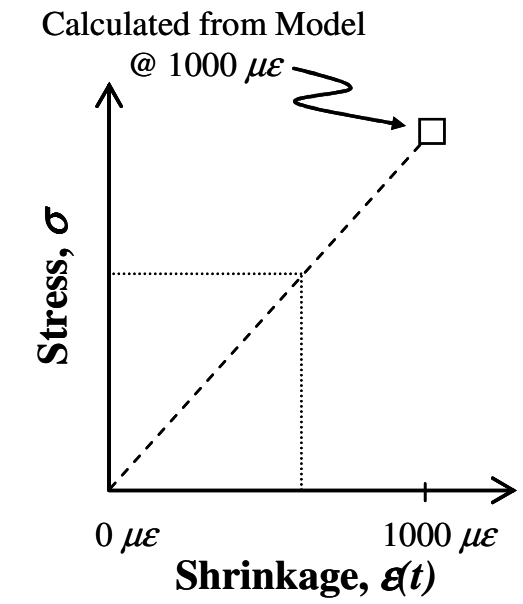

(b) Model Estimate of Stress
Calculated from Model

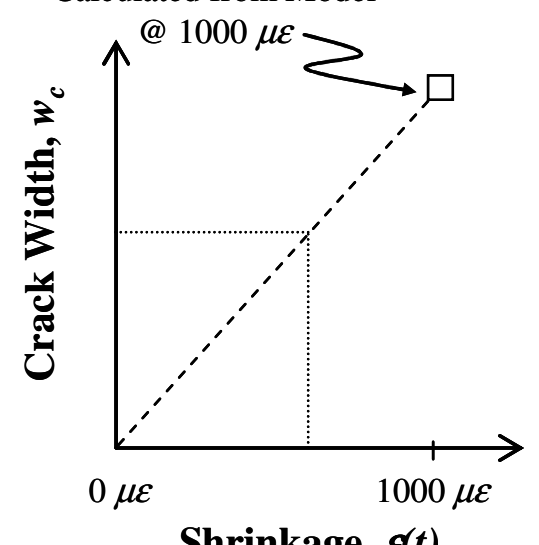

(c) Model Estimate of Crack Widths

\section{Figure 5.20: Relationship of Model Stress and Crack Widths to Time-Dependent Shrinkage}

Free shrinkage was measured in the field for the SR 23 and Thayer Road bridges. Thus, the amount of free shrinkage applied to the models was scaled according to the respective measured shrinkage. In the cases of the SR 18 and I-65 bridges, where free shrinkage was not measured, the shrinkage was estimated based on measurements provided by Blackman Specimen 8 (2002).

\subsection{Comparison of Model Results to Field Studies}

Finite element models were developed for the bridges investigated in this study to further evaluate the overall performance of the analytical model and the method used for modeling cracks. Both uniform and linear shrinkage were applied to the model, and the cracks widths were estimated. 


\subsubsection{State Road 18}

As concrete strength develops, the amount of shrinkage required to initiate cracking varies as predicted by the analysis procedure because of the development of tensile strength in the concrete. The tensile strength in the model is estimated as $6 \sqrt{f_{c}}$ where $f_{c}$ is the compression strength at the time of interest. After Day 7, the compression strength was based on the measured cylinder strength. Prior to Day 7, compressive strengths were estimated as a function of the 28-day compressive strength since compressive strengths were not measured at these early times. ACI 209 (1992) specifies that compressive strength at a given time can be calculated as:

$$
f_{c}(t)=\frac{t}{\alpha+\beta t} f_{c}^{\prime}
$$

where:

$$
\begin{aligned}
f_{c}(t)= & \text { compressive strength of concrete at a given time, } \mathrm{ksi} \\
t & =\text { time }, \text { days } \\
\alpha \quad= & \text { constant: } 4.0 \text { for moist cured concrete with Type I cement } \\
\beta \quad= & \text { constant: } 0.85 \text { for moist cured concrete with Type I } \\
& \text { cement } \\
f_{c}^{\prime}= & 28 \text {-day compressive strength, } \mathrm{ksi}
\end{aligned}
$$

Once an estimate of the tensile strength of the concrete for specific times was determined, the finite element model was used to calculate the shrinkage necessary to initiate cracking at that time. The shrinkage required to develop cracking in the AASHTO and Purdue decks over time is shown in Figure 5.21 and Figure 5.22, respectively. Both uniform and linear shrinkage profiles were evaluated. Circles are provided around shrinkage values that are based on estimates provided by Eq. (5.1). As evident, the Purdue span required slightly less shrinkage than the AASHTO span to initiate cracking.

While crack widths were initially measured on Day 15 , cracking was observed in both spans as early as Day 3. To determine if the model predicts the development of cracking in a similar amount of time, the shrinkage required to form cracks calculated by the model was compared to the amount of shrinkage experienced by the decks. Because the free shrinkage of the concrete in the SR 18 bridge was not measured, the shrinkage was estimated from the shrinkage measured in Specimen 8 of the study by Blackman (Figure 5.6). When this shrinkage is compared to the shrinkage required cracks to develop in the model, it is evident that concrete shrinkage alone is insufficient to develop cracking in the bridge deck (Figure 5.21 and Figure 5.22).

However, during this time, in addition to drying shrinkage, the deck experiences residual strains as a result of high hydration temperatures. If the deck concrete is assumed to be capable of resisting volume change at the time of peak hydration temperature, strains resulting from cooling of the concrete after hydration can be superimposed on shrinkage strains. Thermal strains resulting from cooling of the concrete were calculated by multiplying the coefficient of thermal expansion by the difference between the peak hydration temperature and the temperature at a given time. As illustrated in Figure 5.21 and Figure 5.22, the combination of shrinkage and thermal strains exceed the shrinkage necessary for crack development considering both uniform 
and linear shrinkage profiles during the first three days in both AASHTO and Purdue spans. For the linear profile, combined shrinkage and thermal strains consistently exceed the cracking strains. Based on this analysis, it is anticipated that cracking will initiate within the first 3 days which is consistent with the observed behavior.

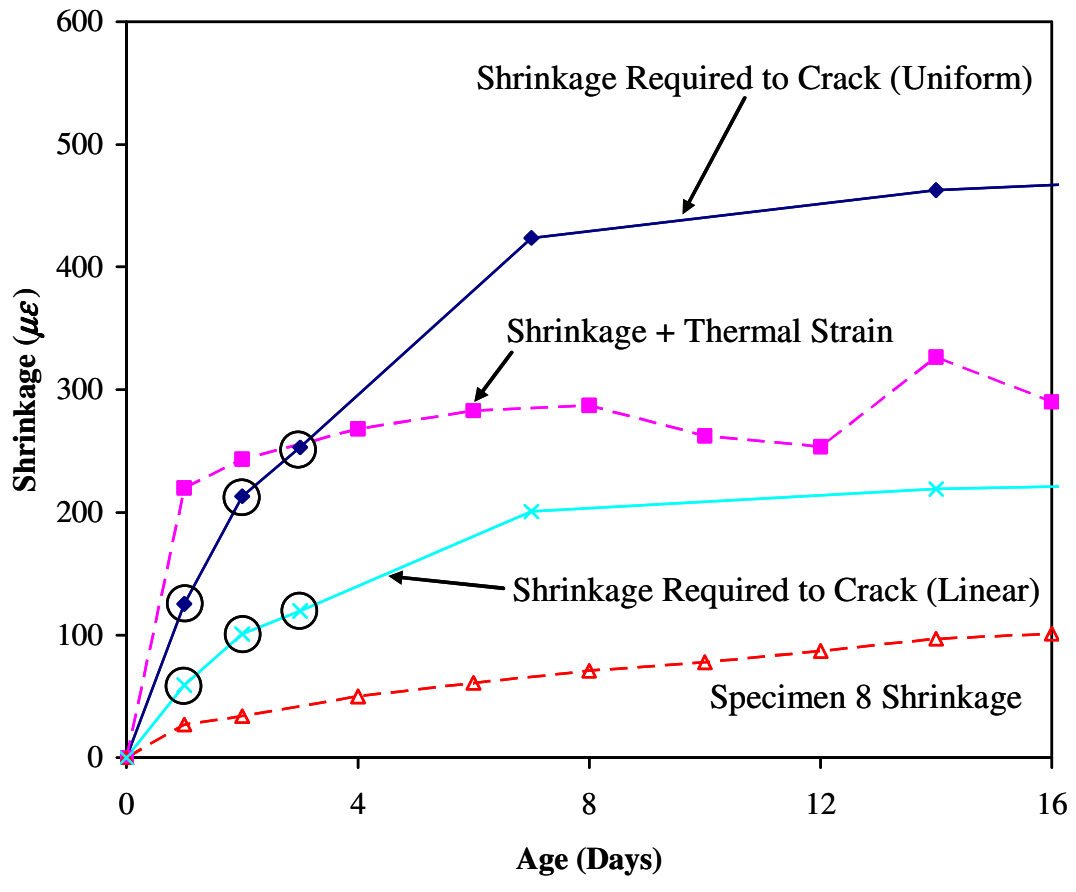

Figure 5.21: SR 18 Shrinkage to Initiate Cracking (AASHTO Span) 


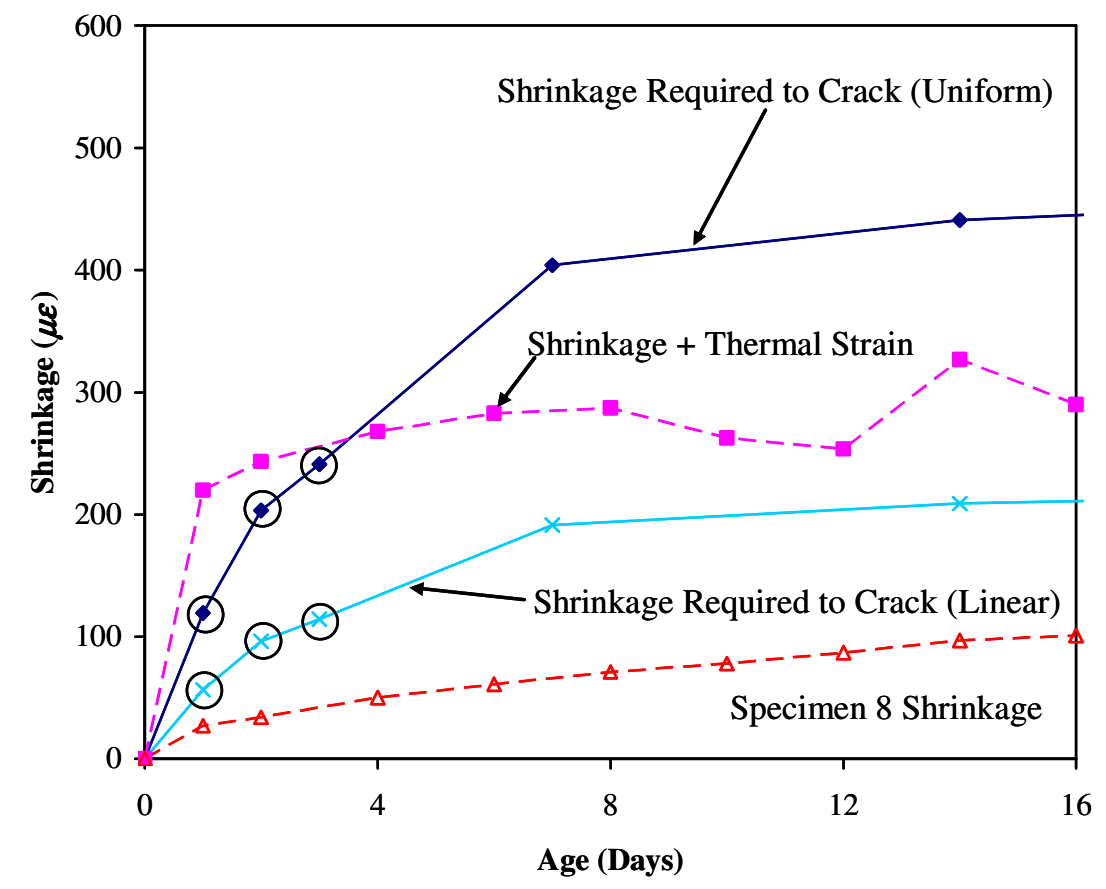

Figure 5.22: SR 18 Shrinkage to Initiate Cracking (Purdue Span)

Crack widths were first measured on Day 15 on the SR 18 bridge. Based on the estimated free shrinkage and thermal strain calculated from temperatures measured onsite, the total shrinkage on Day 15 was $323 \mu \varepsilon$. Crack widths were calculated for this amount of deck shrinkage and are compared to the crack widths measured on the SR 18 bridge deck in Table 5.5 and Table 5.6 for both uniform and linear shrinkage profiles. The average and maximum crack widths predicted by the model are the average and maximum crack width across the width of the deck, as only a single crack is considered.

In the case of uniform shrinkage, the model underestimates the average crack width by $67 \%$ in the AASHTO span and $66 \%$ in the Purdue span. However, the model provides a reasonable estimate of the difference in average crack width between the AASHTO and Purdue spans. The ratio of the measured average crack width between AASHTO and Purdue spans is 1.7 compared to an estimated ratio of 1.8. If crack widths are increased by a factor of 1.5 , the model provides a reasonably accurate estimate of both crack widths and relative performance. 
Table 5.5: Comparison of SR 18 Crack Widths (Uniform Shrinkage)

\begin{tabular}{|c|c|c|c|c|}
\hline \multirow{2}{*}{ Crack Statistics } & \multicolumn{2}{|c|}{ Measured (Day 15) } & \multicolumn{2}{c|}{ Model (Uniform) } \\
\cline { 2 - 5 } & AASHTO & Purdue & AASHTO & Purdue \\
\hline Average Crack Widths (in.) & 0.0066 & 0.0038 & 0.0044 & 0.0025 \\
\hline Standard Deviation (in.) & 0.0021 & 0.0010 & 0.0004 & 0.0003 \\
\hline Maximum Crack Width (in.) & 0.0100 & 0.0050 & 0.0049 & 0.0032 \\
\hline
\end{tabular}

For linear shrinkage, the model provides a reasonable estimate of average crack widths for the AASHTO deck but overestimates average crack widths for the Purdue deck by $61 \%$. In addition, the relative performance of the two spans in not estimated as well as that provided using uniform shrinkage. The ratio of the average estimated crack width between the AASHTO and Purdue spans was computed as 1.4 compared with the measured ratio of 1.7 .

Table 5.6: Comparison of SR 18 Crack Widths (Linear Shrinkage)

\begin{tabular}{|c|c|c|c|c|}
\hline \multirow{2}{*}{ Crack Statistics } & \multicolumn{2}{|c|}{ Measured (Day 15) } & \multicolumn{2}{c|}{ Model (Linear) } \\
\cline { 2 - 5 } & AASHTO & Purdue & AASHTO & Purdue \\
\hline Average Crack Widths (in.) & 0.0066 & 0.0038 & 0.0070 & 0.0062 \\
\hline Standard Deviation (in.) & 0.0021 & 0.0010 & 0.0003 & 0.005 \\
\hline Maximum Crack Width (in.) & 0.0100 & 0.0050 & 0.0077 & 0.0074 \\
\hline
\end{tabular}

While these results illustrate the behavior of the model at Day 15, it is instructive to compare the range of crack widths estimated by the model from the onset of cracking (initial) up to a maximum strain of $1000 \mu \varepsilon$ (final). As shown in Table 5.7, the crack widths measured compared very well with the estimated values. In particular, the linear model provides excellent estimates of crack width. The initial crack widths compare well with the average measurements on Day 15 for both spans. Furthermore, the final widths are in excellent agreement with the maximum widths measured on Day 799. Based on this analysis, the linear model is shown to accurately represent the cracking behavior of the SR 18 bridge deck. 
Table 5.7: Range of Predicted Crack Widths Compared to Measured Crack Widths (SR 18)

\begin{tabular}{|c|c|c|c|c|}
\hline \multirow{2}{*}{ Source } & \multirow{2}{*}{$\begin{array}{c}\text { Shrinkage } \\
\text { Profile }\end{array}$} & \multirow{2}{*}{ Type } & \multicolumn{2}{|c|}{ Crack Width (in.) } \\
\cline { 3 - 5 } & & AASHTO & Purdue \\
\hline \multirow{4}{*}{ Model } & \multirow{2}{*}{ Uniform } & Initial & 0.0058 & 0.0031 \\
\cline { 3 - 5 } & & Final & 0.0138 & 0.0078 \\
\cline { 3 - 5 } & \multirow{2}{*}{ Linear } & Initial & 0.0052 & 0.0036 \\
\cline { 3 - 5 } Measured & Final & 0.0261 & 0.0186 \\
\hline \multirow{3}{*}{ Day 15 } & Average & 0.0066 & 0.0038 \\
\cline { 3 - 5 } & & Maximum & 0.0100 & 0.0050 \\
\cline { 3 - 5 } & \multirow{2}{*}{ Day 799 } & Average & 0.0100 & 0.0070 \\
\cline { 3 - 5 } & & Maximum & 0.0250 & 0.0180 \\
\hline
\end{tabular}

\subsubsection{Thayer Road Bridge}

The Thayer Road Bridge was modeled using the same method as the SR 18 bridge. However, since Thayer Road incorporated FRP in its design, the modulus of elasticity of the FRP bars $\left(E_{r}=6900 \mathrm{ksi}\right)$ was used for the top reinforcement elements. As with the SR 18 bridge, an estimate of the shrinkage in the deck was necessary to compare the model to the actual structure. An embedded concrete control gage was installed in a concrete block on-site to provide a reference for any drift occurring in the concrete embedded gages installed in the Thayer Road Bridge. This control gage also provides an estimate of the shrinkage in the deck concrete. The shrinkage strain measured by the control gage is presented in Figure 5.23. On Day 482, approximately $200 \mu \varepsilon$ of shrinkage had occurred. However, the model predicts that $369 \mu \varepsilon$ of shrinkage is necessary for cracking to initiate in the deck when uniform shrinkage is considered and $396 \mu \varepsilon$ when linear shrinkage was used, and thus the amount measured with the control gage alone would not be enough to cause cracking to form in the deck. Nevertheless, cracks were observed in the bridge deck by Day 7 .

If the concrete in the deck is considered to have the capacity to resist volumetric changes at the time of peak hydration temperatures, then the deck experiences a temperature change as large as $68^{\circ} \mathrm{F}$ between the time of peak hydration temperature and Day 7 (Figure 5.24), which corresponds to a contraction of $408 \mu \varepsilon\left(\alpha_{t}=6.0 \times 10^{-6} /{ }^{\circ} \mathrm{F}\right)$. As this amount is greater than the amount predicted by the model to initiate cracking (361 $\mu \varepsilon, \Delta \mathrm{T}=56.6^{\circ} \mathrm{F}$ ), the model correctly predicts the development of cracking. Once cracks forms, additional concrete drying shrinkage in combination with thermal expansion of the bridge superstructure cause the width of the cracks to increase. However, analysis determined that the change in crack width resulting from thermal effects in the superstructure — opening of the crack as a result of girder expansion—was only $7.36 \times 10^{-5}$ in. $/{ }^{\circ} \mathrm{F}$, and therefore are considered negligible. The width of cracks on Day 482 is estimated by superposition of the crack width resulting from initial opening and subsequent shrinkage of the deck. 


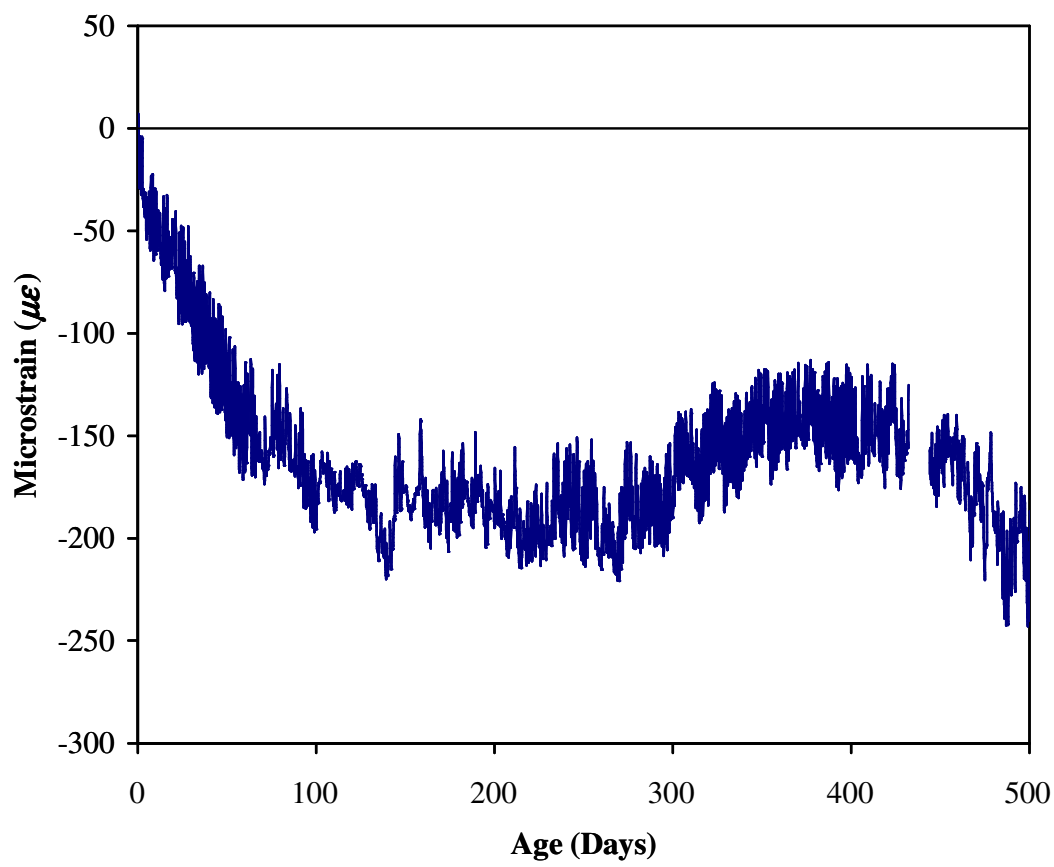

Figure 5.23: Control Gage Free Shrinkage Strain (Thayer Road)

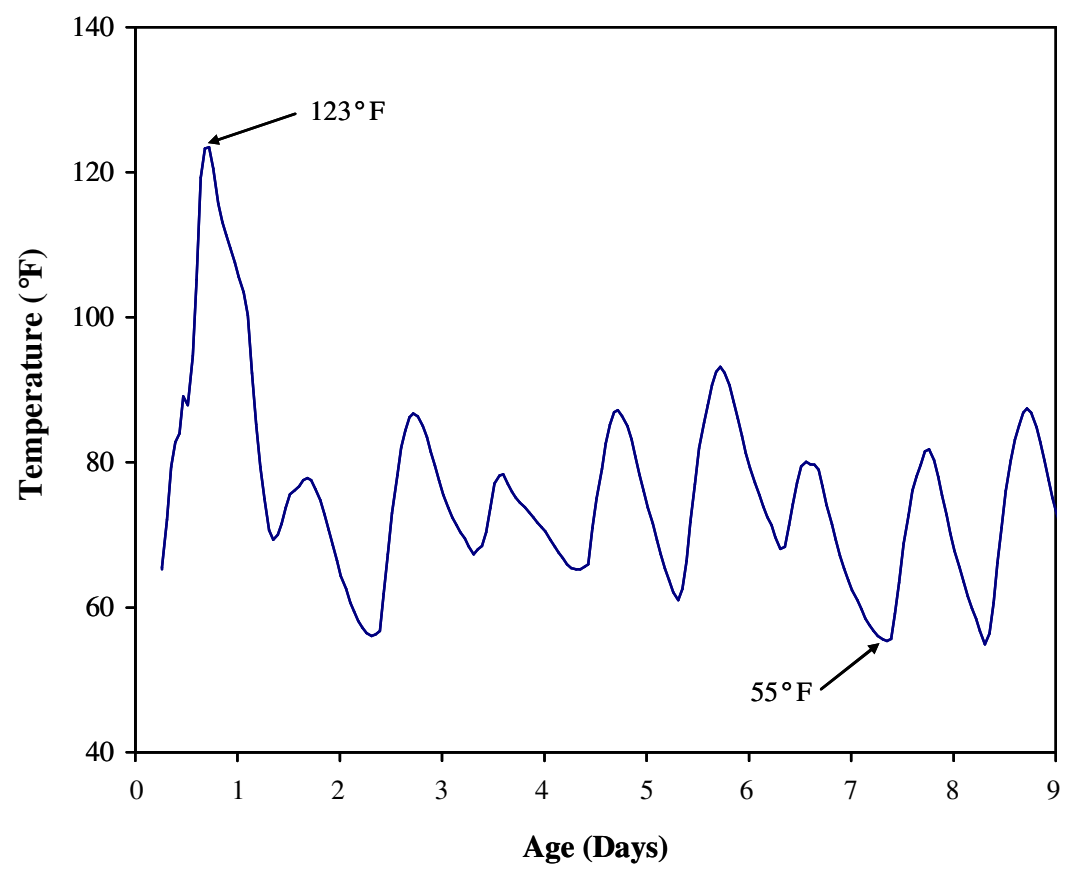

Figure 5.24: Deck Temperatures (Thayer Road) 
The crack widths predicted by the finite element model are compared to those measured on Thayer Road in Table 5.8. The model underestimates the average and maximum crack widths compared to the measured average and maximum crack widths when uniform shrinkage is considered. In contrast, when linear shrinkage was used, the model slightly underestimated the crack width. To provide better agreement with the average crack widths measured, the average crack widths calculated by the model have to be modified by an amplifier which is calculated as 1.56 for a uniform shrinkage profile and 1.29 for a linear shrinkage profile.

Table 5.8: Comparison of Crack Widths (Thayer Road Bridge)

\begin{tabular}{|c|c|c|c|}
\hline \multirow{2}{*}{ Crack Statistics } & Measured (Day 482) & \multicolumn{2}{|c|}{ Model (Day 482) } \\
\cline { 2 - 4 } & Thayer Road Bridge & Uniform & Linear \\
\hline Average Crack Widths (in.) & 0.0100 & 0.0064 & 0.0077 \\
\hline Standard Deviation (in.) & 0.0080 & 0.0002 & 0.00015 \\
\hline Maximum Crack Width (in.) & 0.0260 & 0.0067 & 0.0084 \\
\hline
\end{tabular}

It should be noted that the finite element model does not account for any difference in bond characteristics between steel and FRP reinforcement. ACI Committee 440, Fiber Reinforced Polymer Reinforcement, estimates crack widths using a physical model developed by Frosch (1999) that can be applied regardless of reinforcement type (steel or FRP) except that it should be modified by a bond quality coefficient $k_{b}$ (ACI 440 2006). For FRP reinforcement with bond properties similar to steel, $k_{b}$ is assumed equal to 1.0. For FRP bars with bond characteristics less than steel, $k_{b}$ is greater than 1.0. ACI 440 defines the range of values for $k_{b}$ between 0.60 and 1.72 for various concrete crosssections, bar manufacturers, fiber types, resins, and surface treatments (ACI 440 2006). While data for rough, sand-coated FRP bar surface treatments, such as those incorporated into the FRP reinforcement installed on Thayer Road Bridge, trend towards the lower end of this range, the FRP bars installed in the Thayer Road bridge deck were exposed to a normal construction environment during which time the bars were regularly walked on by construction workers. This activity abraded the surface and noticeably decreased the amount of sand embedded on the surface of the bar. Therefore, as the quality of the surface treatment is degraded, it is appropriate to expect a larger value of $k_{b}$. The calibration factors determined for the Thayer Road bridge deck (1.56 and 1.29 for the uniform and linear shrinkage profiles, respectively) are in the range of coefficients provided by ACI 440 (0.60 to 1.72). Furthermore, ACI 440 recommends a value of 1.4 be used in the absence of other data.

The range of crack widths (initial-final) predicted by the model considering both shrinkage profiles is presented in Table 5.9. The crack widths are presented as estimated by the model (unfactored) as well as modified using the 1.56 and 1.29 FRP factors as recommended above for the uniform and linear shrinkage profiles. As shown, the measured crack widths on Day 482 are outside the range provided by the uniform profile. On the other hand, the linear profile provides reasonable agreement. Considering that 
Day 482 is being considered, crack widths should be approaching their final value. The ratio of calculated to measured maximum crack width is 1.15 which is slightly higher than that demonstrated by SR 18 (Table 5.7). Based on this analysis, it appears that the FRP modifier can be reduced slightly to produce improved results. If a 1.05 ratio is considered, a factor of 1.17 is required for FRP bars using a linear profile.

Table 5.9: Range of Predicted Crack Widths Compared to Measured Crack Widths (Thayer Road)

\begin{tabular}{|c|c|c|c|c|}
\hline \multirow{2}{*}{ Source } & \multirow{2}{*}{$\begin{array}{c}\text { Shrinkage } \\
\text { Profile }\end{array}$} & \multirow{2}{*}{ Type } & \multicolumn{2}{|c|}{ Crack Width (in.) } \\
\hline & & & Unfactored & Factored \\
\hline \multirow{4}{*}{ Model } & \multirow{2}{*}{ Uniform } & Initial & 0.0044 & 0.0069 \\
\hline & & Final & 0.0133 & 0.0207 \\
\hline & \multirow{2}{*}{ Linear } & Initial & 0.0047 & 0.0061 \\
\hline & & Final & 0.0233 & 0.0301 \\
\hline \multirow{2}{*}{ Measured } & \multirow{2}{*}{ Day 482} & Average & \multicolumn{2}{|c|}{0.0100} \\
\hline & & Maximum & \multicolumn{2}{|c|}{0.0260} \\
\hline
\end{tabular}

\subsubsection{State Road 23}

Although no cracking was observed in the deck on SR 23, it was of interest to determine if the model similarly predicted an absence of cracking. The model was analyzed with both uniform and linear shrinkage profiles. The model predicted that with uniform shrinkage, $387 \mu \varepsilon$ of shrinkage would be required to initiate cracking in the deck. By comparison, only $399 \mu \varepsilon$ would be necessary to initiate cracking in the deck when linear shrinkage was used. Becasue the SR 23 bridge was constructed with SIP forms, results provided by linear gradients are considered to be best representative.

As presented in Figure 5.25, the peak hydration temperature was $50^{\circ} \mathrm{F}$, which is significantly lower than the peak hydration temperatures measured on other bridges investigated as a part of the field study (typically $\sim 110^{\circ} \mathrm{F}$ ). The lowest measured temperature experienced by the bridge deck prior to crack mapping on Day 355 was $5^{\circ} \mathrm{F}$ (Day 74). Therefore, the total strain due to cooling after hydration experienced by the SR 23 bridge deck was estimated as $247 \mu \varepsilon$ prior to crack mapping. Considering that 99 me was measured in the on-site specimen on Day 74 (Figure 5.26) the total shrinkage experienced by the SR 23 deck was approximately $346 \mu \varepsilon$, which is less than the $399 \mu \varepsilon$ predicted to initiate cracking. While shrinkage continued to increase after Day 74, temperatures also increased and alleviated thermal strains. On Day 355 (time of crack mapping), strain in the free shrinkage specimen was $115 \mu \varepsilon$ while the deck temperature was $48^{\circ} \mathrm{F}(11 \mu \varepsilon)$ resulting in a total shrinkage strain of approximately $126 \mu \varepsilon$. Again, this value is less than the amount necessary to initiate cracking. Based on this analysis, the model is consistent with the behavior observed in the bridge. 


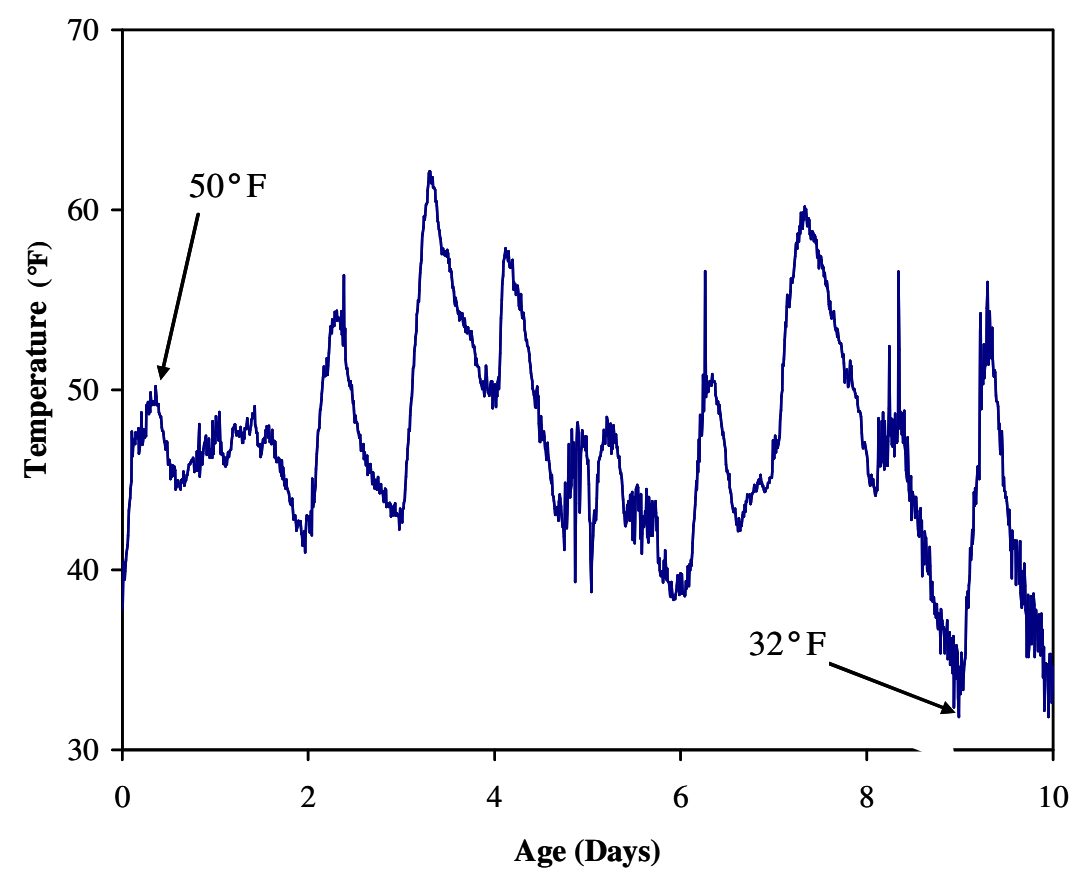

Figure 5.25: Early-Age Deck Temperatures (SR 23)

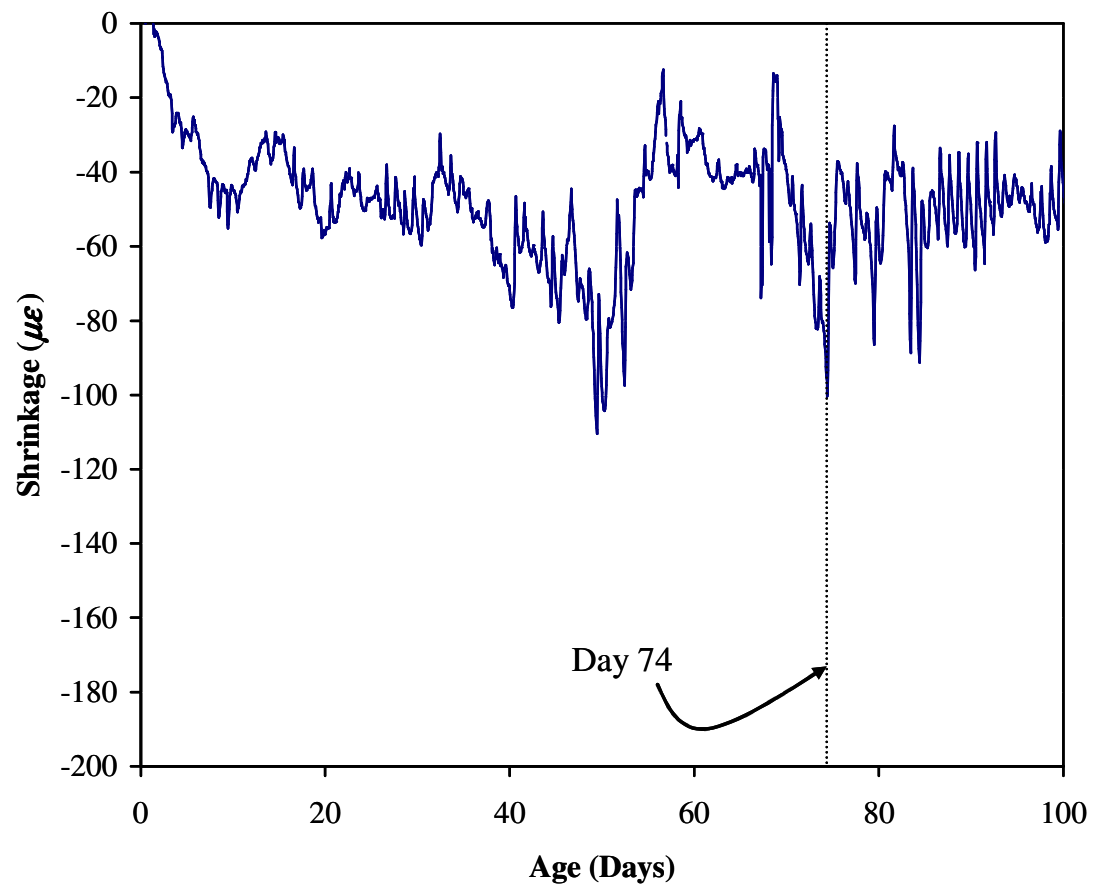

Figure 5.26: On-Site Free Shrinkage (SR 23) 
Though no cracks developed in the SR 23 bridge deck, it is of interest to note the range of crack widths predicted by the model (Table 5.10). The crack widths presented in Table 5.10 are those calculated by the model if a crack was assumed to have developed in the SR 23 bridge deck. The linear model predicted a final crack width which was slightly less than that predicted for SR 18 (0.0261 in.) and Thayer Road Bridge (0.0301 in.).

Table 5.10: Range of Predicted Crack Widths (SR 23)

\begin{tabular}{|c|c|c|c|}
\hline Source & $\begin{array}{c}\text { Shrinkage } \\
\text { Profile }\end{array}$ & Type & $\begin{array}{c}\text { Crack Width } \\
\text { (in.) }\end{array}$ \\
\hline \multirow{3}{*}{ Model } & \multirow{2}{*}{ Uniform } & Initial & 0.0065 \\
\cline { 3 - 4 } & \multirow{2}{*}{ Linear } & Final & 0.0169 \\
\cline { 3 - 4 } & & Initial & 0.0095 \\
\hline
\end{tabular}

\subsubsection{I-65 Bridge}

An analysis was performed on a model of the I- 65 bridge to predict the range of crack widths occurring in the deck. Cracks in the northbound lanes of the I-65 bridge over SR 25 were mapped on Day 2204 and were compared to the range of predicted crack widths (Table 5.11). As cracks were mapped on Day 2204, the crack widths are considered to be final values. The uniform shrinkage model underestimates the final maximum crack width by $69 \%$ while the linear shrinkage model underestimates the maximum crack width by $36 \%$. Closer inspection of the crack width data from the I-65 bridge reveals that the maximum crack width occurs $11 \mathrm{ft}$ from the center of the southern bridge abutment. It is possible that the width of this crack increased as a result of local effects at the end of the deck. The second largest crack measured was 0.028 in. wide and was located at $133 \mathrm{ft}-4 \mathrm{in}$. from the southern abutment $(\sim 19 \mathrm{ft}$ from the northern abutment). If this crack width is considered as more representative of cracks resulting from restrained shrinkage, then the linear shrinkage model underestimates the maximum crack width by $25 \%$. As presented in the field results, strain gage data suggests that the reinforcement yielded. Yielding of the reinforcement likely explains the slightly larger crack widths experienced as the model results are based on linear elastic behavior. 


\section{Table 5.11: Range of Predicted Crack Widths Compared to Measured Crack Widths (Day 2204)}

\begin{tabular}{|c|c|c|c|}
\hline Source & $\begin{array}{c}\text { Shrinkage } \\
\text { Profile }\end{array}$ & Type & $\begin{array}{c}\text { Crack Width } \\
\text { (in.) }\end{array}$ \\
\hline \multirow{3}{*}{ Model } & \multirow{2}{*}{ Uniform } & Initial & 0.0037 \\
\cline { 3 - 4 } & \multirow{2}{*}{ Linear } & Final & 0.0097 \\
\cline { 3 - 4 } & & Initial & 0.0043 \\
\hline \multirow{2}{*}{ Measured } & \multirow{2}{*}{ Day 2204 } & Average & 0.0211 \\
\cline { 3 - 4 } & & Maximum & 0.0203 \\
\hline
\end{tabular}

\subsection{Summary and Conclusions}

A finite element model developed to model shrinkage behavior in a bridge deck was compared and calibrated against data from both laboratory and field studies. Data from the study by Blackman (2002) was used to estimate the amount of free shrinkage occurring in the deck and to develop an appropriate gradient for the shrinkage through the depth of the deck. The free shrinkage loads developed based on the Blackman study were applied to a finite element model of the specimens constructed by Radabaugh (2001). The model behavior compared well with the behavior measured in the Radabaugh laboratory models. Of the two shrinkage profiles considered, the linear shrinkage profile provided the best estimate of the behavior of the as-built specimen. However, the model with uniform shrinkage provided a good estimate of the reinforcement strains in the free shrinkage specimen. Radabaugh concluded that SIP forms provided negligible additional restraint to the deck and the primary effect of these forms was the sealing effect (minimal moisture loss) on the bottom surface of the slab (2001). It was found that the presence of SIP forms could be best estimated using the linear shrinkage profile.

The performance of the model was compared against the behavior observed in the field structures to further evaluate its validity. Based on evaluation of the field response, reasonable estimates of the average crack widths occurring in the bridge decks were developed and the following findings were made:

1. Concrete shrinkage alone was not sufficient to initiate cracking at early ages in the bridge decks observed. It was determined that early-age cracking resulted from a combination of concrete shrinkage and thermal cooling after hydration.

2. The model best predicted the relative average crack width of the AASHTO and Purdue spans of SR 18 when uniform shrinkage was applied. However, the linear shrinkage model provided an excellent estimate of final crack widths in the SR 18 bridge.

3. The model underestimated the average width of cracks in the Thayer Road Bridge which was reinforced with FRP bars. This difference can be attributed to the difference in bond characteristics between steel and FRP reinforcement, which provides for a greater potential for slip between the 
FRP bars and the concrete. The slip can be accounted for by scaling crack widths by 1.56 for uniform shrinkage and 1.29 for linear shrinkage.

However, it may be possible to reduce the factor to 1.17 when linear shrinkage is considered as suggested by consideration of final, maximum crack widths.

4. An absence of cracking in the SR 23 bridge deck was predicted, which further supports the applicability of the finite element model.

5. The linear shrinkage model provided an excellent estimate of crack widths measured in the field structures. Furthermore, the final average crack width can be estimated as $40 \%$ of the predicted final maximum crack width (at $1000 \mu \varepsilon$ ).

Based on these findings it was concluded that the linear shrinkage model provided the best estimate of pre- and post-cracked behavior in bridges constructed with SIP forms. Furthermore, the model with a linear shrinkage profile at $1000 \mu \varepsilon$ should be used to predict final maximum crack widths occurring in bridge decks. The final, average crack widths can be estimated as approximately $40 \%$ of the final, maximum crack width. For bridges constructed with FRP reinforcement the difference in slip between FRP and steel reinforcement should accounted by amplifying the predicted crack widths. While lower values may be justified, it is considered conservative to increase the predicted crack widths by 1.5 when GFRP reinforcement is used. This value is also in agreement with recommendations provided by ACI 440 (2006). 


\section{CHAPTER 6 PARAMETRIC STUDY}

\subsection{Introduction}

The finite element model developed in Chapter 5 was used to perform a parametric analysis to evaluate the influence of various bridge design characteristics that affect the behavior of concrete decks undergoing volumetric changes. Based on the results of this analysis, design recommendations are provided to decrease the width of cracks which form in concrete bridge decks.

\subsection{Range of Variables}

Several previous studies (PCA 1970, Cady et al. 1971, Krauss and Rogalla 1996, Eppers et al. 1998, Le et al. 1998, Frosch et al. 2003, Xi et al. 2003) have determined that the reinforcement, girders, and bridge deck are design elements which influence the width of cracks which form in bridges. The design parameters considered in this parametric study are presented in Table 6.1. The effects of reinforcement amounts and spacing as well as reinforcement type (steel or FRP) are considered. While the primary focus of this study is the influence of reinforcement on control of shrinkage cracks, the effects of other design parameters such as girder depth and spacing, deck thickness, and concrete strength were investigated. 
Table 6.1: Range of Variables in Parametric Study

\begin{tabular}{|c|c|c|c|}
\hline \multicolumn{2}{|c|}{ Variable } & Range & Control \\
\hline \multirow{4}{*}{ Reinforcement } & Area (Bar Size) & $\# 3-\# 7$ & $\# 5$ \\
\cline { 2 - 4 } & Top Mat Spacing (in.) & $3-18$ & 12 \\
\cline { 2 - 4 } & Bottom Mat Spacing (in.) & $3-18$ & 12 \\
\cline { 2 - 4 } & Reinforcement Type & Steel, FRP & Steel \\
\hline \multirow{2}{*}{ Girder } & Depth (in.) & $12-51$ & 51 \\
\cline { 2 - 4 } & Spacing (ft) & $6-10$ & 7 \\
\hline \multirow{2}{*}{ Deck } & Thickness (in.) & $6-12$ & 8 \\
\cline { 2 - 4 } & $\mathrm{f}_{\mathrm{c}}^{\prime}$ (psi) & $3000-10,000$ & 4000 \\
\hline
\end{tabular}

\subsection{Control Model}

The relative influence of various design parameters were compared to a control model. A schematic of the control model is presented in Figure 6.1. The parameters for the control were selected based on the deck and girder characteristics of the SR 18 bridge. However, the amount and spacing of the reinforcement was based on a standard AASHTO design of deck reinforcement which is identical to that used in the I-65 over SR 25 bridge. The length of the specimen was limited to $30 \mathrm{ft}$ to avoid exceeding the finite element program limits for nodes and elements, but still allowed a region of uniform stress along the length of the model to develop. As described in Section 5.3, symmetry boundary conditions were placed along the length of the edges of the deck at the midbays between girders. 

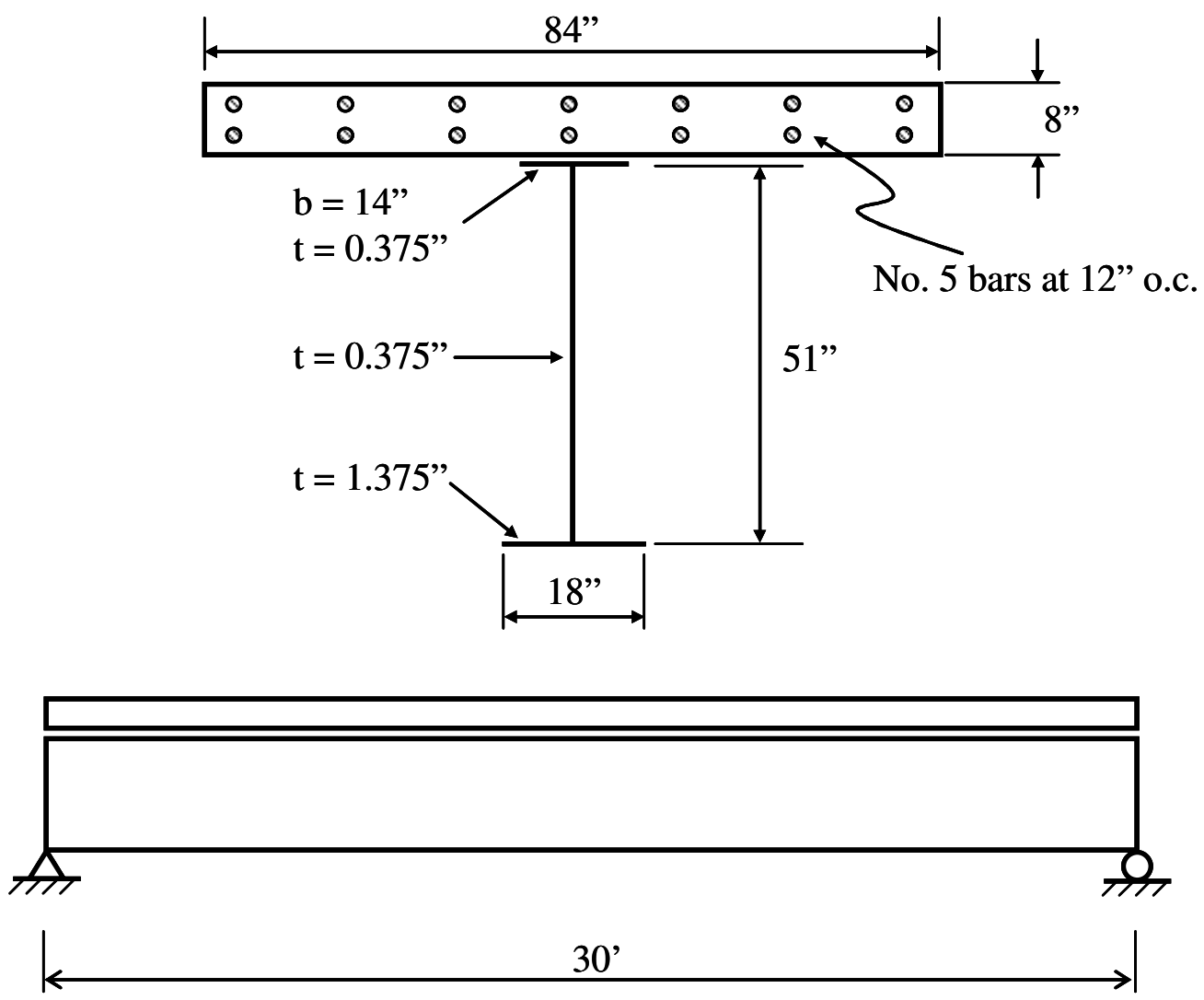

Figure 6.1: Control Model Characteristics

The bridge models were descretized in the same manner as described in Section 5.3. The deck was divided into elements which were $2 \times 3 \times 2$ in. Reinforcement was modeled discretely and shared nodes with the concrete elements along the lines of reinforcement. The model was simply supported at the ends with the UX, UY, and UZ degrees of freedom restrained at the left support and UX and UY degrees of freedom restrained at the right support.

\subsection{Method of Analysis}

The finite element model was used to evaluate the effect of design characteristics on the amount of shrinkage required to initiate cracking in the deck and on both initial and final crack widths. The uncracked model was analyzed with a total shrinkage load equal to $1000 \mu \varepsilon$. Because a static, linear-elastic analysis was performed, the resulting stresses calculated by the model were analyzed, and the shrinkage necessary for initial crack formation was calculated by scaling the applied shrinkage such that stress in the deck was equal to the assumed tensile strength of the concrete $\left(f_{t}=6 \sqrt{f_{c}}\right)$. Once this shrinkage was determined, the model was re-analyzed with the introduction of a single 
crack. The crack was located at midspan, and a free shrinkage load equal to $1000 \mu \varepsilon$ was applied. Final crack widths were calculated based on a total shrinkage of $1000 \mu \varepsilon$ while initial crack widths were determined by scaling the final crack width by the appropriate amount of shrinkage necessary for crack formation.

Analyses were performed considering both uniform and linear shrinkage. Linear shrinkage was based on the gradient measured in Blackman Specimen 8 (2002) and was scaled such that the strain at the top surface of the deck was $1000 \mu \varepsilon$. The two shrinkage profiles are illustrated in Figure 6.2.

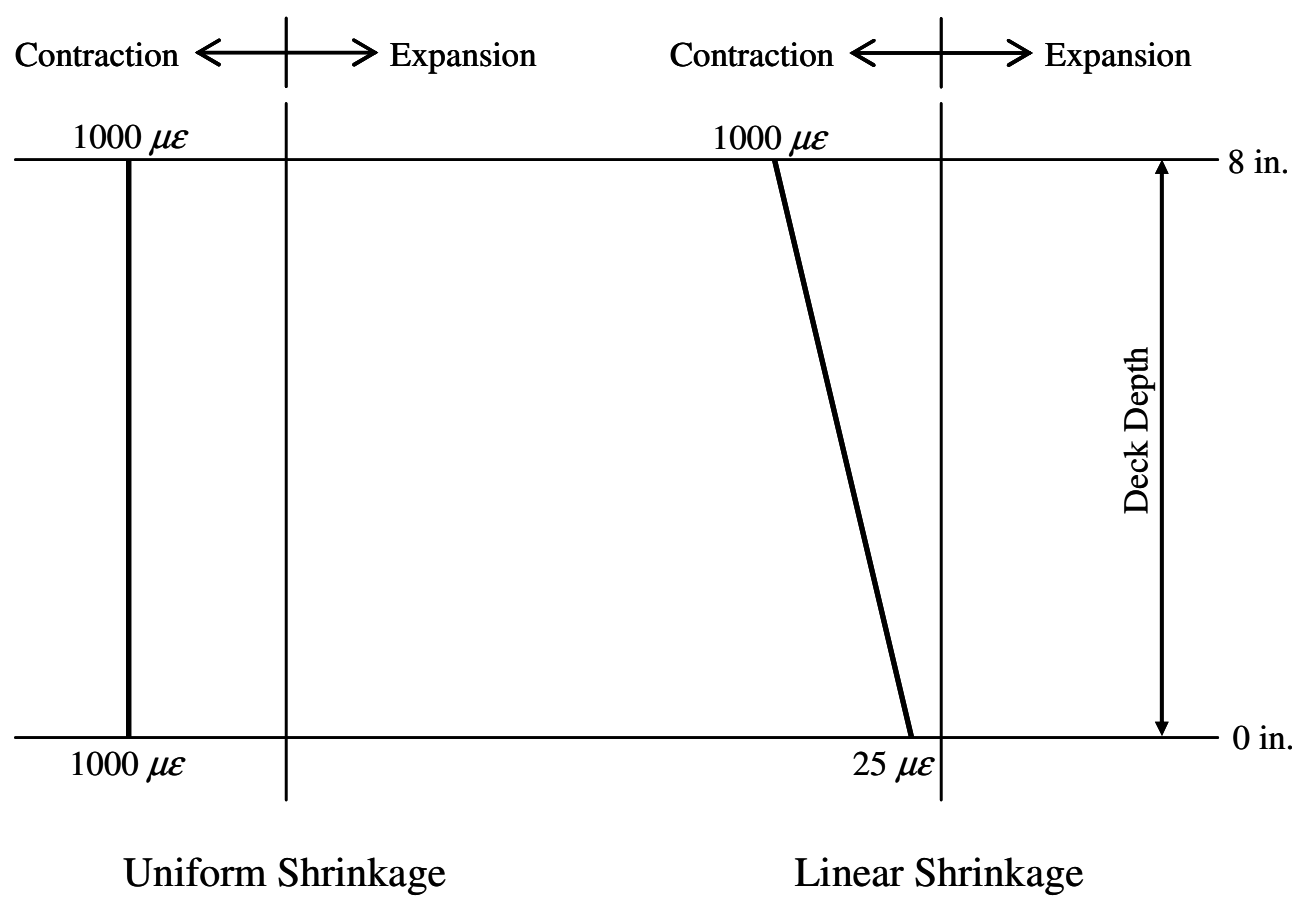

Figure 6.2: Model Shrinkage Profiles

\subsection{Influence of Reinforcement}

The primary focus of this study was to determine the influence of reinforcement on the control of cracks that develop as a result of restrained volume changes. Thus, the amount, spacing, and reinforcement material was varied and compared to the control model.

\subsubsection{Reinforcement Amount}

The amount of reinforcement was changed by increasing the size of reinforcement while maintaining a bar spacing of 12 in. The initial crack widths estimated by the model considering a uniform shrinkage profile for different amounts of reinforcement are presented in Figure 6.3. The estimated crack widths are fairly consistent across the width of the section. The model predicts slightly smaller crack widths over the girder 
relative to the crack widths predicted midbay between girders. This behavior is expected as the girder assists the reinforcement in controlling crack widths. The variation between locations over the girder and at midbay is more pronounced with smaller amounts of reinforcement compared to the models with larger amounts of reinforcement. Nevertheless, the maximum difference in crack widths between a location directly over the girder and at midbay is 0.0013 in. (1.3 mils). Therefore, the average of crack widths across the width of the deck estimated by the model is considered a reasonable representation of the predicted crack width.

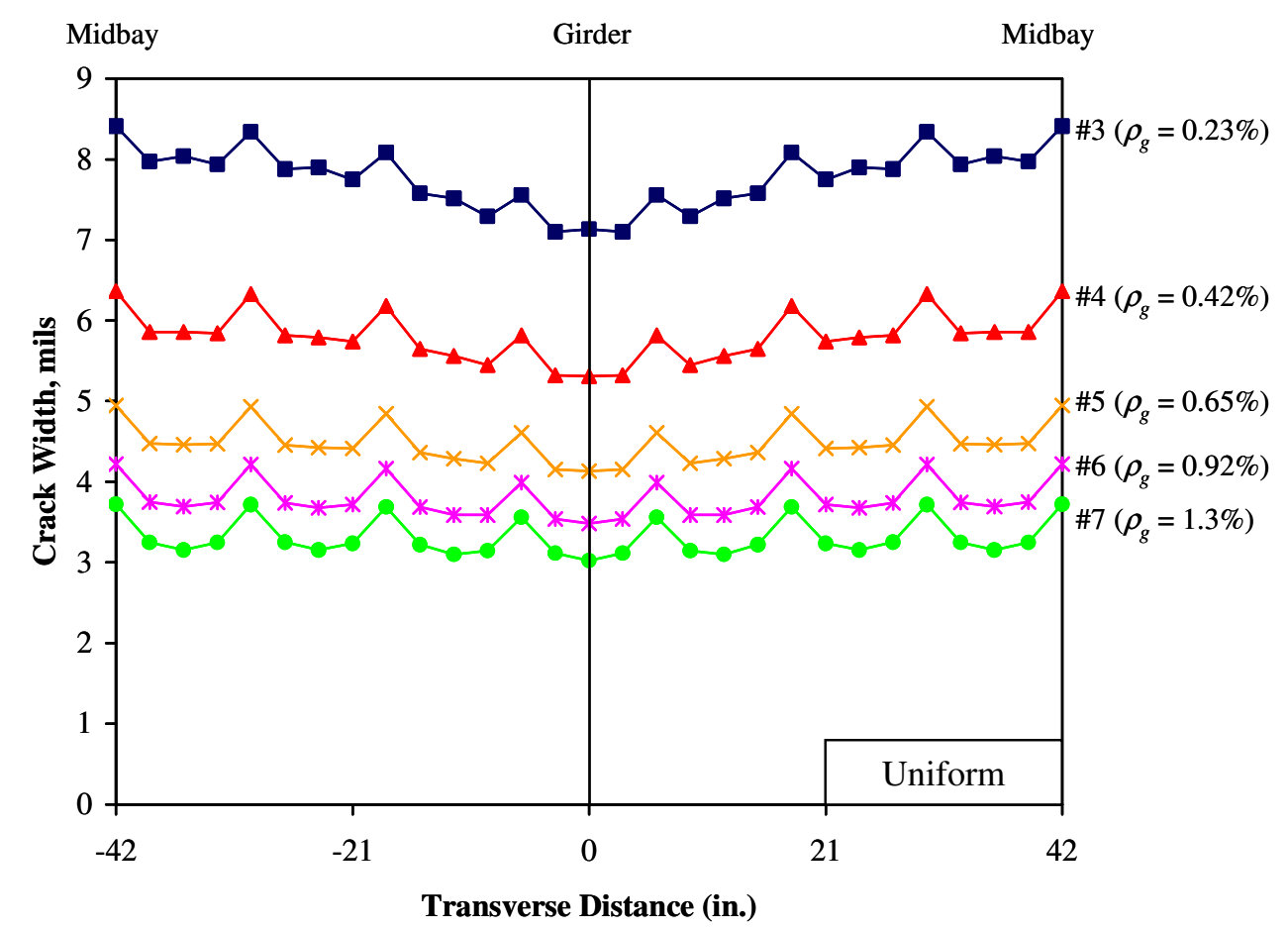

Figure 6.3: Variation of Initial Crack Widths Across Width of Deck

The average estimated crack width is compared to the amount of reinforcement provided in Figure 6.4. Both initial and final crack widths are presented. The average crack width decreases, but with increasingly diminished improvement as the amount of reinforcement provided is increased for both shrinkage cases. While initial crack widths estimated by the linear shrinkage model are generally less than the uniform shrinkage model, final crack widths are greater in the case of linear shrinkage. It is interesting to note that the reinforcement stress estimated by the model demonstrates a similar variation as the amount of reinforcement is increased (Figure 6.5). Furthermore, a clear relationship is noted between the estimated crack widths and the stress developed in the top layer of reinforcement especially for the linear shrinkage profile. This finding suggests that in the case of a bridge deck constructed with SIP forms, the top reinforcement is the primary mechanism for controlling excessive crack widths. The 
similarity in the variation of the crack width and average stress in the top reinforcement further indicates that crack widths in decks constructed with SIP forms can be effectively controlled by limiting the stresses that develop in the top layer of reinforcement.

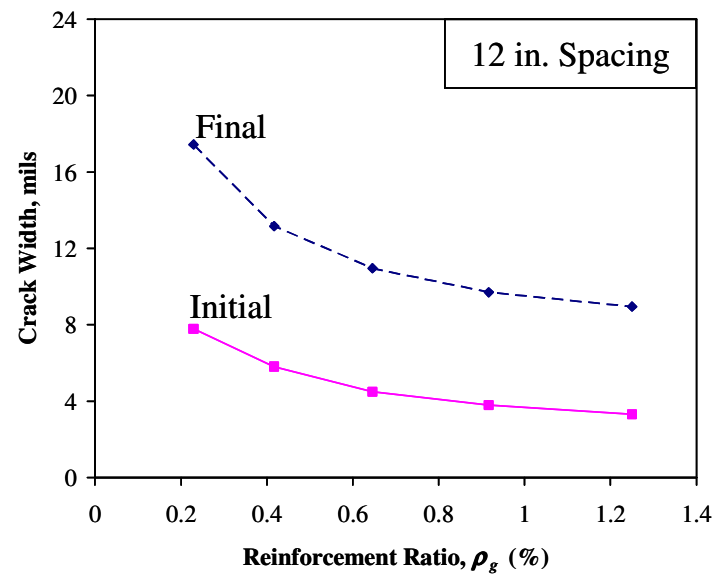

(a) Uniform Shrinkage

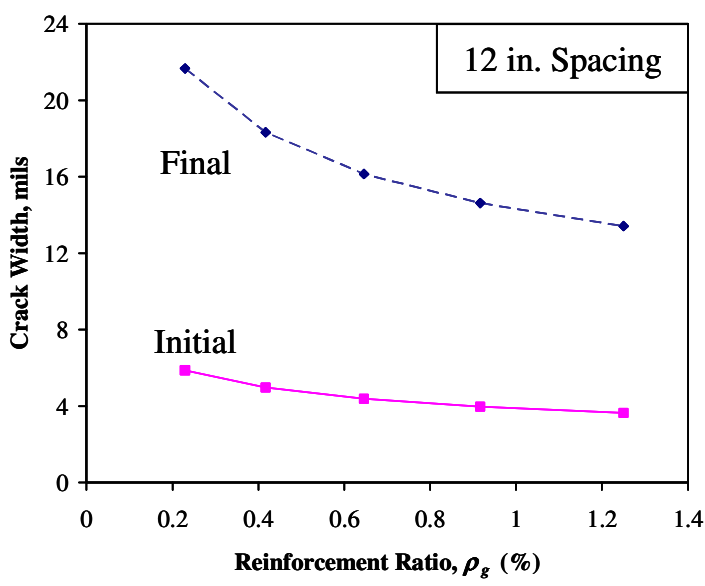

(b) Linear Shrinkage

Figure 6.4: Effect of Reinforcement Amount on Crack Widths

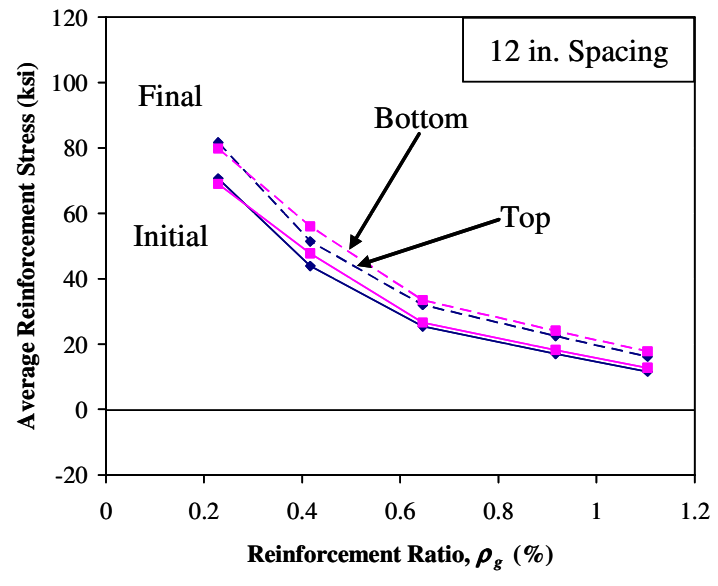

(a) Uniform Shrinkage

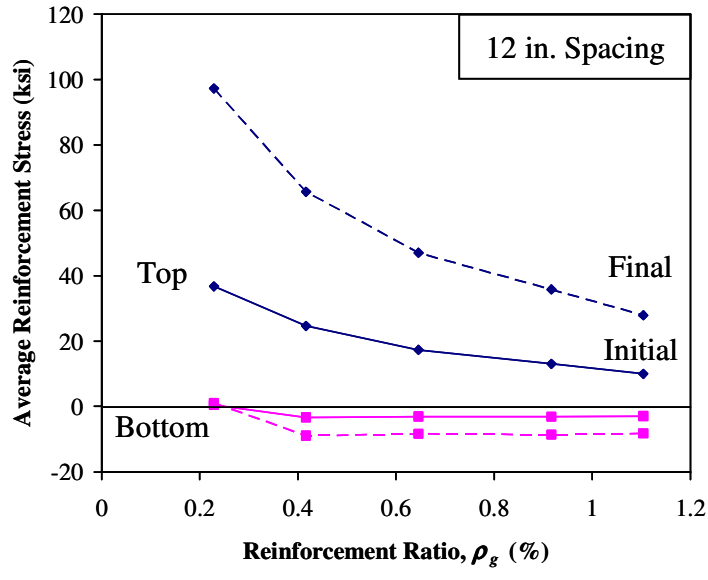

(b) Linear Shrinkage

Figure 6.5: Effect of Reinforcement Amount on Reinforcement Stress

The effect of the amount of reinforcement on the shrinkage required to develop cracking is presented in Figure 6.6. While the results are relatively insensitive to the amount of reinforcement provided in the case of linear shrinkage, larger amounts of 
reinforcement result in slightly lower shrinkage strains required for initial crack formation and a higher susceptibility to cracking in the case of uniform shrinkage. The shrinkage required for cracking decreases from $446 \mu \varepsilon$ to $370 \mu \varepsilon$ as the amount of reinforcement $\left(\rho_{g}\right)$ provided is increased from $0.23 \%$ to $1.10 \%$.

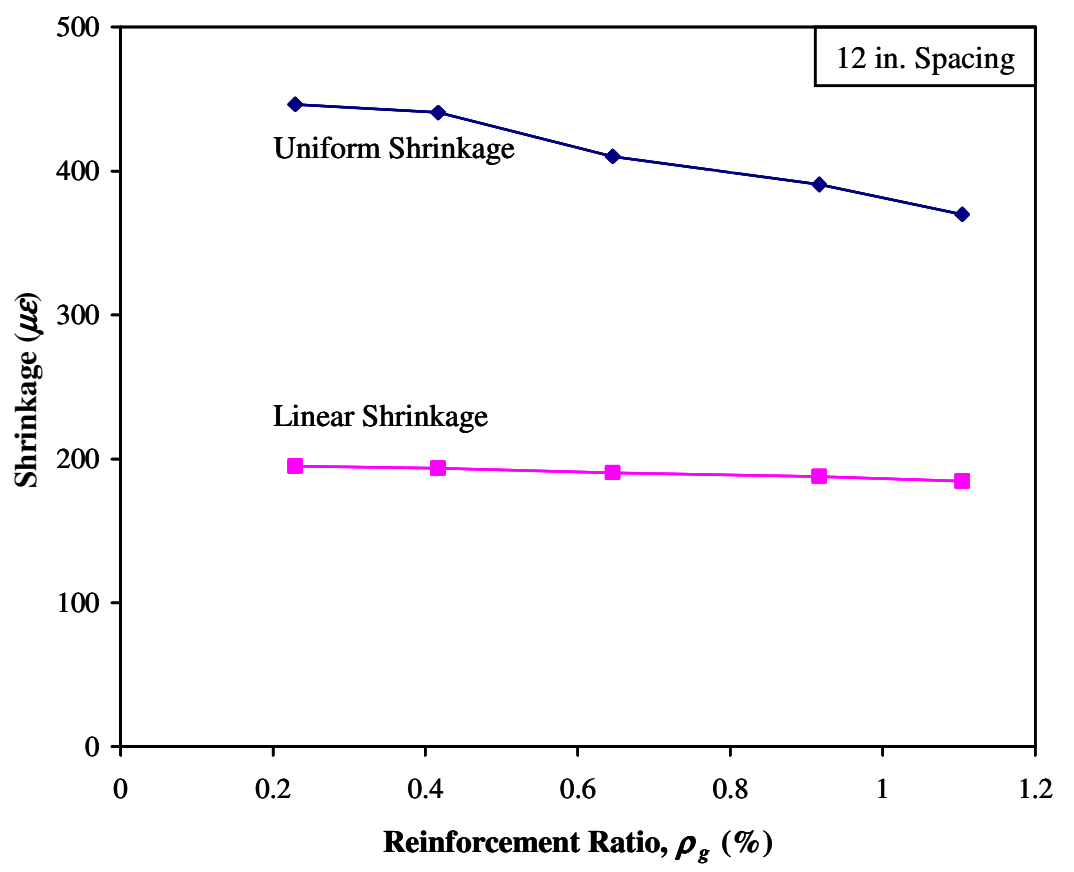

Figure 6.6: Effect of Amount of Reinforcement on Shrinkage Required for Cracking

\subsubsection{Reinforcement Spacing}

The spacing of the reinforcement was varied between 6 in. and 18 in. The effect of spacing was investigated with both the bar size held constant (\#5 bars per the control model) and with constant $\rho_{g}$ to isolate the effect of the spacing from the effect of the amount of reinforcement. Crack widths estimated by the finite element model with uniform shrinkage when the spacing of the reinforcement was varied are presented in Figure 6.7. The size of the reinforcement was modified as the spacing was varied such that the total amount of reinforcement corresponded to the amount of reinforcement provided in the control model $\left(\rho_{g}=0.65 \%\right)$. As shown, both the overall crack widths and the variation in crack widths are affected by the reinforcement spacing. Large bar spacings provide for increased crack widths and increased variability across the width of the bridge. As shown in Figure 6.8, the relationship between average crack width and reinforcement spacing is nearly linear. 


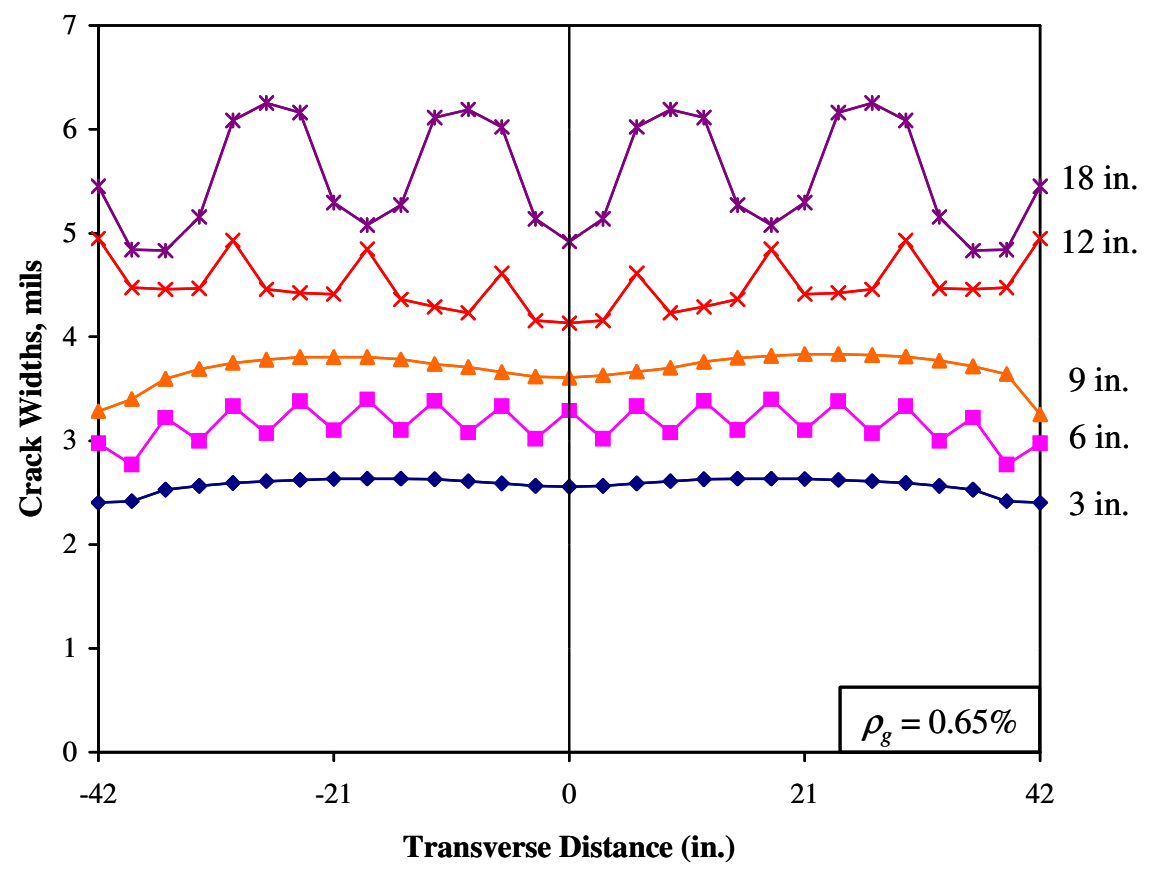

Figure 6.7: Effect of Bar Spacing on Crack Widths (Uniform Shrinkage)

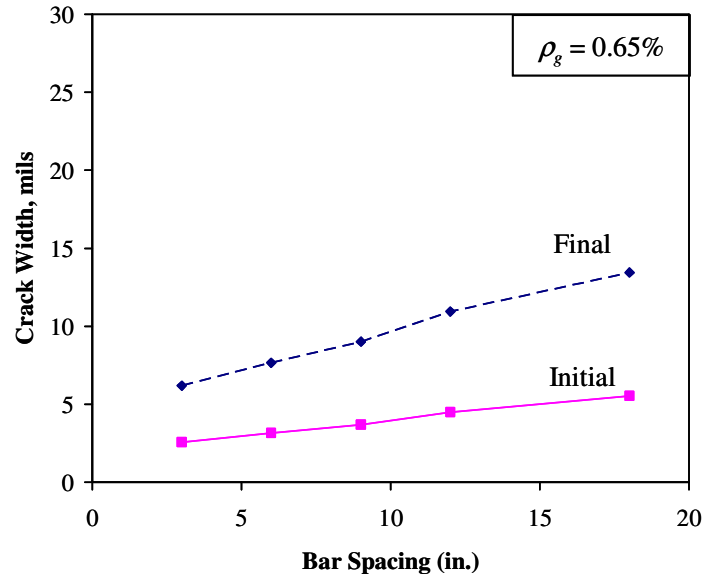

(a) Uniform Shrinkage

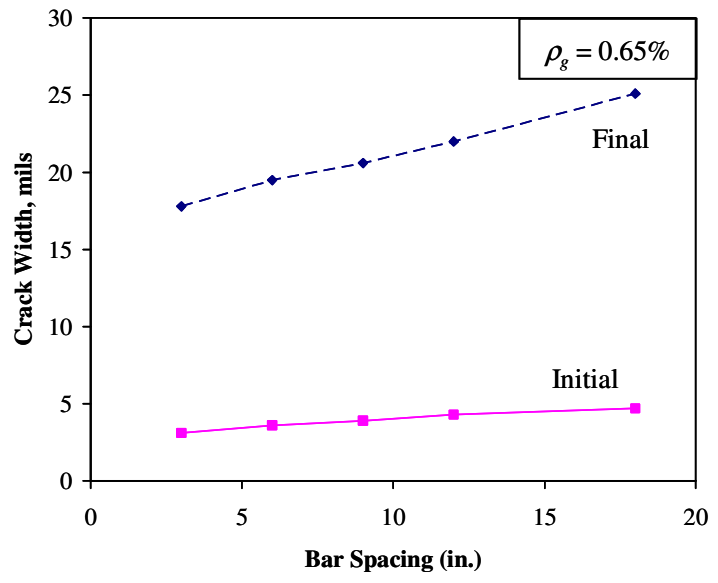

(b) Linear Shrinkage

Figure 6.8: Effect of Bar Spacing on Average Crack Widths

The average stress in the reinforcement at the time of cracking is presented in Figure 6.9. The models do not appear to demonstrate a significant change in average bar stress as the reinforcement spacing is varied. However, if the bar size is held constant (\#5 
bars) while the spacing is varied, a similar trend is obtained as to that observed when the bar size was varied and spacing was held constant (Figure 6.10). Based on this analysis, it can be concluded that the stress which develops in the reinforcement is primarily related to the amount of reinforcement provided and not the spacing of the reinforcement. The crack width on the other hand is controlled by the bar spacing.

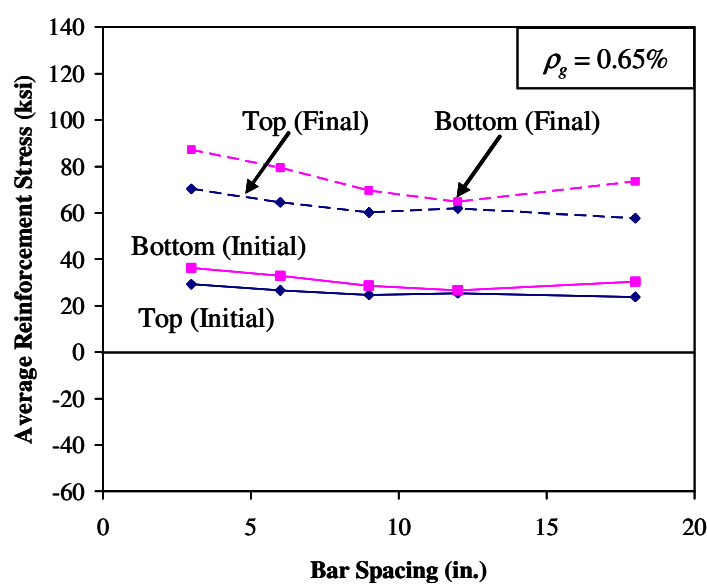

(a) Uniform Shrinkage

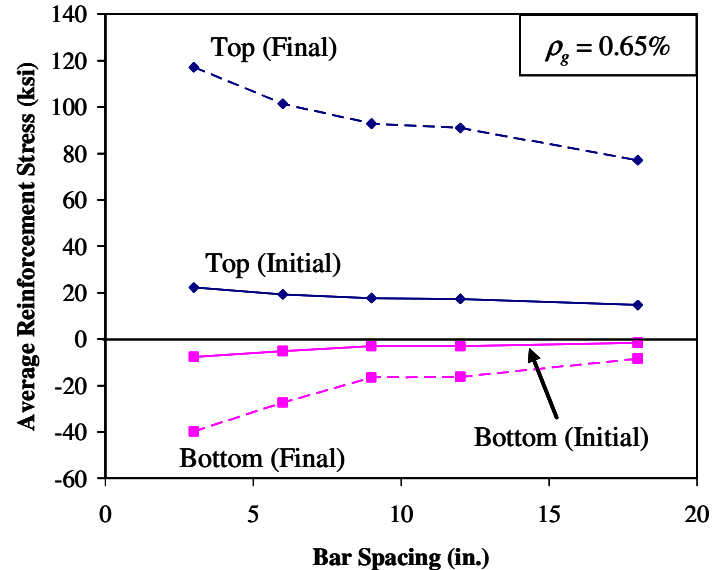

(b) Linear Shrinkage

Figure 6.9: Effect of Bar Spacing on Reinforcement Stress

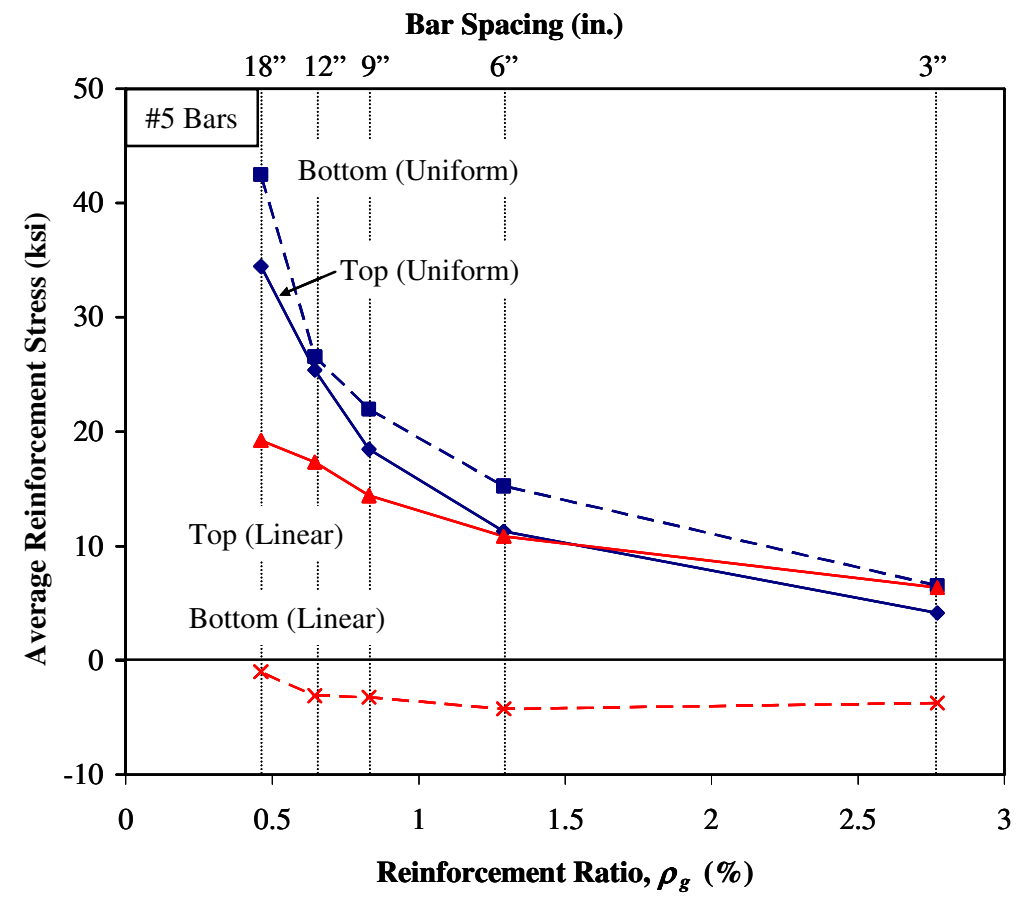

Figure 6.10: Effect of Bar Spacing on Reinforcement Stress (Initial Cracking) 
While the reinforcement spacing affects the width of cracks which develop in the deck, the effect on the amount of shrinkage required to initiate cracking is negligible (Figure 6.11). In this analysis, the amount of reinforcement was held constant to isolate the effect of reinforcement spacing. For both uniform and linear shrinkage, the reinforcement spacing does not contribute toward increasing resistance to the formation of cracks.

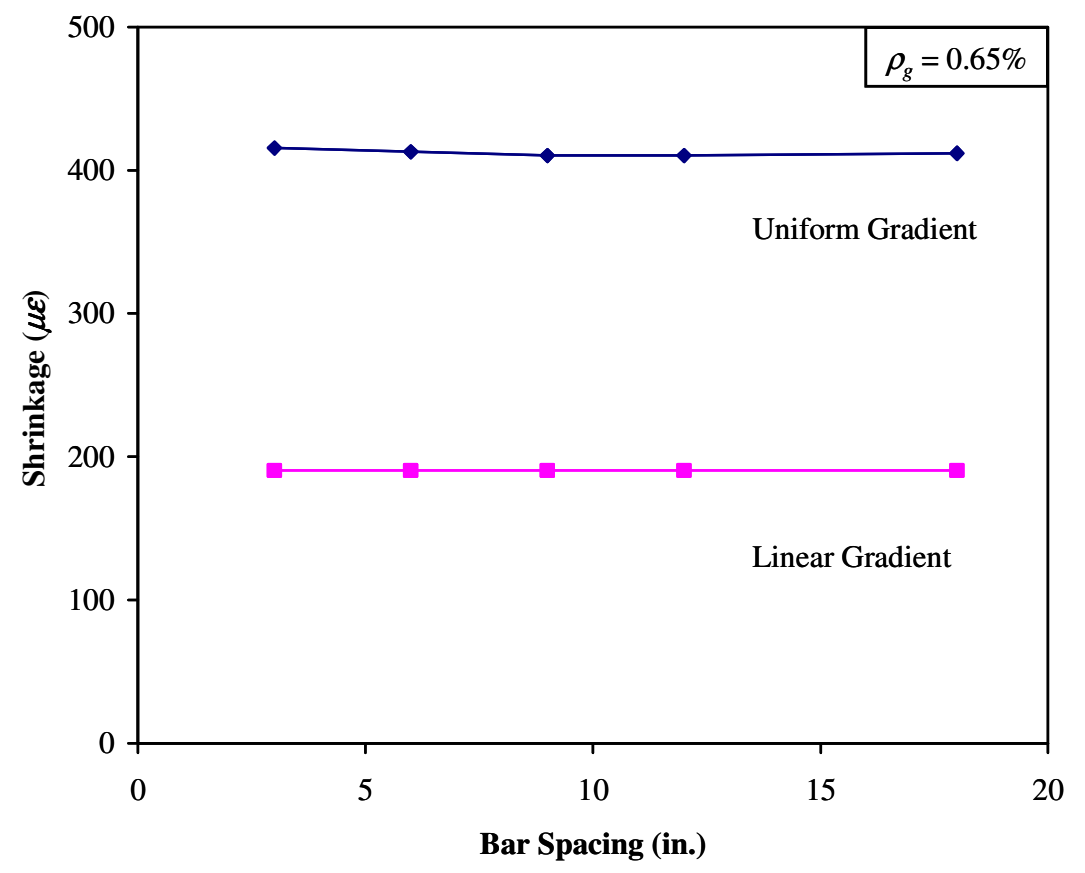

Figure 6.11: Effect of Bar Spacing on Shrinkage Required for Cracking

\subsubsection{Reinforcement Material}

The difference in reinforcement material was investigated by modifying the modulus of elasticity of the reinforcement to match that of FRP reinforcement $\left(E_{f}=6900\right.$ ksi for glass FRP) and by factoring the crack widths calculated by the model to account for the difference in bond characteristics between steel and FRP bars. The performance of a deck reinforced with FRP bars is compared to the performance of a deck reinforced with steel bars in Figure 6.12. The predicted crack widths for the FRP model were factored by 1.5 for the case of uniform shrinkage and 1.3 for the case of linear shrinkage, as discussed in Section 5.4.2, to account for additional slip between the FRP reinforcement and concrete. In both cases, \#5 bars at a spacing of 12 in. were modeled. The model predicts significantly larger crack widths when FRP bars are used as the deck reinforcement. The average crack width at the instant of cracking for the FRP model was $0.017 \mathrm{in}$. while the average width was $0.004 \mathrm{in}$. for the steel reinforcement. Therefore, for a bridge deck with FRP reinforcement spaced at 12 in., the predicted crack width is 4 
times greater than that of a crack in a deck incorporating steel reinforcement with identical bar spacings.

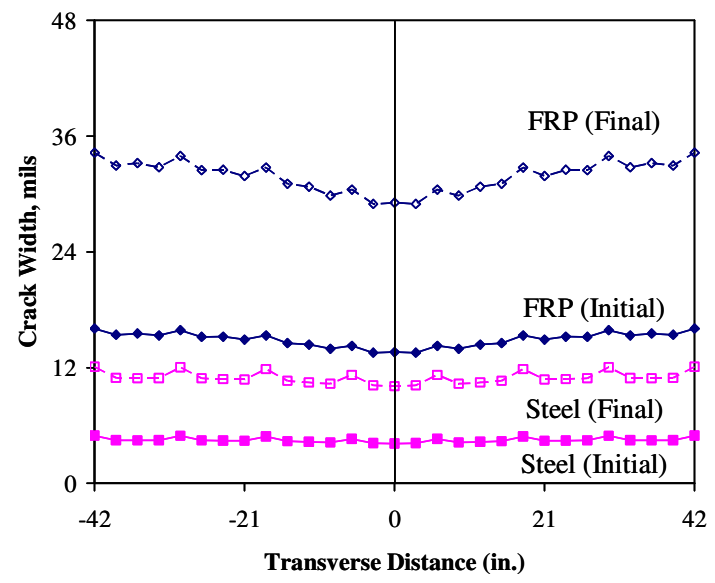

(a) Uniform Shrinkage

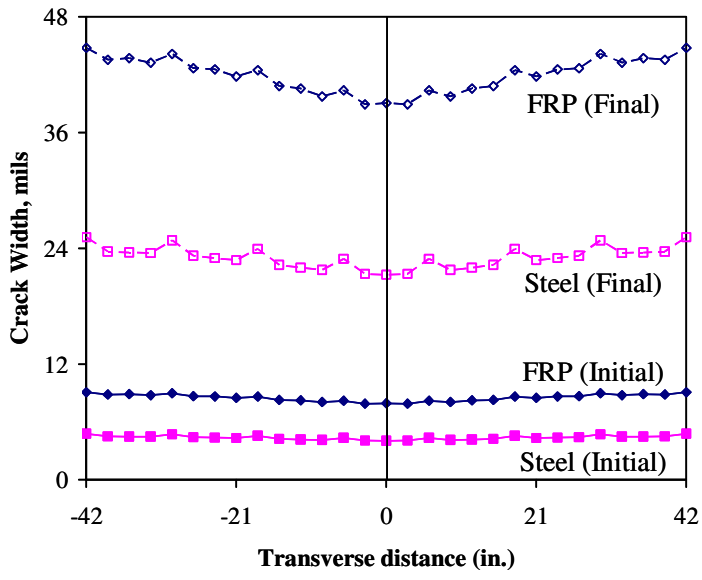

(b) Linear Shrinkage

Figure 6.12: Comparison of Crack Widths (Steel versus FRP)

It was expected that the average crack widths estimated by the model with FRP reinforcement would exhibit a similar variation in crack widths to that of steel reinforcement when the bar spacing was varied (Figure 6.13) for uniform shrinkage. However, it is interesting to note that if the factor used to account for slip between the FRP and concrete (1.5 for uniform and 1.3 for linear) is neglected, the crack widths estimated by the model do not scale between the two materials considering only the modulii of elasticity. The modular ratio, $n$, of steel to FRP in this model is 4.2. The average crack width for an FRP reinforced deck is between 3.1 (3 in. spacing) and 2.0 (18 in. spacing) times larger than those estimated when steel reinforcement is modeled, without accounting for slip. Thus, while the lower stiffness of the FRP reinforcement contributes to increased crack widths, there does not appear to be a direct relationship between crack widths and the stiffness of the reinforcement across the crack.

Furthermore, as the spacing of the reinforcement is decreased, the contribution of the modulus of elasticity to the crack width is reduced. 


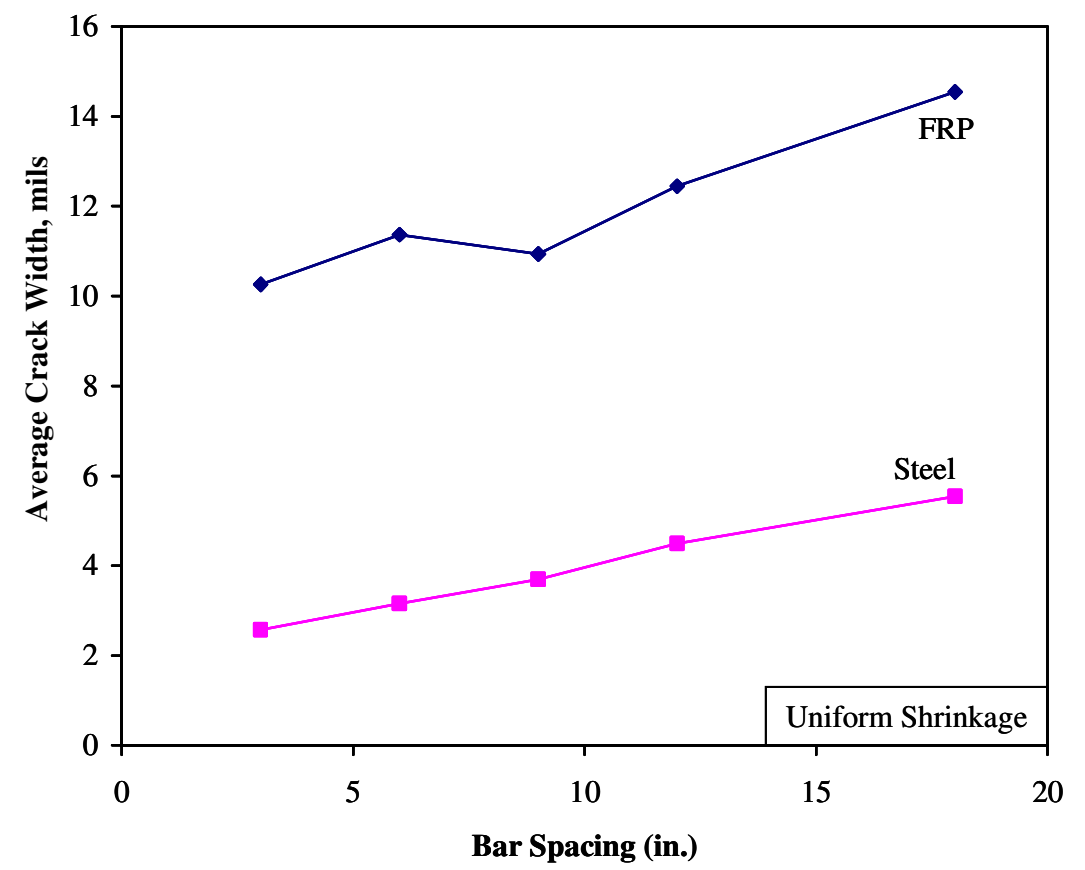

Figure 6.13: Effect of Bar Spacing on Crack Widths (Steel and FRP)

\subsection{Influence of Girders}

The influence of the girders on the cracking behavior of the bridge deck was investigated. The effects of both the depth and spacing of girders in the superstructure were examined.

\subsubsection{Girder Depth}

To investigate the effect of the depth of the girder on the deck behavior, the depth was varied between 12 and $51 \mathrm{in}$. As isolating the influence of the depth of the girder was of interest, the effect of the girder depth was investigated considering varying depth along with its corresponding varying flexural stiffness $\left(I_{g}\right)$ as well as varying depth with a constant flexural stiffness. For the case of varying girder depth with corresponding varying flexural stiffness, the flange and web thicknesses were held constant with the values selected according to the control model. To maintain a constant moment of inertia in the girder as the depth of the girder was decreased, the thickness of the top and bottom flange were varied, as illustrated in Figure 6.14. The widths of the top and bottom flanges were held constant. The top flange width was held constant to ensure similar levels of restraint between the girder and the slab as in the control model. There was some overlap between the web and the flanges occurred as a result of the properties of the plate elements used. 

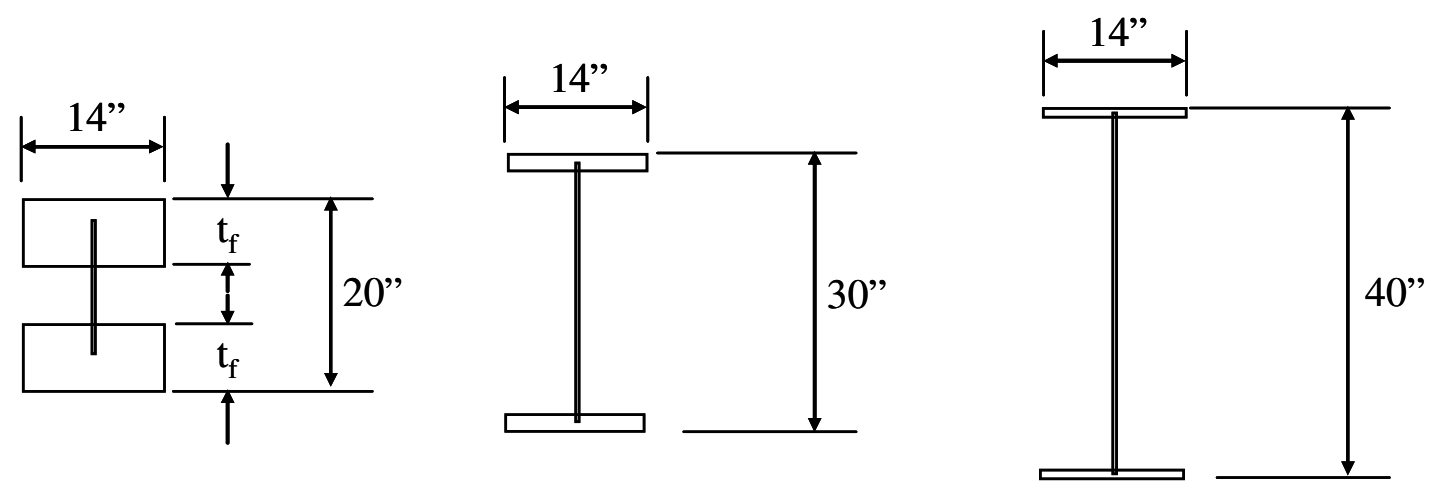

$$
\begin{gathered}
A_{g}=204.9 \text { in. }^{2} \\
I_{g}=26,400 \text { in. }^{4} \\
t_{f}=8.8 \text { in. }
\end{gathered}
$$

$$
\begin{gathered}
\mathrm{A}_{\mathrm{g}}=77.0 \mathrm{in.}^{2} \\
\mathrm{I}_{\mathrm{g}}=26,400 \mathrm{in}^{4}{ }^{4} \\
\mathrm{t}_{\mathrm{f}}=4.1 \mathrm{in} .
\end{gathered}
$$

$$
\begin{gathered}
\mathrm{A}_{g}=48.3 \mathrm{in}^{2} \\
\mathrm{I}_{g}=26,400 \mathrm{in}^{4} \\
t_{f}=2.2 \mathrm{in} .
\end{gathered}
$$

Figure 6.14: Constant Stiffness Girder Dimensions

The effect of girder depth with variable flexural stiffness on crack widths is presented in Figure 6.15. Both initial and final crack widths increase as the girder depth was increased. However, when the effect of the depth of the girder was isolated by holding the flexural stiffness constant (Figure 6.16), initial crack widths were determined to be relatively insensitive to the depth of the girder. Final crack widths were found to decrease as girder depth increased, especially for the uniform shrinkage case. Thus, a relatively flexible, deep girder would result in improved bridge deck performance compared to a girder with the same depth but with greater flexural stiffness.

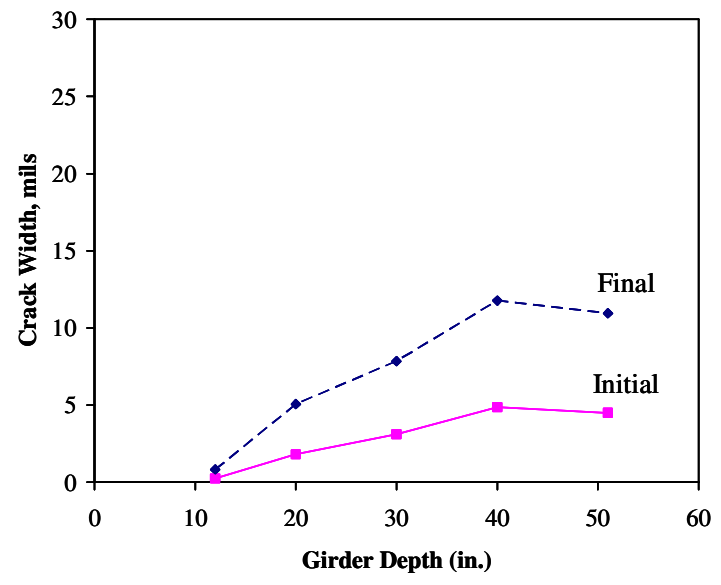

(a) Uniform Shrinkage

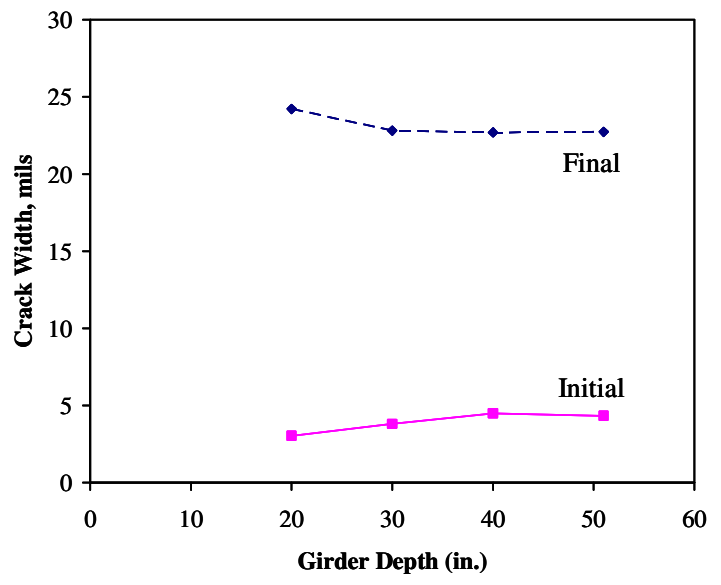

(b) Linear Shrinkage

Figure 6.15: Effect of Girder Depth on Crack Widths (Variable Stiffness) 


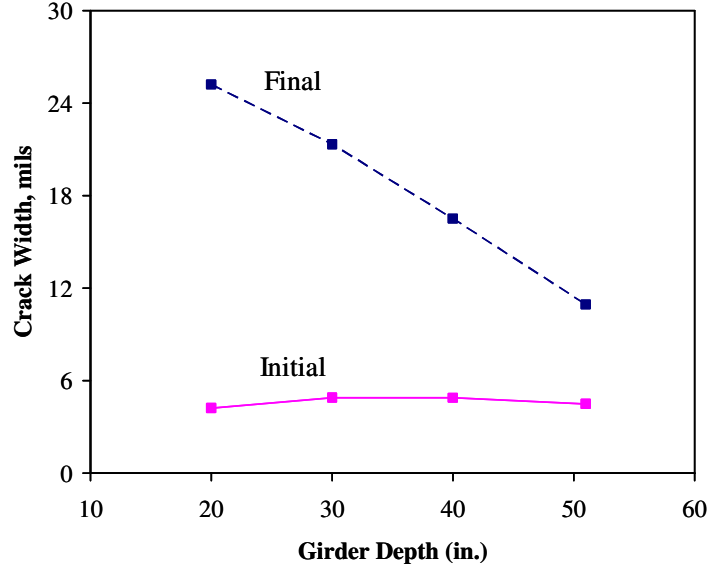

(a) Uniform Shrinkage

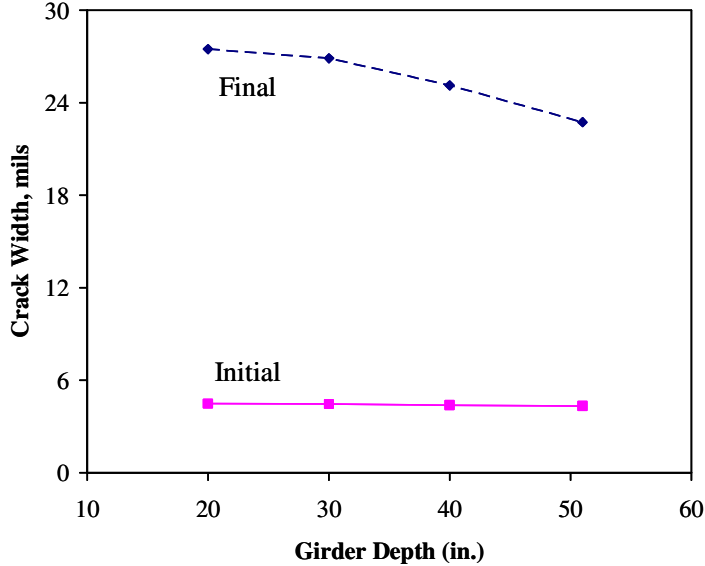

(b) Linear Shrinkage

Figure 6.16: Effect of Girder Depth on Crack Widths (Constant Stiffness)

The average stress in both the top and bottom reinforcement increases as the depth of the girder is increased when uniform shrinkage is applied to the model (Figure 6.17). However, when linear shrinkage is applied there does not appear to be any significant variation in the average reinforcement stress across a crack. Therefore, a deck that has been constructed using SIP forms, which prevents moisture loss from one of the surfaces of the deck, does not appear to be affected by increasing the depth of the girder.

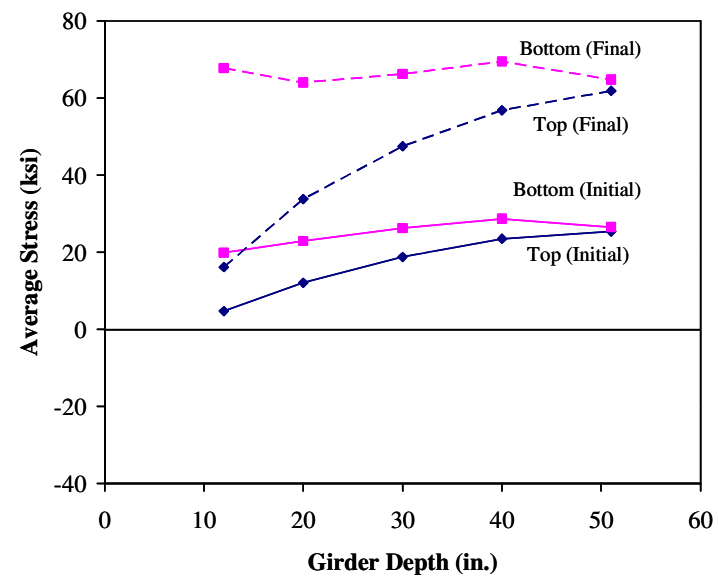

(a) Uniform Shrinkage

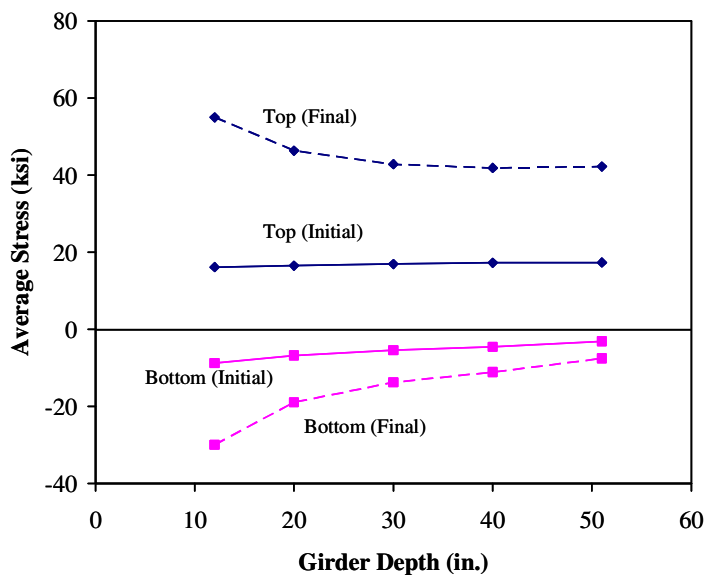

(b) Linear Shrinkage

Figure 6.17: Effect of Girder Depth on Bar Stress (Variable Stiffness) 
It should be noted that as the depth of the girder is increased, the stiffness of the girder in the model is increased. If the stiffness of the girder is held constant by setting the girder moment of inertia $I_{g}$ equal to the moment of inertia of the control model girder $\left(I_{g}=26,400\right.$ in. $\left.^{4}\right)$, the effect of increasing the girder depth on the average reinforcement stress across the crack drops somewhat for a uniform profile, but is negligible for the linear shrinkage case (Figure 6.18). Based on this analysis, the depth of the girder does not significantly affect either the cracking behavior or reinforcement stresses for decks utilizing SIP forms (linear shrinkage profile).

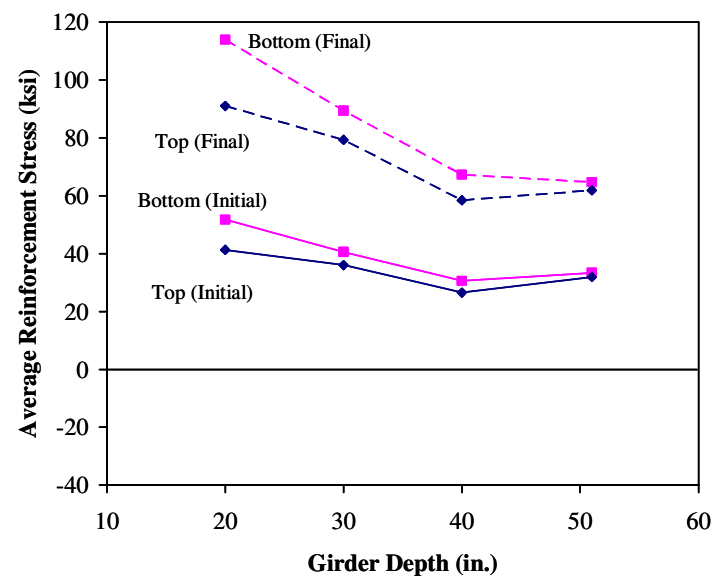

(a) Uniform Shrinkage

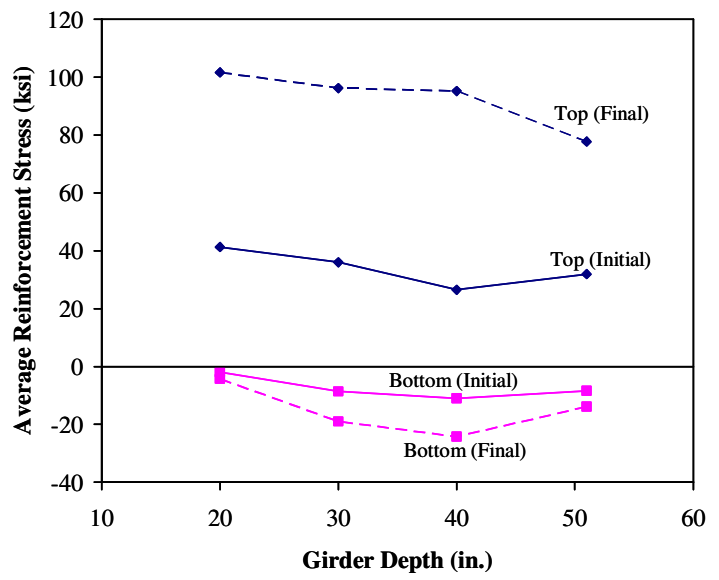

(b) Linear Shrinkage

\section{Figure 6.18: Effect of Girder Depth on Reinforcement Stress (Constant Stiffness)}

It is interesting to note that the amount of free shrinkage required to initiate a crack in the deck increases significantly as the depth of the girder is increased as shown in Figure 6.19. While the amount of free shrinkage required for a crack does not vary significantly with a change in girder depth when linear shrinkage is applied, the shrinkage necessary for cracking for the uniform shrinkage case increases from $213 \mu \varepsilon$ to $410 \mu \varepsilon$ as the girder depth is increased from 20 in. to 51 in., respectively. As noted in Figure 6.19, the girder stiffness was held constant. Thus, by increasing the depth of the girder without increasing the flexural stiffness in a situation where uniform shrinkage would be present (non-permanent forms), the resistance of a bridge deck to cracking can be increased. 


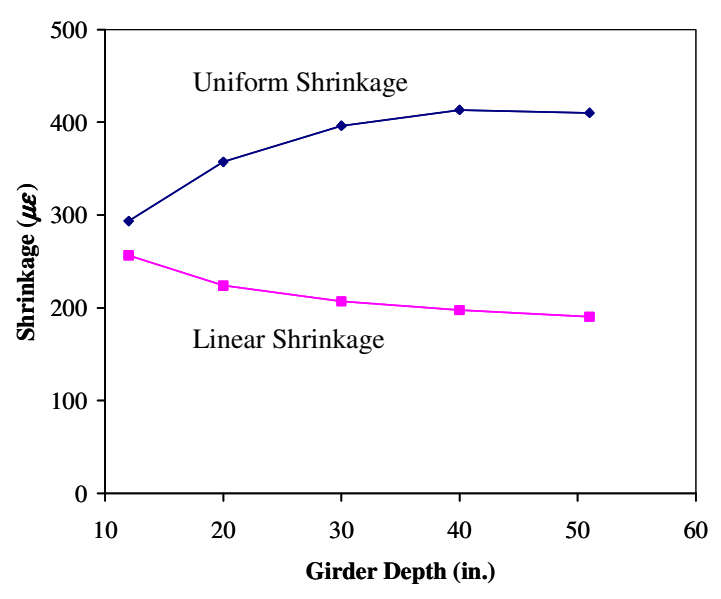

(a) Variable Stiffness

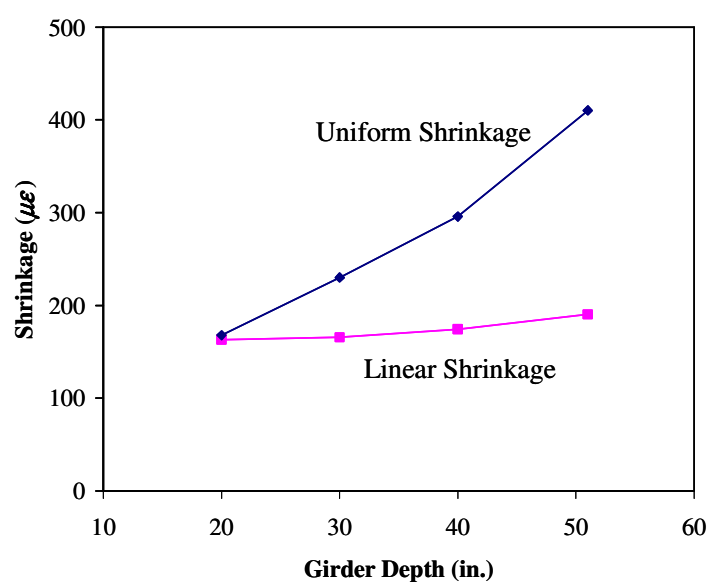

(b) Constant Stiffness

\section{Figure 6.19: Effect of Girder Depth on Shrinkage Required for Cracking (Constant Girder Stiffness)}

\subsubsection{Girder Spacing}

The spacing of the girders was varied by increasing and decreasing the width of the slab over the girder. The reinforcement size and spacing were held constant ( $\# 5$ bars spaced at 12 in.) which maintained a constant reinforcement amount in the deck $\left(\rho_{g}=\right.$ $0.65 \%)$.

The effect of the girder spacing is presented in Figure 6.20. While both initial and final crack widths do not significantly vary with girder spacing in the case of linear shrinkage, final crack widths decrease as the spacing of the girders increase. This trend is expected as the overall amount of restraint in the deck decreases as the girder spacing increases. 


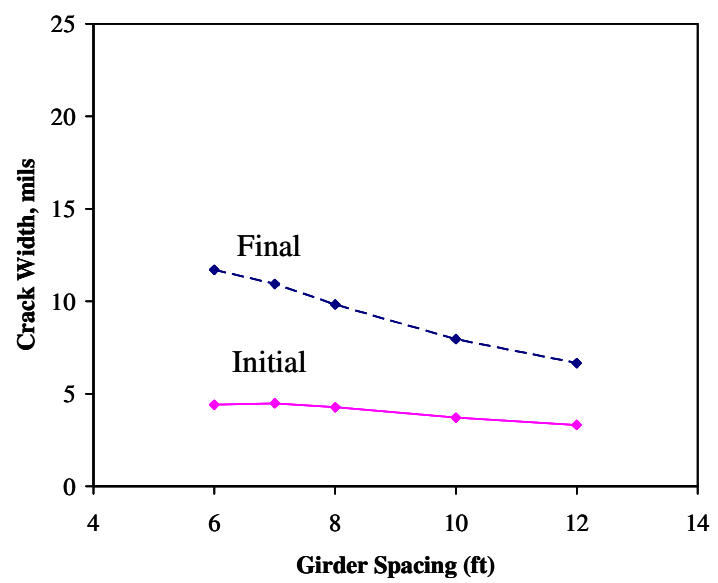

(a) Uniform Shrinkage

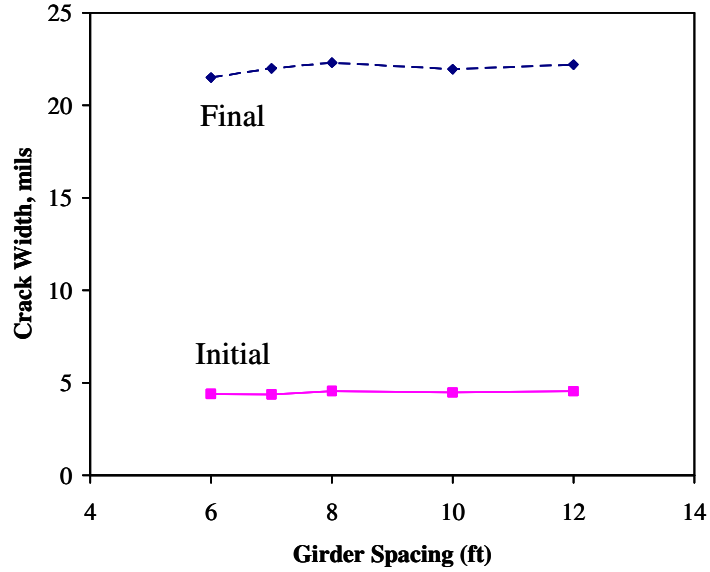

(b) Linear Shrinkage

Figure 6.20: Effect of Girder Spacing on Crack Widths

The variation of the average reinforcement stress crossing a crack as the spacing of the girders is changed is presented in Figure 6.21. As the girder spacing is increased, for uniform shrinkage the average stress in the reinforcement across the crack decreases slightly. When linear shrinkage is considered, there does not appear to be a clear relationship between average stress in the reinforcement and the spacing of the girders in the superstructure.

As presented in Figure 6.22, increased girder spacings are beneficial for increasing the resistance of the bridge deck to the formation of cracks in the deck. When uniform shrinkage is applied, the shrinkage required for crack formation increases from $396 \mu \varepsilon$ to $498 \mu \varepsilon$ as the girder spacing is increased from $6 \mathrm{ft}$ to $12 \mathrm{ft}$, respectively. The benefit of larger girder spacing, however, is marginal in the case of a linear shrinkage as expected with the use of SIP forms. 


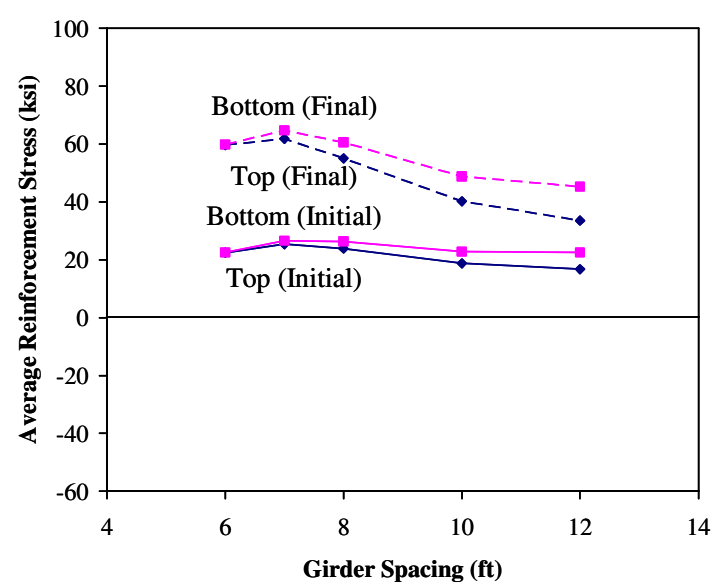

(a) Uniform Shrinkage

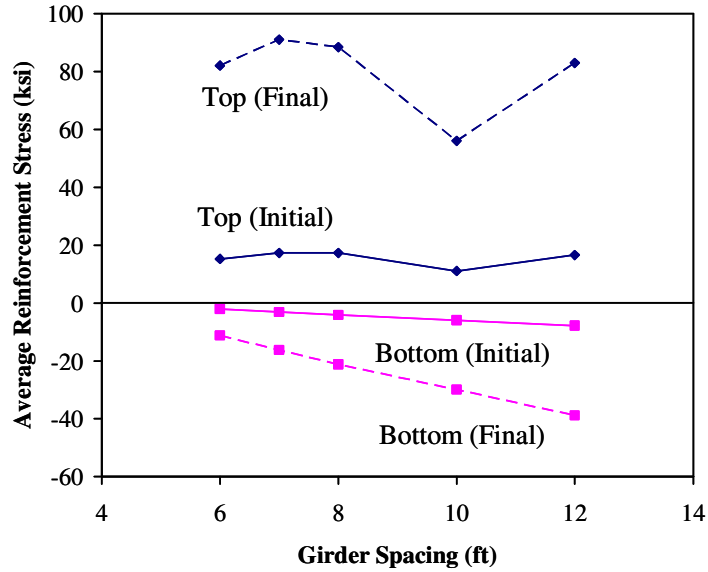

(b) Linear Shrinkage

Figure 6.21: Effect of Girder Spacing on Reinforcement Stress

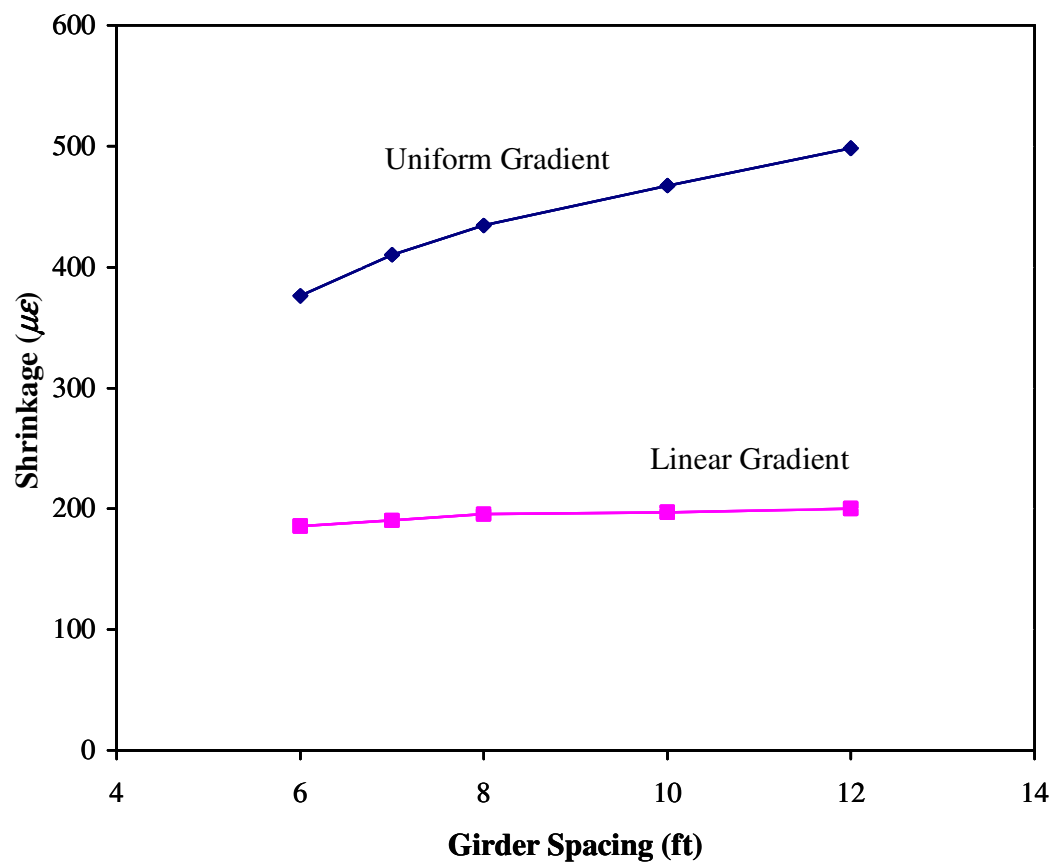

Figure 6.22: Effect of Girder Spacing on Shrinkage Required for Cracking 


\subsection{Influence of the Deck}

The design characteristics of the bridge deck were investigated to assess their influence on the cracking behavior. Apart from reinforcement detailing, the influence of the deck thickness and concrete strength used in the deck were of interest.

\subsubsection{Deck Thickness}

The thickness of the deck was varied between 6 and 12 in. As the deck thickness was varied, the reinforcement size and spacing were held constant which resulted in a decrease in $\rho_{g}$ in the deck. The effect of the deck thickness on crack widths is presented in Figure 6.23. While the width of initial crack widths was relatively insensitive to the deck thickness, the final crack widths decreased slightly as the thickness of the deck increased. Furthermore, final crack widths were significantly larger for the linear shrinkage case.

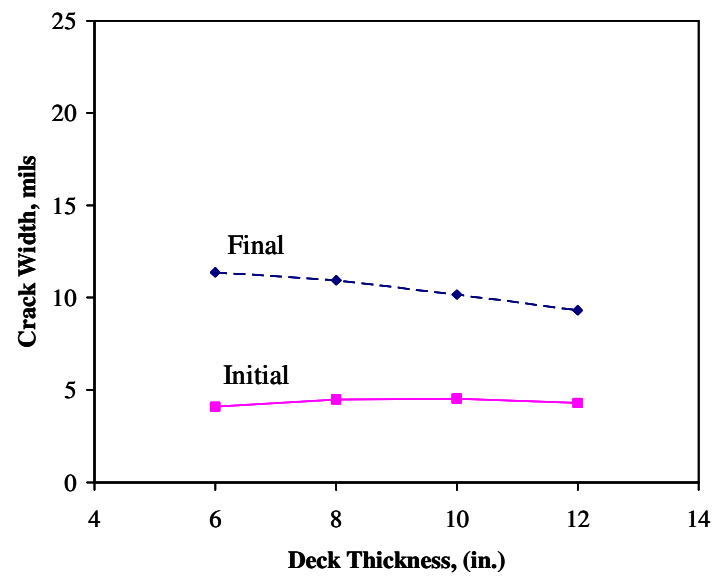

(a) Uniform Shrinkage

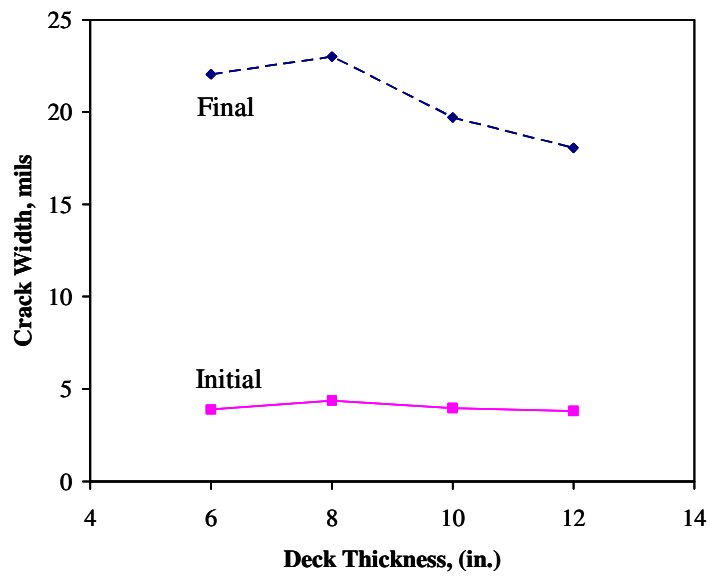

(b) Linear Shrinkage

Figure 6.23: Effect of Deck Thickness on Crack Widths

The variation of the average reinforcement stress across a crack is presented in Figure 6.24. No significant correlation was observed between the average stress and thickness of the deck for the case of uniform shrinkage. For linear shrinkage, however, the average top reinforcement stress increases as the deck thickness increases. While the average bottom stress becomes increasingly compressive, the average top reinforcement stress increases from $12 \mathrm{ksi}$ to $24 \mathrm{ksi}$ in tension and the bottom reinforcement stress increases in compression from $0.2 \mathrm{ksi}$ (tension) to $9 \mathrm{ksi}$ (compression). The change in stress can be attributed to the decrease in $\rho_{g}$ as the deck thickness is increased. 


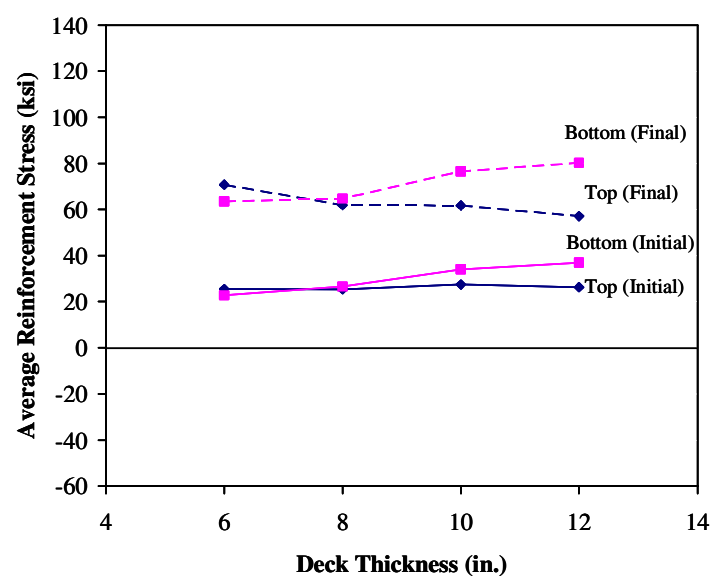

(a) Uniform Shrinkage

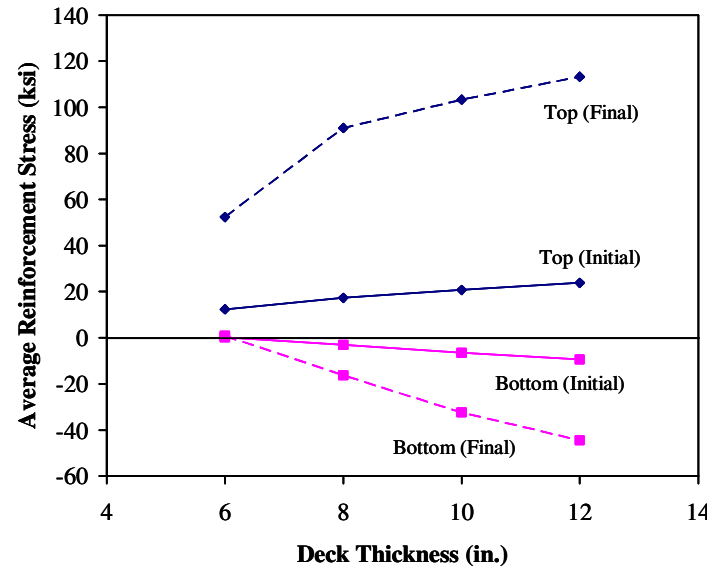

(b) Linear Shrinkage

Figure 6.24: Effect of Deck Thickness on Reinforcement Stress

The amount of shrinkage required to initiate cracking for varying deck thicknesses is presented in Figure 6.25. A strong correlation between the thickness of the deck and the amount of shrinkage required to form a crack does not exist for the linear shrinkage case. For uniform shrinkage, however, thicker decks require more shrinkage than thinner decks to develop cracking. The shrinkage for crack formation increases from $360 \mu \varepsilon$ to $461 \mu \varepsilon$ as the deck thickness is increased from 6 to 12 in. 


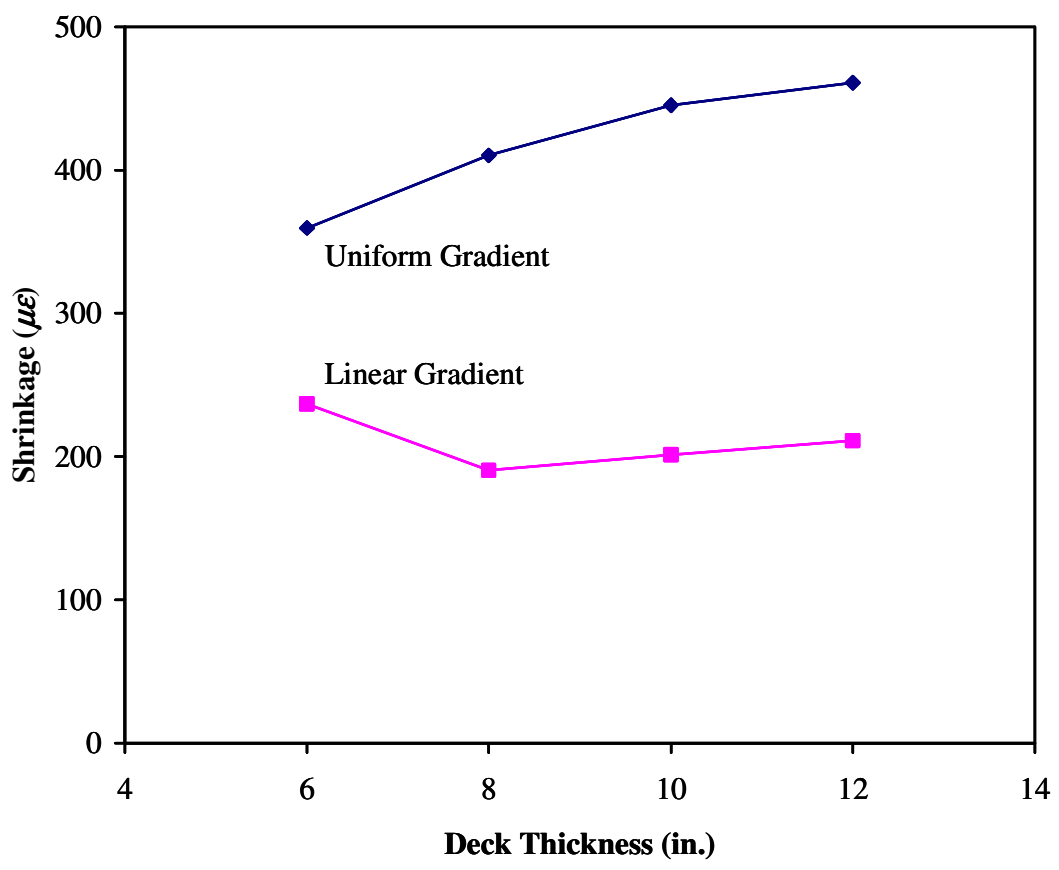

Figure 6.25: Effect of Deck Thickness on Shrinkage Required for Cracking

\subsubsection{Deck Concrete Strength}

The compressive strength $f_{c}$ was varied between $3000 \mathrm{psi}$ and 10,000 psi. The tensile strength of concrete was estimated as $f_{t}=6 \sqrt{f_{c}}$ and varied between $330 \mathrm{psi}$ and $600 \mathrm{psi}$ for the concrete strengths investigated. The modulus of elasticity was computed as $E_{c}=57,000 \sqrt{f_{c}}$ based on ACI 318 (2005) and varied between 3100 psi and 5700 psi.

The effect of the concrete strength on crack widths is presented in Figure 6.26. The initial crack widths for both uniform and linear shrinkage are not significantly affected by a change in the concrete compressive strength. In addition, crack widths for both cases are approximately the same (4.6 mils). Final crack widths demonstrate a similar insensitivity to variations in the concrete strength. Final crack widths, resulting from linear shrinkage however, are, on average, 2.3 times larger than crack widths which develop when uniform shrinkage is applied. 


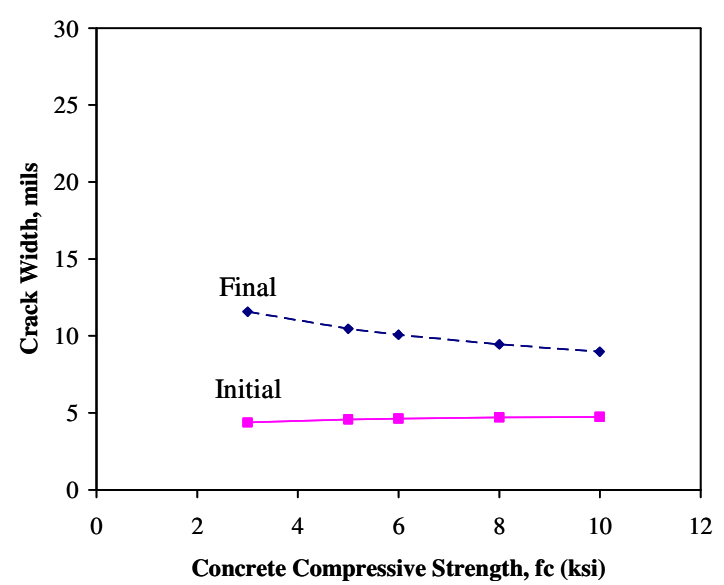

(a) Uniform Shrinkage

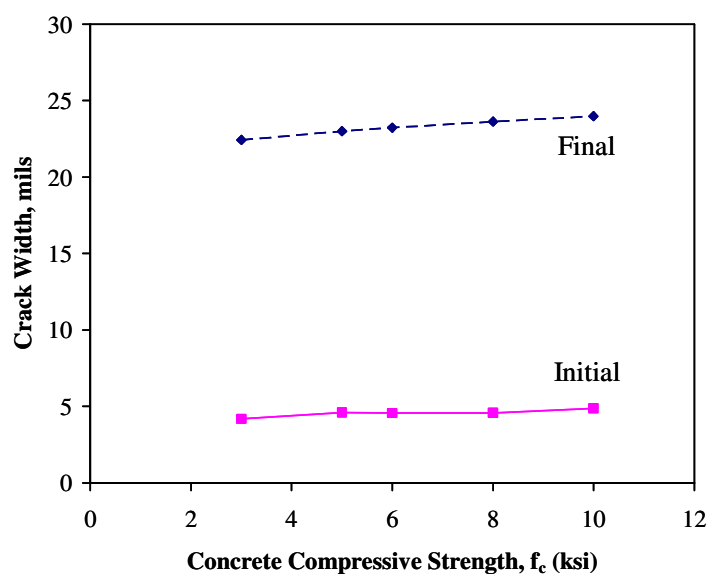

(b) Linear Shrinkage

Figure 6.26: Effect of Concrete Strength on Crack Widths

The variation in average reinforcement stress across the crack with concrete compressive strength is presented in Figure 6.27. For uniform shrinkage, the average reinforcement stress increased as the concrete compressive strength increased. For linear shrinkage, tensile stress in the top reinforcement increased and compressive stress in the bottom reinforcement increased as the compressive strength was increased. While a relationship between concrete compressive strength and reinforcement stress is evident in Figure 6.27, further analysis of the results indicates a direct relationship between the average reinforcement stress and the concrete tensile strength (Figure 6.28).

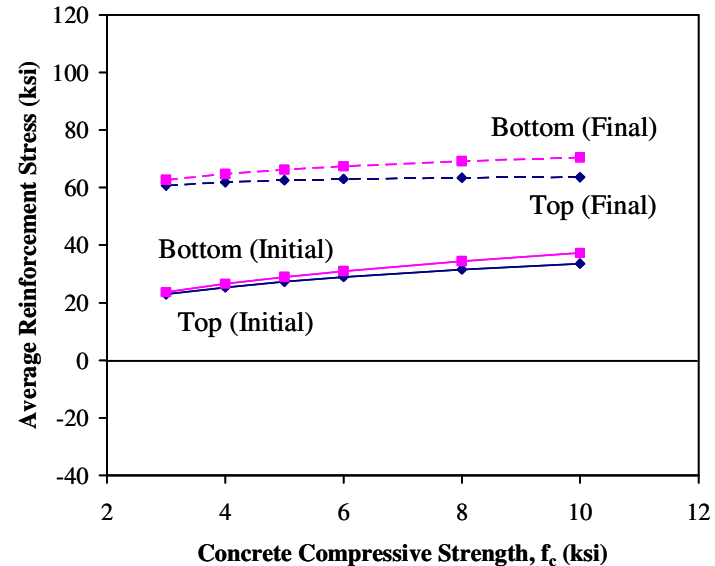

(a) Uniform Shrinkage

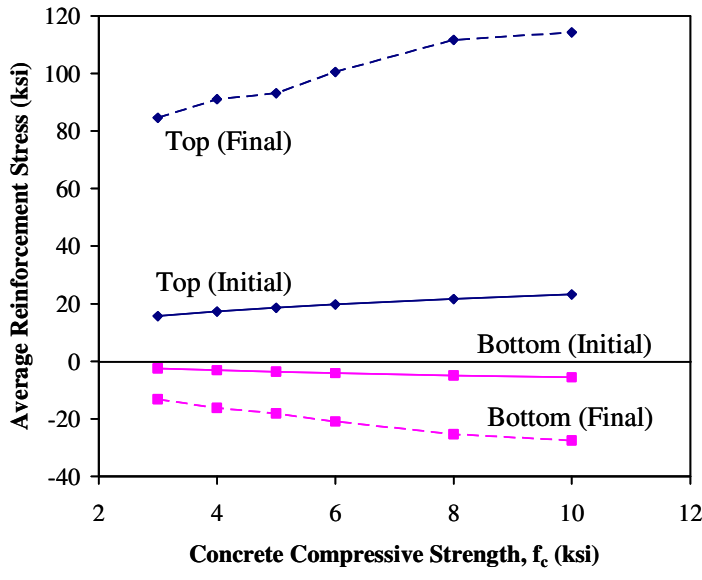

(b) Linear Shrinkage

Figure 6.27: Effect of Concrete Compressive Strength on Reinforcement Stress 


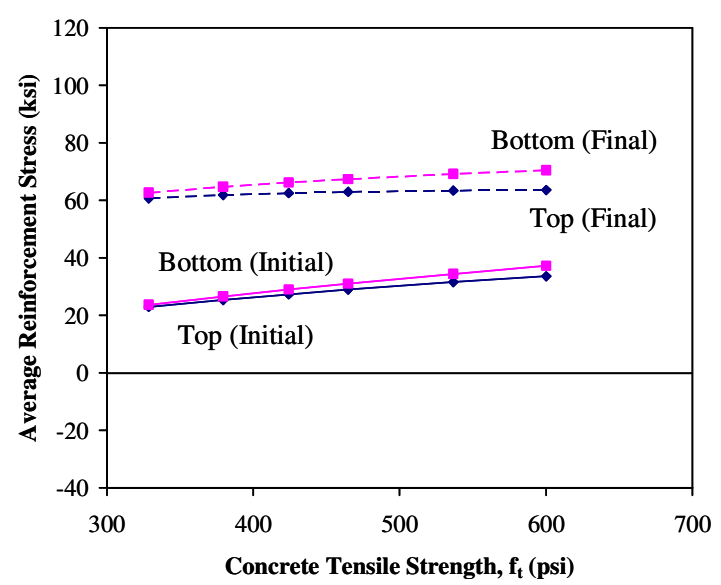

(a) Uniform Shrinkage

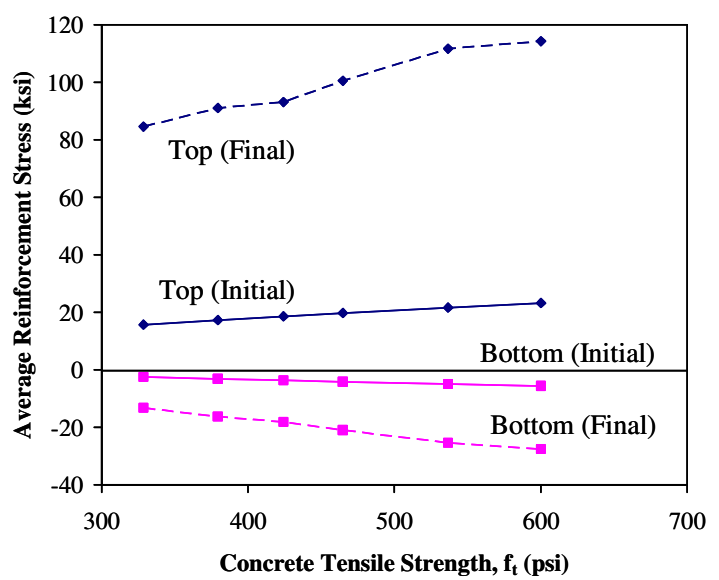

(b) Linear Shrinkage

Figure 6.28: Effect of Concrete Tensile Strength on Reinforcement Stress

The effect of compressive and tensile concrete strengths on the amount of shrinkage required to initiate cracking is presented in Figure 6.29. The uniform shrinkage model indicates that as concrete strength increases, the amount of shrinkage required to initiate cracking increases. However, crack initiation in the linear shrinkage model is generally insensitive to the concrete strength.

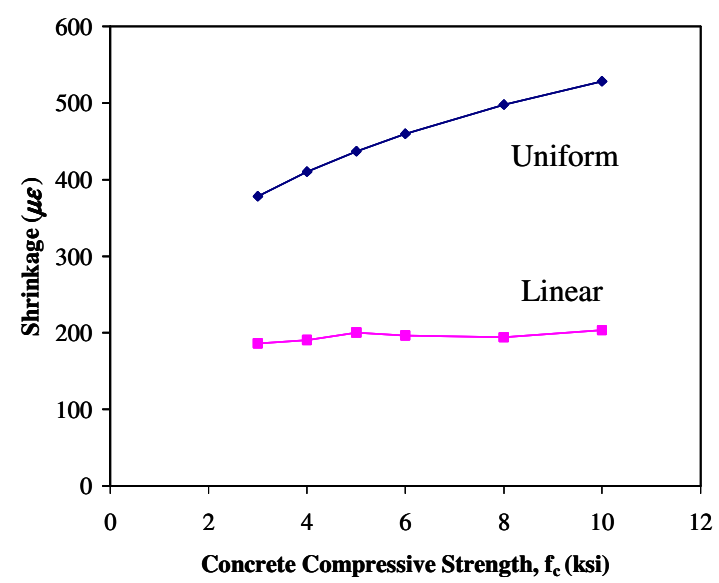

(a) Compressive Strength

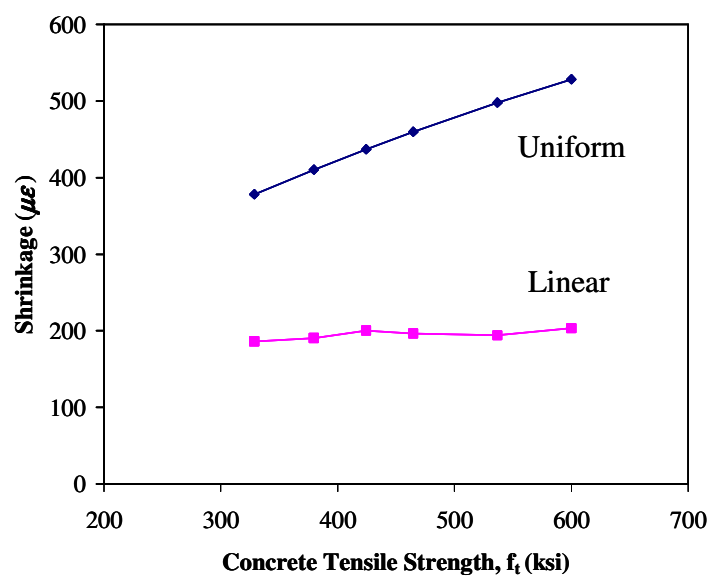

(b) Tensile Strength

Figure 6.29: Effect of Concrete Strength on Shrinkage Required for Cracking 
This analysis indicates that higher strength concrete is beneficial for resisting crack formation. However, previous research (Krauss and Rogalla, 1996) recommended the use of lower strength concretes in bridge decks as lower strength concretes experience more creep, which alleviates cracking.

To account for creep in concrete, ACI committee 209, Creep and Shrinkage of Concrete, recommends adjusting the concrete modulus of elasticity (ACI 209 1992). As the concrete modulus is reduced to account for creep, greater strains in the concrete are required to develop cracking for a given concrete tensile strength. When the concrete tensile strength is held constant $\left(f_{t}=380 \mathrm{psi}\right.$, based on $\left.f_{c}^{\prime}=4000 \mathrm{psi}\right)$ and the modulus is decreased, the shrinkage necessary to initiate cracking increases for both uniform and linear shrinkage (Figure 6.30). Therefore, lower strength concretes will benefit from the increase in cracking resistance provided by creep.

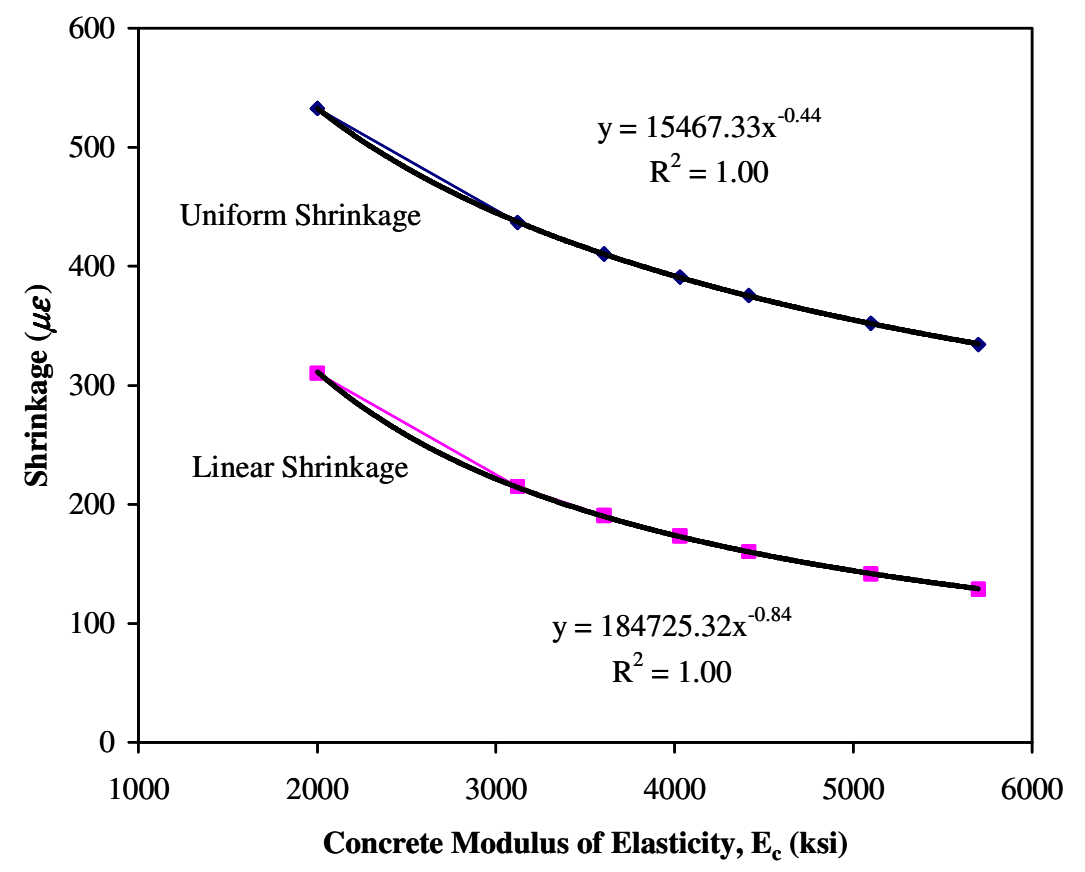

\section{Figure 6.30: Effect of Concrete Modulus of Elasticity on Shrinkage Required for Cracking}

\subsection{Analysis of Parametric Study}

The parametric study investigated the influence of a number of design characteristics on both the amount of shrinkage required to develop cracking in a bridge deck as well as the control of cracks which subsequently formed. For a bridge deck which experiences uniform shrinkage, the amount of shrinkage required to develop cracks in the deck is sensitive to the amount reinforcement provided, the depth and spacing of the girders, the thickness of the deck, and the compressive strength of the 
concrete. Uniform shrinkage provides a reasonable approximation of the shrinkage occurring in bridge decks constructed with non-permanent forms (wood forms).

However, the majority of bridges constructed in Indiana are constructed with SIP forms, which effectively seal one surface of the deck. In these cases, linear shrinkage provides a reasonable approximation of the shrinkage occurring in the bridge deck. For linear shrinkage, the parametric study determined that the amount of shrinkage required to develop cracking in the bridge deck was not significantly sensitive to the variables investigated.

The parameters which most influenced the post-cracking behavior in the models were determined to be the amount of reinforcement provided in the deck, the spacing of the reinforcement, and the flexibility of the girders in the superstructure. By increasing the stiffness of the girders from $1305 \mathrm{in.}^{4}$ (12 in. girder) to $26,400 \mathrm{in}^{4}$ ( $51 \mathrm{in}$. girder), the average stress in the reinforcement across a crack increased from $4.8 \mathrm{ksi}$ to $25.4 \mathrm{ksi}$ (Figure 6.31) for uniform shrinkage. Thus, a 95\% decrease in the stiffness of the girder results in an $81 \%$ decrease in the average stress in the top reinforcement. Minimal effect was observed for the linear profile. Regardless, the stiffness of the girders are typically controlled by load demands or deflections, and particularly in cases where only the deck is replaced on an exisiting bridge, the existing conditions. Therefore, decreasing the stiffness of the girder is not practically possible.

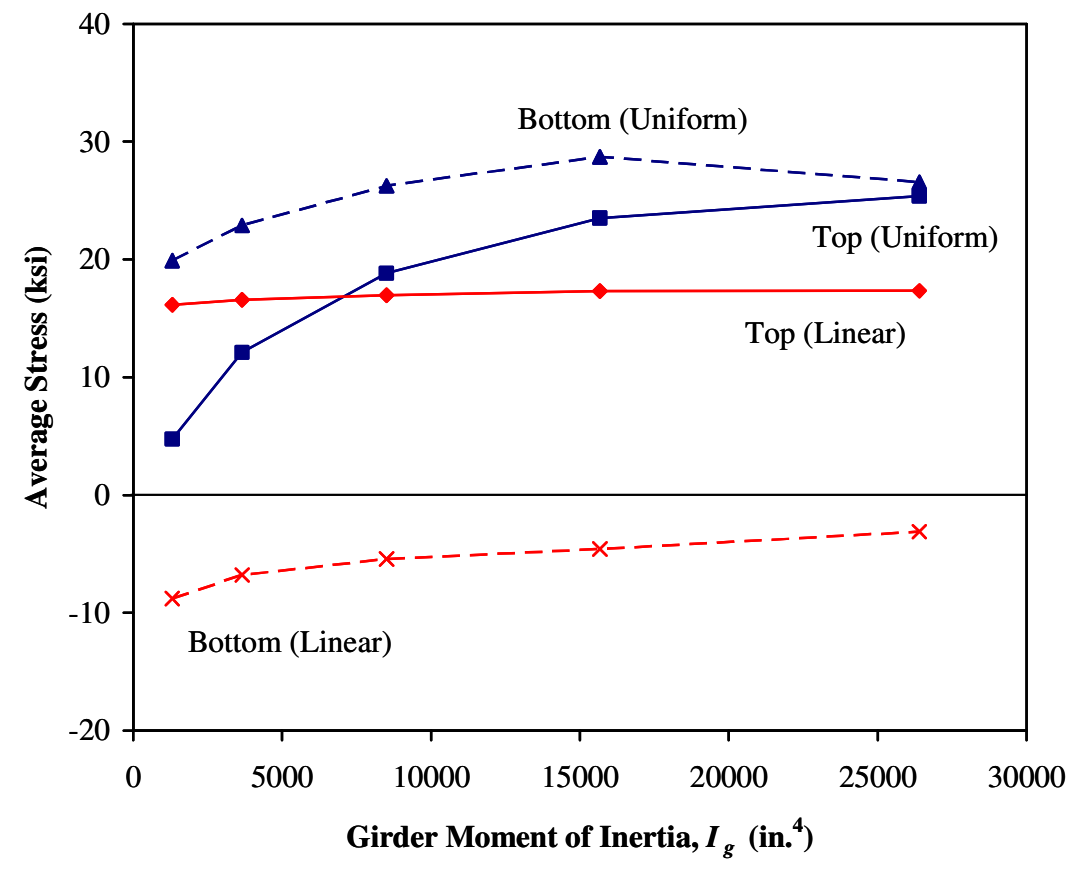

Figure 6.31: Average Stress versus Girder Moment of Inertia 


\subsubsection{Reinforcement Stress}

If no slip is assumed to occur between the reinforcement and the concrete when a crack forms, then all of the stress in the concrete at the time of crack formation is transferred into the reinforcement bridging the crack. If the stress in the concrete when a crack develops is approximated as $6 \sqrt{f_{c}}$, the stress in the reinforcement across the crack, assuming a uniform distribution of stress through the depth of deck, can be calculated by:

$$
f_{s}=\frac{6 \sqrt{f_{c}}}{\rho_{g}}
$$

where:

$$
\begin{array}{ll}
f_{c} & =\text { concrete compressive strength, } \mathrm{psi} \\
f_{s} & =\text { stress in the reinforcement, } \mathrm{psi} \\
\rho_{g} & =\text { reinforcement ratio for the gross section }
\end{array}
$$

However, since bond between the reinforcement and surrounding concrete is not perfect, slip occurs, and the stress in the reinforcement is relieved.

The model developed and calibrated as a part of this study utilized deck elements which were 2 in. wide. The presence of a crack in the deck was simulated by assigning zero stiffness to concrete elements at the location of the crack. As previously discussed, this method has the effect of smearing the crack over the width of the element.

Furthermore, the geometry of the element provides an inherent slip length equal to the width of the element. To evaluate the reduction in stress in the reinforcement resulting from slip between the reinforcement and concrete, the stress in the reinforcement elements at the crack are plotted as a function of $\sqrt{f_{c}} / \rho_{g}$ (Figure 6.32). A linear relationship is observed between average reinforcement stress and $\sqrt{f_{c}} / \rho_{g}$. 


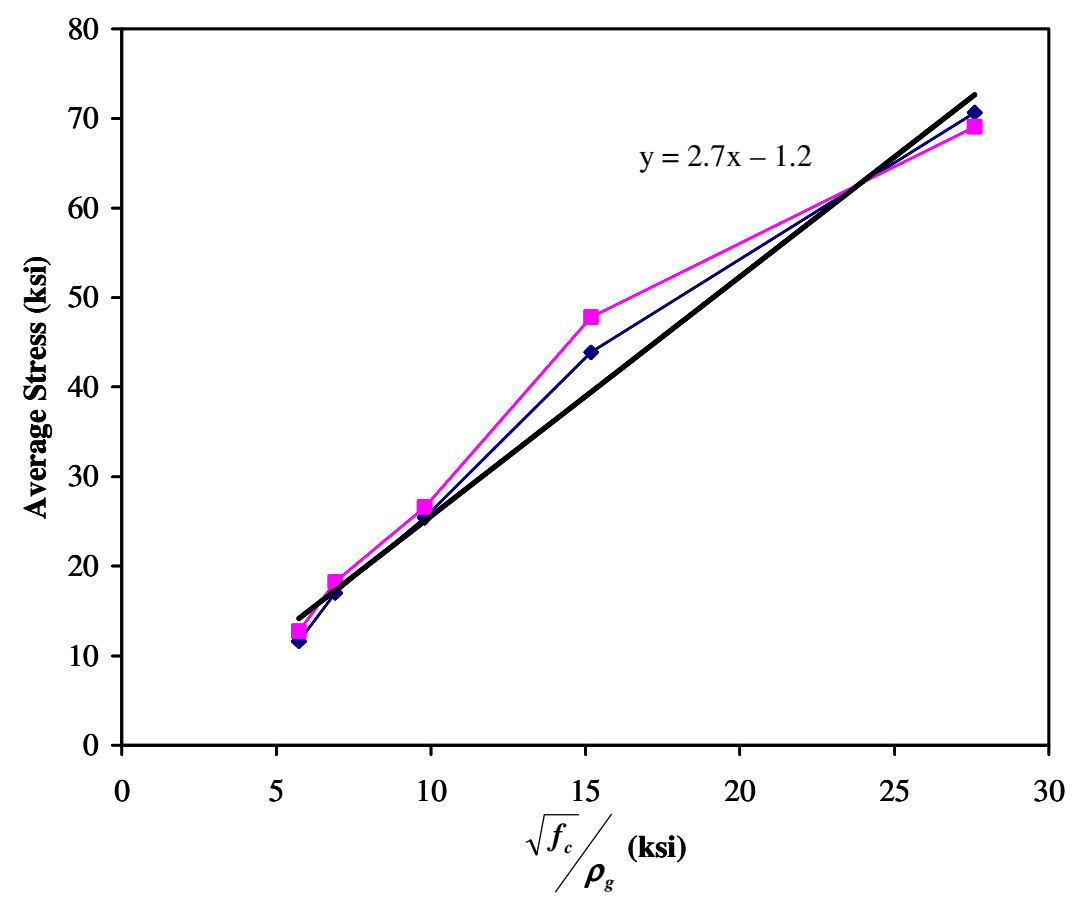

Figure 6.32: Average Stress versus $\sqrt{f_{c}} / \rho_{g}$

A linear fit of the average stress yields a line with a slope of approximately 3 . This indicates that the average stress in the reinforcement across the crack is approximately half of that expected if no slip occurred. As the slip length inherent in the model was 2 in., a relationship between the reduction factor for slip and the slip length can be provided.

\subsubsection{Crack Widths}

If the width of elements in the model is decreased, thereby decreasing the inherent slip length, the model predicts the same average reinforcement stress but calculates a smaller crack width than the model calibrated with a 2 in. element (Figure 6.33). To achieve the same crack width as the model with a 2 in. slip length, the reinforcement must experience additional strain, which results in a higher average stress in the reinforcement. The difference in reinforcement strain between elements with slip lengths other than 2 in. and elements with a 2 in. slip length is calculated as:

$$
\Delta \varepsilon_{c}=\frac{w_{2}-w_{l}}{l}
$$

$\Delta \varepsilon_{c}=$ change in strain needed for a crack width equivalent to a 2 in. element length 


$$
\begin{aligned}
& w_{2}=\text { crack width provided by slip length of } 2 \text { in., in. } \\
& w_{l}=\text { crack width provided by slip length of } l, \text { in. } \\
& l \quad=\text { element length, in. }
\end{aligned}
$$

The additional stress in the reinforcement is subsequently calculated by multiplying the additional strain, $\Delta \varepsilon_{c}$, by the modulus of elasticity of the reinforcement, $E_{r}$. The adjusted stress is then computed by adding the additional stress to the stress predicted by the model for the respective element lengths. The relationship of the adjusted stress to slip length is presented in Figure 6.34. The stress modification factor is simply the reinforcement stress computed for slip length $l$ divided by the stress for the 2 in. slip length.

Recalling that the stress reduction factor for a $2 \mathrm{in}$. slip length was 0.5 (Section 6.8.1), the modification factors presented in Figure 6.34 are reduced by half. The variation in the calibrated modification factor for slip length can be described as presented in Figure 6.35. Thus, the stress modification factor can be calculated as approximately $1 / l_{s}$, where $l_{s}$ is the expected slip length.

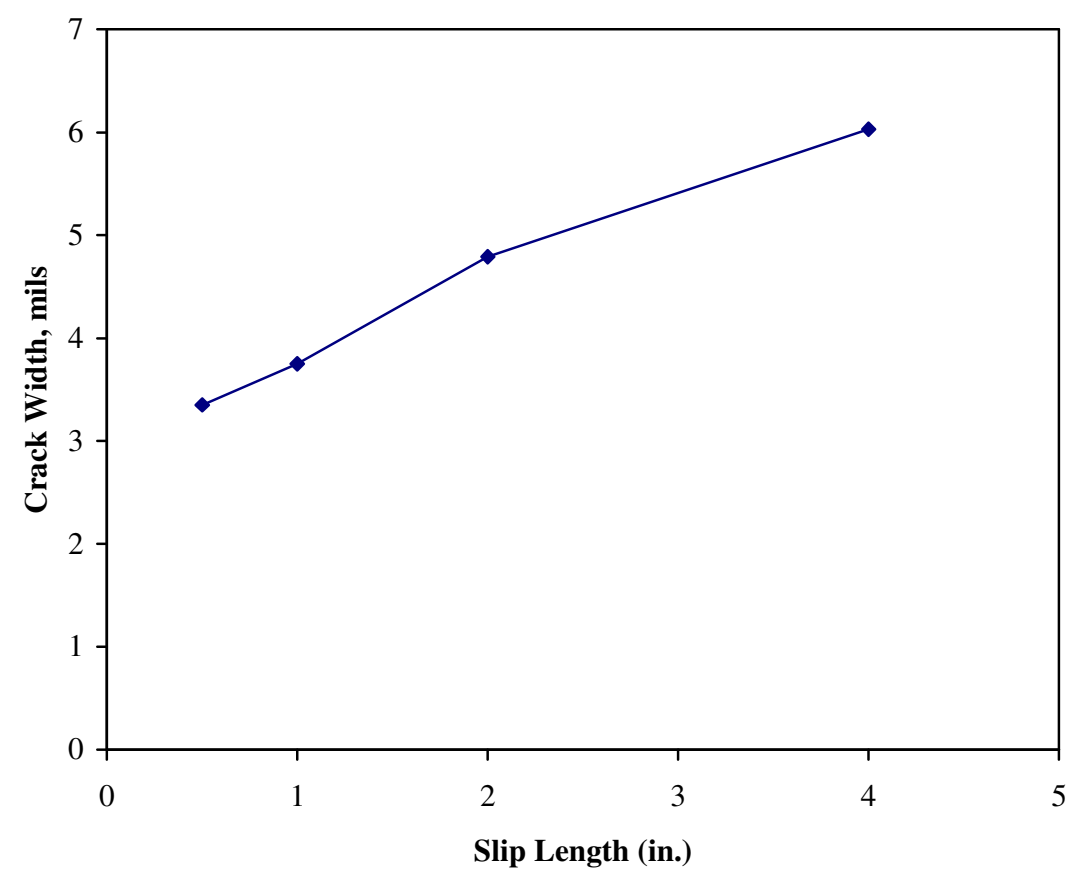

Figure 6.33: Effect of Element Slip Length on Predicted Crack Width 


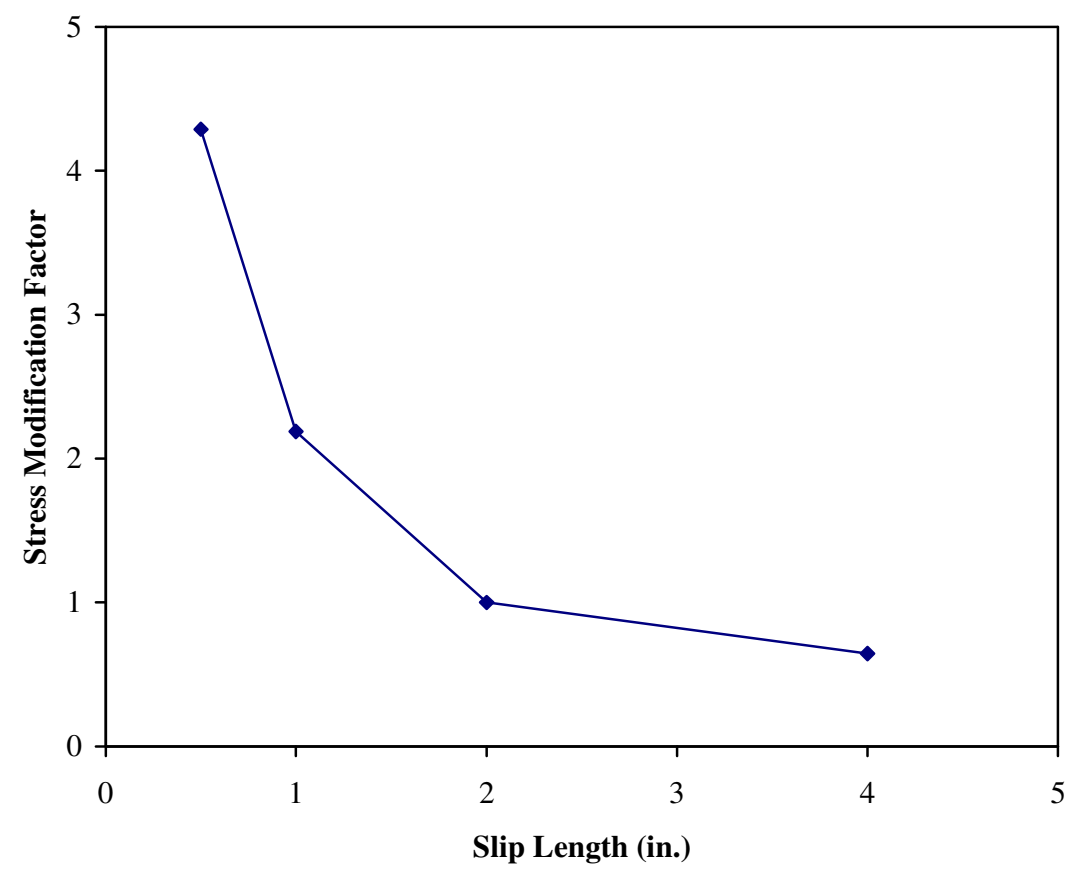

Figure 6.34: Uncalibrated Stress Modification Factor versus Slip Length

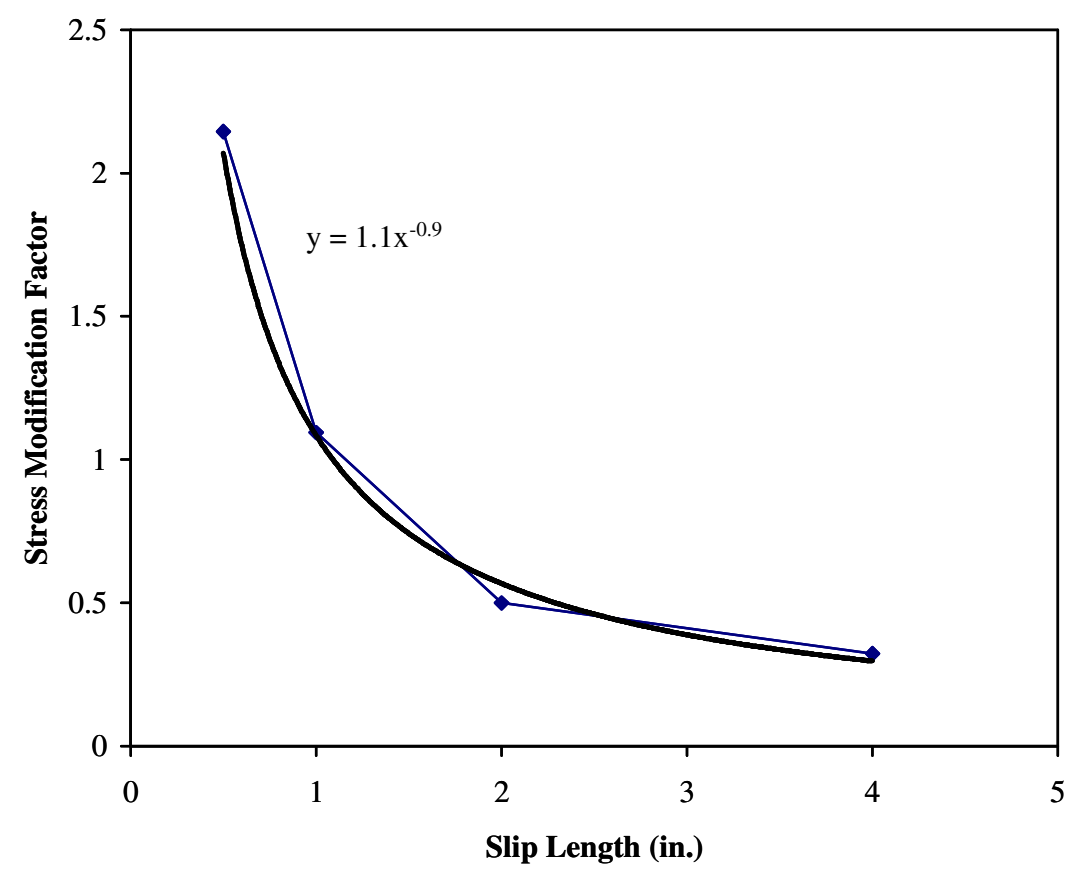

Figure 6.35: Calibrated Stress Modification Factor versus Slip Length 
Incorporating the stress reduction term for slip into Eq. (6.1) results in the following expression for reinforcement stress:

$$
f_{s}=\frac{6 \sqrt{f_{c}}}{\rho_{g}} \frac{1}{l_{s}}
$$

where:

$$
\begin{aligned}
& \rho_{g}=\text { reinforcement ratio of the gross section } \\
& l_{s}=\text { slip length, in. }
\end{aligned}
$$

The crack width can be estimated from the strain in the reinforcement multiplied by the length over which the strain occurs. In addition, the slip of reinforcement adjacent to the crack contributes to the crack width. Equation (6.3) can be subsequently modified to estimate the crack width as follows:

$$
w_{\text {avg }}=\frac{6 \sqrt{f_{c}}}{\rho_{g}} \frac{1}{l_{s}} \frac{1}{E_{r}} l_{e}
$$

where:

$$
\begin{aligned}
& w_{\text {avg }}=\text { average initial crack width, in. } \\
& l_{e}=\text { the strain length, in. } \\
& E_{r}=\text { modulus of elasticity of the reinforcement, psi }
\end{aligned}
$$

The strain length can be estimated as equal to the slip length, and 6.4 simplifies to:

$$
w_{\text {avg }}=\frac{6 \sqrt{f_{c}}}{\rho_{g} E_{r}}
$$

The expression developed for average crack width (Eq. (6.5)) is compared to the average crack widths calculated by the finite element model in Figure 6.36. As shown, this equation for average crack widths underestimates the average crack widths estimated by the model. 


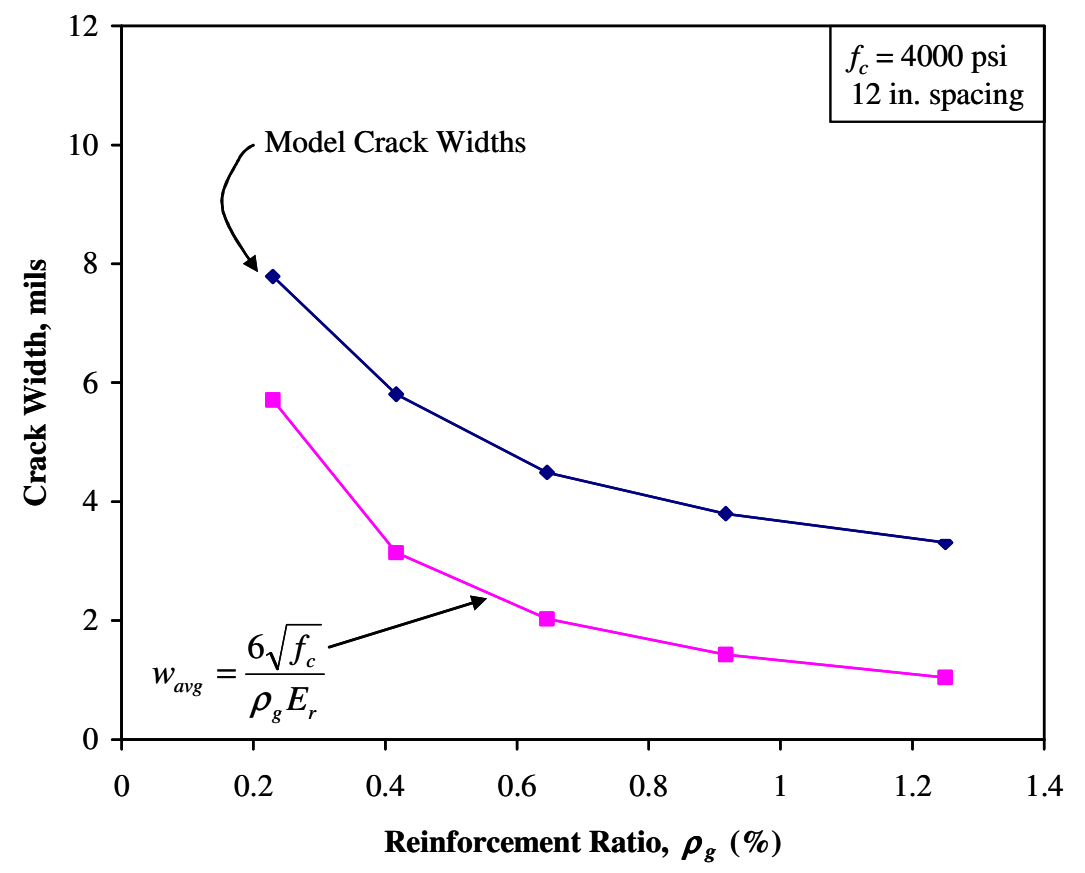

Figure 6.36: Comparison of Crack Width Expression to Model Crack Widths

Equation (6.5) is based on the assumption that the reinforcement strains only over the width of the element where the crack is smeared $\left(l_{e}=l_{s}\right)$. If the strain length is greater than the element length, the strain in the reinforcement is integrated over a greater length and thereby predicts larger crack widths. It is observed that the ratio between the model crack widths and those predicted by the finite element model is not constant, but rather appears to vary with the amount of reinforcement provided. The relationship of the slip length multiplier, $\lambda$, to the amount of reinforcement provided is presented in Figure 6.37. Based on this analysis, the slip length can be increased by a factor, $\lambda$, which is calculated as:

$$
\lambda=26.6 \sqrt{\rho_{g}}
$$

In other words, the strain length is as follows:

$$
l_{e}=26.6 \sqrt{\rho_{g}} l_{s}
$$

Substituting Eq. (6.7) into Eq. (6.4) results in the following expression:

$$
w_{\text {avg }}=\frac{6 \sqrt{f_{c}}}{\rho_{g}} \frac{1}{l_{s}} \frac{1}{E_{r}} 26.6 \sqrt{\rho_{g}} l_{s}
$$

Equation (6.8) simplifies to: 


$$
w_{\text {avg }}=\frac{160}{E_{r}} \sqrt{\frac{f_{c}}{\rho_{g}}}
$$

The modified expression is compared to the initial crack widths predicted by the model in Figure 6.38. The crack width expression which accounts for additional strain length demonstrates very strong agreement with the crack widths predicted by the model. The expression slightly overestimates the crack width by $7 \%$ on average for the reinforcement amounts considered. It should be noted that the crack widths estimated by Eq. (6.9) are at the instant of cracking, immediately after cracking occurs in the deck. Subsequent growth of the crack can take place as additional shrinkage occurs. Equation (6.9) also does not account for the effect of reinforcement spacing on crack widths.

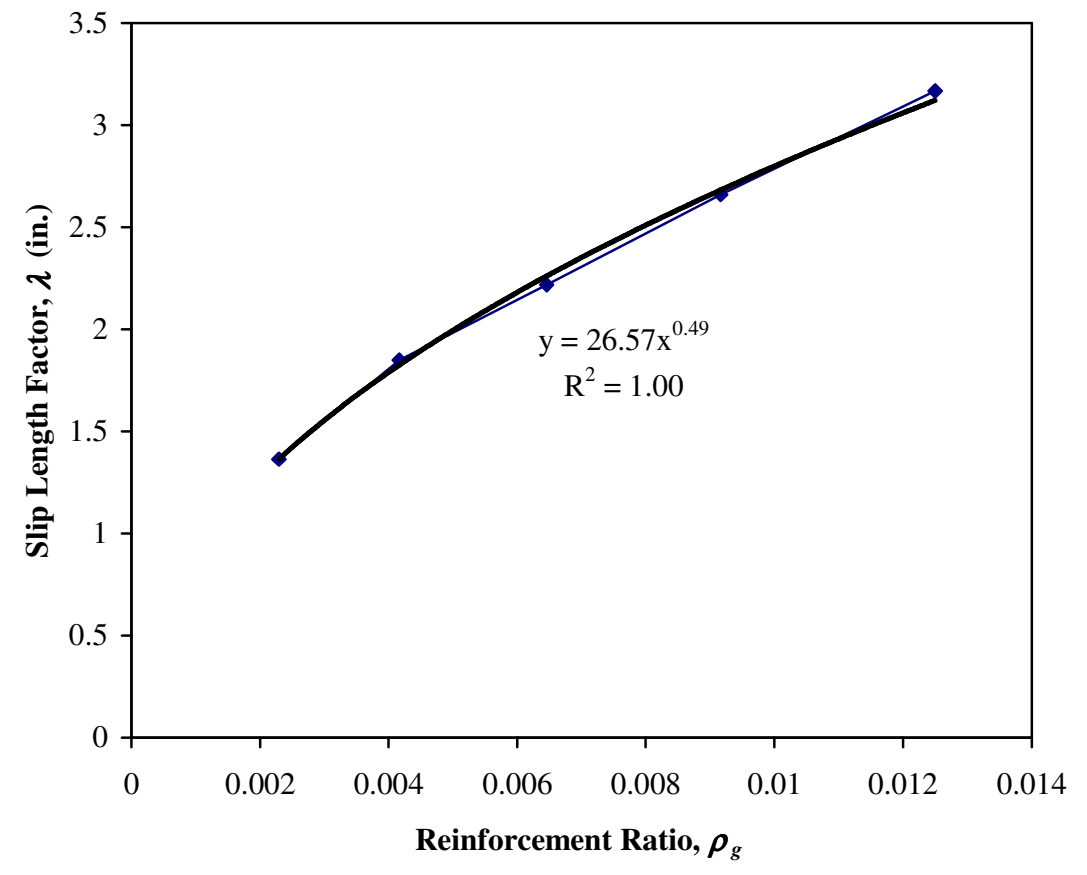

Figure 6.37: Relationship of Slip Length Factor to Reinforcement Amount 


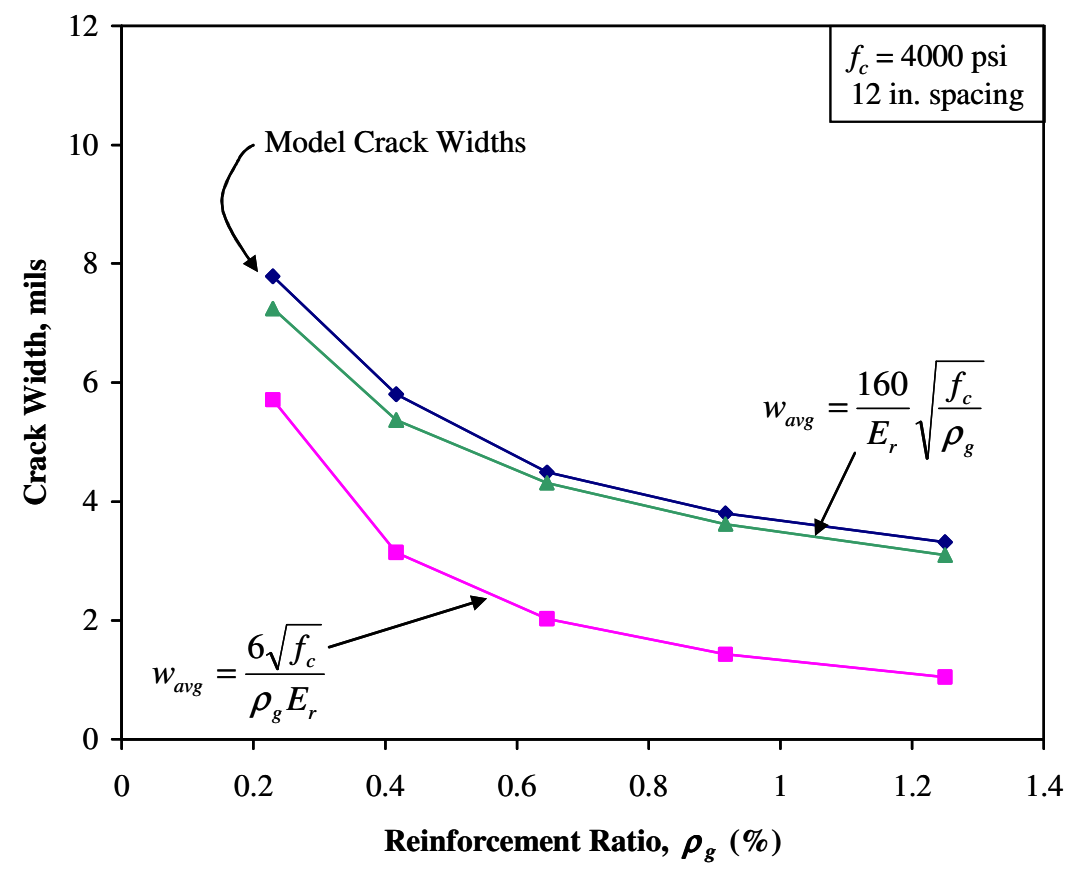

Figure 6.38: Comparison of Crack Width Expressions to Model Crack Widths

It was observed that crack widths varied approximately linearly with reinforcement spacing (Figure 6.8). Considering this relationship, the crack widths estimated by the finite element model can be scaled to account for the spacing of the reinforcement in a bridge deck. The combined effects of reinforcement amount and spacing are presented in Figure 6.39. The model was used to calculate crack widths for varying sizes of reinforcement spaced at $12 \mathrm{in}$. Crack widths were also calculated for varying spacings with a constant reinforcement ratio $\left(\rho_{g}=0.65 \%\right)$. All other points were generated considering the relationship observed between bar sizes at a $12 \mathrm{in}$. spacing and the various spacings at a constant reinforcement ratio $\left(\rho_{g}=0.65 \%\right)$. 


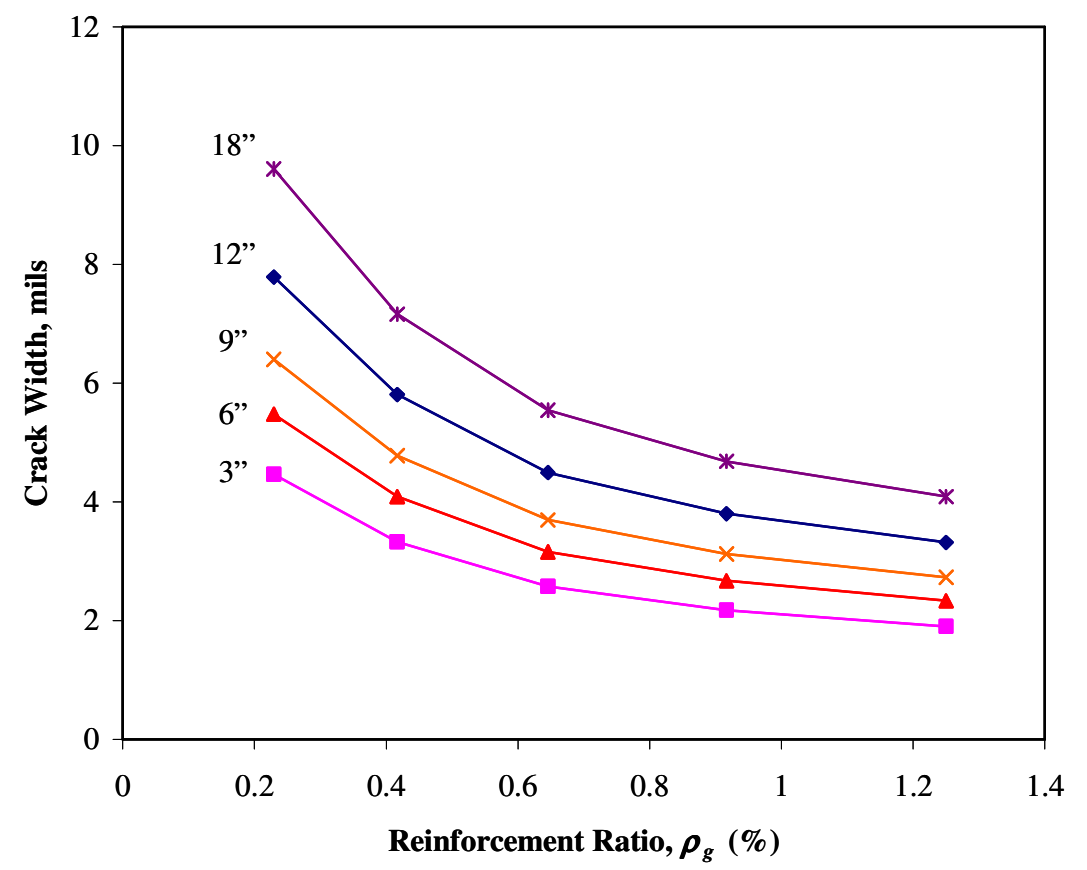

Figure 6.39: Effect of Reinforcement Amount and Spacing on Crack Widths

Broms (1965) determined that crack widths are related to the effective depth of cover, $d^{*}$, which is calculated as:

$$
d^{\star}=\sqrt{d_{c}^{2}+\left(\frac{s}{2}\right)^{2}}
$$

where:

$$
\begin{aligned}
& d^{*}=\text { effective depth of cover, in. } \\
& d_{c}=\text { depth of cover to center of reinforcement, in. } \\
& s \quad=\text { reinforcement spacing, in. }
\end{aligned}
$$

The variation of crack widths with the effective depth of cover is presented in Figure 6.40 where a linear relationship is observed. Therefore, Eq. (6.10) provides a method for accounting for the effect of both the reinforcement spacing and the cover. 


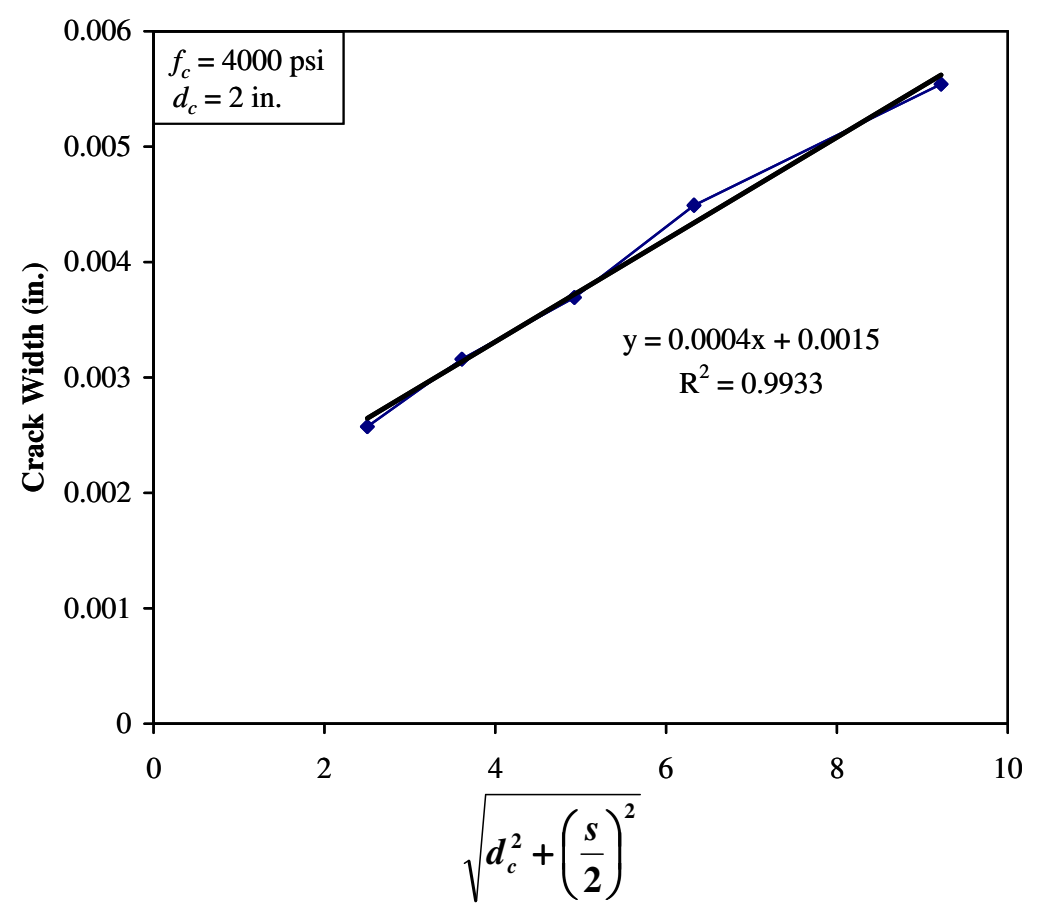

Figure 6.40: Relationship of Crack Width and Effective Depth of Cover

Equation (6.9) was developed considering a reinforcement spacing of $12 \mathrm{in.} \mathrm{and} \mathrm{a}$ cover, $d_{c}$, of 2 in. If the values for the effective depth of cover are normalized with respect to $d^{*}$ for this cover and spacing $\left(d^{*}=6.3\right)$, a spacing factor can be provided to account for various cover and spacing dimensions as shown in Figure 6.41. The linear relationship shown can be approximated as:

$$
\psi_{r}=\frac{1}{6} \sqrt{d_{c}^{2}+\left(\frac{s}{2}\right)^{2}}
$$

where:

$$
\begin{aligned}
\psi_{r} & =\text { reinforcement spacing factor } \\
d_{c} & =\text { cover to center of reinforcement, in } . \\
s & =\text { reinforcement spacing, in. }
\end{aligned}
$$




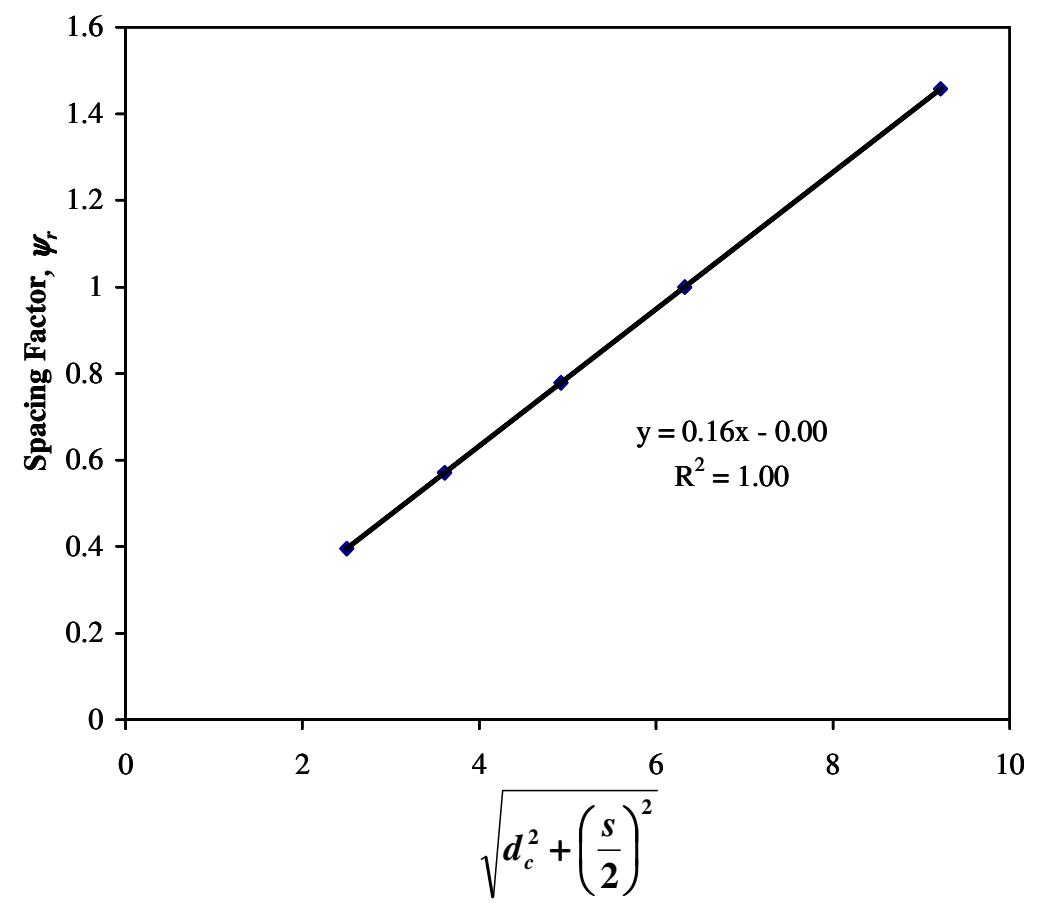

Figure 6.41: Relationship between Spacing Factor and Effective Depth of Cover

The expression for the spacing factor, $\psi_{r}$, presented in Eq. (6.11) is combined with Eq. (6.9) and provides an expression which can estimate crack widths. This expression is defined as:

$$
w_{\text {avg }}=\frac{27}{E_{r}} \sqrt{\frac{f_{c}}{\rho_{g}}} \sqrt{d_{c}^{2}+\left(\frac{s}{2}\right)^{2}}
$$

The crack widths calculated with Eq. (6.11) are compared to those predicted by the model in Figure 6.42. The expression exhibits good agreement with the crack widths predicted by the model and is therefore considered a reasonable estimate of average initial crack widths. 


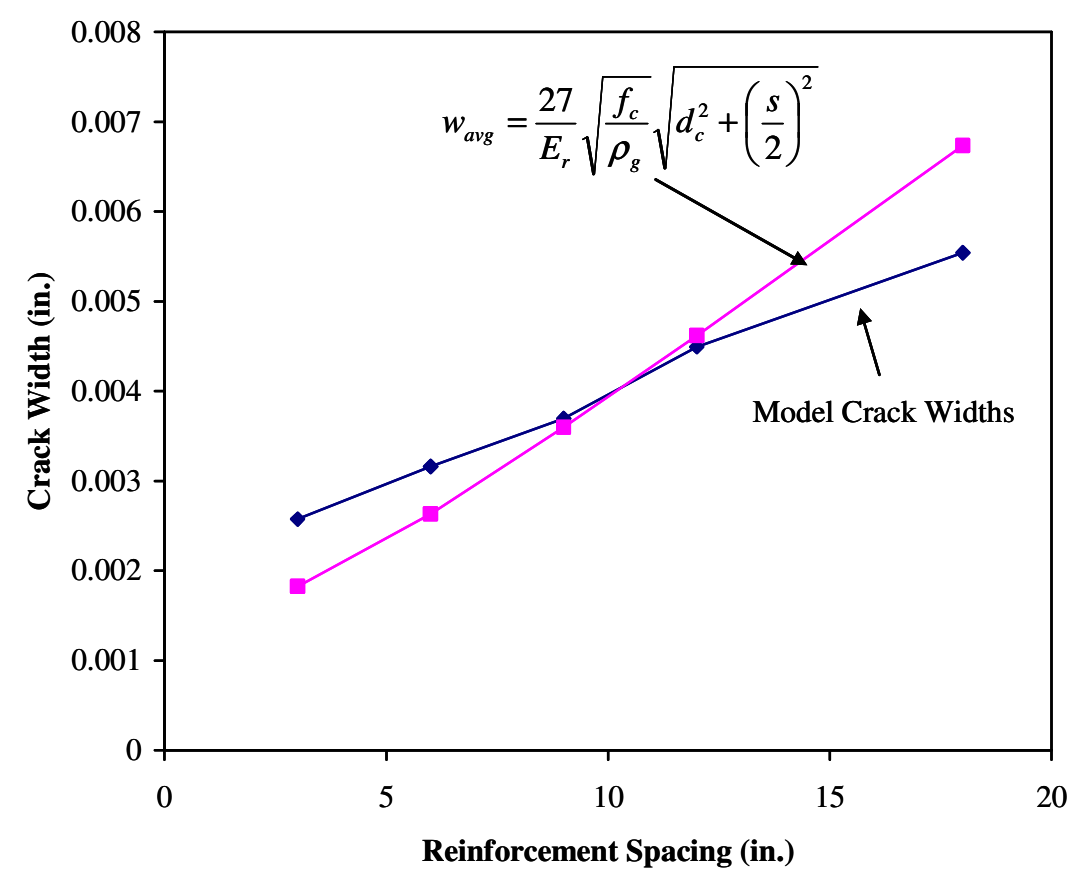

Figure 6.42: Comparison of Crack Width Expression to Predicted Crack Widths

The difference between average crack widths observed at early ages (less than 28 days) and average crack widths observed at later ages (greater than 200 days) on the bridges investigated in the field study indicate that the initial crack width can be increased by a factor of 2.0. Furthermore, the field studies indicated that the final, maximum crack widths were 2.5 times as large as the final, average crack widths.

Therefore, it is considered appropriate to increase initial crack widths by a factor $\phi=5.0$ to estimate additional volume change that occurs after initial cracking and to account for the maximum crack width. This factor is consistent with the variation between average initial and maximum final crack widths observed in the field studies. The difference in bond properties between differing reinforcement materials can also be incorporated by including a bond factor, $\gamma$, such that the expression for crack widths becomes:

$$
w_{\max }=\frac{135}{E_{r}} \gamma \sqrt{\frac{f_{c}}{\rho_{g}}} \sqrt{d_{c}^{2}+\left(\frac{s}{2}\right)^{2}}
$$

where:

$$
\begin{aligned}
\gamma=\text { bond factor } & =1.0 \text { for steel reinforcement } \\
& =1.5 \text { for FRP reinforcement }
\end{aligned}
$$

The value for $\gamma$ is based on the factor calculated as a part the evaluation of field behavior (Section 5.5.2) and is consistent with the current recommendations of ACI 440 (2006). Because all the steel considered in this study was epoxy coated, this equation 
was calibrated accordingly and should be considered as applicable for use with epoxycoated bars, which are typical in bridge decks. For black bars, Eq. (6.13) is conservative.

\subsection{Design Recommendations}

Adequate crack control can be achieved by limiting both the stress in the reinforcement and the spacing of the reinforcement. When steel bars are selected as the reinforcing material, the stress in the reinforcement should not be allowed to exceed the yield stress $f_{y}$ of the reinforcement as uncontrolled crack growth can occur. As demonstrated by Eq. (6.3), limiting the reinforcement stress is a function of the amount of reinforcement provided. Therefore, the amount of reinforcement required to control crack growth can be determined by substituting $f_{y}$, for $f_{s}$ in Eq. (6.3). An appropriate factor should also be incorporated to account for long term shrinkage effects. It was observed that, on average, the reinforcement stress increased by a factor of 2.0 from initial to final (Section 6.5.1). Thus, the recommended reinforcement amount is calculated as follows:

$$
\rho_{g}=2 \frac{6 \sqrt{f_{c}}}{f_{y}} \frac{1}{l_{s}}
$$

If $l_{s}$ is approximated as 2 in. according to the calibrated model developed in this study, Eq. (6.14) simplifies to:

$$
\rho_{g}=\frac{6 \sqrt{f_{c}}}{f_{y}}
$$

It should be noted that $f_{c}$ is the actual concrete compressive strength at the time of cracking. It is often impractical, however, for the designer to predict the concrete strength at the time of crack formation as it is difficult to predict when cracks will develop in the deck. Furthermore, while a designer specifies a design compressive strength, the required average compressive strength is expected to be higher. The average increase with respect to $\sqrt{f_{c}^{\prime}}$ is by a factor of 1.14 based on the required average compressive strengths as defined by ACI 318 Section 5.3.2 (2005). Thus, Eq. (6.15) is modified such that the design compressive strength is incorporated into the expression as:

$$
\rho_{g}=\frac{7 \sqrt{f_{c}^{\prime}}}{f_{y}}
$$

However, because cracking often occurs at early-ages (between Day 3 and 10), Eq. (6.16) is considered a conservative estimate of the necessary reinforcement amount, and, based on observations in the field, Eq. (6.15) is considered appropriate for computing the required reinforcement amount.

The limiting reinforcement spacing can be determined by selecting an acceptable crack width limit and rearranging Eq. ((6.13). ACI 224 (2001) recommends an aesthetic crack width limit of 0.016 in. This value is also consistent with that provided in the ACI building code (ACI 318-05). A 1/3 increase in crack widths (0.021 in.) is considered 
given the large scatter that is inherent in crack widths. Based on these values of crack widths, the graph shown in Figure 6.43 was developed for Grade 60 reinforcement where the limiting stress was selected as $f_{y}=60 \mathrm{ksi}$, and the value for $\rho_{g}$ was computed using Eq. (6.16). A simple design curve is illustated which is defined as:

$$
s=9 \alpha_{s}\left[2.5-\frac{d_{c}}{2 \alpha_{s}}\right] \leq 9 \alpha_{s}
$$

where:

$$
\alpha_{s}=\frac{60}{f_{y}}
$$

$f_{y} \quad=$ yield stress of reinforcement, ksi

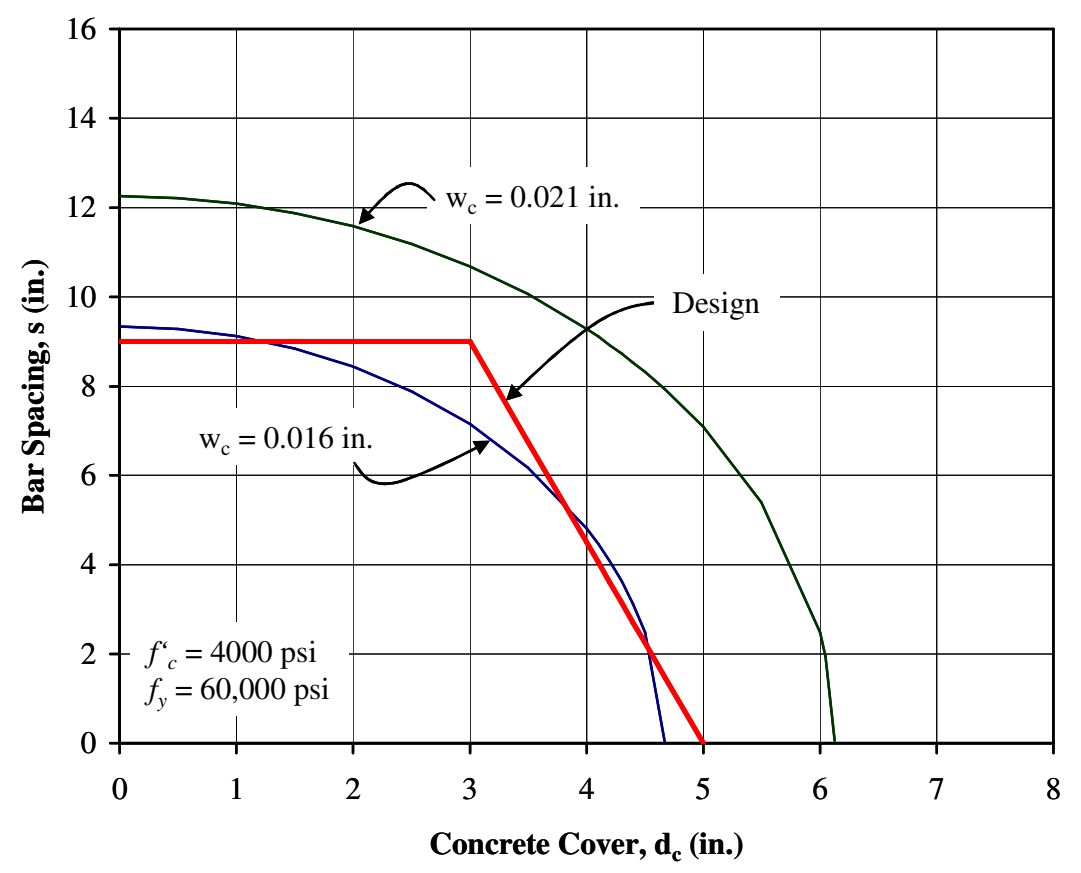

Figure 6.43: Grade 60 Reinforcement Spacing

When FRP reinforcement is selected by the designer Eq. (6.14) can be used by the designer to calculate the amount of FRP reinforcement required by modifying the value of the limiting stress for the FRP reinforcement and accounting for the bond characteristics of the FRP reinforcement. A yield stress is not specified for FRP reinforcement because it does not exhibit a ductile failure, but rather fails through brittle rupture of the bar. The limiting stress for FRP reinforcement is therefore based on preventing failure resulting from cyclic fatigue. ACI 440 recommends limiting the stress in GFRP reinforcement to $0.20 f_{f u}$ to prevent rupture due to cyclic stresses and fatigue of 
the FRP reinforcement, where $f_{f u}$ is the ultimate tensile strength of the FRP reinforcement (ACI 2006). As was observed in the reinforcement in the I-65 over SR 25 bridge, strain in the reinforcement at the location of the crack may experience cyclic tensile loading. Therefore, it is appropriate to limit stresses in the GFRP reinforcement to $0.20 f_{f u}$, per the recommendations of ACI 440 (2006). If the factor $\gamma=1.5$ is incorporated into Eq. (6.16) to account for the difference in bond characteristics between steel and FRP and with the revised stress limit, the recommended amount of FRP reinforcement is calculated as:

$$
\rho_{g}=\frac{6 \sqrt{f_{c}^{\prime}}}{0.2 f_{f u}} \frac{1}{1.5} \approx \frac{20 \sqrt{f_{c}^{\prime}}}{f_{f u}}
$$

where:

$$
f_{f u} \quad=\text { ultimate strength of FRP reinforcement, psi }
$$

Based on the same limiting crack widths as considered for steel reinforcement $(w$ $=0.016$ in.), Figure 6.44 was developed for FRP reinforcement with $f_{f u}=89 \mathrm{ksi}$ and $E_{f}=$ $7000 \mathrm{ksi}$. The reinforcement ratio was calculated using Eq. (6.19). A simple design curve is also developed which is defined by:

$$
s=9 \alpha_{f} \beta_{e}\left[2.5-\frac{d_{c}}{2 \alpha}\right] \leq 9 \alpha_{f} \beta_{e}
$$

where:

$$
\begin{aligned}
& \alpha_{f}=\frac{90}{f_{f u}} \\
& \beta_{e}=\frac{E_{r}}{7000}
\end{aligned}
$$

$f_{f u}=$ ultimate tensile strength of FRP reinforcement, ksi

As noted, the similar format of Eq. (6.17) and (6.20) indicate that design unification can be provided for both steel and FRP reinforcement. Furthermore, this analysis indicates that for typical cover dimensions, a maximum bar spacing of 9 in. should be provided for both steel and FRP reinforcement assuming a sufficient amount of reinforcement is specified as provided by Eq. (6.16) or (6.19). 


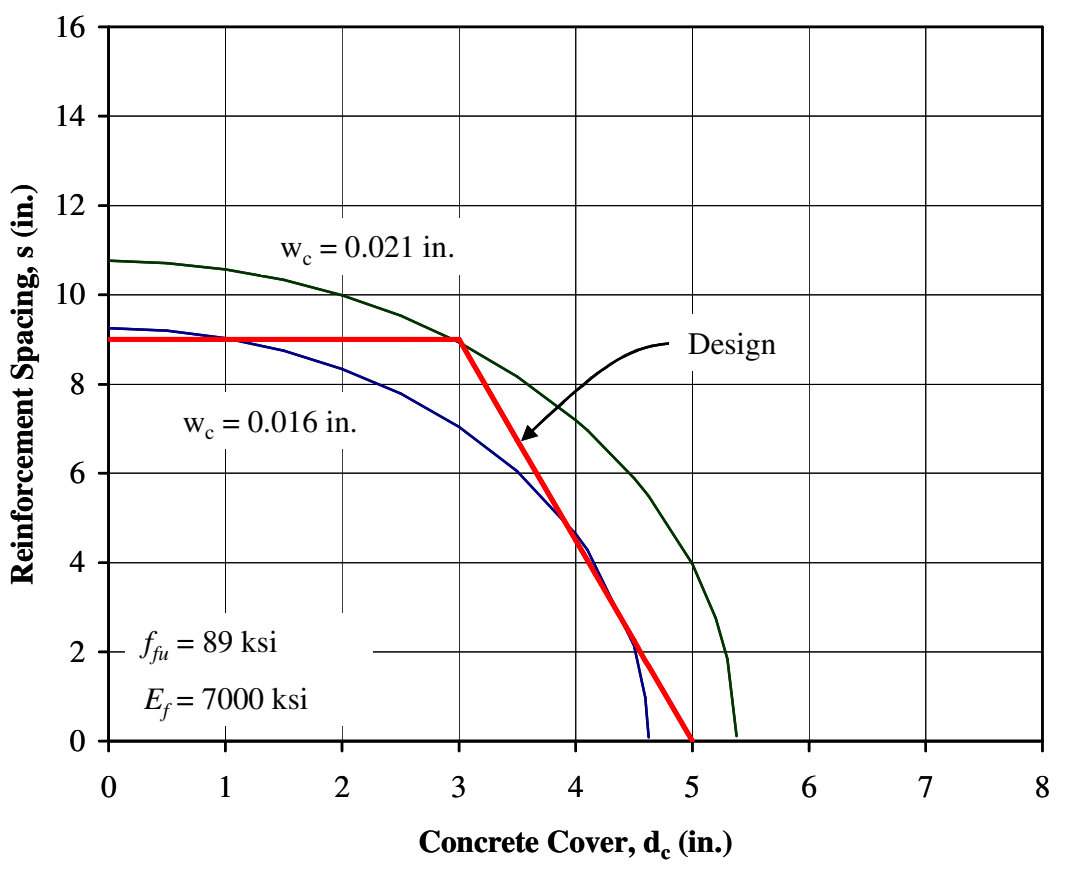

Figure 6.44: Glass FRP Reinforcement Spacing 


\section{CHAPTER 7 SUMMARY AND CONCLUSIONS}

\subsection{Introduction}

Bridge deck cracking can reduce the service life of bridges by providing a means of rapid penetration of deleterious agents, such as chlorides from deicing salts, into the deck. This can often result in corrosion of the reinforcement which leads to further cracking, delamination and spalling of the concrete deck. Transverse cracking in bridge decks has been observed at early ages (less than 28 days), and is attributed to restraint of the deck by the girders to volumetric changes resulting from a combination of thermal effects and shrinkage. However, proper selection of materials, structural design, and construction techniques can mitigate the extent of cracking that occurs in bridge decks.

\subsection{Control of Bridge Deck Cracking}

Limited guidance exists for design methods to control restrained shrinkage cracks. Furthermore, separate design methods are currently used for the steel and FRP reinforcement. The objective of this research is to develop rational design recommendations for the control of restrained shrinkage cracking that can be used for structures which incorporate either steel or FRP reinforcement. This research was conducted in two phases. The first phase was a field investigation of four bridges which incorporated varying designs to evaluate the performance of the respective bridge decks. In the second phase of the research, a simple, finite element model was developed to simulate the behavior observed in the field, which could be used to perform a parametric study considering various design elements.

Based on the results of the first phase, the following conclusions were made:

1. Proper selection of the concrete mix design greatly influenced the performance of the bridge deck with respect to cracking.

2. Thermal effects experienced by the bridge deck as a result of cooling after peak hydration temperatures significantly contributed to the volumetric changes experienced by the deck at early ages.

3. Stress in reinforcement due to the presence of a crack was highly localized. Significant increases in strain were not observed at locations further than $12 \mathrm{in.}$ from a crack.

4. Bridges constructed with integral abutments were not fully restrained by the abutments. Integral abutments which incorporated the use of pile heads covered with expanded polystyrene were relatively free to contract as temperatures decreased. When the bridge expanded and temperatures 
increased beyond the temperature at the time of casting, only a portion (approximately 50\%) of the expansion was resisted by the backfill.

5. The bridge (SR 18) constructed semi-integrally with the abutments exhibited similar behavior as those constructed fully integral with the abutments. However, only $13 \%$ of the expansion and contraction of the bridge appeared to be resisted by the abutments.

6. Bridge decks with reinforcement amounts greater than or equal to $\rho_{g}=6 \sqrt{f_{c}^{\prime}} / f_{y}$ did not demonstrate any large increases in tensile strain during the period of monitoring. In bridge decks with less than this amount of reinforcement, reinforcement strains at probable locations of cracking exhibited large increases in tensile strain.

7. Reinforcement at crack locations can yield if insufficient reinforcement is provided.

8. The FRP bridge deck with \#5 bars at 6 in. in the top mat of reinforcement exhibited cracking similar to that observed in the AASHTO empirical span of SR 18 (\#5 bars at 18 in.).

An analytical model was developed to evaluate the influence of various design characteristics on the behavior of a bridge deck with and without cracks. Two different shrinkage profiles were selected based on data obtained by Blackman (2002). The model performance and the two shrinkage profiles were compared to data from the laboratory study by Radabaugh (2001) and the field studies conducted as a part of this research. Based on these analyses, the following was concluded:

1. Concrete shrinkage alone is insufficient to initiate cracking in the bridge decks observed. Cracking develops as a result of a combination of concrete shrinkage and thermal cooling after hydration.

2. The model with a linear shrinkage profile at an ultimate strain of $1000 \mu \varepsilon$ provided an excellent estimate of final maximum crack widths for bridge decks constructed with SIP forms.

3. A reasonable estimate of the final, average crack width can be made by estimating the final, average width as $40 \%$ of the final maximum width.

4. When FRP reinforcement is considered, crack widths must be scaled to account for additional slip between the FRP reinforcement and surrounding concrete. A conservative estimate of 1.5 is recommended and is consistent with current recommendations provided by ACI committee 440 (2006).

The analytical model was used to perform a parametric study to evaluate the influence of several design characteristics on restrained shrinkage cracking. The effects of the reinforcement, the girders, and the deck on the cracks that develop were considered. Based on the results of these analyses, design recommendations were developed to decrease the width of cracks which form in concrete bridge decks. The following conclusions were made considering the results of the parametric study: 
1. The amount and spacing of the reinforcement has a direct influence on the width of cracks in the bridge deck. The stress in the reinforcement is directly related to the width of the crack.

2. Improved cracking performance can be achieved through the use of flexible girders. However, load demands and deflection control make implementation of this design procedure impossible.

3. Creep provides increased resistance to crack formation in the bridge deck. Thus, lower strength concretes which experience more creep than higher strength concretes provide additional cracking resistance.

4. The maximum crack width in a bridge deck can be calculated as:

$$
w=\frac{135}{E_{r}} \gamma \sqrt{\frac{f_{c}}{\rho_{g}}} \sqrt{d_{c}^{2}+\left(\frac{s}{2}\right)^{2}}
$$

where:

$$
\begin{aligned}
w= & \text { crack width, in. } \\
E_{r}= & \text { reinforcement modulus of elasticity, psi } \\
\gamma \quad= & \text { reinforcement bond factor: } 1.0 \text { for steel bars, } 1.5 \text { for FRP } \\
& \text { bars } \\
f_{c}= & \text { concrete compressive strength, psi } \\
\rho_{g}= & \text { reinforcement ratio of the gross section } \\
d_{c}= & \text { clear cover, in. } \\
s \quad= & \text { reinforcement spacing, in. }
\end{aligned}
$$

\subsection{Design Recommendations}

To prevent excessive crack growth, sufficient reinforcement must be provided to limit stress in the reinforcement. When steel reinforcement is considered, an amount should be provided to ensure yielding does not occur when cracks develop. As cracking often occurs at early-ages (between Day 3 and 10), it is appropriate to compute this minimum amount as:

$$
\rho_{g}=\frac{6 \sqrt{f_{c}^{\prime}}}{f_{y}}
$$

where:

$$
\begin{aligned}
\rho_{g} & =\text { reinforcement ratio of the gross section } \\
f_{c}^{\prime} & =\text { specified } 28 \text {-day concrete compressive strength, psi } \\
f_{y} & =\text { reinforcement yield stress, psi }
\end{aligned}
$$

When FRP reinforcement is considered, an amount must be provided to ensure fatigue failure of the reinforcement does not occur. This minimum amount is calculated as: 


$$
\rho_{g}=\frac{20 \sqrt{f_{c}^{\prime}}}{f_{f u}}
$$

where:

$$
f_{f u}=\text { ultimate strength of FRP reinforcement, psi }
$$
following:

The spacing of reinforcement should not exceed an amount calculated by the

$$
s=9 \alpha_{r} \beta_{e}\left[2.5-\frac{d_{c}}{2 \alpha_{s}}\right] \leq 9 \alpha_{r} \beta_{e}
$$

where:

$$
\begin{aligned}
\alpha_{r}= & \text { stress factor: } \frac{60}{f_{y}} \text { for steel reinforcement } \\
\frac{90}{f_{f u}} \text { for FRP reinforcement } & \\
\beta_{e}= & \text { modular factor: } 1.0 \text { for steel } \\
& \frac{E_{r}}{7000} \text { for FRP } \\
f_{y}=\text { yield stress of steel reinforcement, ksi } & =\text { ultimate tensile strength of FRP reinforcement, ksi }
\end{aligned}
$$

For larger covers, closer spacings are required to provide sufficient reinforcement as calculated by Eq. (7.2) and (7.3). However, for the normal range of covers used in bridge decks, the limiting spacing will be 9 in. for both Grade 60 steel and glass FRP reinforcement.

\subsection{Recommendations for Future Research}

The primary focus of this work was to evaluate the performance of design methods for the control of reinforcement, especially with regard to the effect of reinforcement on cracking. The finite element model and the methods developed in this research provide simple tools for the estimation of crack widths which can occur in bridge decks. However, the finite, element model could be improved to provide a better estimate of the width and spacing of cracks which occur in bridge decks. The model could be refined by incorporating an improved model of slab-girder connectivity and reinforcement-concrete connectivity.

The effect of the shear connectors on bridge deck behavior is not well understood and a lack of published data regarding this subject currently exists. Detailed modeling of the slab-girder interaction calibrated against data from laboratory studies is recommended to improve the modeling of the effect of shear connectors on deck performance. 
The bond coefficient for FRP reinforcement developed as a part of this research can be further refined. Additional research should evaluate the bond behavior of FRP reinforcement with respect to the control of deck cracking. Consideration should also be given to a variety of FRP materials (glass and carbon).

There currently exists a lack of published data on the long-term, in-service behavior of structures reinforced with FRP bars. The Thayer Road bridge is a structure which can provide a means to evaluate the long-term performance of an FRP reinforced bridge. It is recommended that this bridge be monitored and periodically inspected to evaluate and document its performance with respect to durability of both the deck and the superstructure. 


\section{LIST OF REFERENCES}

1. AASHO, 1941, Standard Specifications for Highway Bridges, American Association of State Highway Officials, Washington, D.C.

2. AASHO, 1944, Standard Specifications for Highway Bridges, American Association of State Highway Officials, Washington, D.C.

3. AASHO, 1957, Standard Specifications for Highway Bridges, American Association of State Highway Officials, Washington, D.C.

4. AASHO, 1965, Standard Specifications for Highway Bridges, American Association of State Highway Officials, Washington, D.C.

5. AASHO, 1969, Standard Specifications for Highway Bridges, American Association of State Highway Officials, Washington, D.C.

6. AASHTO, 2004, AASHTO LRFD Design Specifications 3rd edition, American Association of State Highway Officials, Washington, D.C.

7. AASHTO, 2002, Standard Specifications for Highway Bridges 17th edition, American Association of State Highway Officials, Washington, D.C., pp. 749.

8. ACI Committee 209, 1992, Prediction of Creep, Shrinkage, and Temperature Effects in Concrete Structures (ACI 209R-92), American Concrete Institute, Farmington Hills, MI.

9. ACI Committee 224, 2001, Control of Cracking in Concrete Structures (ACI 224R-01), American Concrete Institute, Farmington Hills, MI.

10. ACI Committee 318, 1963, Building Code Requirements for Structural Concrete (ACI 318-63), American Concrete Institute, Farmington Hills, MI.

11. ACI Committee 318, 1963, Commentary on Building Code Requirements for Structural Concrete, ACI SP-10, American Concrete Institute, Farmington Hills, MI.

12. ACI Committee 318, 1971, Building Code Requirements for Structural Concrete (ACI 318-71), American Concrete Institute, Farmington Hills, MI. 
13. ACI Committee 318, 1977, Building Code Requirements for Structural Concrete (ACI 318-77), American Concrete Institute, Farmington Hills, MI.

14. ACI Committee 318, 1995, Building Code Requirements for Structural Concrete (ACI 318-95) and Commentary (ACI 318R-95), American Concrete Institute, Farmington Hills, MI.

15. ACI Committee 440, 2006, Guide for the Design and Construction of Concrete Reinforced with FRP Bars (ACI 440.1R-06), American Concrete Institute, Farmington Hills, MI.

16. Aldea, C.; Shah, S. P.; and Karr, A., 1999, "Effect of Cracking on Water and Chloride Permeability of Concrete," Journal of Materials in Civil Engineering, V. 11, No. 3, American Society of Civil Engineers, pp. $181-186$.

17. Aldridge, T. S., 2005, Structural Behavior of High-Performance Concrete Bridge Decks, Masters Thesis, Purdue University, West Lafayette, IN, $182 \mathrm{pp}$.

18. Alexander, S. J., 2005, "Managing Deflection, Shortening, and Cracking Arising from Restrained Contraction," ACI SP-227: Shrinkage and Creep of Concrete, American Concrete Institute, pp. 1-20.

19. American Concrete Institute, 1920, Standard Specifications No. 23: Standard Building Regulations for the Use of Reinforced Concrete, American Concrete Institute, Farmington Hills, MI.

20. American Concrete Institute, 1936, "Building Regulations for Reinforced Concrete (ACI 501-36-T)," ACI Journal Proceedings, V. 38, MarchApril 1936, American Concrete Institute.

21. Blackman, D., 2002, Evaluation of Design Methods for the Control of Early Age Bridge Deck Cracking, Masters Thesis, Purdue University, West Lafayette, IN.

22. Blackman, D. and Frosch, R. J., 2005, "Epoxy Coated Reinforcement and Crack Control," ACI SP 225: Serviceability of Concrete, American Concrete Institute, pp. 163-178.

23. Broms, B. B., 1965, "Crack Width and Crack Spacing in Reinforced Concrete Members," Proceedings, V. 62, No. 10, American Concrete Institute, pp. 1237-1256.

24. Cady, P. D.; Carrier, R. E.; Bakr, T. A.; and Theisen, J. C., 1971, Final Report on the Durability of Bridge Deck Concrete, Pennsylvania Department of Transportation, Harrisburg, PA, 153 pp. 
25. Carlson, R. W., 1937, "Drying Shrinkage of Large Concrete Members," Journal of the American Concrete Institute, V. 8, No. 3, American Concrete Institute, pp. 327-338.

26. Eppers, L. J.; French, C. E.; and Hajjar, J., 1998, "Transverse Cracking in Bridge Decks: Field Study," Summary Report 1999-05, Minnesota Department of Transportation, St. Paul, MN, 103 pp.

27. Fang, I. K.; Worley, J.; Burns, N. H.; and Klingner, R. E., 1990, "Behavior of Isotropic R/C Bridge Decks on Steel Girders," Journal of Structural Engineering, V. 116, No. 3, American Society of Civil Engineers.

28. Frosch, R. J., 1999, "Another Look at Cracking and Crack Control in Reinforced Concrete," ACI Structural Journal, V. 96, No. 3, American Concrete Institute, pp. 437-442.

29. Frosch, R. J.; Blackman, D. T.; and Radabaugh, R. D., Investigation of Bridge Deck Cracking in Various Bridge Superstructure Systems, Purdue University, West Lafayette, IN, 265 pp.

30. Gruner, P. W. and Plain, G. A., 1993, "Type K Shrinkage-Compensating Cement in Bridge Deck Concrete," Concrete International, V. 15, No. 10, American Concrete Institute, pp. 44-47.

31. Hool, G. A., 1912, Reinforced Concrete Construction Volume 1: Fundamental Principles, McGraw-Hill, New York, NY, pp. 36-37.

32. INDOT, 1999, Standard Specifications, Indiana Department of Transportation, Indianapolis, IN.

33. Krauss, P. D. and Rogalla, E. A., 1996, NCHRP Report 380: Transverse Cracking in Newly Constructed Bridge Decks, Transportation Research Board, Washington, D.C.

34. Large, G. E., 1950, Basic Reinforced Concrete Design, Ronald Press Company, New York, NY, p. 17.

35. Le, Q. T.; French, C. E.; and Hajjar, J., 1998, "Transverse Cracking in Bridge Decks: Parametric Study," Summary Report 1999-05, Minnesota Department of Transportation, St. Paul, MN.

36. Mindness, S., Young, J. F., and Darwin, D., 2003, Concrete, $2^{\text {nd }}$ ed., Prentice Hall, Upper Saddle River, NJ, pp. 417-476.

37. Pay, A. C., 2005, Bond Behavior of Unconfined Steel and Fiber Reinforced Polymer (FRP) Bar Splices in Concrete Beams, Ph.D. Dissertation, Purdue University, West Lafayette, IN. 
38. Portland Cement Association, 1928, Handbook of Reinforced Concrete Building Design, Portland Cement Association, Chicago, IL, pp. 203226.

39. Portland Cement Association, 1970, Final Report-Durability of Concrete Bridge Decks, Portland Cement Association, Skokie, IL, 34 pp.

40. Pultrall, VROD Technical Specifications, Pultrall, Inc. http://www.pultrall.com/products/construction/TechMech2.html (accessed June 19, 2006).

41. Purvis, R.; Babei, K.; Udani, N.; Qanbari, A.; and Williams, W., 1995, "Premature Cracking of Concrete Bridge Decks: Causes and Methods of Prevention," Proceedings of the $4^{\text {th }}$ International Bridge Engineering Conference, Washington, D.C.

42. Radabaugh, R. D., 2001, Investigation of Early Age Bridge Deck Cracking, Masters Thesis, Purdue University, West Lafayette, IN.

43. Rogalla, E. A., Krauss, P. D., and McDonald, D. B., 1995, "Reducing Transverse Cracking in New Concrete Bridge Decks," Concrete Construction, Hanley Wood, LLC, September 1995, pp. 735-738.

44. SAS Inc., 2004, ANSYS Version 9.0, Swanson Analysis Systems, Houston, PA.

45. Schmitt, T. R. and Darwin, D., 1995, "Cracking in Concrete Bridge Decks," Final Report K-TRAN: KU-94-1, Lawrence, KS, 151 pp.

46. Sutherland, H. and Clifford, W. W., 1926, Introduction to Reinforced Concrete Design, John Wiley and Sons, Inc., New York, NY, pp. 351-373.

47. Tarhini, K. M., and Frederick, G. R., 1992, "Wheel Load Distribution in IGirder Highway Bridges," Journal of Structural Engineering, V. 118, No. 5, American Society of Civil Engineers, pp. 1285-1294.

48. Weiss, W. J.; Wang, W.; and Shah, S. P., 1999, "Factors Influencing Durability and Early-age Cracking in High-strength Concrete Structures," ACI SP 189: High-Performance Concrete, American Concrete Institute, Farmington Hills, MI, pp. 387-409.

49. Weiss, W. J., and Shah, S. P., 1998, "Shrinkage Cracking of Restrained Concrete Slabs," Journal of Engineering Mechanics, V. 124, No. 7, American Society of Civil Engineers.

50. Xi, Y.; Shing, B.; Abu-Hejleh, N.; Asiz, A.; Suwito, A.; Xie, Z.; and Ababneh, A., 2003, "Assessment of the Cracking Problem in Newly Constructed Bridge Decks in Colorado," Final Report CDOT-DTD-R-2003-3, Colorado Department of Transportation, Denver, CO. 
APPENDICIES 
Appendix A: Laboratory Specimens 


\section{A.1 Introduction}

Previous research by Blackman (2002) and Radabaugh (2001) investigated the effects of various design parameters on the shrinkage behavior of several laboratory specimens. Blackman performed a shrinkage study on ten specimens free of external restraint, while Radabaugh observed the shrinkage behavior of two different specimens with external restraint provided by composite bridge girders.

\section{A.2 Free Shrinkage Study}

Blackman (2002) constructed ten laboratory specimens to investigate the effect of stay-in-place (SIP) steel deck pans on shrinkage in concrete specimens without external restraint. The study considered specimens constructed with and without deck pans, the orientation of the deck pans, and the presence of reinforcement in the specimens. Complete details of this free-shrinkage experiment are provided by Blackman (2002).

\section{A.2.1 Specimen Design}

The free shrinkage specimens were $2 \mathrm{ft}-9 \mathrm{in}$. wide by $44 \mathrm{in}$. long by $8 \mathrm{in}$. thick. The specimens considered the variables shown in Table A.1. Specimens 1, 2, and 5 were constructed with SIP steel forms while Specimens 3, 4, and 8 were constructed without SIP steel forms, but with the same geometry as the specimens constructed with SIP forms. These specimens were sealed at the bottom surface with aluminum tape to simulate the sealing effect of a SIP form, but without the restraint induced by the presence of the form. 
Table A.1: Characteristics of Free Shrinkage Specimens (Blackman 2002)

\begin{tabular}{|c|c|c|c|c|c|c|}
\hline Specimen & $\begin{array}{c}\text { Form } \\
\text { Shape }\end{array}$ & $\begin{array}{c}\text { Form } \\
\text { Type }\end{array}$ & $\begin{array}{c}\text { Deck Pan } \\
\text { Orientation }\end{array}$ & Sealed & Rebar & $\begin{array}{c}\text { Width } \\
\text { (in.) }\end{array}$ \\
\hline 1 & Deck Pan & Steel & Transverse & Yes & Yes & $97 / 8$ \\
\hline 2 & Deck Pan & Steel & Longitudinal & Yes & No & $97 / 8$ \\
\hline 3 & Deck Pan & Wood & Longitudinal & Yes & No & $97 / 8$ \\
\hline 4 & Deck Pan & Wood & Transverse & Yes & No & $97 / 8$ \\
\hline 5 & Deck Pan & Steel & Transverse & Yes & No & $97 / 8$ \\
\hline 6 & Deck Pan & Wood & Transverse & No & No & $97 / 8$ \\
\hline 7 & Flat & Wood & - & No & Yes & $77 / 8$ \\
\hline 8 & Flat & Wood & - & Yes & No & $77 / 8$ \\
\hline 9 & Flat & Wood & - & No & No & $77 / 8$ \\
\hline 10 & Flat & Wood & - & No & No & $77 / 8$ \\
\hline
\end{tabular}

Blackman also designed two specimens with reinforcement to investigate the effect of restraint provided by the reinforcement. Specimens 1 and 7 were constructed with \#4 bars in the top layer and \#5 bars in the bottom layer, as illustrated by Figure A.1 and Figure A.2.

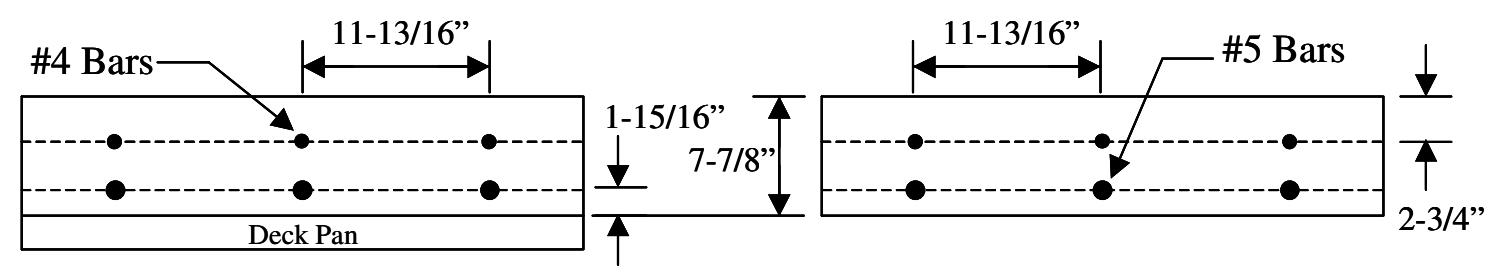

Figure A.1: Cross Section View of Reinforced Specimens (Blackman 2002) 


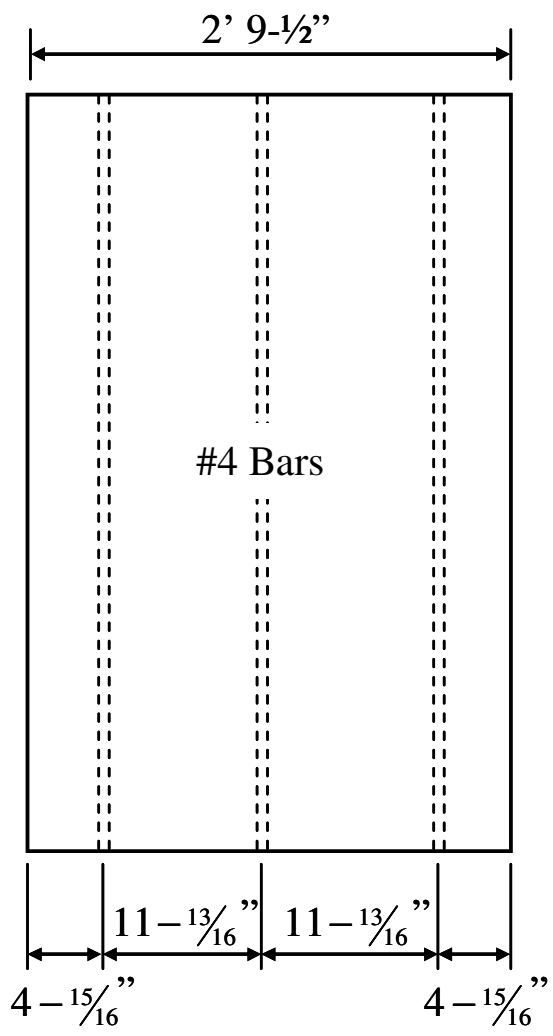

Top

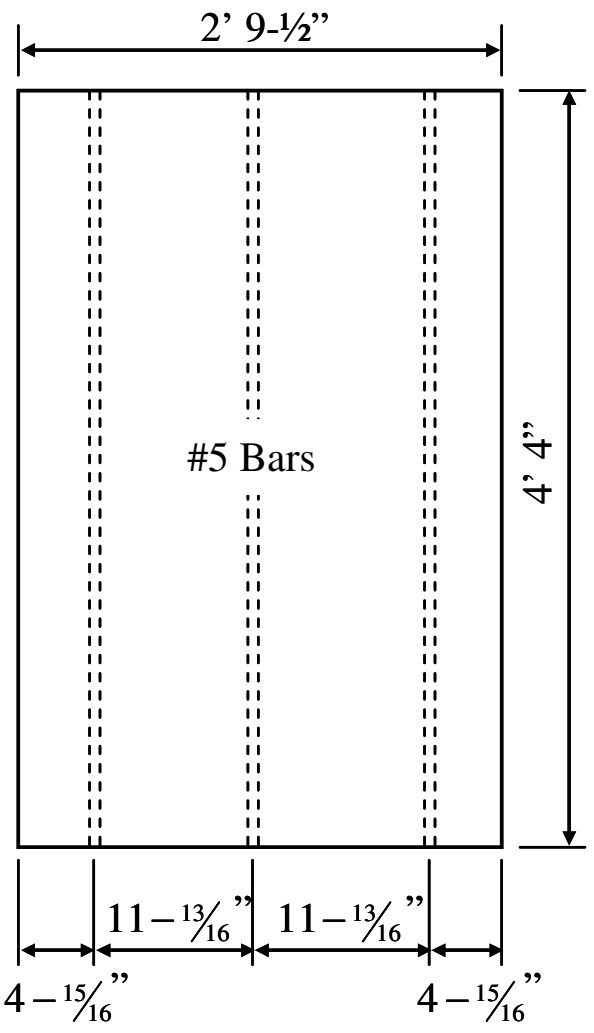

Bottom

Figure A.2: Plan View of Reinforced Specimens (From Blackman 2002)

\section{A.2.2 Materials}

\section{A.2.2.1 Concrete}

An INDOT Class C concrete mix with a design compressive strength of $4000 \mathrm{psi}$ and a maximum aggregate size of $3 / 4$ in. was supplied by Irving Materials, Inc.

Standard 6 in. by 12 in. cylinders were tested to determine the compressive strength of the concrete at Days 1, 3, 7, 14, 21, 28, and 56 in accordance with ASTM C31. The development of compressive strength for the free shrinkage specimens is shown in Figure A.3. The average 28-day compressive strength was determined to be 4780 psi. 


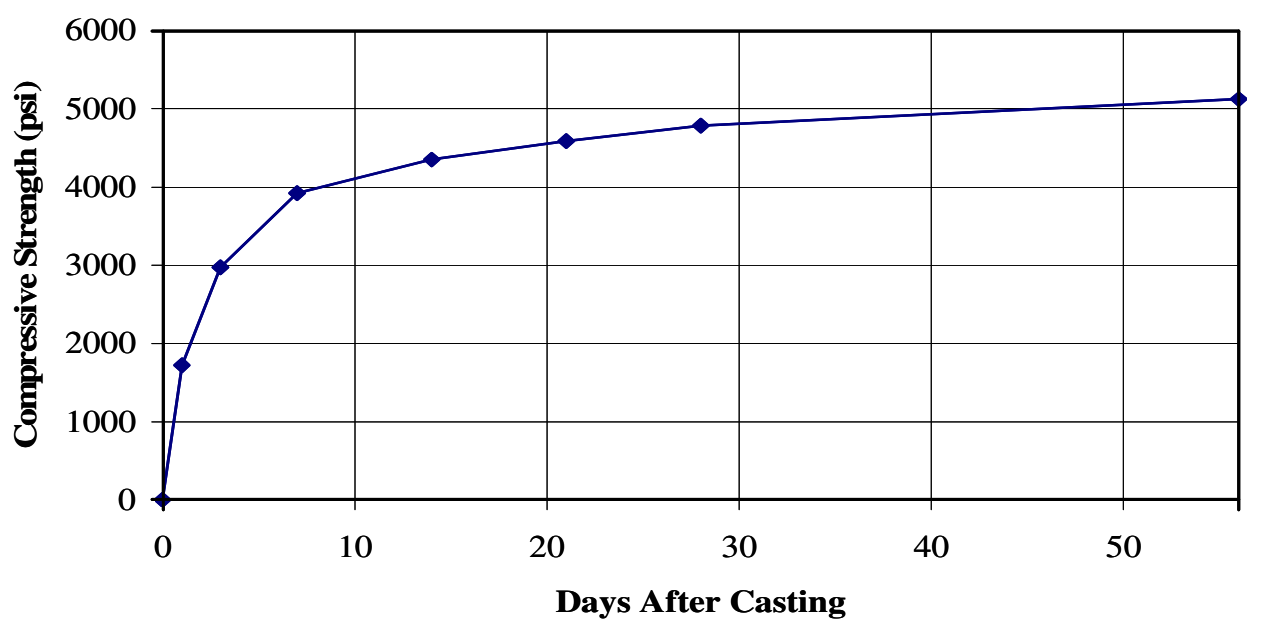

Figure A.3: Concrete Strength - Free Shrinkage Specimens (Blackman 2002)

The modulus of elasticity of the concrete was determined in accordance with ASTM C469, and its development is shown in Figure A.4. The modulus of elasticity at 28 days was $3550 \mathrm{ksi}$. It is interesting to note that the modulus of elasticity increased by less than 500 psi between Day 7 and 56. In comparison, ACI 318-05 estimates the modulus of elasticity to be $3940 \mathrm{ksi}\left(57 \sqrt{f_{c}^{\prime}}\right)$. While the ACI code slightly overestimates the modulus based on the 28-day strength compared to the moduli measured on Days 7 and 14, it provides a good approximation of the modulus after Day 21. 


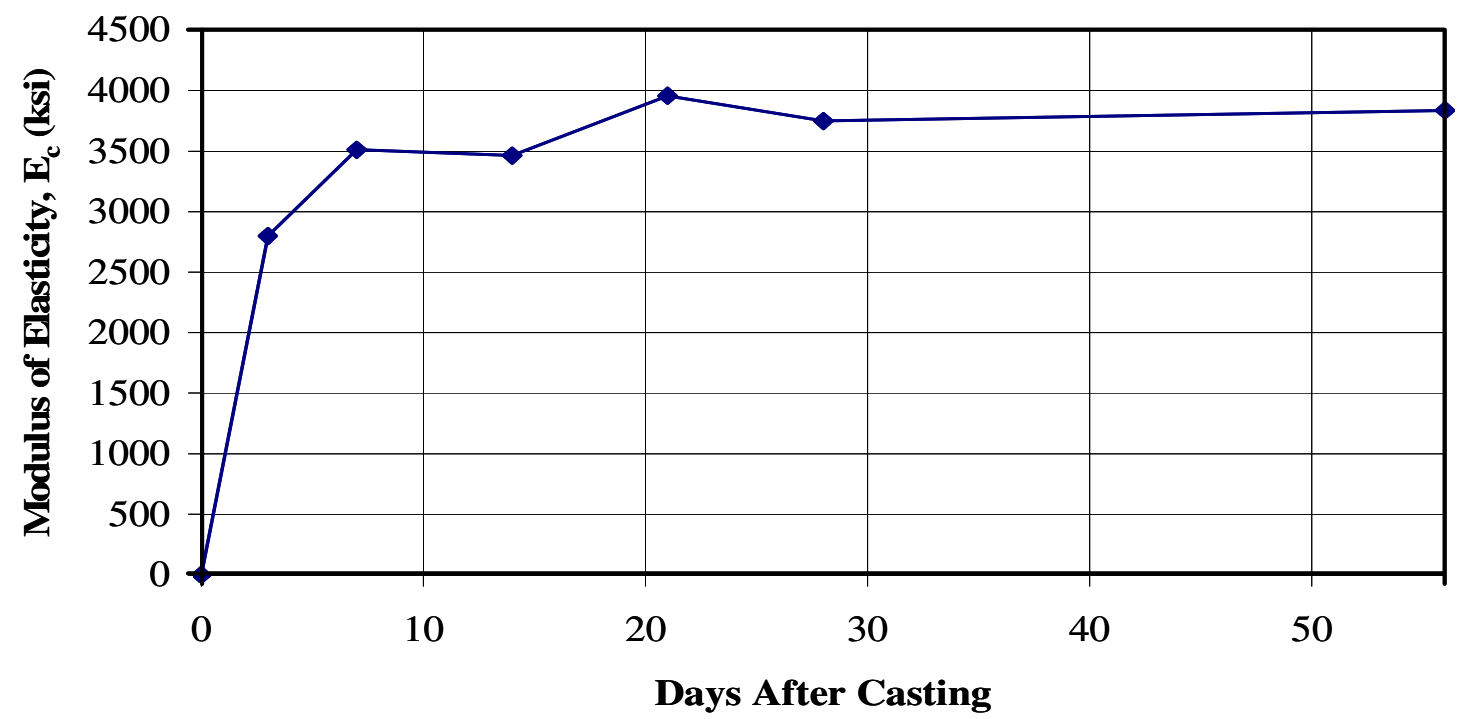

Figure A.4: Concrete Modulus of Elasticity - Free Shrinkage Specimens (Blackman 2002)

\section{A.2.2.2 Reinforcement}

The stress-strain relationship of the \#4 and \#5 bars used in the free shrinkage study are presented in Figure A.5. The \#4 reinforcing bars yielded at an average of 76 ksi, and the \#5 reinforcing bars yielded at an average of $73 \mathrm{ksi}$. 


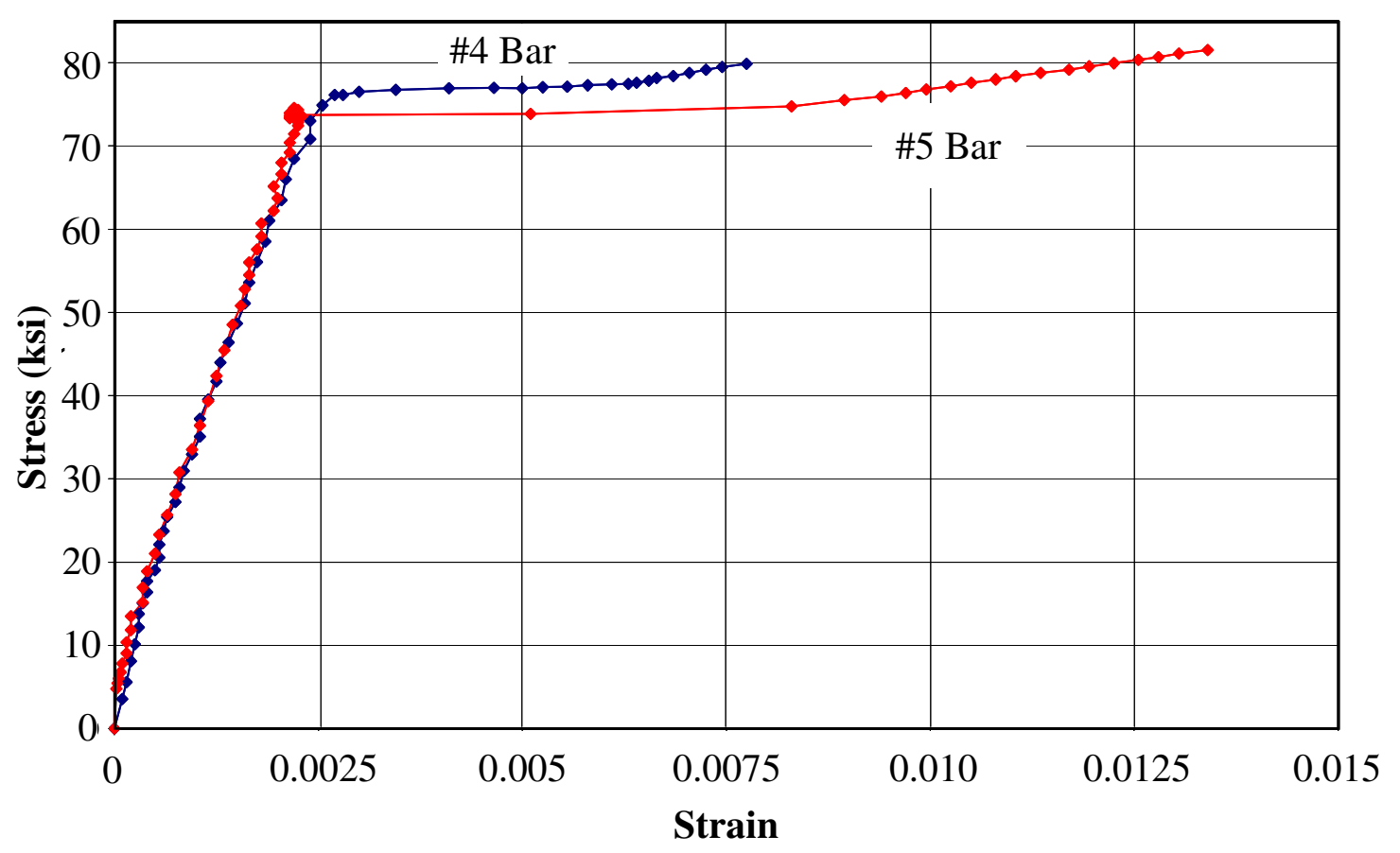

Figure A.5: Reinforcement Stress versus Displacement (Blackman 2002)

\section{A.2.3 Instrumentation}

To monitor the shrinkage and curling of the deck models, Blackman used five different types of instrumentation (2002). Strain gages measured strains on both the reinforcing bars and deck pans. The gages on the reinforcement were installed on both the top and bottom bars as shown in Figure A.6. Embedded concrete strain gages were also installed at the same location at middepth. Strains on the free surface were measured using seven Whittemore points spaced at $5 \mathrm{in}$. along the length of the specimen.

Linear voltage displacement transducers (LVDTs) were used to measure the displacement from the top of each specimen. The LVDTs were located directly in the center of the width and height of the top end of each deck model so that the total magnitude of shrinkage from each specimen could be compared. Finally, both internal and external temperatures were measured with thermocouples. Further details of the instrumentation of the free shrinkage specimens are provided by Blackman (2002). 


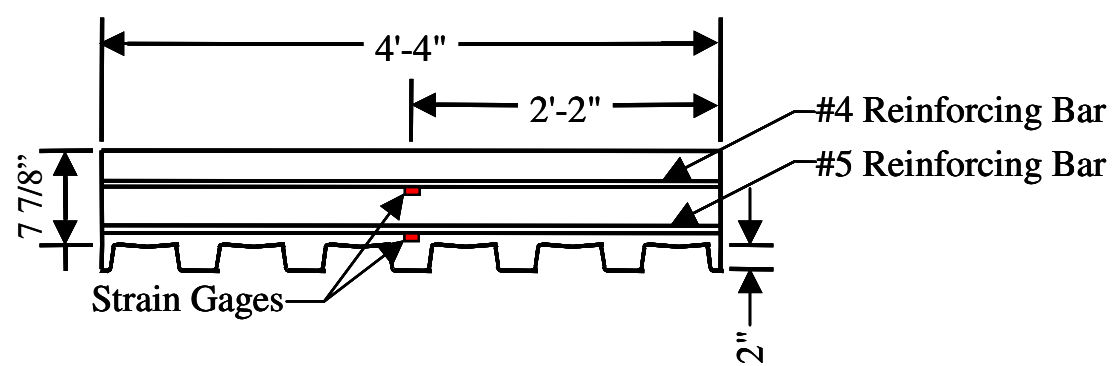

Specimen 1

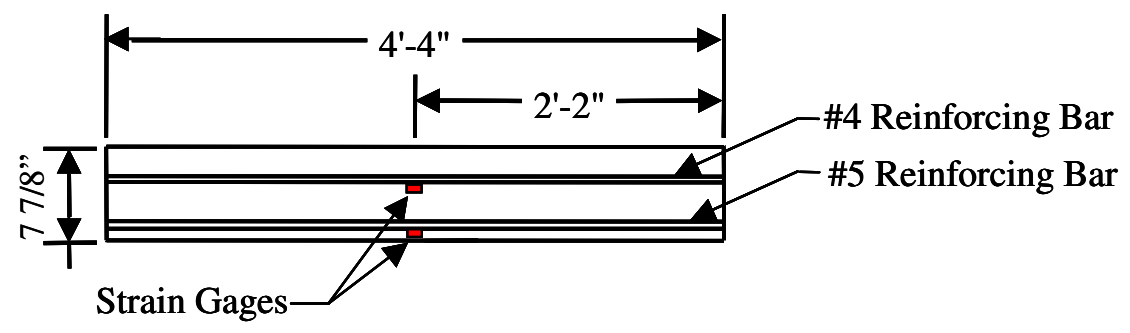

Specimen 7

a) Elevation View

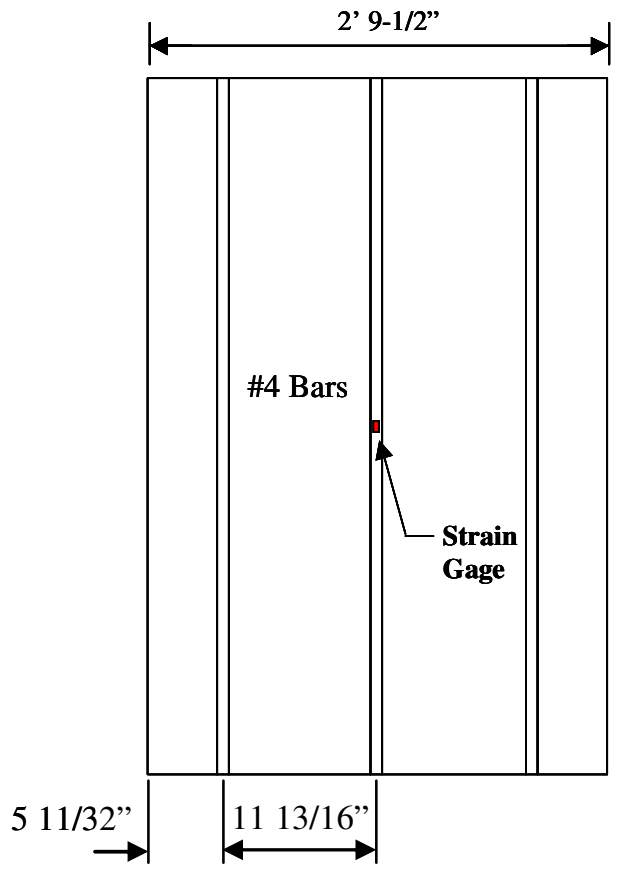

Top

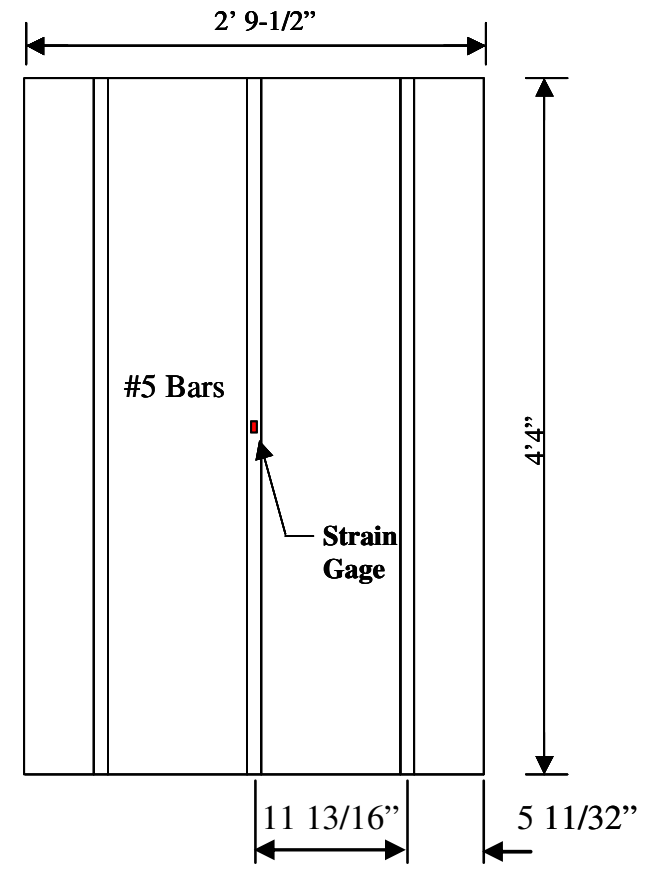

Bottom

b) Plan View

Figure A.6: Reinforcement Strain Gage Locations (Blackman 2002) 


\section{A.3 Restrained Shrinkage Study}

Radabaugh (2001) constructed two laboratory specimens to investigate the restraint due to SIP deck pans. The specimens were full-scale sections designed to be representative of the positive moment region of the bridge deck on I-65 over SR 25 in Lafayette, IN. The models had the same epoxy-coated reinforcing bar size and spacing, girder flange width, shear stud size, girder spacing, and deck thickness. The concrete decks were constructed fully composite with the steel girders.

\section{A.3.1 Specimen Design}

The specimens were designed such that the restraint provided by the SIP forms could be evaluated. Therefore, the only difference between the two specimens was the method used for forming the bottom of the deck. The first model was constructed asbuilt, incorporating SIP steel deck pans as used in the I- 65 over SR 25 bridge. The second specimen was constructed using plywood forms with two layers of 10-mil Teflon sheets on top of the plywood to reduce restraint. The Teflon sheets allowed the concrete to shrink freely without restraint from the formwork. The two specimens are shown in Figure A.7 and Figure A.8.

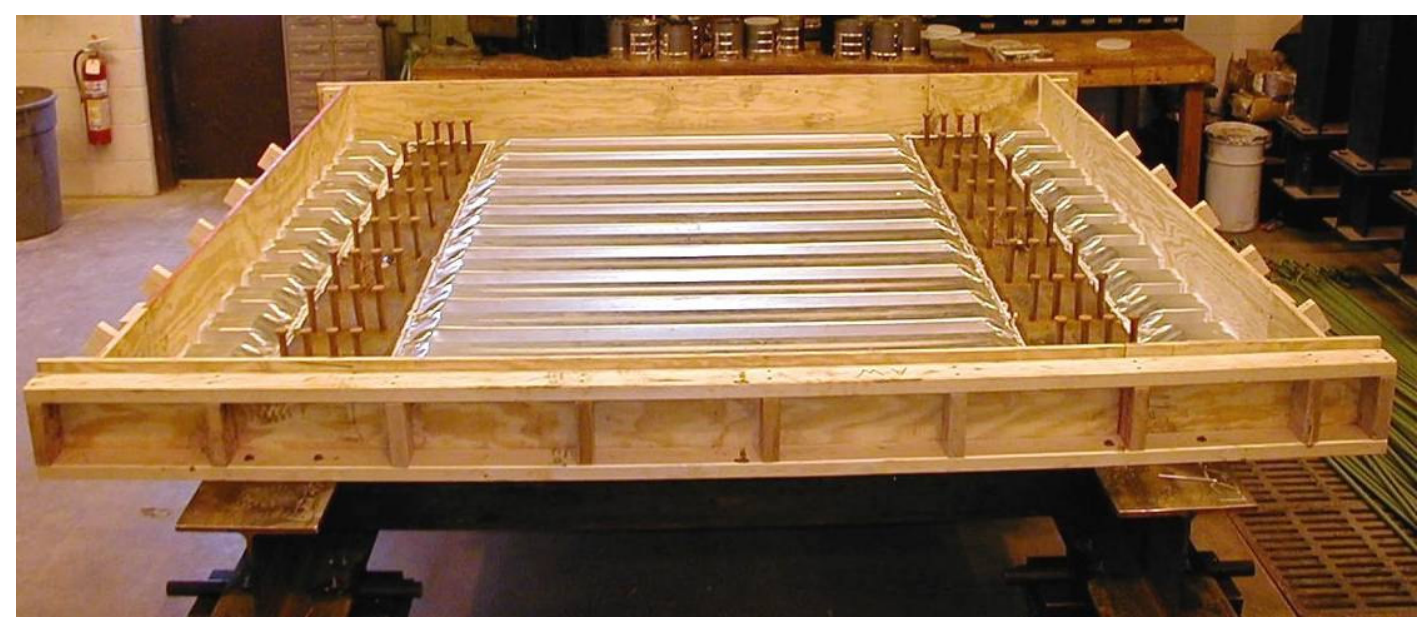

Figure A.7: As-built Specimen without Reinforcement 


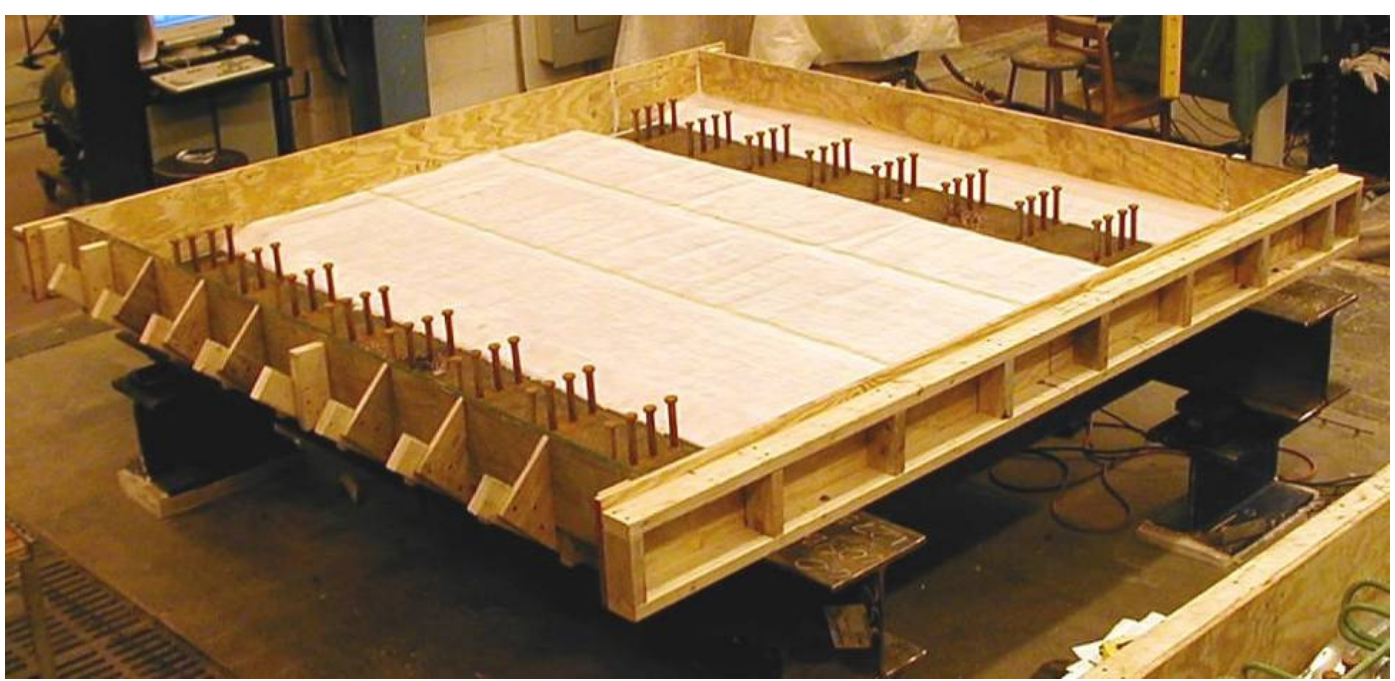

Figure A.8: Free-shrinkage Specimen without Reinforcement

Each model had a $9 \mathrm{ft}$ by $9 \mathrm{ft}$ slab cast on two W12x65 steel girders spaced at 78 in. on-center. Both slabs included a 9 in. cantilevered section outside of the girders to fully develop the reinforcement between the girders. Full composite action between the slab and girders was achieved using 5 in. tall by $7 / 8$ in. diameter shear studs spaced 12 in. along the girders.

The top and bottom reinforcement layout in the restrained shrinkage specimens is presented in Figure A.9 and Figure A.10, respectively. The top reinforcement consisted of \#4 bars spaced 11-13/16 in. on-center in the longitudinal direction and \#5 bars spaced 7$7 / 8$ in. on-center in the transverse direction. The bottom reinforcement consisted of \#5 bars spaced 11- $13 / 16$ in. on-center between the girders in the longitudinal direction and \#5 bars spaced $7-7 / 8$ in. on-center in the transverse direction. The reason for the unusual spacing is that the I-65 bridge was designed in U.S. customary units, transformed to SI units for the plans, and converted back to U.S. units during construction. The original design spacing was 8 in. $x 12$ in. 


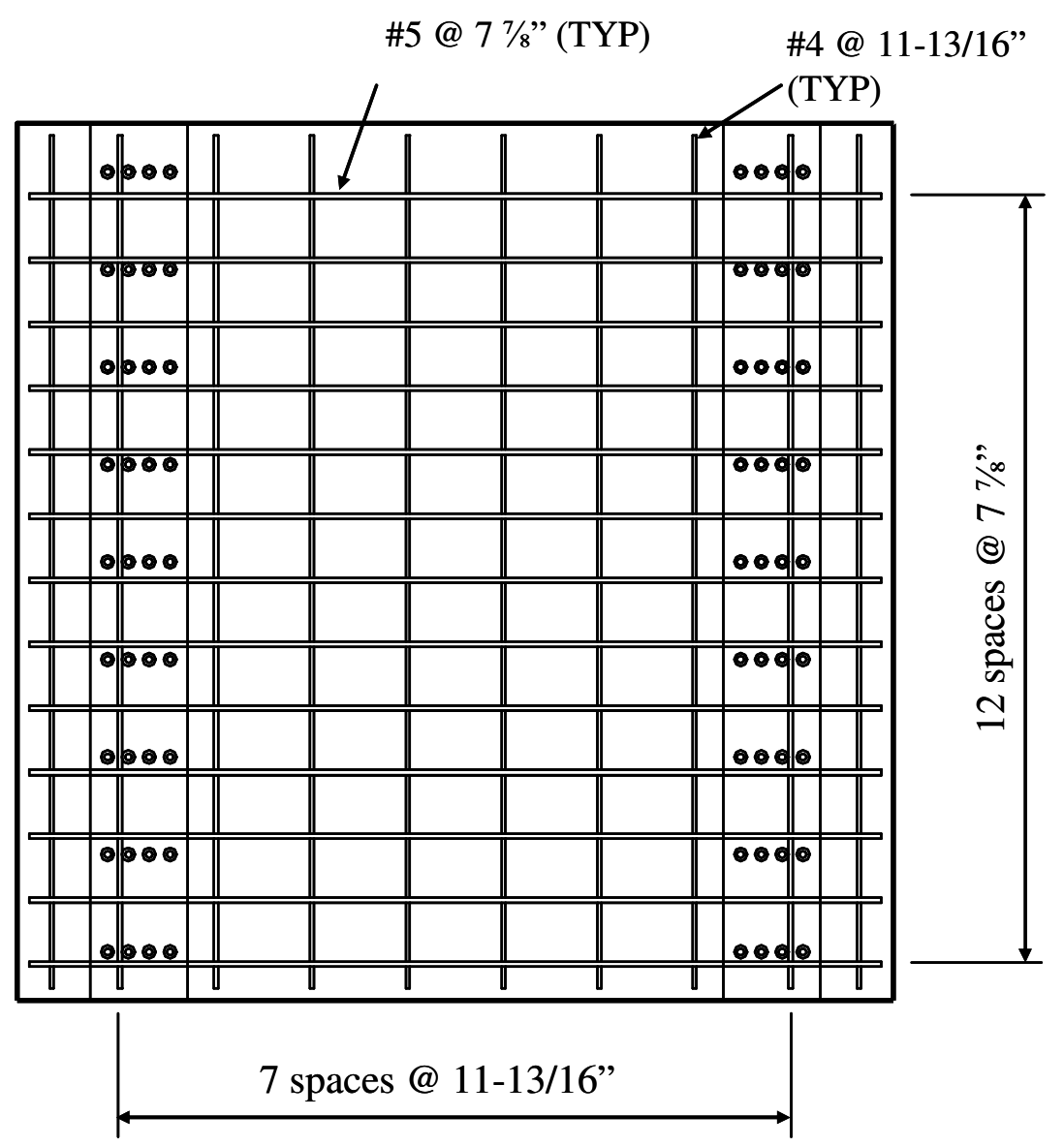

Figure A.9: Top Reinforcement - Restrained Shrinkage Specimens 


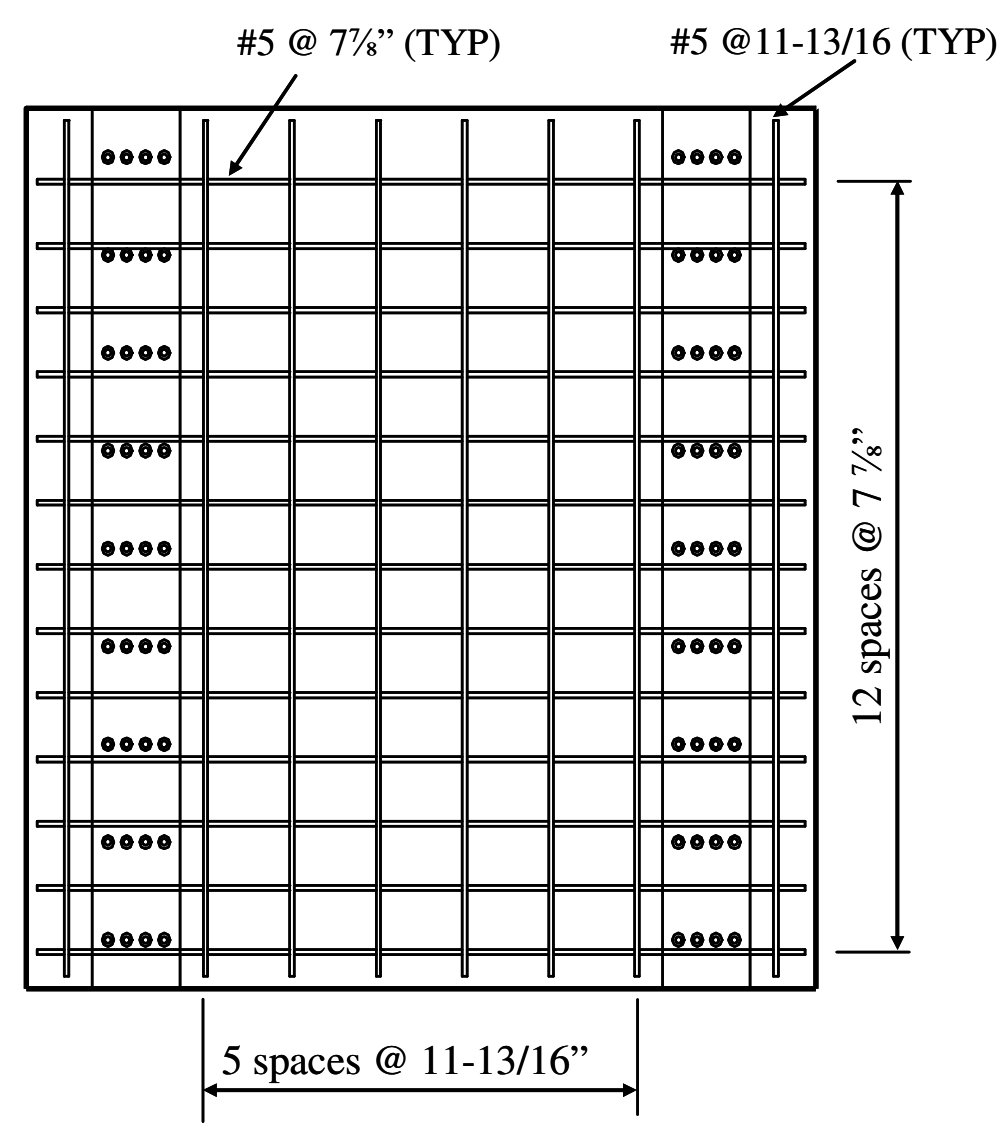

Figure A.10: Bottom Reinforcement - Restrained Shrinkage Specimens

\section{A.3.2 Materials}

\section{A.3.2.1 Concrete}

An INDOT Class C concrete mix with a design compressive strength of $4000 \mathrm{psi}$ and a maximum aggregate size of $3 / 4$ in. was supplied by Irving Materials, Inc.

Standard 6 in. by $12 \mathrm{in}$. cylinder samples were obtained at the time the models were cast and were wet cured in the laboratory for the same duration as the deck. Figure A.11 shows the strength-gain curve for the concrete used in the restrained specimens. The average 21-day compressive strength was 5700 psi (Radabaugh 2001). Radabaugh did not measure the compressive strength of the concrete beyond Day 21 as monitoring of the specimens was discontinued on Day 21. It is likely that Radabaugh stopped recording data at that time as a result of measurements recorded as a part of the field study which indicated the possible development of cracking at Day 19. 


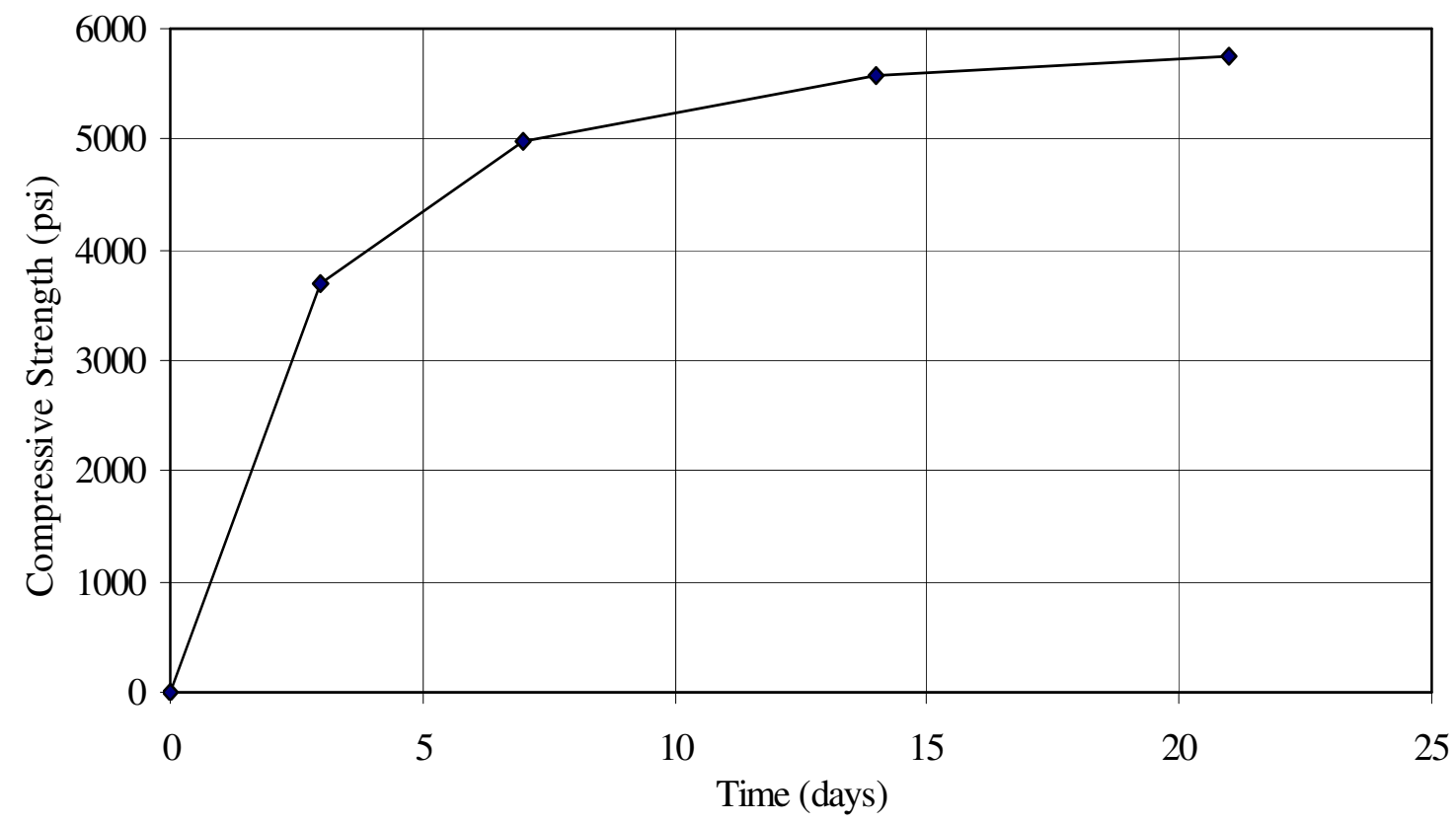

Figure A.11: Strength Gain for Concrete Compressive Cylinders (Radabaugh 2001)

Radabaugh did not measure the development of the modulus of elasticity in the specimen concrete. Therefore, no data is available.

Split cylinder tests were performed using 6 in. by 12 in. cylinders to determine the tensile strength of the concrete used in the restrained specimens (ASTM C496). Figure A.12 shows the tensile strength-gain obtained from these tests. The average 21-day tensile strength was 530 psi (Radabaugh 2001). No data are available for the 28-day tensile strength. 


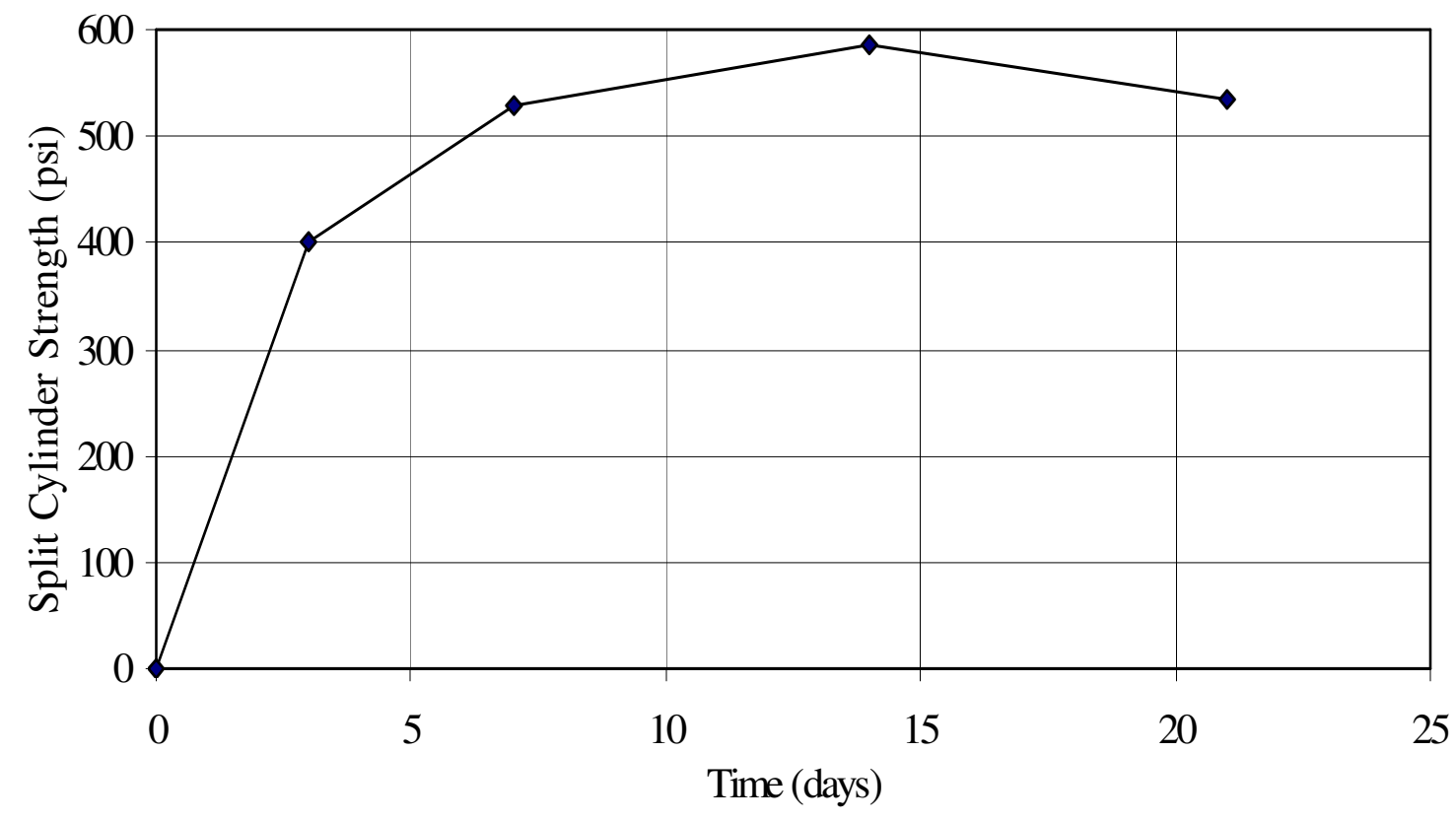

Figure A.12: Strength Gain Curve for Split Cylinder Tests (Radabaugh 2001)

\section{A.3.3 Instrumentation}

As shown in Figure A.13, Radabaugh instrumented the deck models with strain gages, thermocouples, and LVDTs to observe the early-age behavior. Figure A.14 illustrates the instrumentation located at Section A-A while Figure A.15 illustrates the instrumentation located at Section B-B. Strain gages were installed to monitor the behavior of the system with the goal of monitoring the behavior of the reinforcement and deck pans.

LVDTs were mounted at midspan as shown in Figure A.13 and Figure A.14 to measure and record vertical displacements of the girders and deck. Radabaugh also installed LVDTs at the end supports to monitor any support movement over the course of the experiment.

Thermocouples were adhered to the girders and the reinforcement at the locations shown in Figure A.13and Figure A.14 to measure the thermal gradient through the depth of the structure. A thermocouple was also mounted on the as-built specimen to provide ambient air temperature data for comparison with internal concrete temperatures measured during the test. 


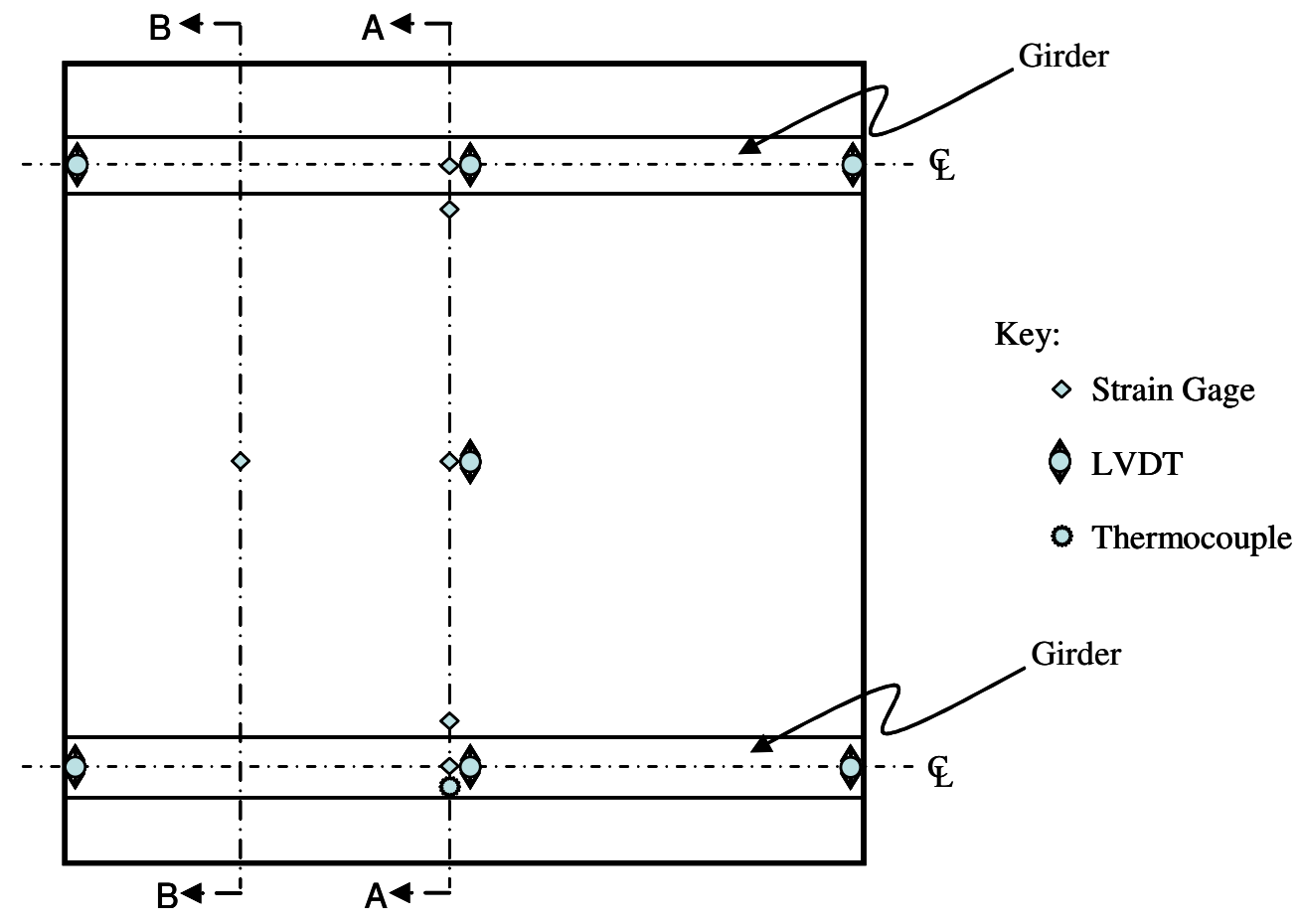

Figure A.13: Restrained Specimen Instrumentation (Plan View)

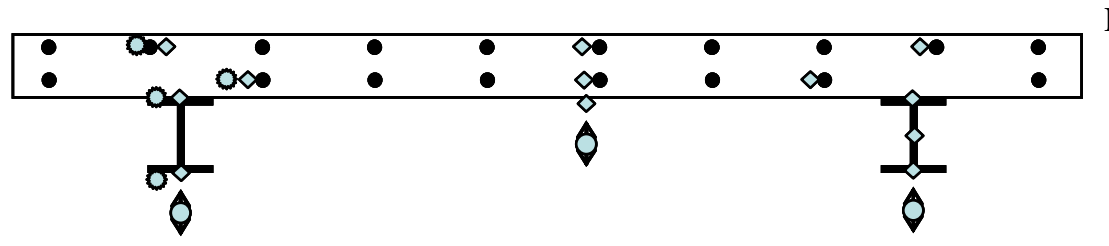

Key:
$\diamond$ Strain Gage
$\theta$ LVDT
- Thermocouple

Figure A.14: Section A-A Instrumentation

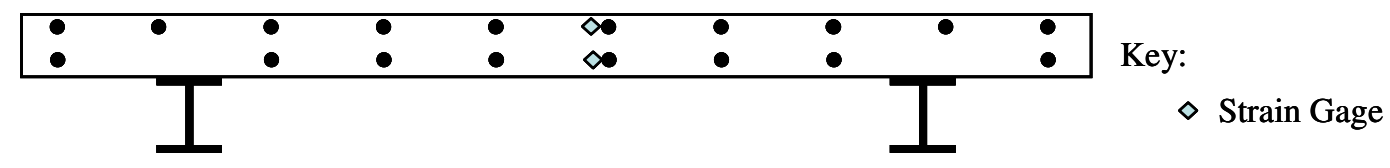

Figure A.15: Section B-B Instrumentation 
Appendix B: Bridge Plans 


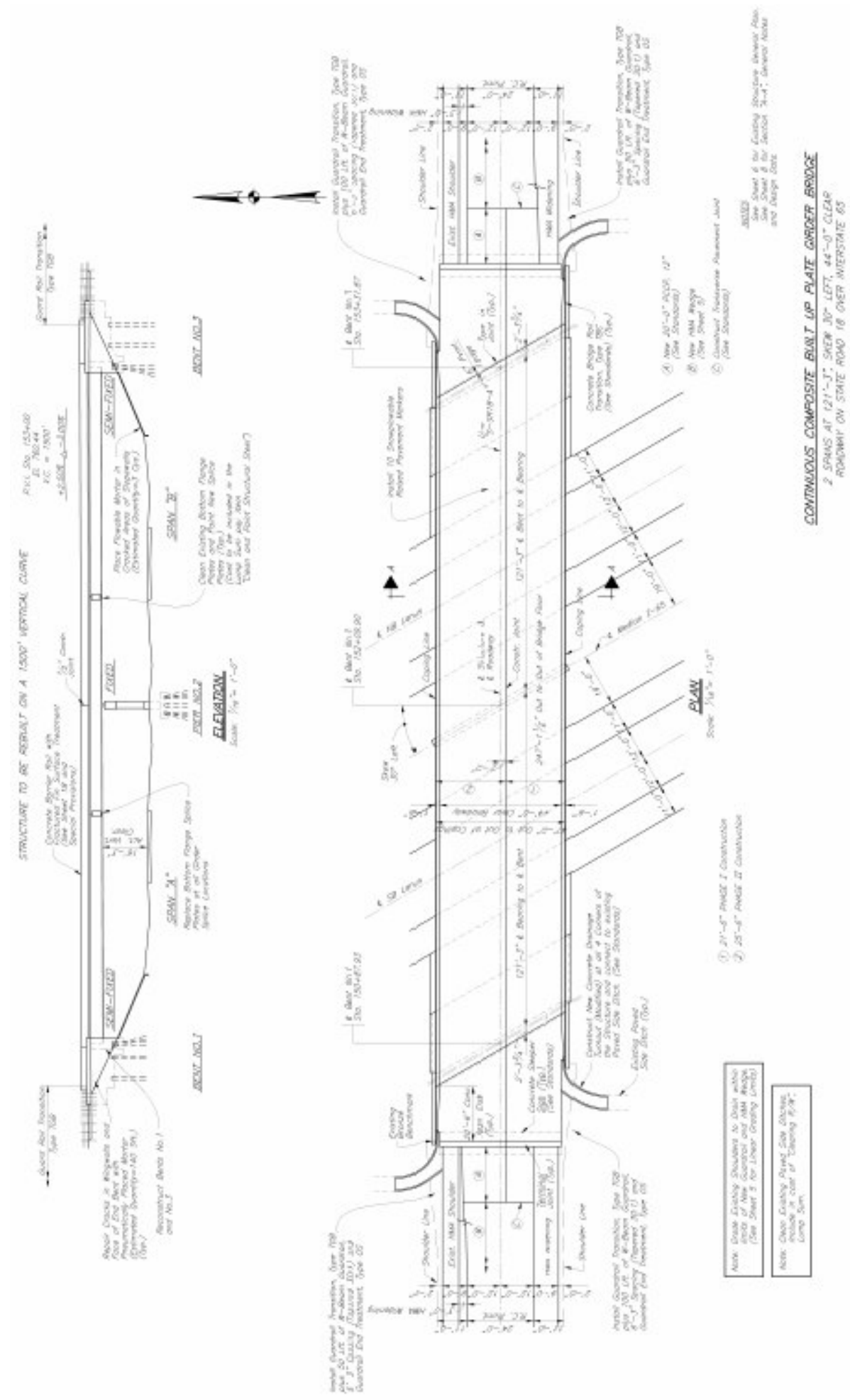

Figure B.1: Plan View (SR 18) 


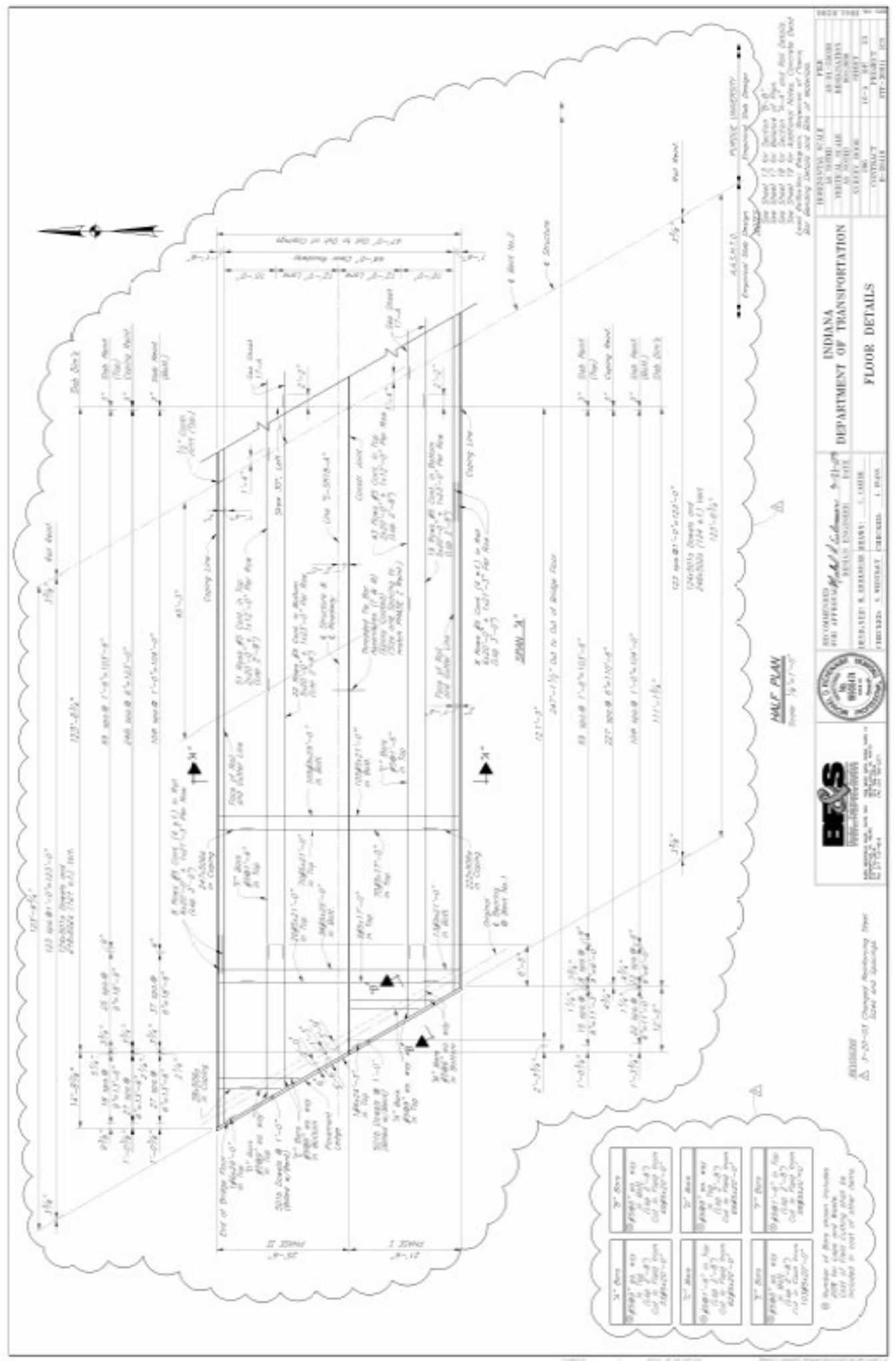

Figure B.2: Half Plan - AASHTO Span (SR 18) 


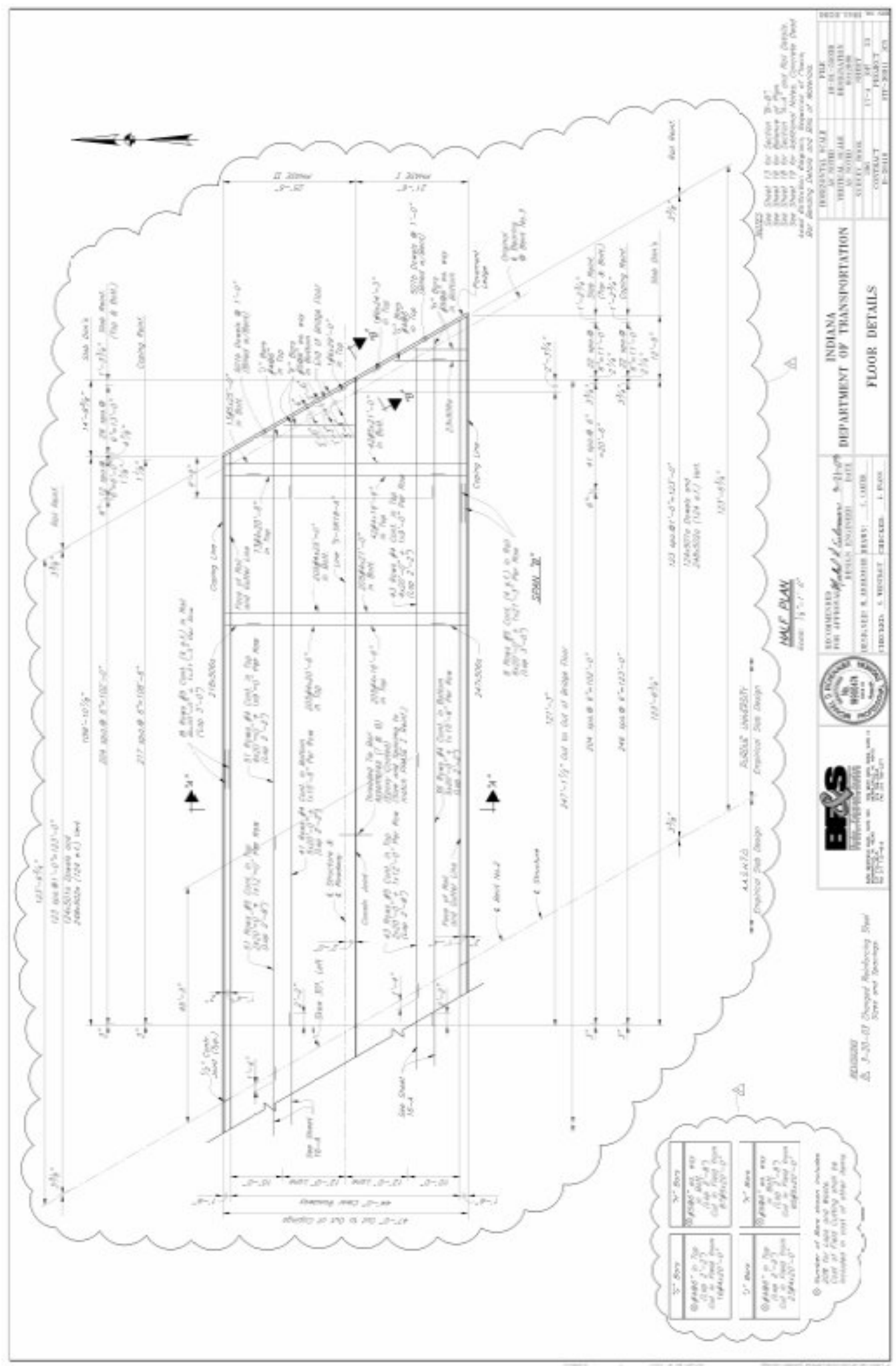

Figure B.3: Half Plan - Purdue Span (SR 18) 


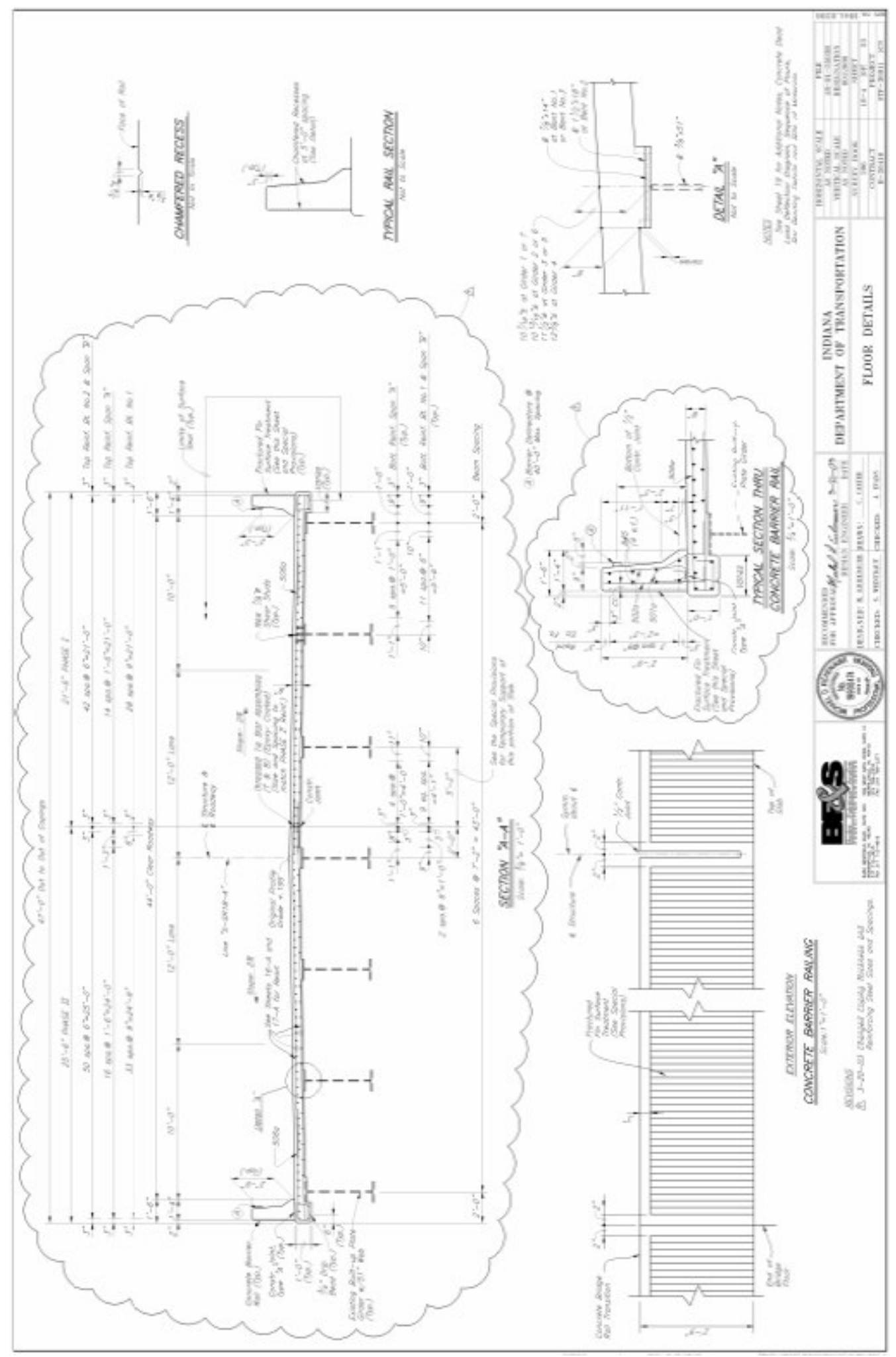

Figure B.4: Floor Details (SR 18) 


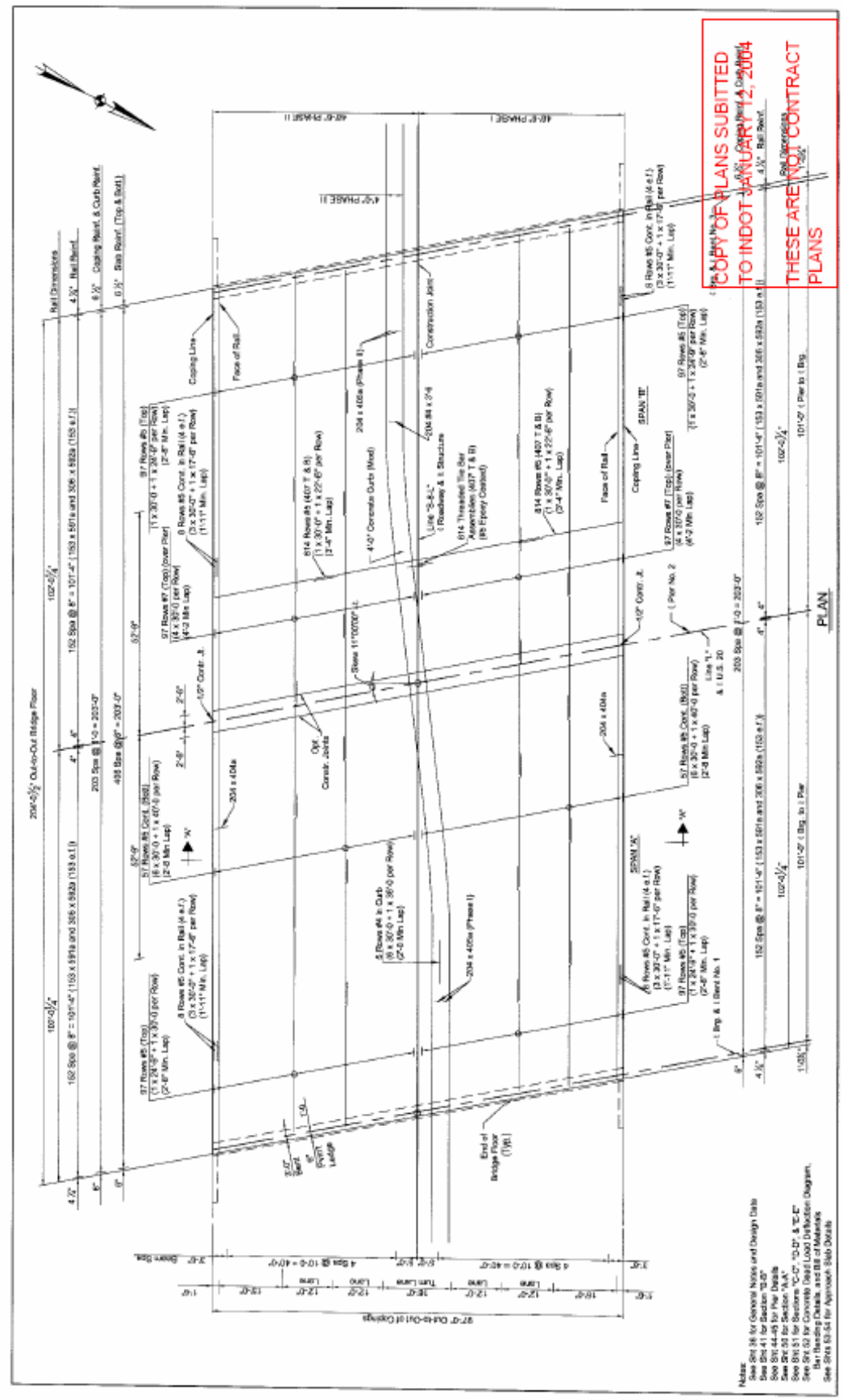

Figure B.5: Plan View (SR 23) 


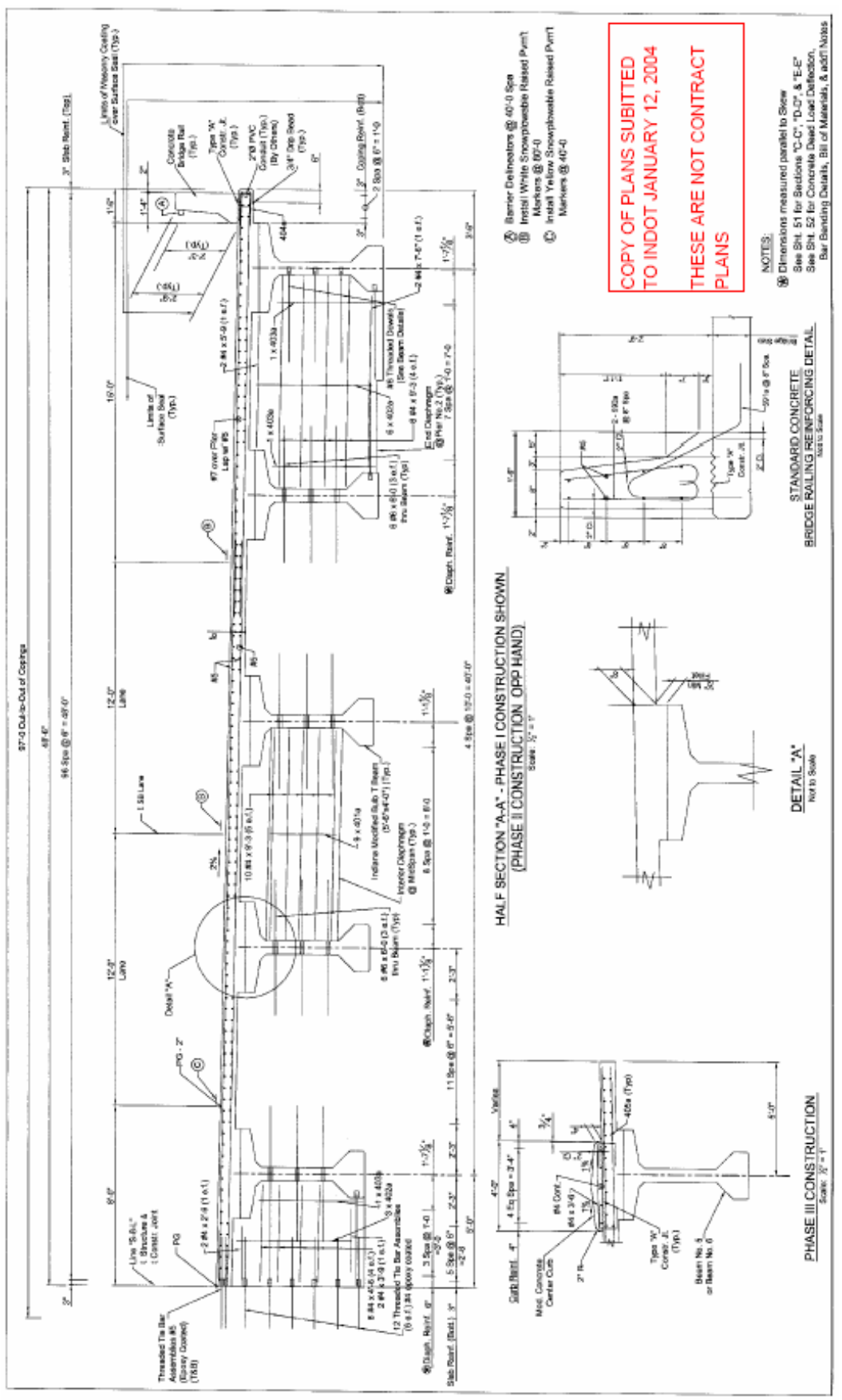

Figure B.6: Floor Details (SR 23) 


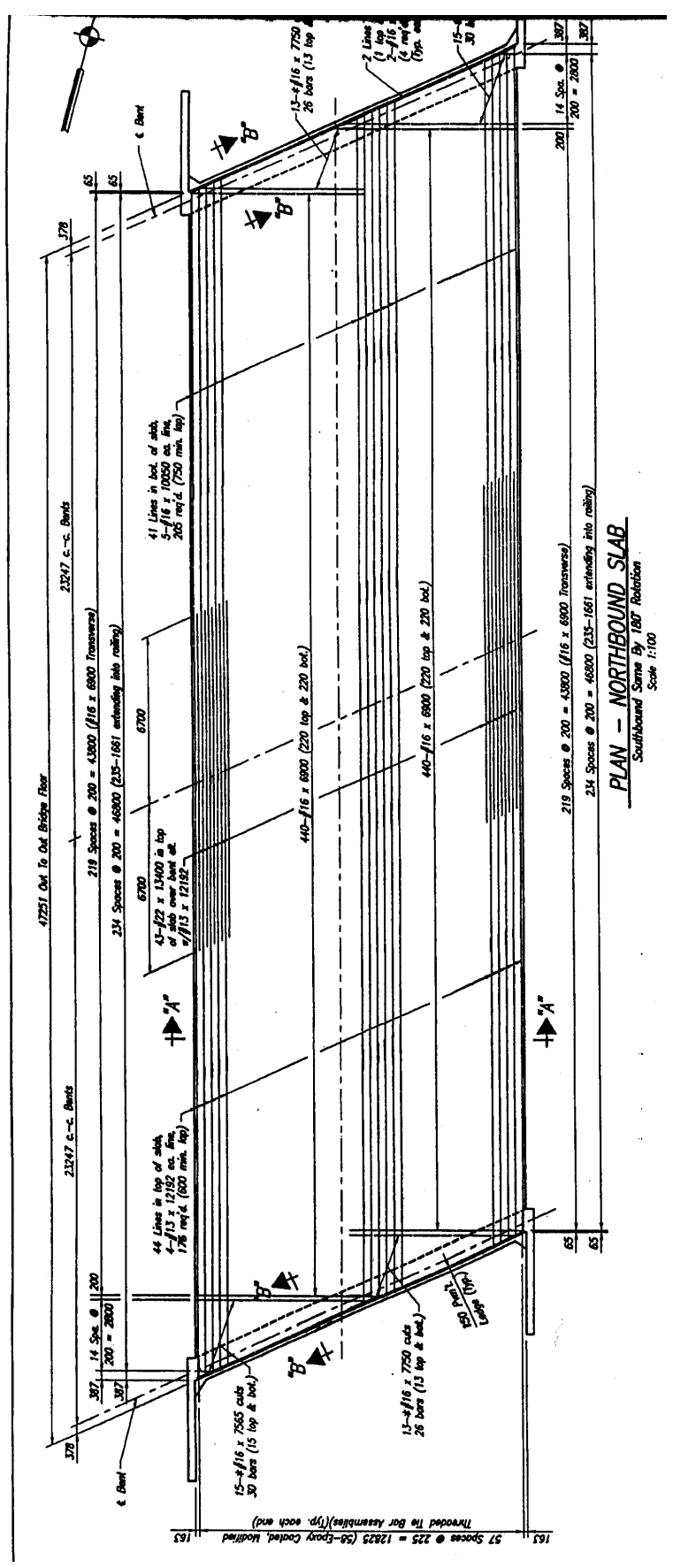

Figure B.7: Plan View (I-65) 


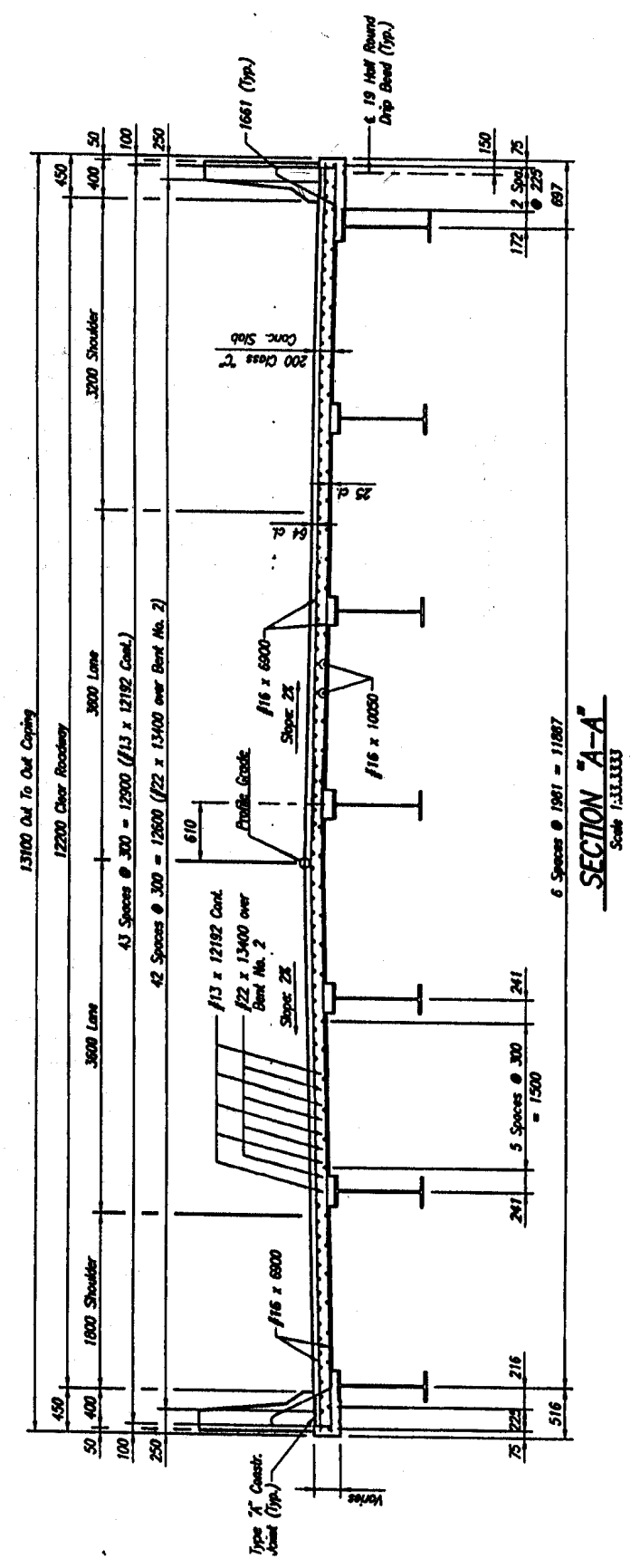

Figure B.8: Floor Detail (I-65) 


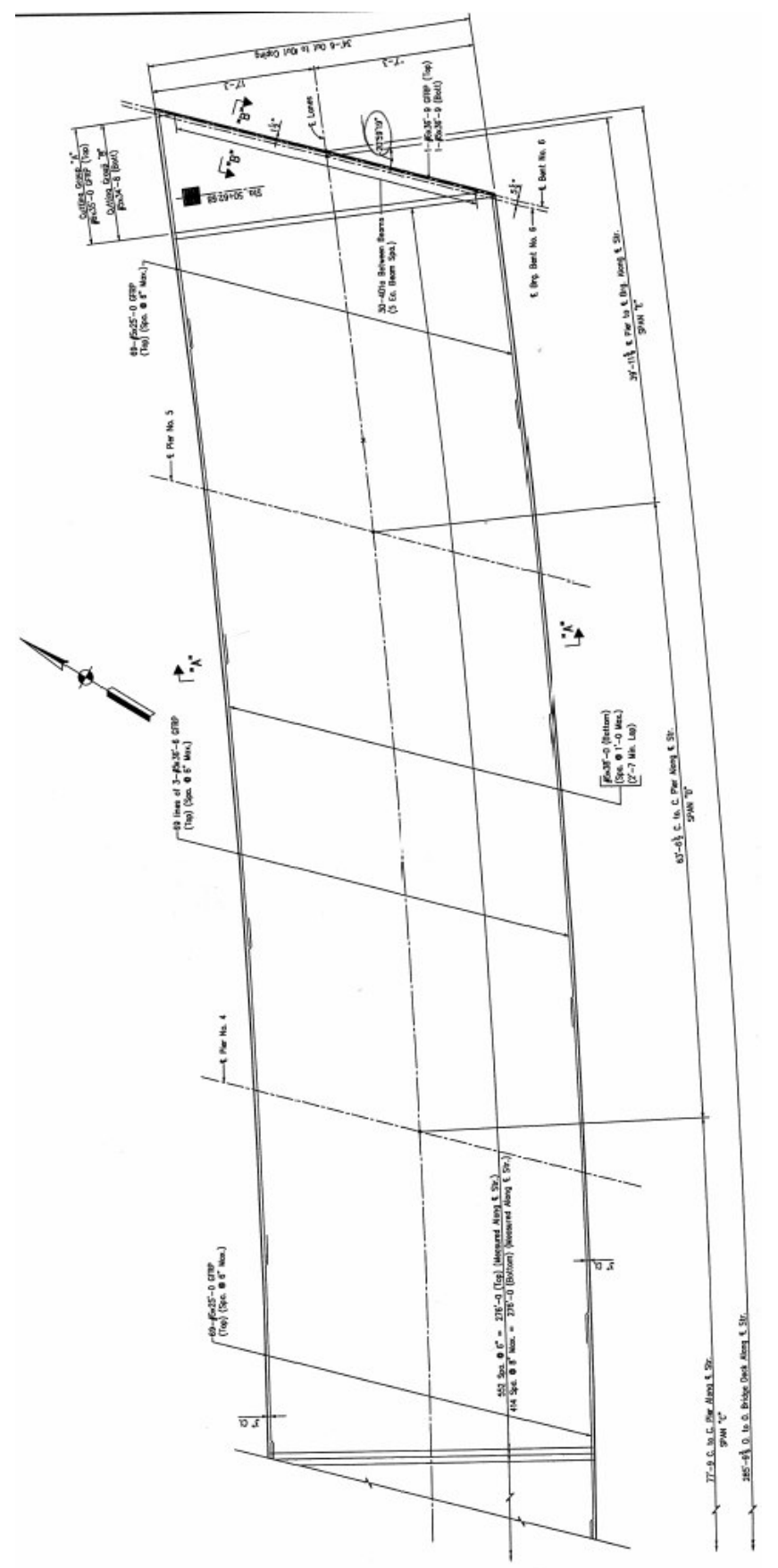

Figure B.9: Plan View (Thayer Road Bridge) 
Appendix C: ANSYS Command Files 


\section{C.1 Control Model}

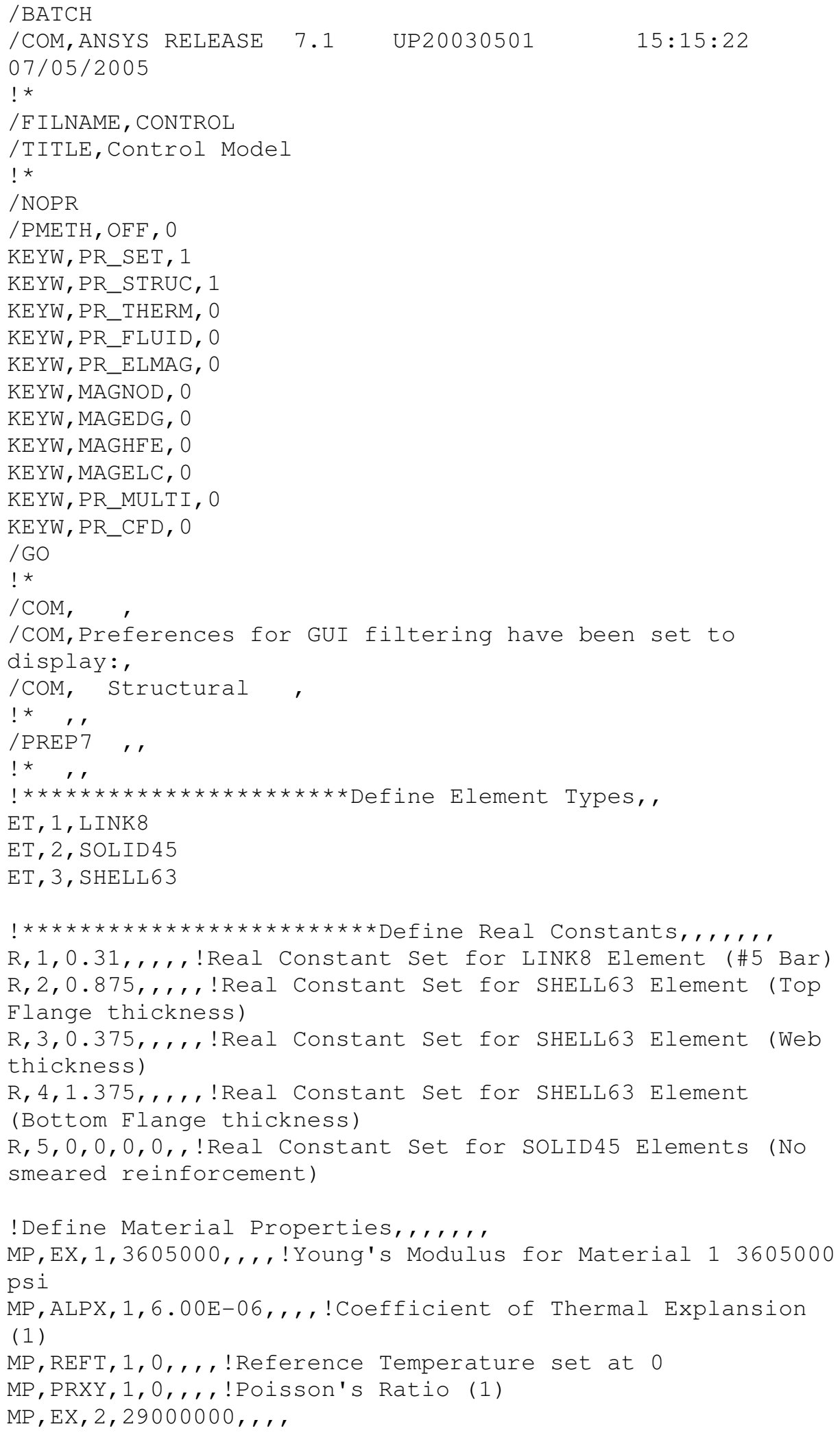




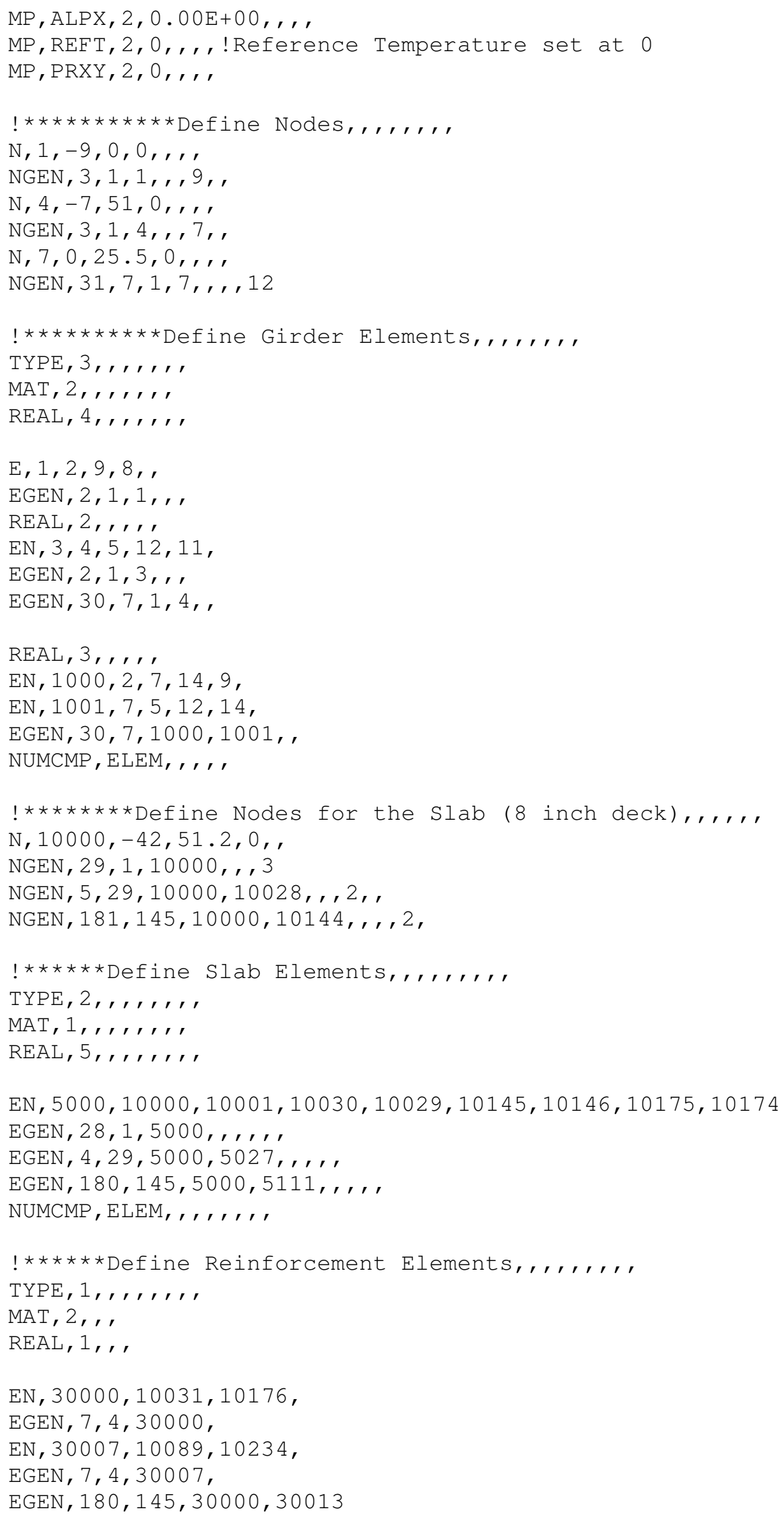




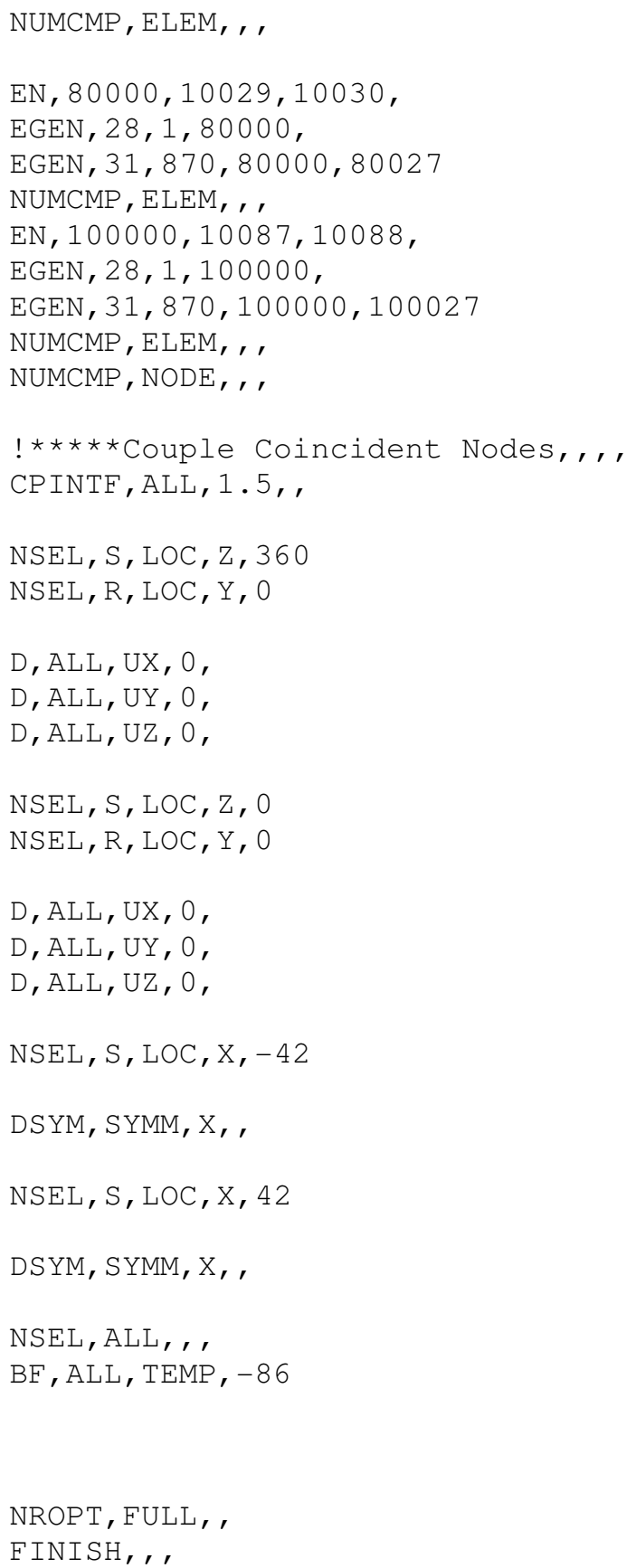

\section{C.2 SR 18 AASHTO Span}

/ BATCH, ,

/COM, ANSYS RELEASE $7.1 \quad$ UP20030501

$15: 15: 22$

$07 / 05 / 2005$,

!* , ,

/FILNAME, CONTROL, /TITLE, Control Model, ! *,

/NOPR , , 


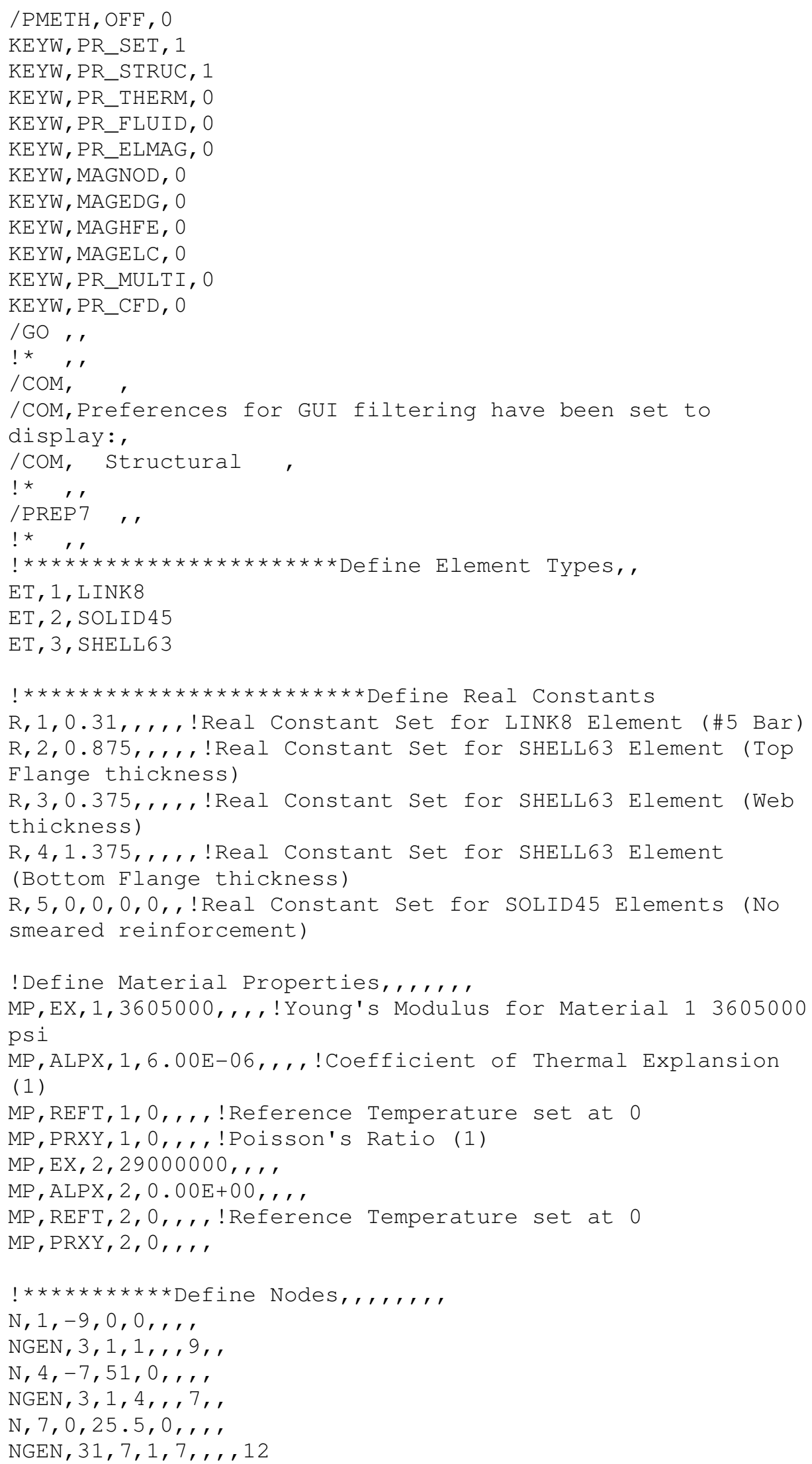




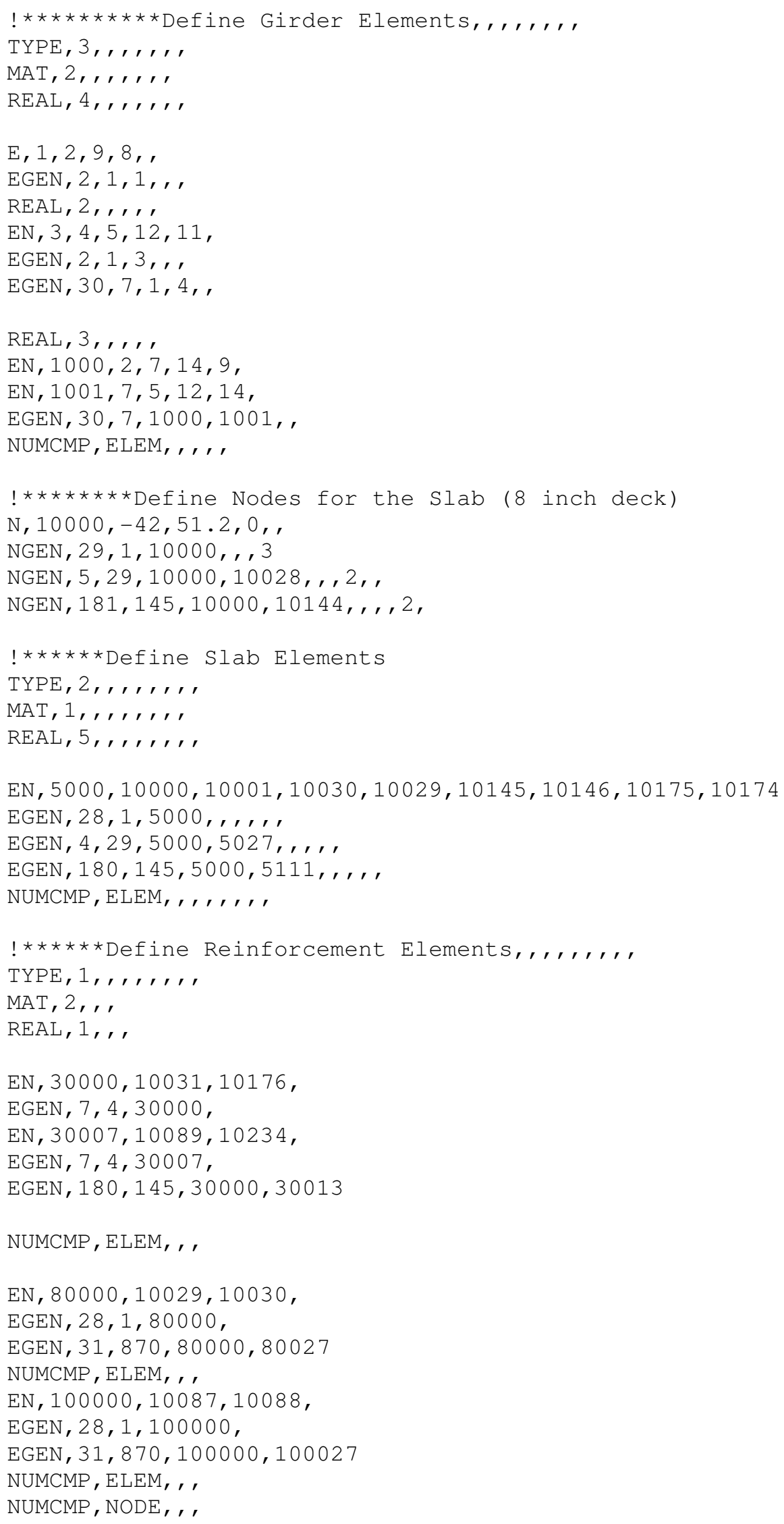




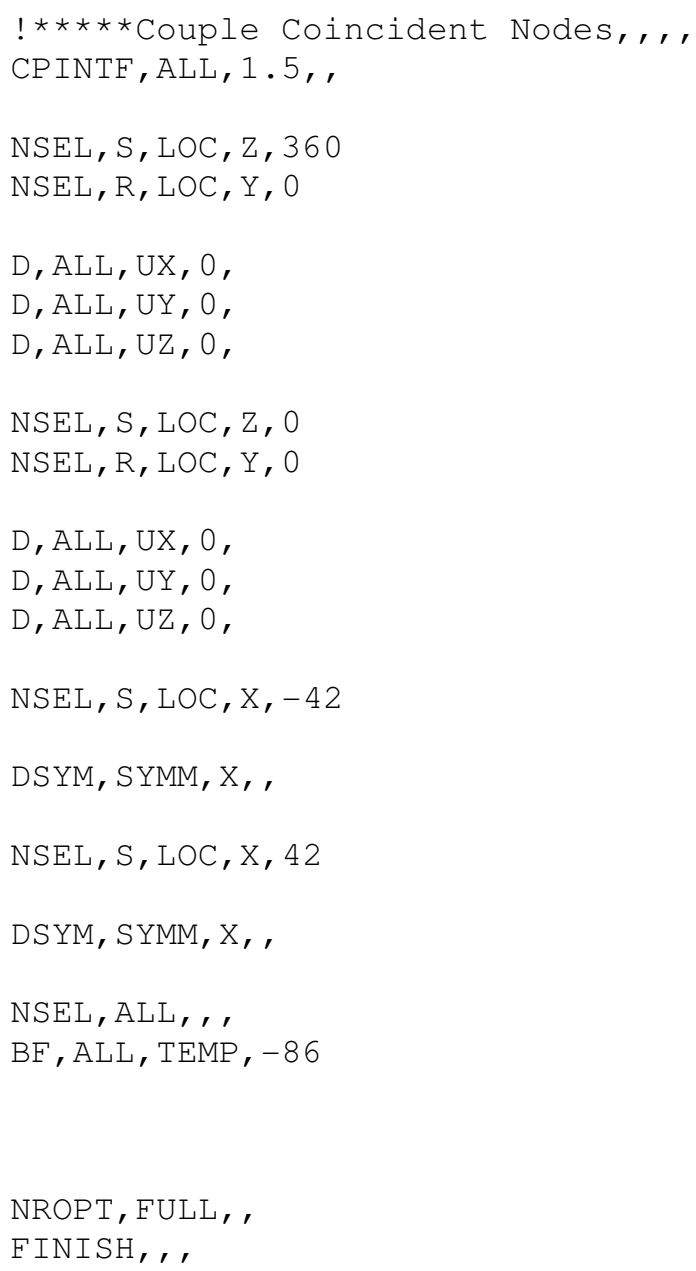

